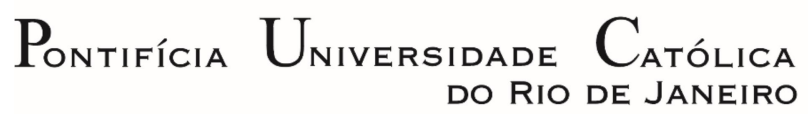

DO RIO DE JANEIRO

Marcos Antonio Campos Rodrigues

\title{
SOLUÇÕES INTEGRADAS PARA AS FORMULAÇÕES DO PROBLEMA DE NÃO LINEARIDADE GEOMÉTRICA
}

\begin{abstract}
Tese de Doutorado
Tese apresentada ao Programa de Pós-Graduação em Engenharia Civil da PUC-Rio como requisito parcial para obtenção do grau de Doutor em Engenharia Civil.
\end{abstract}

Orientadores: Prof. Luiz Fernando Martha

Prof. Rodrigo Bird Burgos

Rio de Janeiro,

Março de 2019 


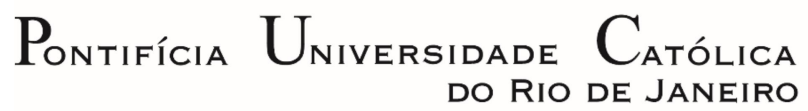

DO RIO DE JANEIRO

Marcos Antonio Campos Rodrigues

\section{SOLUÇÕES INTEGRADAS PARA AS FORMULAÇÕES DO PROBLEMA DE NÃO LINEARIDADE GEOMÉTRICA}

Tese apresentada como requisito parcial para obtenção do grau de Doutor pelo Programa de Pós-Graduação em Engenharia Civil da PUC-Rio. Aprovada pela Comissão Examinadora abaixo.

Luiz Fernando Campos Ramos Martha Orientador

Departamento de Engenharia Civil e Ambiental - PUC-Rio

Rodrigo Bird Burgos

Co-orientador

Faculdade de Engenharia - UERJ

Raul Rosas e Silva

Departamento de Engenharia Civil e Ambiental - PUC-Rio

Ivan Fabio Mota de Menezes Departamento de Engenharia Mecânica - PUC-Rio

André Maués Brabo Pereira Departamento de Engenharia Civil - UFF

André Tenchini da Silva Faculdade de Engenharia - UERJ

Ricardo Azoubel da Mota Silveira Departamento de Engenharia Civil - UFOP

Rio de Janeiro, 15 de março de 2019 
Todos os direitos reservados. É proibida a reprodução total ou parcial do trabalho sem autorização da universidade, do autor e do orientador.

\section{Marcos Antonio Campos Rodrigues}

Graduou-se em Engenharia Civil na Universidade Federal do Espírito Santo (UFES), em 2011, concluiu mestrado em Engenharia Aeronáutica e Mecânica, com ênfase em Mecânica dos Sólidos e Estruturas, no Instituto Tecnológico de Aeronáutica (ITA), em 2014. Professor de Estruturas da Universidade Federal do Espírito Santo (UFES), atuando principalmente com mecânica computacional, projeto estrutural, análise, dimensionamento e detalhamento de estruturas de concreto e aço.

Ficha Catalográfica

Rodrigues, Marcos Antonio Campos

Soluções integradas para as formulações do problema de não linearidade geométrica / Marcos Antonio Campos Rodrigues; orientadores: Luiz Fernando C. R. Martha, Rodrigo Bird Burgos. - 2019.

297 f.: il. (color.); $30 \mathrm{~cm}$

Tese (doutorado) - Pontifícia Universidade Católica do Rio de Janeiro, Departamento de Engenharia Civil e Ambiental, 2019.

Inclui bibliografia.

1. Engenharia Civil e Ambiental - Teses. 2. Matriz de rigidez tangente. 3. Funções de interpolação analíticas. 4. Teoria de flexão de Timoshenko. 5. Análise não linear geométrica. I. Martha, Luiz Fernando Campos Ramos. II. Burgos, Rodrigo Bird. III. Pontifícia Universidade Católica do Rio de Janeiro. Departamento de Engenharia Civil e Ambiental. IV. Título

CDD: 624 


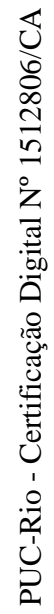

A minha família; 


\section{Agradecimentos}

Aos meus pais, Maria José e Marcos, impossível expressar em palavras. O que sou hoje devo a eles de todas as formas. A minha noiva, Izaura, por todo amor, amizade, apoio e compreensão ao longo de todos esses anos. A minha família e amigos, cujos apoio e carinho me trouxeram até aqui, em especial a Ilzanir.

Aos meus orientadores, Professores Luiz Fernando Martha e Rodrigo Bird Burgos, por me permitirem usufruir dos seus conhecimentos, além do inestimável tempo cedido. Também pelos ensinamentos que me passaram sem perceber, como a dedicação, postura, zelo e esmero com a profissão. Levarei-os para sempre comigo.

Ao Professor Ivan Menezes, pelo apoio com o Framoop e pela motivação frequente. Ao Professor Raul Rosas, por suas valiosas contribuições na qualificação deste trabalho.

Ao Departamento de Engenharia Civil (DEC) da UFES, em especial, aos Professores Lorenzo Luchi e Patrício Pires, por terem me propiciado condições de atuar como docente nesta universidade, sempre confiantes no meu trabalho e nos resultados desta Tese. Este trabalho foi concretizado, sobremaneira, em razão desse apoio. A eles, serei eternamente grato.

Ao amigo Anselmo Leal, cuja parceria me fez ingressar na docência na UFRJ, o que contribuiu de forma imensurável para a realização deste trabalho.

Aos colegas que me ajudaram no Doutorado, pois sem eles também não chegaria a este ponto. Mesmo correndo o risco de cometer injustiças, preciso citar os nome de Pedro Saieg, Maria Flávia, Danielli Cintra, Murillo Santana, Guilherme Barros e Rafael Rangel. Ao Engenheiro Flávio Pol da Opencadd por todo auxílio com o Matlab.

À PUC-Rio e ao CNPq, pelos auxílios concedidos. À UFES e ao ITA, pela minha formação, evidentes neste trabalho.

Especialmente a DEUS, pela vida, saúde, cuidado, proteção, e por guiar meus passos e colocar todas essas pessoas e instituições no meu caminho. 


\section{Resumo}

Rodrigues, Marcos Antonio Campos; Martha, Luiz Fernando Campos Ramos (Orientador); Burgos, Rodrigo Bird (Co-orientador). Soluções integradas para as formulações do problema de não linearidade geométrica. Rio de Janeiro, 2019. 297p. Tese de Doutorado Departamento de Engenharia Civil e Ambiental, Pontifícia Universidade Católica do Rio de Janeiro.

Uma análise não linear geométrica de estruturas, utilizando o Método dos Elementos Finitos (MEF), depende de cinco aspectos: a teoria de flexão, da descrição cinemática, das relações entre deformações e deslocamentos, da metodologia de análise não linear e das funções de interpolação de deslocamentos. Como o MEF é uma solução numérica, a discretização da estrutura fornece grande influência na resposta dessa análise. Contudo, ao se empregar funções de interpolação correspondentes à solução homogênea da equação diferencial do problema, obtêm-se o comportamento exato da estrutura para uma discretização mínima, como ocorre em uma análise linear. Assim, este trabalho visa a integrar as soluções para o problema da não linearidade geométrica, de maneira a tentar reduzir essa influência e permitir uma discretização mínima da estrutura, considerando ainda grandes deslocamentos e rotações. Então, utilizando-se a formulação Lagrangeana atualizada, os termos de ordem elevada no tensor deformação, as teorias de flexão de Euler-Bernoulli e Timoshenko, os algoritmos para solução de problemas não lineares e funções de interpolação, que consideram a influência da carga axial, obtidas da solução da equação diferencial do equilíbrio de um elemento infinitesimal na condição deformada, desenvolve-se um elemento de pórtico espacial com uma formulação "completa". O elemento é implementado no Framoop e sua resposta, utilizandose uma discretização mínima da estrutura, é comparada com formulações usuais, soluções analíticas e com o programa Mastan2 v3.5. Os resultados evidenciam a eficiência da formulação desenvolvida para prever a carga crítica de estruturas planas e espaciais utilizando uma discretização mínima.

\section{Palavras-chave}

Matriz de rigidez tangente; Funções de interpolação analíticas; Teoria de flexão de Timoshenko; Análise não linear geométrica. 


\section{Abstract}

Rodrigues, Marcos Antonio Campos; Martha, Luiz Fernando Campos Ramos (Advisor); Burgos, Rodrigo Bird (Co-advisor). Integrated solutions for the formulations of the geometric nonlinearity problem. Rio de Janeiro, 2019. 297p. Tese de Doutorado - Departamento de Engenharia Civil e Ambiental, Pontifícia Universidade Católica do Rio de Janeiro.

A structural geometric nonlinear analysis, using the finite element method (FEM), depends on the consideration of five aspects: the bending theory, the kinematic description, the strain-displacement relations, the nonlinear solution scheme and the interpolation (shape) functions. As MEF is a numerical solution, the structure discretization provides great influence on the analysis response. However, applying shape functions calculated from the homogenous solution of the differential equation of the problem, the exact behavior of the structure is obtained for a minimum discretization, as for a linear analysis. Thus, this work aims to integrate the solutions for the formulations of the geometric nonlinearity problem, in order to reduce this influence and allow a minimum discretization of the structure, also considering, large displacements and rotations. Then, using an updated Lagrangian kinematic description, considering a higher-order Green strain tensor, The Euler-Bernoulli and Timoshenko beam theories, the nonlinear solutions schemes and the interpolation functions, that includes the influence of axial force, obtained directly from the solution of the equilibrium differential equation of an deformed infinitesimal element, a spatial bar frame element is developed using a "complete" formulation. The element was implemented in the Framoop, and their results, for a minimum discretization, were compared with conventional formulations, analytical solutions and with the software Mastan2 v3.5. Results clearly show the efficiency of the developed formulation to predict the critical load of plane and spatial structures using a minimum discretization.

\section{Keywords}

Tangent stiffness matrix; Analytical interpolation functions; Timoshenko beam theory; Nonlinear geometric analysis. 


\section{Sumário}

1 Introdução 32

1.1 Considerações Iniciais 32

1.2 Motivação 36

1.3 Revisão Bibliográfica 38

1.4 Objetivos e Contribuições 46

1.5 Originalidade 48

1.6 Organização do Trabalho 48

2 Idealização do Comportamento de Barras 51

2.1 Campos de Deslocamentos e de Tensões 51

2.2 Relações entre Deslocamentos e Deformações 52

2.2.1 Teoria de Flexão de Euler-Bernoulli 54

2.2.2 Teoria de Flexão de Timoshenko 55

2.3 Equilíbrio entre Tensões e Esforços Internos 56

2.3.1 Lei Constitutiva Linear para o Material 56

2.3.2Rigidez do Elemento Infinitesimal de Barra 56

2.4 Relações Diferenciais de Equilíbrio em Vigas-Coluna 57

2.4.1Equilíbrio de Elemento Infinitesimal na Configuração Indeformada 58

2.4.1.1 Teoria de Flexão de Euler-Bernoulli 59

2.4.1.2 Teoria de Flexão de Timoshenko 59

2.4.2 Equilíbrio de Elemento Infinitesimal na Configuração Deformada 61

2.4.2.1 Teoria de Flexão de Euler-Bernoulli 62

2.4.2.2 Teoria de Flexão de Timoshenko 62

2.5 Solução das Relações Diferenciais de Equilíbrio em VigasColuna

2.5.1 Equilíbrio de Elemento Infinitesimal na Configuração Indeformada 66

2.5.1.1 Teoria de Flexão de Euler-Bernoulli 66

2.5.1.2 Teoria de Flexão de Timoshenko 67 
2.5.2Equilíbrio de Elemento Infinitesimal na Configuração Deformada 69

2.5.2.1 Teoria de Flexão de Euler-Bernoulli 69

2.5.2.2 Teoria de Flexão de Timoshenko 70

2.6 Resumo da Idealização do Comportamento de Barras à Flexão 72

3 Funções de Interpolação: Comportamento à Flexão 75

3.1 Equilíbrio do Elemento Infinitesimal na Configuração Indeformada $\quad 77$

3.1.1 Funções de Forma: Teoria de Euler-Bernoulli 77

3.1.2 Funções de Forma: Teoria de Timoshenko 79

3.2 Equilíbrio do Elemento Infinitesimal na Configuração Deformada 81

3.2.1 Funções de Forma: Teoria de Euler-Bernoulli 81

3.2.2 Funções de Forma: Teoria de Timoshenko 86

3.3 Funções de Interpolação para Deslocamento Axial 91

4 Matriz de Rigidez Local 93

4.1 Descrição Cinemática 94

4.2 Formulação Lagrangeana Atualizada 96

4.3 Teoria de Flexão de Euler-Bernoulli 98

4.3.1 Matriz de Rigidez Elástica $\quad 99$

4.3.2 Matriz de Rigidez Geométrica 101

4.3.3 Matriz de Rigidez Local de Elemento Espacial (3D) 104

4.3.3.1 Matriz de Rigidez Elástica Local no Plano xz 105

4.3.3.2 Matriz de Rigidez Geométrica Local no Plano xz 107

4.3.3.3 Torção Pura 109

4.3.3.4 Interação entre Torção e Carga Axial 110

4.3.3.5 Rotações Finitas 114

4.3.4 Matriz de Rigidez Local de Elemento com Funções de Forma

Completas $\quad 119$

4.3.4.1 Matriz de Rigidez Elástica com Funções de Forma Completas 120

4.3.4.2 Matriz de Rigidez Geométrica com Funções de Forma

Completas 121

4.3.4.3 Matriz de Rigidez Tangente 123 
4.4 Teoria de Flexão de Timoshenko 124

4.4.1 Matriz de Rigidez Elástica $\quad 124$

4.4.2 Matriz de Rigidez Geométrica 126

4.4.3 Matriz de Rigidez Local de Elemento Espacial (3D) 128

4.4.3.1 Matriz de Rigidez Elástica Local no Plano xz 128

4.4.3.2 Matriz de Rigidez Geométrica Local no Plano xz 132

4.4.3.3 Torção Pura 134

4.4.3.4 Interação entre Torção e Carga Axial 135

4.4.3.5 Rotações Finitas 138

4.4.4 Matriz de Rigidez Local de Elemento com Funções de Forma

Completas 138

4.4.4.1 Matriz de Rigidez Elástica com Funções de Forma Completas 139

4.4.4.2 Matriz de Rigidez Geométrica com Funções de Forma

Completas 140

4.4.4.3 Matriz de Rigidez Tangente 142

5 Cargas Nodais Equivalentes 143

5.1 Equilíbrio de Elemento Infinitesimal na Configuração $\begin{array}{ll}\text { Indeformada } & 147\end{array}$

5.1.1 Teoria de Flexão de Euler-Bernoulli 147

5.1.2 Teoria de Flexão de Timoshenko 147

5.2 Equilíbrio de Elemento Infinitesimal na Configuração Deformada 148

5.2.1 Teoria de Flexão Euler-Bernoulli 148

5.2.2 Teoria de Flexão de Timoshenko 150

6 Aplicações Numéricas 154

6.1 Carga Crítica de Colunas 157

6.1.1 Matriz de Rigidez de Timoshenko considerando Termos de Grau

Elevado no Tensor Deformação e Funções de Forma Cúbicas 158

6.1.2 Matriz de Rigidez Completa de Euler-Bernoulli 161

6.1.3 Matriz de Rigidez Completa de Timoshenko 164

6.2 Carga Crítica de Viga Contínua 166 
6.2.1 Matriz de Rigidez de Timoshenko considerando Termos de Grau Elevado no Tensor Deformação e Funções de Forma Cúbicas 167

6.2.2 Matriz de Rigidez Completa de Euler-Bernoulli 168

6.2.3 Matriz de Rigidez Completa de Timoshenko 169

6.3 Carga Crítica para Pórtico de Roorda 171

6.3.1 Matriz de Rigidez de Timoshenko considerando Termos de Grau

Elevado no Tensor Deformação e Funções de Forma Cúbicas 172

6.3.2 Matriz de Rigidez Completa de Euler-Bernoulli 173

6.3.3 Matriz de Rigidez Completa de Timoshenko 174

6.4 Carga Crítica para Pórtico 176

6.4.1 Matriz de Rigidez de Timoshenko considerando Termos de Grau

Elevado no Tensor Deformação e Funções de Forma Cúbicas 177

6.4.2 Matriz de Rigidez Completa de Euler-Bernoulli 178

6.4.3 Matriz de Rigidez Completa de Timoshenko 179

6.5 Carga Crítica para Pórtico Espacial 180

6.5.1 Matriz de Rigidez de Timoshenko considerando Termos de Grau

Elevado no Tensor Deformação e Funções de Forma Cúbicas 183

6.5.2 Matriz de Rigidez Completa de Euler-Bernoulli 184

6.5.3 Matriz de Rigidez Completa de Timoshenko 185

6.6 Carga Crítica para Pórtico Espacial com Cobertura em Treliça 187

6.6.1 Matriz de Rigidez de Timoshenko considerando Termos de Grau

Elevado no Tensor Deformação e Funções de Forma Cúbicas 188

6.6.2 Matriz de Rigidez Completa de Euler-Bernoulli 189

6.6.3 Matriz de Rigidez Completa de Timoshenko 190

6.7 Carga Crítica para Pórtico de Roorda Espacial 191

6.7.1 Matriz de Rigidez de Timoshenko considerando Termos de Grau

Elevado no Tensor Deformação e Funções de Forma Cúbicas 193

6.7.2 Matriz de Rigidez Completa de Euler-Bernoulli 194

6.7.3 Matriz de Rigidez Completa de Timoshenko 195

6.8 Carga Crítica para Pórtico Espacial com Pilar Inclinado 196 
6.8.1 Matriz de Rigidez de Timoshenko considerando Termos de Grau Elevado no Tensor Deformação e Funções de Forma Cúbicas

6.8.2 Matriz de Rigidez Completa de Euler-Bernoulli 200

6.8.3 Matriz de Rigidez Completa de Timoshenko 201

6.9 Carga Crítica para Pórtico Espacial com Torção 203

6.9.1 Matriz de Rigidez de Timoshenko considerando Termos de Grau

Elevado no Tensor Deformação e Funções de Forma Cúbicas 205

6.9.2 Matriz de Rigidez Completa de Euler-Bernoulli 207

6.9.3 Matriz de Rigidez Completa de Timoshenko 208

6.10 Carga Crítica para Pórtico Espacial com Pilares Inclinados e Torção

6.10.1 Matriz de Rigidez de Timoshenko considerando Termos de Grau Elevado no Tensor Deformação e Funções de Forma Cúbicas 211

6.10.2 Matriz de Rigidez Completa de Euler-Bernoulli 212

6.10.3 Matriz de Rigidez Completa de Timoshenko 214

7 Conclusão 218

7.1 Considerações Finais 218

7.2 Desenvolvimentos Futuros 222

8 Referências bibliográficas 224

Apêndice A Funções de Forma para Elementos Rotulados:

Comportamento à Flexão

A.1 Funções de Forma Segundo a Teoria de Euler-Bernoulli para

Elemento na Configuração Indeformada (Rótula na Esquerda) 230

A.2 Funções de Forma Segundo a Teoria de Euler-Bernoulli para

Elemento na Configuração Indeformada (Rótula na Direita) 231

A.3 Funções de Forma Segundo a Teoria de Timoshenko para

Elemento na Configuração Indeformada (Rótula na Esquerda) 232

A.4 Funções de Forma Segundo a Teoria de Timoshenko para Elemento na Configuração Indeformada (Rótula na Direita) 233

A.5 Funções de Forma Segundo a Teoria de Euler-Bernoulli para Elemento na Configuração Deformada (Rótula na Esquerda) 234 
A.6 Funções de Forma Segundo a Teoria de Euler-Bernoulli para Elemento na Configuração Deformada (Rótula na Direita) 236

A.7 Funções de Forma Segundo a Teoria de Timoshenko para Elemento na Configuração Deformada (Rótula na Esquerda) 238

A.8 Funções de Forma Segundo a Teoria de Timoshenko para Elemento na Configuração Indeformada (Rótula na Direita)

Apêndice B Matrizes de Rigidez Locais Considerando Teoria de Flexão de Euler-Bernoulli

B.1 Matriz de Rigidez Geométrica Local com Funções de Forma Cúbicas: Planos Indepedentes (EBBT_Large)

B.2 Matriz de Rigidez Geométrica Local com Funções de Forma Cúbicas: Interação Torção com Carga Axial (EBBT_Large)

B.3 Matriz de Rigidez Geométrica Local Final com Funções de Forma Cúbicas (EBBT_Large)

B.4 Matriz de Rigidez Local com Funções de Forma Completas: "1a Ordem" (EBBT_Complete) - Tração

B.5 Matriz de Rigidez Local com Funções de Forma Completas: "1a Ordem" (EBBT_Complete) - Compressão

B.6 Matriz de Rigidez Local com Funções de Forma Completas: "2a Ordem" (EBBT_Complete) - Tração

B.7 Matriz de Rigidez Local com Funções de Forma Completas: " 2 a Ordem" (EBBT_Complete) - Compressão

B.8 Matriz de Rigidez Local com Funções de Forma Completas: Interação Torção com Carga Axial (EBBT_Complete) - Tração

B.9 Matriz de Rigidez Local com Funções de Forma Completas: Interação Torção com Carga Axial (EBBT_Complete) Compressão

B.10 Matriz de Rigidez Local com Aproximação em Série de Taylor (EBBT_2tr; EBBT_3tr e EBBT_4tr)

Apêndice C Matrizes de Rigidez Locais Considerando Teoria de Flexão de Timoshenko

C.1 Matriz de Rigidez Geométrica Local com Funções de Forma Cúbicas: Planos Independentes (TBT_Large) 
C.2 Matriz de Rigidez Geométrica Local com Funções de Forma Cúbicas: Interação Torção com Carga Axial (TBT_Large)

C.3 Matriz de Rigidez Geométrica Local Final com Funções de Forma Cúbicas (TBT_Large)

C.4 Matriz de Rigidez Local com Funções de Forma Completas: "1a Ordem" (TBT_Complete) - Tração

C.5 Matriz de Rigidez Local com Funções de Forma Completas: "1a Ordem" (TBT_Complete) - Compressão

C.6 Matriz de Rigidez Local com Funções de Forma Completas: " $2^{a}$ Ordem" (TBT_Complete) - Tração

C.7 Matriz de Rigidez Local com Funções de Forma Completas: "2a Ordem" (TBT_Complete) - Compressão

C.8 Matriz de Rigidez Local com Funções de Forma Completas: Interação Torção com Carga Axial (TBT_Complete) - Tração

C.9 Matriz de Rigidez Local com Funções de Forma Completas: Interação Torção com Carga Axial (TBT_Complete) Compressão

C.10 Matriz de Rigidez Local com Aproximação em Série de Taylor (TBT_2tr; TBT_3tr e TBT_4tr)

Apêndice D Metodologias de Análise Não Linear 291

D.1 Metodologia de Solução 291

D.2 Teoria do Espaço Dimensional $N+1$ 293

D.3 Metodologia Unificada de Solução Não Linear 294

D.3.1 Método de Controle de Carga 294

D.3.2 Método de Controle de Comprimento de Arco 


\section{Lista de Figuras}

Figura 2.1 - Campo de deslocamentos no interior de uma barra.

Figura 2.2 - Componentes de tensões em um elemento infinitesimal de barra

Figura 2.3 - Deformação de Viga

Figura 2.4 - Relação entre forças internas e deformações

Figura 2.5 - Equilíbrio de um elemento de viga-coluna em sua configuração indeformada

Figura 2.6 - Consideração do cisalhamento na viga de Timoshenko

Figura 2.7 - Equilíbrio de um elemento infinitesimal em sua configuração deformada

Figura 2.8 - Esforços e deslocamentos na forma clássica da viga de Timoshenko

Figura 2.9 - Superposição de estágios do método da rigidez direta

Figura 2.10 - Soluções homogêneas e particulares de barra solicitada por carga uniforme

Figura 2.11 - Resumo das teorias de flexão de Euler-Bernoulli e Timoshenko considerando o equilíbrio de elemento infinitesimal na configuração indeformada

Figura 2.12 - Resumo das teorias de flexão de Euler-Bernoulli e Timoshenko considerando o equilíbrio de elemento infinitesimal na configuração deformada

Figura 3.1 - Configuração deformada de barra isolada 75

Figura 3.2 - Elemento infinitesimal na configuração indeformada $\quad 77$

Figura 3.3 - Elemento infinitesimal na configuração deformada 81

Figura 4.1 - Configurações de equilíbrio $C_{0}, C_{i}, C_{n-1}$ e $C_{n}$

Figura 4.2 - Elemento de viga 102

Figura 4.3 - Flexão nos planos principais e torção de uma barra espacial

Figura 4.4 - Elemento 3-D 104

Figura 4.5 - Interação entre torção e carga axial 110 
Figura 4.6 - Equilíbrio de nó

Figura 4.7 - Incremento de momento $\quad 115$

Figura 4.8 - Transformação espacial entre dois vetores 115

Figura 4.9 - Rotação finita de uma seção transversal 116

Figura 5.1 - Teorema de Betti para cálculo da reação vertical na extremidade inicial

Figura 5.2 - Teorema de Betti para cálculo da reação momento na extremidade inicial

Figura 5.3 - Reações de engastamento perfeito de barras isoladas 145

Figura 5.4 - Carregamento externo trapezoidal em barra isolada 145

Figura 5.5 - Composição de carregamento externo trapezoidal em barra isolada

Figura 5.6 - Carregamento axial trapezoidal em barra isolada $\quad 146$

Figura 6.1 - Colunas analisadas $\quad 157$

Figura 6.2 - Curva de Equilíbrio para coluna engastada e livre para diferentes índices de esbeltez com 5 elementos por barra

Figura 6.3 - Curva de Equilíbrio para coluna biapoiada para diferentes índices de esbeltez com 5 elementos por barra

Figura 6.4 - Curva de Equilíbrio para coluna engastada e apoiada diferentes índices de esbeltez com 5 elementos por barra

Figura 6.5 - Curva de Equilíbrio para coluna engastada com

1 elemento por barra

Figura 6.6 - Curva de Equilíbrio para coluna biapoiada com

1 elemento por barra

Figura 6.7 - Curva de Equilíbrio para coluna engastada e apoiada com 1 elemento por barra

Figura 6.8 - Curva de Equilíbrio para coluna engasta com 1 elemento por barra (Timoshenko)

Figura 6.9 - Curva de Equilíbrio para coluna biapoiada com

1 elemento por barra (Timoshenko)

Figura 6.10 - Curva de Equilíbrio para coluna engastada e apoiada com 1 elemento por barra (Timoshenko)

Figura 6.11 - Viga-coluna contínua 
Figura 6.12 - Curva de Equilíbrio para viga-coluna contínua $\lambda=10 \mathrm{e}$ $\lambda=6,6$, com 5 elementos por barra

Figura 6.13 - Curva de Equilíbrio para viga-coluna contínua $\lambda=4,0 \mathrm{e}$ $\lambda=2,0$, com 5 elementos por barra

Figura 6.14 - Curva de Equilíbrio para viga-coluna contínua, com

1 elemento por barra

Figura 6.15 - Curva de Equilíbrio para viga-coluna contínua, com

1 elemento por barra (Timoshenko)

Figura 6.16 - Pórtico de Roorda

Figura 6.17 - Curva de Equilíbrio para Pórtico de Roorda $\lambda=10 \mathrm{e}$ $\lambda=6,6$, com 5 elementos por barra

Figura 6.18 - Curva de Equilíbrio para Pórtico de Roorda $\lambda=4,0$ e $\lambda=2,0$, com 5 elementos por barra

Figura 6.19 - Curva de Equilíbrio para pórtico de Roorda, com

1 elemento por barra

Figura 6.20 - Curva de Equilíbrio para pórtico de Roorda, com

1 elemento por barra (Timoshenko)

Figura 6.21 - Pórtico engastado na base

Figura 6.22 - Curva de Equilíbrio para Pórtico com diferentes $\lambda$, com 5 elementos por barra

Figura 6.23 - Curva de Equilíbrio para pórtico, com 1 elemento por barra

Figura 6.24 - Curva de Equilíbrio para pórtico, com 1 elemento por barra (Timoshenko)

Figura 6.25 - Pórtico espacial

Figura 6.26 - Estudo de convergência para pórtico espacial

Figura 6.27 - Deformada do pórtico espacial

Figura 6.28 - Curva de Equilíbrio para pórtico espacial de um pavimento $\lambda=10$ e $\lambda=6,6$, com 4 elementos por barra

Figura 6.29 - Curva de Equilíbrio para pórtico espacial de um pavimento $\lambda=4,0$ e $\lambda=2,0$, com 4 elementos por barra

Figura 6.30 - Curva de Equilíbrio para pórtico espacial, com 
Figura 6.31 - Curva de Equilíbrio para pórtico espacial, com

1 elemento por barra (Timoshenko)

Figura 6.32 - Pórtico espacial com cobertura em treliça

Figura 6.33 - Deformada do pórtico espacial com cobertura em treliça 188

Figura 6.34 - Curva de Equilíbrio para pórtico espacial com cobertura

em treliça $\lambda=10$ e $\lambda=6,6$, com 4 elementos por barra

Figura 6.35 - Curva de Equilíbrio para pórtico espacial com cobertura em treliça $\lambda=4,0$ e $\lambda=2,0$, com 4 elementos por barra

Figura 6.36 - Curva de Equilíbrio para pórtico espacial com cobertura em treliça, com 1 elemento por barra

Figura 6.37 - Curva de Equilíbrio para pórtico espacial com cobertura em treliça, com 1 elemento por barra (Timoshenko)

Figura 6.38 - Pórtico de Roorda Espacial

Figura 6.39 - Deformada para pórtico de Roorda espacial

Figura 6.40 - Curva de Equilíbrio para pórtico de Roorda espacial $\lambda=10$ e $\lambda=6,6$, com 4 elementos por barra

Figura 6.41 - Curva de Equilibrio para pórtico de Roorda espacial $\lambda=4,0$ e $\lambda=2,0$, com 4 elementos por barra

Figura 6.42 - Curva de Equilíbrio para pórtico de Roorda espacial $\lambda=10$, com 2 elementos por barra (Euler-Bernoulli)

Figura 6.43 - Curva de Equilíbrio para pórticode Roorda espacial $\lambda=4,0$, com 1 elemento por barra (Timoshenko)

Figura 6.44 - Pórtico espacial com pilares inclinados

Figura 6.45 - Estudo de convergência para pórtico espacial com barra inclinada

Figura 6.46 - Deformada para pórtico espacial com pilares inclinados 198

Figura 6.47 - Curva de Equilíbrio para pórtico espacial com pilares inclinados $\lambda=10$ e $\lambda=6,6$, com 4 elementos por barra

Figura 6.48 - Curva de Equilíbrio para pórtico espacial com pilares inclinados $\lambda=4,0$ e $\lambda=2,0$, com 4 elementos por barra

Figura 6.49 - Curva de Equilíbrio para pórtico espacial com pilares inclinados $\lambda=4,0$, com 1 elemento por barra (Euler-Bernoulli)

Figura 6.50 - Curva de Equilíbrio para pórtico espacial com pilares 
inclinados $\lambda=4,0$, com 1 elemento por barra (Timoshenko)

Figura 6.51 - Pórtico espacial com torção 203

Figura 6.52 - Deformada pórtico espacial com torção vista isométrica 204

Figura 6.53 - Deformada pórtico espacial com torção vista superior 204

Figura 6.54 - Deformada pórtico espacial com torção vista frontal 205

Figura 6.55 - Curva de Equilíbrio para pórtico espacial com torção $\lambda=10$ e $\lambda=6,6$, com 4 elementos por barra

Figura 6.56 - Curva de Equilíbrio para pórtico espacial com torção $\lambda=4,0$ e $\lambda=2,0$, com 4 elementos por barra

Figura 6.57 - Curva de Equilíbrio para pórtico espacial com torção $\lambda=10$, com 1 elemento por barra (Euler-Bernoulli)

Figura 6.58 - Curva de Equilíbrio para pórtico espacial com torção $\lambda=4,0$, com 1 elemento por barra (Timoshenko) 208 Figura 6.59 - Pórtico espacial com pilares inclinados e torção 209

Figura 6.60 - Deformada pórtico espacial com pilares inclinados e torção vista isométrica

Figura 6.61 - Deformada pórtico espacial com pilares inclinados e torção vista superior

Figura 6.62 - Curva de Equilíbrio para pórtico espacial com barra inclinada e torção $\lambda=10$ e $\lambda=6,6$, com 4 elementos por barra

Figura 6.63 - Curva de Equilíbrio para pórtico espacial com barra inclinada e torção $\lambda=4,0$ e $\lambda=2,0$, com 4 elementos por barra

Figura 6.64 - Curva de Equilíbrio para pórtico espacial com barra inclinada e torção $\lambda=10$, com 1 elemento por barra (Euler-Bernoulli) 213 Figura 6.65 - Curva de Equilíbrio para pórtico espacial com barra inclinada e torção $\lambda=6,6$, com 1 elemento por barra (Timoshenko) 214 Figura 6.66 - Resumo dos resultados numéricos para a teoria de flexão de Euler-Bernoulli

Figura 6.67 - Resumo dos resultados numéricos para a teoria de flexão de Timoshenko

Figura A.1 - Interpolação de deslocamentos para barra articulada $\quad 230$

Figura D.1 - Método de controle de carga 295

Figura D.2 - Método de controle de comprimento de arco 


\section{Lista de Símbolos}

\section{Parâmetros geométricos gerais}

$X \quad$ eixo global de um modelo estrutural.

$Y \quad$ eixo global de um modelo estrutural.

$Z \quad$ eixo global de um modelo estrutural.

$x \quad$ eixo local de uma barra na sua direção longitudinal

$y$ eixo local de uma barra em uma das direções transversais associada a uma direção principal da seção transversal da barra.

$z \quad$ eixo local de uma barra em uma das direções transversais associada a uma direção principal da seção transversal da barra.

$d x \quad$ comprimento de um elemento infinitesimal de barra.

$l, L \quad$ comprimento de uma barra.

$V_{1} \quad$ posição final de um vetor espacial após rotação.

$V_{0} \quad$ posição inicial de um vetor espacial anterior a rotação.

$R \quad$ matriz de transformação espacial ortogonal.

$\{b\}$ ponto em uma seção transversal após rotação.

$\{a\}$ ponto em uma seção transversal anterior a rotação.

\section{Parâmetros geométricos de seção transversal}

$h$ altura genérica da seção transversal.

A área da seção transversal.

$\chi \quad$ fator de forma que define a área efetiva para cisalhamento.

$A_{s}$ área da seção transversal efetiva para cisalhamento genérica, $A_{s}=A / \chi$.

I momento de inércia à flexão da seção transversal genérico.

$I_{x} \quad$ constante de torção da seção transversal.

$I_{y} \quad$ momento de inércia à flexão da seção transversal em relação ao eixo $y$.

$I_{z} \quad$ momento de inércia à flexão da seção transversal em relação ao eixo $z$.

$J_{p} \quad$ momento polar de inércia da seção transversal.

$\lambda \quad$ índice de esbeltez de barra dado por: $L / h$ 
$\Omega \quad$ parâmetro auxiliar genérico para caracterização de elementos de barra: $\Omega=E I / \chi G A L^{2}$.

$\Omega_{y} \quad$ parâmetro auxiliar para caracterização de elementos de barra no plano $x y: \Omega=E I_{z} / \chi G A L^{2}$

$\Omega_{z} \quad$ parâmetro auxiliar para caracterização de elementos de barra no plano $x Z: \Omega=E I_{y} / \chi G A L^{2}$.

\section{Parâmetros do campo de deslocamentos de barras}

$\delta \quad$ operador diferencial.

[V] matriz de operadores diferenciais que relaciona componentes de deformação com o campo de deslocamentos.

$u \quad$ deslocamento axial de um ponto qualquer do interior de uma barra na direção de $x$.

$v \quad$ deslocamento transversal de um ponto qualquer do interior de uma barra na direção de $y$.

$w \quad$ deslocamento transversal de um ponto qualquer do interior de uma barra na direção de $z$.

deslocamento axial (na direção de $x$ ) de ponto do eixo da barra.

deslocamento transversal na direção de $y$ de ponto do eixo da barra.

parcela local de engastamento perfeito (estágio l) do deslocamento transversal de ponto do eixo da barra.

$v_{0}^{\text {II }} \quad$ parcela global de modelo discreto (estágio II) do deslocamento transversal de ponto do eixo da barra.

$v_{h} \quad$ parcela homogênea da solução analítica do deslocamento transversal de ponto do eixo da barra.

$v_{p} \quad$ parcela particular da solução analítica do deslocamento transversal de ponto do eixo da barra.

$w_{0} \quad$ deslocamento transversal na direção de $z$ de ponto do eixo da barra.

$\Delta_{A} \quad$ deslocamento transversal na extremidade inicial da barra para um carregamento genérico.

$\theta$ rotação da seção transversal por flexão de um ponto de barra.

$\theta_{h} \quad$ parcela homogênea da solução analítica da rotação por flexão de ponto de barra.

$\theta_{p} \quad$ parcela particular da solução analítica da rotação por flexão de ponto de barra. 
$\theta_{x} \quad$ rotação da seção transversal por flexão em torno do eixo $x$ de um ponto de barra.

$\theta_{y} \quad$ rotação da seção transversal por flexão em torno do eixo $y$ de um ponto de barra.

$\theta_{z} \quad$ rotação da seção transversal por flexão em torno do eixo $z$ de um ponto de barra.

$\theta_{A}$ rotação da seção transversal na extremidade inicial da barra para um carregamento genérico.

$\{\tilde{u}\} \quad$ vetor do campo de deslocamentos generalizados em uma barra.

$\rho \quad$ raio de curvatura da elástica transversal $v_{0}$ da barra.

$d_{1}{ }^{\prime}, d_{u 1}$ deslocamento axial na extremidade inicial da barra.

$d_{4}{ }^{\prime}, d_{u 4}$ deslocamento axial na extremidade final da barra.

$d_{2}{ }^{\prime}, d_{v 2}$ deslocamento transversal na extremidade inicial no plano local $x y$ de uma barra.

$d_{w 2} \quad$ deslocamento transversal na extremidade inicial no plano local $x z$ de uma barra.

$d_{3}{ }^{\prime}, d_{v 3}$ rotação na extremidade inicial no plano local xy de uma barra.

$d_{w 3} \quad$ rotação na extremidade inicial no plano local $x z$ de uma barra.

$d_{5}{ }^{\prime}, d_{v 5}$ deslocamento transversal na extremidade final no plano local $x y$ de uma barra.

$d_{w 5} \quad$ deslocamento transversal na extremidade final no plano local $x z$ de uma barra.

$d_{6}{ }^{\prime}, d_{v 6}$ rotação na extremidade final no plano local $x y$ de uma barra.

$d_{w 6} \quad$ rotação na extremidade final no plano local $x z$ de uma barra.

$\left\{d^{\prime}\right\}$ vetor de deslocamentos axiais, transversais e rotações nodais em uma barra.

$\{u\} \quad$ vetor de deslocamentos axiais nodais em uma barra.

$\{v\} \quad$ vetor de deslocamentos transversais e rotações nodais no plano local $x y$ de uma barra.

$\{w\} \quad$ vetor de deslocamentos transversais e rotações nodais no plano local $x z$ de uma barra.

$c_{i} \quad$ constante de integração do campo de deslocamentos e rotações de barra. 
$\{c\}$ vetor das constantes de integração do campo de deslocamentos e rotações de barra.

$[X]$ matriz dos polinômios de interpolação do campo de deslocamentos e rotações de barra.

[H] matriz dos polinômios de interpolação do campo de deslocamentos e rotações avaliados nas coordenadas nodais.

$[N]$ matriz das funções de forma de uma barra genérica.

$\left\{N_{u}\right\} \quad$ vetor das funções de forma de deslocamento axial de uma barra genérica.

$\left\{N_{v}\right\} \quad$ vetor das funções de forma de deslocamento transversal no plano local $x y$ de uma barra genérica.

$\left\{N_{w}\right\} \quad$ vetor das funções de forma de deslocamento transversal no plano local $x z$ de uma barra genérica.

$\left\{N_{\theta x}\right\}$ vetor das funções de forma de rotação em torno do eixo local $x$ de uma barra genérica.

$\left\{N_{\theta z}\right\} \quad$ vetor das funções de forma de rotação no plano local $x y$ de uma barra genérica.

$\left\{N_{\theta y}\right\} \quad$ vetor das funções de forma de rotação no plano local $x z$ de uma barra genérica.

$N_{1}^{u} \quad$ função de forma de deslocamento axial para deslocabilidade axial na extremidade inicial da barra.

$N_{4}^{u} \quad$ função de forma de deslocamento axial para deslocabilidade axial na extremidade final da barra.

$N_{2}^{v} \quad$ função de forma de deslocamento transversal no plano local $x y$ para deslocabilidade transversal na extremidade inicial da barra.

$N_{3}^{v} \quad$ função de forma de deslocamento transversal no plano local $x y$ para deslocabilidade rotação na extremidade inicial da barra.

$N_{5}^{v} \quad$ função de forma de deslocamento transversal no plano local $x y$ para deslocabilidade transversal na extremidade final da barra.

$N_{6}^{v} \quad$ função de forma de deslocamento transversal no plano local $x y$ para deslocabilidade rotação na extremidade final da barra.

$N_{2}^{\theta} \quad$ função de forma de rotação no plano local $x y$ para deslocabilidade transversal na extremidade inicial da barra.

$N_{3}^{\theta} \quad$ função de forma de rotação no plano local xy para deslocabilidade rotação na extremidade inicial da barra. 
$N_{5}^{\theta} \quad$ função de forma de rotação no plano local $x y$ para deslocabilidade transversal na extremidade final da barra.

$N_{6}^{\theta} \quad$ função de forma de rotação no plano local $x y$ para deslocabilidade rotação na extremidade final da barra.

$N_{2}^{w} \quad$ função de forma de deslocamento transversal no plano local $x z$ para deslocabilidade transversal na extremidade inicial da barra.

$N_{3}^{w} \quad$ função de forma de deslocamento transversal no plano local $x z$ para deslocabilidade rotação na extremidade inicial da barra.

$N_{5}^{w} \quad$ função de forma de deslocamento transversal no plano local $X Z$ para deslocabilidade transversal na extremidade final da barra.

$N_{6}^{w} \quad$ função de forma de deslocamento transversal no plano local $x \boldsymbol{Z}$ para deslocabilidade rotação na extremidade final da barra.

$N_{i}^{u} \quad$ função de forma de deslocamento axial para deslocabilidade axial genérica na barra.

$N_{i}^{v} \quad$ função de forma de deslocamento transversal para deslocabilidade transversal genérica na barra.

\section{Parâmetros do campo de deformações de barras}

$\varepsilon_{x}, \varepsilon_{x x}$ deformação normal na direção axial de uma barra.

$\varepsilon_{y} \quad$ deformação normal na direção transversal de uma barra.

$\gamma_{x y} \quad$ distorção de cisalhamento de um ponto de uma barra no plano $x y$.

$\gamma_{x z} \quad$ distorção de cisalhamento de um ponto de uma barra no plano $x z$.

$\varepsilon_{x}^{a} \quad$ deformação normal na direção axial devida ao efeito axial em uma barra: $\varepsilon_{x}^{a}=d u_{0} / d x$.

$\kappa^{f} \quad$ gradiente da rotação por flexão: $\kappa^{f}=d \theta / d x$.

$\varepsilon_{x}^{f} \quad$ deformação normal na direção axial devida ao efeito de flexão em uma barra.

$\gamma \quad$ distorção por cisalhamento genérica.

$\{\varepsilon\} \quad$ vetor de deformações generalizadas do elemento infinitesimal de barra.

$\varepsilon_{i j}{ }^{(t+\Delta t)}$ tensor deformação de Green-Lagrange em uma configuração desconhecida.

$\varepsilon_{i j}{ }^{(t)}$ tensor deformação de Green-Lagrange em uma configuração conhecida.

$\Delta \varepsilon_{i j} \quad$ incremento de deformação entre duas configurações. 
$\Delta e_{i j} \quad$ parcela linear genérica do tensor deformação de Green-Lagrange.

$\Delta e_{x x} \quad$ parcela linear do tensor deformação de Green-Lagrange na direção axial em uma barra.

$\Delta e_{x y} \quad$ parcela linear da distorção de cisalhamento do tensor deformação de Green-Lagrange de uma barra no plano xy.

$\Delta e_{x z} \quad$ parcela linear da distorção de cisalhamento do tensor deformação de Green-Lagrange de uma barra no plano Xz.

$\Delta \eta_{i j} \quad$ parcela não linear genérica do tensor deformação de GreenLagrange.

$\Delta \eta_{x x} \quad$ parcela não linear do tensor deformação de Green-Lagrange na direção axial em uma barra.

$\Delta \eta_{x y} \quad$ parcela não linear da distorção de cisalhamento do tensor deformação de Green-Lagrange de uma barra no plano xy.

$\Delta \eta_{x z}$ parcela não linear da distorção de cisalhamento do tensor deformação de Green-Lagrange de uma barra no plano xy.

\section{Parâmetros do campo de tensões de barras}

$\sigma_{x}, \tau_{x x}$ tensão normal na direção $x$.

$\sigma_{y} \quad$ tensão normal na direção $y$.

$\tau_{x y} \quad$ tensão de cisalhamento por efeito cortante na direção local $y$.

$\tau_{x z} \quad$ tensão de cisalhamento por efeito cortante na direção local $z$.

$S_{i j}^{(t+\Delta t)}$ segundo tensor tensão de Piola-Kirchoff.

$\tau_{i j}^{(t)} \quad$ tensor tensão de Cauchy.

$\Delta \tau_{i j} \quad$ incremento de tensão entre duas configurações.

\section{Parâmetros da lei constitutiva de materiais e rigidez}

E módulo de elasticidade para uma solicitação uniaxial (propriedade de material).

$G \quad$ módulo de cisalhamento (propriedade de material).

$v \quad$ coeficiente de Poisson (propriedade de material).

$C_{i j k l}$ relação constitutiva do material.

$[S] \quad$ matriz de rigidez do elemento infinitesimal de barra.

\section{Parâmetros das solicitações externas aplicadas em barras}

$p(x)$ taxa de carregamento de força longitudinal distribuída (na direção local $x$ ) na barra. 
$p_{a} \quad$ taxa de carregamento de força longitudinal distribuída no início da barra.

$p_{b} \quad$ taxa de carregamento de força longitudinal distribuída no final da barra.

$P_{j} \quad$ carga concentrada aplicada em um elemento de barra.

$M_{j} \quad$ carga momento aplicada em um elemento de barra.

$q \quad$ taxa de carregamento de força transversal na barra.

$q_{i} \quad$ taxa de carregamento transversal distribuído no início da barra.

$q_{f} \quad$ taxa de carregamento transversal distribuído no final da barra.

$q_{0} \quad$ componente uniforme da taxa de carregamento distribuído $q$.

$q_{1} \quad$ componente linear da taxa de carregamento distribuído $q$.

$P \quad$ carga axial genérica constante atuante em elemento infinitesimal.

$P_{c r} \quad$ carga crítica de flambagem da estrutura.

M momento fletor genérico, ou força no binário de flexão.

$T$ força nos binários de torção.

$\mu \quad$ parâmetro auxiliar para o desenvolvimento da equação diferencial do equilíbrio de elemento infinitesimal deformado: $\mu=\sqrt{ \pm P / E I}$.

$\Lambda \quad$ parâmetro auxiliar para o desenvolvimento da equação diferencial do equilíbrio de elemento infinitesimal deformado (teoria de flexão de Timoshenko): $\Lambda=\mu / \sqrt{1 \pm \Omega \mu^{2} L^{2}}$.

\section{Parâmetros dos esforços internos de barras}

$N$ esforço normal (esforço interno axial ou longitudinal).

$V$ esforço cortante (esforço interno transversal de cisalhamento) genérico ou parcela vertical da força atuante em uma seção transversal.

$V_{A} \quad$ reação vertical que atua na extremidade inicial de uma barra para um carregamento genérico.

$V_{B} \quad$ reação vertical que atua na extremidade final de uma barra para um carregamento genérico.

$Q_{y} \quad$ esforço cortante (esforço interno transversal de cisalhamento) na direção do eixo $y$.

$Q_{z} \quad$ esforço cortante (esforço interno transversal de cisalhamento) na direção do eixo $z$.

$Q \quad$ esforço cortante (esforço interno transversal de cisalhamento). 
$\alpha \quad$ parcela do momento fletor (esforço interno de flexão) na direção de rotação em torno do eixo $x$.

$M_{x} \quad$ momento fletor (esforço interno de flexão) na direção de rotação em torno do eixo $x$.

$M_{y} \quad$ momento fletor (esforço interno de flexão) na direção de rotação em torno do eixo $y$.

$M_{y 1} \quad$ momento fletor na extremidade inicial da barra (em torno do eixo local $y$ ).

$M_{y 2} \quad$ momento fletor na extremidade final da barra (em torno do eixo local $y$ ).

$M_{z} \quad$ momento fletor (esforço interno de flexão) na direção de rotação em torno do eixo $z$.

$M_{Z 1} \quad$ momento fletor na extremidade inicial da barra (em torno do eixo local z).

$M_{Z 2} \quad$ momento fletor na extremidade final da barra (em torno do eixo local $z)$.

$M_{A} \quad$ momento fletor que atua na extremidade inicial de uma barra para um carregamento genérico.

$M_{B} \quad$ momento fletor que atua na extremidade final de uma barra para um carregamento genérico.

$\{m\} \quad$ vetor de esforços internos do elemento infinitesimal.

\section{Parâmetros da formulação das cargas nodais equivalentes}

$\hat{f}_{i}^{\prime} \quad$ reação de engastamento perfeito de barra no sistema local: reação força ou momento que atua na direção da coordenada generalizada local $i^{\prime}$, na direção de um dos eixos locais, de uma barra com as extremidades fixas para equilibrá-la quando há uma solicitação externa genérica.

$f_{1}{ }^{\prime} \quad$ força axial que atua na extremidade inicial de uma barra para um carregamento genérico.

$f_{2}{ }^{\prime} \quad$ força transversal que atua na extremidade inicial de uma barra para um carregamento genérico.

$f_{3}{ }^{\prime} \quad$ momento de flexão que atua na extremidade inicial de uma barra para um carregamento genérico.

$f_{4}{ }^{\prime} \quad$ força axial que atua na extremidade inicial de uma barra para um carregamento genérico.

$f_{5}{ }^{\prime} \quad$ força transversal que atua na extremidade final de uma barra para um carregamento genérico. 
$f_{6}{ }^{\prime} \quad$ momento de flexão que atua na extremidade final de uma barra para um carregamento genérico.

$f_{02}$ força transversal que atua na extremidade inicial de uma barra para a componente uniforme $\left(q_{0}\right)$ da taxa de carregamento distribuído $q$.

$f_{03} \quad$ momento de flexão que atua na extremidade inicial de uma barra para a componente uniforme $\left(q_{0}\right)$ da taxa de carregamento distribuído $q$.

$f_{05} \quad$ força transversal que atua na extremidade final de uma barra para a componente uniforme $\left(q_{0}\right)$ da taxa de carregamento distribuído $q$.

$f_{06}$ momento de flexão que atua na extremidade final de uma barra para a componente uniforme $\left(q_{0}\right)$ da taxa de carregamento distribuído $q$.

$f_{0 i} \quad$ reação de engastamento perfeito de barra no sistema local: reação força ou momento que atua na direção da coordenada generalizada local $i^{\prime}$, para a componente uniforme $\left(q_{0}\right)$ da taxa de carregamento distribuído $q$.

$f_{x 2}$ força transversal que atua na extremidade inicial de uma barra para a componente linear $\left(q_{1}\right)$ da taxa de carregamento distribuído $q$.

$f_{x 3} \quad$ momento de flexão que atua na extremidade inicial de uma barra para a componente linear $\left(q_{1}\right)$ da taxa de carregamento distribuído $q$.

$f_{x 5} \quad$ força transversal que atua na extremidade final de uma barra para a componente linear $\left(q_{1}\right)$ da taxa de carregamento distribuído $q$.

$f_{x 6} \quad$ momento de flexão que atua na extremidade final de uma barra para a componente linear $\left(q_{1}\right)$ da taxa de carregamento distribuído $q$.

$f_{x i} \quad$ reação de engastamento perfeito de barra no sistema local: reação força ou momento que atua na direção da coordenada generalizada local $i^{\prime}$, para a componente linear $\left(q_{1}\right)$ da taxa de carregamento distribuído $q$.

$F \quad$ reação de engastamento perfeito de barra no sistema local calculada pela soma componente uniforme $\left(q_{0}\right)$ com a componente linear $\left(q_{1}\right)$ da taxa de carregamento distribuído $q$. 


\section{Parâmetros da formulação da matriz de rigidez tangente}

$c_{0}$ configuração inicial indeformada de um elemento de barra.

$c_{i} \quad$ configuração intermediária de um elemento de barra.

$c_{\mathrm{n}-1} \quad$ configuração imediatamente anterior à final de um elemento de barra.

$c_{\mathrm{n}} \quad$ configuração final de um elemento de barra.

$c_{0 \mathrm{n}} \quad$ configuração indeformada desconhecida de um elemento de barra devido ao movimento de corpo rígido.

$R^{(t+\Delta t)}$ trabalho virtual devido das forças externas em uma configuração desconhecida.

$U$ parcela linear da energia de deformação interna.

$U_{N L} \quad$ parcela não linear da energia de deformação interna.

$\left[K_{e, x y}\right]$ matriz de rigidez elástica de um elemento plano genérico no plano local $x y$.

$\left[K_{e, x z}\right]$ matriz de rigidez elástica de um elemento plano genérico no plano local $x z$.

$\left[K_{e}\right] \quad$ matriz de rigidez elástica de um elemento espacial genérico.

$\left[K_{g, x y}\right]$ matriz de rigidez geométrica de um elemento plano genérico no plano local $x y$.

$\left[K_{g, x z}\right]$ matriz de rigidez geométrica de um elemento plano genérico no plano local $x z$.

$\left[K_{\theta x}\right] \quad$ matriz de rigidez elástica de um elemento plano genérico devido à torção pura.

$\left[K_{g, R o f f i n}\right]$ influência das rotações finitas na matriz de rigidez geométrica de um elemento plano genérico.

\section{Parâmetros para metodologias de análise não linear}

$u_{j}^{i} \quad$ deslocamentos nodais do elemento de barra.

$u^{i-1} \quad$ deslocamentos nodais da configuração de equilíbrio previamente convergida.

$\Delta u_{j}^{i} \quad$ vetor de incremento dos deslocamentos nodais fornecidas pela iteração $j$, do incremento $i$.

$\Delta u_{j-1}^{i} \quad$ atualização nos deslocamentos nodais fornecidas pela iteração anterior $j-1$, da iteração $j$. 
$\delta u_{j}^{i} \quad$ vetor dos deslocamentos nodais da iteração $j$, do incremento $i$.

$q\left(u_{j}^{i}\right)$ forças internas (funções dos deslocamentos nodais) do elemento de barra.

$p_{j}^{i} \quad$ vetor de incremento das forças externas aplicadas ao elemento de barra.

$p^{i-1}$ forças externas da configuração de equilibrio previamente convergida.

$\Delta p_{j}^{i} \quad$ vetor de incremento das forças externas fornecidas pela iteração $j$, do incremento $i$.

$\Delta p_{j-1}^{i} \quad$ atualização forças externas fornecidas pela iteração anterior $j-1$, da iteração $j$.

$\delta p_{j}^{i} \quad$ vetor das forças externas da iteração $j$, do incremento $i$.

$r_{j}^{i} \quad$ força total residual (diferença entre as forças internas e externas).

$K_{j-1}^{i} \quad$ matriz de rigidez tangente da estrutura.

$\lambda_{j}^{i} \quad$ fator de carga.

$\overline{\Delta \lambda} \quad$ parâmetro de carga inicial.

$\bar{p} \quad$ vetor de carregamento de referência.

$a_{j}^{i}, b_{j}^{i}, c_{j}^{i}$ parâmetros de restrição.

$\Delta s_{j}^{i} \quad$ comprimento de arco que restringe o caminho de solução.

$\eta \quad$ parâmetros que específica o método do comprimento de arco. 
“l Senhor, o meu coração não é orgulhoso e os meus olhos não são arrogantes.

Não me envolvo com coisas grandiosas nem maravilhosas demais pra mim. ${ }^{2}$ De fato, acalmei meu coração e tranquilizei a minha alma. Sou como uma criança recém-amamentada por sua mãe; a minha alma é como essa criança. ${ }^{3}$ Ponha a sua esperança no Senhor, ó Israel, Desde agora e para sempre!"

$(\mathrm{S} 1,131,1-3)$ 


\section{Introdução}

\section{1}

\section{Considerações Iniciais}

O Método dos Elementos Finitos (MEF) possibilita a resolução dos meios contínuos mais complexos. A sua utilização permite escrever problemas da Engenharia, que podem ser representados matematicamente na forma de equações diferenciais, através de formulações variacionais, envolvendo equações integrais. Esse método torna possível resolver, por aproximação, o problema escrito na forma variacional, em que o domínio é discretizado em elementos (subdomínios) e as integrais do problema são calculadas em nível de elemento.

Com base em uma interpretação mais física, o comportamento estrutural analítico de um meio contínuo pode ser substituído por um comportamento discreto, no qual os parâmetros adotados no modelo discreto dependem do método de análise utilizado. O Método Clássico dos Deslocamentos para a análise de estruturas pode ser interpretado como um caso particular do MEF para barras, em que a configuração deformada da estrutura representa a solucão contínua, enquanto os deslocamentos nodais representam a solução discreta do problema. A solução contínua, neste método clássico, baseado em deslocamentos, pode ser encontrada por interpolação dos valores discretos dos deslocamentos e rotações nodais.

Em geral, para estruturas reticuladas com barras prismáticas, com seção transversal constante, a solução obtida pela interpolação é a mesma da solução analítica do problema. Este fato ocorre porque as funções de interpolação que definem a configuração deformada contínua são compatíveis com a idealização matemática do comportamento das barras, feita pela mecânica dos sólidos (Martha, 2018).

A diferença básica entre o Método dos Deslocamentos para a análise de pórticos planos e o MEF está situada no modelo estrutural. Apesar de ambos serem formados pela montagem de elementos individuais, no método dos 
deslocamentos os elementos aparecem naturalmente, a partir da própria concepção da estrutura, enquanto no MEF, a estrutura é modelada por um número finito de elementos.

Segundo Martha (2018), essa discretização da estrutura, com a utilização de elementos finitos, introduz simplificações em relação à idealização matemática feita para o comportamento da estrutura, tendo em vista que, em geral, as funções de interpolação que definem a configuração deformada de uma estrutura não são compatíveis com a idealização matemática do comportamento do meio contínuo. Assim, a solução do modelo discreto de elementos finitos é uma aproximação da solução analítica, enquanto a solução do modelo discreto de uma estrutura com barras prismáticas é igual à solução analítica da mecânica dos sólidos.

Dessa maneira, o resultado do MEF melhora à medida que a estrutura for mais discretizada. No entanto, com a utilização de funções de interpolação exatas, nas quais o comportamento contínuo de uma barra pode ser representado por parâmetros nodais, sem a consideração de nenhuma aproximação adicional, além das já contidas na idealização analítica do comportamento de barras, consegue-se uma discretização quase natural da estrutura.

Em outras palavras, a partir das soluções das equações diferenciais, que descrevem o equilíbrio de um elemento infinitesimal de barra, podem ser deduzidas expressões para a solução dos deslocamentos e rotações ao longo de uma barra. Então, quando as funções de forma são obtidas diretamente dessa solução homogênea da equação diferencial do problema contínuo, a discretização da barra não é necessária.

Para o problema linear, as equações de interpolação cúbicas representam esse resultado. Entretanto, para uma análise não linear geométrica, essa solução não consegue descrever completamente o problema, exigindo a utilização de um maior número de elementos na análise. Segundo Burgos \& Martha (2013), em geral, os programas de computador utilizam uma solução numérica para o problema, entretanto, como a análise de estabilidade é baseada em uma série de simplificações, as soluções numéricas dependem da discretização da estrutura.

Dessa forma, para este tipo de análise, tentando-se aproximar ao máximo o resultado exato do problema, pode-se empregar uma análise não linear em nível infinitesimal. Ou seja, a equação diferencial do problema e a sua solução 
consideram o equilíbrio de um elemento infinitesimal na sua configuração deformada.. Assim, nessa solução e nas funções de interpolação é levada em consideração a carga axial que atua no elemento infinitesimal.

Além disso, uma análise não linear geométrica de estruturas, utilizando o MEF, dependerá da teoria de flexão empregada, da descrição cinemática do problema, das relações entre deformações e deslocamentos e da metodologia de análise não linear utilizada.

Com relação à teoria de flexão, o comportamento da barra pode ser idealizado pelas teorias de Euler-Bernoulli e de Timoshenko, que leva em consideração a deformação por cisalhamento, e por teorias refinadas ou de alta ordem. A solução mais comum para flexão de barras é a utilização da teoria de Euler-Bernoulli, devido ao seu bom desempenho para descrever o comportamento de estruturas usuais. Esta teoria é a mais usualmente implementada em programas de análise estrutural e com um vasto número de aplicações.

Entretanto, em algumas situações, essa teoria não consegue predizer de forma satisfatória o comportamento da estrutura e, assim, faz-se necessária a consideração da teoria de flexão de Timoshenko, ou até mesmo teorias de alta ordem. Uma das aplicações mais usuais para a teoria de Timoshenko acontece para estruturas com baixo índice de esbeltez. Barras com comprimento muito maior que a sua altura, a distorção por cisalhamento não possui muita relevância. Mas, quando a relação comprimento e altura (índice de esbeltez) é relativamente pequena, o efeito do cisalhamento gera alterações significativas e deve ser considerado na análise. Outra importante aplicação desta teoria ocorre na análise de estruturas laminadas, em que a consideração da deformação por cisalhamento é importante devido à diferença de comportamento em cada lâmina da seção transversal.

A descrição cinemática do problema também desempenha um importante papel na análise, pois essa influenciará diretamente no desenvolvimento das equações do problema. Uma análise não linear geométrica empregando o MEF pode ser realizada pela formulação Lagrangeana total, Lagrangeana atualizada e pela formulação corrotacional, sendo que essas descrições diferenciam-se entre si basicamente com respeito à configuração de referência do elemento. 
Com respeito às relações entre deformações e deslocamentos, a matriz de rigidez geométrica de um elemento depende dessas relações, sendo que, usualmente, costuma-se desprezar os termos de ordem elevada do tensor deformação na construção dessa matriz, mas, a medida que se queira refinar a solução, pode-se empregar mais termos do tensor na análise.

Todas essas considerações: descrição cinemática, relações entre deformações e deslocamentos, e funções de interpolação, que consideram o carregamento axial, fornecem não linearidade ao problema. Neste trabalho, todos esses efeitos serão integrados.

Finalmente, para descrever a curva de equilíbrio em uma análise não linear geométrica é fundamental a utilização de algoritmos para solução das equações não lineares, que, dependendo do problema e da intensidade das não linearidades, exigem maiores esforços computacionais. Um único algoritmo não será capaz de resolver qualquer tipo de problema não linear e um programa computacional deve fornecer metodologias diferentes para um sistema não linear (Leon et al., 2011).

Com base nestas análises, este trabalho desenvolve uma formulação que integra as soluções para o problema de não linearidade geométrica e reduz a influência da discretização da barra, em um contexto de grandes deslocamentos e rotações. A partir de uma descrição Lagrangeana atualizada, dos termos de ordem elevada no tensor deformação de Green-Lagrange, das teorias de flexão de EulerBernoulli e de Timoshenko, calcula-se a matriz de rigidez tangente do elemento. Nenhum termo adicional se faz necessário, pois, as funções de interpolação dos deslocamentos utilizadas levam em consideração o carregamento axial e são obtidas diretamente da solução da equação diferencial do equilíbrio de um elemento infinitesimal na sua configuração deformada. Essas funções e a formulação delas obtidas são chamadas, neste trabalho, de funções de forma "completas" e formulação "completa", respectivamente. Acrescido a essa solução, empregam-se algoritmos de análise não linear para descrever a trajetória de equilíbrio da estrutura.

Para isso, primeiramente obtém-se as soluções das equações diferenciais do equilíbrio de um elemento infinitesimal na sua configuração deformada, considerando-se as teorias de flexão de Euler-Bernoulli e Timoshenko. Na sequência, obtêm-se as funções de interpolação. Essas funções completas geram a formulação completa, entretanto, ela pode ser escrita na forma de aproximação em 
série de Taylor, fornecendo mais termos para a matriz de rigidez tangente do que as formulações usuais. Essas aproximações fornecem uma maior precisão nos resultados e nesse trabalho foram desenvolvidas matrizes tangentes com até 3 e 4 termos. É importante observar que a aproximação em 2 termos fornece as matrizes de rigidez elástica e tangente usuais.

Todo o desenvolvimento é realizado para estruturas espaciais, considerandose inicialmente os planos com comportamento independente, o que gera uma análise plana. Em seguida, adiciona-se à matriz de rigidez tangente do elemento a interação entre torção e carga axial, como também as rotações finitas.

Dessa forma, o elemento proposto é capaz de considerar a não linearidade geométrica em estruturas 3-D sujeitas a grandes deslocamentos e rotações. Tanto a matriz de rigidez tangente como as cargas equivalentes nodais são construídas empregando-se a formulação completa.

\section{2 Motivação}

Os métodos numéricos para a análise das estruturas, como o MEF, necessitam de uma discretização para aproximar ao resultado contínuo da estrutura, formando a malha de elementos finitos. Por se tratar de uma aproximação, o resultado está susceptível à discretização da malha, convergindo para a solução exata com o maior refinamento dessa malha. Em razão disso, a análise por elementos finitos, em geral, exige um estudo de convergência, impondo a realização de mais testes e maior tempo de análise para estruturas de grande porte. Essa ação exige experiência do engenheiro, para que se possa definir a melhor discretização do problema proposto.

Com a interpolação dos parâmetros considerados através das funções de forma, funções estas calculadas a partir das equações diferenciais que governam os problemas, e desconsiderando quaisquer aproximações adicionais, além das já contidas na idealização analítica do comportamento de barras, consegue-se alcançar o resultado analítico sem a necessidade de uma intensa discretização da malha. Ante isso, os problemas podem ser resolvidos, utilizando-se de uma discretização mínima, quase que imediata. 
Para o caso de vigas-coluna, em que se apresenta o problema de estabilidade, é necessário realizar uma análise não linear de segunda ordem. Da mesma maneira, a solução do problema por elementos finitos exige um estudo de subdivisão da malha de elementos. Entretanto, com a utilização de funções de interpolação completas, este problema pode ser amenizado. Para se encontrar essas funções é necessário calcular a equação diferencial que rege o comportamento do elemento. Sendo assim, é preciso realizar o equilíbrio do elemento infinitesimal de barra em sua configuração deformada, para levar em consideração a carga axial atuante no elemento. $\mathrm{O}$ desenvolvimento e implementação dessas funções de interpolação contribuem para a análise não linear geométrica das estruturas.

Além disso, outros parâmetros influenciam no comportamento da estrutura para fornecer resultados mais próximos dos analíticos. Para vigas com baixa relação entre o seu comprimento e a sua altura, a consideração da deformação por cisalhamento, da teoria de flexão de Timoshenko, gera diferenças expressivas no comportamento dessas vigas quando comparadas à teoria de vigas de EullerBernoulli.

Outro fator que influencia nos resultados da análise não linear geométrica são os termos considerados no tensor deformação, ou seja, na relação entre deformações e deslocamentos. Além disso, a metodologia para solução do sistema não linear desempenha uma importante função na resposta final da estrutura.

Dessa forma, todas as questões até aqui apontadas serviram como motivação para o desenvolvimento deste trabalho, que objetivou especialmente investigar soluções integradas para as formulações do problema de não linearidade geométrica, considerando deformação por cisalhamento, grandes deslocamentos e rotações, e empregando-se os termos de ordem elevada do tensor deformação e funções de interpolação, obtidas diretamente da solução homogênea da equação diferencial do equilíbrio de um elemento infinitesimal na sua configuração deformada. Desse modo, espera-se reduzir a necessidade de discretização de uma estrutura em uma análise não linear geométrica.

Esses efeitos são tratados de forma unificada para análise de estruturas 3-D. A equação diferencial geral do problema é desenvolvida, envolvendo-se todas essas variáveis, que podem ser reduzidas ao se desconsiderar alguma das 
características específicas, a exemplo da deformação por cisalhamento ou da carga axial.

A partir das funções de forma obtidas, calcula-se a matriz de rigidez tangente da estrutura. Essa matriz espacial é obtida separando-se as influências de maneira didática. Primeiramente, os planos trabalham de modo independente e, na sequência, são inseridas a interação entre torção e carga axial, assim como a influência das rotações finitas.

Desse modo, investiga-se e avalia-se a influência das funções de forma na resposta do problema, como também da teoria de flexão empregada e da consideração ou não dos termos de ordem elevada no tensor deformação. Essa ação leva à busca de soluções mais próximas das analíticas, com uma mínima discretização das barras da estrutura.

A formulação desenvolvida é implementada no Framoop, processador do programa para análise de estruturas Ftool (Martha, 1999), para constar como uma possível escolha do usuário de matriz de rigidez tangente ao realizar análise não linear em futuras versões do programa. Por isso, também são desenvolvidas formulações, considerando a expansão em série de Taylor, de maneira a aperfeiçoar as matrizes usuais e contornar os problemas de instabilidade numérica da formulação completa.

\section{3 \\ Revisão Bibliográfica}

Problemas geometricamente não lineares, como a estabilidade de colunas, são bem conhecidos, desde a dedução de uma expressão para a carga crítica de uma viga biapoiada, submetida a carregamento axial. O tema tem sido estudado por diversos pesquisadores, tendo em vista a sua importância para a engenharia estrutural. A exemplo, a análise de vigas-coluna submetida a diferentes tipos de carregamento é apresentada e estudada de maneira didática em referências como Timoshenko \& Gere (1963) e Bazant \& Cedolin (2010), .

De fato, o efeito da não linearidade geométrica ganha importante relevância em elementos compridos. Entretanto, embora existam soluções analíticas, em geral, emprega-se uma solução numérica para o problema. Como essa análise de 
segunda ordem é baseada em uma série de simplificações, as soluções numéricas (MEF) empregadas nesse contexto de não linearidade geométrica dependem da discretização das barras da estrutura.

Para melhorar a resposta da análise numérica, cinco importantes fatores podem ser citados: a teoria de flexão considerada, a descrição cinemática do problema, as relações entre deformações e deslocamentos, a metodologia de análise não linear empregada e as funções de interpolação utilizadas.

A teoria de flexão de Euler-Bernoulli é a mais empregada para os problemas de não linearidade geométrica, com um grande número de aplicações, e implementada na maioria dos softwares de análise estrutural.

Contudo, em alguns casos, essa teoria não consegue predizer de forma correta o comportamento da estrutura. Para descrever elementos com seções laminadas ou com reduzido índice de esbeltez, a teoria de flexão de Timoshenko fornece melhores resultados. Essa teoria de flexão é apresentada por diversos autores, podendo-se citar Timoshenko \& Gere (1963), Friedman \& Kosmatka (1993), Pilkey et al. (1995) que desenvolve matriz de rigidez, de massa e geométrica para essa teoria, e Schramm et al. (1994), que trata o coeficiente de cisalhamento.

Além disso, diversos pesquisadores buscaram ainda teorias de flexão de ordem mais elevada, como em Levison (1981), Bickford (1982), Heyliger \& Reddy (1988), Reddy (1984), Petrolito (1995), Reddy et al. (1997), Reddy (1997), Tessler \& Gherlone (2007) e Meghare \& Jadhao (2015). Porém, os trabalhos não inserem essas teorias em um contexto de análise não linear geométrica, integrando com algoritmos de solução de sistemas não lineares, e poucos são os trabalhos que utilizam a teoria de Timoshenko para uma análise de segunda ordem.

Com relação à descrição cinemática, uma análise não linear geométrica pode ser realizada a partir de um referencial corrotacional, Lagrangeano total ou Lagrangeano atualizado. Essas descrições diferem basicamente com respeito a configuração de referência considerada (Felippa, 2017). Quando desenvolvidas consistentemente, a formulação Lagrangeana total e a atualizada produzem os mesmos resultados (McGuire et al., 2000). Essas formulações são bem desenvolvidas na literatura, como em Bathe (1996), Bathe \& Bolourchi (1979), no qual é realizada uma análise não linear tridimensional, usando-se os dois referenciais Lagrangeanos. Nanakorn \& Vu (2006) empregam a descrição 
Lagrangeana total para analisar elementos planos submetidos à grandes deslocamentos e, em Al-Bermani \& Kitipornchai (1990), é calculada uma matriz de rigidez tangente para elementos vigas-coluna com seções assimétricas de paredes finas. Porém, em geral os trabalhos consideram a teoria de flexão de Euller Bernoulli e funções de forma Hermitianas.

Outros estudos abordam referencial corrotacional, que inclusive considera os efeitos por deformação cisalhante, como proposto em Crisfield (1991), Pacoste \& Eriksson $(1995,1997)$ e Battini (2012). Mais recentemente, Santana \& Silveira (2014) e Silva et al. (2016) desenvolveram uma matriz de rigidez tangente, considerando a teoria de Timoshenko em uma formulação corrotacional, enquanto Kien (2012) desenvolveu um elemento plano para grandes deslocamentos, usando a teoria de flexão de Timoshenko. Oliveira \& Silva (2017) utilizaram um elemento de unificado de Euler-Bernoulli e Timoshenko. Teh \& Clarke (1998) compararam as formulações Lagrangeanas com a corrotacional para estruturas tridimensionais.

A relação entre deformação e deslocamento também desempenha um importante papel na análise não linear geométrica. Usualmente, a matriz de rigidez geométrica desconsidera os termos de ordem elevada do tensor deformação de Green, como feito em McGuire et al. (2000).

Neste trabalho, a matriz de rigidez geométrica é desenvolvida, considerando estes termos de ordem elevada, baseando-se em uma descrição Lagrangeana atualizada para formular as equações de equilíbrio. De acordo com Conci (1988), em elementos espaciais as rotações finitas devem satisfazer a compatibilidade cinemática na junção de elementos em ângulo. Portanto, neste trabalho, a matriz de rigidez geométrica é corrigida para considerar as rotações finitas.

As etapas para a construção dessa matriz é bem desenvolvida em Bathe \& Bolourchi (1979), Yang \& Leu (1994), Yang \& Kuo (1994), Chen (1994) e Bathe (1996). Em Conci (1988), esse desenvolvimento também é feito para vigas de parede fina, considerando o empenamento da seção transversal e, em Aguiar et al. (2014), esse mesmo desenvolvimento é feito para análise de risers, limitando-se à seções circulares. Em geral, a matriz de rigidez que considera todos os termos de ordem elevada do tensor deformação não é elaborada tendo em vista a teoria de flexão de Timsohenko. Neste trabalho, ela será desenvolvida com base nos 
estudos de Yang \& Leu (1994), Yang \& Kuo (1994), Chen (1994), McGuire et al. (2000) e Burgos \& Martha (2013).

Uma das maneiras de formular a matriz de rigidez elástica e geométrica, considerando a deformação por cisalhamento para vigas-coluna, é com o emprego dos deslocamentos nodais usuais, levando em conta a distorção por cisalhamento como variável independente. Essa formulação resulta em termos adicionais para a matriz de rigidez, transformando a matriz de rigidez local do elemento para a ordem de 14. Em geral, utiliza-se de condensação estática para reduzir a ordem da matriz de rigidez para 12, conforme Bathe \& Bolourchi (1979) e Aguiar et al. (2014).

Em alguns casos, apenas a matriz de rigidez elástica, considerando a teoria de flexão de Timsohenko é desenvolvida. Ou, então, a matriz de rigidez geométrica despreza os termos de ordem elevada do tensor deformação, como em Davis et al. (1972), Friedman \& Kosmatka (1993) e Yunhua (1998).

Com relação à metodologia de solução de sistemas não lineares, há métodos bem conhecidos sendo apresentados por diversos autores, como por Bathe (1996), Crisfield (1991), Yang \& Kuo (1994), McGuire et al. (2000), Krenk (2009) e Felippa (2017). Diversos estudos foram realizados na área em busca de maior eficiência, no entanto, um único algoritmo não é capaz de solucionar todos os problemas não lineares (Bergan et al., 1696, apud Leon et al., 2011). Dessa forma, muitas pesquisas se fundamentam na unificação dos métodos.

Em geral, essa unificação dos métodos é realizada em um único parâmetro de carga, como em Yang \& Kuo (1994), e incluiu ainda o método de controle de deslocamento generalizado (GDCM), ou em Leon et al. (2011), do qual esse trabalho se utiliza, em que foi elaborada uma biblioteca de solução não linear unificada, que inclui o método de controle de carga, controle de deslocamento, controle de energia, controle de comprimento de arco, controle de deslocamento generalizado e a estratégia do resíduo ortogonal. Além disso, esta pesquisa ainda se utiliza do trabalho elaborado em Rangel (2019), que realiza a implementação apresentada em Leon et al. (2011) no programa computacional Ftool (Martha, 1999).

Com relação às funções de interpolação, as polinomiais (cúbicas) são as mais utilizadas. Entretanto, elas correspondem à solução da equação diferencial do equilíbrio de um elemento infinitesimal na sua configuração indeformada, 
sendo precisa apenas para análises lineares. Em caso de não linearidade geométrica, esse fato não acontece, gerando a necessidade de discretização da estrutura. Por isso, para contornar este problema, muitos autores elaboram maneiras alternativas para análise, sendo um campo de pesquisa profícuo.

So \& Chan (1991) desenvolveram um elemento plano de ordem superior, introduzindo um grau de liberdade no meio desse, obtendo, assim, a carga crítica de colunas com diferentes condições de contorno, com o uso de apenas um elemento por barra, considerando também apenas a teoria de flexão de EulerBernoulli. Burgos et al. (2005) fez uso da linearização clássica do problema de estabilidade, na qual a carga de instabilidade é calculada por meio de uma análise de autovalor. Para isso, foram utilizados graus de liberdade adicionais, no interior dos elementos.

Chen \& Lui (1991) formulam uma matriz de rigidez empregando funções de estabilidade. Aristizabal-Ochoa $(1997,2008)$ apresentou um elemento plano para análise de segunda ordem de vigas-coluna, considerando deformação por cisalhamento e ligações semirrígidas, empregando funções de estabilidade apresentadas em Timoshenko e Gere (1963) e métodos usuais de análise, como o processo de Cross, e usando apenas um elemento. Aristizabal-Ochoa (2012) empregou funções de estabilidade modificadas para construir a matriz de primeira e segunda ordem, como também o vetor de carregamento de uma viga-coluna, considerando o efeito da carga axial, deformação por cisalhamento e ligações semirrígidas. Em Aristizabal-Ochoa (2007), o desenvolvimento é feito para sistemas tridimensionais com multi colunas.

Alguns autores utilizaram abordagem de campos consistentes, transformam os deslocamentos nodais axiais, transversais e rotações em uma série de potências, de maneira a eliminar os efeitos de "shear locking" e "membrane locking", a exemplo de Yunhua (1998) e Tang et al. (2015). Neste trabalho, o deslocamento axial foi interpolado com funções apenas lineares.

Outros buscam soluções baseadas no equilíbrio de elementos infinitesimais em suas configurações deformadas, levando em consideração a carga axial do elemento. Essa solução baseada nas equações diferenciais do problema é, muitas vezes, conhecida como "exata".

Em Davis et al. (1972) é elaborado um elemento que considera a teoria de Timsohenko a partir do equílibrio de um elemento infinitesimal em sua condição 
deformada, mas sem considerar a carga axial, resultando em uma interpolação cúbica para os deslocamentos. Em Nukulchai et al. (1981), são formuladas soluções exatas para elementos finitos de vigas, considerando a deformação por cisalhamento da teoria de vigas de Timoshenko.

Muitos trabalhos nessa área inserem bases elásticas na análise, como em Zhaohua \& Cook (1983), em que são desenvolvidos elementos finitos para analisar vigas sob bases elásticas desconsiderando deformação por cisalhamento e não linearidade geométrica. Nessa análise, ante as funções cúbicas, precisa-se de uma elevada discretização, enquanto para a função exata do deslocamento poucos elementos são necessários. Em casos de cargas simples, apenas um elemento leva ao resultado.

A partir da teoria de vigas de Euler-Bernoulli e o modelo de Winkler para fundações, Ting \& Mockry (1984) desenvolveram uma matriz de rigidez e um vetor de carregamento, com base em soluções exatas, relacionadas às equações diferenciais, para aplicação no método dos deslocamentos para elementos apoiados sobre base elástica, obtendo resultados satisfatórios, independentemente do refinamento da malha. Igualmente em Eisenberger \& Yankelevsky (1985), foi formulada uma matriz de rigidez exata de um elemento apoiado em uma fundação de Winkler, a partir da equação diferencial do problema, sem considerar deformação por cisalhamento.

Além disso, Chiwanga \& Valsangkar (1988) calcularam a matriz de rigidez e o vetor de carregamentos nodais de uma viga apoiada em uma base elástica de dois parâmetros, sem também considerar deformação por cisalhamento. Do mesmo modo, a formulação foi baseada na solução exata da equação diferencial. As análises numéricas demonstraram que os elementos são independentes do refinamento da malha.

Ampliando os estudos, Shirima \& Giger (1992) desenvolveram a relação força-deslocamento para uma viga apoiada em fundação elástica de dois parâmetros, considerando a teoria de vigas de Timoshenko. Nela, a matriz de rigidez e o vetor das cargas externas são derivados da solução exata das equações diferenciais do problema. Nesse sentido, os autores indicaram que os erros causados por se ignorar as deformações por cisalhamento podem ser de relevante importância. Esses dois autores apresentaram, ainda, uma função auxiliar para 
desacoplar as equações diferenciais do problema, que é utilizada em Burgos \& Martha (2013).

Em Ha (1993), são desenvolvidos uma matriz de rigidez exata e procedimentos para análise de vigas-coluna sanduíche, em que a deformação por cisalhamento possui importante função e necessita de teorias refinadas para a sua análise. Girhammar \& Gopu (1993) apresentaram uma análise exata de vigas mistas com interação parcial, submetidas a carregamentos transversais e axiais, para análises de primeira e de segunda ordem. As soluções foram extraídas da equação diferencial dos sistemas.

Aydogan (1995) desenvolveu uma matriz de rigidez exata para um elemento de viga, considerando deformação por cisalhamento em uma fundação de Winkler. Onu (2000) formulou um elemento de viga baseado na solução exata, que também considera a deformação por cisalhamento, com a fundação elástica possuindo dois parâmetros, obtendo-se, assim, uma matriz de rigidez que independe da malha utilizada.

$\mathrm{Na}$ literatura pesquisada, destacam-se ainda Morfidis \& Avramidis (2002), que desenvolveram um elemento finito de viga, apoiado em base elástica de dois parâmetros generalizados e baseado na solução das equações diferenciais do problema. Esse modelo desenvolvido também considera ligações semirrígidas e barras rígidas. Areiza-Hurtado et al. (2005) apresentaram a matriz de rigidez e o vetor de carregamento de uma viga-coluna, incluindo os efeitos de força axial constante, a base elástica de Winkler, a teoria de vigas de Timoshenko e as conexões elásticas dos extremos do elemento. Morfidis (2007) formulou ainda a matriz de rigidez e o vetor de carregamento de um elemento de viga de Timoshenko, apoiada em uma base elástica de três-parâmetros, de acordo com as equações diferenciais que regem a estrutura.

O problema resolvido por Onu (2008) considerou o efeito de cargas axiais, o carregamento transversal, a deformação por cisalhamento e a fundação elástica de dois parâmetros. Ao discorrer ainda sobre esses estudos, Burgos \& Martha (2013) apresentaram o cálculo das soluções analíticas para as funções de forma, incluídos o carregamento transversal e axial e a deformação por cisalhamento.

Sem a consideração de base elástica, destacam-se, ainda, Goto \& Chen (1987), que desenvolveram uma matriz de rigidez das soluções analíticas de um elemento de barra e utilizaram alguns termos não lineares do tensor deformação, 
ignorando a deformação por cisalhamento. Chan \& Gu (2000) elaboraram uma matriz de rigidez exata para vigas-coluna planas com imperfeição geométrica, a partir da equação diferencial do elemento, obtendo bons resultados para análise pré-crítica e pós-crítica de estruturas planas com discretização reduzida, em que as curvas de equilíbrio são traçadas.

Balling \& Lyon (2011) propuseram um elemento baseado na solução das equações diferencias de uma análise de segunda ordem, empregando uma formulação corrotacional para análises não lineares com um elemento por barra, sem, no entanto, considerarem a deformação por cisalhamento. Obtiveram bons resultados e mostraram que a matriz encontrada correspondia à matriz de rigidez tangente usual para teoria de Euler-Bernoulli, desconsiderando os termos de ordem elevada do tensor deformação.

Tudjono et al. (2017) utilizaram o príncipio de Hamilton no desenvolvimento das funções de interpolação exatas para elementos não prismáticos e não homogêneos, considerando a teoria de flexão de Timoshenko.

Entretanto, pode-se observar que poucos trabalhos desenvolvem e mostram as funções de interpolação dos deslocamentos baseado no equilíbrio de um elemento infinitesimal em sua configuração deformada, principalmente considerando a teoria de flexão de Timoshenko. A maioria restringe-se a estruturas planas e não empregam os termos de ordem elevada do tensor deformação de Green-Lagrange. Em geral, também não calculam a trajetória de equilíbrio da estrutura, e sim diretamente a carga crítica.

Desse modo, o presente trabalho busca integrar esses efeitos em conjunto com uma descrição Lagrangeana atualizada e metodologias de solução de sistemas não lineares.

O objetivo principal, então, é desenvolver uma matriz de rigidez tangente tridimensional e cargas equivalentes nodais, por meio das funções de interpolação, considerando a carga axial presente no elemento, a deformação por cisalhamento e os termos de ordem elevada do tensor deformação, de maneira a melhorar a resposta de análises não lineares geométricas ao se empregar uma discretização mínima, ou reduzida, em métodos numéricos, como o MEF. 


\section{4 \\ Objetivos e Contribuições}

Reiterando, o presente trabalho tem como objetivos principais:

- Desenvolver uma fomulação "completa", de maneira a reduzir a necessidade de discretização de estruturas para uma análise não linear geométrica espacial de barras e considerar grandes deslocamentos e rotações. Por formulação "completa" deve se entender o desenvolvimento de elementos, de matriz de rigidez tangente e de cargas equivalentes nodais, por meio das funções de interpolação, obtidas diretamente da solução da equação diferencial do equilíbrio de um elemento infinitesimal de barra em sua configuração deformada, levandose em consideração, portanto, a carga axial presente no elemento. Considera ainda, o emprego dos termos de ordem elevada do tensor deformação, as teorias de flexão de Euler-Bernoulli e Timoshenko em uma descição Lagrangeana atualizada

- Desenvolver, a partir da formulação "completa", a matriz de rigidez tangente, espacial utilizando expansão em série de Taylor, considerando 3 e 4 termos, com vistas a fornecer uma matriz geométrica mais completa, aperfeiçoando as formulações usuais para ambas as teorias de flexão.

- Desenvolver, a partir de uma formulação Lagrangeana atualizada e do emprego de funções de forma cúbicas, obtidas da solução da equação diferencial de um elemento infinitesimal em sua configuração indeformada, uma matriz de rigidez tangente, que considere a teoria de flexão de Timoshenko, grandes deslocamentos e rotações. Essa matriz é equivalente a usual de Euler-Bernoulli, com parâmetros que consideram a deformação por cisalhamento.

- Avaliar a capacidade da formulação completa e das expansões em série de Taylor para descrever o comportamento não linear geométrico com uma discretização mínima da estrutura.

- Verificar a influência das teorias de flexão na resposta das estruturas.

- Avaliar a influência dos termos de ordem elevada no tensor deformação no comportamento não linear geométrico de estruturas. 
Para alcançar os objetivos propostos, as seguintes etapas foram desenvolvidas e cumpridas:

- Estabelecimento de metodologia geral para definir as funções de interpolação, considerando o equilíbrio de um elemento infinitesimal em sua configuração indeformada e deformada, obtidas a partir da expressão analítica da solução homogênea de todos os comportamentos matemáticos adotados para o elemento, para as teorias de flexão de Euler-Bernoulli e Timoshenko. Como consequência, revisão do desenvolvimento das funções de forma cúbicas, obtidas do equilíbrio de elemento infinitesimal em sua condição indeformada (não linearidade em nível infinitesimal).

- Desenvolvimento didático da matriz de rigidez tangente de estruturas espaciais, baseado em uma formulação Lagangeana atualizada para teoria de flexão de Euler-Bernoulli, com funções de interpolação Hermitianas, e com o emprego dos termos de ordem elevada do tensor deformação (não linearidade em nível de elemento). Inicialmente, calculam-se os planos com comportamento independente e, na sequência, acresce-se a influência da interação entre torção e carga axial, assim como a influência das rotações finitas.

- Desenvolvimento da matriz de rigidez tangente para grandes deslocamentos e rotações, considerando a teoria de flexão de Timoshenko e funções de forma cúbicas.

- Desenvolvimento da matriz de rigidez tangente completa, obtida a partir das funções de forma "completas", empregando a descrição Lagrangeana atualizada, todos os termos do tensor deformação e as teorias de flexão de Euler-Bernoulli e Timoshenko.

- Expansão da formulação "completa" em série de Taylor com 3 e 4 termos.

- Implementação da formulação desenvolvida no Framoop.

- Elaboração de exemplos para validação das formulações.

Enfim, pode-se indicar que as principais contribuições desse trabalho são o desenvolvimento de uma formulação "completa" espacial para análise não linear de estruturas, empregando funções de interpolação que consideram a carga axial 
no elemento, obtidas diretamente da solução da equação diferencial do problema, e a formulação de matriz de rigidez geométrica com termos adicionais aos convencionais (expansão em série de Taylor), aperfeiçoando as matrizes usuais, para as teorias de flexão de Euler-Bernoulli e Timoshenko.

Secundariamente, outra contribuição que este trabalho traz é o desenvolvimento de uma matriz de rigidez geométrica 3-D, considerando a teoria de flexão de Timoshenko para grandes deslocamentos e rotações, em que são utilizados os termos de ordem elevada do tensor deformação, correspondente à usual utilizada para teoria de Euler-Bernoulli.

\section{5}

\section{Originalidade}

De maneira resumida, essa Tese basea-se fundamentalmente em Chen (1994), Yang \& Leu (1994), Yang \& Kuo (1994), McGuire et al. (2000) e Burgos \& Martha (2013).

No entanto, o que destaca este trabalho dos demais é o desenvolvimento da matriz de rigidez geométrica considerando todos os termos do tensor deformação, inclusive os de ordem elevada, empregando não apenas a teoria de flexão de Euler-Bernoulli, mas também a de Timoshenko.

Além disso, são desenvolvidas funções de interpolação que levam em consideração a carga axial atuante no elemento, calculadas a partir da solução homogênea da equação diferencial do equilíbrio de um elemento infinitesimal deformado. Essas funções de interpolação também são utilizadas para o desenvolvimento de uma matriz de rigidez tangente que emprega os termos de ordem elevada no tensor deformação, para ambas as teorias de flexão.

\section{6}

\section{Organização do Trabalho}

Este trabalho compõe-se de sete capítulos e quatro apêndices. Neste primeiro capítulo, a tese discutiu, nas considerações iniciais, o conceito de elementos finitos, as suas particularidades e a vantagem em se obter o resultado da equação diferencial do problema em mecânica dos sólidos para interpolação dos 
deslocamentos. Discorrreu sobre os apectos que influenciam na resposta de uma estrutura em uma análise não linear empregando o MEF. Neste mesmo capítulo, são apresentadas, ainda, a motivação para elaboração deste trabalho e a revisão bibliográfica sobre o assunto tratado, que situa a tese aqui desenvolvida. Finalizando, foram descritos os objetivos e as principais contribuições deste trabalho.

No segundo capítulo, formulou-se a idealização do comportamento de barras. São ilustradas as teorias de flexão de Euler-Bernoulli e Timoshenko, assim como é apresentado o desenvolvimento das equações diferenciais dos modelos analíticos de barras, tanto para elementos infinitesimais em suas configurações indeformadas quanto deformadas.

O terceiro capítulo demonstra os cálculos das funções de interpolação de deslocamentos para um elemento de barra, considerando as teoria de flexão de Euler-Bernoulli e Timoshenko. Nele são desenvolvidas tanto as funções de forma cúbicas (obtidas da equação diferencial do equilíbrio de elemento infinitesimal na sua configuração indeformada), quanto às funções de interpolação completas (calculadas a partir da equação diferencial do equilíbrio de elemento infinitesimal em sua condição deformada). Baseado nesse capítulo é desenvolvido o apêndice A, em que é feito o cálculo das funções de interpolação para barras com rótulas nas extremidades.

O quarto capítulo apresenta o desenvolvimento da matriz de rigidez tangente de um elemento para as teorias de flexão de Euler-Bernoulli e Timoshenko. Inicialmente, apresenta-se a formulação Lagrangeana atualizada e, na sequência, são desenvolvidas a matriz de rigidez elástica e geométrica de elementos, com os planos trabalhando independentemente, considerando os termos de ordem elevada do tensor deformação, e as funções de forma cúbicas (equilíbrio de um elemento infinitesimal na sua configuração indeformada). Em seguida, é adicionada a matriz de rigidez tangente à influência da interação entre torção e carga axial, bem como a das rotações finitas. Por fim, para o mesmo desenvolvimento apresentado, são empregadas as funções de interpolação "completas" (equilíbrio de um elemento infinitesimal na sua condição deformada), resultando na matriz de rigidez tangente "completa". Os apêndices B e C são construídos com a partir desse capítulo. 
No capítulo cinco, são apresentados os cálculos das cargas equivalentes nodais, para ambas as teorias de flexão utilizadas nesse trabalho. Primeiro, são recalculadas as cargas equivalentes nodais, considerando as funções de interpolação cúbicas e, na sequência, empregando-se as funções de forma "completas".

No capítulo seis, são avaliadas as formulações desenvolvidas através de aplicações numéricas. Inicialmente, avaliam-se os elementos formulados em estruturas planas, em seguida, em estruturas espaciais, e, finalmente, com exemplos de pórticos espaciais com torção. Para cada exemplo é realizado, primeiro, um estudo da influência da teoria de flexão e da consideração dos termos de ordem elevada do tensor deformação e, após, é empregada uma discretização mínima da estrutura. A formulação completa e as baseadas na expansão em série de Taylor são, então, avaliadas. Os resultados alcançados são comparados com soluções analíticas e numéricas obtidas com o software Mastan2 v3.5 (McGuire et al., 2000).

Por último, o sétimo capítulo traz as conclusões e considerações finais, em que são apresentados e discutidos os resultados encontrados neste trabalho, e encaminhadas as sugestões que visam a subsidiar futuras pesquisas na área.

O apêndice D expõe as metodologias da análise não linear de estruturas. Nele, é apresentada a condição de equilíbrio que deve ser satisfeita em todos os nós da estrutura e conceito de vetor de forças residuais. São discutidos também os meios de solução do sistema de equações não lineares e, em seguida, é apresentado o método de Newton-Raphson padrão, com as estratégias de iteração e de incremento de carga. $\mathrm{O}$ apêndice é baseado fundamentalmente em Leon et al. (2011). 


\section{2 \\ Idealização do Comportamento de Barras}

Este capítulo apresenta as equações diferenciais, que definem o comportamento analítico de um elemento infinitesimal de barra para efeitos axiais e de flexão, a partir das condições de compatibilidade entre deslocamentos e deformações, das condições de equilíbrio e das leis constitutivas do material.

\section{1}

\section{Campos de Deslocamentos e de Tensões}

As teorias mais utilizadas para o comportamento à flexão de barras, oriundas de Euler-Bernoulli e Timoshenko, fundamentam-se em quatro hipóteses básicas:

- As seções planas permanecem planas após a deformação.

- O ângulo de rotação da seção transversal é muito pequeno e pode ser aproximado por sua tangente.

- As deformações e tensões normais na direção vertical são desprezadas.

- O comportamento à flexão de barras considera um estado plano de tensões.

Assim, de acordo com a Figura 2.1, o campo de deslocamentos no interior de uma barra é definido de acordo com a equação (2.1).

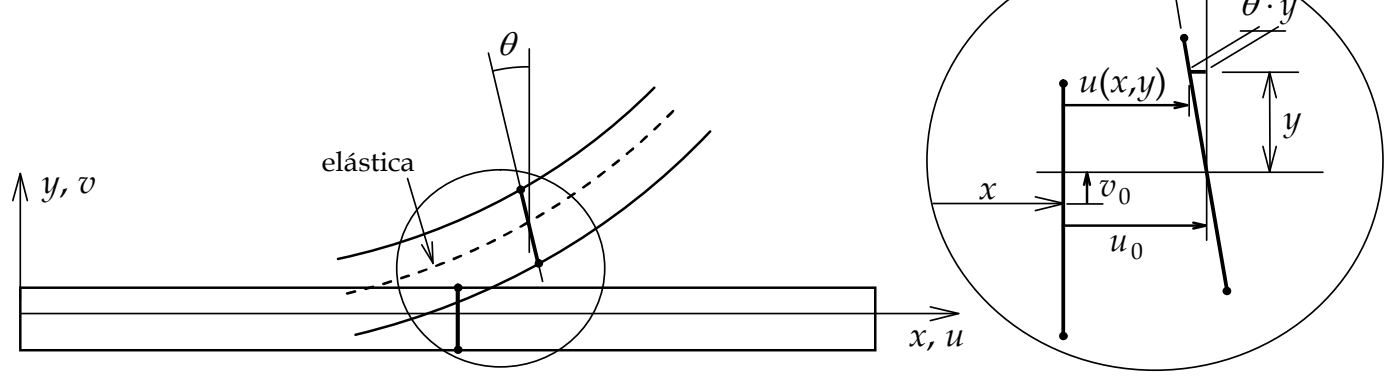

Figura 2.1 - Campo de deslocamentos no interior de uma barra.

Fonte: Martha (2018). 


$$
\begin{gathered}
u(x, y)=u_{0}(x)-\theta(x) \cdot y \\
v(x, y)=v_{0}(x)
\end{gathered}
$$

Em que os deslocamentos $u_{0}(x)$ e $v_{0}(x)$ são, respectivamente, o deslocamento axial e o deslocamento transversal do centróide da seção, definindo a elástica da barra, $\theta(x)$ a rotação da seção transversal por flexão e $u(x, y)$ e $v(x, y)$ correspondentes aos deslocamentos longitudinal e transversal de um ponto qualquer da seção. Pode-se notar que o campo de deslocamentos de uma barra para o comportamento plano é definido por três parâmetros, que podem ser agrupados em um vetor de campo de deslocamentos generalizados de um modelo estrutural $(\tilde{u})$, conforme a expressão (2.2).

$$
\{\tilde{u}\}=\left\{\begin{array}{l}
u_{0}(x) \\
v_{0}(x) \\
\theta(x)
\end{array}\right\}
$$

As componentes de tensões são indicadas na Figura 2.2, sendo $\sigma_{x}$ a tensão normal na direção longitudinal da barra, $\sigma_{y}$ a tensão normal na direção transversal da barra e $\tau_{x y}$ a tensão de cisalhamento da barra.

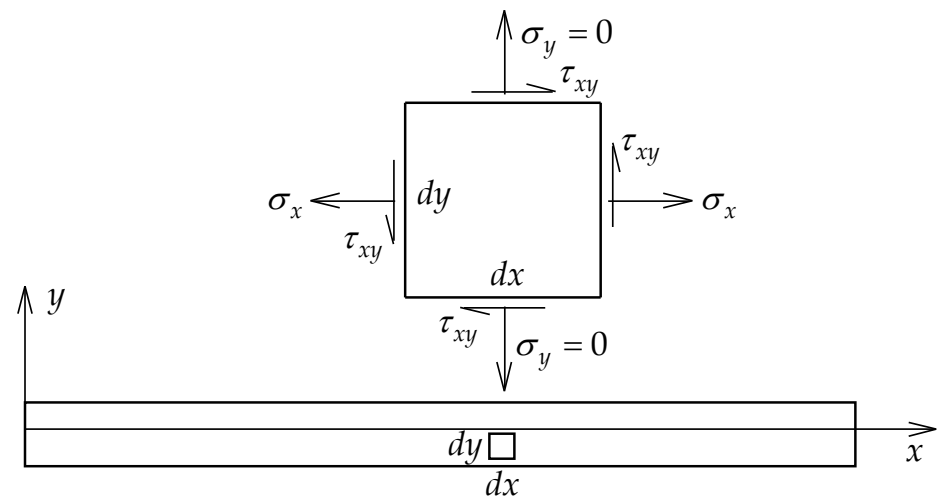

Figura 2.2 - Componentes de tensões em um elemento infinitesimal de barra

Fonte: Martha (2018).

\section{2}

\section{Relações entre Deslocamentos e Deformações}

O campo de deslocamentos e o campo de deformações devem ser compatíveis entre si para qualquer estrutura e a continuidade deles é uma premissa fundamental da análise estrutural. Quando o gradiente do deslocamento é 
pequeno, a ponto de se desprezar os produtos entre eles, os componentes de deformação são considerados funções lineares, conforme o tensor deformação linear de Green-Lagrange, equações (2.3), (2.4) e (2.5).

$$
\begin{gathered}
\varepsilon_{x}=\frac{\partial u}{\partial x} \\
\varepsilon_{y}=\frac{\partial v}{\partial y} \\
\gamma_{x y}=\frac{\partial v}{\partial x}+\frac{\partial u}{\partial y}
\end{gathered}
$$

Em que $\varepsilon_{x}$ é a deformação normal na direção longitudinal da barra, $\varepsilon_{y}$ a deformação normal na direção transversal da barra e $\gamma_{x y}$ a distorção por cisalhamento. A partir do campo de deslocamentos adotado para o comportamento de barras, equação (2.1), as relações deformação-deslocamento podem ser reescritas como as equações (2.6), (2.7) e (2.8).

$$
\begin{gathered}
\varepsilon_{x}=\frac{d u_{0}}{d x}-\frac{d \theta}{d x} \cdot y \\
\varepsilon_{y}=0 \\
\gamma_{x y}=\frac{d v_{0}}{d x}-\theta
\end{gathered}
$$

Nota-se que a deformação longitudinal, apresentada em (2.6), tem duas parcelas: uma axial $\left(\varepsilon_{x}^{a}\right)$ e uma de flexão $\left(\varepsilon_{x}^{f}\right)$, conforme explicitado em (2.9) e (2.10).

$$
\begin{gathered}
\varepsilon_{x}^{a}=\frac{d u_{0}}{d x} \\
\varepsilon_{x}^{f}=-k^{f} \cdot y \\
k^{f}=\frac{d \theta}{d x}
\end{gathered}
$$

A equação (2.8) indica uma relação de compatibilidade entre a distorção por cisalhamento por efeito cortante, a rotação da seção e o deslocamento transversal. 


\subsection{1}

\section{Teoria de Flexão de Euler-Bernoulli}

A teoria de flexão de Euler-Bernoulli considera, além das quatro hipóteses básicas, que a seção da barra, ao sofrer uma rotação na flexão, permanece perpendicular ao eixo deformado da barras. Considerando também que os deslocamentos são pequenos, aproxima-se a rotação da seção transversal pela tangente da elástica, conforme a Figura 2.3.

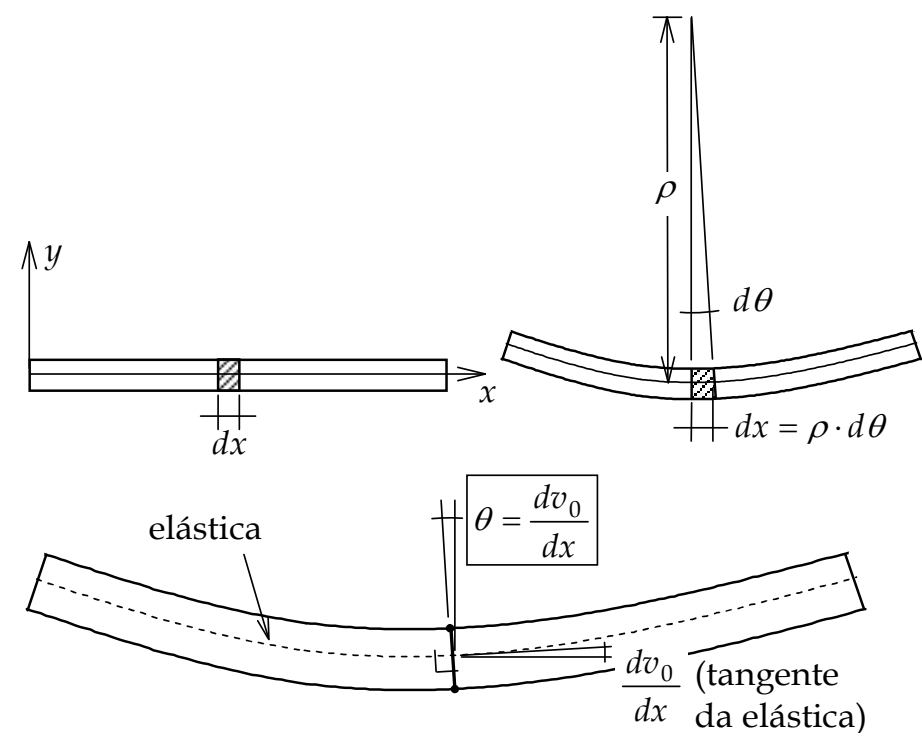

Figura 2.3 - Deformação de Viga

Fonte: Martha (2018).

Assim, o deslocamento transversal é associado à rotação da seção transversal, segundo a equação (2.11).

$$
\theta=\frac{d v_{0}}{d x}
$$

Utilizando a equação (2.10) em (2.11), pode-se escrever a deformação por flexão, conforme (2.12).

$$
\varepsilon_{x}^{f}=-\frac{d^{2} v_{0}}{d x^{2}} \cdot y, k^{f}=\frac{d^{2} v_{0}}{d x^{2}}
$$

Dessa forma, a deformação normal na direção longitudinal e a distorção por cisalhamento podem ser agrupados no vetor de deformações pontuais, para o comportamento plano de uma barra, sendo então escritos como em (2.13). A distorção por cisalhamento é nula, adotando-se a teoria de flexão de EulerBernoulli. 


$$
\left\{\begin{array}{c}
\varepsilon_{x} \\
\gamma_{x y}
\end{array}\right\}=\left[\begin{array}{ccc}
d / d x & -\left(d^{2} / d x^{2}\right) \cdot y & 0 \\
0 & 0 & 0
\end{array}\right] \cdot\left\{\begin{array}{c}
u_{0} \\
v_{0} \\
\theta
\end{array}\right\}
$$

As deformações podem ser agrupadas no vetor de deformações generalizadas do elemento infinitesimal de barra $(\varepsilon)$, em que cada componente representa uma das deformações elementares do elemento infinitesimal, conforme (2.14).

$$
\{\varepsilon\}=\left\{\begin{array}{c}
\varepsilon_{x}^{a} \\
\gamma_{x y} \\
k^{f}
\end{array}\right\}=\left[\begin{array}{ccc}
d / d x & 0 & 0 \\
0 & 0 & 0 \\
0 & d^{2} / d x^{2} & 0
\end{array}\right] \cdot\left\{\begin{array}{c}
u_{0} \\
v_{0} \\
\theta
\end{array}\right\}
$$

\subsection{2}

\section{Teoria de Flexão de Timoshenko}

A teoria de flexão de Timoshenko considera a existência de uma distorção por cisalhamento, que faz com que a seção transversal não permaneça normal em relação ao eixo da viga que sofre flexão. A rotação fica desassociada da tangente da elástica, de acordo com a equação (2.15).

$$
\frac{d v_{0}}{d x}=\theta+\gamma
$$

Assim, no caso da teoria de flexão de Timoshenko, as relações completas de compatibilidade pontuais entre deformações e deslocamentos são apresentadas em (2.16) e o vetor de deformações generalizadas é dado conforme a equação (2.17).

$$
\begin{aligned}
& \left\{\begin{array}{c}
\varepsilon_{x} \\
\gamma_{x y}
\end{array}\right\}=\left[\begin{array}{ccc}
d / d x & 0 & -(d / d x) \cdot y \\
0 & d / d x & -1
\end{array}\right] \cdot\left\{\begin{array}{c}
u_{0} \\
v_{0} \\
\theta
\end{array}\right\} \\
& \{\varepsilon\}=\left\{\begin{array}{c}
\varepsilon_{x}^{a} \\
\gamma_{x y} \\
k_{f}^{f}
\end{array}\right\}=\left[\begin{array}{ccc}
d / d x & 0 & 0 \\
0 & d / d x & -1 \\
0 & 0 & d / d x
\end{array}\right] \cdot\left\{\begin{array}{c}
u_{0} \\
v_{0} \\
\theta
\end{array}\right\}
\end{aligned}
$$

De forma genérica, tanto as matrizes das equações (2.14) quanto às apresentadas em (2.17), podem ser representadas pela expressão (2.18).

$$
\{\varepsilon\}=[\nabla]\{\tilde{u}\}
$$

$\{\varepsilon\}$ sendo o deformações generalizadas do elemento infinitesimal de barra, $\{\tilde{u}\}$ o vetor de campo de deslocamentos generalizados de um modelo estrutural e [V] a matriz de operadores diferenciais. Nos demais tópicos deste trabalho, para simplificação, as variáveis $u_{0}$ e $v_{0}$ são escritas como $u$ e $v$, respectivamente. 


\section{3}

\section{Equilíbrio entre Tensões e Esforços Internos}

Para descrever o comportamento de uma estrutura, além das relações deformação-deslocamento, deve-se respeitar as condições de equilíbrio. Nesta seção, será verificada a associação entre tensões e forças internas.

\subsection{1}

\section{Lei Constitutiva Linear para o Material}

Pela lei de Hooke, a relação constitutiva entre tensões normais e deformações normais é dada pela equação (2.19). A lei constitutiva que relaciona tensões cisalhantes com distorções de cisalhamento é dada em (2.20).

$$
\begin{aligned}
\sigma_{x} & =E \varepsilon_{x} \\
\tau & =G \gamma
\end{aligned}
$$

Em que $\sigma_{x}$ é a tensão normal na seção, $\varepsilon_{x}$ a deformação normal, $E$ o módulo de elasticidade do material, $\tau$ a tensão de cisalhamento da seção, $\gamma$ a distorção por cisalhamento e $G$ o módulo de cisalhamento do material. A relação matricial para barras pode ser escrita pela equação (2.21).

$$
\left\{\begin{array}{c}
\sigma_{x} \\
\tau
\end{array}\right\}=\left[\begin{array}{cc}
E & 0 \\
0 & G
\end{array}\right]\left\{\begin{array}{c}
\varepsilon_{x} \\
\gamma
\end{array}\right\}
$$

\subsection{2}

\section{Rigidez do Elemento Infinitesimal de Barra}

A relação diferencial entre as deformações elementares de um elemento infinitesimal de barra e a correspondente força interna é caracterizada pelos deslocamentos relativos internos. Essa relação é apresentada na Figura 2.4 e nas equações (2.22), (2.23) e (2.24).
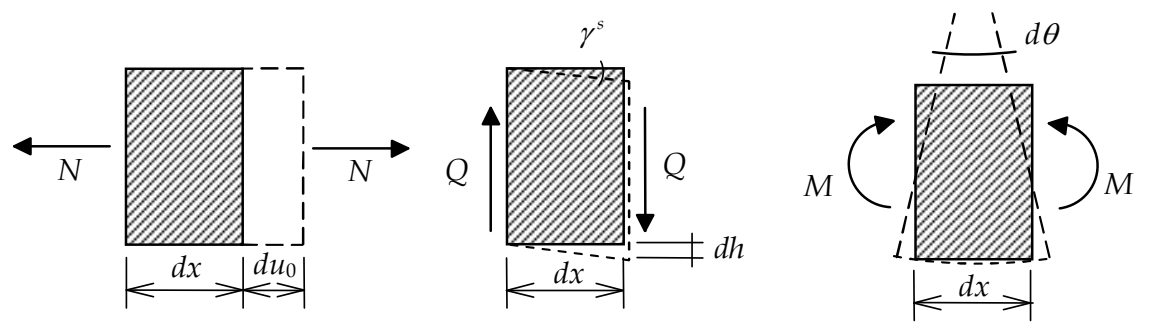

Figura 2.4 - Relação entre forças internas e deformações

Fonte: Adaptado de Martha (2018). 


$$
\begin{gathered}
N=E A \frac{d u_{0}}{d x}=E A \varepsilon_{x}^{a} \\
Q=-G A_{s}\left(\frac{d v_{0}}{d x}-\theta\right)=-G A_{s} \gamma, A_{s}=\chi A \\
M=E I \frac{d \theta}{d x}=E I k^{f}
\end{gathered}
$$

Assim, a relação matricial de rigidez do elemento infinitesimal de barra de pórtico plano, de acordo com a teoria de flexão de Euler-Bernoulli, é apresentada em (2.25), enquanto para a teoria de Timoshenko, na equação (2.26).

$$
\begin{gathered}
\left\{\begin{array}{l}
N \\
M
\end{array}\right\}=\left[\begin{array}{cc}
E A & 0 \\
0 & E I
\end{array}\right]\left\{\begin{array}{c}
\varepsilon_{x}^{a} \\
k^{f}
\end{array}\right\} \\
\left\{\begin{array}{l}
N \\
Q \\
M
\end{array}\right\}=\left[\begin{array}{ccc}
E A & 0 & 0 \\
0 & -G A_{S} & 0 \\
0 & 0 & E I
\end{array}\right]\left\{\begin{array}{c}
\varepsilon_{x}^{a} \\
\gamma \\
k^{f}
\end{array}\right\}
\end{gathered}
$$

Então, as relações matriciais de rigidez de um elemento infinitesimal podem ser representadas, de maneira genérica, pela equação (2.27).

$$
\{m\}=[S]\{\varepsilon\}
$$

Em que $\{m\}$ é o vetor de forças internas do elemento infinitesimal, $[S]$ é a matriz de rigidez do elemento infinitesimal e $\{\varepsilon\}$ é o vetor de deformações generalizadas do elemento infinitesimal. O sinal negativo vem das diferentes convenções de sinais entre o esforço cortante e a tensão de cisalhamento.

\section{4}

\section{Relações Diferenciais de Equilíbrio em Vigas-Coluna}

Como visto anteriormente, existem diferentes teorias para descrever o comportamento à flexão de uma barra. A mais usual destas teorias é a de EulerBernoulli, em que a rotação é considerada a derivada do deslocamento transversal. A outra teoria apresentada é a de Timoshenko, na qual é levada em consideração uma distorção por cisalhamento, que pode ser interpretada como uma rotação adicional da seção tranversal. Martha \& Burgos $(2014,2015)$ apontam uma formulação alternativa à tradicional apresentada em Timoshenko \& Gere (1963), em que a deformação por cisalhamento é interpretada como uma distorção cisalhante do elemento infinitesimal da viga e não como uma rotação adicional da seção transversal. 
Para Martha \& Burgos (2014, 2015), a consideração clássica da teoria de Timoshenko apresenta uma inconsistência na relação de compatibilidade para deformações axiais. Quando são levadas em consideração análises não lineares geométricas, com efeitos de segunda ordem, surgem discrepâncias na formulação matématica do problema. Isto, entretanto, não será escopo deste trabalho.

A representação do comportamento de estruturas de barras considera que as condições de equilíbrio devem ser satisfeitas para toda a estrutura, o que inclui um elemento infinitesimal de barra. Assim, esta seção pretende demonstrar o desenvolvimento das relações diferenciais para vigas-coluna, considerando efeitos de segunda ordem, para diferentes teorias de flexão.

\subsection{1}

\section{Equilíbrio de Elemento Infinitesimal na Configuração Indeformada}

A Figura 2.5 ilustra a configuração indeformada do elemento infinitesimal.
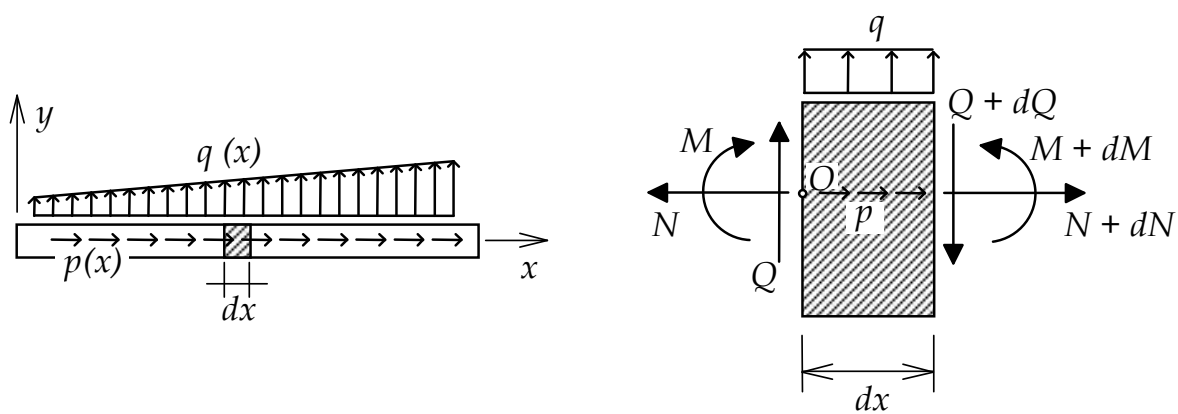

Figura 2.5 - Equilíbrio de um elemento de viga-coluna em sua configuração indeformada Fonte: Adaptado de Martha (2018).

A partir do equilíbrio de um elemento infinitesimal de barra, utilizando as equações universais da estática, as equações (2.28) e (2.29) podem ser escritas como se seguem:

$$
\begin{gathered}
\sum F_{y}=0:-d Q+q(x) d x=0 \rightarrow \frac{d Q(x)}{d x}=q(x) \\
\sum M_{0}=0: d M-(Q+d Q) d x+q(x) \frac{d x^{2}}{2}=0 \rightarrow \frac{d M(x)}{d x}=Q(x)
\end{gathered}
$$

Em que $q(x)$ é a carga transversal distribuída no elemento infinitesimal, $Q(x)$ a componente vertical do esforço na seção transversal e $M(x)$ o momento fletor na seção transversal.

Utilizando a equação da linha elástica, equação (2.30), 


$$
M(x)=E I \frac{d \theta}{d x}
$$

em que $E$ é o módulo de elasticidade do material, $I$ a inércia à flexão da seção transversal e $\theta$ a rotação desta seção, pode-se substituir a equação (2.28) na (2.29), obtendo-se o resultado apresentado na equação (2.31).

$$
E I \frac{d^{2} \theta}{d x^{2}}-Q(x)=0
$$

\subsubsection{1}

\section{Teoria de Flexão de Euler-Bernoulli}

A teoria de flexão de Euler-Bernoulli considera a rotação como sendo a derivada do deslocamento transversal, conforme a equação (2.32).

$$
\theta=\frac{d v}{d x}
$$

Dessa maneira, de acordo como a teoria de flexão de Euler-Bernoulli, a equação diferencial que rege o comportamento de um elemento infinitesimal de viga, apresentada em (2.31), pode ser escrita pela equação (2.33).

$$
E I \frac{d^{4} v(x)}{d x^{4}}-\frac{d Q(x)}{d x}=0
$$

Ou também pela equação (2.34).

$$
E I \frac{d^{4} v(x)}{d x^{4}}=q(x)
$$

A solução da equação fornece o deslocamento transversal $v(x)$, podendo-se calcular a rotação da seção transversal com a relação $\theta(x)=d v(x) / d x$.

\subsubsection{2}

\section{Teoria de Flexão de Timoshenko}

Na teoria de flexão de Timoshenko considera-se a distorção por cisalhamento como uma rotação adicional, conforme a Figura 2.6, levando-se em conta a rotação da seção transversal e o deslocamento transversal como variáveis independentes. 


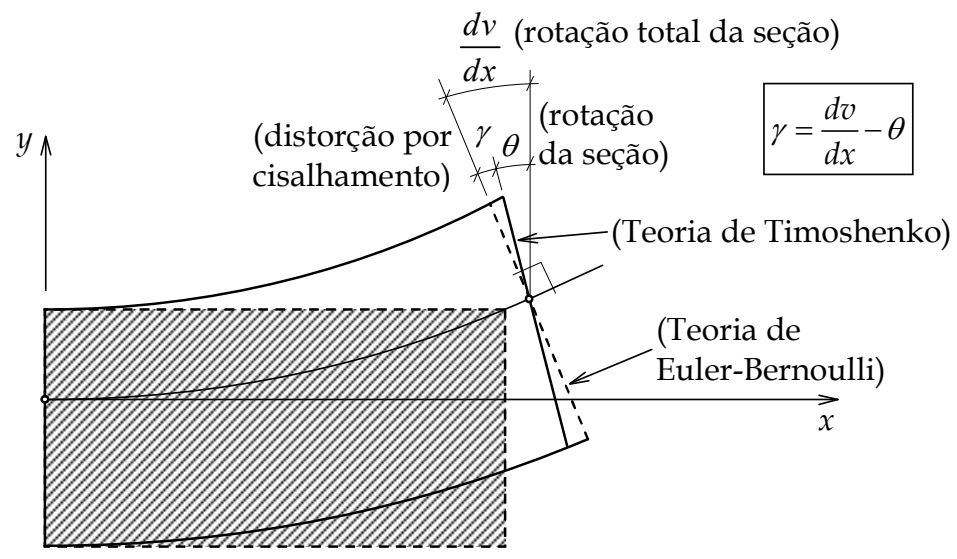

Figura 2.6 - Consideração do cisalhamento na viga de Timoshenko

Fonte: Adaptado de Martha (2018).

Logo, a rotação total da seção $(d v / d x)$ é composta pela rotação por flexão $(\theta)$, acrescida da distorção por cisalhamento $(\gamma)$, conforme a equação (2.35).

$$
\frac{d v}{d x}=\theta+\gamma
$$

Nesta hipótese, a equação diferencial desenvolvida em (2.34) precisa ser alterada, pois é necessário incluir a distorção por cisalhamento provocada pelo esforço cortante. A força cortante atuante na seção é dada pela equação (2.36).

$$
Q(x)=-\chi G A \cdot \gamma(x)
$$

Em que $G$ é o módulo de cisalhamento do material, $A$ é a área da seção transversal, $\chi$ é o fator que define a área efetiva para cisalhamento da seção transversal e $Q$ é a força cortante atuante na seção. O sinal negativo vem das diferentes convenções de sinais entre o esforço cortante e a tensão de cisalhamento (observar Figura 2.4).

Substituindo-se a equação (2.35) na (2.36), que apresenta a força cortante atuante na seção, encontra-se a relação apresentada em (2.37).

$$
Q(x)=\chi G A \cdot\left[\theta(x)-\frac{d v(x)}{d x}\right]
$$

Das equações diferenciais (2.28) e (2.31) do equilíbrio de um elemento infinitesimal de barra, pode-se calcular as equações (2.38) e (2.39), substituindose o valor da força cortante $Q(x)$ e a distorção por cisalhamento $\gamma(x)$.

$$
\frac{d Q(x)}{d x}=q(x) \Rightarrow \chi G A\left[\frac{d \theta(x)}{d x}-\frac{d^{2} v(x)}{d x^{2}}\right]=q(x)
$$




$$
E I \frac{d^{2} \theta}{d x^{2}}-Q(x)=0 \Rightarrow E I \frac{d^{2} \theta}{d x^{2}}+\chi G A\left[\frac{d v(x)}{d x}-\theta(x)\right]=0
$$

\subsection{2}

\section{Equilíbrio de Elemento Infinitesimal na Configuração Deformada}

Na Figura 2.7 é apresentado um elemento infinitesimal na condição deformada, submetido a um carregamento distribuído $(q)$ e a uma carga axial constante $(P)$.

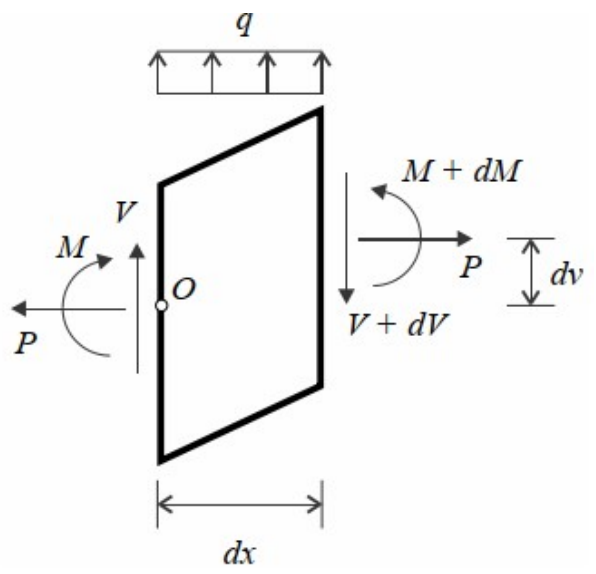

Figura 2.7 - Equilíbrio de um elemento infinitesimal em sua configuração deformada Fonte: Martha e Burgos (2015).

A imposição do equilíbrio do elemento leva à construção das equações (2.40) e (2.41).

$$
\begin{gathered}
\sum F_{y} \rightarrow-d V+q(x) d x=0 \rightarrow \frac{d V(x)}{d x}=q(x) \\
\sum M_{o} \rightarrow d M-(V+d V) d x-P . d v+q(x) \frac{d x^{2}}{2}=0
\end{gathered}
$$

Em que $v(x)$ é o deslocamento transversal, $q(x)$ a carga distribuída, $V(x)$ a componente vertical do esforço na seção transversal, $P$ a componente horizontal do esforço na seção transversal e $M(x)$ o momento fletor na seção transversal.

Utilizando-se a equação da linha elástica, dada em (2.30), $M(x)=E I d \theta / d x$, pode-se desenvolver a equação diferencial que descreve o problema, conforme (2.42). 


$$
\begin{gathered}
E I \frac{d^{2} \theta(x)}{d x^{2}}-V(x)-P \frac{d v(x)}{d x}=0 \\
\rightarrow E I \frac{d^{3} \theta(x)}{d x^{3}}-\frac{d V(x)}{d x}-P \frac{d^{2} v(x)}{d x^{2}}=0
\end{gathered}
$$

Como conhecido, pelas equações fundamentais da estática, o carregamento atuante em uma viga é igual à derivada do esforço cortante, equação (2.43).

$$
q(x)=\frac{d V}{d x}
$$

Dessa maneira, a equação diferencial que rege o problema do equilíbrio de um elemento infinitesimal em sua configuração indeformada pode ser expressa de acordo com a equação (2.44).

$$
E I \frac{d^{3} \theta}{d x^{3}}-P \frac{d^{2} v(x)}{d x^{2}}=q(x)
$$

\subsubsection{1}

\section{Teoria de Flexão de Euler-Bernoulli}

Conforme já explicitado na teoria de flexão de Euler-Bernoulli, a rotação pode se considerada como a derivada do deslocamento transversal $(\theta=d v / d x)$. Dessa forma, a relação diferencial anteriormente desenvolvida em (2.44) pode ser reescrita conforme a equação (2.45),

$$
E I \frac{d^{4} v(x)}{d x^{4}}-P \frac{d^{2} v(x)}{d x^{2}}=q(x)
$$

ou, ainda, conforme (2.46).

$$
\frac{d^{4} v(x)}{d x^{4}}-\frac{P}{E I} \frac{d^{2} v(x)}{d x^{2}}=\frac{q(x)}{E I}
$$

\subsubsection{2}

\section{Teoria de Flexão de Timoshenko}

Conforme já discutido, na teoria clássica de flexão de Timoshenko ocorre uma distorção por cisalhamento como uma rotação adicional, desassociando a rotação do deslocamento transversal da seção, ilustrada na Figura 2.6. 
Assim, quando o elemento se deforma, a projeção dos esforços é obtida utilizando a rotação total da seção, não apenas a rotação por flexão (Reddy et al. 1997; Martha \& Burgos 2014, 2015).

A Figura 2.8 ilustra esses esforços e deslocamentos em um elemento infinitesimal deformado de viga para a teoria clássica de flexão de Timoshenko.
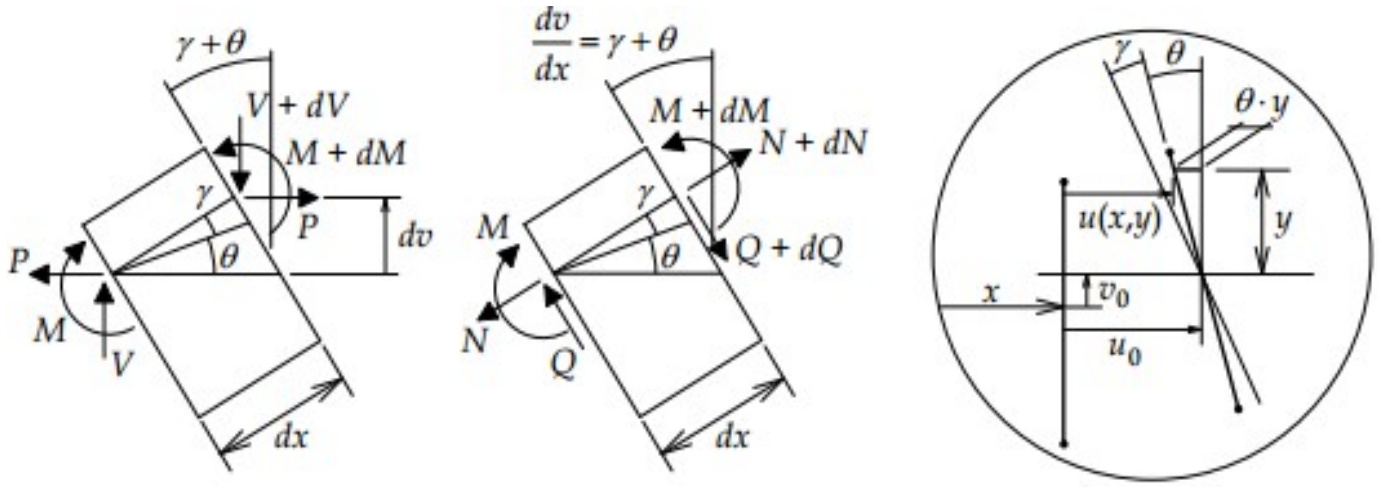

Figura 2.8 - Esforços e deslocamentos na forma clássica da viga de Timoshenko Fonte: Martha e Burgos (2015).

Considerando pequenos deslocamentos e rotações, a análise da Figura 2.8 indica que os esforços solicitantes na seção transversal podem ser apresentados nas equações (2.47) e (2.48).

$$
\begin{gathered}
N(x)=P \cos (\theta+\gamma)-V(x) \operatorname{sen}(\theta+\gamma)=P-V(x)(\theta+\gamma) \\
\rightarrow N(x)=P-V(x) \frac{d v(x)}{d x} \\
Q(x)=P \operatorname{sen}(\theta+\gamma)+V(x) \cos (\theta+\gamma)=P(\theta+\gamma)+V(x) \\
\rightarrow Q(x)=P \frac{d v(x)}{d x}+V(x)
\end{gathered}
$$

Substituindo (2.48) na equação (2.41) obtém-se a consagrada relação fundamental da estática entre o esforço cortante e o momento fletor, equação (2.49).

$$
\frac{d M(x)}{d x}=Q(x)
$$

Por essa razão, pode-se reescrever a equação (2.37) em função do momento fletor, conforme a expressão (2.50).

$$
\frac{d M(x)}{d x}=\chi G A \cdot\left[\theta(x)-\frac{d v(x)}{d x}\right]
$$


Utilizando-se a relação (2.30), equação da linha elástica, a equação anterior (2.50) pode ser analisada conforme a apresentada em (2.51).

$$
\frac{d v(x)}{d x}=\theta(x)-\frac{E I}{\chi G A} \frac{d^{2} \theta}{d x^{2}}
$$

Dessa forma, substitutindo a equação (2.51) na (2.44), obtém-se a relação diferencial que rege o problema, de acordo com a formulação clássica de flexão de Timoshenko, equação (2.52) ou (2.53).

$$
\begin{gathered}
E I\left(1+\frac{P}{\chi G A}\right) \frac{d^{3} \theta}{d x^{3}}-P \frac{d \theta(x)}{d x}=q(x) \\
\frac{d^{3} \theta}{d x^{3}}-\frac{P}{\left(1+\frac{P}{\chi G A}\right) E I} \frac{d \theta(x)}{d x}=\frac{q(x)}{\left(1+\frac{P}{\chi G A}\right) E I}
\end{gathered}
$$

\section{5 \\ Solução das Relações Diferenciais de Equilíbrio em Vigas-Coluna}

A partir das soluções das equações diferenciais, que descrevem o equilíbrio de um elemento infinitesimal, podem ser deduzidas expressões para a solução dos deslocamentos e rotações ao longo de uma barra.

Essa solução completa, $v(x)$, pode ser obtida pela composição da solução homogênea, $v_{h}(x)$, com a solução particular da estrutura, $v_{p}(x)$, conforme equação (2.54). A solução homogênea corresponde a uma situação de barra descarregada e depende apenas das condições de contorno da barra. A solução particular depende do carregamento aplicado $q(x)$.

$$
v(x)=v_{h}(x)+v_{p}(x)
$$

Assim, as parcelas homogêneas são obtidas, considerando $q(x)=0$. Essa solução será utilizada no próximo capítulo para o cálculo das funções de interpolação de um elemento.

Martha (2018) explica que o método da rigidez direta é composto pela superposição dos estágios I e II, conforme Figura 2.9. 


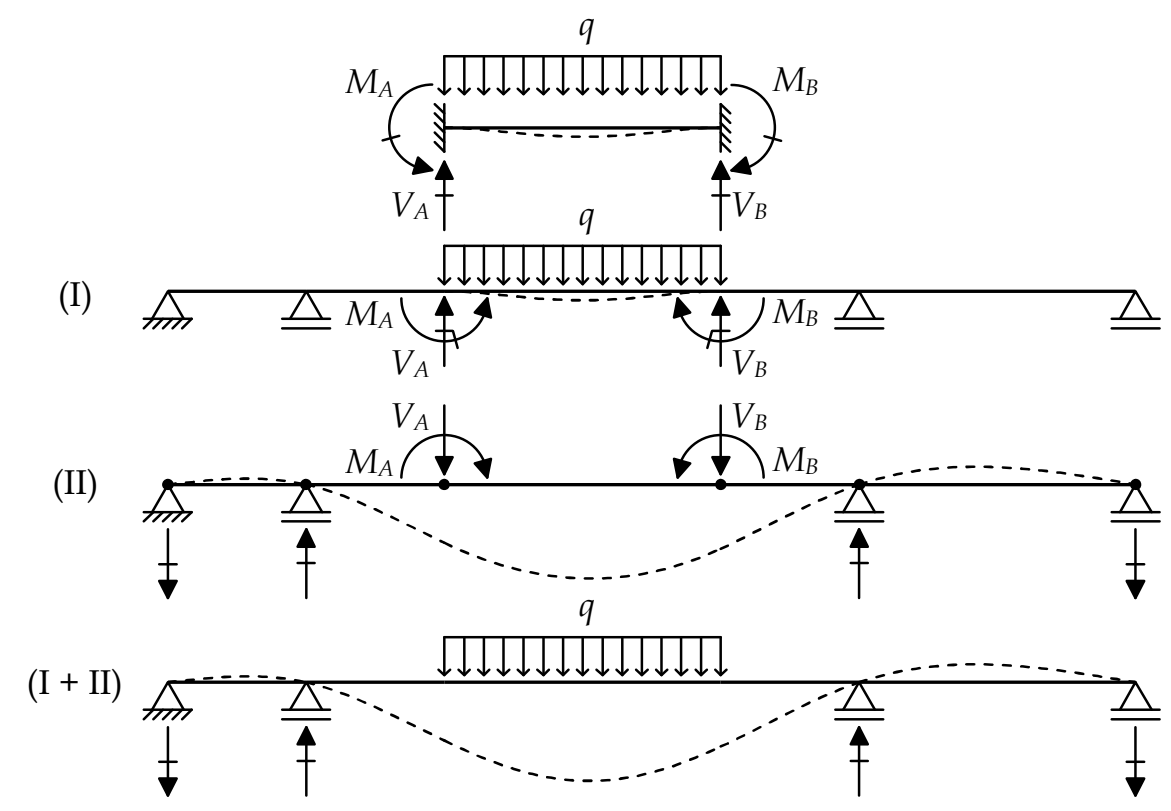

Figura 2.9 - Superposição de estágios do método da rigidez direta Fonte: Martha (2018).

Ainda segundo Martha (2018), o estágio II corresponde ao comportamento global discretizado da estrutura, pois em termos de deslocamentos e rotações nodais, os resultados do estágio II são os da estrutura com carregamento original, enquanto o estágio I corresponde à situação local do trecho carregado.

Dessa forma, a solução homogênea, situação de barra sem carregamento, considera as condições de contorno não nulas nas extremidades da barra e a solução particular se relaciona a condições de contorno com valores nulos, podendo ser interpretadas como soluções locais de engastamento de barras com carregamento, de acordo com a Figura 2.10.

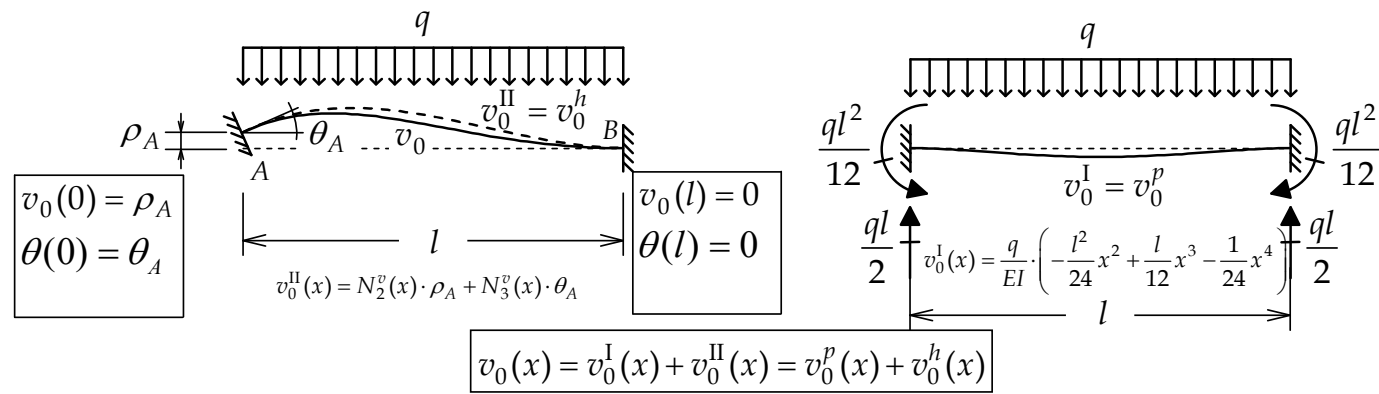

Figura 2.10 - Soluções homogêneas e particulares de barra solicitada por carga uniforme Fonte: Adaptada de Martha (2018).

Essa conclusão relaciona as soluções particulares com as locais (estágio I) e as soluções homogêneas analíticas com a solução global discreta do método da rigidez direta (estágio II). Assim, quando se adota soluções analíticas para o 
comportamento das barras, os deslocamentos e rotações nodais do modelo discreto são exatos, independendo de discretização. Ou seja, no método da rigidez direta o comportamento contínuo de um elemento pode ser representado pelo modelo discreto sem nenhuma aproximação adicional além das já contidas na idealização analítica da barra. Justificando assim a posterior utilização de soluções homogêneas como funções de interpolação de deslocamentos e rotações nodais.

\subsection{1}

\section{Equilíbrio de Elemento Infinitesimal na Configuração Indeformada}

Para o equilíbrio de um elemento infinitesimal em sua configuração indeformada, as equações diferenciais não levam em consideração a carga axial $P$ atuante na seção transversal. Essas equações diferenciais foram desenvolvidas ao longo da seção 2.4 , resultando nas expressões (2.34) para a teoria de flexão de Euler-Bernoulli, (2.38) e (2.39) para a teoria de flexão de Timoshenko.

\subsubsection{1}

\section{Teoria de Flexão de Euler-Bernoulli}

Conforme já explicado, a teoria de flexão de Euler-Bernoulli considera a rotação como sendo a derivada do deslocamento transversal e a equação diferencial do equilíbrio de um elemento infinitesimal, conforme a equação (2.34).

As parcelas homogêneas da solução dessa equação diferencial são calculadas, considerando uma situação de barra descarregada, $q(x)=0$. Assim, ante a teoria de flexão de Euler-Bernoulli, a equação (2.34) toma o formato de (2.55).

$$
E I \frac{d^{4} v_{h}(x)}{d x^{4}}=0
$$

A solução da equação (2.55) é a solução da parcela homogênea da equação (2.54), dada conforme a expressão (2.56):

$$
v_{h}(x)=c_{1}+c_{2} x+c_{3} \frac{x^{2}}{2}+c_{4} \frac{x^{3}}{6}
$$


Em que, $c_{1}, c_{2}, c_{3}$ e $c_{4}$ são os coeficientes de um polinômino de grau três. $\mathrm{O}$ cálculo da rotação da seção transversal pode ser realizado com a relação $\theta(x)=$ $d v(x) / d x$, conforme (2.57).

$$
\theta_{h}(x)=c_{2}+c_{3} x+c_{4} \frac{x^{2}}{2}
$$

A solução particular não introduz nenhum coeficiente adicional a ser determinado. Assim, os coeficientes do polinômio podem ser calculados a partir das condições de contorno, empregando a equação da linha elástica e as equações fundamentais da estática.

\subsubsection{2 \\ Teoria de Flexão de Timoshenko}

Na teoria de flexão de Timoshenko considera-se a distorção por cisalhamento como uma rotação adicional, levando-se em consideração a rotação da seção transversal e o deslocamento transversal como variáveis independentes.

Essa distorção por cisalhamento faz com que a rotação da seção transversal esteja desassociada da tangente da elástica. Por isso, não é possível escrever apenas uma equação diferencial para o problema em função de uma única variável.

As equações diferenciais que descrevem o problema, considerando a teoria de Timoshenko, são as apresentadas em (2.38) e (2.39), e possuem duas variáveis: o deslocamento transversal $v(x)$ e a rotação da seção transversal $\theta(x)$.

Existem diferentes formas para resolver as equações diferenciais que regem o comportamento de um elemento infinitesimal na condição indeformada, considerando a teoria de Timoshenko. Pode-se empregar a função auxiliar, como apresentado em Shirima \& Giger (1992), que será utilizada no capítulo 3, ou a metodologia apresentada em Onu (2008) que separa o deslocamento transversal da estrutura em uma parcela devido à flexão e do cisalhamento $v_{b}(x)$ e $v_{S}(x)$, respectivamente.

Neste ítem, será utilizada a formulação apresentada por Reddy (1997) e Martha (2018). Primeiramente, as soluções das equações (2.38) e (2.39) possuem uma parcela homogênea e outra particular, conforme (2.58) e (2.59). 


$$
\begin{aligned}
& v(x)=v_{h}(x)+v_{p}(x) \\
& \theta(x)=\theta_{h}(x)+\theta_{p}(x)
\end{aligned}
$$

As parcelas homogêneas são obtidas, considerando $q(x)=0$. Assim, pela teoria de flexão de Timoshenko, as equações (2.38) e (2.39) são escritas no formato de (2.60) e (2.61).

$$
\begin{gathered}
\chi G A\left[\frac{d \theta_{h}(x)}{d x}-\frac{d^{2} v_{h}(x)}{d x^{2}}\right]=0 \\
E I \frac{d^{2} \theta_{h}(x)}{d x^{2}}+\chi G A\left[\frac{d v_{h}(x)}{d x}-\theta_{h}(x)\right]=0
\end{gathered}
$$

Ao se derivar a equação (2.61) em relação a $x$ e utilizando-se a equação (2.60), obtém-se a relação (2.62).

$$
E I \frac{d^{3} \theta_{h}(x)}{d x^{3}}=0
$$

Então, a solução homogênea para a rotação da seção transversal $\theta(x)$ é dada por um polinômio de grau dois, da mesma forma que para a teoria de EulerBernoulli, reescrita em (2.63).

$$
\theta_{h}(x)=c_{2}+c_{3} x+c_{4} \frac{x^{2}}{2}
$$

Substituindo $\theta_{h}(x)$ na equação (2.61), tem-se a relação (2.64).

$$
E I c_{4}+\chi G A\left[\frac{d v_{h}(x)}{d x}-\left(c_{2}+c_{3} x+c_{4} \frac{x^{2}}{2}\right)\right]=0
$$

$\mathrm{Ou}$, reescrevendo em função da derivada do deslocamento transversal, conforme (2.65).

$$
\frac{d v_{h}(x)}{d x}=c_{2}+c_{3} x+c_{4} \frac{x^{2}}{2}-\frac{E I c_{4}}{\chi G A}
$$

O deslocamento transversal pode ser escrito então, integrando uma vez a relação anterior, obtendo-se a equação (2.66) como solução homogênea do problema, considerando a teoria de Timoshenko.

$$
v_{h}(x)=c_{1}+c_{2} x+c_{3} \frac{x^{2}}{2}+c_{4}\left(\frac{x^{3}}{6}-\frac{E I x}{\chi G A}\right)
$$


À medida que o valor da inércia ao cisalhamento $\chi G A$ for considerado muito grande em relação ao valor da rigidez à flexão $E I$, a equação (2.66) se reduz à teoria de flexão de Euler-Bernoulli.

Da mesma forma que na teoria de Euler-Bernouli, os coeficientes do polinômio da equação (2.66) podem ser calculados a partir das condições de contorno, empregando-se a equação da linha elástica e as equações fundamentais da estática.

\subsection{2}

\section{Equilíbrio de Elemento Infinitesimal na Configuração Deformada}

No caso do equilíbrio de um elemento infinitesimal na configuração deformada, as equações diferenciais levam em consideração a carga axial $P$ atuante na seção transversal, podendo-se interpretar como uma análise não linear em nível infinitesimal. Essas equações diferenciais foram desenvolvidas ao longo da seção 2.4, resultando nas expressões (2.46), para a teoria de flexão de EulerBernoulli, e (2.51) e (2.53), para a teoria de Timoshenko.

\subsubsection{1}

\section{Teoria de Flexão de Euler-Bernoulli}

Conforme calculado na seção 2.4 , a equação diferencial do equilíbrio de um elemento infinitesimal na configuração deformada, considerando a teoria de flexão de Euler-Bernoulli é dada conforme a equação (2.46).

Seguindo a mesma metodologia do elemento na condição indeformada, as parcelas homogêneas da solução dessa equação diferencial são calculadas, considerando uma situação de barra descarregada, $q(x)=0$. Assim, considerando-se a teoria de flexão de Euler-Bernoulli, a equação (2.46) toma o formato de (2.67).

$$
\frac{d^{4} v(x)}{d x^{4}}-\mu^{2} \frac{d^{2} v(x)}{d x^{2}}=0, \quad \mu=\sqrt{\frac{P}{E I}}
$$

A solução da equação (2.67) é a solução da parcela homogênea da equação (2.54), dada conforme a expressão (2.68). 


$$
v_{h}(x)=c_{1} e^{\mu x}+c_{2} e^{-\mu x}+c_{3} x+c_{4}
$$

Em que $c_{1}, c_{2}, c_{3}$ e $c_{4}$ são os coeficientes de uma função exponencial.

Como a teoria de flexão de Euler-Bernoulli considera a rotação como sendo a derivada do deslocamento transversal, o cálculo da rotação da seção transversal pode ser realizado com a relação $\theta(x)=d v(x) / d x$, conforme (2.69).

$$
\theta_{h}(x)=c_{1} \mu e^{\mu x}-c_{2} \mu e^{-\mu x}+c_{3}
$$

A solução particular não introduz nenhum coeficiente adicional a ser determinado. Assim, os coeficientes da função exponencial podem ser calculados a partir das condições de contorno, empregando-se a equação da linha elástica e as equações fundamentais da estática.

Caso a força axial seja de tração, o valor de $\mu$ é um número real e a solução homogênea da equação diferencial pode ser escrita por funções hiperbólicas, conforme a expressão (2.70). A rotação da seção transversal é dada pela diferenciação do deslocamento transversal, equação (2.71).

$$
\begin{gathered}
v_{h}(x)=c_{1} \operatorname{senh}(\mu x)+c_{2} \cosh (\mu x)+c_{3} x+c_{4}, \mu=\sqrt{\frac{P}{E I}} \\
\theta_{h}(x)=c_{1} \mu \cosh (\mu x)+c_{2} \mu \operatorname{senh}(\mu x)+c_{3}
\end{gathered}
$$

Por outro lado, se a força axial for de compressão, o valor de $\mu$ é um número complexo e o deslocamento pode ser escrito por funções trigonométricas, conforme (2.72) e (2.73).

$$
\begin{gathered}
v_{h}(x)=c_{1} \operatorname{sen}(\mu x)+c_{2} \cos (\mu x)+c_{3} x+c_{4}, \mu=\sqrt{\frac{-P}{E I}} \\
\theta_{h}(x)=c_{1} \mu \cos (\mu x)-c_{2} \mu \operatorname{senh}(\mu x)+c_{3}
\end{gathered}
$$

\subsubsection{2}

\section{Teoria de Flexão de Timoshenko}

As equações diferenciais que descrevem o problema, considerando a teoria de flexão de Timoshenko e o equilíbrio de um elemento infinitesimal na configuração deformada, são as apresentadas em (2.51) e (2.53) e possuem duas variáveis: o deslocamento transversal $v(x)$ e a rotação da seção transversal $\theta(x)$, 
não sendo possível escrever apenas uma equação diferencial para o problema em função de uma única variável.

Conforme explicado anteriormente, isso acontece porque a distorção por cisalhamento faz com que a rotação da seção transversal esteja desassociada da tangente da elástica.

As soluções das equações (2.51) e (2.53) também possuem uma parcela homogênea e outra particular. As parcelas homogêneas são obtidas considerando $q(x)=0$. Assim, considerando a teoria de flexão de Timoshenko, as equações (2.51) e (2.53) podem ser escritas no formato de (2.74) e (2.75), com $\Lambda$ sendo dado pela relação (2.76).

$$
\begin{gathered}
\frac{d v(x)}{d x}=\theta(x)-\frac{E I}{\chi G A} \frac{d^{2} \theta}{d x^{2}} \\
\frac{d^{3} \theta}{d x^{3}}-\Lambda^{2} \frac{d \theta(x)}{d x}=0, \quad \Lambda=\frac{\mu}{\sqrt{1+\frac{E I}{\chi G A} \cdot \mu^{2}}} \\
\Lambda=\frac{\mu}{\sqrt{1+\frac{E I}{\chi G A} \cdot \mu^{2}}}, \mu=\sqrt{\frac{P}{E I}}
\end{gathered}
$$

Utilizando-se a constante $\Omega$, equação (2.77), introduzida por Reddy (1997) e ainda utilizada em Burgos \& Martha (2013), como também em Martha \& Burgos (2014, 2015), as equações diferenciais do problema podem ser reescritas em função dessa constante, de acordo com as expressões (2.78) e (2.79).

$$
\begin{gathered}
\Omega=\frac{E I}{\chi G A} \frac{1}{L^{2}} \\
\frac{d v(x)}{d x}=\theta(x)-\Omega L^{2} \frac{d^{2} \theta}{d x^{2}} \\
\frac{d^{3} \theta}{d x^{3}}-\Lambda^{2} \frac{d \theta(x)}{d x}=0, \quad \Lambda=\frac{\mu}{\sqrt{1+\Omega \mu^{2} L^{2}}}
\end{gathered}
$$

Usando da mesma metodologia anterior, para o caso da teoria de EulerBernoulli, e seguindo o que é apresentado em Martha \& Burgos (2014), primeiro resolve-se a equação (2.79). Assim, a solução homogênea para a rotação da seção transversal $\theta(x)$, é dada por uma função exponencial, conforme expressão (2.80).

$$
\theta_{h}(x)=\Lambda\left(c_{1} e^{\Lambda x}-c_{2} e^{-\Lambda x}\right)+c_{3}
$$


Substituindo $\theta_{h}(x)$ na equação (2.78), resulta a relação (2.81).

$$
\frac{d v(x)}{d x}=\left[\Lambda\left(c_{1} e^{\Lambda x}-c_{2} e^{-\Lambda x}\right)\right]+c_{3}-\Omega L^{2} \Lambda\left(c_{1} \Lambda^{2} e^{\Lambda x}-c_{2} \Lambda^{2} e^{-\Lambda x}\right)
$$

O deslocamento transversal pode ser escrito, integrando uma vez a relação anterior, obtendo-se a equação (2.82) como solução homogênea do problema, considerando a teoria de Timoshenko.

$$
v_{h}(x)=\left(1-\Omega L^{2} \Lambda^{2}\right)\left[c_{1} e^{\Lambda x}-c_{2} e^{-\Lambda x}\right]+c_{3} x+c_{4}
$$

Caso a força axial seja de tração, o valor de $\mu$ é um número real e a solução homogênea da equação diferencial pode ser escrita por funções hiperbólicas, de acordo com as equações (2.83) e (2.84).

$$
\begin{gathered}
\theta_{h}(x)=\Lambda\left[c_{1} \cosh (\Lambda x)+c_{2} \operatorname{senh}(\Lambda x)\right]+c_{3} \\
v_{h}(x)=\left(1-\Omega L^{2} \Lambda^{2}\right)\left[c_{1} \operatorname{senh}(\Lambda x)+c_{2} \cosh (\Lambda x)\right]+c_{3} x+c_{4}
\end{gathered}
$$

Em caso de a força axial ser de compressão, o valor de $\mu$ é um número complexo e o deslocamento pode ser escrito por funções trigonométricas, conforme (2.85) e (2.86).

$$
\begin{gathered}
\theta_{h}(x)=\Lambda\left[c_{1} \cos (\Lambda x)-c_{2} \operatorname{sen}(\Lambda x)\right]+c_{3} \\
v_{h}(x)=\left(1+\Omega L^{2} \Lambda^{2}\right)\left[c_{1} \operatorname{sen}(\Lambda x)+c_{2} \cos (\Lambda x)\right]+c_{3} x+c_{4}
\end{gathered}
$$

\section{6 \\ Resumo da Idealização do Comportamento de Barras à Flexão}

A formulação do comportamento à flexão é resumida na Figura 2.11 para o equilíbrio de um elemento infinitesimal na sua configuração indeformada. As expressões de compatibilidade, equilíbrio e leis constitutivas associadas às teorias de flexão de Euler-Bernoulli e Timoshenko vistas nesta capítulo são expostas de forma compacta. Na Figura 2.12 esse resumo é desenvolvido para o equilíbrio de um elemento infinitesimal na condição deformada.

É importante observar que se o valor da inércia ao cisalhamento $(\chi G A=$ $G A_{s}$ ) for considerado elevado em relação a inércia à flexão $(E I)$, o parâmetro $\Omega$ se anula. Assim, as equações para rotação e deslocamento de seção transversal considerando à teoria de flexão de Timoshenko correspondem as desenvolvidas para a teoria de flexão de Euler-Bernoulli. 


\section{RESUMO DO EQUILÍBRIO DE UM ELEMENTO INFINITESIMAL NA CONFIGURAÇÃO INDEFORMADA}
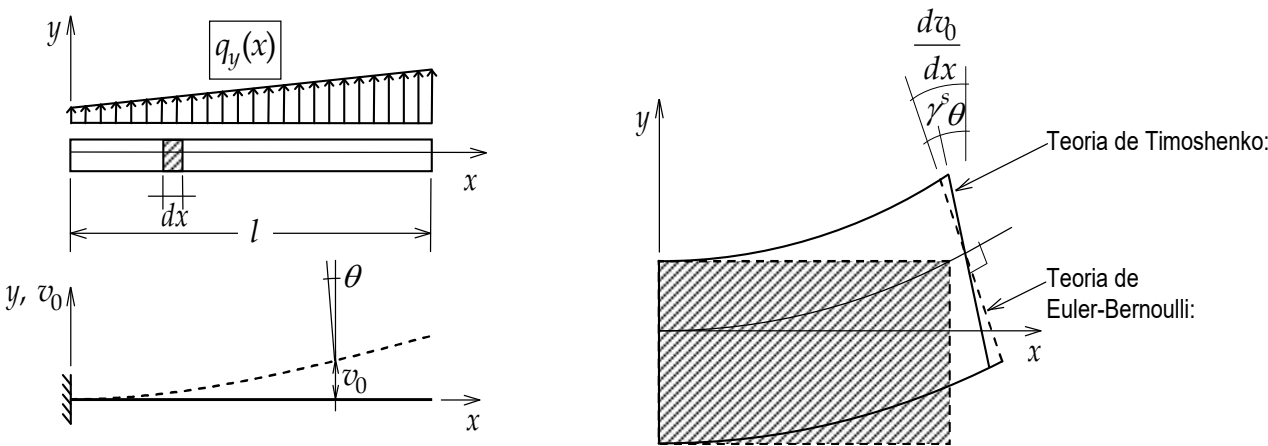

\section{Relações de compatibilidade:}

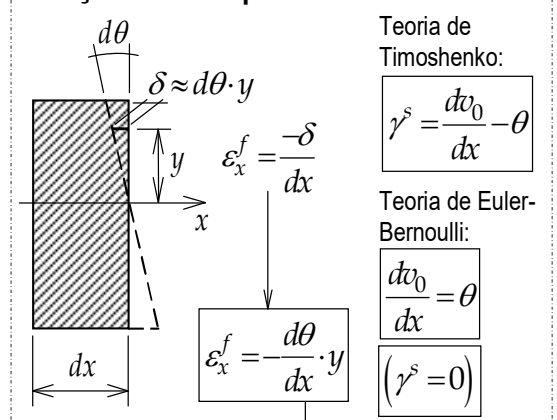

\section{$\tau_{x y}=G \cdot \gamma^{s}$<smiles>[C]1C=CC=C1</smiles> $v$ \\ $d A$

$$
Q=-G A_{s} \cdot \gamma^{s} M=\int_{A}(-y) \cdot E \cdot\left(-\frac{d \theta}{d x} \cdot y\right) d A
$$

\section{Teoria de Timoshenko:}

\section{Relações de equilíbrio:}

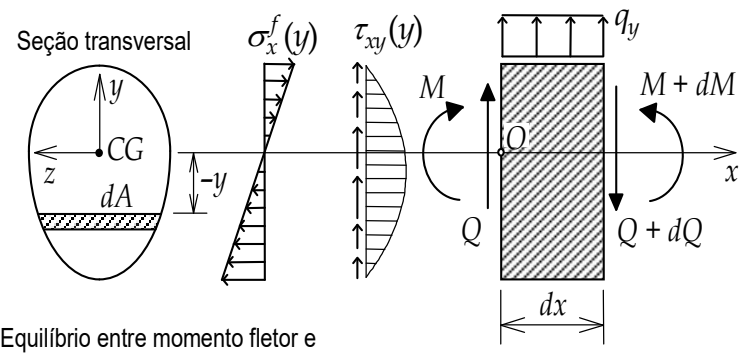

Equilíbrio entre momento fletor $e$ tensões normais:

$M=\int_{A}(-y) \cdot \sigma_{x}^{f} d A$

Equilíbrio entre esforço cortante e tensões cisalhantes:

$Q=\int_{A}-\tau_{x y} \cdot d A$ $\sum F_{y}=0 \rightarrow \frac{d Q}{d x}=q_{y}(x)$

$\sum M_{O}=0 \rightarrow \frac{d M}{d x}=Q(x)$

$\checkmark$ $\frac{d^{2} M}{d x^{2}}=q_{y}(x)<$

$\gamma^{s}=\frac{d v_{0}}{d x}-\theta>Q=G A_{s} \cdot\left(\theta-\frac{d v_{0}}{d x}\right) \rightarrow \frac{d 0_{0}}{d x}=-\frac{E I}{G A_{s}} \cdot \frac{d^{2} \theta}{d x^{2}}+\theta$

Teoria de Euler-Bernoulli:

$$
\frac{d v_{0}}{d x}=\theta \rightarrow M=E I \cdot \frac{d^{2} v_{0}}{d x^{2}} \rightarrow E I \cdot \frac{d^{4} v_{0}}{d x^{4}}=q_{y}(x)
$$

\section{Solução homogênea das equações}

\section{atseranass}

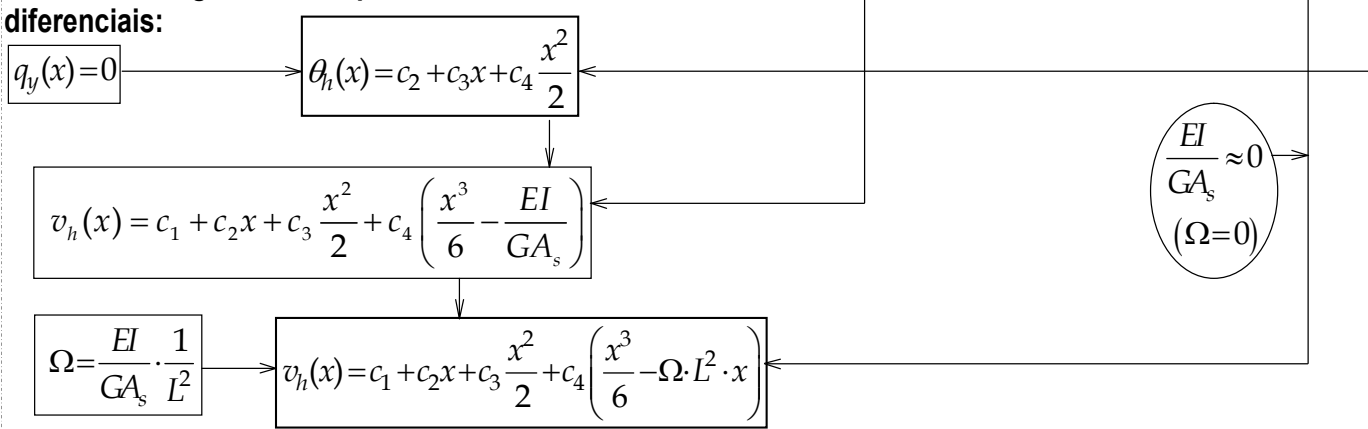

Figura 2.11 - Resumo das teorias de flexão de Euler-Bernoulli e Timoshenko considerando o equilíbrio de elemento infinitesimal na configuração indeformada

Fonte: Adaptada de Martha (2018). 


\section{RESUMO DO EQUILÍBRIO DE UM ELEMENTO INFINITESIMAL NA CONFIGURAÇÃO DEFORMADA}
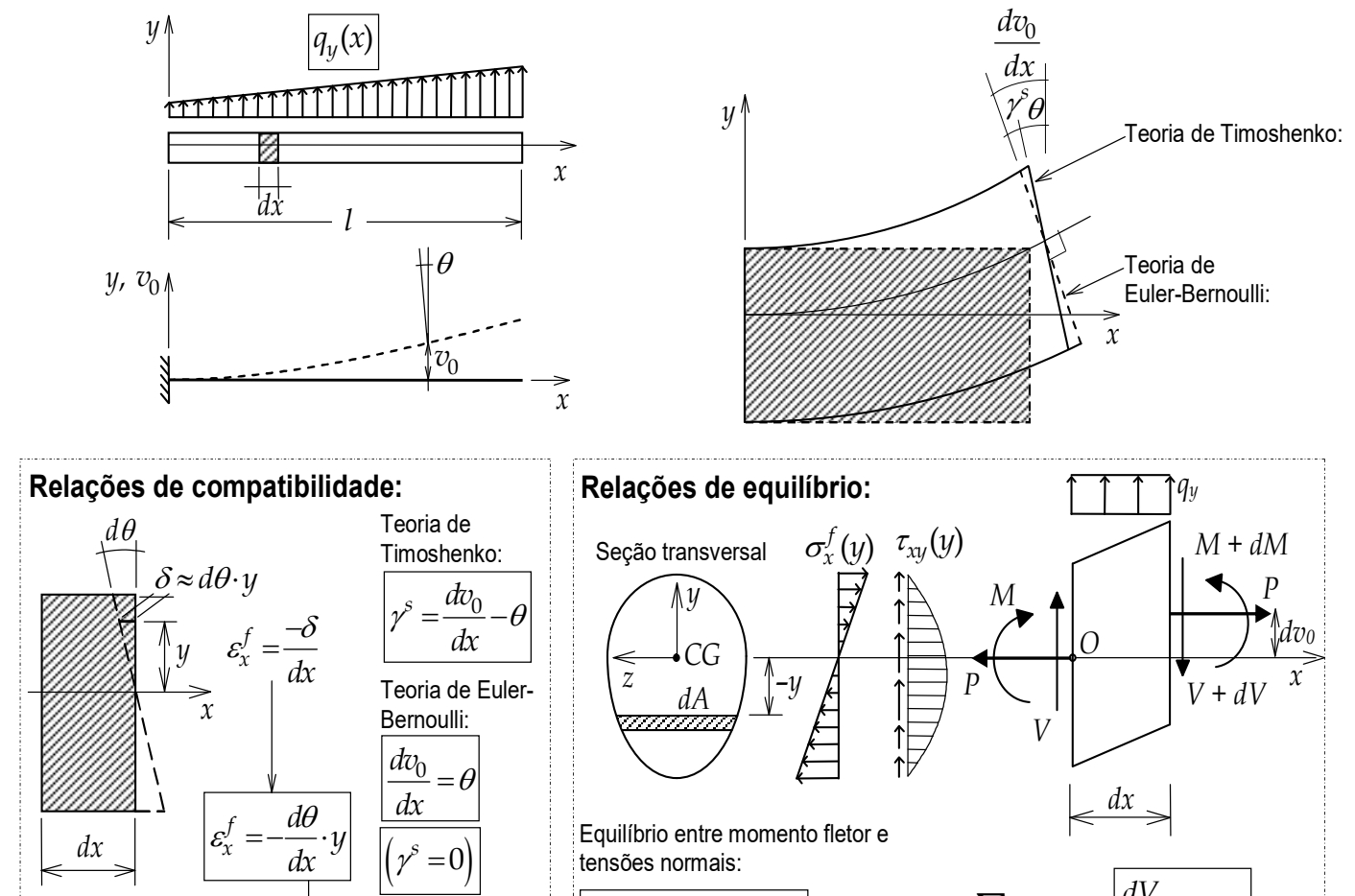

\section{Relações tensão} vs. deformação:

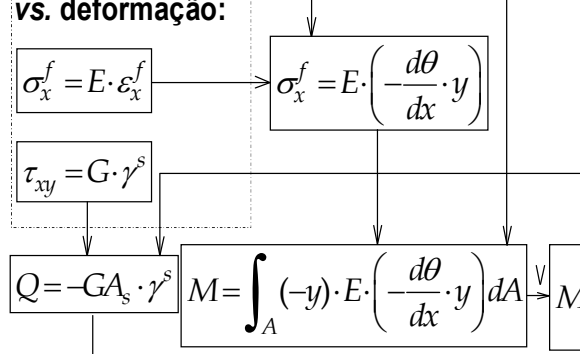

\section{Relações de equilíbrio:}

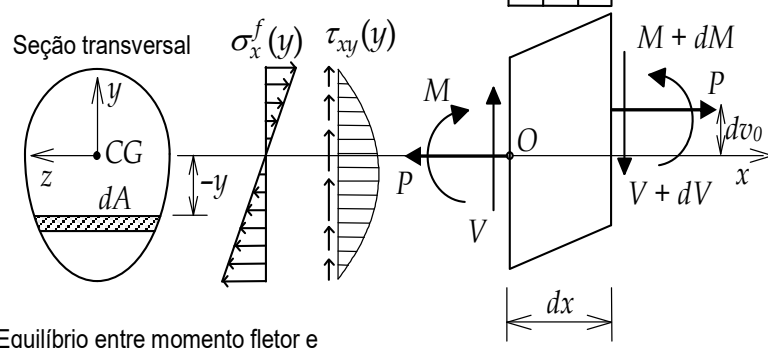

Equilíbrio entre momento fletor e tensões normais:

$M=\int_{A}(-y) \cdot \sigma_{x}^{f} d A$

$$
\sum F_{y}=0 \rightarrow \frac{d V}{d x}=q_{y}(x)
$$

Equilíbrio entre esforço cortante e tensões cisalhantes: $Q=\int_{A}-\tau_{x y} \cdot d A$ $\sum M_{O}=0 \rightarrow \frac{d M}{d x}=V+P \frac{d v_{0}}{d x}$ $\frac{d^{2} M}{d x^{2}}=\frac{d V}{d x}+P \frac{d^{2} v_{0}}{d x^{2}}$ $\frac{v_{0}}{d x^{2}}=\forall$

Teoria de Timoshenko:

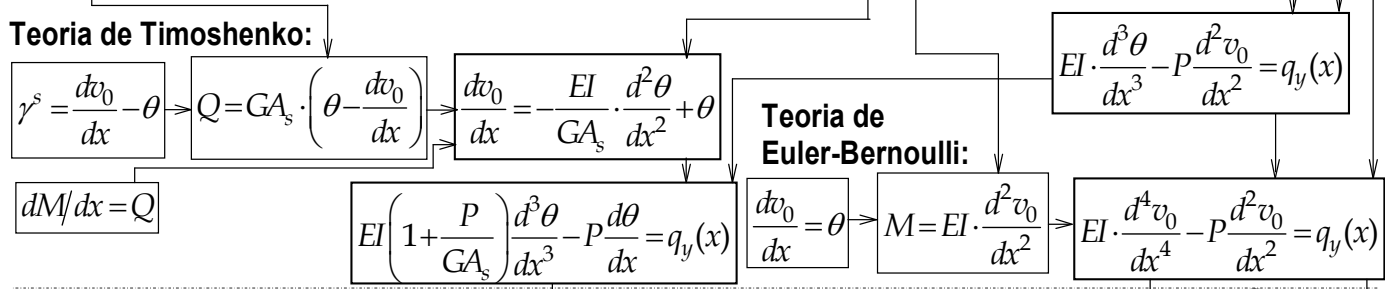

Solução homogênea das equações diferenciais:

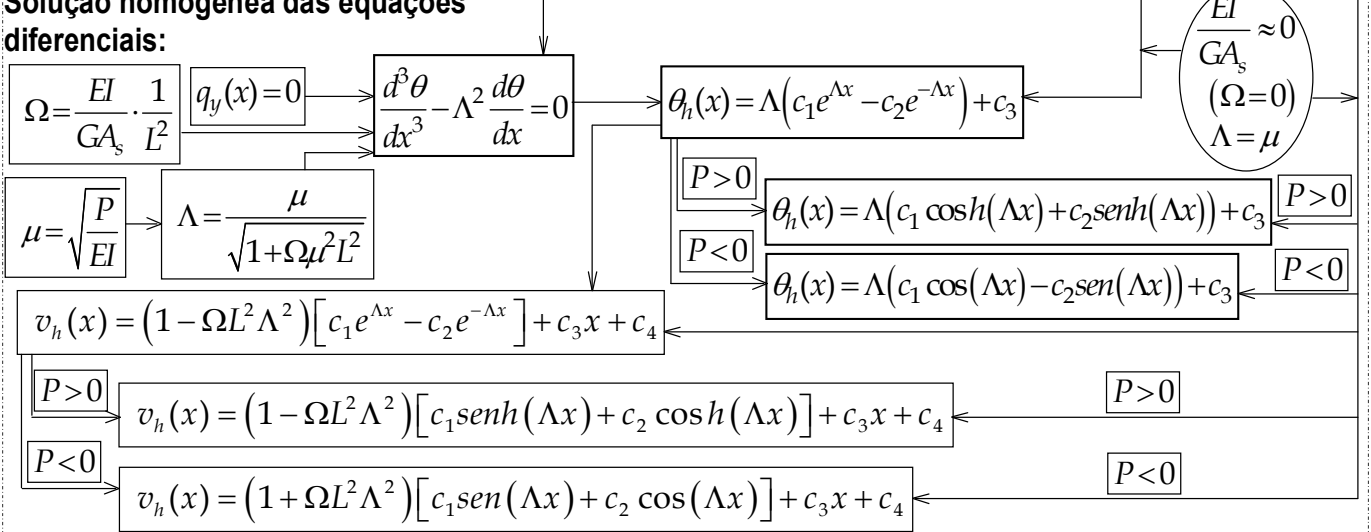

Figura 2.12 - Resumo das teorias de flexão de Euler-Bernoulli e Timoshenko considerando o equilíbrio de elemento infinitesimal na configuração deformada Fonte: Elaborada pelo Autor (2019) - Adaptada de Martha (2018). 


\section{3 \\ Funções de Interpolação: Comportamento à Flexão}

Em uma análise, em que se utiliza o MEF, o comportamento analítico de um sólido pode ser representado por um comportamento discreto. Geralmente, a solução discreta é obtida pelos deslocamentos nodais e a solução do problema contínuo pode ser encontrada interpolando os deslocamentos nodais, com a utilização das funções de forma.

Portanto, as configurações deformadas elementares de uma barra isolada resultam da imposição individual dos deslocamentos nas suas extremidades, conforme pode ser observado na Figura 3.1.

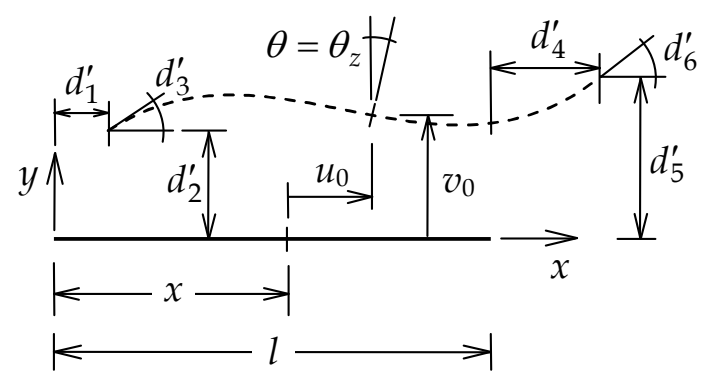

Figura 3.1 - Configuração deformada de barra isolada

Fonte: Adaptada de Martha (2018).

As soluções homogêneas para o comportamento de barras descrevem uma elástica que pode ser representada em função dos seus deslocamentos nodais, empregando funções de interpolação, conforme equações (3.1), (3.2) e (3.3).

$$
\begin{gathered}
u_{0}(x)=N_{1}^{u}(x) d_{1}^{\prime}+N_{4}^{u}(x) d_{4}^{\prime} \\
v_{0}(x)=N_{2}^{v}(x) d_{2}^{\prime}+N_{3}^{v}(x) d_{3}^{\prime}+N_{5}^{v}(x) d_{5}^{\prime}+N_{6}^{v}(x) d_{6}^{\prime} \\
\theta(x)=N_{2}^{\theta}(x) d_{2}^{\prime}+N_{3}^{\theta}(x) d_{3}^{\prime}+N_{5}^{\theta}(x) d_{5}^{\prime}+N_{6}^{\theta}(x) d_{6}^{\prime}
\end{gathered}
$$

Essas equações podem ser apresentadas de maneira matricial, conforme (3.4), e de uma forma condensada, como na expressão (3.5), em que [N] é a matriz que reúne as funções de forma consideradas. 


$$
\begin{gathered}
\left\{\begin{array}{l}
u_{0}(x) \\
v_{0}(x) \\
\theta(x)
\end{array}\right\}=\left[\begin{array}{cccccc}
N_{1}^{u}(x) & 0 & 0 & N_{4}^{u}(x) & 0 & 0 \\
0 & N_{2}^{v}(x) & N_{3}^{v}(x) & 0 & N_{5}^{v}(x) & N_{6}^{v}(x) \\
0 & N_{2}^{\theta}(x) & N_{3}^{\theta}(x) & 0 & N_{5}^{\theta}(x) & N_{6}^{\theta}(x)
\end{array}\right] \cdot\left\{\begin{array}{l}
d_{1}^{\prime} \\
d_{2}^{\prime} \\
d_{3}^{\prime} \\
d_{4}^{\prime} \\
d_{5}^{\prime} \\
d_{6}^{\prime}
\end{array}\right\} \\
\left\{\begin{array}{l}
u_{0}(x) \\
v_{0}(x) \\
\theta(x)
\end{array}\right\}=[N] .\left\{d^{\prime}\right\}
\end{gathered}
$$

Quando estas funções de forma são obtidas diretamente da solução homogênea da equação diferencial do problema contínuo, a discretização da barra não é necessária, conforme explicado no capítulo 2. Isto acontece, porque o comportamento contínuo do elemento pode ser representado por parâmetros nodais, sem a consideração de outras aproximações, além das já consideradas na idealização analítica do comportamento do elemento.

As funções de forma podem englobar a não linearidade geométrica no nível infinitesimal, ao se considerar, no desenvolvimento da equação diferencial do problema, o equilíbrio de um elemento em sua configuração deformada, fazendo com que a carga axial esteja presente nessas funções de interpolação.

Assim, neste capítulo, são desenvolvidas as funções de forma usuais, Hermitianas, para a teoria de flexão de Euler-Bernoulli e a de Timoshenko. Nelas a não linearidade geométrica em nível de elemento infinitesimal é desconsiderada, gerando as funções cúbicas conhecidas.

Também são calculadas as funções de forma a partir do equilíbrio de um elemento infinitesimal em sua configuração deformada, em que a carga axial é levada em consideração, sendo então realizada uma análise não linear geométrica em nível infinitesimal. Essas funções também são calculadas para ambas as teorias de flexão apresentadas neste trabalho.

O desenvolvimento das funções de forma, para cada caso específico, além de ser importante do ponto de vista didático, também se faz necessário ao o desenvolvimento de programas gráficos. A metodologia utilizada neste trabalho para cálculo das funções de forma encontra-se contida em Burgos \& Martha (2013). 


\section{1}

\section{Equilíbrio do Elemento Infinitesimal na Configuração Indeformada}

Conforme já mencionado, as funções de forma podem ser obtidas diretamente da solução homogênea da equação diferencial do problema. Se o problema for descrito a partir do equilíbrio de um elemento infinitesimal na configuração indeformada, Figura 3.2, as funções de interpolação são as Hermitianas (cúbicas).

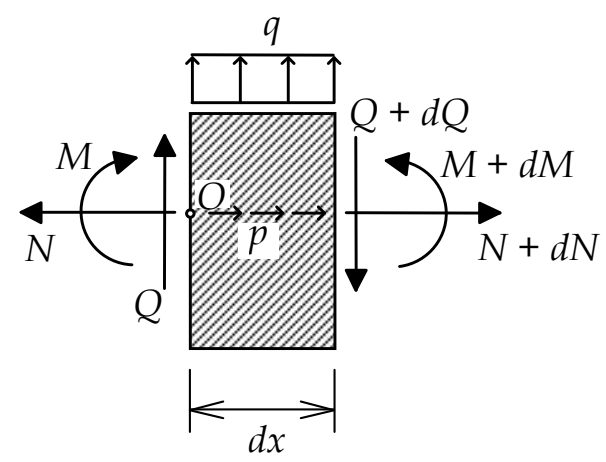

Figura 3.2 - Elemento infinitesimal na configuração indeformada Fonte: Adaptado de Martha (2018).

O desenvolvimento das equações diferenciais do problema foi realizado no capítulo 2. Portanto, a partir da solução dessas equações, que fornece o deslocamento e a rotação da estrutura, são desenvolvidas as funções de interpolação, considerando a teoria de flexão de Euler-Bernoulli e a de Timoshenko.

\subsection{1}

\section{Funções de Forma: Teoria de Euler-Bernoulli}

Conforme visto no capítulo 2, para um elemento infinitesimal, a solução homogênea da equação diferencial para o equilíbrio de elemento na configuração indeformada, empregando-se a teoria de flexão de Euler-Bernoulli, é dada conforme as equações (2.56) e (2.57) e repetida em (3.6) e (3.7), por conveniência.

$$
\begin{gathered}
v_{h}(x)=c_{1}+c_{2} x+c_{3} \frac{x^{2}}{2}+c_{4} \frac{x^{3}}{6} \\
\theta_{h}(x)=c_{2}+c_{3} x+c_{4} \frac{x^{2}}{2}
\end{gathered}
$$


Assim, o deslocamento da barra pode ser escrito de forma matricial, de acordo com a equação (3.8).

$$
\left\{\begin{array}{c}
\boldsymbol{v}_{0}(\boldsymbol{x}) \\
\boldsymbol{\theta}(\boldsymbol{x})
\end{array}\right\}=[\boldsymbol{X}] .\{\boldsymbol{C}\},[\boldsymbol{X}]=\left[\begin{array}{cccc}
1 & x & \frac{x^{2}}{2} & \frac{x^{3}}{6} \\
0 & 1 & x & \frac{x^{2}}{2}
\end{array}\right] \quad\{\boldsymbol{C}\}=\left\{\begin{array}{l}
c_{1} \\
c_{2} \\
c_{3} \\
c_{4}
\end{array}\right\}
$$

A matriz $[\boldsymbol{X}]$ é composta pelas funções que descrevem os deslocamentos e o vetor $\{\boldsymbol{C}\}$ é formado pelas constantes que multiplicam essas funções.

As condições de contorno são obtidas, avaliando a solução homogênea da equação diferencial nos nós das barras, conforme Figura 3.1 e equação (3.9).

$$
\left\{\boldsymbol{d}^{\prime}\right\}=\left\{\begin{array}{l}
d_{2}^{\prime} \\
d_{3}^{\prime} \\
d_{5}^{\prime} \\
d_{6}^{\prime}
\end{array}\right\}=\left\{\begin{array}{c}
v_{0}(0) \\
\theta(0) \\
v_{0}(L) \\
\theta(L)
\end{array}\right\}=\left\{\begin{array}{c}
c_{1} \\
c_{2} \\
c_{1}+c_{2} L+c_{3} \frac{L^{2}}{2}+c_{4} \frac{L^{3}}{6} \\
c_{2}+c_{3} L+c_{4} \frac{L^{2}}{2}
\end{array}\right\}
$$

De forma análoga ao deslocamento, as condições de contorno apresentadas na equação (3.9) também podem ser escritas matricialmente, utilizando-se a matriz $[\boldsymbol{H}]$ e o vetor de constantes $\{\boldsymbol{C}\}$, de acordo com a equação (3.10).

$$
\begin{aligned}
\left\{\boldsymbol{d}^{\prime}\right\}=\left\{\begin{array}{l}
d_{2}^{\prime} \\
d_{3}^{\prime} \\
d_{5}^{\prime} \\
d_{6}^{\prime}
\end{array}\right\}=\left\{\begin{array}{c}
v_{0}(0) \\
\theta(0) \\
v_{0}(L) \\
\theta(L)
\end{array}\right\} & \rightarrow\left\{d^{\prime}\right\}=\left[\begin{array}{cccc}
1 & 0 & 0 & 0 \\
0 & 1 & 0 & 0 \\
1 & L & \frac{L^{2}}{2} & \frac{L^{3}}{6} \\
0 & 1 & L & \frac{L^{2}}{2}
\end{array}\right] \cdot\left\{\begin{array}{l}
c_{1} \\
c_{2} \\
c_{3} \\
c_{4}
\end{array}\right\} \\
& \rightarrow[\boldsymbol{H}] .\{\boldsymbol{C}\}=\left\{\boldsymbol{d}^{\prime}\right\}
\end{aligned}
$$

Como já tratado, as funções de forma interpolam os deslocamentos, solução discreta, para obter a solução contínua do problema, conforme a equação (3.5), $\left\{v_{0}(x) \quad \theta(x)\right\}^{t}=[N] .\left\{d^{\prime}\right\}$, sem a parcela axial. Assim, os deslocamentos podem ser calculados, substituindo-se a equação (3.10) na (3.8), obtendo-se a relação (3.11) para as funções de forma.

$$
\left\{\begin{array}{c}
v_{0}(x) \\
\theta(x)
\end{array}\right\}=[X] \cdot[H]^{-1} \cdot\left\{d^{\prime}\right\} \Rightarrow[N]=[X] \cdot[H]^{-1}
$$

Desse modo, as funções de interpolação desenvolvidas a partir da solução homogênea do equilíbrio de um elemento infinitesimal na configuração 
indeformada, considerando a teoria de flexão de Euler-Bernoulli são as já conhecidas e apresentadas nas expressões de (3.12) a (3.15).

$$
\begin{array}{cc}
N_{2}^{v}(x)=2 \frac{x^{3}}{L^{3}}-3 \frac{x^{2}}{L^{2}}+1 & N_{2}^{\theta}(x)=\frac{6 x^{2}}{L^{3}}-\frac{6 x}{L^{2}} \\
N_{3}^{v}(x)=\frac{x^{3}}{L^{2}}-2 \frac{x^{2}}{L}+\mathrm{x} & N_{3}^{\theta}(x)=3 \frac{x^{2}}{L^{2}}-\frac{4 x}{L}+1 \\
N_{5}^{v}(x)=3 \frac{x^{2}}{L^{2}}-2 \frac{x^{3}}{L^{3}} & N_{5}^{\theta}(x)=\frac{6 x}{L^{2}}-\frac{6 x^{2}}{L^{3}} \\
N_{6}^{v}(x)=\frac{x^{3}}{L^{2}}-\frac{x^{2}}{L} & N_{6}^{\theta}(x)=3 \frac{x^{2}}{L^{2}}-\frac{2 x}{L}
\end{array}
$$

Nos apêndices A.1 e A.2, são calculadas as funções de forma, considerando rótulas nas extremidades da barra e teoria de flexão de Euller-Bernoulli, para o equilíbrio de um elemento infinitesimal na configuração indeformada.

\subsection{2}

\section{Funções de Forma: Teoria de Timoshenko}

Para um elemento infinitesimal de viga, a solução homogênea da equação diferencial para o equilíbrio de elemento na configuração indeformada, empregando-se a teoria de flexão de Timoshenko, também foi desenvolvida no capítulo 2, equações (2.63) e (2.66), e repetida em (3.16) e (3.17), por conveniência, empregando $\Omega$.

$$
\begin{gathered}
v_{h}(x)=c_{1}+c_{2} x+c_{3} \frac{x^{2}}{2}+c_{4}\left(\frac{x^{3}}{6}-\Omega L^{2} x\right), \Omega=\frac{E I}{\chi G A} \frac{1}{L^{2}} \\
\theta_{h}(x)=c_{2}+c_{3} x+c_{4} \frac{x^{2}}{2}
\end{gathered}
$$

Utilizando-se da mesma metodologia anterior, o deslocamento da barra pode ser escrito de forma matricial, de acordo com a equação (3.18).

$$
\left\{\begin{array}{c}
\boldsymbol{v}_{\mathbf{0}}(\boldsymbol{x}) \\
\boldsymbol{\theta}(\boldsymbol{x})
\end{array}\right\}=[\boldsymbol{X}] .\{\boldsymbol{C}\},[\boldsymbol{X}]=\left[\begin{array}{ccccc}
1 & x & \frac{x^{2}}{2} & \frac{x^{3}}{6}-\Omega L^{2} x \\
& 0 & 1 & x & \frac{x^{2}}{2}
\end{array}\right]\{\boldsymbol{C}\}=\left\{\begin{array}{l}
c_{1} \\
c_{2} \\
c_{3} \\
c_{4}
\end{array}\right\}
$$

As condições de contorno são obtidas, avaliando a solução homogênea da equação diferencial nos nós das barras, conforme equação (3.19). 


$$
\left\{\boldsymbol{d}^{\prime}\right\}=\left\{\begin{array}{l}
d_{2}^{\prime} \\
d_{3}^{\prime} \\
d_{5}^{\prime} \\
d_{6}^{\prime}
\end{array}\right\}=\left\{\begin{array}{c}
v_{0}(0) \\
\theta(0) \\
v_{0}(L) \\
\theta(L)
\end{array}\right\}=\left\{\begin{array}{c}
c_{1} \\
c_{2} \\
c_{1}+c_{2} L+c_{3} \frac{L^{2}}{2}+c_{4}\left(\frac{L^{3}}{6}-\frac{E I}{\chi G A}\right) \\
c_{2}+c_{3} L+c_{4} \frac{L^{2}}{2}
\end{array}\right\}
$$

Ao se escrever as condições de contorno matricialmente, utilizando-se a matriz $[\boldsymbol{H}]$ e o vetor de coeficiente $\{\boldsymbol{C}\}$, obtém-se a equação (3.20).

$$
\begin{aligned}
\left\{\boldsymbol{d}^{\prime}\right\}=\left\{\begin{array}{l}
d_{2}^{\prime} \\
d_{3}^{\prime} \\
d_{5}^{\prime} \\
d_{6}^{\prime}
\end{array}\right\}=\left\{\begin{array}{c}
v_{0}(0) \\
\theta(0) \\
v_{0}(L) \\
\theta(L)
\end{array}\right\} & \rightarrow\left\{d^{\prime}\right\}=\left[\begin{array}{cccc}
1 & 0 & 0 & 0 \\
0 & 1 & 0 & 0 \\
1 & L & \frac{L^{2}}{2} & \left.\left(\frac{1}{6}-\Omega\right) L^{3}\right] \cdot\left\{\begin{array}{c}
c_{1} \\
c_{2} \\
c_{3} \\
c_{4}
\end{array}\right\} \\
0 & 1 & L & \frac{L^{2}}{2}
\end{array}\right] \\
& \rightarrow[\boldsymbol{H}] .\{\boldsymbol{C}\}=\left\{\boldsymbol{d}^{\prime}\right\}
\end{aligned}
$$

Assim, as funções de forma podem ser calculadas com relação a (3.11), $[\boldsymbol{N}]=[\boldsymbol{X}] \cdot[\boldsymbol{H}]^{-1}$, fornecendo as funções apresentadas nas expressões (3.21) a (3.24).

$$
\begin{gathered}
N_{2}^{v}(x)=1+\frac{2\left(\frac{x}{L}\right)^{3}-3\left(\frac{x}{L}\right)^{2}-12 \Omega \frac{x}{L}}{(1+12 \Omega)} \quad N_{2}^{\theta}(x)=\frac{6}{L} \frac{\left(\frac{x}{L}\right)^{2}-\frac{x}{L}}{(1+12 \Omega)} \\
N_{3}^{v}(x)=\frac{x\left[\left(\frac{x}{L}\right)^{2}-2(1+3 \Omega) \frac{x}{L}+1+6 \Omega\right]}{(1+12 \Omega)} \quad N_{3}^{\theta}(x)=1+\frac{3\left(\frac{x}{L}\right)^{2}-4(1+3 \Omega) \frac{x}{L}}{(1+12 \Omega)} \\
N_{5}^{v}(x)=\frac{3\left(\frac{x}{L}\right)^{2}-2\left(\frac{x}{L}\right)^{3}+12 \Omega \frac{x}{L}}{(1+12 \Omega)} \quad N_{5}^{\theta}(x)=\frac{6}{L} \frac{x}{L}-\left(\frac{x}{L}\right)^{2} \\
N_{6}^{v}(x)=\frac{x\left[\left(\frac{x}{L}\right)^{2}-(1+6 \Omega) \frac{x}{L}-6 \Omega\right]}{(1+12 \Omega)} \quad N_{6}^{\theta}(x)=\frac{3\left(\frac{x}{L}\right)^{2}-2(1-6 \Omega) \frac{x}{L}}{(1+12 \Omega)}
\end{gathered}
$$

Nos apêndices A.3 e A.4, são calculadas as funções de forma, considerando rótulas nas extremidades da barra e teoria de flexão de Timoshenko, para o equilíbrio de um elemento infinitesimal na configuração indeformada. 


\section{2}

\section{Equilíbrio do Elemento Infinitesimal na Configuração Deformada}

De maneira a considerar uma não-linearidade no nível infinitesimal, as funções de forma podem ser obtidas diretamente da solução homogênea da equação diferencial do problema de equilíbrio de um elemento infinitesimal na configuração deformada, conforme a Figura 3.3.

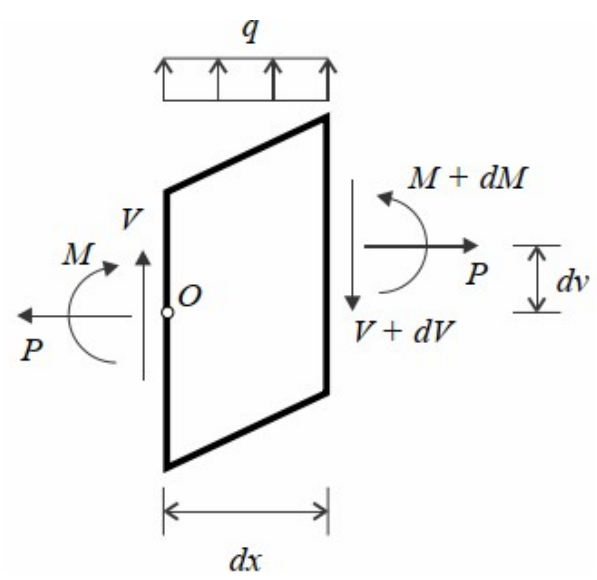

Figura 3.3 - Elemento infinitesimal na configuração deformada Fonte: Martha e Burgos (2015).

A solução, neste caso, para o deslocamento transversal e a rotação da seção, é dada por funções exponenciais, conforme calculado no capítulo 2, podendo-se escrevê-las como trigonométricas, no caso de forças de compressão, e como hiperbólicas, para cargas de tração.

O desenvolvimento das equações diferenciais do problema já foi realizado no capítulo 2 de maneira completa. Portanto, a partir da solução dessas equações, que fornece o deslocamento e a rotação da seção transversal, são desenvolvidas as funções de interpolação, considerando a teoria de flexão de Euler-Bernoulli e a de Timoshenko.

\subsection{1}

\section{Funções de Forma: Teoria de Euler-Bernoulli}

Conforme visto anteriormente, no capítulo 2, para um elemento infinitesimal de viga, a solução homogênea da equação diferencial para o equilíbrio de elemento na configuração deformada, empregando-se a teoria de flexão de EulerBernoulli, é dada conforme a equação (2.46) para o deslocamento transversal, 
com a rotação sendo fornecida por $\theta(x)=d v(x) / d x$. A solução é dada em (2.68) e (2.69) e reescrita, por conveniência, em (3.25) e (3.26).

$$
\begin{gathered}
v_{h}(x)=c_{1} e^{\mu x}+c_{2} e^{-\mu x}+c_{3} x+c_{4} \\
\theta_{h}(x)=c_{1} \mu e^{\mu x}-c_{2} \mu e^{-\mu x}+c_{3}
\end{gathered}
$$

O deslocamento da barra escrito de forma matricial é dado de acordo com a equação (3.27).

$$
\left\{\begin{array}{c}
\boldsymbol{v}_{0}(\boldsymbol{x}) \\
\boldsymbol{\theta}(\boldsymbol{x})
\end{array}\right\}=[\boldsymbol{X}] .\{\boldsymbol{C}\},[\boldsymbol{X}]=\left[\begin{array}{cccc}
e^{\mu x} & e^{-\mu x} & x & 1 \\
\mu e^{\mu x} & -\mu e^{-\mu} & 1 & 0
\end{array}\right] \quad\{\boldsymbol{C}\}=\left\{\begin{array}{l}
c_{1} \\
c_{2} \\
c_{3} \\
c_{4}
\end{array}\right\}
$$

As condições de contorno são obtidas, avaliando a solução homogênea da equação diferencial nos nós das barras, conforme equação (3.28).

$$
\left\{\boldsymbol{d}^{\prime}\right\}=\left\{\begin{array}{l}
d_{2}^{\prime} \\
d_{3}^{\prime} \\
d_{5}^{\prime} \\
d_{6}^{\prime}
\end{array}\right\}=\left\{\begin{array}{c}
v_{0}(0) \\
\theta(0) \\
v_{0}(L) \\
\theta(L)
\end{array}\right\}=\left\{\begin{array}{c}
c_{1}+c_{2}+c_{4} \\
c_{1} \mu-c_{2} \mu+c_{3} \\
c_{1} e^{\mu L}+c_{2} e^{-\mu}+c_{3} L+c_{4} \\
c_{1} \mu e^{\mu L}-c_{2} \mu e^{-\mu L}+c_{3}
\end{array}\right\}
$$

Escrevendo-se as condições de contorno matricialmente, com a utilização da matriz $[\boldsymbol{H}]$ e do vetor de constantes $\{\boldsymbol{C}\}$, obtém-se a equação (3.29).

$$
\begin{aligned}
\left\{\boldsymbol{d}^{\prime}\right\}=\left\{\begin{array}{l}
d_{2}^{\prime} \\
d_{3}^{\prime} \\
d_{5}^{\prime} \\
d_{6}^{\prime}
\end{array}\right\}=\left\{\begin{array}{c}
v_{0}(0) \\
\theta(0) \\
v_{0}(L) \\
\theta(L)
\end{array}\right\} & \rightarrow\left\{d^{\prime}\right\}=\left[\begin{array}{llll}
1 & 1 & 0 & 1 \\
\mu & -\mu & 1 & 0 \\
e^{L \mu} & e^{-L \mu} & L & 1 \\
\mu e^{L \mu} & -\mu e^{-L \mu} & 1 & 0
\end{array}\right] \cdot\left\{\begin{array}{l}
c_{1} \\
c_{2} \\
c_{3} \\
c_{4}
\end{array}\right\} \\
& \rightarrow[\boldsymbol{H}] .\{\boldsymbol{C}\}=\left\{\boldsymbol{d}^{\prime}\right\}
\end{aligned}
$$

Assim, as funções de forma podem ser novamente calculadas com relação a (3.11), $[\boldsymbol{N}]=[\boldsymbol{X}] .[\boldsymbol{H}]^{-1}$, fornecendo as funções apresentadas nas expressões (3.30) a (3.37).

$$
\begin{gathered}
N_{2}^{v}=-\frac{e^{\mu(L+x)}+e^{L \mu}-e^{\mu x}-e^{2 \mu x}-L \mu e^{\mu(L+x)}+\mu x e^{\mu(L+x)}-L \mu e^{\mu x}+\mu x e^{\mu x}}{2 e^{x \mu}-2 e^{\mu(L+x)}+L \mu e^{\mu(L+x)}+L \mu e^{\mu x}} \\
N_{3}^{v}=\frac{e^{L \mu}-e^{2 L \mu}-e^{\mu x}+e^{2 \mu x}-e^{\mu(L+2 x)}+e^{\mu(2 L+x)}+L \mu e^{2 L \mu}-2 \mu x e^{\mu(L+x)}}{\mu\left(2 e^{x \mu}-4 e^{\mu(L+x)}+2 e^{\mu(2 L+x)}+L \mu e^{\mu x}-L \mu e^{\mu(2 L+x)}\right)}+ \\
+\frac{-L \mu e^{\mu x}-L \mu e^{2 \mu x}-L \mu e^{\mu(2 L+x)}+\mu x e^{\mu x}+\mu x e^{\mu(2 L+x)}}{\mu\left(2 e^{x \mu}-4 e^{\mu(L+x)}+2 e^{\mu(2 L+x)}+L \mu e^{\mu x}-L \mu e^{\mu(2 L+x)}\right)}
\end{gathered}
$$




$$
\begin{gathered}
N_{5}^{v}=\frac{e^{L \mu}-e^{\mu(L+x)}+e^{\mu x}-e^{2 \mu x}+\mu x e^{\mu(L+x)}+\mu x e^{\mu x}}{2 e^{x \mu}-2 e^{\mu(L+x)}+L \mu e^{\mu(L+x)}+L \mu e^{\mu x}} \\
N_{6}^{v}=-\frac{e^{L \mu}-e^{2 L \mu}-e^{\mu x}+e^{2 \mu x}-e^{\mu(L+2 x)}+e^{\mu(2 L+x)}-2 L \mu e^{\mu(L+x)}+L \mu e^{L \mu}}{\mu\left(2 e^{x \mu}-4 e^{\mu(L+x)}+2 e^{\mu(2 L+x)}+L \mu e^{\mu x}-L \mu e^{\mu(2 L+x)}\right)}+ \\
+\frac{2 \mu x e^{\mu(L+x)}+L \mu e^{\mu(L+2 x)}-\mu x e^{\mu x}-\mu x e^{\mu(2 L+x)}}{\mu\left(2 e^{x \mu}-4 e^{\mu(L+x)}+2 e^{\mu(2 L+x)}+L \mu e^{\mu x}-L \mu e^{\mu(2 L+x)}\right)} \\
N_{3}^{\theta}=\frac{\mu\left(e^{\mu(L+x)}-e^{L \mu}+e^{\mu x}-e^{2 \mu x}\right)}{2 e^{x \mu}-2 e^{\mu(L+x)}+L \mu e^{\mu(L+x)}+L \mu e^{\mu x}} \\
2 e^{x \mu}-4 e^{\mu(L+x)}+2 e^{\mu(2 L+x)}+L \mu e^{\mu x}-L \mu e^{\mu(2 L+x)} \\
N_{5}^{\theta}=\frac{\mu\left(e^{\mu(L+x)}-e^{L \mu}+e^{\mu x}-e^{2 \mu x}\right)}{2 e^{x \mu}-2 e^{\mu(L+x)}+L \mu e^{\mu(L+x)}+L \mu e^{\mu x}} \\
N_{6}^{\theta}=\frac{e^{L \mu}-2 e^{\mu(L+x)}-e^{2 L \mu}+e^{\mu x}-e^{2 \mu x}+e^{\mu(L+2 x)}+e^{\mu(2 L+x)}+L \mu e^{L \mu}-L \mu e^{\mu(L+2 x)}}{2 e^{x \mu}-4 e^{\mu(L+x)}+2 e^{\mu(2 L+x)}+L \mu e^{\mu x}-L \mu e^{\mu(2 L+x)}}
\end{gathered}
$$

Caso a força axial seja de tração, o valor de $\mu$ é um número real e a solução homogênea da equação diferencial (o deslocamento transversal) pode ser escrita por funções hiperbólicas, conforme as expressões (2.70) e (2.71), reapresentadas em (3.38) e (3.39), com a rotação da seção transversal dada pela diferenciação do deslocamento transversal.

$$
\begin{gathered}
v_{h}(x)=c_{1} \operatorname{senh}(\mu x)+c_{2} \cosh (\mu x)+c_{3} x+c_{4}, \mu=\sqrt{\frac{P}{E I}} \\
\theta_{h}(x)=c_{1} \mu \cosh (\mu x)+c_{2} \mu \operatorname{senh}(\mu x)+c_{3}
\end{gathered}
$$

Matricialmente, o deslocamento da barra escrito conforme equação (3.40).

$$
\left\{\begin{array}{c}
\boldsymbol{v}_{\mathbf{0}}(\boldsymbol{x}) \\
\boldsymbol{\theta}(\boldsymbol{x})
\end{array}\right\}=[\boldsymbol{X}] .\{\boldsymbol{C}\},[\boldsymbol{X}]=\left[\begin{array}{cccc}
\operatorname{senh}(\mu x) & \cosh (\mu x) & x & 1 \\
\mu \cosh (\mu x) & \mu \operatorname{senh}(\mu x) & 1 & 0
\end{array}\right] \quad\{\boldsymbol{C}\}=\left\{\begin{array}{c}
c_{1} \\
c_{2} \\
c_{3} \\
c_{4}
\end{array}\right\}
$$

Avaliam-se as condições de contorno, conforme relação (3.41), que são escritas matricialmente, de acordo com a equação (3.42).

$$
\left\{\boldsymbol{d}^{\prime}\right\}=\left\{\begin{array}{l}
d_{2}^{\prime} \\
d_{3}^{\prime} \\
d_{5}^{\prime} \\
d_{6}^{\prime}
\end{array}\right\}=\left\{\begin{array}{c}
v_{0}(0) \\
\theta(0) \\
v_{0}(L) \\
\theta(L)
\end{array}\right\}=\left\{\begin{array}{c}
c_{2}+c_{4} \\
c_{1} \mu+c_{3} \\
c_{1} \operatorname{senh}(\mu L)+c_{2} \cosh (\mu L)+c_{3} x+c_{4} \\
c_{1} \mu \cosh (\mu L)+c_{2} \mu \operatorname{senh}(\mu L)+c_{3}
\end{array}\right\}
$$




$$
\left\{\boldsymbol{d}^{\prime}\right\}=\left[\begin{array}{cccc}
0 & 1 & 0 & 1 \\
\mu & 0 & 1 & 0 \\
\operatorname{senh}(\mu L) & \cosh (\mu L) & L & 1 \\
\mu \cosh (\mu L) & \mu \operatorname{senh}(\mu L) & 1 & 0
\end{array}\right] \cdot\left\{\begin{array}{l}
c_{1} \\
c_{2} \\
c_{3} \\
c_{4}
\end{array}\right\} \rightarrow[\boldsymbol{H}] .\{\boldsymbol{C}\}=\left\{\boldsymbol{d}^{\prime}\right\}
$$

Utilizando-se a relação já apresentada em (3.11), calculam-se as funções de forma conforme as equações (3.43) a (3.50).

$$
\begin{gathered}
N_{2}^{v}=-\frac{\cosh (L \mu)-\cosh (\mu x)+\cosh (\mu(L-x))-L \mu \operatorname{senh}(L \mu)+\mu x \operatorname{senh}(L \mu)-1}{L \mu \operatorname{senh}(L \mu)-2 \cosh (L \mu)+2} \\
N_{3}^{v}=\frac{\operatorname{senh}(\mu x)-\operatorname{senh}(L \mu)+\operatorname{senh}(\mu(L-x))+\mu x+L \mu \cosh (L \mu)}{\mu(L \mu \operatorname{senh}(L \mu)-2 \cosh (L \mu)+2)}+ \\
+\frac{-\mu x \cosh (L \mu)-L \mu \cosh (\mu(L-x))}{\mu(L \mu \operatorname{senh}(L \mu)-2 \cosh (L \mu)+2)} \\
N_{5}^{v}=\frac{\cosh (\mu(L-x))-\cosh (\mu x)-\cosh (L \mu)+\mu x \operatorname{senh}(L \mu)+1}{L \mu \operatorname{senh}(L \mu)-2 \cosh (L \mu)+2} \\
+\frac{\operatorname{senh}(\mu x)-\operatorname{senh}(L \mu)+\operatorname{senh}(\mu(L-x))+L \mu-\mu x-L \mu \cosh (\mu x)}{\mu(L \mu \operatorname{senh}(L \mu)-2 \cosh (L \mu)+2)}+ \\
\quad \frac{\mu x \cosh (L \mu)}{\mu(L \mu \operatorname{senh}(L \mu)-2 \cosh (L \mu)+2)} \\
N_{3}^{\theta}=\frac{\cosh (\mu x)-\cosh (L \mu)-\cosh (\mu(L-x))+L \mu \operatorname{senh}(\mu(L-x))+1}{L \mu \operatorname{senh}(L \mu)-2 \cosh (L \mu)+2} \\
N_{2}^{\theta}=\frac{\mu(\operatorname{senh}(\mu x)-\operatorname{senh}(L \mu)+\operatorname{senh}(\mu(L-x)))}{L \mu \operatorname{senh}(L \mu)-2 \cosh (L \mu)+2} \\
N_{5}^{\theta}=-\frac{\mu(\operatorname{senh}(\mu x)-\operatorname{senh}(L \mu)+\operatorname{senh}(\mu(L-x)))}{L \mu \operatorname{senh}(L \mu)-2 \cosh (L \mu)+2} \\
L \mu \operatorname{cosenh}(L \mu)-2 \cosh (L \mu)+2
\end{gathered}
$$

Por outro lado, se a força axial for de compressão, o valor de $\mu$ é um número complexo e o deslocamento pode ser escrito por funções trigonométricas, conforme as expressões (2.72) e (2.73), reapresentadas em (3.51) e (3.52), novamente com a rotação da seção sendo dada pela derivada do deslocamento.

$$
\begin{gathered}
v_{h}(x)=c_{1} \operatorname{sen}(\mu x)+c_{2} \cos (\mu x)+c_{3} x+c_{4}, \mu=\sqrt{\frac{-P}{E I}} \\
\theta_{h}(x)=c_{1} \mu \cos (\mu x)-c_{2} \mu \operatorname{senh}(\mu x)+c_{3}
\end{gathered}
$$


O desenvolvimento para o cálculo das funções de forma pode ser refeito, empregando-se a mesma metodologia anterior, com as equações de (3.53) a (3.55).

$$
\begin{aligned}
& \left\{\begin{array}{c}
\boldsymbol{v}_{\mathbf{0}}(\boldsymbol{x}) \\
\boldsymbol{\theta}(\boldsymbol{x})
\end{array}\right\}=[\boldsymbol{X}] .\{\boldsymbol{C}\}, \quad[\boldsymbol{X}]=\left[\begin{array}{cccc}
\operatorname{sen}(\mu x) & \cos (\mu x) & x & 1 \\
\mu \cos (\mu x) & -\mu \operatorname{sen}(\mu x) & 1 & 0
\end{array}\right] \quad\{\boldsymbol{C}\}=\left\{\begin{array}{l}
c_{1} \\
c_{2} \\
c_{3} \\
c_{4}
\end{array}\right\} \\
& \left\{\boldsymbol{d}^{\prime}\right\}=\left\{\begin{array}{l}
d_{2}^{\prime} \\
d_{3}^{\prime} \\
d_{5}^{\prime} \\
d_{6}^{\prime}
\end{array}\right\}=\left\{\begin{array}{c}
v_{0}(0) \\
\theta(0) \\
v_{0}(L) \\
\theta(L)
\end{array}\right\}=\left\{\begin{array}{c}
c_{2}+c_{4} \\
c_{1} \mu+c_{3} \\
c_{1} \operatorname{sen}(\mu L)+c_{2} \cos (\mu L)+c_{3} L+c_{4} \\
c_{1} \mu \cos (\mu L)-c_{2} \mu \operatorname{senh}(\mu L)+c_{3}
\end{array}\right\} \\
& \left\{\boldsymbol{d}^{\prime}\right\}=\left[\begin{array}{cccc}
0 & 1 & 0 & 1 \\
\mu & 0 & 1 & 0 \\
\operatorname{sen}(\mu L) & \cos (\mu L) & L & 1 \\
\mu \cos (\mu L) & -\mu \operatorname{sen}(\mu L) & 1 & 0
\end{array}\right] \cdot\left\{\begin{array}{l}
c_{1} \\
c_{2} \\
c_{3} \\
c_{4}
\end{array}\right\} \rightarrow[\boldsymbol{H}] \cdot\{\boldsymbol{C}\}=\left\{\boldsymbol{d}^{\prime}\right\}
\end{aligned}
$$

Utilizando-se novamente a relação (3.11), as funções de interpolação são dadas pelas expressões (3.56) a (3.63).

$$
\begin{gathered}
N_{2}^{v}=\frac{\cos (L \mu)-\cos (\mu x)+\cos (\mu(L-x))+L \mu \operatorname{sen}(L \mu)-\mu x \operatorname{sen}(L \mu)-1}{2 \cos (L \mu)+L \mu \operatorname{sen}(L \mu)-2} \\
N_{3}^{v}=-\frac{\operatorname{sen}(\mu x)-\operatorname{sen}(L \mu)+\operatorname{sen}(\mu(L-x))+\mu x+L \mu \cos (L \mu)}{\mu(2 \cos (L \mu)+L \mu \operatorname{sen}(L \mu)-2)}+ \\
+\frac{-\mu x \cos (L \mu)-L \mu \cos (\mu(L-x))}{\mu(2 \cos (L \mu)+L \mu \operatorname{sen}(L \mu)-2)} \\
N_{5}^{v}=\frac{\cos (L \mu)+\cos (\mu x)-\cos (\mu(L-x))+\mu x \operatorname{sen}(L \mu)-1}{2 \cos (L \mu)+L \mu \operatorname{sen}(L \mu)-2} \\
N_{6}^{v}=\frac{\operatorname{sen}(\mu x)-\operatorname{sen}(L \mu)+\operatorname{sen}(\mu(L-x))+L \mu-\mu x-L \mu \cos (\mu x)}{\mu(2 \cos (L \mu)+L \mu \operatorname{sen}(L \mu)-2)}+ \\
+\frac{\mu x \cos (L \mu)}{\mu(2 \cos (L \mu)+L \mu \operatorname{sen}(L \mu)-2)} \\
N_{3}^{\theta}=\frac{\cos (L \mu)-\cos (\mu x)+\cos (\mu(L-x))+L \mu \operatorname{sen}(\mu(L-x))-1}{2 \cos (L \mu)+L \mu \operatorname{sen}(L \mu)-2} \\
N_{5}^{\theta}=-\frac{\mu(\operatorname{sen}(\mu x)-\operatorname{sen}(L \mu)+\operatorname{sen}(\mu(L)-x)))}{2 \cos (L \mu)+L \mu \operatorname{sen}(L \mu)-2}
\end{gathered}
$$




$$
N_{6}^{\theta}=\frac{\cos (L \mu)+\cos (\mu x)-\cos (\mu(L-x))+L \mu \operatorname{sen}(\mu x)-1}{2 \cos (L \mu)+L \mu \operatorname{sen}(L \mu)-2}
$$

Nos apêndices A.5 e A.6, são calculadas as funções de forma, considerando rótulas nas extremidades da barra e teoria de flexão de Euler-Bernoulli, para o equilíbrio de um elemento infinitesimal na configuração deformada.

\section{2 .2}

\section{Funções de Forma: Teoria de Timoshenko}

Conforme desenvolvido no capítulo 2, para um elemento infinitesimal de viga, a solução homogênea da equação diferencial para o equilíbrio de elemento na configuração deformada, empregando-se a teoria de flexão de Timoshenko, é dada conforme a equação (2.80) e (2.82), repetidas em (3.64) e (3.65), por conveniência.

$$
\begin{gathered}
\theta_{h}(x)=\Lambda\left(c_{1} e^{\Lambda x}+c_{2} e^{-\Lambda x}\right)+c_{3} \\
v_{h}(x)=\left(1-\Omega L^{2} \Lambda^{2}\right)\left[c_{1} e^{\Lambda x}-c_{2} e^{-\Lambda x}\right]+c_{3} x+c_{4}
\end{gathered}
$$

Empregando-se a mesma metodologia já apresentada, o cálculo das funções de interpolação pode ser realizado a partir da solução homogênea da equação diferencial, através das equações (3.66) a (3.68).

$$
\begin{aligned}
& {[\boldsymbol{X}]=\left[\begin{array}{cccc}
\left(1-\Omega L^{2} \Lambda^{2}\right) e^{\Lambda x} & \left(1-\Omega L^{2} \Lambda^{2}\right) e^{-\Lambda x} & x & 1 \\
\Lambda e^{\Lambda x} & \Lambda e^{-\Lambda x} & 1 & 0
\end{array}\right] \quad\{\boldsymbol{C}\}=\left\{\begin{array}{l}
c_{1} \\
c_{2} \\
c_{3} \\
c_{4}
\end{array}\right\}} \\
& \left\{d^{\prime}\right\}=\left\{\begin{array}{l}
d_{2}^{\prime} \\
d_{3}^{\prime} \\
d_{5}^{\prime} \\
d_{6}^{\prime}
\end{array}\right\}=\left\{\begin{array}{c}
v_{0}(0) \\
\theta(0) \\
v_{0}(L) \\
\theta(L)
\end{array}\right\}=\left\{\begin{array}{c}
\left(1-\Omega L^{2} \Lambda^{2}\right)\left(c_{1}-c_{2}\right)+c_{4} \\
\Lambda\left(c_{1}+c_{2}\right)+c_{3} \\
\left(1-\Omega L^{2} \Lambda^{2}\right)\left[c_{1} e^{\Lambda L}-c_{2} e^{-\Lambda L}\right]+c_{3} L+c_{4} \\
\Lambda\left(c_{1} e^{\Lambda L}+c_{2} e^{-\Lambda L}\right)+c_{3}
\end{array}\right\} \\
& \left\{\boldsymbol{d}^{\prime}\right\}=\left[\begin{array}{cccc}
\left(1-\Omega L^{2} \Lambda^{2}\right) & \left(\Omega L^{2} \Lambda^{2}-1\right) & 0 & 1 \\
\Lambda & \Lambda & 1 & 0 \\
e^{L \Lambda}\left(1-\Omega L^{2} \Lambda^{2}\right) & e^{-L \Lambda}\left(\Omega L^{2} \Lambda^{2}-1\right) & L & 1 \\
\Lambda e^{L \Lambda} & \Lambda e^{-L \Lambda} & 1 & 0
\end{array}\right] \cdot\left\{\begin{array}{l}
c_{1} \\
c_{2} \\
c_{3} \\
c_{4}
\end{array}\right\} \rightarrow[\boldsymbol{H}] .\{\boldsymbol{C}\}=\left\{\boldsymbol{d}^{\prime}\right\}
\end{aligned}
$$

Utilizando-se a relação (3.11), calculam-se as funções de forma conforme as expressões (3.69) a (3.76). 


$$
\begin{aligned}
& N_{2}^{v}=-\frac{e^{\Lambda(L+x)}+e^{L \Lambda}-e^{\Lambda x}-e^{2 \Lambda x}-L \Lambda e^{\Lambda(L+x)}+\Lambda x e^{\Lambda(L+x)}-L \Lambda e^{\Lambda x}+\Lambda x e^{\Lambda x}}{2 e^{x \Lambda}-2 e^{\Lambda(L+x)}+L \Lambda e^{\Lambda(L+x)}+L \Lambda e^{\Lambda x}+2 L^{2} \Lambda^{2} \Omega e^{\Lambda(L+x)}-2 L^{2} \Lambda^{2} \Omega e^{\Lambda x}}+ \\
& +\frac{-L^{2} \Lambda^{2} \Omega e^{\Lambda(L+x)}-L^{2} \Lambda^{2} \Omega e^{L \Lambda}+L^{2} \Lambda^{2} \Omega e^{\Lambda x}+L^{2} \Lambda^{2} \Omega e^{2 \Lambda x}}{2 e^{x \Lambda}-2 e^{\Lambda(L+x)}+L \Lambda e^{\Lambda(L+x)}+L \Lambda e^{\Lambda x}+2 L^{2} \Lambda^{2} \Omega e^{\Lambda(L+x)}-2 L^{2} \Lambda^{2} \Omega e^{\Lambda x}} \\
& N_{3}^{v}=\frac{e^{\Lambda(L-x)}\left(L^{2} \Lambda^{2} \Omega-1\right)\left(e^{\Lambda(L+x)}-e^{L \Lambda}-e^{2 \Lambda x}-e^{-\Lambda(L-x)}+e^{-\Lambda(L-2 x)}-L^{2} \Lambda^{2} \Omega\right)}{\Lambda\left(e^{L \Lambda}-1\right)\left(L \Lambda-2 e^{L \Lambda}-2 L^{2} \Lambda^{2} \Omega+L \Lambda e^{L \Lambda}+2 L^{2} \Lambda^{2} \Omega e^{L \Lambda}+2\right)}+ \\
& +\frac{e^{\Lambda(L-x)}\left(L^{2} \Lambda^{2} \Omega-1\right)\left(-L \Lambda e^{\Lambda(L+x)}+L \Lambda e^{L \Lambda}+\Lambda x e^{\Lambda(L+x)}-L \Lambda e^{-\Lambda(L-x)}+L \Lambda e^{-\Lambda(L-2 x)}\right)}{\Lambda\left(e^{L \Lambda}-1\right)\left(L \Lambda-2 e^{L \Lambda}-2 L^{2} \Lambda^{2} \Omega+L \Lambda e^{L \Lambda}+2 L^{2} \Lambda^{2} \Omega e^{L \Lambda}+2\right)}+ \\
& +\frac{e^{\Lambda(L-x)}\left(L^{2} \Lambda^{2} \Omega-1\right)\left(-2 \Lambda x e^{\Lambda x}+\Lambda x e^{-\Lambda(L-x)}-L^{2} \Lambda^{2} \Omega e^{\Lambda(L+x)}+L\right)}{\Lambda\left(e^{L \Lambda}-1\right)\left(L \Lambda-2 e^{L \Lambda}-2 L^{2} \Lambda^{2} \Omega+L \Lambda e^{L \Lambda}+2 L^{2} \Lambda^{2} \Omega e^{L \Lambda}+2\right)} \\
& N_{5}^{v}=\frac{e^{L \Lambda}-e^{\Lambda(L+x)}+e^{\Lambda x}-e^{2 \Lambda x}+\Lambda x e^{\Lambda(L+x)}+\Lambda x e^{\Lambda x}+L^{2} \Lambda^{2} \Omega e^{\Lambda(L+x)}}{2 e^{x \Lambda}-2 e^{\Lambda(L+x)}+L \Lambda e^{\Lambda(L+x)}+L \Lambda e^{\Lambda x}+2 L^{2} \Lambda^{2} \Omega e^{\Lambda(L+x)}-2 L^{2} \Lambda^{2} \Omega e^{\Lambda x}}+ \\
& \frac{-L^{2} \Lambda^{2} \Omega e^{L \Lambda}-L^{2} \Lambda^{2} \Omega e^{\Lambda x}+L^{2} \Lambda^{2} \Omega e^{2 \Lambda x}}{2 e^{x \Lambda}-2 e^{\Lambda(L+x)}+L \Lambda e^{\Lambda(L+x)}+L \Lambda e^{\Lambda x}+2 L^{2} \Lambda^{2} \Omega e^{\Lambda(L+x)}-2 L^{2} \Lambda^{2} \Omega e^{\Lambda x}} \\
& N_{6}^{v}=-\frac{e^{\Lambda(L-x)}\left(L^{2} \Lambda^{2} \Omega-1\right)\left(e^{\Lambda(L+x)}-e^{L \Lambda}-e^{2 \Lambda x}-e^{-\Lambda(L-x)}+e^{-\Lambda(L-2 x)}+L \Lambda-L^{2} \Lambda^{2} \Omega\right)}{\Lambda\left(e^{L \Lambda}-1\right)\left(L \Lambda-2 e^{L \Lambda}-2 L^{2} \Lambda^{2} \Omega+L \Lambda e^{L \Lambda}+2 L^{2} \Lambda^{2} \Omega e^{L \Lambda}+2\right)}+ \\
& +\frac{e^{\Lambda(L-x)}\left(L^{2} \Lambda^{2} \Omega-1\right)\left(-\Lambda x e^{\Lambda(L+x)}-2 L \Lambda e^{\Lambda x}+L \Lambda e^{2 \Lambda x}+2 \Lambda x e^{\Lambda x}-\Lambda x e^{-\Lambda(L-x)}-L^{2} \Lambda^{2} \Omega e^{\Lambda(L+x)}\right)}{\Lambda\left(e^{L \Lambda}-1\right)\left(L \Lambda-2 e^{L \Lambda}-2 L^{2} \Lambda^{2} \Omega+L \Lambda e^{L \Lambda}+2 L^{2} \Lambda^{2} \Omega e^{L \Lambda}+2\right)}+ \\
& +\frac{e^{\Lambda(L-x)}\left(L^{2} \Lambda^{2} \Omega-1\right)\left(L^{2} \Lambda^{2} \Omega e^{L \Lambda}+L^{2} \Lambda^{2} \Omega e^{2 \Lambda x}+L^{2} \Lambda^{2} \Omega e^{-\Lambda(L-x)}-L^{2} \Lambda^{2} \Omega e^{-\Lambda(L-2 x)}+1\right)}{\Lambda\left(e^{L \Lambda}-1\right)\left(L \Lambda-2 e^{L \Lambda}-2 L^{2} \Lambda^{2} \Omega+L \Lambda e^{L \Lambda}+2 L^{2} \Lambda^{2} \Omega e^{L \Lambda}+2\right)} \\
& N_{2}^{\theta}=-\frac{\Lambda\left(e^{\Lambda(L+x)}-e^{L \Lambda}+e^{\Lambda x}-e^{2 \Lambda x}\right)}{2 e^{x \Lambda}-2 e^{\Lambda(L+x)}+L \Lambda e^{\Lambda(L+x)}+L \Lambda e^{\Lambda x}+2 L^{2} \Lambda^{2} \Omega e^{\Lambda(L+x)}-2 L^{2} \Lambda^{2} \Omega e^{\Lambda x}} \\
& N_{3}^{\theta}=-\frac{e^{-\Lambda x}\left(e^{2 L \Lambda}+e^{\Lambda x}+e^{2 \Lambda x}+e^{2 L \Lambda} e^{\Lambda x}-L \Lambda e^{2 L \Lambda}+L \Lambda e^{2 \Lambda x}-L^{2} \Lambda^{2} \Omega e^{2 L \Lambda}-L^{2} \Lambda^{2} \Omega e^{\Lambda x}\right)}{\left(e^{L \Lambda}-1\right)\left(L \Lambda-2 e^{L \Lambda}-2 L^{2} \Lambda^{2} \Omega+L \Lambda e^{L \Lambda}+2 L^{2} \Lambda^{2} \Omega e^{L \Lambda}+2\right)}+ \\
& +\frac{e^{-\Lambda x}\left(-L^{2} \Lambda^{2} \Omega e^{2 \Lambda x}-L^{2} \Lambda^{2} \Omega e^{2 L \Lambda} e^{\Lambda x}\right)}{\left(e^{L \Lambda}-1\right)\left(L \Lambda-2 e^{L \Lambda}-2 L^{2} \Lambda^{2} \Omega+L \Lambda e^{L \Lambda}+2 L^{2} \Lambda^{2} \Omega e^{L \Lambda}+2\right)}+ \\
& +\frac{-e^{L \Lambda} e^{-\Lambda x}\left(2 e^{\Lambda x}+e^{2 \Lambda x}-L^{2} \Lambda^{2} \Omega-2 L^{2} \Lambda^{2} \Omega e^{\Lambda x}-2 L^{2} \Lambda^{2} \Omega e^{2 \Lambda x}+1\right)}{\left(e^{L \Lambda}-1\right)\left(L \Lambda-2 e^{L \Lambda}-2 L^{2} \Lambda^{2} \Omega+L \Lambda e^{L \Lambda}+2 L^{2} \Lambda^{2} \Omega e^{L \Lambda}+2\right)} \\
& N_{5}^{\theta}=\frac{\Lambda\left(e^{\Lambda(L+x)}-e^{L \Lambda}+e^{\Lambda x}-e^{2 \Lambda x}\right)}{2 e^{x \Lambda}-2 e^{\Lambda(L+x)}+L \Lambda e^{\Lambda(L+x)}+L \Lambda e^{\Lambda x}+2 L^{2} \Lambda^{2} \Omega e^{\Lambda(L+x)}-2 L^{2} \Lambda^{2} \Omega e^{\Lambda x}} \\
& N_{6}^{\theta}=-\frac{e^{-\Lambda x}\left(e^{\Lambda x}-1\right)\left(e^{2 L \Lambda}-e^{\Lambda x}-L^{2} \Lambda^{2} \Omega e^{2 L \Lambda}+L^{2} \Lambda^{2} \Omega e^{\Lambda x}\right)}{\left(e^{L \Lambda}-1\right)\left(L \Lambda-2 e^{L \Lambda}-2 L^{2} \Lambda^{2} \Omega+L \Lambda e^{L \Lambda}+2 L^{2} \Lambda^{2} \Omega e^{L \Lambda}+2\right)}+ \\
& \frac{-e^{L \Lambda} e^{-\Lambda x}\left(e^{\Lambda x}-1\right)\left(L \Lambda-e^{\Lambda x}-L^{2} \Lambda^{2} \Omega+L \Lambda e^{\Lambda x}+L^{2} \Lambda^{2} \Omega e^{\Lambda x}+1\right)}{\left(e^{L \Lambda}-1\right)\left(L \Lambda-2 e^{L \Lambda}-2 L^{2} \Lambda^{2} \Omega+L \Lambda e^{L \Lambda}+2 L^{2} \Lambda^{2} \Omega e^{L \Lambda}+2\right)}
\end{aligned}
$$

Caso a força axial seja de tração, o valor de $\mu$ é um número real e a solução homogênea da equação diferencial, tanto o deslocamento transversal como a 
rotação da seção transversal podem ser escritos por funções hiperbólicas, conforme as expressões (2.83) e (2.84), reapresentadas em (3.77) e (3.78).

$$
\begin{gathered}
\theta_{h}(x)=\Lambda\left[c_{1} \cosh (\Lambda x)+c_{2} \operatorname{senh}(\Lambda x)\right]+c_{3} \\
v_{h}(x)=\left(1-\Omega L^{2} \Lambda^{2}\right)\left[c_{1} \operatorname{senh}(\Lambda x)+c_{2} \cosh (\Lambda x)\right]+c_{3} x+c_{4}
\end{gathered}
$$

A solução homogênea da equação diferencial fornece as relações (3.79) a (3.81).

$$
\begin{aligned}
& {[\boldsymbol{X}]=\left[\begin{array}{cccc}
\left(1-\Omega L^{2} \Lambda^{2}\right) \operatorname{senh}(\Lambda x) & \left(1-\Omega L^{2} \Lambda^{2}\right) \cosh (\Lambda x) & x & 1 \\
\Lambda \cosh (\Lambda x) & \Lambda \operatorname{senh}(\Lambda x) & 1 & 0
\end{array}\right] \quad\{\boldsymbol{C}\}=\left\{\begin{array}{l}
c_{1} \\
c_{2} \\
c_{3} \\
c_{4}
\end{array}\right\}} \\
& \left\{\boldsymbol{d}^{\prime}\right\}=\left\{\begin{array}{c}
\boldsymbol{v}_{\mathbf{0}}(\mathbf{0}) \\
\boldsymbol{\theta}(\mathbf{0}) \\
\boldsymbol{v}_{\mathbf{0}}(\boldsymbol{L}) \\
\boldsymbol{\theta}(\boldsymbol{L})
\end{array}\right\}=\left\{\begin{array}{c}
\left(1-\Omega L^{2} \Lambda^{2}\right) c_{2}+c_{4} \\
c_{1} \Lambda+c_{3} \\
\left(1-\Omega L^{2} \Lambda^{2}\right)\left[c_{1} \operatorname{senh}(\Lambda L)+c_{2} \cosh (\Lambda L)\right]+c_{3} L+c_{4} \\
\Lambda\left[c_{1} \cosh (\Lambda L)+c_{2} \operatorname{senh}(\Lambda L)\right]+c_{3}
\end{array}\right\} \\
& \left\{\boldsymbol{d}^{\prime}\right\}=\left[\begin{array}{cccc}
0 & \left(1-L^{2} \Lambda^{2} \Omega\right) & 0 & 1 \\
\Lambda & 0 & 1 & 0 \\
\left(1-L^{2} \Lambda^{2} \Omega\right) \operatorname{senh}(L \Lambda) & \left(1-L^{2} \Lambda^{2} \Omega\right) \cosh (L \Lambda) & L & 1 \\
\Lambda \cosh (L \Lambda) & \Lambda \operatorname{senh}(\Lambda L) & 1 & 0
\end{array}\right] \cdot\left\{\begin{array}{l}
c_{1} \\
c_{2} \\
c_{3} \\
c_{4}
\end{array}\right\} \\
& \rightarrow[\boldsymbol{H}] .\{\boldsymbol{C}\}=\left\{\boldsymbol{d}^{\prime}\right\}
\end{aligned}
$$

Assim, as funções de forma são dadas pelas equações (3.82) a (3.89).

$$
\begin{gathered}
N_{2}^{v}=-\frac{\cosh (L \Lambda)-\cosh (\Lambda x)+\cosh (\Lambda(L-x))+L^{2} \Lambda^{2} \Omega-L \Lambda \operatorname{senh}(L \Lambda)}{L \Lambda \operatorname{senh}(L \Lambda)-2 L^{2} \Lambda^{2} \Omega-2 \cosh (L \Lambda)+2 L^{2} \Lambda^{2} \Omega \cosh (L \Lambda)+2}+ \\
+\frac{\Lambda x \operatorname{senh}(L \Lambda)-L^{2} \Lambda^{2} \Omega \cosh (L \Lambda)+L^{2} \Lambda^{2} \Omega \cosh (\Lambda x)-L^{2} \Lambda^{2} \Omega \cosh (\Lambda(L-x))-1}{L \Lambda \operatorname{senh}(L \Lambda)-2 L^{2} \Lambda^{2} \Omega-2 \cosh (L \Lambda)+2 L^{2} \Lambda^{2} \Omega \cosh (L \Lambda)+2} \\
N_{3}^{v}=\frac{\left(L^{2} \Lambda^{2} \Omega-1\right)(\operatorname{senh}(L \Lambda)-\operatorname{senh}(\Lambda x)-\operatorname{senh}(\Lambda(L-x))-\Lambda x-L \Lambda \cosh (L \Lambda))}{\Lambda\left(L \Lambda \operatorname{senh}(L \Lambda)-2 L^{2} \Lambda^{2} \Omega-2 \cosh (L \Lambda)+2 L^{2} \Lambda^{2} \Omega \cosh (L \Lambda)+2\right)}+ \\
+\frac{\left(L^{2} \Lambda^{2} \Omega-1\right)\left(\Lambda x \cosh (L \Lambda)+L \Lambda \cosh (\Lambda(L-x))-L^{2} \Lambda^{2} \Omega \operatorname{senh}(L \Lambda)\right)}{\Lambda\left(L \Lambda \operatorname{senh}(L \Lambda)-2 L^{2} \Lambda^{2} \Omega-2 \cosh (L \Lambda)+2 L^{2} \Lambda^{2} \Omega \cosh (L \Lambda)+2\right)}+ \\
+\frac{\left(L^{2} \Lambda^{2} \Omega-1\right)\left(L^{2} \Lambda^{2} \Omega \operatorname{senh}(\Lambda x)+L^{2} \Lambda^{2} \Omega \operatorname{senh}(\Lambda(L-x))\right)}{\Lambda\left(L \Lambda \operatorname{senh}(L \Lambda)-2 L^{2} \Lambda^{2} \Omega-2 \cosh (L \Lambda)+2 L^{2} \Lambda^{2} \Omega \cosh (L \Lambda)+2\right)} \\
N_{5}^{v}=\frac{\cosh (\Lambda(L-x))-\cosh ^{2}(\Lambda x)-\cosh (L \Lambda)-L^{2} \Lambda^{2} \Omega+\Lambda x \operatorname{senh}(L \Lambda)}{L \Lambda \operatorname{senh}(L \Lambda)-2 L^{2} \Lambda^{2} \Omega-2 \cosh (L \Lambda)+2 L^{2} \Lambda^{2} \Omega \cosh (L \Lambda)+2}+ \\
+\frac{L^{2} \Lambda^{2} \Omega \cosh (L \Lambda)+L^{2} \Lambda^{2} \Omega \cosh (\Lambda x)-L^{2} \Lambda^{2} \Omega \cosh (\Lambda(L-x))-1}{L \Lambda \operatorname{senh}(L \Lambda)-2 L^{2} \Lambda^{2} \Omega-2 \cosh (L \Lambda)+2 L^{2} \Lambda^{2} \Omega \cosh (L \Lambda)+2}
\end{gathered}
$$




$$
\begin{gathered}
N_{6}^{v}=\frac{-\left(L^{2} \Lambda^{2} \Omega-1\right)(\operatorname{senh}(L \Lambda)-\operatorname{senh}(\Lambda x)-\operatorname{senh}(\Lambda(L-x))+\Lambda x+L \Lambda)}{\Lambda\left(L \Lambda \operatorname{senh}(L \Lambda)-2 L^{2} \Lambda^{2} \Omega-2 \cosh (L \Lambda)+2 L^{2} \Lambda^{2} \Omega \cosh (L \Lambda)+2\right)}+ \\
+\frac{-\left(L^{2} \Lambda^{2} \Omega-1\right)\left(L \Lambda \cosh (\Lambda x)-\Lambda x \cosh (L \Lambda)-L^{2} \Lambda^{2} \Omega \operatorname{senh}(L \Lambda)\right)}{\Lambda\left(L \Lambda \operatorname{senh}(L \Lambda)-2 L^{2} \Lambda^{2} \Omega-2 \cosh (L \Lambda)+2 L^{2} \Lambda^{2} \Omega \cosh (L \Lambda)+2\right)}+ \\
+\frac{-\left(L^{2} \Lambda^{2} \Omega-1\right)\left(L^{2} \Lambda^{2} \Omega \operatorname{senh}(\Lambda x)+L^{2} \Lambda^{2} \Omega \operatorname{senh}(\Lambda(L-x))\right)}{\Lambda\left(L \Lambda \operatorname{senh}(L \Lambda)-2 L^{2} \Lambda^{2} \Omega-2 \cosh (L \Lambda)+2 L^{2} \Lambda^{2} \Omega \cosh (L \Lambda)+2\right)} \\
N_{3}^{\theta}=\frac{\cosh (\Lambda x)-\cosh (L \Lambda)-\cosh (\Lambda(L-x))-L^{2} \Lambda^{2} \Omega+L \Lambda \operatorname{senh}(\Lambda(L-x))}{L \Lambda \operatorname{senh}(L \Lambda)-2 L^{2} \Lambda^{2} \Omega-2 \cosh (L \Lambda)+2 L^{2} \Lambda^{2} \Omega \cosh (L \Lambda)+2}+ \\
+\frac{L^{2} \Lambda^{2} \Omega \cosh (L \Lambda)-L^{2} \Lambda^{2} \Omega \cosh (\Lambda x)+L^{2} \Lambda^{2} \Omega \cosh (\Lambda(L-x))+1}{L \Lambda \operatorname{senh}(L \Lambda)-2 L^{2} \Lambda^{2} \Omega-2 \cosh (L \Lambda)+2 L^{2} \Lambda^{2} \Omega \cosh (L \Lambda)+2} \\
N_{5}^{\theta}=-\frac{\Lambda(\operatorname{senh}(\Lambda x)-\operatorname{senh}(L \Lambda)+\operatorname{senh}(\Lambda(L-x)))}{L \Lambda \operatorname{senh}(L \Lambda)-2 L^{2} \Lambda^{2} \Omega-2 \cosh (L \Lambda)+2 L^{2} \Lambda^{2} \Omega \cosh (L \Lambda)+2} \\
N_{6}^{\theta}=\frac{\cosh (\Lambda(L-x))-\cosh ^{2}(\Lambda x)-\cosh (L \Lambda)-L^{2} \Lambda^{2} \Omega+L \Lambda \operatorname{senh}(\Lambda x)}{L \Lambda \operatorname{senh}(L \Lambda)-2 L^{2} \Lambda^{2} \Omega-2 \cosh (L \Lambda)+2 L^{2} \Lambda^{2} \Omega \cosh (L \Lambda)+2}+ \\
\frac{L^{2} \Lambda^{2} \Omega \cosh (L \Lambda)+L^{2} \Lambda^{2} \Omega \cosh (\Lambda x)-L^{2} \Lambda^{2} \Omega \cosh (\Lambda(L-x))+1}{L \Lambda \operatorname{senh}(L \Lambda)-2 L^{2} \Lambda^{2} \Omega-2 \cosh (L \Lambda)+2 L^{2} \Lambda^{2} \Omega \cosh (L \Lambda)+2}
\end{gathered}
$$

Se a força axial for de compressão, o valor de $\mu$ é um número complexo e o deslocamento pode ser escrito por funções trigonométricas, conforme as expressões (2.85) e (2.86), reapresentadas em (3.90) e (3.91), novamente com a rotação da seção sendo dada pela derivada do deslocamento.

$$
\begin{gathered}
v_{h}(x)=\left(1+\Omega L^{2} \Lambda^{2}\right)\left[c_{1} \operatorname{sen}(\Lambda x)+c_{2} \cos (\Lambda x)\right]+c_{3} x+c_{4} \\
\theta_{h}(x)=\Lambda\left[c_{1} \cos (\Lambda x)-c_{2} \operatorname{sen}(\Lambda x)\right]+c_{3}
\end{gathered}
$$

O cálculo das funções de forma pode ser feito empregando-se a mesma metodologia anterior, com as equações de (3.92) a (3.94).

$$
\begin{aligned}
& {[\boldsymbol{X}]=\left[\begin{array}{cccc}
\left(1+\Omega L^{2} \Lambda^{2}\right) \operatorname{sen}(\Lambda x) & \left(1+\Omega L^{2} \Lambda^{2}\right) \cos (\Lambda x) & x & 1 \\
\Lambda \cos (\Lambda x) & -\Lambda \operatorname{sen}(\Lambda x) & 1 & 0
\end{array}\right] \quad\{\boldsymbol{C}\}=\left\{\begin{array}{l}
c_{1} \\
c_{2} \\
c_{3} \\
c_{4}
\end{array}\right\}} \\
& \left\{\boldsymbol{d}^{\prime}\right\}=\left\{\begin{array}{c}
\boldsymbol{v}_{\mathbf{0}}(\mathbf{0}) \\
\boldsymbol{\theta}(\mathbf{0}) \\
\boldsymbol{v}_{\mathbf{0}}(\boldsymbol{L}) \\
\boldsymbol{\theta}(\boldsymbol{L})
\end{array}\right\}=\left\{\begin{array}{c}
\left(1+\Omega L^{2} \Lambda^{2}\right) c_{2}+c_{4} \\
c_{1} \Lambda+c_{3} \\
\left(1+\Omega L^{2} \Lambda^{2}\right)\left[c_{1} \operatorname{sen}(\Lambda L)+c_{2} \cos (\Lambda L)\right]+c_{3} L+c_{4} \\
\Lambda\left[c_{1} \cos (\Lambda L)-c_{2} \operatorname{sen}(\Lambda L)\right]+c_{3}
\end{array}\right\}
\end{aligned}
$$




$$
\left\{\boldsymbol{d}^{\prime}\right\}=\left[\begin{array}{cccc}
0 & \left(1+\Omega L^{2} \Lambda^{2}\right) & 0 & 1 \\
\Lambda & 0 & 1 & 0 \\
\left(1+\Omega L^{2} \Lambda^{2}\right) \operatorname{sen}(\Lambda L) & \left(1+\Omega L^{2} \Lambda^{2}\right) \cos (\Lambda L) & L & 1 \\
\Lambda \cos (\mu L) & -\Lambda \operatorname{sen}(\mu L) & 1 & 0
\end{array}\right] \cdot\left\{\begin{array}{l}
c_{1} \\
c_{2} \\
c_{3} \\
c_{4}
\end{array}\right\}
$$

$$
\rightarrow[\boldsymbol{H}] .\{\boldsymbol{C}\}=\left\{\boldsymbol{d}^{\prime}\right\}
$$

Empregando-se a relação (3.11), as funções de interpolação são calculadas como as expressões dadas em (3.95) a (3.102).

$$
\begin{aligned}
& N_{2}^{v}=\frac{\cos (L \Lambda)-\cos (\Lambda x)+\cos (\Lambda(L-x))-L^{2} \Lambda^{2} \Omega+L \Lambda \operatorname{sen}(L \Lambda)-\Lambda x \operatorname{sen}(L \Lambda)}{2 \cos (L \Lambda)-2 L^{2} \Lambda^{2} \Omega+L \Lambda \operatorname{sen}(L \Lambda)+2 L^{2} \Lambda^{2} \Omega \cos (L \Lambda)-2}+ \\
& +\frac{L^{2} \Lambda^{2} \Omega \cos (L \Lambda)-L^{2} \Lambda^{2} \Omega \cos (\Lambda \mathrm{x})+L^{2} \Lambda^{2} \Omega \cos (\Lambda(L-x))-1}{2 \cos (L \Lambda)-2 L^{2} \Lambda^{2} \Omega+L \Lambda \operatorname{sen}(L \Lambda)+2 L^{2} \Lambda^{2} \Omega \cos (L \Lambda)-2} \\
& N_{3}^{v}=\frac{-\left(1+L^{2} \Lambda^{2} \Omega\right)(\operatorname{sen}(\Lambda x)-\operatorname{sen}(L \Lambda)+\operatorname{sen}(\Lambda(L-x))+\Lambda x+L \Lambda \cos (L \Lambda))}{\Lambda\left(2 \cos (L \Lambda)-2 L^{2} \Lambda^{2} \Omega+L \Lambda \operatorname{sen}(L \Lambda)+2 L^{2} \Lambda^{2} \Omega \cos (L \Lambda)-2\right)}+ \\
& +\frac{-\left(1+L^{2} \Lambda^{2} \Omega\right)\left(-\Lambda x \cos (L \Lambda)-L \Lambda \cos (\Lambda(L-x))-L^{2} \Lambda^{2} \Omega \operatorname{sen}(L \Lambda)\right)}{\Lambda\left(2 \cos (L \Lambda)-2 L^{2} \Lambda^{2} \Omega+L \Lambda \operatorname{sen}(L \Lambda)+2 L^{2} \Lambda^{2} \Omega \cos (L \Lambda)-2\right)}+ \\
& \frac{-\left(1+L^{2} \Lambda^{2} \Omega\right)\left(L^{2} \Lambda^{2} \Omega \operatorname{sen}(\Lambda \mathrm{x})+L^{2} \Lambda^{2} \Omega \operatorname{sen}(\Lambda(L-x))\right)}{\Lambda\left(2 \cos (L \Lambda)-2 L^{2} \Lambda^{2} \Omega+L \Lambda \operatorname{sen}(L \Lambda)+2 L^{2} \Lambda^{2} \Omega \cos (L \Lambda)-2\right)} \\
& N_{5}^{v}=\frac{\cos (L \Lambda)+\cos (\Lambda x)-\cos (\Lambda(L-x))-L^{2} \Lambda^{2} \Omega+\Lambda x \operatorname{sen}(L \Lambda)+}{2 \cos (L \Lambda)-2 L^{2} \Lambda^{2} \Omega+L \Lambda \operatorname{sen}(L \Lambda)+2 L^{2} \Lambda^{2} \Omega \cos (L \Lambda)-2}+ \\
& +\frac{L^{2} \Lambda^{2} \Omega \cos (L \Lambda)+L^{2} \Lambda^{2} \Omega \cos (\Lambda \mathrm{x})-L^{2} \Lambda^{2} \Omega \cos (\Lambda(L-x))-1}{2 \cos (L \Lambda)-2 L^{2} \Lambda^{2} \Omega+L \Lambda \operatorname{sen}(L \Lambda)+2 L^{2} \Lambda^{2} \Omega \cos (L \Lambda)-2} \\
& N_{6}^{v}=\frac{\left(1+L^{2} \Lambda^{2} \Omega\right)(\operatorname{sen}(\Lambda x)-\operatorname{sen}(L \Lambda)+\operatorname{sen}(\Lambda(L-x))-\Lambda x+L \Lambda)}{\Lambda\left(2 \cos (L \Lambda)-2 L^{2} \Lambda^{2} \Omega+L \Lambda \operatorname{sen}(L \Lambda)+2 L^{2} \Lambda^{2} \Omega \cos (L \Lambda)-2\right)}+ \\
& +\frac{\left(1+L^{2} \Lambda^{2} \Omega\right)\left(-L \Lambda \cos (\Lambda \mathrm{x})+\Lambda x \cos (L \Lambda)-L^{2} \Lambda^{2} \Omega \operatorname{sen}(L \Lambda)\right)}{\Lambda\left(2 \cos (L \Lambda)-2 L^{2} \Lambda^{2} \Omega+L \Lambda \operatorname{sen}(L \Lambda)+2 L^{2} \Lambda^{2} \Omega \cos (L \Lambda)-2\right)}+ \\
& \frac{\left(1+L^{2} \Lambda^{2} \Omega\right)\left(L^{2} \Lambda^{2} \Omega \operatorname{sen}(\Lambda \mathrm{x})+L^{2} \Lambda^{2} \Omega \operatorname{sen}(\Lambda(L-x))\right)}{\Lambda\left(2 \cos (L \Lambda)-2 L^{2} \Lambda^{2} \Omega+L \Lambda \operatorname{sen}(L \Lambda)+2 L^{2} \Lambda^{2} \Omega \cos (L \Lambda)-2\right)} \\
& N_{2}^{\theta}=\frac{\Lambda(\operatorname{sen}(\Lambda x)-\operatorname{sen}(L \Lambda)+\operatorname{sen}(\Lambda(L-x)))}{2 \cos (L \Lambda)-2 L^{2} \Lambda^{2} \Omega+L \Lambda \operatorname{sen}(L \Lambda)+2 L^{2} \Lambda^{2} \Omega \cos (L \Lambda)-2} \\
& N_{3}^{\theta}=\frac{\cos (L \Lambda)-\cos (\Lambda x)+\cos (\Lambda(L-x))-L^{2} \Lambda^{2} \Omega+L \Lambda \operatorname{sen}(\Lambda(L-x))}{2 \cos (L \Lambda)-2 L^{2} \Lambda^{2} \Omega+L \Lambda \operatorname{sen}(L \Lambda)+2 L^{2} \Lambda^{2} \Omega \cos (L \Lambda)-2}+ \\
& \frac{L^{2} \Lambda^{2} \Omega \cos (L \Lambda)-L^{2} \Lambda^{2} \Omega \cos (\Lambda x)+L^{2} \Lambda^{2} \Omega \cos (\Lambda(L-x))-1}{2 \cos (L \Lambda)-2 L^{2} \Lambda^{2} \Omega+L \Lambda \operatorname{sen}(L \Lambda)+2 L^{2} \Lambda^{2} \Omega \cos (L \Lambda)-2}
\end{aligned}
$$




$$
\begin{gathered}
N_{5}^{\theta}=-\frac{\Lambda(\operatorname{sen}(\Lambda x)-\operatorname{sen}(L \Lambda)+\operatorname{sen}(\Lambda(L-x)))}{2 \cos (L \Lambda)-2 L^{2} \Lambda^{2} \Omega+L \Lambda \operatorname{sen}(L \Lambda)+2 L^{2} \Lambda^{2} \Omega \cos (L \Lambda)-2} \\
N_{6}^{\theta}=\frac{\cos (L \Lambda)+\cos (\Lambda x)-\cos (\Lambda(L-x))-L^{2} \Lambda^{2} \Omega+L \Lambda \operatorname{sen}(\Lambda x)}{2 \cos (L \Lambda)-2 L^{2} \Lambda^{2} \Omega+L \Lambda \operatorname{sen}(L \Lambda)+2 L^{2} \Lambda^{2} \Omega \cos (L \Lambda)-2}+ \\
\frac{L^{2} \Lambda^{2} \Omega \cos (L \Lambda)+L^{2} \Lambda^{2} \Omega \cos (\Lambda x)-L^{2} \Lambda^{2} \Omega \cos (\Lambda(L-x))-1}{2 \cos (L \Lambda)-2 L^{2} \Lambda^{2} \Omega+L \Lambda \operatorname{sen}(L \Lambda)+2 L^{2} \Lambda^{2} \Omega \cos (L \Lambda)-2}
\end{gathered}
$$

Nos apêndices A.7 e A.8, são calculadas as funções de forma, considerando rótulas nas extremidades da barra e teoria de flexãos de Timoshenko, para o equilíbrio de um elemento infinitesimal na configuração deformada.

\section{3}

\section{Funções de Interpolação para Deslocamento Axial}

Para a interpolação dos deslocamentos axiais do elemento, foram utilizadas funções de forma lineares, como é utilizado em McGuire et al. (2000), inclusive para a rotação em torno do eixo x, de acordo com o apresentado em (3.103).

$$
u_{0}(x)=N_{1}^{u}(x) d_{1}^{\prime}+N_{4}^{u}(x) d_{4}^{\prime} \quad N_{1}^{u}(x)=1-\frac{x}{L} \quad N_{4}^{u}(x)=\frac{x}{L}
$$

Entretanto, ao se utilizar funções de deslocamento de baixa ordem de interpolação, o elemento viga-coluna pode apresentar um aumento de rigidez espúrio, “locking”, e ao se utilizar apenas um elemento por barra, esse efeito tende a aumentar, pois os procedimentos usuais para evitá-lo, como a integração reduzida e o emprego de uma ordem mais elevada das funções de interpolação, não são satisfatórios, por necessitarem de uma boa discretização da estrutura (Silva et al., 2016).

De acordo com Silva et al. (2016) quando se utiliza uma função de interpolação linear para o deslocamento axial surge o efeito de travamento de membrana, "membrane locking”, no elemento de viga-coluna. Para uma análise linear a interpolação linear é consistente com a teoria de deformação, pois $\varepsilon=d u / d x$, independendo do deslocamento transversal. Entretanto em uma análise não linear, há um acoplamento da deformação axial e a deformação devido a flexão, conforme equação (3.104), obtida do tensor deformação de GreenLagrange, e dessa maneira, a interpolação linear axial reduz o correspondente 
deslocamento axial devido ao deslocamento transversal, não sendo portanto, uma hipótese consistente.

$$
\varepsilon=\frac{\partial u}{\partial x}+\frac{1}{2}\left(\frac{\partial u^{2}}{\partial x}+\frac{\partial v^{2}}{\partial x}\right)
$$

Tang et al. (2015) e Silva et al. (2016) apresentam funções interpoladoras consistentes conforme o exposto em um referencial corrotacional. Essa consideração não foi adotada nesse trabalho. 


\section{4 \\ Matriz de Rigidez Local}

A análise não linear, utilizando-se do $\mathrm{MEF}$, varia com relação a 5 distintos aspectos: a teoria de flexão considerada, a descrição cinemática, as relações entre deformação e deslocamento, a metodologia de análise não linear e as funções de interpolação. Todos esses apectos influenciam no desenvolvimento da matriz de rigidez local de um elemento.

Neste trabalho, é desenvolvida uma matriz com formulação tridimensional, considerando as teorias de flexão de Euler-Bernoulli e Timoshenko. Como descrição cinemática, emprega-se a formulação Lagrangeana atualizada, bem desenvolvida em várias referências, como McGuire et al. (2000), Bathe (1996), Bathe \& Bolourchi (1979).

Para a relação entre deformação e deslocamento, emprega-se o tensor deformação de Green, considerando todos os seus termos, inclusive os de alta ordem, sendo este um dos objetivos principais deste trabalho. A utilização de todos esses termos é bem apresentada em Yang \& Leu (1994) ou em Yang \& Kuo (1994). Na literatura a consideração de todos os termos do tensor deformação emprega apenas a teoria de flexão de Euler-Bernoulli.

Para a metodologia de análise não linear, utilizou-se os algoritmos implementados por Rangel (2019), essas soluções não lineares foram programadas no Ftool (Martha, 1999) e foram baseadas no trabalho de Leon et al. (2011).

Com relação às funções de interpolação dos deslocamentos, elas possuem uma importante função no resultado final da análise, pois, a partir delas, calcula-se a matriz de rigidez local de um elemento e, conforme comentado no capítulo 2, quando estas funções de forma são obtidas diretamente da solução homogênea da equação diferencial do problema contínuo, a discretização da barra não é necessária.

Para o problema linear, as equações de interpolação cúbicas representam esse resultado, sendo por isso, desnecessário a discretização de barras, independentemente da teoria de flexão utilizada. Entretanto, na análise não linear, 
essa solução não consegue descrever completamente o problema, exigindo a utilização de um maior número de elementos na análise.

Para buscar solucionar esse problema, pode-se empregar uma análise não linear em nível infinitesimal, na qual a equação diferencial do problema e a sua solução consideram o equilíbrio de um elemento infinitesimal na configuração deformada, levando-se em conta a carga axial que atua no elemento infinitesimal.

Nesta pesquisa, apresenta-se então, uma formulação para o cálculo da matriz de rigidez local, empregando-se essas funções de forma obtidas do equilíbrio de um elemento infinitesimal na condição deformada, chamada neste trabalho de funções "completas", considerando ambas as teorias de flexão, Euler-Bernoulli e Timoshenko, e empregando todos os termos do tensor deformação de Green.

A matriz de rigidez local do elemento foi calculada, analisando-se uma estrutura bidimensional, considerando os planos xy e xz em separado, como se fossem independentes, obtendo-se então a matriz de rigidez elástica e a geométrica. Na sequência, para a construção da matriz tridimensional, integrou-se a ação dos planos, adicionando-se a interação entre torção e carga axial e por fim, o efeito das rotações finitas.

\section{1 \\ Descrição Cinemática}

Para se predizer o comportamento não linear geométrico de estruturas com o MEF, podem ser utilizadas três distintas formulações: a lagrangeana total, a lagrangeana atualizada e, mais recentemente, a corrotacional (Krenk, 2009; Felippa, 2017; Menin \& Silva, 2003).

Essencialmente, essas descrições cinemáticas se diferenciam com relação à configuração de referência considerada. Yshii (2002) e Monteiro (2004) utilizam a Figura 4.1 para fazer uma abordagem didática das diferentes considerações acerca dessas formulações. 


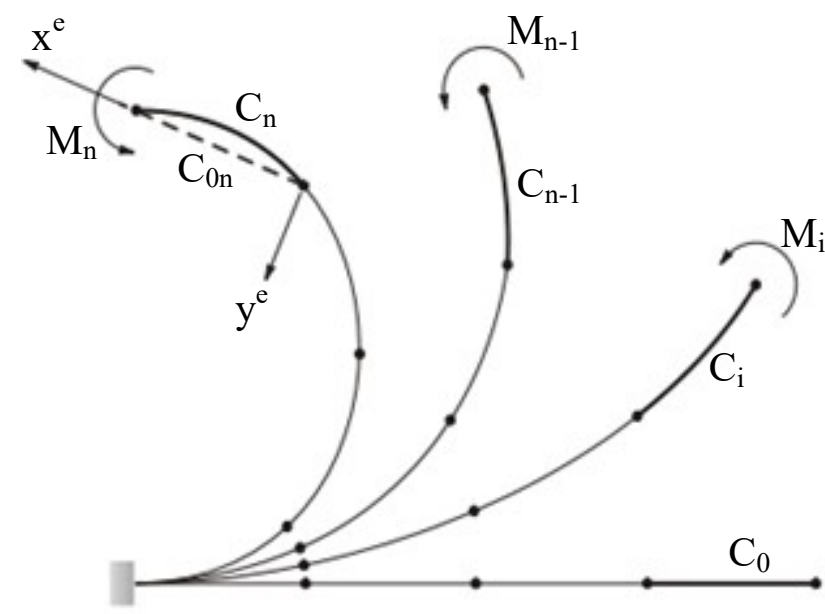

Figura 4.1 - Configurações de equilíbrio $C_{0}, C_{i}, C_{n-1}$ e $C_{n}$

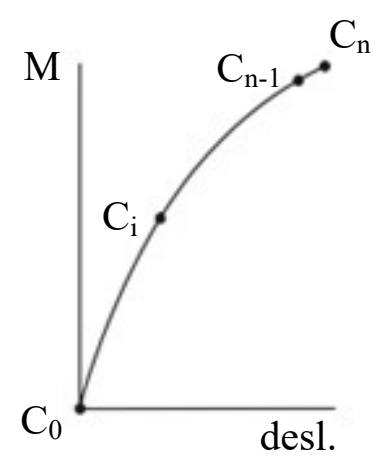

Fonte: Yshii (2002); Monteiro (2004).

A Figura 4.1 apresenta uma viga sujeita a grandes rotações e composta por quatro elementos finitos. A viga é engastada em uma das extremidades e, na outra, é aplicada uma carga-momento. Supondo que se pretende obter a configuração final $C_{n}$ do elemento na extremidade livre da estrutura, devido à natureza não linear do problema, é necessário conhecer as configurações de equilíbrio anteriores, sendo $\mathrm{C}_{0}$, a configuração inicial indeformada, $\mathrm{C}_{\mathrm{i}}$ uma configuração intermediária e $\mathrm{C}_{\mathrm{n}-1}$ uma configuração imediatamente anterior à final $\mathrm{C}_{\mathrm{n}}$.

A descrição Lagrangeana é caracterizada pela determinação da configuração final $\mathrm{C}_{\mathrm{n}}$, estabelecendo-se equações que utilizam como referência uma configuração de equilíbrio conhecida. Se esta configuração de referência é dada pela inicial $\mathrm{C}_{0}$, tem-se uma descrição Lagrangeana total. Caso seja utilizada a configuração $\mathrm{C}_{\mathrm{n}-1}$, a descrição é conhecida como Lagrangeana atualizada. É preciso destacar que, em caso de se utilizar como referência a configuração final desconhecida $\mathrm{C}_{\mathrm{n}}$, obtém-se uma descrição Euleriana.

Em problemas geometricamente lineares, a descrição Euleriana e Lagrangeana total é semelhante, devido à proximidade das configurações inicial e final. Nesses problemas geometricamente lineares, a descrição Lagrangeana total se apresenta como a mais intuitiva, tendo em vista a proximidade entre a configuração inicial e a final de equilíbrio.

$\mathrm{Na}$ formulação corrotacional, a configuração de referência é dividida em duas partes, com as tensões e deformações medidas em função de uma 
configuração corrotacionada e os deslocamentos de corpo rígido, medidos em função da configuração inicial. Utilizando a Figura 4.1, tem-se uma configuração indeformada desconhecida $\mathrm{C}_{0 \mathrm{n}}$, encontrada unicamente por movimento de corpo rígido do elemento. Essa configuração é bem próxima à final e o movimento entre $\mathrm{C}_{0 \mathrm{n}}$ e $\mathrm{C}_{\mathrm{n}}$ é o que realmente deforma o elemento e gera tensões.

\section{2}

\section{Formulação Lagrangeana Atualizada}

Neste trabalho, empregou-se a descrição Lagrangeana atualizada e sua formulação é apresentada em McGuire et al. (2000). Nessa formulação, as equações de equilíbrio de uma configuração desconhecida $t+\Delta t$ precisam ser escritas utilizando variáveis conhecidas de uma configuração referência $t$. Assim, para a configuração $t+\Delta t$, o trabalho virtual das forças internas deve ser igual ao trabalho virtual das forças externas, de acordo com a equação (4.1).

$$
\int_{V} S_{i j}^{(t+\Delta t)} \delta \varepsilon_{i j}^{(t+\Delta t)} d V=R^{(t+\Delta t)}
$$

Em que $S_{i j}^{(t+\Delta t)}$ corresponde ao segundo tensor tensão de Piola-Kirchoff, ao $\varepsilon_{i j}^{(t+\Delta t)}$ tensor deformação de Green-Lagrange, e $R^{(t+\Delta t)}$ ao trabalho virtual devido ao carregamento externo.

As equações incrementais linearizadas requerem pequenos incrementos de deslocamentos. Assim, o segundo tensor de tensão de Piola-Kirchoff e o tensor deformação de Green Lagrange podem ser escritos de acordo com a equação $(4.2)$,

$$
S_{i j}^{(t+\Delta t)}=\tau_{i j}^{t}+\Delta \tau_{i j} \quad \varepsilon_{i j}^{(t+\Delta t)}=\varepsilon_{i j}^{t}+\Delta \varepsilon_{i j}
$$

$\operatorname{com} \tau_{i j}^{t}$ correspondendo ao tensor tensão de Cauchy, $\Delta \tau_{i j}$ ao incremento de tensão e $\Delta \varepsilon_{i j}$ ao incremento de deformação, que pode ser calculado com o tensor deformação de Green Lagrange.

Sabendo que na configuração de referência o elemento está sujeito apenas a movimentos de corpo rígido e não possui deformação, $\delta \varepsilon_{i j}^{t}=0$, a equação (4.3) é assim obtida. 


$$
\int_{V}\left(\tau_{i j}^{t}+\Delta \tau_{i j}\right) \delta\left(\Delta \varepsilon_{i j}\right) d V=\int_{V} \Delta \tau_{i j} \delta \Delta \varepsilon_{i j} d V+\int_{V} \tau_{i j}^{t} \delta \Delta \varepsilon_{i j} d V=R^{(t+\Delta t)}
$$

O tensor deformação de Green-Lagrange no plano xy é representado pelas relações (4.4) e (4.5).

$$
\begin{aligned}
& \varepsilon_{x x}=\frac{\partial u}{\partial x}+\frac{1}{2}\left[\left(\frac{\partial u}{\partial x}\right)^{2}+\left(\frac{\partial v}{\partial x}\right)^{2}\right] \\
& \gamma_{x y}=\frac{\partial u}{\partial y}+\frac{\partial v}{\partial x}+\frac{\partial u}{\partial x} \frac{\partial v}{\partial y}+\frac{\partial v}{\partial x} \frac{\partial v}{\partial y}
\end{aligned}
$$

Nota-se que o tensor deformação de Green-Lagrange possui uma parcela linear $\left(\Delta e_{i j}\right)$ e uma parcela não linear $\left(\Delta \eta_{i j}\right)$, ou alta ordem. Assim, a decomposição apresentada nas expressões (4.6) a (4.9) pode ser adotada.

$$
\begin{gathered}
\Delta \varepsilon_{i j}=\Delta e_{i j}+\Delta \eta_{i j} \\
\Delta e_{x x}=\frac{\partial u}{\partial x} \quad \Delta e_{x y}=\frac{\partial u}{\partial y}+\frac{\partial v}{\partial x} \\
\Delta \eta_{x x}=\frac{1}{2}\left[\left(\frac{\partial u}{\partial x}\right)^{2}+\left(\frac{\partial v}{\partial x}\right)^{2}\right] \\
\Delta \eta_{x y}=\frac{\partial u}{\partial x} \frac{\partial v}{\partial y}+\frac{\partial v}{\partial x} \frac{\partial u}{\partial y}
\end{gathered}
$$

O incremento de tensão é obtido da relação constitutiva do material, considerando uma aproximação linear para o incremento de tensão e deformação, e leva a expressão apresentada em (4.10).

$$
\Delta \tau_{i j}=C_{i j k l} \Delta \varepsilon_{k l}=C_{i j k l} \Delta e_{k l} \quad \Delta \varepsilon_{i j}=\Delta e_{i j}
$$

Então, a expressão do trabalho virtual pode ser escrita conforme (4.11)

$$
\begin{gathered}
\int_{V} C_{i j k l} \Delta e_{k l} \delta \Delta e_{i j} d V+\int_{V} \tau_{i j}^{t} \delta\left(\Delta e_{i j}+\Delta \eta_{i j}\right) d V=R^{(t+\Delta t)} \\
\int_{V} C_{i j k l} \Delta e_{k l} \delta \Delta e_{i j} d V+\int_{V} \tau_{i j}^{t} \delta \Delta e_{i j} d V+\int_{V} \tau_{i j} \Delta \eta_{i j} d V=R^{(t+\Delta t)}
\end{gathered}
$$

No plano, o vetor tensão, a matriz constitutiva, os vetores deformação lineares e não lineares são dados conforme (4.12). 


$$
\tau=\left\{\begin{array}{l}
\tau_{x x} \\
\tau_{x y}
\end{array}\right\} \quad C=\left[\begin{array}{ll}
E & 0 \\
0 & G
\end{array}\right] \quad e=\left\{\begin{array}{l}
\varepsilon_{x x} \\
\gamma_{x y}
\end{array}\right\} \quad \eta=\left\{\begin{array}{l}
\eta_{x x} \\
\eta_{x y}
\end{array}\right\}
$$

Assim, a equação do trabalho virtual pode ser expandida, de acordo com as equações (4.13), (4.14) e (4.15).

$$
\begin{aligned}
\int_{V} C_{i j k l} \Delta e_{k l} \delta \Delta e_{i j} d V & =\int_{V} \varepsilon_{x x} \cdot E \delta \varepsilon_{x x} d V+\int_{V} \gamma_{x y} \cdot G \delta \gamma_{x y} d V \\
\int_{V} \tau_{i j}^{t} \delta \Delta e_{i j} d V & =\int_{V} \tau_{x x} \delta \varepsilon_{x x} d V+\int_{V} \tau_{x y} \delta \gamma_{x y} d V \\
\int_{V} \tau_{i j} \Delta \eta_{i j} d V & =\int_{V} \tau_{x x} \delta \eta_{x x} d V+\int_{V} \tau_{x y} \delta \eta_{x y} d V
\end{aligned}
$$

\section{3}

\section{Teoria de Flexão de Euler-Bernoulli}

Neste item, empregou-se a descrição Lagrangeana atualizada e a sua formulação é apresentada em McGuire et al. (2000). Todos os termos do tensor deformação de Green-Lagrange foram considerados, utilizando-se a teoria de flexão de Euler-Bernoulli. Também foram empregadas funções de forma cúbicas (equilíbrio de um elemento infinitesimal na configuração indeformada) e funções de interpolação completas (equilíbrio de um elemento infinitesimal na configuração deformada).

De acordo com o campo de deslocamentos de barras, equação (2.1), e considerando a teoria de flexão de Euler-Bernoulli, as parcelas lineares e não lineares do tensor deformação de Green-Lagrange, relações (4.4) e (4.5), podem ser reescritas conforme as equações (4.16), parcela linear, (4.17) e (4.18), parcela não linear.

$$
\begin{gathered}
\varepsilon_{x x}=\frac{\partial u}{\partial x}=\frac{\partial u_{0}}{\partial x}-y \frac{\partial^{2} v}{\partial x^{2}} \quad \gamma_{x y}=\frac{\partial v}{\partial x}+\frac{\partial u}{\partial y}=\frac{\partial v_{0}}{\partial x}-\frac{\partial v_{0}}{\partial x}=0 \\
\eta_{x x}=\frac{1}{2}\left(\left(\frac{\partial u}{\partial x}\right)^{2}+\left(\frac{\partial v}{\partial x}\right)^{2}\right)=\frac{1}{2}\left(\left(\frac{\partial u}{\partial x}\right)^{2}+\left(\frac{\partial v}{\partial x}\right)^{2}+y^{2}\left(\frac{\partial^{2} v}{\partial x^{2}}\right)^{2}\right)-y \frac{\partial^{2} v}{\partial x^{2}} \frac{\partial u}{\partial x} \\
\eta_{x y}=\frac{\partial u}{\partial x} \frac{\partial u}{\partial y}+\frac{\partial v}{\partial x} \frac{\partial v}{\partial y}=y \frac{\partial^{2} v}{\partial x^{2}} \frac{\partial v}{\partial x}-\frac{\partial v}{\partial x} \frac{\partial u}{\partial x}
\end{gathered}
$$




\subsection{1}

\section{Matriz de Rigidez Elástica}

A matriz de rigidez elástica de um elemento é obtida a partir da parcela linear do tensor deformação de Green-Lagrange, equação (4.16). Empregando a equação (4.13) dos trabalhos virtuais, $\delta U$, obtém-se a expressão (4.19), que pode ser reescrita, conforme as equações (4.20), (4.21) e (4.22).

$$
\begin{gathered}
\delta U=\int_{A}\left(\int_{0}^{L}\left(\frac{\partial u}{\partial x}-y \frac{\partial^{2} v}{\partial x^{2}}\right) E\left(\delta \frac{\partial u}{\partial x}-y \delta \frac{\partial^{2} v}{\partial x^{2}}\right) d x\right) d A \\
\delta U=E \int_{A}\left(\int_{0}^{L}\left(\frac{\partial u}{\partial x} \delta \frac{\partial u}{\partial x}+y^{2} \frac{\partial^{2} v}{\partial x^{2}} \delta \frac{\partial^{2} v}{\partial x^{2}}-y \frac{\partial^{2} v}{\partial x^{2}} \delta \frac{\partial u}{\partial x}-\frac{\partial u}{\partial x} y \delta \frac{\partial^{2} v}{\partial x^{2}}\right) d x\right) d A \\
\delta U=E \int_{A}\left(\int_{0}^{L} \frac{\partial u}{\partial x} \delta \frac{\partial u}{\partial x} d x\right) d A+E \int_{A}\left(\int_{0}^{L} y^{2} \frac{\partial^{2} v}{\partial x^{2}} \delta \frac{\partial^{2} v}{\partial x^{2}} d x\right) d A- \\
-E \int_{A}^{L}\left(\int_{0}^{L} y \frac{\partial^{2} v}{\partial x^{2}} \delta \frac{\partial u}{\partial x} d x\right) d A-E \int_{A}\left(\int_{0}^{L} \frac{\partial u}{\partial x} y \delta \frac{\partial^{2} v}{\partial x^{2}} d x\right) d A \\
\delta U=\left(\int_{0}^{L} \frac{\partial u}{\partial x} \delta \frac{\partial u}{\partial x} d x\right) E \int_{A} d A+\left(\int_{0}^{L} \frac{\partial^{2} v}{\partial x^{2}} \delta \frac{\partial^{2} v}{\partial x^{2}} d x\right) E \int_{A} y^{2} d A- \\
-\left(\int_{0}^{L} \frac{\partial^{2} v}{\partial x^{2}} \delta \frac{\partial u}{\partial x} d x\right) E \int_{A} y d A-\left(\int_{0}^{L} \frac{\partial u}{\partial x} \delta \frac{\partial^{2} v}{\partial x^{2}} d x\right) E \int_{A} y d A
\end{gathered}
$$

No eixo centroidal da seção transversal, pode-se considerar as propriedades:

$\int_{A} y^{2} d A=I_{z}, \int_{A} y d A=0$. Assim, o problema é reduzido à equação (4.23).

$$
\delta U=\left(\int_{0}^{L} \frac{\partial u}{\partial x} \delta \frac{\partial u}{\partial x} d x\right) E A+\left(\int_{0}^{L} \frac{\partial^{2} v}{\partial x^{2}} \delta \frac{\partial^{2} v}{\partial x^{2}} d x\right) E I_{z}-0-0
$$

De acordo com as equações de interpolação (3.1), (3.2) e (3.3), os deslocamentos do elemento são dados em função dos deslocamentos nodais, conforme (4.24).

$$
u_{0}(x)=\left\{N_{u}(x)\right\}\{u\} \quad v_{0}(x)=\left\{N_{v}(x)\right\}\{v\} \quad \theta_{z}(x)=\left\{N_{\theta z}(x)\right\}\{v\}
$$

As funções de interpolação são as obtidas anteriormente, considerando o equilíbrio de um elemento infinitesimal na configuração indeformada, rearranjadas vetorialmente, de acordo com as expressões (4.25) e (4.26). 


$$
\begin{gathered}
N_{u}=\left\{\begin{array}{cc}
\left.N_{1}(x) \quad N_{4}(x)\right\}=\left\{1-\frac{x}{L} \quad \frac{x}{L}\right.
\end{array}\right\} \\
N_{v}=\left\{\begin{array}{lll}
N_{2}^{v}(x) & N_{3}^{v}(x) \quad N_{5}^{v}(x) \quad N_{6}^{v}(x)
\end{array}\right\} \\
N_{v}=\left\{2 \frac{x^{3}}{L^{3}}-3 \frac{x^{2}}{L^{2}}+1 \quad \frac{x^{3}}{L^{2}}-2 \frac{x^{2}}{L}+\mathrm{x} \quad 3 \frac{x^{2}}{L^{2}}-2 \frac{x^{3}}{L^{3}} \quad \frac{x^{3}}{L^{2}}-\frac{x^{2}}{L}\right\}
\end{gathered}
$$

Os vetores referentes aos deslocamentos nodais podem ser escritos conforme (4.27), baseado na Figura 3.1.

$$
\{u\}=\left\{\begin{array}{lll}
d_{u 1} & d_{u 4}
\end{array}\right\} \quad\{v\}=\left\{\begin{array}{llll}
d_{v 2} & d_{v 3} & d_{v 5} & d_{v 6}
\end{array}\right\}
$$

Assim, a equação (4.23) dos trabalhos virtuais pode ser escrita, utilizando-se as funções de forma, os deslocamentos nodais e a notação $\partial / \partial x=($ )', conforme expressão (4.28).

$$
\delta U=\{\delta u\}^{T} \int_{0}^{L} E A\left\{N_{u}{ }^{\prime}\right\}\left\{N_{u}{ }^{\prime}\right\}^{T} d x\{u\}+\{\delta v\}^{T} \int_{0}^{L} E I_{z}\left\{N_{v}{ }^{\prime \prime}\right\}\left\{N_{v}{ }^{\prime \prime}\right\}^{T} d x\{v\}
$$

Nota-se que a teoria de Euler-Bernoulli não considera as funções de interpolação referentes às rotações $\boldsymbol{N}_{\boldsymbol{\theta} \mathbf{z}}(\boldsymbol{x})$.

Substituindo-se as funções de forma e resolvendo as integrais do problema, encontra-se a já estabelecida matriz de rigidez elástica de um elemento plano, considerando a teoria de flexão de Euler-Bernoulli, equação (4.29).

$$
K_{e, x y}=\left[\begin{array}{cccccc}
\frac{E A}{L} & 0 & 0 & -\frac{E A}{L} & 0 & 0 \\
0 & \frac{12 E I_{Z}}{L^{3}} & \frac{6 E I_{Z}}{L^{2}} & 0 & -\frac{12 E I_{Z}}{L^{3}} & \frac{6 E I_{Z}}{L^{2}} \\
0 & \frac{6 E I_{Z}}{L^{2}} & \frac{4 E I_{Z}}{L} & 0 & -\frac{6 E I_{Z}}{L^{2}} & \frac{2 E I_{Z}}{L} \\
-\frac{E A}{L} & 0 & 0 & \frac{E A}{L} & 0 & 0 \\
0 & -\frac{12 E I_{Z}}{L^{3}} & -\frac{6 E I_{Z}}{L^{2}} & 0 & \frac{12 E I_{Z}}{L^{3}} & -\frac{6 E I_{Z}}{L^{2}} \\
0 & \frac{6 E I_{Z}}{L^{2}} & \frac{2 E I_{Z}}{L} & 0 & -\frac{6 E I_{Z}}{L^{2}} & \frac{4 E I_{Z}}{L}
\end{array}\right]
$$




\subsection{2}

\section{Matriz de Rigidez Geométrica}

A matriz de rigidez geométrica é calculada utilizando-se a parcela não linear da equação dos trabalhos virtuais, equação (4.15), ou seja, emprega-se a parcela não linear do tensor deformação de Green Lagrange, conforme as equações (4.17) e (4.18), desenvolvidas anteriormente.

Assim, a equação (4.15) pode ser escrita, conforme expressão (4.30).

$$
\begin{aligned}
\delta U_{N L}= & \int_{A}\left(\int_{0}^{L} t_{x x} \delta\left(\frac{1}{2}\left(\left(\frac{\partial u}{\partial x}\right)^{2}+\left(\frac{\partial v}{\partial x}\right)^{2}+y^{2}\left(\frac{\partial^{2} v}{\partial x^{2}}\right)^{2}\right)-y \frac{\partial^{2} v}{\partial x^{2}} \frac{\partial u}{\partial x}\right) d x\right) d A+ \\
& +\int_{A}\left(\int_{0}^{L} t_{x y} \delta\left(y \cdot \frac{\partial^{2} v}{\partial x^{2}} \cdot \frac{\partial v}{\partial x}-\frac{\partial v}{\partial x} \cdot \frac{\partial u}{\partial x}\right) d x\right) d A
\end{aligned}
$$

É importante observar que é usual desconsiderar os termos de segunda ordem, conforme em McGuire et al. (2000), obtendo-se a a relação (4.31).

$$
\left.\eta_{x x}=\frac{1}{2}\left(\frac{\partial u^{2}}{\partial x}+\frac{\partial v^{2}}{\partial x}\right)\right\} \rightarrow \delta U_{N L}=\int_{A}\left(\int_{0}^{L} t_{x x} \delta\left(\frac{1}{2}\left(\left(\frac{\partial u}{\partial x}\right)^{2}+\left(\frac{\partial v}{\partial x}\right)^{2}\right)\right) d x\right) d A
$$

Entretanto, neste trabalho, estes termos serão considerados. Assim, expandindo-se a equação (4.30), chega-se a relação (4.32), que pode ser escrita como em (4.33).

$$
\begin{aligned}
\delta U_{N L}= & \frac{1}{2} \int_{A}\left(\int_{0}^{L} t_{x x} \delta\left(\frac{\partial u}{\partial x}\right)^{2} d x\right) d A+\frac{1}{2} \int_{A}\left(\int_{0}^{L} t_{x x} \delta\left(\frac{\partial v}{\partial x}\right)^{2} d x\right) d A+\frac{1}{2} \int_{A}\left(\int_{0}^{L} t_{x x} \delta y^{2}\left(\frac{\partial^{2} v}{\partial x^{2}}\right)^{2} d x\right) d A- \\
& -\int_{A}\left(\int_{0}^{L} t_{x x} \delta y \frac{\partial^{2} v}{\partial x^{2}} \frac{\partial u}{\partial x} d x\right) d A+\int_{A}\left(\int_{0}^{L} t_{x y} \delta y \frac{\partial^{2} v}{\partial x^{2}} \frac{\partial v}{\partial x} d x\right) d A-\iint_{A}^{L}\left(\int_{0}^{L} t_{x y} \delta \frac{\partial v}{\partial x} \frac{\partial u}{\partial x} d x\right) d A \\
\delta U_{N L}= & \frac{1}{2}\left(\int_{0}^{L} \delta\left(\frac{\partial u}{\partial x}\right)^{2} d x\right) \int_{A} t_{x x} d A+\frac{1}{2}\left(\int_{0}^{L} \delta\left(\frac{\partial v}{\partial x}\right)^{2} d x\right) \int_{A} t_{x x} d A+\frac{1}{2}\left(\int_{0}^{L} \delta\left(\frac{\partial^{2} v}{\partial x^{2}}\right)^{2} d x\right) \int_{A} y^{2} t_{x x} d A- \\
& -\left(\int_{0}^{L} \delta \frac{\partial^{2} v}{\partial x^{2}} \frac{\partial u}{\partial x} d x\right) \int_{A} t_{x x} y d A+\left(\int_{0}^{L} \delta \frac{\partial^{2} v}{\partial x^{2}} \frac{\partial v}{\partial x} d x\right) \int_{A} t_{x y} y d A-\left(\int_{0}^{L} \delta \frac{\partial v}{\partial x} \frac{\partial u}{\partial x} d x\right) \int_{A} t_{x y} d A
\end{aligned}
$$

Aplicando-se as relações apresentadas em (4.34), pode-se reescrever a equação anterior conforme (4.35) e (4.36). 


$$
\begin{gathered}
\int_{A} t_{x x} d A=P ; \quad \int_{A} t_{x x} y d A=-M_{z} ; \quad \int_{A} t_{x y} d A=Q_{y} \\
\delta U_{N L}=\frac{1}{2}\left(\int_{0}^{L} \delta\left(\frac{\partial u}{\partial x}\right)^{2} d x\right) P+\frac{1}{2}\left(\int_{0}^{L} \delta\left(\frac{\partial v}{\partial x}\right)^{2} d x\right) P+\frac{1}{2}\left(\int_{0}^{L} \delta\left(\frac{\partial^{2} v}{\partial x^{2}}\right)^{2} d x\right) P \frac{I_{z}}{A}+ \\
+\left(\int_{0}^{L} \delta \frac{\partial^{2} v}{\partial x^{2}} \frac{\partial u}{\partial x} d x\right) M_{z}-\left(\int_{0}^{L} \delta \frac{\partial v}{\partial x} \frac{\partial u}{\partial x} d x\right) Q_{y} \\
\delta U_{N L}=\frac{1}{2} \int_{0}^{L}\left[P \delta\left(\left(\frac{\partial u}{\partial x}\right)^{2}+\left(\frac{\partial v}{\partial x}\right)^{2}\right)+P \frac{I_{z}}{A} \delta\left(\left(\frac{\partial^{2} v}{\partial x^{2}}\right)^{2}\right)\right] d x+ \\
+\int_{0}^{L}\left[M_{z} \delta\left(\frac{\partial^{2} v}{\partial x^{2}} \frac{\partial u}{\partial x}\right)-Q_{y} \delta\left(\frac{\partial v}{\partial x} \frac{\partial u}{\partial x}\right)\right] d x
\end{gathered}
$$

Novamente, de acordo com as equações de interpolação (3.1), (3.2) e (3.3), a equação (4.36) dos trabalhos virtuais pode ser escrita, utilizando-se as funções de forma e os deslocamentos nodais, conforme expressão (4.37).

$$
\begin{aligned}
\delta U_{N L} & =\{\delta u\}^{T} \int_{0}^{L} P\left\{N_{u}{ }^{\prime}\right\}\left\{N_{u}{ }^{\prime}\right\}^{T} d x\{u\}+\{\delta v\}^{T} \int_{0}^{L} P\left\{N_{v}{ }^{\prime}\right\}\left\{N_{v}{ }^{\prime}\right\}^{T} d x\{v\}+ \\
& +\{\delta v\}^{T} \int_{0}^{L} P \frac{I_{z}}{A}\left\{N_{v}{ }^{\prime \prime}\right\}\left\{N_{v}{ }^{\prime \prime}\right\}^{T} d x\{v\}+\{\delta v\}^{T} \int_{0}^{L} M_{z}\left\{N_{v}{ }^{\prime \prime}\right\}\left\{N_{u}{ }^{\prime}\right\}^{T} d x\{u\}+ \\
& +\{\delta u\}^{T} \int_{0}^{L} M_{z}\left\{N_{u}{ }^{\prime}\right\}\left\{N_{v}{ }^{\prime \prime}\right\}^{T} d x\{v\}-\{\delta v\}^{T} \int_{0}^{L} Q_{y}\left\{N_{v}{ }^{\prime}\right\}\left\{N_{u}{ }^{\prime}\right\}^{T} d x\{u\}- \\
& -\{\delta u\}^{T} \int_{0}^{L} Q_{y}\left\{N_{u}{ }^{\prime}\right\}\left\{N_{v}{ }^{\prime}\right\}^{T} d x\{v\}
\end{aligned}
$$

De acordo com a Figura 4.2, considerando uma força cortante constante, o momento fletor e a força cortante podem ser calculados conforme equação (4.38).

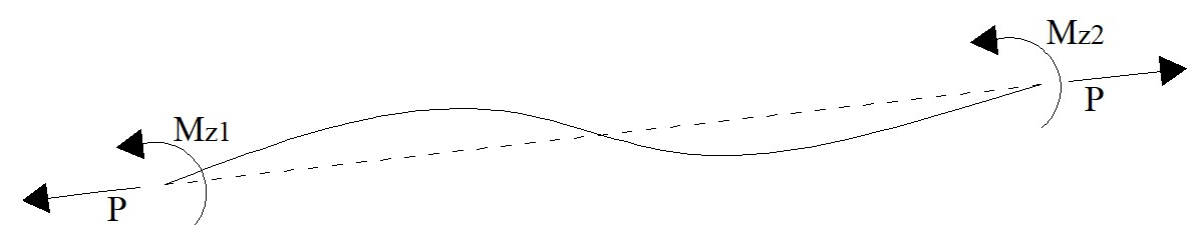

Figura 4.2 - Elemento de viga

Fonte: Adaptado de Pereira (2002).

$$
M_{Z}=-M_{Z 1}+\frac{\left(M_{Z 1}+M_{Z 2}\right) x}{L} \quad Q_{y}=-\frac{\left(M_{Z 1}+M_{Z 2}\right)}{L}
$$


Substituindo-se as funções de forma consideradas e resolvendo-se as integrais do problema, encontra-se a matriz de rigidez geométrica local do elemento, baseada na teoria de flexão de Euler-Bernoulli e termos de ordem elevada do tensor deformação de Green-Lagrange, conforme (4.39).

$$
K_{g, x y}=\left[\begin{array}{cccccc}
\frac{P}{L} & 0 & -\frac{M_{Z 1}}{L} & -\frac{P}{L} & 0 & -\frac{M_{Z 2}}{L} \\
0 & \frac{6 P}{5 L}+\frac{12 P I_{Z}}{A L^{3}} & \frac{P}{10}+\frac{6 P I_{Z}}{A L^{2}} & 0 & -\frac{6 P}{5 L}-\frac{12 P I_{Z}}{A L^{3}} & \frac{P}{10}+\frac{6 P I_{Z}}{A L^{2}} \\
-\frac{M_{z 1}}{L} & \frac{P}{10}+\frac{6 P I_{Z}}{A L^{2}} & \frac{2 L P}{15}+\frac{4 P I_{Z}}{A L} & \frac{M_{Z 1}}{L} & -\frac{P}{10}-\frac{6 P I_{Z}}{A L^{2}} & -\frac{L P}{30}+\frac{2 P I_{Z}}{A L} \\
-\frac{P}{L} & 0 & \frac{M_{Z 1}}{L} & \frac{P}{L} & 0 & \frac{M_{z 2}}{L} \\
0 & -\frac{6 P}{5 L}-\frac{12 P I_{Z}}{A L^{3}} & -\frac{P}{10}-\frac{6 P I_{Z}}{A L^{2}} & 0 & \frac{6 P}{5 L}+\frac{12 P I_{Z}}{A L^{3}} & -\frac{P}{10}-\frac{6 P I_{Z}}{A L^{2}} \\
-\frac{M_{z 2}}{L} & \frac{P}{10}+\frac{6 P I_{Z}}{A L^{2}} & -\frac{L P}{30}+\frac{2 P I_{Z}}{A L} & \frac{M_{z 2}}{L} & -\frac{P}{10}-\frac{6 P I_{Z}}{A L^{2}} & \frac{2 L P}{15}+\frac{4 P I_{Z}}{A L}
\end{array}\right]
$$

É importante notar que, ao se desconsiderar os termos de ordem mais elevada do tensor deformação, como em McGuire et al. (2000), a equação (4.36) se reduziria a expressão (4.40), levando a matriz geométrica usual apresentada em (4.41).

$$
\begin{gathered}
\delta U_{N L}=\frac{1}{2} \int_{0}^{L}\left[P \delta\left(\left(\frac{\partial u}{\partial x}\right)^{2}+\left(\frac{\partial v}{\partial x}\right)^{2}\right)\right] d x \\
K_{g, x y}=\left[\begin{array}{cccccc}
\frac{P}{L} & 0 & 0 & -\frac{P}{L} & 0 & 0 \\
0 & \frac{6 P}{5 L} & \frac{P}{10} & 0 & -\frac{6 P}{5 L} & \frac{P}{10} \\
0 & \frac{P}{10} & \frac{2 L P}{15} & 0 & -\frac{P}{10} & -\frac{L P}{30} \\
-\frac{P}{L} & 0 & 0 & \frac{P}{L} & 0 & 0 \\
0 & -\frac{6 P}{5 L} & -\frac{P}{10} & 0 & \frac{6 P}{5 L} & -\frac{P}{10} \\
0 & \frac{P}{10} & -\frac{L P}{30} & 0 & -\frac{P}{10} & \frac{2 L P}{15}
\end{array}\right]
\end{gathered}
$$




\subsection{3}

Matriz de Rigidez Local de Elemento Espacial (3D)

Realizando apenas uma análise no plano, considerou-se o plano xy, devido ao momento fletor em torno do eixo z. Entretanto, ao se estudar um elemento espacial (3D), Figura 4.3, deve-se levar em consideração o momento fletor em torno do eixo y, em uma análise do plano xz. Além disso, também se deve ter em conta a interação entre a torção e a força axial, como também as rotações finitas.
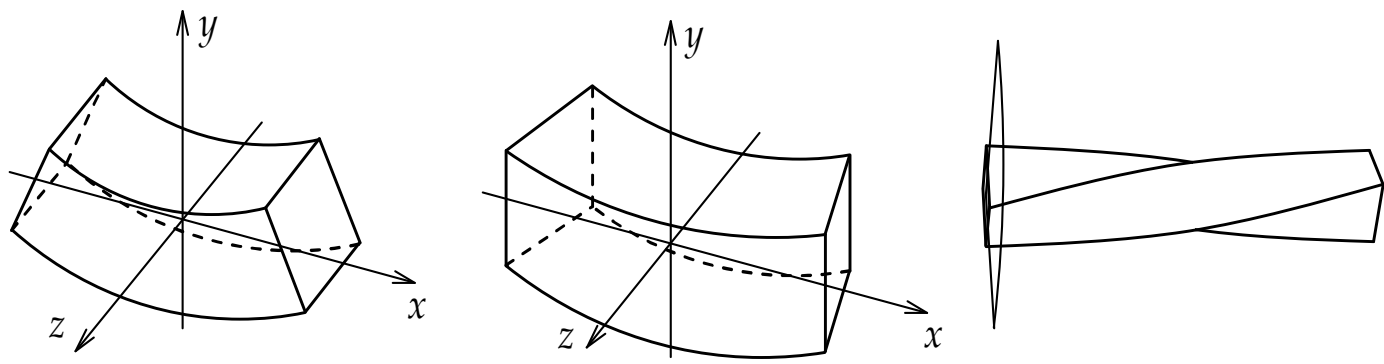

Figura 4.3 - Flexão nos planos principais e torção de uma barra espacial

Fonte: Adaptado de Martha (2018).

Para a montagem da matriz de rigidez local final do elemento, todas essas condições são levadas em consideração, calculando-se a matriz de rigidez correspondente a essas interações e adicionando-se a sua influência na matriz de rigidez local inicial (4.39) do elemento. Dessa forma, um elemento de pórtico espacial pode ser representado como apresentado na Figura 4.4.

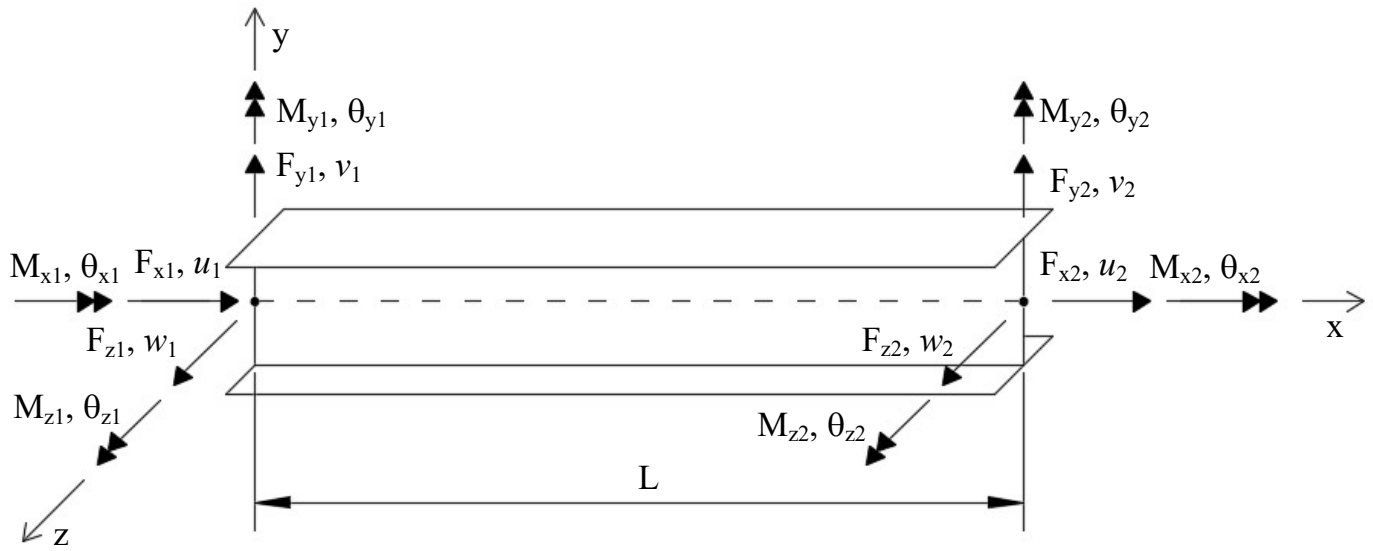

Figura 4.4 - Elemento 3-D

Fonte: Adaptado de McGuire et al. (2000). 


\subsubsection{1}

\section{Matriz de Rigidez Elástica Local no Plano xz}

Para o plano xz trabalhando independentemente, a análise é análoga à realizada no plano xy. Portanto, sendo $w$ o deslocamento na direção z, o tensor deformação de Green-Lagrange pode ser escrito, conforme relações (4.42), (4.43) e (4.44). Pode-se notar que o deslocamento $w$, no plano $\mathrm{xz}$, corresponde ao deslocamento $v$, no plano xy.

$$
\begin{gathered}
\varepsilon_{x x}=\frac{\partial u}{\partial x}=\frac{\partial u_{0}}{\partial x}-z \frac{\partial^{2} w}{\partial x^{2}} \quad \gamma_{x z}=\frac{\partial w}{\partial x}+\frac{\partial u}{\partial y}=\frac{\partial w_{0}}{\partial x}-\frac{\partial w_{0}}{\partial x}=0 \\
\eta_{x x}=\frac{1}{2}\left(\left(\frac{\partial u}{\partial x}\right)^{2}+\left(\frac{\partial w}{\partial x}\right)^{2}\right)=\frac{1}{2}\left(\left(\frac{\partial u}{\partial x}\right)^{2}+\left(\frac{\partial w}{\partial x}\right)^{2}+y^{2}\left(\frac{\partial^{2} w}{\partial x^{2}}\right)^{2}\right)-y \frac{\partial^{2} w}{\partial x^{2}} \frac{\partial u}{\partial x} \\
\eta_{x z}=\frac{\partial u}{\partial x} \frac{\partial u}{\partial y}+\frac{\partial w}{\partial x} \frac{\partial w}{\partial y}=y \frac{\partial^{2} w}{\partial x^{2}} \frac{\partial w}{\partial x}-\frac{\partial w}{\partial x} \frac{\partial u}{\partial x}
\end{gathered}
$$

Assim, com o mesmo desenvolvimento feito para o eixo xy, encontra-se a equação (4.45) para o cálculo da matriz de rigidez elástica.

$$
\delta U=\left(\int_{0}^{L} \frac{\partial u}{\partial x} \delta \frac{\partial u}{\partial x} d x\right) E A+\left(\int_{0}^{L} \frac{\partial^{2} w}{\partial x^{2}} \delta \frac{\partial^{2} w}{\partial x^{2}} d x\right) E I_{y}
$$

A parcela axial já foi utilizada no plano xy, não sendo necessário sobrepor. Assim, a equação se resume a expressão (4.46).

$$
\delta U=\left(\int_{0}^{L} \frac{\partial^{2} w}{\partial x^{2}} \delta \frac{\partial^{2} w}{\partial x^{2}} d x\right) E I_{y}
$$

Empregando-se as mesmas funções de interpolação do plano xy, alterando apenas a nomenclatura, por conveniência, para as funções de forma do deslocamento transversal, obtém-se a expressão (4.47).

$$
N_{w}=\left\{2 \frac{x^{3}}{L^{3}}-3 \frac{x^{2}}{L^{2}}+1 \quad \frac{x^{3}}{L^{2}}-2 \frac{x^{2}}{L}+\mathrm{x} \quad 3 \frac{x^{2}}{L^{2}}-2 \frac{x^{3}}{L^{3}} \quad \frac{x^{3}}{L^{2}}-\frac{x^{2}}{L}\right\}
$$

Os vetores referentes aos deslocamentos nodais podem ser escritos conforme (4.48).

$$
\{u\}=\left\{d_{u 1} \quad d_{u 4}\right\} \quad\{w\}=\left\{\begin{array}{llll}
d_{w 2} & d_{w 3} & d_{w 5} & d_{w 6}
\end{array}\right\}
$$


Dessa forma, a equação dos trabalhos virtuais, pode ser escrita, utilizando-se as funções de forma e os deslocamentos nodais, conforme expressão (4.49).

$$
\delta U=\{\delta w\}^{T} \int_{0}^{L} E I_{y}\left\{N_{w}{ }^{\prime \prime}\right\}\left\{N_{w}{ }^{\prime \prime}\right\}^{T} d x\{w\}
$$

Substituindo-se as funções de forma e resolvendo-se as integrais do problema, encontra-se a já estabelecida matriz de rigidez elástica de um elemento plano (xz), considerando a teoria de flexão de Euler-Bernoulli, equação (4.50).

$$
K_{e, x z}=\left[\begin{array}{cccccc}
0 & 0 & 0 & 0 & 0 & 0 \\
0 & \frac{12 E I_{y}}{L^{3}} & -\frac{6 E I_{y}}{L^{2}} & 0 & -\frac{12 E I_{y}}{L^{3}} & -\frac{6 E I_{y}}{L^{2}} \\
0 & -\frac{6 E I_{y}}{L^{2}} & \frac{4 E I_{y}}{L} & 0 & \frac{6 E I_{y}}{L^{2}} & \frac{2 E I_{y}}{L} \\
0 & 0 & 0 & 0 & 0 & 0 \\
0 & -\frac{12 E I_{y}}{L^{3}} & \frac{6 E I_{y}}{L^{2}} & 0 & \frac{12 E I_{y}}{L^{3}} & \frac{6 E I_{y}}{L^{2}} \\
0 & -\frac{6 E I_{y}}{L^{2}} & \frac{2 E I_{y}}{L} & 0 & \frac{6 E I_{y}}{L^{2}} & \frac{4 E I_{y}}{L}
\end{array}\right]
$$

A matriz geométrica espacial é dada somando-se a influência dos dois planos, obtendo-se a matriz (4.51).

$$
K_{e}=\left[\begin{array}{cccccccccccc}
\frac{E A}{L} & 0 & 0 & 0 & 0 & 0 & -\frac{E A}{L} & 0 & 0 & 0 & 0 & 0 \\
0 & \frac{12 E I_{Z}}{L^{3}} & 0 & 0 & 0 & \frac{6 E I_{z}}{L^{2}} & 0 & -\frac{12 E I_{z}}{L^{3}} & 0 & 0 & 0 & \frac{6 E I_{z}}{L^{2}} \\
0 & 0 & \frac{12 E I_{y}}{L^{3}} & 0 & -\frac{6 E I_{y}}{L^{2}} & 0 & 0 & 0 & -\frac{12 E I_{y}}{L^{3}} & 0 & -\frac{6 E I_{y}}{L^{2}} & 0 \\
0 & 0 & 0 & 0 & 0 & 0 & 0 & 0 & 0 & 0 & 0 & 0 \\
0 & 0 & -\frac{6 E I_{y}}{L^{2}} & 0 & \frac{4 E I_{y}}{L} & 0 & 0 & 0 & \frac{6 E I_{y}}{L^{2}} & 0 & \frac{2 E I_{y}}{L} & 0 \\
0 & \frac{6 E I_{z}}{L^{2}} & 0 & 0 & 0 & \frac{4 E I_{z}}{L} & 0 & -\frac{6 E I_{z}}{L^{2}} & 0 & 0 & 0 & \frac{2 E I_{z}}{L} \\
-\frac{E A}{L} & 0 & 0 & 0 & 0 & 0 & \frac{E A}{L} & 0 & 0 & 0 & 0 & 0 \\
0 & -\frac{12 E I_{z}}{L^{3}} & 0 & 0 & 0 & -\frac{6 E I_{z}}{L^{2}} & 0 & \frac{12 E I_{z}}{L^{3}} & 0 & 0 & 0 & -\frac{6 E I_{z}}{L^{2}} \\
0 & 0 & -\frac{12 E I_{y}}{L^{3}} & 0 & \frac{6 E I_{y}}{L^{2}} & 0 & 0 & 0 & \frac{12 E I_{y}}{L^{3}} & 0 & \frac{6 E I_{y}}{L^{2}} & 0 \\
0 & 0 & 0 & 0 & 0 & 0 & 0 & 0 & 0 & 0 & 0 & 0 \\
0 & 0 & -\frac{6 E I_{y}}{L^{2}} & 0 & \frac{2 E I_{y}}{L} & 0 & 0 & 0 & \frac{6 E I_{y}}{L^{2}} & 0 & \frac{4 E I_{y}}{L} & 0 \\
0 & \frac{6 E I_{z}}{L^{2}} & 0 & 0 & 0 & \frac{2 E I_{z}}{L} & 0 & -\frac{6 E I_{z}}{L^{2}} & 0 & 0 & 0 & \frac{4 E I_{z}}{L}
\end{array}\right]
$$




\subsubsection{2}

\section{Matriz de Rigidez Geométrica Local no Plano xz}

Para o cálculo da matriz de rigidez geométrica do elemento, utilizando-se a parcela não linear do tensor deformação de Green-Lagrange, equações (4.43) e (4.44), de maneira análoga ao plano xy, pode-se escrever a expressão (4.52) e (4.53).

$$
\begin{aligned}
\delta U_{N L} & =\frac{1}{2} \int_{A}\left(\int_{0}^{L} t_{x x} \delta\left(\frac{\partial u}{\partial x}\right)^{2} d x\right) d A+\frac{1}{2} \int_{A}\left(\int_{0}^{L} t_{x x} \delta\left(\frac{\partial w}{\partial x}\right)^{2} d x\right) d A+\frac{1}{2} \int_{A}\left(\int_{0}^{L} t_{x x} \delta z^{2}\left(\frac{\partial^{2} w}{\partial x^{2}}\right)^{2} d x\right) d A- \\
& -\int_{A}^{L}\left(\int_{0}^{L} t_{x x} \delta z \frac{\partial^{2} w}{\partial x^{2}} \frac{\partial u}{\partial x} d x\right) d A+\int_{A}^{L}\left(\int_{0}^{L} t_{x z} \delta z \frac{\partial^{2} w}{\partial x^{2}} \frac{\partial w}{\partial x} d x\right) d A-\int_{A}^{L}\left(\int_{0}^{L} t_{x z} \delta \frac{\partial w}{\partial x} \frac{\partial u}{\partial x} d x\right) d A \\
\delta U_{N L} & =\frac{1}{2}\left(\int_{0}^{L} \delta\left(\frac{\partial u}{\partial x}\right)^{2} d x\right) \int_{A} t_{x x} d A+\frac{1}{2}\left(\int_{0}^{L} \delta\left(\frac{\partial w}{\partial x}\right)^{2} d x\right) \int_{A} t_{x x} d A+\frac{1}{2}\left(\int_{0}^{L} \delta\left(\frac{\partial^{2} w}{\partial x^{2}}\right)^{2} d x\right) \int_{A} z^{2} t_{x x} d A- \\
& -\left(\int_{0}^{L} \delta \frac{\partial^{2} w}{\partial x^{2}} \frac{\partial u}{\partial x} d x\right) \int_{A} t_{x x} z d A+\left(\int_{0}^{L} \delta \frac{\partial^{2} w}{\partial x^{2}} \frac{\partial w}{\partial x} d x\right) \int_{A} t_{x z} z d A-\left(\int_{0}^{L} \delta \frac{\partial w}{\partial x} \frac{\partial u}{\partial x} d x\right) \int_{A} t_{x z} d A
\end{aligned}
$$

Empregando-se as relações mostradas em (4.54), escreve-se (4.55) e (4.56).

$$
\begin{gathered}
\int_{A} t_{x x} d A=P ; \quad \int_{A} t_{x x} z d A=M_{y} ; \quad \int_{A} t_{x z} d A=Q_{z} \\
\delta U_{N L}=\frac{1}{2}\left(\int_{0}^{L} \delta\left(\frac{\partial u}{\partial x}\right)^{2} d x\right) P+\frac{1}{2}\left(\int_{0}^{L} \delta\left(\frac{\partial w}{\partial x}\right)^{2} d x\right) P+\frac{1}{2}\left(\int_{0}^{L} \delta\left(\frac{\partial^{2} w}{\partial x^{2}}\right)^{2} d x\right) P \frac{I_{y}}{A}- \\
-\left(\int_{0}^{L} \delta \frac{\partial^{2} w}{\partial x^{2}} \frac{\partial u}{\partial x} d x\right) M_{y}-\left(\int_{0}^{L} \delta \frac{\partial w}{\partial x} \frac{\partial u}{\partial x} d x\right) Q_{z} \\
\delta U_{N L}=\frac{1}{2} \int_{0}^{L}\left[P \delta\left(\left(\frac{\partial u}{\partial x}\right)^{2}+\left(\frac{\partial w}{\partial x}\right)^{2}\right)+P \frac{I_{y}}{A} \delta\left(\left(\frac{\partial^{2} w}{\partial x^{2}}\right)^{2}\right)\right] d x- \\
-\int_{0}^{L}\left[M_{y} \delta\left(\frac{\partial^{2} w}{\partial x^{2}} \frac{\partial u}{\partial x}\right)+Q_{z} \delta\left(\frac{\partial w}{\partial x} \frac{\partial u}{\partial x}\right)\right] d x
\end{gathered}
$$

Nota-se que a parcela (4.57) já foi utilizada no plano xy. Assim, de acordo com as equações de interpolação (3.1) a (3.3), a equação dos trabalhos virtuais pode ser escrita, utilizando-se as funções de forma e os deslocamentos nodais, conforme expressão (4.58). 


$$
\begin{gathered}
\frac{1}{2} \int_{0}^{L}\left[P \delta\left(\frac{\partial u}{\partial x}\right)^{2}\right] d x \\
\delta U_{N L}=\{\delta w\}^{T} \int_{0}^{L} P\left\{N_{w}{ }^{\prime}\right\}\left\{N_{w}{ }^{\prime}\right\}^{T} d x\{w\}+\{\delta w\}^{T} \int_{0}^{L} P \frac{I_{y}}{A}\left\{N_{w}{ }^{\prime \prime}\right\}\left\{N_{w}{ }^{\prime \prime}\right\}^{T} d x\{w\}- \\
-\{\delta w\}^{T} \int_{0}^{L} M_{y}\left\{N_{w}{ }^{\prime}\right\}\left\{N_{u}{ }^{\prime}\right\}^{T} d x\{u\}-\{\delta u\}^{T} \int_{0}^{L} M_{y}\left\{N_{u}{ }^{\prime}\right\}\left\{N_{w}{ }^{\prime \prime}\right\}^{T} d x\{w\}- \\
-\{\delta w\}^{T} \int_{0}^{L} Q_{z}\left\{N_{w}{ }^{\prime}\right\}\left\{N_{u}{ }^{\prime}\right\}^{T} d x\{u\}-\{\delta u\}^{T} \int_{0}^{L} Q_{z}\left\{N_{u}{ }^{\prime}\right\}\left\{N_{w}{ }^{\prime}\right\}^{T} d x\{w\}
\end{gathered}
$$

Novamente, considerando uma força cortante constante, o momento fletor e a força cortante podem ser calculados, conforme equação (4.59).

$$
M_{y}=-M_{y 1}+\frac{\left(M_{y 1}+M_{y 2}\right) x}{L} \quad Q_{z}=\frac{\left(M_{y 1}+M_{y 2}\right)}{L}
$$

Substituindo-se as funções de forma consideradas e resolvendo-se as integrais do problema, encontra-se a matriz de rigidez geométrica local do elemento, tendo em conta o plano xz, teoria de flexão de Euler-Bernoulli e termos de ordem elevada do tensor deformação de Green-Lagrange, conforme (4.60).

$$
K_{g, x z}=\left[\begin{array}{cccccc}
0 & 0 & -\frac{M_{y 1}}{L} & 0 & 0 & -\frac{M_{y 2}}{L} \\
0 & \frac{6 P}{5 L}+\frac{12 P I_{y}}{A L^{3}} & -\frac{P}{10}-\frac{6 P I_{y}}{A L^{2}} & 0 & -\frac{6 P}{5 L}-\frac{12 P I_{y}}{A L^{3}} & -\frac{P}{10}-\frac{6 P I_{y}}{A L^{2}} \\
-\frac{M_{y 1}}{L} & -\frac{P}{10}-\frac{6 P I_{y}}{A L^{2}} & \frac{2 L P}{15}+\frac{4 P I_{y}}{A L} & \frac{M_{y 1}}{L} & \frac{P}{10}+\frac{6 P I_{y}}{A L^{2}} & -\frac{L P}{30}+\frac{2 P I_{y}}{A L} \\
0 & 0 & \frac{M_{y 1}}{L} & 0 & 0 & \frac{M_{y 2}}{L} \\
0 & -\frac{6 P}{5 L}-\frac{12 P I_{y}}{A L^{3}} & \frac{P}{10}+\frac{6 P I_{y}}{A L^{2}} & 0 & \frac{6 P}{5 L}+\frac{12 P I_{y}}{A L^{3}} & \frac{P}{10}+\frac{6 P I_{y}}{A L^{2}} \\
-\frac{M_{y 2}}{L} & -\frac{P}{10}-\frac{6 P I_{y}}{A L^{2}} & -\frac{L P}{30}+\frac{2 P I_{y}}{A L} & \frac{M_{y 2}}{L} & \frac{P}{10}+\frac{6 P I_{y}}{A L^{2}} & \frac{2 L P}{15}+\frac{4 P I_{y}}{A L}
\end{array}\right]
$$

A matriz geométrica espacial é dada, somando-se a influência dos dois planos, obtendo-se a matriz apresentada no apêndice B.1 


\subsubsection{3}

\section{Torção Pura}

Matematicamente, um elemento submetido à torção pura é idêntico ao problema de um elemento submetido à carga axial, podendo-se então escrever a equação (4.61).

$$
\delta U=\left(\int_{0}^{L} \frac{\partial \theta_{x}}{\partial x} \delta \frac{\partial \theta_{x}}{\partial x} d x\right) G I_{x}
$$

Em que $I_{x}$ é a constante de torção referente à seção transversal e $G$ é o módulo de rigidez ao cisalhamento transversal.

Conforme especificado no capítulo 3, equação (3.103), as funções de forma para o deslocamento axial, como também a rotação em torno do eixo x (torção), são funções lineares, equação (4.62). Assim, a equação (4.61) pode ser escrita utilizando-se essas funções, de acordo com (4.63).

$$
\begin{gathered}
N_{\theta x}=N_{u}=\left\{N_{1}(x) \quad N_{4}(x)\right\}=\left\{1-\frac{x}{L} \quad \frac{x}{L}\right\} \\
\delta U=\left\{\delta \theta_{x}\right\}^{T} \int_{0}^{L} G I_{x}\left\{N_{\theta x}{ }^{\prime}\right\}\left\{N_{\theta x}\right\}^{T} d x\left\{\theta_{x}\right\}
\end{gathered}
$$

Substituindo-se as funções de forma e resolvendo-se as integrais do problema, encontra-se a influência da torção pura, conforme matriz (4.64).

$$
K_{\theta x}=\left[\begin{array}{cc}
\frac{G I_{x}}{L} & -\frac{G I_{x}}{L} \\
-\frac{G I_{x}}{L} & \frac{G I_{x}}{L}
\end{array}\right]
$$

Assim, a matriz de rigidez elástica final de um elemento espacial é dada conforme (4.65). 


$$
K_{e}=\left[\begin{array}{cccccccccccc}
\frac{E A}{L} & 0 & 0 & 0 & 0 & 0 & -\frac{E A}{L} & 0 & 0 & 0 & 0 & 0 \\
0 & \frac{12 E I_{Z}}{L^{3}} & 0 & 0 & 0 & \frac{6 E I_{Z}}{L^{2}} & 0 & -\frac{12 E I_{Z}}{L^{3}} & 0 & 0 & 0 & \frac{6 E I_{Z}}{L^{2}} \\
0 & 0 & \frac{12 E I_{y}}{L^{3}} & 0 & -\frac{6 E I_{y}}{L^{2}} & 0 & 0 & 0 & -\frac{12 E I_{y}}{L^{3}} & 0 & -\frac{6 E I_{y}}{L^{2}} & 0 \\
0 & 0 & 0 & \frac{G I_{x}}{L} & 0 & 0 & 0 & 0 & 0 & -\frac{G I_{x}}{L} & 0 & 0 \\
0 & 0 & -\frac{6 E I_{y}}{L^{2}} & 0 & \frac{4 E I_{y}}{L} & 0 & 0 & 0 & \frac{6 E I_{y}}{L^{2}} & 0 & \frac{2 E I_{y}}{L} & 0 \\
0 & \frac{6 E I_{Z}}{L^{2}} & 0 & 0 & 0 & \frac{4 E I_{Z}}{L} & 0 & -\frac{6 E I_{Z}}{L^{2}} & 0 & 0 & 0 & \frac{2 E I_{Z}}{L} \\
-\frac{E A}{L} & 0 & 0 & 0 & 0 & 0 & \frac{E A}{L} & 0 & 0 & 0 & 0 & 0 \\
0 & -\frac{12 E I_{Z}}{L^{3}} & 0 & 0 & 0 & -\frac{6 E I_{Z}}{L^{2}} & 0 & \frac{12 E I_{Z}}{L^{3}} & 0 & 0 & 0 & -\frac{6 E I_{Z}}{L^{2}} \\
0 & 0 & -\frac{12 E I_{y}}{L^{3}} & 0 & \frac{6 E I_{y}}{L^{2}} & 0 & 0 & 0 & \frac{12 E I_{y}}{L^{3}} & 0 & \frac{6 E I_{y}}{L^{2}} & 0 \\
0 & 0 & 0 & -\frac{G I_{x}}{L} & 0 & 0 & 0 & 0 & 0 & \frac{G I_{x}}{L} & 0 & 0 \\
0 & 0 & -\frac{6 E I_{y}}{L^{2}} & 0 & \frac{2 E I_{y}}{L} & 0 & 0 & 0 & \frac{6 E I_{y}}{L^{2}} & 0 & \frac{4 E I_{y}}{L} & 0 \\
0 & \frac{6 E I_{Z}}{L^{2}} & 0 & 0 & 0 & \frac{2 E I_{Z}}{L} & 0 & -\frac{6 E I_{Z}}{L^{2}} & 0 & 0 & 0 & \frac{4 E I_{Z}}{L}
\end{array}\right]
$$

\subsubsection{4}

\section{Interação entre Torção e Carga Axial}

Anteriormente, o elemento foi analisado considerando seu comportamento com os planos trabalhando independentemente. Entretanto, a torção e outras interações de esforços podem ter uma importante influência no comportamento do elemento estrutural (McGuire et al. 2000).

A torção e a carga axial possuem um importante papel na matriz de rigidez geométrica. A Figura 4.5 ilustra um elemento submetido à torção e a um carregamento axial.

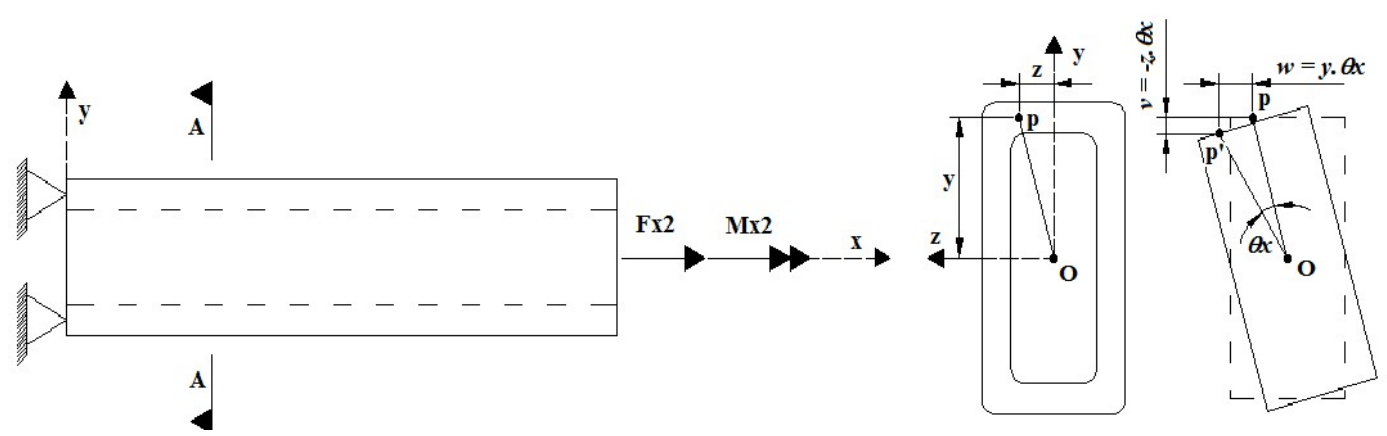

Figura 4.5 - Interação entre torção e carga axial

Fonte: McGuire et al. (2000). 
Ao ocorrer a rotação da seção transversal em torno do eixo $\mathrm{x}$, os deslocamentos transversais, $v$ e $w$, precisam levar em consideração esse efeito. Assim, analisando a Figura 4.5, pode-se escrever o campo de deslocamentos, conforme equação (4.66).

$$
u=u_{0}-z \frac{\partial w}{\partial x}-y \frac{\partial v}{\partial x} \quad v=v_{0}-z \theta_{x} \quad w=w_{0}+y \theta_{x}
$$

Dessa forma, a parcela não linear do tensor deformação de Green-Lagrange pode ser escrita de acordo com a expressão (4.67).

$$
\begin{gathered}
\eta_{x x}=\frac{1}{2}\left(\left(\frac{\partial u}{\partial x}\right)^{2}+\left(\frac{\partial v}{\partial x}\right)^{2}+\left(\frac{\partial w}{\partial x}\right)^{2}\right) \\
\rightarrow \eta_{x x}=\frac{1}{2}\left[\left(\frac{\partial u}{\partial x}-z \frac{\partial^{2} w}{\partial x^{2}}-y \frac{\partial^{2} v}{\partial x^{2}}\right)^{2}+\left(\frac{\partial v}{\partial x}-z \frac{\partial \theta_{x}}{\partial x}\right)^{2}+\left(\frac{\partial w}{\partial x}+y \frac{\partial \theta_{x}}{\partial x}\right)^{2}\right]
\end{gathered}
$$

Entretanto, alguns termos da equação (4.67) já foram utilizados ao se analisar os planos independentemente. Os termos correspondem ao deslocamento axial, que já foram todos considerados, e ao deslocamento transversal. Faltou considerar apenas os termos que correspondem à rotação em torno do eixo $\mathrm{x}$. Conforme mostrado na expressão (4.68), restando apenas no tensor deformação de Green-Lagrange o apresentado na equação (4.69).

$$
\begin{gathered}
v=-z \theta_{x} \quad w=y \theta_{x} \\
\eta_{x x}=\frac{1}{2}\left(z\left(\frac{\partial \theta_{x}}{\partial x}\right)^{2}+y\left(\frac{\partial \theta_{x}}{\partial x}\right)^{2}\right)-z \frac{\partial v}{\partial x} \frac{\partial \theta_{x}}{\partial x}+y \frac{\partial w}{\partial x} \frac{\partial \theta_{x}}{\partial x} \\
\rightarrow \eta_{x x}=\frac{1}{2}\left(z^{2}+y^{2}\right)\left(\left(\frac{\partial \theta_{x}}{\partial x}\right)^{2}\right)-z \frac{\partial v}{\partial x} \frac{\partial \theta_{x}}{\partial x}+y \frac{\partial w}{\partial x} \frac{\partial \theta_{x}}{\partial x}
\end{gathered}
$$

Assim, a equação dos trabalhos virtuais pode ser aplicada, conforme a equação (4.70).

$$
\begin{aligned}
& \delta U_{N L}=\int_{A}\left(\int_{0}^{L} t_{x x} \delta \eta_{x x} d x\right) d A \\
& \delta U_{N L}=\int_{A}\left(\int_{0}^{L} t_{x x} \delta\left[\frac{1}{2}\left(z^{2}+y^{2}\right)\left(\left(\frac{\partial \theta_{x}}{\partial x}\right)^{2}\right)-z \frac{\partial v}{\partial x} \frac{\partial \theta_{x}}{\partial x}+y \frac{\partial w}{\partial x} \frac{\partial \theta_{x}}{\partial x}\right] d x\right) d A
\end{aligned}
$$




$$
\begin{aligned}
\delta U_{N L}= & \frac{1}{2}\left(\int_{0}^{L} \delta\left(\frac{\partial \theta_{x}}{\partial x}\right)^{2} d x\right) \int_{A} t_{x x}\left(z^{2}+y^{2}\right) d A-\left(\int_{0}^{L} \delta \frac{\partial v}{\partial x} \frac{\partial \theta_{x}}{\partial x} d x\right) \int_{A} t_{x x} z d A \\
& +\left(\int_{0}^{L} \delta \frac{\partial w}{\partial x} \frac{\partial \theta_{x}}{\partial x} d x\right) \int_{A} t_{x x} y d A
\end{aligned}
$$

Utilizando-se as propriedades anteriores, e o momento polar de inércia $\int_{A}\left(z^{2}+y^{2}\right) d A=J_{p}$, a equação anterior pode ser escrita como (4.71).

$$
\delta U_{N L}=\frac{1}{2} \frac{P J_{p}}{A} \int_{0}^{L} \delta\left(\frac{\partial \theta_{x}}{\partial x}\right)^{2} d x-M_{y} \int_{0}^{L} \delta\left(\frac{\partial v}{\partial x} \frac{\partial \theta_{x}}{\partial x}\right) d x+\left(-M_{z}\right) \int_{0}^{L} \delta\left(\frac{\partial w}{\partial x} \frac{\partial \theta_{x}}{\partial x}\right) d x
$$

Adotando a interpolação linear para o deslocamento $\theta_{x}$, equação (4.72), o principio dos trabalhos virtuais pode ser escrito, empregando-se as funções de forma conforme (4.73).

$$
\begin{aligned}
\theta_{x}(x)=\left\{N_{\theta x}(x)\right\}\left\{\theta_{x}\right\} \quad\left\{\theta_{\mathrm{x}}\right\}=\left\{\theta_{\mathrm{x} 1} \quad \theta_{\mathrm{x} 4}\right\} \quad \mathrm{N}_{\theta \mathrm{x}}=\left\{1-\frac{\mathrm{x}}{\mathrm{L}} \frac{\mathrm{x}}{\mathrm{L}}\right\} \\
\delta U_{N L}=\left\{\delta \theta_{x}\right\}^{T} \int_{0}^{L} \frac{P J_{p}}{A}\left\{N_{\theta x}{ }^{\prime}\right\}\left\{N_{\theta x}{ }^{\prime}\right\}^{T} d x\left\{\theta_{x}\right\}-\{\delta v\}^{T} \int_{0}^{L} M_{y}\left\{N_{v}{ }^{\prime}\right\}\left\{N_{\theta x}\right\}^{T} d x\left\{\theta_{x}\right\}- \\
-\left\{\delta \theta_{x}\right\}^{T} \int_{0}^{L} M_{y}\left\{N_{\theta x}{ }^{\prime}\right\}\left\{N_{v}\right\}^{\prime T} d x\{v\}-\{\delta w\}^{T} \int_{0}^{L} M_{z}\left\{N_{w}{ }^{\prime}\right\}\left\{N_{\theta x}{ }^{\prime}\right\}^{T} d x\left\{\theta_{x}\right\}- \\
\left.-\left\{\delta \theta_{x}\right\}^{T} \int_{0}^{L} M_{z}\left\{N_{\theta x}{ }^{\prime}\right\}\left\{N_{w}\right\}^{\prime}\right\}^{T} d x\{w\}
\end{aligned}
$$

Substituindo-se as funções de forma e resolvendo-se as integrais, obtém-se a influência na matriz de rigidez geométrica da interação entre torção e carga axial, empregando-se a parcela não linear da deformação axial do tensor deformação.

Entretanto, também se deve considerar a parcela não linear da deformação por cisalhamento do tensor deformação, conforme as equações (4.74) e (4.75).

$$
\begin{aligned}
& \eta_{x y}=\frac{\partial u}{\partial x} \frac{\partial u}{\partial y}+\frac{\partial v}{\partial x} \frac{\partial v}{\partial y}+\frac{\partial w}{\partial x} \frac{\partial w}{\partial y}=-\frac{\partial u}{\partial x} \frac{\partial v}{\partial x}+z \frac{\partial^{2} w}{\partial x^{2}} \frac{\partial v}{\partial x}+y \frac{\partial^{2} v}{\partial x^{2}} \frac{\partial v}{\partial x}+\frac{\partial w}{\partial x} \theta_{x}+y \frac{\partial \theta_{x}}{\partial x} \theta_{x} \\
& \eta_{x z}=\frac{\partial u}{\partial x} \frac{\partial u}{\partial z}+\frac{\partial v}{\partial x} \frac{\partial v}{\partial z}+\frac{\partial w}{\partial x} \frac{\partial w}{\partial z}=-\frac{\partial u}{\partial x} \frac{\partial w}{\partial x}+z \frac{\partial^{2} w}{\partial x^{2}} \frac{\partial w}{\partial x}+y \frac{\partial^{2} v}{\partial x^{2}} \frac{\partial w}{\partial x}-\frac{\partial v}{\partial x} \theta_{x}+z \frac{\partial \theta_{x}}{\partial x} \theta_{x}
\end{aligned}
$$

Mais uma vez, alguns componentes já foram utilizados no desenvolvimento dos planos trabalhando independentemente, restando apenas os fatores apresentados em (4.76) e (4.77) para serem considerados. 


$$
\begin{gathered}
\eta_{x y}=z \frac{\partial^{2} w}{\partial x^{2}} \frac{\partial v}{\partial x}+\frac{\partial w}{\partial x} \theta_{x}+y \frac{\partial \theta_{x}}{\partial x} \theta_{x} \\
\eta_{x z}=y \frac{\partial^{2} v}{\partial x^{2}} \frac{\partial w}{\partial x}-\frac{\partial v}{\partial x} \theta_{x}+z \frac{\partial \theta_{x}}{\partial x} \theta_{x}
\end{gathered}
$$

Dessa maneira, o príncipio dos trabalhos virtuais pode ser aplicado novamente, obtendo-se a expressão apresentada em (4.78).

$$
\begin{aligned}
\delta U_{N L}=\int_{A}\left(\int_{0}^{L} t_{x y} \delta \eta_{x y} d x\right) d A+\iint_{A}\left(\int_{0}^{L} t_{x z} \delta \eta_{x z} d x\right) d A \\
\delta U_{N L}=\left(\int_{0}^{L} \delta\left(\frac{\partial^{2} w}{\partial x^{2}} \frac{\partial v}{\partial x}\right) d x\right) \int_{A} t_{x y} z d A+\left(\int_{0}^{L} \delta\left(\frac{\partial w}{\partial x} \theta_{x}\right) d x\right) \int_{A} t_{x y} d A+ \\
+\left(\int_{0}^{L} \delta\left(\frac{\partial \theta_{x}}{\partial x} \theta_{x}\right) d x\right) \int_{A} t_{x y} y d A+\left(\int_{0}^{L} \delta\left(\frac{\partial^{2} v}{\partial x^{2}} \frac{\partial w}{\partial x}\right) d x\right) \int_{A} t_{x z} y d A- \\
-\left(\int_{0}^{L} \delta\left(\frac{\partial v}{\partial x} \theta_{x}\right) d x\right) \int_{A} t_{x z} d A+\left(\int_{0}^{L} \delta\left(\frac{\partial \theta_{x}}{\partial x} \theta_{x}\right) d x\right) \int_{A} t_{x z} z d A
\end{aligned}
$$

Para seções bissimétricas, a força cortante e o momento torçor são definidos conforme as expressões apresentadas em (4.79). Desconsiderando a parcela $\left(\partial \theta_{x} / \partial x\right) \theta_{x}$, pode-se reescrever a equação anterior, de acordo com (4.80).

$$
\begin{aligned}
\int_{A} t_{x y} d A=Q_{y} ; \quad \int_{A} t_{x z} d A=Q_{z} ; \quad \int_{A} t_{x z} y d A=\alpha M_{x} ; \quad \int_{A} t_{x y} z d A=(\alpha-1) M_{x} \\
\delta U_{N L}=\left(\int_{0}^{L} \delta \frac{\partial^{2} w}{\partial x^{2}} \frac{\partial v}{\partial x} d x\right)(\alpha-1) M_{x}+\left(\int_{0}^{L} \delta\left(\frac{\partial w}{\partial x} \theta_{x}\right) d x\right) Q_{y}+ \\
+\left(\int_{0}^{L} \delta\left(\frac{\partial^{2} v}{\partial x^{2}} \frac{\partial w}{\partial x}\right) d x\right) \alpha M_{x}-\left(\int_{0}^{L} \delta\left(\frac{\partial v}{\partial x} \theta_{x}\right) d x\right) Q_{z}
\end{aligned}
$$

Considerando que a seção é limitada à torção pura de Saint Venant, pode ser utilizado $M_{x}=M_{x 2}$ e $\alpha=1 / 2$ (parcela do momento torçor total). Assim, escrevendo os deslocamentos com as funções de interpolação, obtém-se a equação (4.81). 


$$
\begin{aligned}
\delta U_{N L} & =-\{\delta w\}^{T} \int_{0}^{L} \frac{M_{x}}{2}\left\{N_{w}{ }^{\prime \prime}\right\}\left\{N_{v}{ }^{\prime}\right\}^{T} d x\{v\}-\{\delta v\}^{T} \int_{0}^{L} \frac{M_{x}}{2}\left\{N_{v}{ }^{\prime}\right\}\left\{N_{w}{ }^{\prime \prime}\right\}^{T} d x\{w\}+ \\
& +\{\delta v\}^{T} \int_{0}^{L} \frac{M_{x}}{2}\left\{N_{v}{ }^{\prime}\right\}\left\{N_{w}{ }^{\prime}\right\}^{T} d x\{w\}+\{\delta w\}^{T} \int_{0}^{L} \frac{M_{x}}{2}\left\{N_{w}{ }^{\prime}\right\}\left\{N_{v}{ }^{\prime \prime}\right\}^{T} d x\{v\}+ \\
& +\{\delta w\}^{T} \int_{0}^{L} Q_{y}\left\{N_{w}{ }^{\prime}\right\}\left\{N_{\theta x}\right\}^{T} d x\left\{\theta_{x}\right\}+\left\{\delta \theta_{x}\right\}^{T} \int_{0}^{L} Q_{y}\left\{N_{\theta x}\right\}\left\{N_{w}{ }^{\prime}\right\}^{T} d x\{w\}- \\
& -\{\delta v\}^{T} \int_{0}^{L} Q_{z}\left\{N_{v}{ }^{\prime}\right\}\left\{N_{\theta x}\right\}^{T} d x\left\{\theta_{x}\right\}-\left\{\delta \theta_{x}\right\}^{T} \int_{0}^{L} Q_{z}\left\{N_{\theta x}\right\}\left\{N_{v}{ }^{\prime}\right\}^{T} d x\{v\}
\end{aligned}
$$

Resolvendo-se as integrais, obtém-se a contribuição da interação entre torção e carga axial na matriz geométrica espacial. Essa contribuição é apresentada no apêndice B.2.

\subsubsection{5}

\section{Rotações Finitas}

A matriz de rigidez geométrica de um elemento deve incluir os efeitos das rotações finitas. McGuire et al. (2000) explica essa influência com a Figura 4.6. Quando uma carga é aplicada ao elemento "bc", o equilíbrio no ponto "b" é garantido pelo momento que surge na barra "bc", devido à carga aplicada, e pelo torçor que ocorre no elemento "ab".
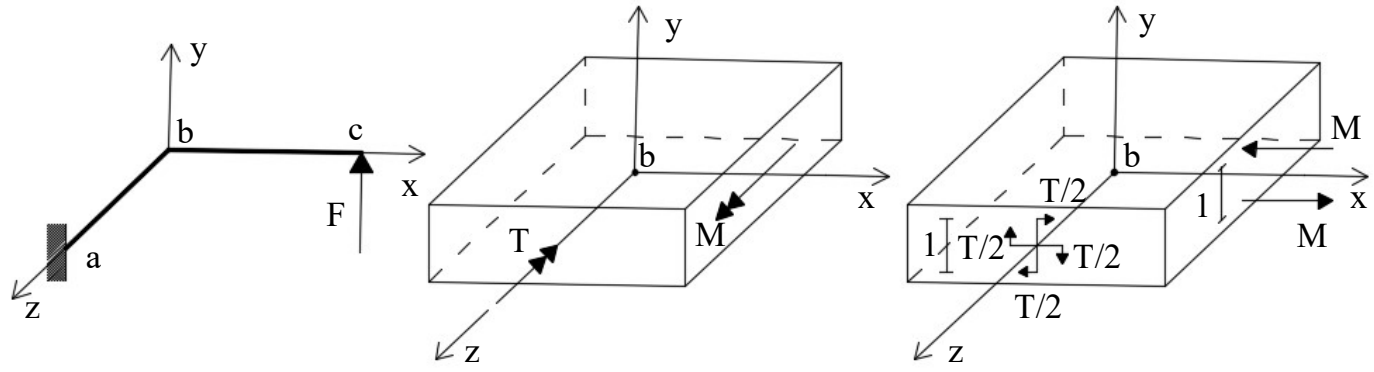

Figura 4.6 - Equilíbrio de nó

Fonte: Adaptado de McGuire et al. (2000).

Entretanto, McGuire et al. (2000) explica que se o nó "b" está sujeito a uma pequena rotação de corpo rígido, em torno do eixo $\mathrm{x}, \theta_{x}$, o equilíbrio será desfeito. Isso ocorre porque o incremento de momento em torno do eixo y, gerado pelo momento fletor, será duas vezes maior que o incremento de torção, de acordo com a Figura 4.7 e equação (4.82). 

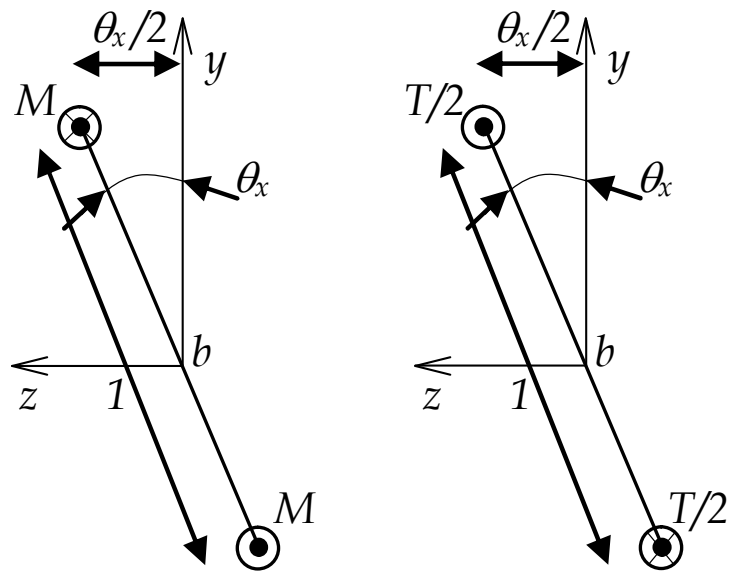

Figura 4.7 - Incremento de momento

Fonte: Adaptado de McGuire et al. (2000).

$$
M_{y}=-M \theta_{x} \quad M_{y}=\frac{T \theta_{x}}{2}
$$

Para a rotação de um vetor espacial, Figura 4.8, a equação (4.83) é utilizada. Essa é uma maneira alternativa de escrever a equação original de rotação de um vetor, desenvolvida por Euler.

$$
V_{1}=R(\theta) V_{0}
$$

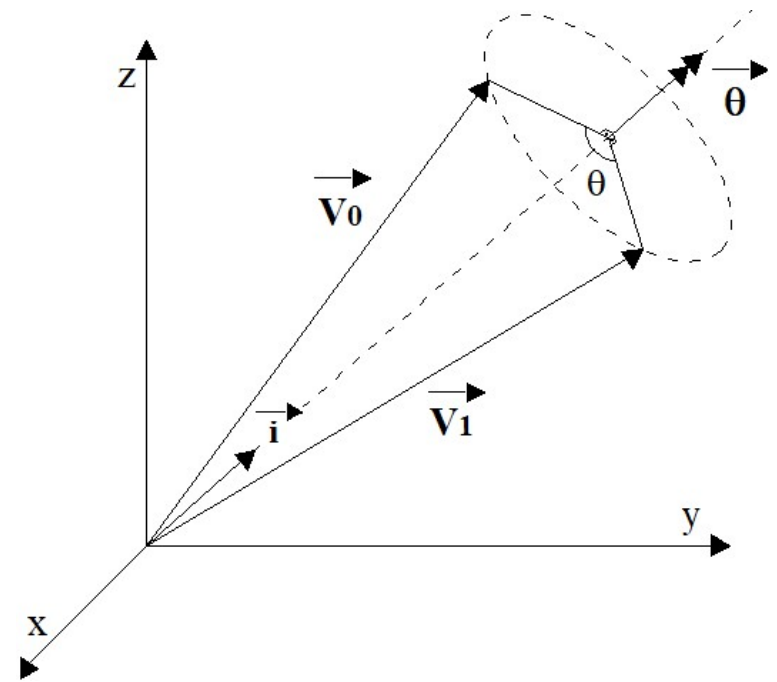

Figura 4.8 - Transformação espacial entre dois vetores

Fonte: Adaptado de Aguiar et al. (2014)

A matriz de transformação espacial ortogonal é expressa pela equação (4.84), 


$$
\boldsymbol{R}=\boldsymbol{I}+\frac{\operatorname{sen}(\theta)}{\theta} \boldsymbol{W}(\boldsymbol{\theta})+\frac{1-\cos (\theta)}{\theta^{2}} \boldsymbol{W}(\boldsymbol{\theta})^{2}
$$

em que $\boldsymbol{I}$ é a matriz identidade, $\boldsymbol{W}(\boldsymbol{\theta})$ e $\boldsymbol{\theta}$ são definidos como funções das componentes $\theta_{x}, \theta_{y}$ e $\theta_{z}$, conforme (4.85).

$$
W(\theta)=\left[\begin{array}{ccc}
0 & -\theta_{z} & \theta_{y} \\
\theta_{z} & 0 & -\theta_{x} \\
-\theta_{y} & \theta_{x} & 0
\end{array}\right], \theta=\left\{\begin{array}{l}
\theta_{x} \\
\theta_{y} \\
\theta_{z}
\end{array}\right\}
$$

O seno e cosseno do ângulo podem ser aproximados por uma série trigonométrica, de acordo com a equação (4.86).

$$
\operatorname{sen}(\theta)=\theta-\frac{\theta^{3}}{3 !}+\frac{\theta^{5}}{5 !}-\frac{\theta^{7}}{7 !}+\cdots \quad \cos (\theta)=1-\frac{\theta^{2}}{2 !}+\frac{\theta^{4}}{4 !}-\frac{\theta^{6}}{6 !}+\cdots
$$

Assim, a matriz de rotação pode ser escrita, levando-se em consideração apenas termos até a segunda ordem, de acordo com a expressão (4.87).

$$
\begin{gathered}
R(\theta)=\left[\begin{array}{ccc}
1 & 0 & 0 \\
0 & 1 & 0 \\
0 & 0 & 1
\end{array}\right]+\left[\begin{array}{ccc}
0 & -\theta_{z} & \theta_{y} \\
\theta_{z} & 0 & -\theta_{x} \\
-\theta_{y} & \theta_{x} & 0
\end{array}\right]+\left[\begin{array}{ccc}
-\frac{\theta_{y}{ }^{2}+\theta_{z}{ }^{2}}{2} & \frac{\theta_{x} \theta_{y}}{2} & \frac{\theta_{x} \theta_{z}}{2} \\
\frac{\theta_{x} \theta_{y}}{2} & -\frac{\theta_{x}{ }^{2}+\theta_{z}{ }^{2}}{2} & \frac{\theta_{y} \theta_{z}}{2} \\
\frac{\theta_{x} \theta_{z}}{2} & \frac{\theta_{y} \theta_{z}}{2} & -\frac{\theta_{x}{ }^{2}+\theta_{y}{ }^{2}}{2}
\end{array}\right] \\
\boldsymbol{R}(\boldsymbol{\theta})=\boldsymbol{I}+\boldsymbol{W}(\boldsymbol{\theta})+\frac{1}{2} \boldsymbol{W}(\boldsymbol{\theta})^{2}
\end{gathered}
$$

Considerando rotação finita para seções transversais bissimétricas, na Figura 4.9, o vetor posição de um ponto, $\{\boldsymbol{a}\}$, e após a rotação, $\{\boldsymbol{b}\}$, pode ser escrito conforme equação (4.88).

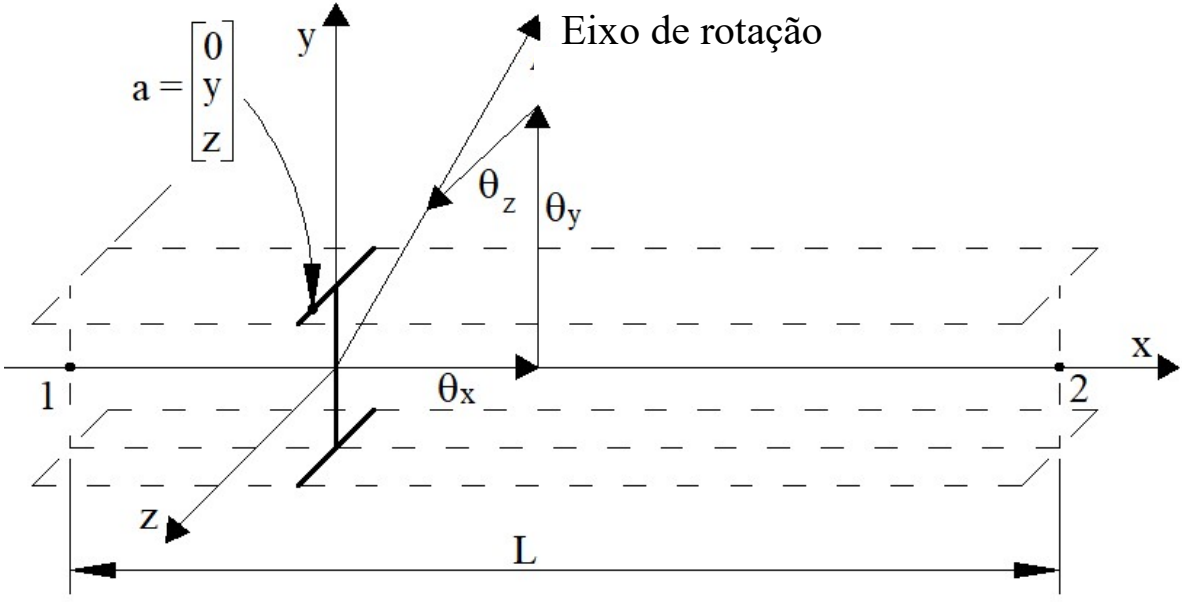

Figura 4.9 - Rotação finita de uma seção transversal Fonte: Adaptado de McGuire et al. (2000). 


$$
\{\boldsymbol{b}\}=\left[\boldsymbol{I}+\boldsymbol{W}(\boldsymbol{\theta})+\frac{1}{2} \boldsymbol{W}(\boldsymbol{\theta})^{2}\right]\{\boldsymbol{a}\}
$$

O deslocamento pode ser escrito como: $\{\boldsymbol{b}\}-\{\boldsymbol{a}\}$ ou $\{\boldsymbol{u}\}$. Entretanto, $\boldsymbol{W}(\boldsymbol{\theta})$ já foi levado em conta nas análises anteriores, ao ser calculado o príncipio dos trabalhos virtuais com $\int_{V} \tau_{i j} \Delta \eta_{i j} d V$. Assim, o deslocamento pode ser escrito em função de $\boldsymbol{W}(\boldsymbol{\theta})^{2}$, conforme expressão (4.89).

$$
\{\boldsymbol{u}\}=\left[\frac{1}{2} \boldsymbol{W}(\boldsymbol{\theta})^{2}\right]\{\boldsymbol{a}\} \Rightarrow\left\{\begin{array}{c}
u \\
v \\
w
\end{array}\right\}=\left[\begin{array}{ccc}
-\frac{\theta_{y}{ }^{2}+\theta_{z}{ }^{2}}{2} & \frac{\theta_{x} \theta_{y}}{2} & \frac{\theta_{x} \theta_{z}}{2} \\
\frac{\theta_{x} \theta_{y}}{2} & -\frac{\theta_{x}{ }^{2}+\theta_{z}{ }^{2}}{2} & \frac{\theta_{y} \theta_{z}}{2} \\
\frac{\theta_{x} \theta_{z}}{2} & \frac{\theta_{y} \theta_{z}}{2} & -\frac{\theta_{x}{ }^{2}+\theta_{y}{ }^{2}}{2}
\end{array}\right]\left\{\begin{array}{l}
0 \\
y \\
z
\end{array}\right\}
$$

Dessa forma, os deslocamentos são dados, conforme o apresentado em (4.90).

$$
u=\frac{\theta_{x} \cdot \theta_{y} \cdot y}{2}+\frac{\theta_{x} \cdot \theta_{z} \cdot \mathrm{z}}{2} \quad v=\frac{\theta_{y} \cdot \theta_{z} \cdot \mathrm{z}}{2}-y\left(\frac{\theta_{x}^{2}}{2}+\frac{\theta_{z}^{2}}{2}\right) \quad w=\frac{\theta_{y} \cdot \theta_{z} \cdot \mathrm{y}}{2}-z\left(\frac{\theta_{x}^{2}}{2}+\frac{\theta_{y}^{2}}{2}\right)
$$

As derivadas dos deslocamentos são dadas, conforme equações (4.91) a (4.93).

$$
\begin{gathered}
\frac{\partial u}{\partial x}=\frac{1}{2}\left(\theta_{x} \frac{\partial \theta_{y}}{\partial x}+\theta_{y} \frac{\partial \theta_{x}}{\partial x}\right) y+\frac{1}{2}\left(\theta_{x} \frac{\partial \theta_{z}}{\partial x}+\theta_{z} \frac{\partial \theta_{x}}{\partial x}\right) z \quad \frac{\partial u}{\partial y}=\frac{\theta_{x} \cdot \theta_{y}}{2} \quad \frac{\partial u}{\partial z}=\frac{\theta_{x} \cdot \theta_{z}}{2} \\
\frac{\partial v}{\partial x}=-\left(\theta_{x} \frac{\partial \theta_{x}}{\partial x}+\theta_{z} \frac{\partial \theta_{z}}{\partial x}\right) y+\frac{1}{2}\left(\theta_{y} \frac{\partial \theta_{z}}{\partial x}+\theta_{z} \frac{\partial \theta_{y}}{\partial x}\right) z \\
\frac{\partial w}{\partial x}=\frac{1}{2}\left(\theta_{y} \frac{\partial \theta_{z}}{\partial x}+\theta_{z} \frac{\partial \theta_{y}}{\partial x}\right) y-\left(\theta_{x} \frac{\partial \theta_{x}}{\partial x}+\theta_{y} \frac{\partial \theta_{y}}{\partial x}\right) z
\end{gathered}
$$

Ao se usar a segunda integral do príncipio dos trabalhos virtuais, equação (4.14), obtém-se a expressão (4.94).

$$
\begin{aligned}
& \int_{V} t_{i j} \Delta e_{i j}=\int_{A}\left(\int_{0}^{L} t_{x x} \delta e_{x x} d x\right) d A+\int_{A}\left(\int_{0}^{L} t_{x y} \delta e_{x y} d x\right) d A+\int_{A}\left(\int_{0}^{L} t_{x z} \delta e_{x z} d x\right) d A= \\
& =\int_{A}\left[\int_{0}^{L} t_{x x} \delta\left(\frac{\partial u}{\partial x}\right) d x\right] d A+\int_{A}^{L}\left[\int_{0}^{L} t_{x y} \delta\left(\frac{\partial v}{\partial x}+\frac{\partial u}{\partial y}\right) d x\right] d A+\int_{A}\left[\int_{0}^{L} t_{x z} \delta\left(\frac{\partial w}{\partial x}+\frac{\partial u}{\partial z}\right) d x\right] d A
\end{aligned}
$$


Substituindo-se os deslocamentos e seus gradientes na equação anterior, obtém-se a relação (4.95).

$$
\begin{aligned}
\int_{V} t_{i j} \Delta e_{i j} & =\int_{A}\left\{\int_{0}^{L} \frac{t_{x x}}{2}\left[\delta \frac{\partial\left(\theta_{x} \theta_{y}\right)}{\partial x} y+\delta \frac{\partial\left(\theta_{x} \theta_{z}\right)}{\partial x} \mathrm{z}\right] d x\right\} d A+ \\
& +\int_{A}\left\{\int_{0}^{L} \frac{t_{x y}}{2}\left[\delta\left(\theta_{x} \theta_{y}\right)+\delta \frac{\partial\left(\theta_{y} \theta_{z}\right)}{\partial x} \mathrm{z}\right] d x\right\} d A+ \\
& +\int_{A}\left\{\int_{0}^{L} \frac{t_{x z}}{2}\left[\delta\left(\theta_{x} \theta_{z}\right)+\delta \frac{\partial\left(\theta_{y} \theta_{z}\right)}{\partial x} \mathrm{y}\right] d x\right\} d A
\end{aligned}
$$

Empregando-se todas as relações anteriores para momento fletor, torçor, força cortante e carga axial, pode-se reescrever a relação anterior conforme equação (4.96).

$$
\begin{aligned}
\int_{V} t_{i j} \Delta e_{i j} & =\int_{0}^{L} \frac{-M_{z}}{2} \delta \frac{\partial\left(\theta_{x} \theta_{y}\right)}{\partial x} d x+\int_{0}^{L} \frac{M_{y}}{2} \delta \frac{\partial\left(\theta_{x} \theta_{z}\right)}{\partial x} d x+\int_{0}^{L} \frac{Q_{y}}{2} \delta\left(\theta_{x} \theta_{y}\right) d x+ \\
& +\int_{0}^{L} \frac{(\alpha-1) M_{x}}{2} \delta \frac{\partial\left(\theta_{y} \theta_{z}\right)}{\partial x} d x+\int_{0}^{L} \frac{Q_{z}}{2} \delta\left(\theta_{x} \theta_{z}\right) d x+\int_{0}^{L} \frac{\alpha M_{x}}{2} \delta \frac{\partial\left(\theta_{y} \theta_{z}\right)}{\partial x} d x
\end{aligned}
$$

Mais uma vez, adotando $\alpha=1 / 2$, para torção pura de Saint Venant, as parcelas referentes à torção, representada por $M_{x}$, cancelam-se, resultando apenas na expressão (4.97).

$$
\begin{aligned}
\int_{V} t_{i j} \Delta e_{i j}= & \int_{0}^{L} \frac{-M_{z}}{2} \delta \frac{\partial\left(\theta_{x} \theta_{y}\right)}{\partial x} d x+\int_{0}^{L} \frac{M_{y}}{2} \delta \frac{\partial\left(\theta_{x} \theta_{z}\right)}{\partial x} d x+ \\
& +\int_{0}^{L} \frac{Q_{y}}{2} \delta\left(\theta_{x} \theta_{y}\right) d x+\int_{0}^{L} \frac{Q_{z}}{2} \delta\left(\theta_{x} \theta_{z}\right) d x
\end{aligned}
$$

De acordo com McGuire et al. (2000), o aparente desequilíbrio do nó na Figura 4.6 pode ser explicado e retificado pela consideração dessas quatro parcelas restantes no cálculo.

Integrando por partes as parcelas dos momentos fletores, resulta a equação (4.98). 


$$
\begin{aligned}
\int_{V} t_{i j} \Delta e_{i j}= & \left.\frac{-M_{z}}{2} \delta\left(\theta_{x} \theta_{y}\right)\right|_{0} ^{L}+\int_{0}^{L} \frac{1}{2} \frac{\partial M_{z}}{\partial x} \delta\left(\theta_{x} \theta_{y}\right) d x+\left.\frac{M_{y}}{2} \delta\left(\theta_{x} \theta_{z}\right)\right|_{0} ^{L}- \\
& -\int_{0}^{L} \frac{1}{2} \frac{\partial M_{y}}{\partial x} \delta\left(\theta_{x} \theta_{z}\right) d x+\int_{0}^{L} \frac{Q_{y}}{2} \delta\left(\theta_{x} \theta_{y}\right) d x+\int_{0}^{L} \frac{Q_{z}}{2} \delta\left(\theta_{x} \theta_{z}\right) d x
\end{aligned}
$$

Como $M_{z}^{\prime}=-Q_{y}$ e $M_{y}^{\prime}=Q_{z}$, a parcela da força cortante também é cancelada, resultando na expressão (4.99)

$$
\int_{V} t_{i j} \Delta e_{i j}=\left.\frac{-M_{z}}{2} \delta\left(\theta_{x} \theta_{y}\right)\right|_{0} ^{L}+\left.\frac{M_{y}}{2} \delta\left(\theta_{x} \theta_{z}\right)\right|_{0} ^{L}
$$

Relembrando que $M_{z}=-M_{z 1}+\left(M_{z 1}+M_{z 2}\right)^{x} / L \quad$ e $\quad M_{y}=-M_{y 1}+$ $\left(M_{y 1}+M_{y 2}\right)^{x} / L$, a equação anterior pode ser reescrita conforme (4.100) e em formato matricial, de acordo com (4.101).

$$
\int_{V} t_{i j} \Delta e_{i j}=\frac{1}{2}\left[-M_{z 1} \delta\left(\theta_{x 1} \theta_{y 1}\right)+M_{y 1} \delta\left(\theta_{x 1} \theta_{z 1}\right)-M_{z 2} \delta\left(\theta_{x 2} \theta_{y 2}\right)+M_{y 2} \delta\left(\theta_{x 2} \theta_{z 2}\right)\right]
$$

$$
K_{\mathrm{g}, \mathrm{Rotfin}}=\frac{1}{2}\left[\begin{array}{cccccc}
0 & -M_{z 1} & M_{y 1} & 0 & 0 & 0 \\
-M_{z 1} & 0 & 0 & 0 & 0 & 0 \\
M_{y 1} & 0 & 0 & 0 & 0 & 0 \\
0 & 0 & 0 & 0 & -M_{z 1} & M_{y 2} \\
0 & 0 & 0 & -M_{z 1} & 0 & 0 \\
0 & 0 & 0 & M_{y 2} & 0 & 0
\end{array}\right] \begin{aligned}
& \theta_{x 1} \\
& \theta_{y 1} \\
& \theta_{z 1} \\
& \theta_{x 2} \\
& \theta_{y 2} \\
& \theta_{z 2}
\end{aligned}
$$

A influência das rotações finitas é dada pela matriz apresentada em (4.101) e também é adicionada à matriz de rigidez geométrica do elemento. Obtém-se então a matriz de rigidez geométrica final para um elemento, considerando a teoria de flexão de Euler-Bernoulli. Esta matriz é apresentada no apêndice B.3.

\subsection{4}

\section{Matriz de Rigidez Local de Elemento com Funções de Forma Completas}

Com o desenvolvimento exposto, nota-se que agora o cálculo da matriz de rigidez local do elemento depende apenas da função de forma utilizada.

No item anterior, a matriz de rigidez local do elemento, considerando a teoria de flexão de Euler-Bernoulli, foi calculada empregando funções de forma cúbicas (Hermitianas). Essas funções de interpolação são obtidas diretamente da 
solução da equação diferencial do equilíbrio de um elemento infinitesimal na configuração indeformada. Por isso, em uma análise linear da estrutura, a discretização da barra não é necessária, empregando-se apenas uma discretização mínima da estrutura.

Para a análise não linear, pode-se considerar funções de forma que consideram a força axial atuante no elemento. Neste tipo de análise, a função de interpolação é obtida da solução homogênea da equação diferencial do equilíbrio de um elemento infinitesimal na configuração deformada (funções completas).

Ao se construir a matriz de rigidez local do elemento, utilizando essas funções, busca-se uma discretização mínima da barra, de forma análoga ao que ocorre na análise linear.

Ao se empregar funções de forma completas, a diferença entre matriz elástica e matriz de rigidez geométrica não é totalmente explícita, como ocorre com as funções cúbicas, pois, mesmo na própria função de interpolação, existe a influência da carga axial atuante.

Entretanto, para se utilizar os termos do tensor deformação de GreenLagrange, a matriz final será construída da mesma maneira anterior, obtendo-se a matriz de rigidez tangente final, que é a soma da elástica com a geométrica (ainda que em ambas as matrizes exista a influência da carga axial).

\subsubsection{1}

\section{Matriz de Rigidez Elástica com Funções de Forma Completas}

O cálculo para encontrar a matriz de rigidez local do elemento, considerando as funções de forma completas, é realizado utilizando-se os mesmos passos anteriores.

A matriz de rigidez elástica do elemento é dada conforme a expressão (4.28), reapresentada em (4.102).

$$
\delta U=\{\delta u\}^{T} \int_{0}^{L} E A\left\{N_{u}{ }^{\prime}\right\}\left\{N_{u}{ }^{\prime}\right\}^{T} d x\{u\}+\left\{\delta v^{T} \int_{0}^{L} E I_{z}\left\{N_{v}{ }^{\prime}\right\}\left\{N_{v}{ }^{\prime}\right\}^{T} d x\{v\}\right.
$$

Chama-se a atenção novamente, que não existe diferenciação entre matriz de rigidez elástica e geométrica ao se utilizar funções de forma completas, pois, dentro da própria função de interpolação, está presente a influência da carga axial. 
No entanto, para um desenvolver mais didático da matriz de rigidez local do elemento e utilizando-se todos os componentes do tensor deformação de GreenLagrange, os passos anteriores são seguidos, sendo somente necessária a alteração das funções de forma.

Assim, para o caso em questão, na equação (4.102), devem ser utilizadas as funções de forma para o deslocamento transversal, $N_{v}$, apresentadas em (3.30) a (3.33). No caso de cargas de tração, pode-se empregar as funções (3.43) a (3.46) e, no caso de compressão, as funções em (3.56) a (3.59).

Para o plano xz, essas mesmas funções de interpolação devem ser substitutídas na equação apresentada em (4.49) e repetida em (4.103), por conveniência. Entretanto, essas funções representam o deslocamento transversal no vetor $N_{w}$.

$$
\delta U=\{\delta w\}^{T} \int_{0}^{L} E I_{y}\left\{N_{w}^{\prime}\right\}\left\{N_{w}^{\prime}\right\}^{T} d x\{w\}
$$

Para o caso de torção pura, desenvolvida no item 4.3.3.3, as funções de forma não são alteradas, pois para o deslocamento axial foram adotadas funções de interpolação lineares, $N_{\theta x}$, que independem do equilíbrio do elemento infinitesimal. Assim, a equação (4.63), reescrita em (4.104) emprega as mesmas funções de forma.

$$
\delta U=\left\{\delta \theta_{x}\right\}^{T} \int_{0}^{L} G I_{x}\left\{N_{\theta x}{ }^{\prime}\right\}\left\{N_{\theta x}\right\}^{\prime T} d x\left\{\theta_{x}\right\} \quad N_{\theta x}=\left\{1-\frac{x}{L} \quad \frac{x}{L}\right\}
$$

A matriz desenvolvida, empregando as equações (4.102), (4.103) e (4.104) é apresentada no apêndice B.4, no caso de tração, e apêndice B.5, para situação de compressão. Essa matriz é nomeada como " 1 a ordem" por ser referente à parcela linear da formulação Lagrangeana atualizada e do tensor deformação.

\subsubsection{2 \\ Matriz de Rigidez Geométrica com Funções de Forma Completas}

Empregando-se o mesmo desenvolvimento utilizado com as funções de interpolação cúbicas, também se pode escrever a matriz de rigidez geométrica, considerando funções de forma completas. 
No plano xy, utiliza-se a expressão (4.28), reescrita em (4.105). Mais uma vez, devem-se utilizar as funções de forma para o deslocamento transversal, $N_{v}$, apresentadas em (3.30) a (3.33). No caso de cargas de tração, pode-se empregar as funções (3.43) a (3.46) e, no caso de compressão, as funções em (3.56) a (3.59).

$$
\begin{aligned}
\delta U_{N L} & =\{\delta u\}^{T} \int_{0}^{L} P\left\{N_{u}{ }^{\prime}\right\}\left\{N_{u}{ }^{\prime}\right\}^{T} d x\{u\}+\{\delta v\}^{T} \int_{0}^{L} P\left\{N_{v}{ }^{\prime}\right\}\left\{N_{v}{ }^{\prime}\right\}^{T} d x\{v\}+ \\
& +\{\delta v\}^{T} \int_{0}^{L} P \frac{I_{z}}{A}\left\{N_{v}{ }^{\prime \prime}\right\}\left\{N_{v}{ }^{\prime \prime}\right\}^{T} d x\{v\}+\{\delta v\}^{T} \int_{0}^{L} M_{z}\left\{N_{v}{ }^{\prime \prime}\right\}\left\{N_{u}{ }^{\prime}\right\}^{T} d x\{u\}+ \\
& +\{\delta u\}^{T} \int_{0}^{L} M_{z}\left\{N_{u}{ }^{\prime}\right\}\left\{N_{v}{ }^{\prime \prime}\right\}^{T} d x\{v\}-\{\delta v\}^{T} \int_{0}^{L} Q_{y}\left\{N_{v}{ }^{\prime}\right\}\left\{N_{u}{ }^{\prime}\right\}^{T} d x\{u\}- \\
& -\{\delta u\}^{T} \int_{0}^{L} Q_{y}\left\{N_{u}{ }^{\prime}\right\}\left\{N_{v}{ }^{\prime}\right\}^{T} d x\{v\}
\end{aligned}
$$

No plano xz, utiliza-se a equação (4.58), apresentada novamente em (4.106). As funções de forma são substituídas em $N_{w}$.

$$
\begin{aligned}
\delta U_{N L} & =\{\delta w\}^{T} \int_{0}^{L} P\left\{N_{w}{ }^{\prime}\right\}\left\{N_{w}{ }^{\prime}\right\}^{T} d x\{w\}+\{\delta w\}^{T} \int_{0}^{L} P \frac{I_{y}}{A}\left\{N_{w}{ }^{\prime \prime}\right\}\left\{N_{w}{ }^{\prime \prime}\right\}^{T} d x\{w\}- \\
& -\{\delta w\}^{T} \int_{0}^{L} M_{y}\left\{N_{w}{ }^{\prime}\right\}\left\{N_{u}{ }^{\prime}\right\}^{T} d x\{u\}-\{\delta u\}^{T} \int_{0}^{L} M_{y}\left\{N_{u}{ }^{\prime}\right\}\left\{N_{w}{ }^{\prime}\right\}^{T} d x\{w\}- \\
& -\{\delta w\}^{T} \int_{0}^{L} Q_{z}\left\{N_{w}{ }^{\prime}\right\}\left\{N_{u}{ }^{\prime}\right\}^{T} d x\{u\}-\{\delta u\}^{T} \int_{0}^{L} Q_{z}\left\{N_{u}{ }^{\prime}\right\}\left\{N_{w}{ }^{\prime}\right\}^{T} d x\{w\}
\end{aligned}
$$

A matriz obtida, considerando apenas as direções trabalhando isoladamente, ou seja, empregando as equações (4.105) e (4.106), pode ser visualizada nos apêndices B.6 e B.7, para os casos de tração e compressão respectivamente, sendo chamada de " $2^{\mathrm{a}}$ ordem" por ser referente à parcela não linear da formulação Lagrangeana atualizada e do tensor deformação.

Para a interação entre torção e carga axial, devem-se utilizar as equações apresentadas em (4.73) e (4.81), repetidas nas expressões (4.107) e (4.108).

$$
\begin{aligned}
\delta U_{N L}= & \left\{\delta \theta_{x}\right\}^{T} \int_{0}^{L} \frac{P J_{p}}{A}\left\{N_{\theta x}{ }^{\prime}\right\}\left\{N_{\theta x}{ }^{\prime}\right\}^{T} d x\left\{\theta_{x}\right\}-\{\delta v\}^{T} \int_{0}^{L} M_{y}\left\{N_{v}{ }^{\prime}\right\}\left\{N_{\theta x}\right\}^{T} d x\left\{\theta_{x}\right\}- \\
& -\left\{\delta \theta_{x}\right\}^{T} \int_{0}^{L} M_{y}\left\{N_{\theta x}{ }^{\prime}\right\}\left\{N_{v}{ }^{\prime}\right\}^{T} d x\{v\}-\{\delta w\}^{T} \int_{0}^{L} M_{z}\left\{N_{w}{ }^{\prime}\right\}\left\{N_{\theta x}{ }^{\prime}\right\}^{T} d x\left\{\theta_{x}\right\}- \\
& -\left\{\delta \theta_{x}\right\}^{T} \int_{0}^{L} M_{z}\left\{N_{\theta x}{ }^{\prime}\right\}\left\{N_{w}{ }^{\prime}\right\}^{T} d x\{w\}
\end{aligned}
$$




$$
\begin{aligned}
\delta U_{N L} & =-\{\delta w\}^{T} \int_{0}^{L} \frac{M_{x}}{2}\left\{N_{w}{ }^{\prime}\right\}\left\{N_{v}{ }^{\prime}\right\}^{T} d x\{v\}-\{\delta v\}^{T} \int_{0}^{L} \frac{M_{x}}{2}\left\{N_{v}{ }^{\prime}\right\}\left\{N_{w}{ }^{\prime \prime}\right\}^{T} d x\{w\}+ \\
& +\{\delta v\}^{T} \int_{0}^{L} \frac{M_{x}}{2}\left\{N_{v}{ }^{\prime}\right\}\left\{N_{w}{ }^{\prime}\right\}^{T} d x\{w\}+\{\delta w\}^{T} \int_{0}^{L} \frac{M_{x}}{2}\left\{N_{w}{ }^{\prime}\right\}\left\{N_{v}{ }^{\prime \prime}\right\}^{T} d x\{v\}+ \\
& +\{\delta w\}^{T} \int_{0}^{L} Q_{y}\left\{N_{w}{ }^{\prime}\right\}\left\{N_{\theta x}\right\}^{T} d x\left\{\theta_{x}\right\}+\left\{\delta \theta_{x}\right\}^{T} \int_{0}^{L} Q_{y}\left\{N_{\theta x}\right\}\left\{N_{w}{ }^{\prime}\right\}^{T} d x\{w\}- \\
& -\{\delta v\}^{T} \int_{0}^{L} Q_{z}\left\{N_{v}{ }^{\prime}\right\}\left\{N_{\theta x}\right\}^{T} d x\left\{\theta_{x}\right\}-\left\{\delta \theta_{x}\right\}^{T} \int_{0}^{L} Q_{z}\left\{N_{\theta x}\right\}\left\{N_{v}{ }^{\prime}\right\}^{T} d x\{v\}
\end{aligned}
$$

As funções de interpolação que devem ser utilizadas nesse caso para o deslocamento transversal, $N_{v}$ e $N_{w}$, são as funções completas, em que existe a presença da influência da carga axial.

Para considerar as rotações finitas, não é necessário alterar as funções de forma, pois as rotações não foram escritas utilizando as funções de interpolação. Sendo assim, considera-se a mesma matriz apresentada em (4.101).

A matriz que leva em consideração a interação entre torção e carga axial, como também as rotações finitas, é apresentada no apêndice B.8, para casos de tração, e no apêndice B.9, para situação de compressão.

\subsubsection{3 \\ Matriz de Rigidez Tangente}

A matriz de rigidez local do elemento, matriz tangente, é dada pela soma da matriz elástica e geométrica. Essa matriz, tendo em conta a teoria de flexão de Euler-Bernoulli, funções de forma completas e todos os termos do tensor deformação de Green-Lagrange, é dada pela soma das matrizes dos apêndices B.4, B.6 e B.8, quando o elemento está submetido à tração. Quando a carga é de compressão, essa soma é feita com as matrizes apresentadas nos apêndices B.5, B.7 e B.9.

Essa matriz também pode ser expandida em uma série de Taylor até $\mu^{6}$, $\mu=\sqrt{P / E I}$, ou em função apenas da carga axial até $P^{3}$, e esse resultado é apresentado no apêndice B.10. Pode-se notar que os fatores até $\mu^{2}$ correspondem à matriz elástica e geométrica usuais, considerando funções de forma cúbicas. 


\section{4}

\section{Teoria de Flexão de Timoshenko}

Empregando as funções de interpolação desenvolvidas no capítulo 3, tendo em conta a teoria de flexão de Timoshenko, em conjunto com a descrição Lagrangeana atualizada, considerando os termos de ordem elevada do tensor deformação, de maneira análoga a que foi feita para a teoria de Euler-Bernoulli, pode-se desenvolver a matriz de rigidez de um elemento, para grandes gradientes de deslocamento e grandes rotações, com base na teoria de flexão de Timoshenko.

De acordo com o campo de deslocamentos de barras, equação (2.1), considerando a teoria de flexão de Timoshenko, as parcelas lineares e não lineares do tensor deformação de Green-Lagrange, relações (4.4) e (4.5), podem ser reescritas conforme as equações (4.109), parcela linear, (4.110) e (4.111), parcela não linear.

$$
\begin{gathered}
\varepsilon_{x x}=\frac{\partial u}{\partial x}=\frac{\partial u_{0}}{\partial x}-y \frac{\partial \theta_{Z}}{\partial x} \quad \gamma_{x y}=\frac{\partial v}{\partial x}+\frac{\partial u}{\partial y}=\frac{\partial v_{0}}{\partial x}-\theta_{Z} \\
\eta_{x x}=\frac{1}{2}\left(\left(\frac{\partial u}{\partial x}\right)^{2}+\left(\frac{\partial v}{\partial x}\right)^{2}\right)=\frac{1}{2}\left(\left(\frac{\partial u}{\partial x}\right)^{2}+\left(\frac{\partial v}{\partial x}\right)^{2}+y^{2}\left(\frac{\partial \theta_{z}}{\partial x}\right)^{2}\right)-y \frac{\partial u}{\partial x} \frac{\partial \theta_{z}}{\partial x} \\
\eta_{x y}=\frac{\partial u}{\partial x} \frac{\partial u}{\partial y}+\frac{\partial v}{\partial x} \frac{\partial v}{\partial y}=y \frac{\partial \theta_{z}}{\partial x} \theta_{z}-\theta_{z} \frac{\partial u}{\partial x}
\end{gathered}
$$

\subsection{1}

\section{Matriz de Rigidez Elástica}

A matriz de rigidez elástica de um elemento é obtida a partir da parcela linear do tensor deformação de Green-Lagrange, equação (4.109). Empregando-se a equação (4.13) dos trabalhos virtuais, $\delta U$, e dividindo-se essa parcela linear em duas partes $\left(\delta U_{1}, \delta U_{2}\right)$, obtêm-se as expressões (4.112) e (4.113).

$$
\delta U_{1}=\int_{A}\left(\int_{0}^{L}\left(\frac{\partial u}{\partial x}-y \frac{\partial \theta_{z}}{\partial x}\right) E\left(\frac{\partial u}{\partial x}-y \frac{\partial \theta_{z}}{\partial x}\right) d x\right) d A
$$




$$
\begin{array}{r}
\rightarrow \delta U_{1}=\left(\int_{0}^{L} \frac{\partial u}{\partial x} \delta \frac{\partial u}{\partial x} d x\right) E \int_{A} d A+\left(\int_{0}^{L} \frac{\partial \theta_{z}}{\partial x} \delta \frac{\partial \theta_{z}}{\partial x} d x\right) E \int_{A} y^{2} d A+ \\
-\left(\int_{0}^{L} \frac{\partial \theta_{z}}{\partial x} \delta \frac{\partial u}{\partial x} d x\right) E \int_{A} y d A-\left(\int_{0}^{L} \frac{\partial u}{\partial x} \delta \frac{\partial \theta_{z}}{\partial x} d x\right) E \int_{A} y d A \\
\delta U_{2}=\int_{A}\left(\int_{0}^{L}\left(\frac{\partial v}{\partial x}-\theta_{Z}\right) G\left(\delta \frac{\partial v}{\partial x}-\delta \theta_{Z}\right) d x\right) d A \\
\rightarrow \delta U_{2}=\left(\int_{0}^{L} \frac{\partial v}{\partial x} \delta \frac{\partial v}{\partial x} d x\right) G \int_{A} d A+\left(\int_{0}^{L} \theta_{Z} \delta \theta_{Z} d x\right) G \int_{A} d A+ \\
-\left(\int_{0}^{L} \theta_{Z} \delta \frac{\partial v}{\partial x} d x\right) G \int_{A} d A-\left(\int_{0}^{L} \frac{\partial v}{\partial x} \delta \theta_{Z} d x\right) G \int_{A} d A
\end{array}
$$

No eixo centroidal da seção transversal, pode-se considerar as propriedades: $\int_{A} y^{2} d A=I_{z}, \int_{A} y d A=0$. Assim, o problema é reduzido às equações (4.114) e

(4.115).

$$
\begin{aligned}
\delta U_{1}= & \left(\int_{0}^{L} \frac{\partial u}{\partial x} \delta \frac{\partial u}{\partial x} d x\right) E A+\left(\int_{0}^{L} \frac{\partial \theta_{Z}}{\partial x} \delta \frac{\partial \theta_{Z}}{\partial x} d x\right) E I_{z} \\
\delta U_{2}= & \left(\int_{0}^{L} \frac{\partial v}{\partial x} \delta \frac{\partial v}{\partial x} d x\right) G A+\left(\int_{0}^{L} \theta_{Z} \delta \theta_{Z} d x\right) G A+ \\
& -\left(\int_{0}^{L} \theta_{Z} \delta \frac{\partial v}{\partial x} d x\right) G A-\left(\int_{0}^{L} \frac{\partial v}{\partial x} \delta \theta_{Z} d x\right) G A
\end{aligned}
$$

De acordo com as equações de interpolação (3.1), (3.2) e (3.3), os deslocamentos do elemento são dados em função dos deslocamentos nodais, conforme (4.24). As funções de forma são as obtidas anteriormente, considerandoo equilíbrio de um elemento infinitesimal em sua configuração indeformada e a teoria de flexão de Timoshenko, (3.21) a (3.24).

Assim, as equações (4.114) e (4.115) dos trabalhos virtuais podem ser escritas utilizando-se as funções de forma e os deslocamentos nodais, conforme as expressões (4.116) e (4.117).

$$
\delta U_{1}=\{\delta u\}^{T} \int_{0}^{L} E A\left\{N_{u}{ }^{\prime}\right\}\left\{N_{u}{ }^{\prime}\right\}^{T} d x\{u\}+\{\delta v\}^{T} \int_{0}^{L} E I_{z}\left\{N_{\theta z}{ }^{\prime}\right\}\left\{N_{\theta z}{ }^{\prime}\right\}^{T} d x\{v\}
$$




$$
\begin{aligned}
\delta U_{2}= & \{\delta v\}^{T} \int_{0}^{L} G A\left\{N_{v}{ }^{\prime}\right\}\left\{N_{v}{ }^{\prime}\right\}^{T} d x\{v\}+\{\delta v\}^{T} \int_{0}^{L} G A\left\{N_{\theta z}\right\}\left\{N_{\theta z}\right\}^{T} d x\{v\}+ \\
& -\{\delta v\}^{T} \int_{0}^{L} G A\left\{N_{\theta z}\right\}\left\{N_{v}{ }^{\prime}\right\}^{T} d x\{v\}-\{\delta v\}^{T} \int_{0}^{L} G A\left\{N_{v}{ }^{\prime}\right\}\left\{N_{\theta z}\right\}^{T} d x\{v\}
\end{aligned}
$$

Substituindo-se as funções de forma e resolvendo-se as integrais do problema, encontra-se a matriz de rigidez elástica de um elemento plano, considerando a teoria de flexão de Timoshenko, equação (4.118).

$$
\begin{aligned}
& K_{e, x y}= \\
& {\left[\begin{array}{cccccc}
\frac{E A}{L} & 0 & 0 & -\frac{E A}{L} & 0 & 0 \\
0 & \frac{12 E I_{Z}}{L^{3}\left(12 \Omega_{Y}+1\right)} & \frac{6 E I_{Z}}{L^{2}\left(12 \Omega_{Y}+1\right)} & 0 & -\frac{12 E I_{Z}}{L^{3}\left(12 \Omega_{Y}+1\right)} & \frac{6 E I_{Z}}{L^{2}(12 \Omega+1)} \\
0 & \frac{6 E I_{Z}}{L^{2}\left(12 \Omega_{Y}+1\right)} & \frac{4 E I_{Z}\left(3 \Omega_{Y}+1\right)}{L\left(12 \Omega_{Y}+1\right)} & 0 & -\frac{6 E I_{Z}}{L^{2}\left(12 \Omega_{Y}+1\right)} & -\frac{2 E I_{Z}\left(6 \Omega_{Y}-1\right)}{L\left(12 \Omega_{Y}+1\right)} \\
-\frac{E A}{L} & 0 & 0 & \frac{E A}{L} & 0 & 0 \\
0 & -\frac{12 E I_{Z}}{L^{3}\left(12 \Omega_{Y}+1\right)} & -\frac{6 E I_{Z}}{L^{2}\left(12 \Omega_{Y}+1\right)} & 0 & \frac{12 E I_{Z}}{L^{3}\left(12 \Omega_{Y}+1\right)} & -\frac{6 E I_{Z}}{L^{2}\left(12 \Omega_{Y}+1\right)} \\
0 & \frac{6 E I_{Z}}{L^{2}\left(12 \Omega_{Y}+1\right)} & -\frac{2 E I_{Z}\left(6 \Omega_{Y}-1\right)}{L\left(12 \Omega_{Y}+1\right)} & 0 & -\frac{6 E I_{Z}}{L^{2}\left(12 \Omega_{Y}+1\right)} & \frac{4 E I_{Z}\left(3 \Omega_{Y}+1\right)}{L\left(12 \Omega_{Y}+1\right)}
\end{array}\right]}
\end{aligned}
$$

\subsection{2}

\section{Matriz de Rigidez Geométrica}

A matriz de rigidez geométrica é calculada com a utilização da parcela não linear da equação dos trabalhos virtuais, equação (4.15). Ou seja, emprega-se a parcela não linear do tensor deformação de Green Lagrange, conforme as equações (4.17) e (4.18) desenvolvidas anteriormente.

Assim, a equação (4.15) pode ser escrita conforme expressão (4.119) ou de forma expandida, de acordo com (4.120).

$$
\begin{aligned}
\delta U_{N L}= & \int_{A}\left(\int_{0}^{L} t_{x x} \delta\left(\frac{1}{2}\left(\left(\frac{\partial u}{\partial x}\right)^{2}+\left(\frac{\partial v}{\partial x}\right)^{2}+y^{2}\left(\frac{\partial \theta_{z}}{\partial x}\right)^{2}\right)-y \frac{\partial \theta_{z}}{\partial x} \frac{\partial u}{\partial x}\right) d x\right) d A+ \\
& +\int_{A}\left(\int_{0}^{L} t_{x y} \delta\left(y \frac{\partial \theta_{z}}{\partial x} \theta_{z}-\theta_{z} \frac{\partial u}{\partial x}\right) d x\right) d A
\end{aligned}
$$




$$
\begin{aligned}
\delta U_{N L} & =\frac{1}{2}\left(\int_{0}^{L} \delta\left(\frac{\partial u}{\partial x}\right)^{2} d x\right) \int_{A} t_{x x} d A+\frac{1}{2}\left(\int_{0}^{L} \delta\left(\frac{\partial v}{\partial x}\right)^{2} d x\right) \int_{A} t_{x x} d A+\frac{1}{2}\left(\int_{0}^{L} \delta\left(\frac{\partial \theta_{z}}{\partial x}\right)^{2} d x\right) \int_{A} y^{2} t_{x x} d A+ \\
& -\left(\int_{0}^{L} \delta \frac{\partial \theta_{z}}{\partial x} \frac{\partial u}{\partial x} d x\right) \int_{A} t_{x x} y d A+\left(\int_{0}^{L} \delta \frac{\partial \theta_{z}}{\partial x} \theta_{z} d x\right) \int_{A} t_{x y} y d A-\left(\int_{0}^{L} \delta \theta_{z} \frac{\partial u}{\partial x} d x\right) \int_{A} t_{x y} d A
\end{aligned}
$$

Aplicando-se as relações apresentadas em (4.34), pode-se reescrever as equações anteriores conforme (4.121).

$$
\begin{aligned}
\delta U_{N L}= & \frac{1}{2} \int_{0}^{L}\left[P \delta\left(\left(\frac{\partial u}{\partial x}\right)^{2}+\left(\frac{\partial v}{\partial x}\right)^{2}\right)+P \frac{I_{z}}{A} \delta\left(\left(\frac{\partial \theta_{z}}{\partial x}\right)^{2}\right)\right] d x \\
& +\int_{0}^{L}\left[M_{z} \delta\left(\frac{\partial \theta_{z}}{\partial x} \frac{\partial u}{\partial x}\right)-Q_{y} \delta\left(\theta_{z} \frac{\partial u}{\partial x}\right)\right] d x
\end{aligned}
$$

Para melhor visualização, a equação dos trabalhos virtuais (4.121) pode ser dividida em duas parcelas e os deslocamentos escritos utilizando-se as funções de interpolação, de acordo com as expressões (4.122) e (4.123).

$$
\begin{aligned}
& \text { - } \int_{0}^{L}\left[P \delta\left(\left(\frac{\partial u}{\partial x}\right)^{2}+\left(\frac{\partial v}{\partial x}\right)^{2}\right)+P \frac{I_{z}}{A} \delta\left(\left(\frac{\partial \theta_{z}}{\partial x}\right)^{2}\right)\right] d x= \\
& =\{\delta u\}^{T} \int_{0}^{L} P\left\{N_{u}{ }^{\prime}\right\}\left\{N_{u}{ }^{\prime}\right\}^{T} d x\{u\}+\{\delta\}^{T} \int_{0}^{L} P\left\{N_{v}{ }^{\prime}\right\}\left\{N_{v}{ }^{\prime}\right\}^{T} d x\{v\} \\
& +\{\delta v\}^{T} \int_{0}^{L} P \frac{I_{z}}{A}\left\{N_{\theta z}{ }^{\prime}\right\}\left\{N_{\theta z}{ }^{\prime}\right\}^{T} d x\{v\} \\
& -\int_{0}^{L}\left[M_{z} \delta\left(\frac{\partial \theta_{z}}{\partial x} \frac{\partial u}{\partial x}\right)-Q_{y} \delta\left(\theta_{z} \frac{\partial u}{\partial x}\right)\right] d x= \\
& \left.=\{\delta v\}^{T} \int_{0}^{L} M_{z}\left\{N_{\theta z}{ }^{\prime}\right\}\left\{N_{u}{ }^{\prime}\right\}^{T} d x\{u\}+\{\delta u\}^{T} \int_{0}^{L} M_{z}\left\{N_{u}{ }^{\prime}\right\}\left\{N_{\theta z}\right\}^{\prime}\right\}^{T} d x\{v\}+ \\
& -\{\delta v\}^{T} \int_{0}^{L} Q_{y}\left\{N_{\theta z}\right\}\left\{N_{u}{ }^{\prime}\right\}^{T} d x\{u\}-\{\delta u\}^{T} \int_{0}^{L} Q_{y}\left\{N_{u}{ }^{\prime}\right\}\left\{N_{\theta z}\right\}^{T} d x\{v\}
\end{aligned}
$$

Empregando-se a relação (4.38), com a substituição das funções de forma consideradas, e resolvendo-se as integrais do problema, encontra-se a matriz de rigidez geométrica local do elemento. Essa matriz considera a teoria de flexão de Timoshenko e termos de ordem elevada do tensor deformação de GreenLagrange, conforme (4.124). 


$$
\begin{aligned}
& K_{x y}^{g}= \\
& {\left[\begin{array}{ccc}
\frac{P}{L} & 0 & -\frac{M_{Z 1}}{L} \\
0 & \frac{6 P\left(120 \Omega_{Y}{ }^{2}+20 \Omega_{Y}+1\right)}{5 L\left(12 \Omega_{Y}+1\right)^{2}}+\frac{12 P I_{Z}}{A L^{3}\left(12 \Omega_{Y}+1\right)^{2}} & \frac{P}{10\left(12 \Omega_{Y}+1\right)^{2}}+\frac{6 P I_{Z}}{A L^{2}\left(12 \Omega_{Y}+1\right)^{2}} \\
-\frac{M_{z 1}}{L} & \frac{P}{10\left(12 \Omega_{Y}+1\right)^{2}}+\frac{6 P I_{Z}}{A L^{2}\left(12 \Omega_{Y}+1\right)^{2}} & \frac{2 L P\left(90 \Omega_{Y}{ }^{2}+15 \Omega_{Y}+1\right)}{15\left(12 \Omega_{Y}+1\right)^{2}}+\frac{4 P I_{Z}\left(36 \Omega_{Y}{ }^{2}+6 \Omega_{Y}+1\right)}{A L\left(12 \Omega_{Y}+1\right)^{2}} \\
-\frac{P}{L} & 0 & \frac{M_{Z 1}}{L} \\
0 & -\frac{6 P\left(120 \Omega_{Y}{ }^{2}+20 \Omega_{Y}+1\right)}{5 L\left(12 \Omega_{Y}+1\right)^{2}}-\frac{12 P I_{Z}}{A L^{3}\left(12 \Omega_{Y}+1\right)^{2}} & -\frac{P}{10\left(12 \Omega_{Y}+1\right)^{2}}-\frac{6 P I_{Z}}{A L^{2}\left(12 \Omega_{Y}+1\right)^{2}} \\
-\frac{M_{z 2}}{L} & \frac{P}{10\left(12 \Omega_{Y}+1\right)^{2}}+\frac{6 P I_{Z}}{A L^{2}\left(12 \Omega_{Y}+1\right)^{2}} & -\frac{L P\left(360 \Omega_{Y}{ }^{2}+60 \Omega_{Y}+1\right)}{30\left(12 \Omega_{Y}+1\right)^{2}}-\frac{2 P I_{Z}\left(72 \Omega_{Y}{ }^{2}+12 \Omega_{Y}-1\right)}{A L\left(12 \Omega_{Y}+1\right)^{2}} \\
-\frac{P}{L} & 0 & -\frac{M_{Z 2}}{L} \\
0 & -\frac{6 P\left(120 \Omega_{Y}{ }^{2}+20 \Omega_{Y}+1\right)}{5 L\left(12 \Omega_{Y}+1\right)^{2}}-\frac{12 P I_{Z}}{A L^{3}\left(12 \Omega_{Y}+1\right)^{2}} & \frac{P}{10\left(12 \Omega_{Y}+1\right)^{2}}+\frac{6 P I_{Z}}{A L^{2}\left(12 \Omega_{Y}+1\right)^{2}} \\
\frac{M_{Z 1}}{L} & -\frac{P}{10\left(12 \Omega_{Y}+1\right)^{2}}-\frac{6 P I_{Z}}{A L^{2}\left(12 \Omega_{Y}+1\right)^{2}} & -\frac{L P\left(360 \Omega_{Y}{ }^{2}+60 \Omega_{Y}+1\right)}{30\left(12 \Omega_{Y}+1\right)^{2}}-\frac{2 P I_{Z}\left(72 \Omega_{Y}{ }^{2}+12 \Omega_{Y}-1\right)}{A L\left(12 \Omega_{Y}+1\right)^{2}} \\
\frac{P}{L} & 0 & \frac{M_{z 2}}{L} \\
0 & \frac{6 P\left(120 \Omega_{Y}{ }^{2}+20 \Omega_{Y}+1\right)}{5 L\left(12 \Omega_{Y}+1\right)^{2}}+\frac{12 P I_{Z}}{A L^{3}\left(12 \Omega_{Y}+1\right)^{2}} & -\frac{P}{10\left(12 \Omega_{Y}+1\right)^{2}}-\frac{6 P I_{Z}}{A L^{2}\left(12 \Omega_{Y}+1\right)^{2}} \\
\frac{M_{z 2}}{L} & -\frac{P}{10\left(12 \Omega_{Y}+1\right)^{2}}-\frac{6 P I_{Z}}{A L^{2}\left(12 \Omega_{Y}+1\right)^{2}} & \frac{2 L P\left(90 \Omega_{Y}{ }^{2}+15 \Omega_{Y}+1\right)}{15\left(12 \Omega_{Y}+1\right)^{2}}+\frac{4 P I_{Z}\left(36 \Omega_{Y}{ }^{2}+6 \Omega_{Y}+1\right)}{A L\left(12 \Omega_{Y}+1\right)^{2}}
\end{array}\right]}
\end{aligned}
$$

\subsection{3 \\ Matriz de Rigidez Local de Elemento Espacial (3D)}

Em prosseguimento à mesma metodologia adotada anteriormente para a teoria de flexão de Euler-Bernoulli, primeiramente considerou-se o plano xy para análise, devido ao momento fletor em torno do eixo z. Entretanto, ao se estudar um elemento espacial (3D), Figura 4.4, deve-se atentar para o momento fletor em torno do eixo y em uma análise do plano xz.

Além disso, é preciso também considerar a interação entre a torção e a força axial, como também as rotações finitas.

\subsubsection{1}

\section{Matriz de Rigidez Elástica Local no Plano xz}

Para o caso do plano xz trabalhando independentemente, a análise é análoga à realizada no plano xy. Sendo $w$ o deslocamento na direção $\mathrm{Z}$, o tensor 
deformação de Green-Lagrange pode ser escrito, conforme as relações (4.125), (4.126) e (4.127). Pode-se notar que o deslocamento $w$ no plano xz corresponde ao deslocamento $v$ no plano xy.

$$
\begin{gathered}
\varepsilon_{x x}=\frac{\partial u}{\partial x}=\frac{\partial u_{0}}{\partial x}-z \frac{\partial \theta_{y}}{\partial x} \quad \gamma_{x z}=\frac{\partial w}{\partial x}+\frac{\partial u}{\partial z}=\frac{\partial w_{0}}{\partial x}-\theta_{y} \\
\eta_{x x}=\frac{1}{2}\left(\left(\frac{\partial u}{\partial x}\right)^{2}+\left(\frac{\partial w}{\partial x}\right)^{2}\right)=\frac{1}{2}\left(\left(\frac{\partial u}{\partial x}\right)^{2}+\left(\frac{\partial w}{\partial x}\right)^{2}+z^{2}\left(\frac{\partial \theta_{y}}{\partial x}\right)^{2}\right)-z \frac{\partial u}{\partial x} \frac{\partial \theta_{y}}{\partial x} \\
\eta_{x z}=\frac{\partial u}{\partial x} \frac{\partial u}{\partial z}+\frac{\partial w}{\partial x} \frac{\partial w}{\partial z}=z \frac{\partial \theta_{y}}{\partial x} \theta_{y}-\theta_{y} \frac{\partial u}{\partial x}
\end{gathered}
$$

Assim, encontram-se as equações (4.128) e (4.129) para o cálculo da matriz de rigidez elástica.

$$
\begin{aligned}
\delta U_{1}= & \left(\int_{0}^{L} \frac{\partial u}{\partial x} \delta \frac{\partial u}{\partial x} d x\right) E A+\left(\int_{0}^{L} \frac{\partial \theta_{y}}{\partial x} \delta \frac{\partial \theta_{y}}{\partial x} d x\right) E I_{y} \\
\delta U_{2}= & \left(\int_{0}^{L} \frac{\partial w}{\partial x} \delta \frac{\partial w}{\partial x} d x\right) G A+\left(\int_{0}^{L} \theta_{y} \delta \theta_{y} d x\right) G A+ \\
& -\left(\int_{0}^{L} \theta_{y} \delta \frac{\partial w}{\partial x} d x\right) G A-\left(\int_{0}^{L} \frac{\partial w}{\partial x} \delta \theta_{y} d x\right) G A
\end{aligned}
$$

Empregando-se as mesmas funções de interpolação do plano xy, $N_{w}=N_{v}$, a equação dos trabalhos virtuais pode ser escrita, utilizando-se as funções de forma e os deslocamentos nodais, conforme expressões (4.130) e (4.131).

$$
\begin{gathered}
\delta U_{1}=\{\delta w\}^{T} \int_{0}^{L} E I_{y}\left\{N_{\theta y}{ }^{\prime}\right\}\left\{N_{\theta y}{ }^{\prime}\right\}^{T} d x\{w\} \\
\delta U_{2}=\{\delta w\}^{T} \int_{0}^{L} G A\left\{N_{w}{ }^{\prime}\right\}\left\{N_{w}{ }^{\prime}\right\}^{T} d x\{w\}+\{\delta w\}^{T} \int_{0}^{L} G A\left\{N_{\theta y}\right\}\left\{N_{\theta y}\right\}^{T} d x\{w\}+ \\
-\{\delta w\}^{T} \int_{0}^{L} G A\left\{N_{\theta y}\right\}\left\{N_{w}{ }^{\prime}\right\}^{T} d x\{w\}-\{\delta w\}^{T} \int_{0}^{L} G A\left\{N_{w}{ }^{\prime}\right\}\left\{N_{\theta y}\right\}^{T} d x\{w\}
\end{gathered}
$$

Substituindo-se as funções de forma e resolvendo-se as integrais do problema, encontra-se a matriz de rigidez elástica de um elemento plano, considerando a teoria de flexão de Timoshenko, matriz (4.132). 


$$
\begin{aligned}
& K_{e, x z}= \\
& {\left[\begin{array}{cccccc}
\frac{E A}{L} & 0 & 0 & -\frac{E A}{L} & 0 & 0 \\
0 & \frac{12 E I_{Y}}{L^{3}\left(12 \Omega_{Z}+1\right)}-\frac{6 E I_{Y}}{L^{2}\left(12 \Omega_{Z}+1\right)} & 0 & -\frac{12 E I_{Y}}{L^{3}\left(12 \Omega_{Z}+1\right)}-\frac{6 E I_{Y}}{L^{2}(12 \Omega+1)}
\end{array}\right.} \\
& 0-\frac{6 E I_{Y}}{L^{2}\left(12 \Omega_{Z}+1\right)} \frac{4 E I_{Y}\left(3 \Omega_{Z}+1\right)}{L\left(12 \Omega_{Z}+1\right)} \quad 0 \quad \frac{6 E I_{Y}}{L^{2}\left(12 \Omega_{Z}+1\right)} \frac{2 E I_{Y}\left(1-6 \Omega_{Z}\right)}{L\left(12 \Omega_{Z}+1\right)} \\
& \begin{array}{cccccc}
-\frac{E A}{L} & 0 & 0 & \frac{E A}{L} & 0 & 0
\end{array} \\
& 0-\frac{12 E I_{Y}}{L^{3}\left(12 \Omega_{Z}+1\right)} \frac{6 E I_{Y}}{L^{2}\left(12 \Omega_{Z}+1\right)} \quad 0 \quad \frac{12 E I_{Y}}{L^{3}\left(12 \Omega_{Z}+1\right)} \frac{6 E I_{Y}}{L^{2}\left(12 \Omega_{Z}+1\right)} \\
& 0-\frac{6 E I_{Y}}{L^{2}\left(12 \Omega_{Z}+1\right)} \frac{2 E I_{Y}\left(1-6 \Omega_{Z}\right)}{L\left(12 \Omega_{Z}+1\right)} \quad 0 \quad \frac{6 E I_{Y}}{L^{2}\left(12 \Omega_{Z}+1\right)} \frac{4 E I_{Y}\left(3 \Omega_{Z}+1\right)}{L\left(12 \Omega_{Z}+1\right)}
\end{aligned}
$$

A matriz elástica espacial, ante os dois planos trabalhando isoladamente, é obtida somando-se as duas matrizes elásticas desenvolvidas no plano xy e xz, obtendo-se a matriz (4.133). 


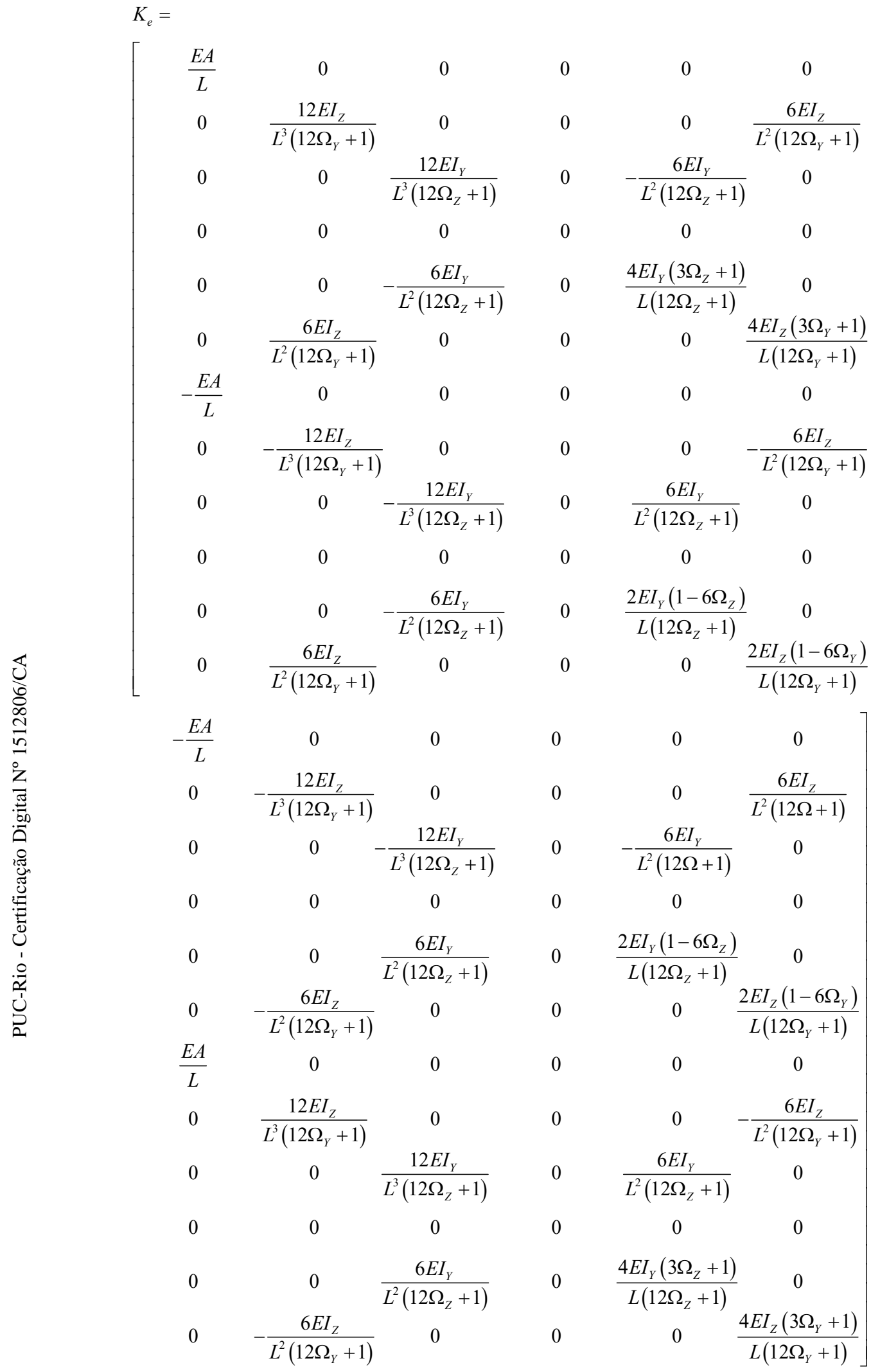




\subsubsection{2}

\section{Matriz de Rigidez Geométrica Local no Plano xz}

Para o cálculo da matriz de rigidez geométrica do elemento, utilizando-se a parcela não linear do tensor deformação de Green-Lagrange, equações (4.126) e (4.127), de maneira análoga ao plano xy, pode-se definir as expressões (4.134) e (4.135).

$$
\begin{aligned}
\delta U_{N L} & =\frac{1}{2} \int_{A}\left(\int_{0}^{L} t_{x x} \delta\left(\frac{\partial u}{\partial x}\right)^{2} d x\right) d A+\frac{1}{2} \int_{A}\left(\int_{0}^{L} t_{x x} \delta\left(\frac{\partial w}{\partial x}\right)^{2} d x\right) d A+\frac{1}{2} \int_{A}\left(\int_{0}^{L} t_{x x} \delta z^{2}\left(\frac{\partial \theta_{y}}{\partial x}\right)^{2} d x\right) d A+ \\
& \left.-\int\left(\int_{A}^{L} t_{x x} \delta z \frac{\partial \theta_{y}}{\partial x} \frac{\partial u}{\partial x} d x\right) d A+\int_{A}\left(\int_{0}^{L} t_{x z} \delta z \frac{\partial \theta_{y}}{\partial x} \theta_{y} d x\right) d A-\int_{A} \int_{A}^{L} t_{x z} \delta \theta_{y} \frac{\partial u}{\partial x} d x\right) d A \\
\delta U_{N L} & =\frac{1}{2}\left(\int_{0}^{L} \delta\left(\frac{\partial u}{\partial x}\right)^{2} d x\right) \int_{A} t_{x x} d A+\frac{1}{2}\left(\int_{0}^{L} \delta\left(\frac{\partial w}{\partial x}\right)^{2} d x\right) \int_{A} t_{x x} d A+\frac{1}{2}\left(\int_{0}^{L} \delta\left(\frac{\partial \theta_{y}}{\partial x}\right)^{2} d x\right) \int_{A} z^{2} t_{x x} d A+ \\
& -\left(\int_{0}^{L} \delta \frac{\partial \theta_{y}}{\partial x} \frac{\partial u}{\partial x} d x\right) \int_{A} t_{x x} z d A+\left(\int_{0}^{L} \delta \frac{\partial \theta_{y}}{\partial x} \theta_{y} d x\right) \int_{A} t_{x z} z d A-\left(\int_{0}^{L} \delta \theta_{y} \frac{\partial u}{\partial x} d x\right) \int_{A} t_{x z} d A
\end{aligned}
$$

Empregando-se as mesmas relações apresentadas em (4.54), escreve-se (4.136) e (4.137).

$$
\begin{aligned}
\delta U_{N L}= & \frac{1}{2}\left(\int_{0}^{L} \delta\left(\frac{\partial u}{\partial x}\right)^{2} d x\right) P+\frac{1}{2}\left(\int_{0}^{L} \delta\left(\frac{\partial w}{\partial x}\right)^{2} d x\right) P+\frac{1}{2}\left(\int_{0}^{L} \delta\left(\frac{\partial \theta_{y}}{\partial x}\right)^{2} d x\right) P \frac{I_{y}}{A}+ \\
& -\left(\int_{0}^{L} \delta \frac{\partial \theta_{y}}{\partial x} \frac{\partial u}{\partial x} d x\right) M_{y}-\left(\int_{0}^{L} \delta \theta_{y} \frac{\partial u}{\partial x} d x\right) Q_{z} \\
\delta U_{N L}= & \frac{1}{2} \int_{0}^{L}\left[P \delta\left(\left(\frac{\partial u}{\partial x}\right)^{2}+\left(\frac{\partial w}{\partial x}\right)^{2}\right)+P \frac{I_{y}}{A} \delta\left(\left(\frac{\partial \theta_{y}}{\partial x}\right)^{2}\right)\right] d x+ \\
& -\int_{0}^{L}\left[M_{y} \delta\left(\frac{\partial \theta_{y}}{\partial x} \frac{\partial u}{\partial x}\right)+Q_{z} \delta\left(\theta_{y} \frac{\partial u}{\partial x}\right)\right] d x
\end{aligned}
$$

A parcela (4.138) já foi utilizada no plano xy, assim, a equação dos trabalhos virtuais pode ser escrita, utilizando-se as funções de forma e os deslocamentos nodais, conforme expressão (4.139).

$$
\frac{1}{2} \int_{0}^{L}\left[P \delta\left(\frac{\partial u}{\partial x}\right)^{2}\right] d x
$$




$$
\begin{aligned}
\delta U_{N L} & =\{\delta w\}^{T} \int_{0}^{L} P\left\{N_{w}{ }^{\prime}\right\}\left\{N_{w}{ }^{\prime}\right\}^{T} d x\{w\}+\{\delta w\}^{T} \int_{0}^{L} P \frac{I_{y}}{A}\left\{N_{\theta y}{ }^{\prime}\right\}\left\{N_{\theta y}{ }^{\prime}\right\}^{T} d x\{w\}+ \\
& -\{\delta w\}^{T} \int_{0}^{L} M_{y}\left\{N_{\theta y}{ }^{\prime}\right\}\left\{N_{u}{ }^{\prime}\right\}^{T} d x\{u\}-\{\delta u\}^{T} \int_{0}^{L} M_{y}\left\{N_{u}{ }^{\prime}\right\}\left\{N_{\theta y}{ }^{\prime}\right\}^{T} d x\{w\}+ \\
& -\{\delta w\}^{T} \int_{0}^{L} Q_{z}\left\{N_{\theta y}\right\}\left\{N_{u}{ }^{\prime}\right\}^{T} d x\{u\}-\{\delta u\}^{T} \int_{0}^{L} Q_{z}\left\{N_{u}{ }^{\prime}\right\}\left\{N_{\theta y}\right\}^{T} d x\{w\}
\end{aligned}
$$

Novamente, considerando-se uma força cortante constante, o momento fletor e a força cortante podem ser calculados, conforme equação (4.59).

Substituindo-se as funções de forma utilizadas, e resolvendo-se as integrais do problema, encontra-se a matriz de rigidez geométrica local do elemento, considerando o plano xz, teoria de flexão de Timoshenko e termos de ordem elevada do tensor deformação de Green-Lagrange, conforme (4.140).

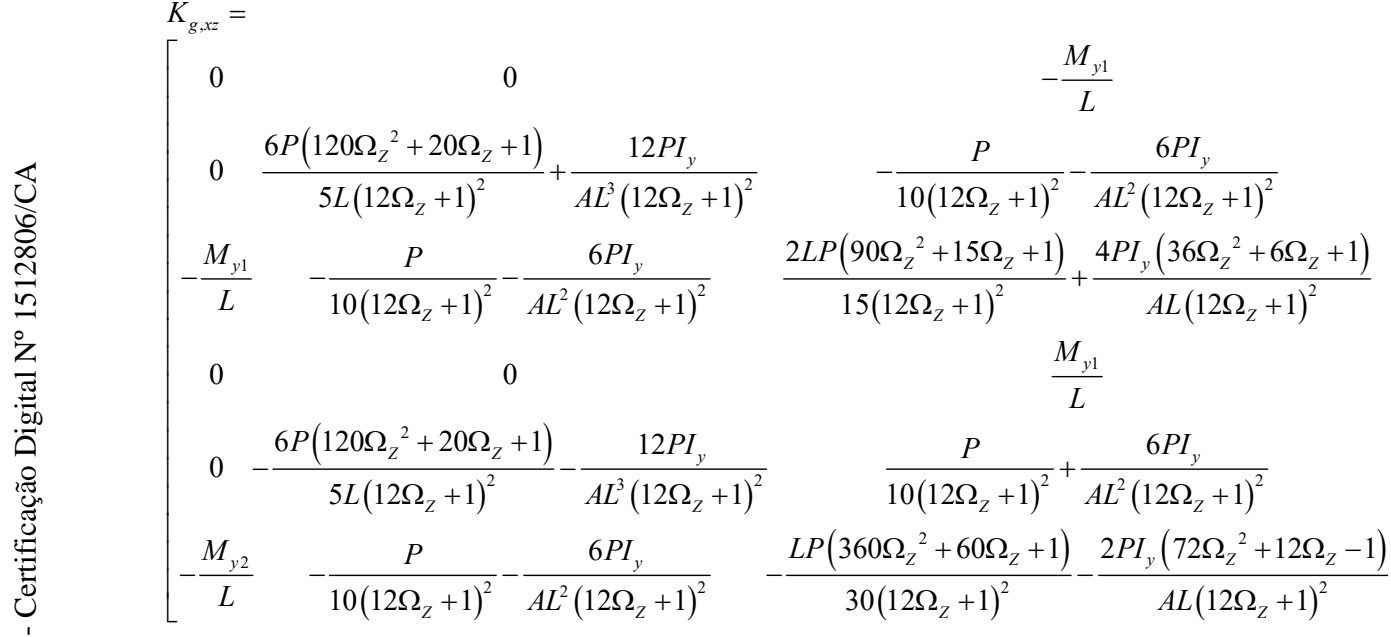

$$
\begin{aligned}
& \text { 总 } \\
& 0 \quad 0 \quad-\frac{M_{y 2}}{L} \\
& 0-\frac{6 P\left(120 \Omega_{Z}{ }^{2}+20 \Omega_{Z}+1\right)}{5 L\left(12 \Omega_{Z}+1\right)^{2}}-\frac{12 P I_{y}}{A L^{3}\left(12 \Omega_{Z}+1\right)^{2}} \quad-\frac{P}{10\left(12 \Omega_{Z}+1\right)^{2}}-\frac{6 P I_{y}}{A L^{2}\left(12 \Omega_{Z}+1\right)^{2}} \\
& \frac{M_{y 1}}{L} \quad \frac{P}{10\left(12 \Omega_{z}+1\right)^{2}}+\frac{6 P I_{y}}{A L^{2}\left(12 \Omega_{Z}+1\right)^{2}} \quad-\frac{L P\left(360 \Omega_{z}{ }^{2}+60 \Omega_{Z}+1\right)}{30\left(12 \Omega_{z}+1\right)^{2}}-\frac{2 P I_{y}\left(72 \Omega_{Z}{ }^{2}+12 \Omega_{Z}-1\right)}{A L\left(12 \Omega_{Z}+1\right)^{2}} \\
& 0 \quad 0 \quad \frac{M_{y 2}}{L} \\
& 0 \frac{6 P\left(120 \Omega_{Z}{ }^{2}+20 \Omega_{Z}+1\right)}{5 L\left(12 \Omega_{Z}+1\right)^{2}}+\frac{12 P I_{y}}{A L^{3}\left(12 \Omega_{Z}+1\right)^{2}} \quad \frac{P}{10\left(12 \Omega_{Z}+1\right)^{2}}+\frac{6 P I_{y}}{A L^{2}\left(12 \Omega_{Z}+1\right)^{2}} \\
& \left.\frac{M_{y 2}}{L} \quad \frac{P}{10\left(12 \Omega_{Z}+1\right)^{2}}+\frac{6 P I_{y}}{A L^{2}\left(12 \Omega_{Z}+1\right)^{2}} \quad \frac{2 L P\left(90 \Omega_{z}{ }^{2}+15 \Omega_{Z}+1\right)}{15\left(12 \Omega_{Z}+1\right)^{2}}+\frac{4 P I_{y}\left(36 \Omega_{z}{ }^{2}+6 \Omega_{Z}+1\right)}{A L\left(12 \Omega_{Z}+1\right)^{2}}\right]
\end{aligned}
$$

A matriz geométrica espacial é dada, somando-se a influência dos dois planos, que resulta na matriz apresentada no apêndice C.1 


\subsubsection{3}

\section{Torção Pura}

A torção pura não sofre influência da teoria de flexão definida, pois utilizam apenas as funções de interpolação axiais, que, neste trabalho, foram consideradas as mesmas para ambas as teorias, $N_{\theta x}=N_{u}=\left\{N_{1}(x) \quad N_{4}(x)\right\}$.

Assim, o problema se resume na mesma equação (4.61), resultando na matriz (4.64) já desenvolvida, que deve ser adicionada à matriz (4.133). Dessa forma, a matriz de rigidez elástica final de um elemento espacial é dada conforme (4.141).

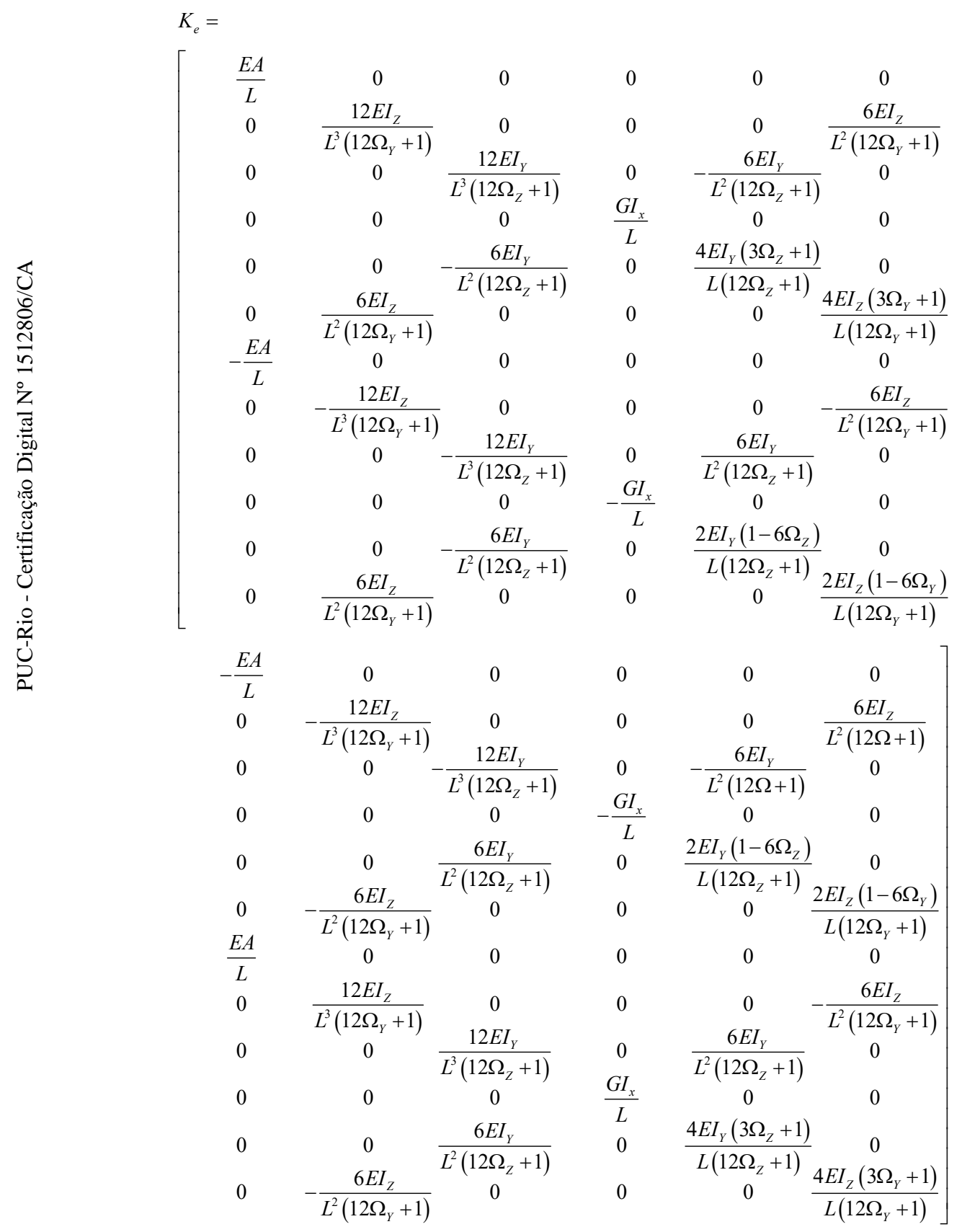




\subsubsection{4}

\section{Interação entre Torção e Carga Axial}

Mais uma vez, o elemento foi analisado inicialmente, considerando seu comportamento com os planos trabalhando independentemente. Entretanto, conforme já mencionado, a interação entre torção e a carga axial, Figura 4.5, possui um importante papel na matriz de rigidez geométrica.

A partir da Figura 4.5, pode-se escrever o campo de deslocamentos, conforme (4.142), baseado na teoria de flexão de Timoshenko.

$$
u=u_{0}-z \theta_{y}-y \theta_{z} \quad v=v_{0}-z \theta_{x} \quad w=w_{0}+y \theta_{x}
$$

Dessa forma, a parcela não linear do tensor deformação de Green-Lagrange pode ser escrita de acordo com a expressão (4.143).

$$
\begin{gathered}
\eta_{x x}=\frac{1}{2}\left(\left(\frac{\partial u}{\partial x}\right)^{2}+\left(\frac{\partial v}{\partial x}\right)^{2}+\left(\frac{\partial w}{\partial x}\right)^{2}\right) \\
\rightarrow \eta_{x x}=\frac{1}{2}\left[\left(\frac{\partial u}{\partial x}-z \frac{\partial \theta_{y}}{\partial x}-y \frac{\partial \theta_{z}}{\partial x}\right)^{2}+\left(\frac{\partial v}{\partial x}-z \frac{\partial \theta_{x}}{\partial x}\right)^{2}+\left(\frac{\partial w}{\partial x}+y \frac{\partial \theta_{x}}{\partial x}\right)^{2}\right]
\end{gathered}
$$

Pode-se observar que alguns termos da equação (4.143) já foram utilizados ao se analisar os planos independentemente, parcelas apresentadas em (4.144), restando apenas no tensor deformação de Green-Lagrange o apresentado na equação (4.145).

$$
\begin{gathered}
\frac{1}{2}\left(\frac{\partial u}{\partial x}-z \frac{\partial \theta_{y}}{\partial x}-y \frac{\partial \theta_{z}}{\partial x}\right)^{2} \quad\left(\frac{\partial v}{\partial x}\right)^{2} \quad\left(\frac{\partial w}{\partial x}\right)^{2} \\
\eta_{x x}=\frac{1}{2}\left(z\left(\frac{\partial \theta_{x}}{\partial x}\right)^{2}+y\left(\frac{\partial \theta_{x}}{\partial x}\right)^{2}\right)-z \frac{\partial v}{\partial x} \frac{\partial \theta_{x}}{\partial x}+y \frac{\partial w}{\partial x} \frac{\partial \theta_{x}}{\partial x} \\
\rightarrow \eta_{x x}=\frac{1}{2}\left(z^{2}+y^{2}\right)\left(\frac{\partial \theta_{x}}{\partial x}\right)^{2}-z \frac{\partial v}{\partial x} \frac{\partial \theta_{x}}{\partial x}+y \frac{\partial w}{\partial x} \frac{\partial \theta_{x}}{\partial x}
\end{gathered}
$$

Assim, a equação dos trabalhos virtuais pode ser aplicada, conforme a equação (4.146). 


$$
\begin{aligned}
\delta U_{N L} & =\int_{A}\left(\int_{0}^{L} t_{x x} \delta \eta_{x x} d x\right) d A \\
\delta U_{N L} & =\int_{A}\left(\int_{0}^{L} t_{x x} \delta\left[\frac{1}{2}\left(z^{2}+y^{2}\right)\left(\frac{\partial \theta_{x}}{\partial x}\right)^{2}-z \frac{\partial v}{\partial x} \frac{\partial \theta_{x}}{\partial x}+y \frac{\partial w}{\partial x} \frac{\partial \theta_{x}}{\partial x}\right] d x\right) d A \\
\delta U_{N L} & =\frac{1}{2}\left(\int_{0}^{L} \delta\left(\frac{\partial \theta_{x}}{\partial x}\right)^{2} d x\right) \int_{A} t_{x x}\left(z^{2}+y^{2}\right) d A-\left(\int_{0}^{L} \delta \frac{\partial v}{\partial x} \frac{\partial \theta_{x}}{\partial x} d x\right) \int_{A} t_{x x} z d A+ \\
& +\left(\int_{0}^{L} \delta \frac{\partial w}{\partial x} \frac{\partial \theta_{x}}{\partial x} d x\right) \int_{A} t_{x x} y d A
\end{aligned}
$$

Utilizando-se as propriedades anteriores já estabelecidas, a equação anterior pode ser escrita como (4.147).

$$
\delta U_{N L}=\frac{1}{2} \frac{P J_{p}}{A} \int_{0}^{L} \delta\left(\frac{\partial \theta_{x}}{\partial x}\right)^{2} d x-M_{y} \int_{0}^{L} \delta\left(\frac{\partial v}{\partial x} \frac{\partial \theta_{x}}{\partial x}\right) d x+\left(-M_{z}\right) \int_{0}^{L} \delta\left(\frac{\partial w}{\partial x} \frac{\partial \theta_{x}}{\partial x}\right) d x
$$

Adotando-se a interpolação dos deslocamentos pelas funções de forma obtém-se a expressão (4.148).

$$
\begin{aligned}
\delta U_{N L}= & \left\{\delta \theta_{x}\right\}^{T} \int_{0}^{L} \frac{P J_{p}}{A}\left\{N_{\theta x}{ }^{\prime}\right\}\left\{N_{\theta x}{ }^{\prime}\right\}^{T} d x\left\{\theta_{x}\right\}-\{\delta v\}^{T} \int_{0}^{L} M_{y}\left\{N_{v}{ }^{\prime}\right\}\left\{N_{\theta x}\right\}^{T} d x\left\{\theta_{x}\right\}- \\
& -\left\{\delta \theta_{x}\right\}^{T} \int_{0}^{L} M_{y}\left\{N_{\theta x}{ }^{\prime}\right\}\left\{N_{v}{ }^{\prime}\right\}^{T} d x\{v\}-\{\delta w\}^{T} \int_{0}^{L} M_{z}\left\{N_{w}{ }^{\prime}\right\}\left\{N_{\theta x}{ }^{\prime}\right\}^{T} d x\left\{\theta_{x}\right\}- \\
& -\left\{\delta \theta_{x}\right\}^{T} \int_{0}^{L} M_{z}\left\{N_{\theta x}{ }^{\prime}\right\}\left\{N_{w}{ }^{\prime}\right\}^{T} d x\{w\}
\end{aligned}
$$

Substituindo-se as funções de interpolação, considerando a teoria de flexão de Timoshenko e resolvendo-se as integrais, obtém-se a influência na matriz de rigidez geométrica da interação entre torção e carga axial, com o emprego da parcela não linear da deformação axial do tensor deformação.

Entretanto, ainda se deve considerar a parcela não linear da deformação por cisalhamento do tensor deformação, conforme as equações (4.149) e (4.150).

$$
\begin{aligned}
& \eta_{x y}=\frac{\partial u}{\partial x} \frac{\partial u}{\partial y}+\frac{\partial v}{\partial x} \frac{\partial v}{\partial y}+\frac{\partial w}{\partial x} \frac{\partial w}{\partial y}=-\frac{\partial u}{\partial x} \theta_{z}+z \frac{\partial \theta_{y}}{\partial x} \theta_{z}+y \frac{\partial \theta_{z}}{\partial x} \theta_{z}+\frac{\partial w}{\partial x} \theta_{x}+y \frac{\partial \theta_{x}}{\partial x} \theta_{x} \\
& \eta_{x z}=\frac{\partial u}{\partial x} \frac{\partial u}{\partial z}+\frac{\partial v}{\partial x} \frac{\partial v}{\partial z}+\frac{\partial w}{\partial x} \frac{\partial w}{\partial z}=-\frac{\partial u}{\partial x} \theta_{y}+z \frac{\partial \theta_{y}}{\partial x} \theta_{y}+y \frac{\partial \theta_{z}}{\partial x} \theta_{y}-\frac{\partial v}{\partial x} \theta_{x}+z \frac{\partial \theta_{x}}{\partial x} \theta_{x}
\end{aligned}
$$


Também se pode notar que alguns componentes já foram utilizados no desenvolvimento dos planos trabalhando independentemente, parcelas mostradas em (4.151). Finalmente, restam apenas os fatores apresentados em (4.152) e (4.153) para serem considerados.

$$
\begin{gathered}
\eta_{x y}=-\frac{\partial u}{\partial x} \theta_{z}+y \frac{\partial \theta_{z}}{\partial x} \theta_{z} \quad \eta_{x z}=-\frac{\partial u}{\partial x} \theta_{y}+z \frac{\partial \theta_{y}}{\partial x} \theta_{y} \\
\eta_{x y}=z \frac{\partial \theta_{y}}{\partial x} \theta_{z}+\frac{\partial w}{\partial x} \theta_{x}+y \frac{\partial \theta_{x}}{\partial x} \theta_{x} \\
\eta_{x z}=y \frac{\partial \theta_{z}}{\partial x} \theta_{y}-\frac{\partial v}{\partial x} \theta_{x}+z \frac{\partial \theta_{x}}{\partial x} \theta_{x}
\end{gathered}
$$

Portanto, o príncipio dos trabalhos virtuais pode ser aplicado novamente, obtendo-se a expressão apresentada em (4.154).

$$
\begin{aligned}
\delta U_{N L}=\int_{A}\left(\int_{0}^{L} t_{x y} \delta \eta_{x y} d x\right) d A+\int_{A}\left(\int_{0}^{L} t_{x z} \delta \eta_{x z} d x\right) d A \\
\delta U_{N L}=\left(\int_{0}^{L} \delta\left(\frac{\partial \theta_{y}}{\partial x} \theta_{z}\right) d x\right) \int_{A} t_{x y} z d A+\left(\int_{0}^{L} \delta\left(\frac{\partial w}{\partial x} \theta_{x}\right) d x\right) \int_{A} t_{x y} d A+ \\
+\left(\int_{0}^{L} \delta\left(\frac{\partial \theta_{x}}{\partial x} \theta_{x}\right) d x\right) \int_{A} t_{x y} y d A+\left(\int_{0}^{L} \delta\left(\frac{\partial \theta_{z}}{\partial x} \theta_{y}\right) d x\right) \int_{A} t_{x z} y d A+ \\
-\left(\int_{0}^{L} \delta\left(\frac{\partial v}{\partial x} \theta_{x}\right) d x\right) \int_{A} t_{x z} d A+\left(\int_{0}^{L} \delta\left(\frac{\partial \theta_{x}}{\partial x} \theta_{x}\right) d x\right) \int_{A} t_{x z} z d A
\end{aligned}
$$

Utilizando-se as relações apresentadas em (4.79) para seções bissimétricas e ignorando-se a parcela $\left(\partial \theta_{x} / \partial x\right) \theta_{x}$, pode-se reescrever a equação anterior, de acordo com (4.155). Define-se $\alpha$ e $(\alpha-1)$ como as parcelas do momento $M_{x}$, resistido pelas tensões $\tau_{x z}$ e $\tau_{x y}$, respectivamente.

$$
\begin{aligned}
\delta U_{N L} & =\left(\int_{0}^{L} \delta \frac{\partial \theta_{y}}{\partial x} \theta_{z} d x\right)(\alpha-1) M_{x}+\left(\int_{0}^{L} \delta\left(\frac{\partial w}{\partial x} \theta_{x}\right) d x\right) Q_{y}+ \\
& +\left(\int_{0}^{L} \delta\left(\frac{\partial \theta_{z}}{\partial x} \theta_{y}\right) d x\right) \alpha M_{x}-\left(\int_{0}^{L} \delta\left(\frac{\partial v}{\partial x} \theta_{x}\right) d x\right) Q_{z}
\end{aligned}
$$

Tendo em vista a seção ser limitada à torção pura de Saint Venant, pode ser utilizado $M_{x}=M_{x 2}$ e $\alpha=1 / 2$. Assim, escrevendo os deslocamentos com as funções de interpolação, obtém-se a expressão (4.156). 


$$
\begin{aligned}
\delta U_{N L}= & -\left\{\delta \theta_{y}\right\}^{T} \int_{0}^{L} \frac{M_{x}}{2}\left\{N_{\theta y}{ }^{\prime}\right\}\left\{N_{\theta z}\right\}^{T} d x\left\{\theta_{z}\right\}-\left\{\delta \theta_{z}\right\}^{T} \int_{0}^{L} \frac{M_{x}}{2}\left\{N_{\theta z}\right\}\left\{N_{\theta y}\right\}^{T} d x\left\{\theta_{y}\right\} \\
& +\left\{\delta \theta_{z}\right\}^{T} \int_{0}^{L} \frac{M_{x}}{2}\left\{N_{\theta z}{ }^{\prime}\right\}\left\{N_{\theta y}\right\}^{T} d x\left\{\theta_{y}\right\}+\left\{\delta \theta_{y}\right\}^{T} \int_{0}^{L} \frac{M_{x}}{2}\left\{N_{\theta y}\right\}\left\{N_{\theta z}\right\}^{\prime T} d x\left\{\theta_{z}\right\} \\
& +\{\delta w\}^{T} \int_{0}^{L} Q_{y}\left\{N_{w}{ }^{\prime}\right\}\left\{N_{\theta x}\right\}^{T} d x\left\{\theta_{x}\right\}+\left\{\delta \theta_{x}\right\}^{T} \int_{0}^{L} Q_{y}\left\{N_{\theta x}\right\}\left\{N_{w}{ }^{\prime}\right\}^{T} d x\{w\} \\
& -\{\delta v\}^{T} \int_{0}^{L} Q_{z}\left\{N_{v}{ }^{\prime}\right\}\left\{N_{\theta x}\right\}^{T} d x\left\{\theta_{x}\right\}-\left\{\delta \theta_{x}\right\}^{T} \int_{0}^{L} Q_{z}\left\{N_{\theta x}\right\}\left\{N_{v}{ }^{\prime}\right\}^{T} d x\{v\}
\end{aligned}
$$

Resolvendo-se as integrais, obtém-se a contribuição da interação entre torção e carga axial na matriz geométrica espacial, considerando a teoria de flexão de Timoshenko. Essa contribuição é apresentada no apêndice C.2.

\subsubsection{5 Rotações Finitas}

A matriz de rigidez geométrica de um elemento deve incluir os efeitos das rotações finitas. Com o desenvolvimento feito anteriormente, considerando a teoria de flexão de Euler-Bernoulli, pode-se notar que é indiferente a teoria de vigas empregada.

Sendo assim, a influência das rotações finitas para a matriz de rigidez geométrica, levando em conta a teoria de flexão de Timoshenko, também é dada pela matriz apresentada em (4.101). Dessa maneira, a matriz pode ser atualizada, calculando-se então a matriz de rigidez geométrica final para um elemento, considerando essa teoria de flexão. Essa matriz é apresentada no apêndice C.3.

\subsection{4 Matriz de Rigidez Local de Elemento com Funções de Forma Completas}

No item anterior, a matriz de rigidez local do elemento, considerando a teoria de Timoshenko, foi calculada por meio de funções de forma cúbicas. Conforme já mencionado, essas funções são obtidas diretamente da solução da equação diferencial do equilíbrio de um elemento infinitesimal em sua configuração indeformada. Por isso, em uma análise linear da estrutura, a discretização da barra não é necessária. 
Para a análise não linear, pode-se utilizar funções de forma que consideram à força axial atuante no elemento. Neste tipo de análise, a função de interpolação é obtida da solução homogênea da equação diferencial do equilíbrio de um elemento infinitesimal em sua configuração deformada (funções completas).

Neste tópico, será calculada a matriz de rigidez local de um elemento, a partir dessas funções de interpolação, que levam em conta a carga axial em nível infinitesimal e também a teoria de flexão de Timoshenko.

Como explicado anteriormente, ao se empregar funções de forma completas, inexiste a diferenciação entre matriz elástica e matriz de rigidez geométrica, como ocorre com as funções cúbicas, pois, mesmo na própria função de interpolação, existe a influência da carga axial atuante.

Entretanto, para se utilizar os termos do tensor deformação de GreenLagrange, a matriz final será construída da mesma maneira, obtendo-se a matriz de rigidez tangente final, que é a soma da matriz elástica com a geométrica (ainda que essa diferenciação não exista).

\subsubsection{1}

\section{Matriz de Rigidez Elástica com Funções de Forma Completas}

A matriz de rigidez elástica do elemento, frente à teoria de flexão de Timoshenko, é dada pelas expressões (4.116) e (4.117), reapresentadas, por conveniência, em (4.157) e (4.158).

$$
\begin{aligned}
\delta U_{1}= & \{\delta u\}^{T} \int_{0}^{L} E A\left\{N_{u}{ }^{\prime}\right\}\left\{N_{u}{ }^{\prime}\right\}^{T} d x\{u\}+\{\delta v\}^{T} \int_{0}^{L} E I_{z}\left\{N_{\theta z}{ }^{\prime}\right\}\left\{N_{\theta z}{ }^{\prime}\right\}^{T} d x\{v\} \\
\delta U_{2}= & \{\delta v\}^{T} \int_{0}^{L} G A\left\{N_{v}{ }^{\prime}\right\}\left\{N_{v}{ }^{\prime}\right\}^{T} d x\{v\}+\{\delta v\}^{T} \int_{0}^{L} G A\left\{N_{\theta z}\right\}\left\{N_{\theta z}\right\}^{T} d x\{v\}+ \\
& -\{\delta v\}^{T} \int_{0}^{L} G A\left\{N_{\theta z}\right\}\left\{N_{v}\right\}^{T} d x\{v\}-\{\delta v\}^{T} \int_{0}^{L} G A\left\{N_{v}{ }^{\prime}\right\}\left\{N_{\theta z}\right\}^{T} d x\{v\}
\end{aligned}
$$

Assim, para o cálculo da matriz de rigidez local, empregando-se as funções de forma completas, deve-se utilizar as funções de forma para o deslocamento transversal, $N_{v}$ e $N_{\theta z}$, apresentadas em (3.69) a (3.76). No caso de cargas de tração, pode-se empregar as funções (3.82) a (3.89) e, no caso de compressão, as funções em (3.95) a (3.102). 
Para o plano xz, essas mesmas funções de interpolação devem ser substitutídas nas expressões (4.159) e (4.160). Entretanto, essas funções representam o deslocamento transversal no vetor $N_{w}$ e $N_{\theta y}$.

$$
\begin{gathered}
\delta U_{1}=\{\delta w\}^{T} \int_{0}^{L} E I_{y}\left\{N_{\theta y}{ }^{\prime}\right\}\left\{N_{\theta y}{ }^{\prime}\right\}^{T} d x\{w\} \\
\delta U_{2}=\{\delta w\}^{T} \int_{0}^{L} G A\left\{N_{w}{ }^{\prime}\right\}\left\{N_{w}{ }^{\prime}\right\}^{T} d x\{w\}+\{\delta w\}^{T} \int_{0}^{L} G A\left\{N_{\theta y}\right\}\left\{N_{\theta y}\right\}^{T} d x\{w\}+ \\
-\{\delta w\}^{T} \int_{0}^{L} G A\left\{N_{\theta y}\right\}\left\{N_{w}{ }^{\prime}\right\}^{T} d x\{w\}-\{\delta w\}^{T} \int_{0}^{L} G A\left\{N_{w}{ }^{\prime}\right\}\left\{N_{\theta y}\right\}^{T} d x\{w\}
\end{gathered}
$$

Para o caso de torção pura, as funções de forma não são alteradas, pois, para o deslocamento axial, foram adotadas funções de forma lineares, $N_{\theta x}$, que independem do equilíbrio do elemento infinitesimal. Assim, emprega-se a equação (4.161).

$$
\delta U=\left\{\delta \theta_{x}\right\}^{T} \int_{0}^{L} G I_{x}\left\{N_{\theta x}{ }^{\prime}\right\}\left\{N_{\theta x}{ }^{\prime}\right\}^{T} d x\left\{\theta_{x}\right\} \quad N_{\theta x}=\left\{1-\frac{x}{L} \quad \frac{x}{L}\right\}
$$

A matriz desenvolvida empregando-se as relações em (4.157), (4.158), (4.159), (4.160) e (4.161) é apresentada no apêndice C.4, no caso de tração, e apêndice C.5, para situação de compressão. Essa matriz é nomeada como " 1 a ordem”, por ser referente à parcela linear (elástica) da formulação Lagrangeana atualizada e do tensor deformação.

\subsubsection{2}

\section{Matriz de Rigidez Geométrica com Funções de Forma Completas}

Baseado no mesmo desenvolvimento utilizado com as funções de interpolação cúbicas, pode-se escrever a matriz de rigidez geométrica, considerando funções de forma completas.

No plano xy, são utilizadas as expressões (4.122) e (4.123), reapresentadas em (4.162) e (4.163). Deve-se utilizar as funções de forma para o deslocamento transversal, $N_{v}$ e $N_{\theta z}$, apresentadas em (3.69) a (3.76).N caso de cargas de tração, pode-se empregar as funções (3.82) a (3.89) e, no caso de compressão, as funções em (3.95) a (3.102). 


$$
\begin{aligned}
& -\int_{0}^{L}\left[P \delta\left(\frac{\partial u^{2}}{\partial x}+\frac{\partial v^{2}}{\partial x}\right)+P \frac{I_{z}}{A} \delta\left(\frac{\partial \theta_{z}{ }^{2}}{\partial x}\right)\right] d x= \\
= & \{\delta u\}^{T} \int_{0}^{L} P\left\{N_{u}{ }^{\prime}\right\}\left\{N_{u}^{\prime}\right\}^{T} d x\{u\}+\{\delta v\}^{T} \int_{0}^{L} P\left\{N_{v}^{\prime}\right\}\left\{N_{v}^{\prime}\right\}^{T} d x\{v\} \\
& +\{\delta v\}^{T} \int_{0}^{L} P \frac{I_{z}}{A}\left\{N_{\theta z}{ }^{\prime}\right\}\left\{N_{\theta z}{ }^{\prime}\right\}^{T} d x\{v\} \\
- & \int_{0}^{L}\left[M_{z} \delta\left(\frac{\partial \theta_{z}}{\partial x} \frac{\partial u}{\partial x}\right)-Q_{y} \delta\left(\theta_{z} \frac{\partial u}{\partial x}\right)\right] d x= \\
= & \left.\{\delta v\}^{T} \int_{0}^{L} M_{z}\left\{N_{\theta z}{ }^{\prime}\right\}\left\{N_{u}^{\prime}\right\}^{T} d x\{u\}+\{\delta u\}^{T} \int_{0}^{L} M_{z}\left\{N_{u}{ }^{\prime}\right\}\left\{N_{\theta z}\right\}^{\prime}\right\}^{T} d x\{v\}+ \\
& -\{\delta v\}^{T} \int_{0}^{L} Q_{y}\left\{N_{\theta z}\right\}\left\{N_{u}^{\prime}\right\}^{T} d x\{u\}-\{\delta u\}^{T} \int_{0}^{L} Q_{y}\left\{N_{u}{ }^{\prime}\right\}\left\{N_{\theta z}\right\}^{T} d x\{v\}
\end{aligned}
$$

No plano xz, utiliza-se a equação (4.139), apresentada novamente em (4.164). As funções de forma são substituídas em $N_{w}$ e $N_{\theta y}$.

$$
\begin{aligned}
\delta U_{N L} & =\{\delta w\}^{T} \int_{0}^{L} P\left\{N_{w}{ }^{\prime}\right\}\left\{N_{w}{ }^{\prime}\right\}^{T} d x\{w\}+\{\delta w\}^{T} \int_{0}^{L} P \frac{I_{y}}{A}\left\{N_{\theta y}{ }^{\prime}\right\}\left\{N_{\theta y}{ }^{\prime}\right\}^{T} d x\{w\}+ \\
& -\{\delta w\}^{T} \int_{0}^{L} M_{y}\left\{N_{\theta y}{ }^{\prime}\right\}\left\{N_{u}{ }^{\prime}\right\}^{T} d x\{u\}-\{\delta u\}^{T} \int_{0}^{L} M_{y}\left\{N_{u}{ }^{\prime}\right\}\left\{N_{\theta y}{ }^{\prime}\right\}^{T} d x\{w\}+ \\
& -\{\delta w\}^{T} \int_{0}^{L} Q_{z}\left\{N_{\theta y}\right\}\left\{N_{u}{ }^{\prime}\right\}^{T} d x\{u\}-\{\delta u\}^{T} \int_{0}^{L} Q_{z}\left\{N_{u}{ }^{\prime}\right\}\left\{N_{\theta y}\right\}^{T} d x\{w\}
\end{aligned}
$$

A matriz obtida apenas com as direções trabalhando isoladamente, ou seja, empregando-se as equações (4.162), (4.163) e (4.164), pode ser visualizada nos apêndices C.6 e C.7, para os casos de tração e compressão respectivamente, sendo chamada de " $2^{\mathrm{a}}$ ordem", por ser referente à parcela não linear da formulação Lagrangeana atualizada e do tensor deformação.

Para a interação entre torção e carga axial, necessário utilizar as equações apresentadas em (4.148) e (4.156), repetidas nas expressões (4.165) e (4.166).

$$
\begin{aligned}
\delta U_{N L}= & \left\{\delta \theta_{x}\right\}^{T} \int_{0}^{L} \frac{P J_{p}}{A}\left\{N_{\theta x}{ }^{\prime}\right\}\left\{N_{\theta x}\right\}^{\prime T} d x\left\{\theta_{x}\right\}-\{\delta v\}^{T} \int_{0}^{L} M_{y}\left\{N_{v}{ }^{\prime}\right\}\left\{N_{\theta x}{ }^{\prime}\right\}^{T} d x\left\{\theta_{x}\right\}- \\
& -\left\{\delta \theta_{x}\right\}^{T} \int_{0}^{L} M_{y}\left\{N_{\theta x}{ }^{\prime}\right\}\left\{N_{v}^{\prime}\right\}^{T} d x\{v\}-\{\delta w\}^{T} \int_{0}^{L} M_{z}\left\{N_{w}{ }^{\prime}\right\}\left\{N_{\theta x}{ }^{\prime}\right\}^{T} d x\left\{\theta_{x}\right\}- \\
& -\left\{\delta \theta_{x}\right\}^{T} \int_{0}^{L} M_{z}\left\{N_{\theta x}{ }^{\prime}\right\}\left\{N_{w}{ }^{\prime}\right\}^{T} d x\{w\}
\end{aligned}
$$




$$
\begin{aligned}
\delta U_{N L}= & -\left\{\delta \theta_{y}\right\}^{T} \int_{0}^{L} \frac{M_{x}}{2}\left\{N_{\theta y}{ }^{\prime}\right\}\left\{N_{\theta z}\right\}^{T} d x\left\{\theta_{z}\right\}-\left\{\delta \theta_{z}\right\}^{T} \int_{0}^{L} \frac{M_{x}}{2}\left\{N_{\theta z}\right\}\left\{N_{\theta y}\right\}^{T} d x\left\{\theta_{y}\right\} \\
& +\left\{\delta \theta_{z}\right\}^{T} \int_{0}^{L} \frac{M_{x}}{2}\left\{N_{\theta z}{ }^{\prime}\right\}\left\{N_{\theta y}\right\}^{T} d x\left\{\theta_{y}\right\}+\left\{\delta \theta_{y}\right\}^{T} \int_{0}^{L} \frac{M_{x}}{2}\left\{N_{\theta y}\right\}\left\{N_{\theta z}\right\}^{\prime T} d x\left\{\theta_{z}\right\} \\
& +\{\delta w\}^{T} \int_{0}^{L} Q_{y}\left\{N_{w}{ }^{\prime}\right\}\left\{N_{\theta x}\right\}^{T} d x\left\{\theta_{x}\right\}+\left\{\delta \theta_{x}\right\}^{T} \int_{0}^{L} Q_{y}\left\{N_{\theta x}\right\}\left\{N_{w}{ }^{\prime}\right\}^{T} d x\{w\} \\
& -\{\delta v\}^{T} \int_{0}^{L} Q_{z}\left\{N_{v}{ }^{\prime}\right\}\left\{N_{\theta x}\right\}^{T} d x\left\{\theta_{x}\right\}-\left\{\delta \theta_{x}\right\}^{T} \int_{0}^{L} Q_{z}\left\{N_{\theta x}\right\}\left\{N_{v}{ }^{\prime}\right\}^{T} d x\{v\}
\end{aligned}
$$

As funções de interpolação a serem utilizadas nesse caso para o deslocamento transversal, $N_{v}, N_{w}, N_{\theta z}$ e $N_{\theta y}$, são as funções completas, em que existe a presença da influência da carga axial.

Para considerar as rotações finitas, não houve diferenciação, pois as rotações não foram escritas, com a utilização das funções de interpolação. Sendo assim, considera-se a mesma matriz apresentada em (4.101).

A matriz que leva em consideração a interação entre torção e carga axial, como também as rotações finitas, é apresentada no apêndice C.8, para casos de tração, e no apêndice C.9, para situação de compressão.

\subsubsection{3 Matriz de Rigidez Tangente}

A matriz de rigidez local do elemento, matriz tangente, é dada pela soma da matriz elástica e da geométrica. Essa matriz, considerando a teoria de flexão de Timoshenko, as funções de forma completas e todos os termos do tensor deformação de Green-Lagrange, é dada pela soma das matrizes dos apêndices C.4, C.6 e C.8, quando o elemento está submetido à tração. Quando a carga é de compressão, essa soma é feita com as matrizes apresentadas nos apêndices C.5, C.7 e C.9.

Essa matriz de rigidez também pode ser expandida em uma série de Taylor até $\mu^{6}$, ou $P^{3}$, e esse resultado é apresentado no apêndice C.10. Pode-se notar, que os fatores até $\mu^{2}$ correspondem à matriz elástica e à geométrica usuais, considerando funções de forma cúbicas. No apêndice D são apresentadas as metodologias de análise não linear utilizadas em conjunto com a matriz de rigidez desenvolvida. 


\section{5}

\section{Cargas Nodais Equivalentes}

A discretização de um modelo estrutural está fundamentada na representação do comportamento contínuo do modelo por parâmetros de rigidez e de solicitações externas (carregamentos) nos nós (pontos de discretização).

Tanto no método da rigidez direta como no dos elementos finitos, as solicitações externas atuantes no modelo estrutural devem ser transformadas em cargas nodais combinadas, superpondo-se as cargas nodais propriamente ditas com as equivalentes nodais. Entretanto, no método da rigidez direta, essas cargas equivalentes nodais correspondem às reações de engastamento perfeito dos elementos de barra carregados, com sentidos invertidos.

De acordo com Martha (2017), a determinação das reações de engastamento perfeito de uma barra é feita, utilizando-se o teorema de Betti. Esse procedimento pode ser ilustrado pela Figura 5.1.
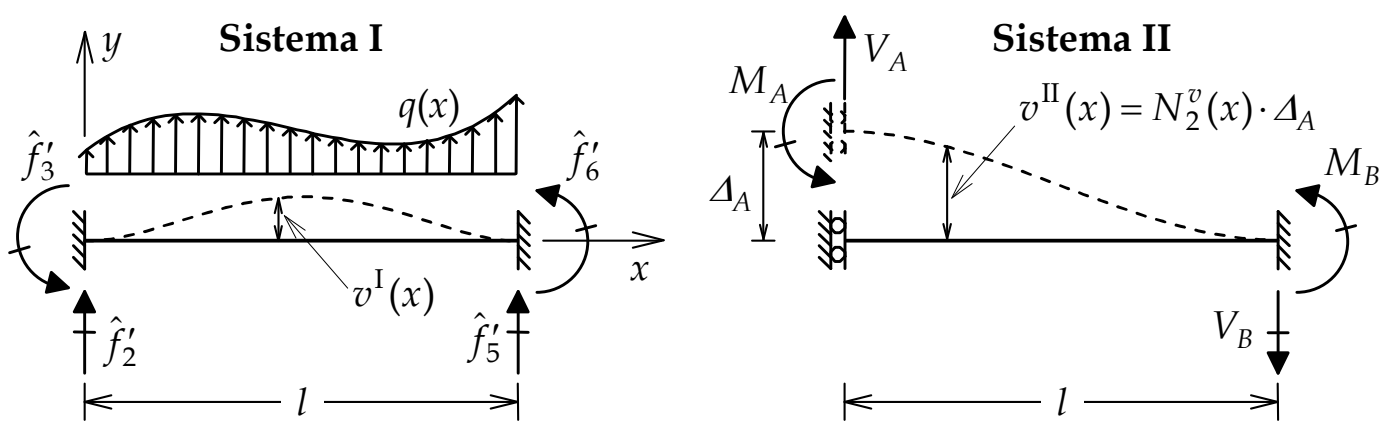

Figura 5.1 - Teorema de Betti para cálculo da reação vertical na extremidade inicial Fonte: Martha (2017).

Nesta Figura 5.1 podem ser observados dois distintos sistemas: o sistema I, composto pela barra biengastada com o carregamento externo aplicado e as devidas reações de apoio; e o sistema II, que libera o vínculo correspondente à reação vertical no ponto $A$, e a ele aplica uma força $V_{A}$. A deformada do sistema II é proporcional à função de forma correspondente. 
Com a aplicação do teorema de Betti, o trabalho das forças externas do sistema I, com os deslocamentos correspondentes do sistema II, é igual ao realizado pelas forças externas do sistema II, com os respectivos deslocamentos do sistema I.

Como todas as forças e momentos externos do sistema II possuem deslocamentos e rotações correspondentes nulos no sistema I, o trabalho das forças do sistema I com os deslocamentos do sistema II deve ser nulo, equação (5.1), que corresponde à expressão para o cálculo da reação, em função do carregamento transversal $q(x)$.

$$
\hat{f}_{2}^{\prime} \Delta_{A}+\int_{0}^{l} q(x) \cdot N_{2}^{v}(x) \cdot \Delta_{A} \cdot d x=0 \rightarrow \hat{f}_{2}^{\prime}=-\int_{0}^{l} q(x) \cdot N_{2}^{v}(x) \cdot d x
$$

De maneira análoga, pode-se calcular a reação momento $\hat{f}_{3}^{\prime}$ na extremidade inicial pelo teorema de Betti, utilizando-se um sistema II, em que é liberada a rotação associada a essa reação no apoio $\hat{f}_{3}^{\prime}$ da extremidade inicial, conforme pode ser visualizado na Figura 5.2.
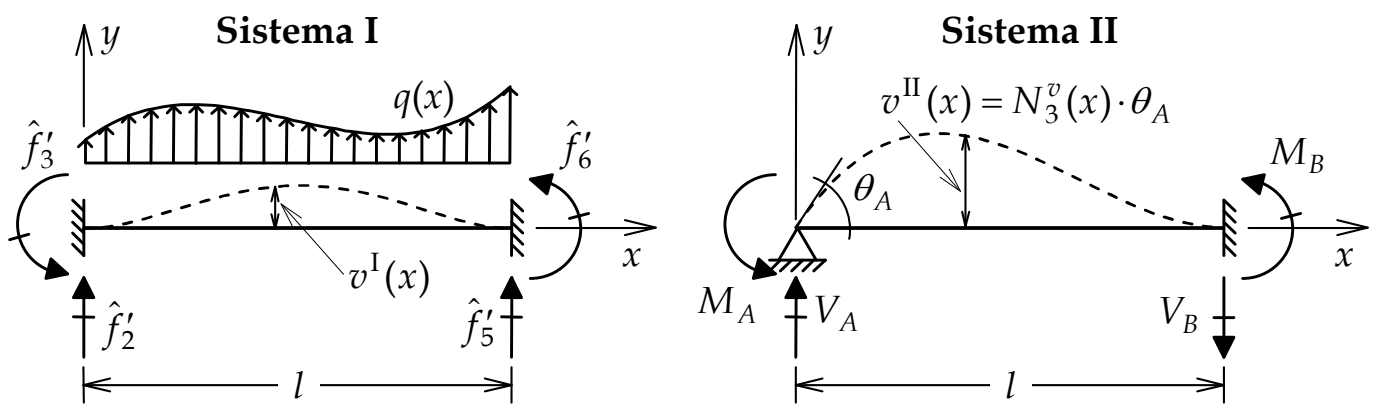

Figura 5.2 - Teorema de Betti para cálculo da reação momento na extremidade inicial Fonte: Martha (2017).

A aplicação do teorema de Betti para essa situação resulta em (5.2).

$$
\hat{f}_{3}^{\prime} \theta_{A}+\int_{0}^{l} q(x) \cdot N_{3}^{v}(x) \cdot \theta_{A} \cdot d x=0 \rightarrow \hat{f}_{3}^{\prime}=-\int_{0}^{l} q(x) \cdot N_{3}^{v}(x) \cdot d x
$$

Assim, de forma geral, a expressão para o cálculo dos carregamentos equivalentes nodais pode ser escrita de acordo com as equações (5.3), para carregamento axial, e (5.4), para carregamento transversal, conforme demonstra a Figura 5.3. 

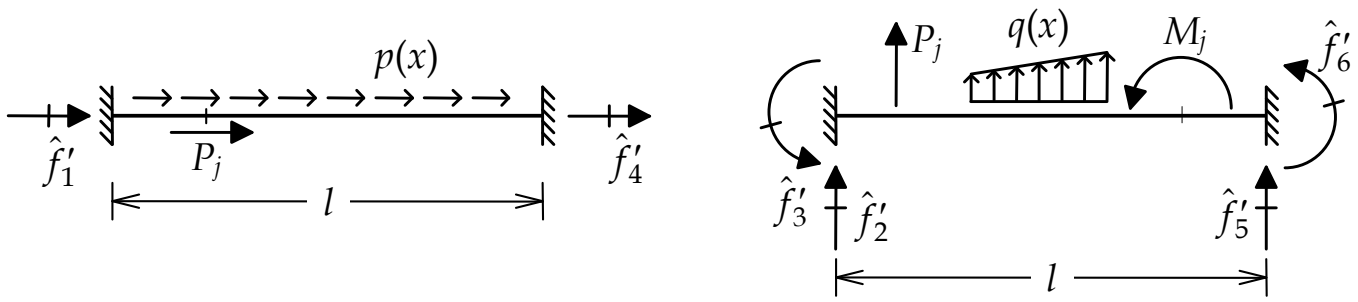

Figura 5.3 - Reações de engastamento perfeito de barras isoladas

Fonte: Martha (2017).

$$
\begin{gathered}
\hat{f}_{i}^{\prime}=-\int_{0}^{l} N_{i}^{u}(x) \cdot p(x) \cdot d x-\sum_{j} N_{i}^{u}\left(x_{j}\right) \cdot P_{j} \quad(i=1,4) \\
\hat{f}_{i}^{\prime}=-\int_{0}^{l} N_{i}^{v}(x) \cdot q(x) \cdot d x-\sum_{j} N_{i}^{v}\left(x_{j}\right) \cdot P_{j}-\sum_{j} \frac{d N_{i}^{v}\left(x_{j}\right)}{d x} \cdot M_{j}
\end{gathered}
$$

Dessa forma, verifica-se que as reações de engastamento perfeito dependem das funções de forma e, por meio delas, podem ser calculadas. Sendo assim, podese empregar as funções de forma, para elemento infinitesimal na configuração indeformada, funções cúbicas, ou as funções completas, ao se considerar o equilíbrio de um elemento infinitesimal na condição deformada. Além disso, a teoria de flexão adotada também influenciará nas reações de engastamento, pois as funções de forma são diferentes.

Em estruturas usuais, o caso mais geral de carregamento considerado para a obtenção de reações de engastamento de barras é o de uma força linearmente distribuída, conforme ilustrado na (5.4).

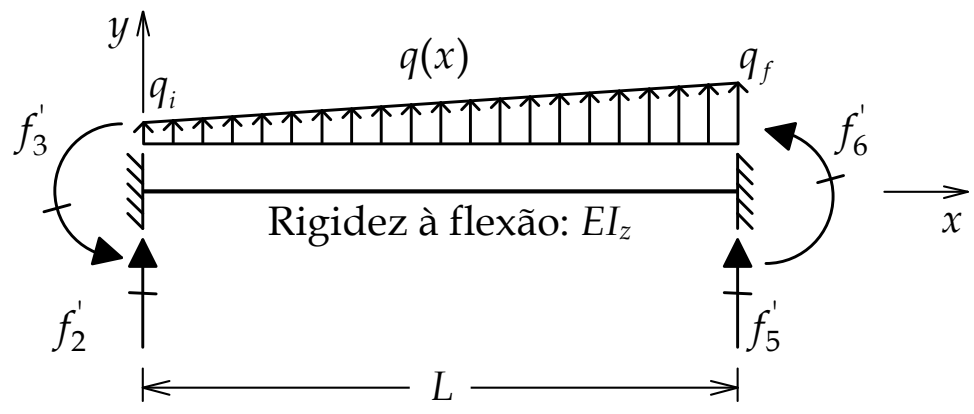

Figura 5.4 - Carregamento externo trapezoidal em barra isolada Fonte: Adaptado de Martha (2018).

Esse carregamento linear pode ser escrito pela composição de um carregamento uniformemente distribuído $\left(q_{0}\right)$, com um carregamento linear (triangular), $q_{1}=q_{f}-q_{i}$, de acordo com a Figura 5.5 e expressão 5.5. 


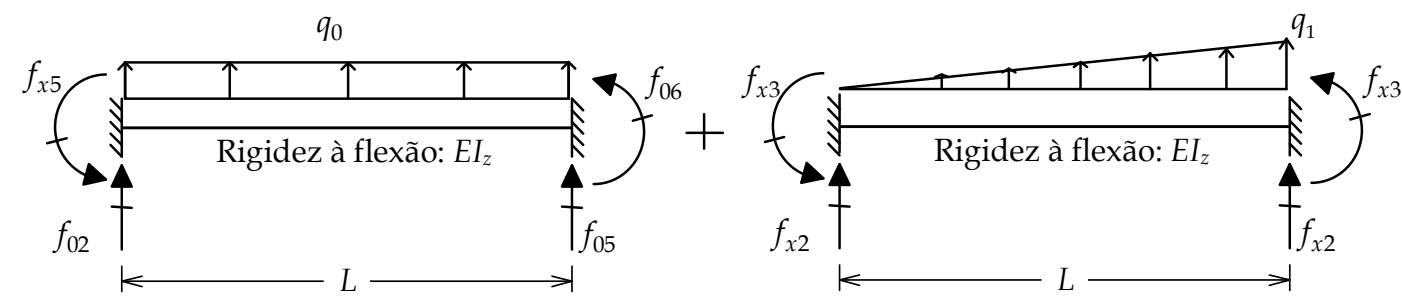

Figura 5.5 - Composição de carregamento externo trapezoidal em barra isolada Fonte: Adaptado de Burgos e Martha (2013).

$$
q(x)=q_{0}+q_{1} \frac{x}{L} \quad \rightarrow \quad q_{0}=q_{i} \quad q_{1}=q_{f}-q_{i}
$$

Assim, substituindo-se o carregamento apresentado em (5.5) na equação (5.4), obtém-se a expressão para o cálculo das reações de engastamento perfeito para o caso de carregamento linear, conforme as expressões (5.6) e (5.7).

$$
\begin{gathered}
F=-q_{0} \int_{0}^{l} N_{i}^{v}(x) d x-\frac{q_{1}}{L} \int_{0}^{l} N_{i}^{v}(x) \cdot x d x \rightarrow F=f_{0 i}+f_{x i} \\
f_{0 i}=-q_{0} \int_{0}^{l} N_{i}^{v}(x) d x \quad f_{x i}=-\frac{q_{1}}{L} \int_{0}^{l} N_{i}^{v}(x) \cdot x d x
\end{gathered}
$$

Para um carregamento linear agindo axialmente, conforme a Figura 5.6, o desenvolvimento é o mesmo, podendo-se também utilizar as expressões (5.6) e (5.7).
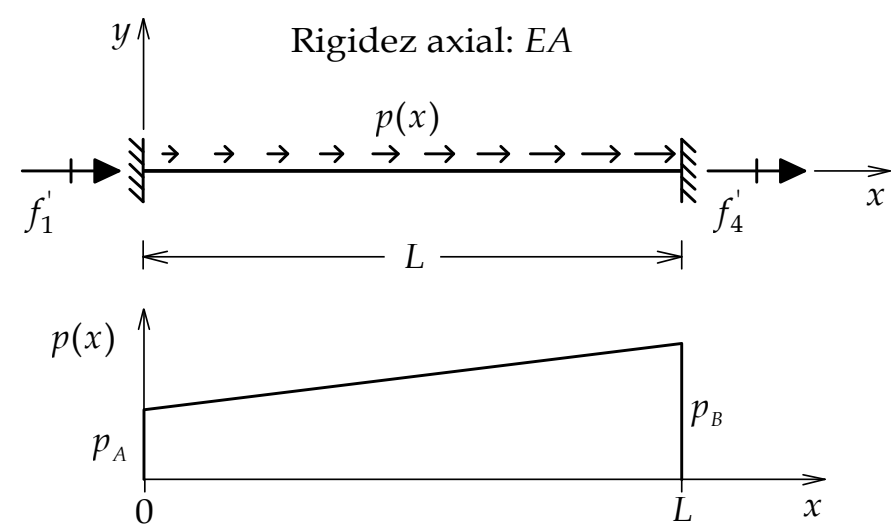

Figura 5.6 - Carregamento axial trapezoidal em barra isolada Fonte: Adaptado de Martha (2018).

Dessa maneira, o cálculo das reações de engastamento perfeito se resume a substituir as funções de forma desenvolvidas no capítulo 3, na equação (5.6). 


\section{1}

\section{Equilíbrio de Elemento Infinitesimal na Configuração Indeformada}

O cálculo das cargas nodais equivalentes, considerando as funções de forma cúbicas, desenvolvidas a partir da solução homogênea da equação diferencial do equilíbrio de um elemento infinitesimal em sua configuração indeformada, já é bem conhecido na literatura.

\section{1 .1}

\section{Teoria de Flexão de Euler-Bernoulli}

As cargas nodais equivalentes, considerando a teoria de flexão de EulerBernoulli e o equilíbrio de um elemento infinitesimal em sua configuração indeformada, levam ao emprego das funções de forma Hermitianas. Essas funções foram reproduzidas no capítulo 3, expressões de (3.12) a (3.15).

Assim, utilizando-se as equações (5.6) e (5.7) para o cálculo das reações de engastamento perfeito de uma barra isolada, obtém-se os já conhecidos resultados apresentados em (5.8) e (5.9).

$$
\begin{gathered}
f_{02}=f_{05}=\frac{-q_{0} L}{2} \quad f_{03}=\frac{-q_{0} L^{2}}{12} \quad f_{06}=\frac{q_{0} L^{2}}{12} \\
f_{x 2}=\frac{-3 q_{1} L}{20} \quad f_{x 5}=\frac{-q_{1} L^{2}}{30} \quad f_{x 3}=\frac{-7 q_{1} L}{20} \quad f_{x 6}=\frac{q_{1} L^{2}}{20}
\end{gathered}
$$

\section{1 .2}

\section{Teoria de Flexão de Timoshenko}

Para o caso de se considerar a teoria de flexão de Timoshenko e o equilíbrio de um elemento infinitesimal em sua configuração indeformada, empregam-se as funções de interpolação cúbicas também reproduzidas no capítulo 3 , expressões de (3.21) a (3.24).

Utilizando-se novamente as equações para o cálculo das reações de engastamento perfeito de uma barra isolada, (5.6) e (5.7), encontram-se os valores para as cargas nodais equivalentes, conforme as expressões (5.10) a (5.12).

$$
f_{02}=f_{05}=\frac{-q_{0} L}{2} \quad f_{03}=\frac{-q_{0} L^{2}}{12} \quad f_{06}=\frac{q_{0} L^{2}}{12}
$$




$$
\begin{gathered}
f_{x 2}=\frac{-q_{1} L\left(2 \Omega+\frac{3}{20}\right)}{1+12 \Omega} \quad f_{x 3}=\frac{-q_{1} L^{2}(15 \Omega+1)}{30(1+12 \Omega)} \\
f_{x 5}=\frac{-q_{1} L\left(4 \Omega+\frac{7}{20}\right)}{1+12 \Omega} \quad f_{x 6}=\frac{q_{1} L^{2}(10 \Omega+1)}{20(1+12 \Omega)}
\end{gathered}
$$

Pode-se observar que as reações de engastamento devidas à carga uniformemente distribuída não dependem do cisalhamento, não existindo diferença entre as teorias de flexão de Euler-Bernoulli e de Timoshenko.

\section{2}

\section{Equilíbrio de Elemento Infinitesimal na Configuração Deformada}

O cálculo das cargas nodais equivalentes também pode levar em consideração a carga axial no elemento. Para essa situação, empregam-se as funções de forma desenvolvidas a partir da solução homogênea da equação diferencial do equilíbrio de um elemento infinitesimal em sua configuração deformada.

\subsection{1 \\ Teoria de Flexão Euler-Bernoulli}

As cargas nodais equivalentes, diante da teoria de vigas de Euler-Bernoulli e do equilíbrio de um elemento infinitesimal em sua configuração deformada, levam ao emprego das funções exponencias que consideram a influência das cargas axiais dentro das próprias funções. Essas funções foram desenvolvidas no capítulo 3 , expressões de (3.30) a (3.33)(3.37).

Aplicando-se essas funções de forma nas equações (5.6) e (5.7), são calculadas as reações de engastamento, conforme as expressões de (5.13) a (5.17).

$$
\begin{gathered}
f_{02}=f_{05}=\frac{-q_{0} L}{2} \quad f_{03}=\frac{-q_{0}\left(\frac{L \mu}{2}-e^{L \mu}+\frac{L \mu e^{L \mu}}{2}+1\right)}{\mu^{2}\left(e^{L \mu}-1\right)}=-f_{06} \\
f_{x 2}=\frac{-q_{1}\left(6 L \mu-12 e^{L \mu}+3 L^{2} \mu^{2}+L^{3} \mu^{3}-3 L^{2} \mu^{2} e^{L \mu}+L^{3} \mu^{3} e^{L \mu}+6 L \mu e^{L \mu}+12\right)}{6 L \mu^{2}\left(L \mu-2 e^{L \mu}+L \mu e^{L \mu}+2\right)}
\end{gathered}
$$




$$
\begin{gathered}
f_{x 3}=\frac{-q_{1}\left(\frac{L^{2}\left(3 e^{2 L \mu}-3\right)}{6}-\mu\left(\frac{2 L^{3} e^{L \mu}}{3}+\frac{L^{2}\left(L+L e^{2 L \mu}\right)}{6}\right)\right)}{L \mu\left(e^{L \mu}-1\right)\left(L \mu-2 e^{L \mu}+L \mu e^{L \mu}+2\right)} \\
f_{x 5}=\frac{-q_{1}\left(12 e^{L \mu}-6 L \mu+3 L^{2} \mu^{2}+2 L^{3} \mu^{3}-3 L^{2} \mu^{2} e^{L \mu}+2 L^{3} \mu^{3} e^{L \mu}-6 L \mu e^{L \mu}-12\right)}{6 L \mu^{2}\left(L \mu-2 e^{L \mu}+L \mu e^{L \mu}+2\right)} \\
f_{x 6}=\frac{-q_{1}\left(2 L\left(e^{L \mu}-1\right)^{2}+\frac{L^{3} \mu^{2}\left(e^{L \mu}+e^{2 L \mu}+1\right)}{3}-\frac{3 L^{2} \mu\left(e^{2 L \mu}-1\right)}{6}\right)}{L \mu^{2}\left(e^{L \mu}-1\right)\left(L \mu-2 e^{L \mu}+L \mu e^{L \mu}+2\right)}
\end{gathered}
$$

Caso a força axial seja de tração, o valor de $\mu$ é um número real e a solução e as funções de interpolação podem ser escritas por funções hiperbólicas, desenvolvidas em (3.43) a (3.46).

Assim, as cargas equivalentes nodais são calculadas, aplicando-se essas funções de interpolação nas equações (5.6) e (5.7), obtendo-se as relações (5.18) a (5.23).

$$
\begin{gathered}
f_{02}=f_{05}=\frac{-q_{0} L}{2} \\
f_{03}=\frac{-q_{0}(L \mu-2 \operatorname{senh}(L \mu)-2 \cosh (L \mu)+L \mu(\cosh (L \mu)+\operatorname{senh}(L \mu))+2)}{2\left(\mu^{2}(\cosh (L \mu)+\operatorname{senh}(L \mu))-\mu^{2}\right)}=-f_{06} \\
f_{x 2}=\frac{-q_{1}\left(6 L \mu-12 \operatorname{senh}(L \mu)-12 \cosh (L \mu)+3 L^{2} \mu^{2}+L^{3} \mu^{3}\right)}{6 L \mu^{2}(L \mu-2 \operatorname{senh}(L \mu)-2 \cosh (L \mu)+L \mu(\cosh (L \mu)+\operatorname{senh}(L \mu))+2)}+ \\
\frac{-q_{1}\left(-3 L^{2} \mu^{2}(\cosh (L \mu)+\operatorname{senh}(L \mu))+L^{3} \mu^{3}(\cosh (L \mu)+\operatorname{senh}(L \mu))\right)}{6 L \mu^{2}(L \mu-2 \operatorname{senh}(L \mu)-2 \cosh (L \mu)+L \mu(\cosh (L \mu)+\operatorname{senh}(L \mu))+2)}+ \\
\frac{-q_{1}(6 L \mu(\cosh (L \mu)+\operatorname{senh}(L \mu))+12)}{6 L \mu^{2}(L \mu-2 \operatorname{senh}(L \mu)-2 \cosh (L \mu)+L \mu(\cosh (L \mu)+\operatorname{senh}(L \mu))+2)} \\
f_{x 5}=\frac{-q_{1} L(2 L \mu-3 \operatorname{senh}(L \mu)+L \mu \cosh (L \mu))}{6 L \mu(L \mu \operatorname{senh}(L \mu)-2 \cosh (L \mu)+2)} \\
f_{x 6}=\frac{-q_{1}\left(12 \operatorname{senh}(L \mu)+12 \cosh (L \mu)-6 L \mu+3 L^{2} \mu^{2}+2 L^{3} \mu^{3}\right)}{6 L \mu^{2}(L \mu-2 \operatorname{senh}(L \mu)-2 \cosh (L \mu)+L \mu(\cosh (L \mu)+\operatorname{senh}(L \mu))+2)}+ \\
\frac{-q_{1}\left(-3 L^{2} \mu^{2}(\cosh (L \mu)+\operatorname{senh}(L \mu))+2 L^{3} \mu^{3}(\cosh (L \mu)+\operatorname{senh}(L \mu))\right.}{6 L \mu^{2}(L \mu-2 \operatorname{senh}(L \mu)-2 \cosh (L \mu)+L \mu(\cosh (L \mu)+\operatorname{senh}(L \mu))+2)}+ \\
\frac{-q_{1}(-6 L \mu(\cosh (L \mu)+\operatorname{senh}(L \mu))-12)}{6 L \mu^{2}(L \mu-2 \operatorname{senh}(L \mu)-2 \cosh (L \mu)+L \mu(\cosh (L \mu)+\operatorname{senh}(L \mu))+2)} \\
\left.\frac{(L \operatorname{sesh}(L \mu)-12)}{6}-\frac{3 L^{2} \mu \operatorname{senh}(L \mu)}{2}+\frac{L \mu^{2}\left(2 L^{2} \cosh (L \mu)+L^{2}\right)}{6}\right)
\end{gathered}
$$


Caso a força axial seja de compressão, o valor de $\mu$ é um número complexo e as funções de interpolação podem ser escritas por funções trigonométricas, desenvolvidas nas equações (3.56) a (3.59).

Aplicando-se as equações (5.6) e (5.7), obtém-se as expressões (5.24) a (5.29) para as cargas equivalentes nodais.

$$
\begin{gathered}
f_{02}=f_{05}=\frac{-q_{0} L}{2} \\
f_{03}=\frac{-q_{0}\left(L^{2} \mu^{2}-4 \cos (L \mu)+L^{2} \mu^{2} \cos (L \mu)-4 L \mu \operatorname{sen}(L \mu)+4\right)}{2 \mu^{2}(2 \cos (L \mu)+L \mu \operatorname{sen}(L \mu)-2)}=-f_{06} \\
f_{x 2}=\frac{-q_{1}\left(12 \cos (L \mu)+3 L^{2} \mu^{2}-3 L^{2} \mu^{2} \cos (L \mu)+L^{3} \mu^{3} \operatorname{sen}(L \mu)+6 L \mu \operatorname{sen}(L \mu)-12\right)}{6 L \mu^{2}(2 \cos (L \mu)+L \mu \operatorname{sen}(L \mu)-2)} \\
f_{x 5}=\frac{-q_{1}\left(6 \cos (L \mu)-\frac{3 L^{2} \mu^{2}}{2}+\frac{3 L^{2} \mu^{2} \cos (L \mu)}{2}+L^{3} \mu^{3} \operatorname{sen}(L \mu)+3 L \mu \operatorname{sen}(L \mu)-6\right)}{3 L \mu^{2}(2 \cos (L \mu)+L \mu \operatorname{Len}(L \mu)-2)} \\
f_{x 3}=\frac{\left.-q_{1}\left(L^{2} \mu^{2}-12 \cos (L \mu)+2 L^{2} \mu^{2} \cos (L \mu)-9 L \mu \operatorname{Lsen}(L \mu)+L \mu \cos (L \mu)\right)+12\right)}{6 \mu^{2}(2 \cos (L \mu)+L \mu \operatorname{sen}(L \mu)-2)}
\end{gathered}
$$

\section{2 .2}

\section{Teoria de Flexão de Timoshenko}

As cargas nodais equivalentes, considerando a teoria de flexão de Timoshenko e o equilíbrio de um elemento infinitesimal em sua configuração deformada, levam ao emprego das funções exponencias que têm em conta a influência das cargas axiais dentro das próprias funções. Essas funções foram desenvolvidas no capítulo 3, expressões de (3.69) a (3.72).

Aplicando-se essas funções de forma nas equações (5.6) e (5.7), são calculadas as reações de engastamento, conforme as expressões de (5.30) a (5.34).

$$
\begin{gathered}
f_{02}=f_{05}=\frac{-q_{0} L}{2} \quad f_{03}=\frac{-q_{0}\left(L^{2} \Lambda^{2} \Omega-1\right)\left(L \Lambda-2 e^{L \Lambda}+L \Lambda e^{L \Lambda}+2\right)}{2 \Lambda^{2}\left(e^{L \Lambda}-1\right)}=-f_{06} \\
f_{x 2}=\frac{-q_{1}\left(3 L^{2} \Lambda^{2}-12 e^{L \Lambda}+L^{3} \Lambda^{3}+6 L \Lambda-12 L^{2} \Lambda^{2} \Omega-6 L^{3} \Lambda^{3} \Omega-3 L^{4} \Lambda^{4} \Omega\right)}{6 L \Lambda^{2}\left(L \Lambda-2 e^{L \Lambda}-2 L^{2} \Lambda^{2} \Omega+L \Lambda e^{L \Lambda}+2 L^{2} \Lambda^{2} \Omega e^{L \Lambda}+2\right)}+ \\
\frac{-q_{1}\left(-3 L^{2} \Lambda^{2} e^{L \Lambda}+L^{3} \Lambda^{3} e^{L \Lambda}+6 L \Lambda e^{L \Lambda}+12 L^{2} \Lambda^{2} \Omega e^{L \Lambda}-6 L^{3} \Lambda^{3} \Omega e^{L \Lambda}+3 L^{4} \Lambda^{4} \Omega e^{L \Lambda}+12\right)}{6 L \Lambda^{2}\left(L \Lambda-2 e^{L \Lambda}-2 L^{2} \Lambda^{2} \Omega+L \Lambda e^{L \Lambda}+2 L^{2} \Lambda^{2} \Omega e^{L \Lambda}+2\right)}
\end{gathered}
$$




$$
\begin{gathered}
f_{x 3}=\frac{L q_{1}\left(L^{2} \Lambda^{2} \Omega-1\right)\left(L \Lambda-3 e^{2 L \Lambda}-3 L^{2} \Lambda^{2} \Omega-6 L \Lambda \Omega+4 L \Lambda e^{L \Lambda}+L \Lambda e^{2 L \Lambda}\right)}{6 \Lambda\left(e^{L \Lambda}-1\right)\left(L \Lambda-2 e^{L \Lambda}-2 L^{2} \Lambda^{2} \Omega+L \Lambda e^{L \Lambda}+2 L^{2} \Lambda^{2} \Omega e^{L \Lambda}+2\right)}+ \\
\frac{L q_{1}\left(L^{2} \Lambda^{2} \Omega-1\right)\left(3 L^{2} \Lambda^{2} \Omega e^{2 L \Lambda}+12 L \Lambda \Omega e^{L \Lambda}-6 L \Lambda \Omega e^{2 L \Lambda}+3\right)}{6 \Lambda\left(e^{L \Lambda}-1\right)\left(L \Lambda-2 e^{L \Lambda}-2 L^{2} \Lambda^{2} \Omega+L \Lambda e^{L \Lambda}+2 L^{2} \Lambda^{2} \Omega e^{L \Lambda}+2\right)} \\
f_{x 5}=\frac{-q_{1}\left(12 e^{L \Lambda}+3 L^{2} \Lambda^{2}+2 L^{3} \Lambda^{3}-6 L \Lambda+12 L^{2} \Lambda^{2} \Omega+6 L^{3} \Lambda^{3} \Omega-3 L^{4} \Lambda^{4} \Omega\right)}{6 L \Lambda^{2}\left(L \Lambda-2 e^{L \Lambda}-2 L^{2} \Lambda^{2} \Omega+L \Lambda e^{L \Lambda}+2 L^{2} \Lambda^{2} \Omega e^{L \Lambda}+2\right)}+ \\
\frac{-q_{1}\left(-3 L^{2} \Lambda^{2} e^{L \Lambda}+2 L^{3} \Lambda^{3} e^{L \Lambda}-6 L \Lambda e^{L \Lambda}-12 L^{2} \Lambda^{2} \Omega e^{L \Lambda}+6 L^{3} \Lambda^{3} \Omega e^{L \Lambda}+3 L^{4} \Lambda^{4} \Omega e^{L \Lambda}-12\right)}{6 L \Lambda^{2}\left(L \Lambda-2 e^{L \Lambda}-2 L^{2} \Lambda^{2} \Omega+L \Lambda e^{L \Lambda}+2 L^{2} \Lambda^{2} \Omega e^{L \Lambda}+2\right)} \\
f_{x 6}=\frac{-q_{1}\left(L^{2} \Lambda^{2} \Omega-1\right)\left(12 e^{2 L \Lambda}-24 e^{L \Lambda}+2 L^{2} \Lambda^{2}+9 L \Lambda-6 L^{2} \Lambda^{2} \Omega-3 L^{3} \Lambda^{3} \Omega\right)}{6 \Lambda^{2}\left(e^{L \Lambda}-1\right)\left(L \Lambda-2 e^{L \Lambda}-2 L^{2} \Lambda^{2} \Omega+L \Lambda e^{L \Lambda}+2 L^{2} \Lambda^{2} \Omega e^{L \Lambda}+2\right)}+ \\
\frac{-q_{1}\left(L^{2} \Lambda^{2} \Omega-1\right)\left(2 L^{2} \Lambda^{2} e^{L \Lambda}+2 L^{2} \Lambda^{2} e^{2 L \Lambda}-9 L \Lambda e^{2 L \Lambda}+12 L^{2} \Lambda^{2} \Omega e^{L \Lambda}\right)}{6 \Lambda^{2}\left(e^{L \Lambda}-1\right)\left(L \Lambda-2 e^{L \Lambda}-2 L^{2} \Lambda^{2} \Omega+L \Lambda e^{L \Lambda}+2 L^{2} \Lambda^{2} \Omega e^{L \Lambda}+2\right)}+ \\
\frac{-q_{1}\left(L^{2} \Lambda^{2} \Omega-1\right)\left(-6 L^{2} \Lambda^{2} \Omega e^{2 L \Lambda}+3 L^{3} \Lambda^{3} \Omega e^{2 L \Lambda}+12\right)}{6 \Lambda^{2}\left(e^{L \Lambda}-1\right)\left(L \Lambda-2 e^{L \Lambda}-2 L^{2} \Lambda^{2} \Omega+L \Lambda e^{L \Lambda}+2 L^{2} \Lambda^{2} \Omega e^{L \Lambda}+2\right)}
\end{gathered}
$$

As cargas equivalentes nodais também podem ser escritas em termos de funções hiperbólicas, empregando-se as funções de forma, desenvolvidas nas expressões (3.69) a (3.72). Aplicando-se as equações (5.6) e (5.7), as reações de engastamento também podem ser escritas conforme as expressões de (5.35) a (5.40).

$$
\begin{gathered}
f_{02}=f_{05}=\frac{-q_{0} L}{2} \\
f_{03}=\frac{q_{0}\left(L^{2} \Lambda^{2} \Omega-1\right)(L \Lambda-2 \operatorname{senh}(L \Lambda)-2 \cosh (L \Lambda)+L \Lambda(\cosh (L \Lambda)+\operatorname{senh}(L \Lambda))+2)}{2 \Lambda^{2}(\cosh (L \Lambda)+\operatorname{senh}(L \Lambda)-1)} \\
=-f_{06} \\
f_{x 2}=\frac{-q_{1}\left(L^{3} \Lambda^{3} \cosh \left(\frac{L \Lambda}{2}\right)-12 \operatorname{senh}\left(\frac{L \Lambda}{2}\right)-3 L^{2} \Lambda^{2} \operatorname{senh}\left(\frac{L \Lambda}{2}\right)+6 L \Lambda \cosh \left(\frac{L \Lambda}{2}\right)\right)}{6 L \Lambda^{2}\left(L \Lambda \cosh \left(\frac{L \Lambda}{2}\right)-2 \operatorname{senh}\left(\frac{L \Lambda}{2}\right)+2 L^{2} \Lambda^{2} \Omega \operatorname{senh}\left(\frac{L \Lambda}{2}\right)\right)}+ \\
\frac{-q_{1}\left(-6 L^{3} \Lambda^{3} \Omega \cosh \left(\frac{L \Lambda}{2}\right)+12 L^{2} \Lambda^{2} \Omega \operatorname{senh}\left(\frac{L \Lambda}{2}\right)+3 L^{4} \Lambda^{4} \Omega \operatorname{senh}\left(\frac{L \Lambda}{2}\right)\right)}{6 L \Lambda^{2}\left(L \Lambda \cosh \left(\frac{L \Lambda}{2}\right)-2 \operatorname{senh}\left(\frac{L \Lambda}{2}\right)+2 L^{2} \Lambda^{2} \Omega \operatorname{senh}\left(\frac{L \Lambda}{2}\right)\right)} \\
f_{x 3}=\frac{q_{1} L\left(L^{2} \Lambda^{2} \Omega-1\right)(2 L \Lambda-3 \operatorname{senh}(L \Lambda)+6 L \Lambda \Omega+L \Lambda \cosh (L \Lambda))}{6 \Lambda\left(L \Lambda \operatorname{senh}(L \Lambda)-2 L^{2} \Lambda^{2} \Omega-2 \cosh (L \Lambda)+2 L^{2} \Lambda^{2} \Omega \cosh (L \Lambda)+2\right)}+ \\
\frac{q_{1} L\left(L^{2} \Lambda^{2} \Omega-1\right)\left(3 L^{2} \Lambda^{2} \Omega \operatorname{senh}(L \Lambda)-6 L \Lambda \Omega \cosh (L \Lambda)\right)}{6 \Lambda\left(L \Lambda \operatorname{senh}(L \Lambda)-2 L^{2} \Lambda^{2} \Omega-2 \cosh (L \Lambda)+2 L^{2} \Lambda^{2} \Omega \cosh (L \Lambda)+2\right)}
\end{gathered}
$$




$$
\begin{gathered}
f_{x 5}=\frac{-q_{1}\left(12 \operatorname{senh}\left(\frac{L \Lambda}{2}\right)+2 L^{3} \Lambda^{3} \cosh \left(\frac{L \Lambda}{2}\right)-3 L^{2} \Lambda^{2} \operatorname{senh}\left(\frac{L \Lambda}{2}\right)-6 L \Lambda \cosh \left(\frac{L \Lambda}{2}\right)\right)}{6 L \Lambda^{2}\left(L \Lambda \cosh \left(\frac{L \Lambda}{2}\right)-2 \operatorname{senh}\left(\frac{L \Lambda}{2}\right)+2 L^{2} \Lambda^{2} \Omega \operatorname{senh}\left(\frac{L \Lambda}{2}\right)\right)}+ \\
\frac{-q_{1}\left(6 L^{3} \Lambda^{3} \Omega \cosh \left(\frac{L \Lambda}{2}\right)-12 L^{2} \Lambda^{2} \Omega \operatorname{senh}\left(\frac{L \Lambda}{2}\right)+3 L^{4} \Lambda^{4} \Omega \operatorname{senh}\left(\frac{L \Lambda}{2}\right)\right)}{6 L \Lambda^{2}\left(L \Lambda \cosh \left(\frac{L \Lambda}{2}\right)-2 \operatorname{senh}\left(\frac{L \Lambda}{2}\right)+2 L^{2} \Lambda^{2} \Omega \operatorname{senh}\left(\frac{L \Lambda}{2}\right)\right)} \\
f_{x 6}=\frac{-q_{1}\left(L^{2} \Lambda^{2} \Omega-1\right)\left(12 \cosh (L \Lambda)+L^{2} \Lambda^{2}+6 L^{2} \Lambda^{2} \Omega+2 L^{2} \Lambda^{2} \cosh (L \Lambda)\right)}{6 \Lambda^{2}\left(L \Lambda \operatorname{senh}(L \Lambda)-2 L^{2} \Lambda^{2} \Omega-2 \cosh (L \Lambda)+2 L^{2} \Lambda^{2} \Omega \cosh (L \Lambda)+2\right)}+ \\
\frac{-q_{1}\left(L^{2} \Lambda^{2} \Omega-1\right)\left(-9 L \Lambda \operatorname{senh}(L \Lambda)-6 L^{2} \Lambda^{2} \Omega \cosh (L \Lambda)+3 L^{3} \Lambda^{3} \Omega \operatorname{senh}(L \Lambda)-12\right)}{6 \Lambda^{2}\left(L \Lambda \operatorname{senh}(L \Lambda)-2 L^{2} \Lambda^{2} \Omega-2 \cosh (L \Lambda)+2 L^{2} \Lambda^{2} \Omega \cosh (L \Lambda)+2\right)}
\end{gathered}
$$

Em termos de funções trigonométricas, funções de forma desenvolvidas nas expressões (3.82) a (3.85), as reações de engastamento podem ser calculadas empregando-se as equações (5.6) e (5.7), obtendo-se então as expressões de (5.41) a (5.46).

$$
\begin{gathered}
f_{02}=f_{05}=\frac{-q_{0} L}{2} \\
f_{03}=\frac{-q_{0}\left(L^{2} \Lambda^{2} \Omega+1\right)\left(4 \cos (L \Lambda)-L^{2} \Lambda^{2}-4 L^{2} \Lambda^{2} \Omega-L^{2} \Lambda^{2} \cos (L \Lambda)+4 L \Lambda \operatorname{sen}(L \Lambda)\right)}{2 \Lambda^{2}\left(2 \cos (L \Lambda)-2 L^{2} \Lambda^{2} \Omega+L \Lambda \operatorname{sen}(L \Lambda)+2 L^{2} \Lambda^{2} \Omega \cos (L \Lambda)-2\right)}+ \\
\frac{-q_{0}\left(L^{2} \Lambda^{2} \Omega+1\right)\left(4 L^{2} \Lambda^{2} \Omega \cos (L \Lambda)+2 L^{3} \Lambda^{3} \Omega \operatorname{sen}(L \Lambda)-4\right)}{2 \Lambda^{2}\left(2 \cos (L \Lambda)-2 L^{2} \Lambda^{2} \Omega+L \Lambda \operatorname{sen}(L \Lambda)+2 L^{2} \Lambda^{2} \Omega \cos (L \Lambda)-2\right)}=-f_{06} \\
f_{x 2}=\frac{-q_{1}\left(12 \cos (L \Lambda)+3 L^{2} \Lambda^{2}-12 L^{2} \Lambda^{2} \Omega+3 L^{4} \Lambda^{4} \Omega-3 L^{2} \Lambda^{2} \cos (L \Lambda)\right)}{6 L \Lambda^{2}\left(2 \cos (L \Lambda)-2 L^{2} \Lambda^{2} \Omega+L \Lambda \operatorname{sen}(L \Lambda)+2 L^{2} \Lambda^{2} \Omega \cosh (L \Lambda)-2\right)}+ \\
\frac{-q_{1}\left(-L^{3} \Lambda^{3} \operatorname{sen}(L \Lambda)+6 L \Lambda \operatorname{sen}(L \Lambda)+12 L^{2} \Lambda^{2} \Omega \cos (L \Lambda)-3 L^{4} \Lambda^{4} \Omega \cos (L \Lambda)\right)}{6 L \Lambda^{2}\left(2 \cos (L \Lambda)-2 L^{2} \Lambda^{2} \Omega+L \Lambda \operatorname{sen}(L \Lambda)+2 L^{2} \Lambda^{2} \Omega \cosh (L \Lambda)-2\right)}+ \\
\frac{-q_{1}\left(6 L^{3} \Lambda^{3} \Omega \operatorname{sen}(L \Lambda)-12\right)}{6 L \Lambda^{2}\left(2 \cos (L \Lambda)-2 L^{2} \Lambda^{2} \Omega+L \Lambda \operatorname{sen}(L \Lambda)+2 L^{2} \Lambda^{2} \Omega \cosh (L \Lambda)-2\right)} \\
\frac{-q_{1} L\left(L^{2} \Lambda^{2} \Omega+1\right)(3 \operatorname{sen}(L \Lambda)-2 L \Lambda-6 L \Lambda \Omega-L \Lambda \cos (L \Lambda))}{6 \Lambda\left(2 \cos (L \Lambda)-2 L^{2} \Lambda^{2} \Omega+L \Lambda \operatorname{sen}(L \Lambda)+2 L^{2} \Lambda^{2} \Omega \cosh (L \Lambda)-2\right)}+ \\
\frac{-q_{1} L\left(L^{2} \Lambda^{2} \Omega-1\right)\left(3 L^{2} \Lambda^{2} \Omega \operatorname{sen}(L \Lambda)+6 L \Lambda \Omega \cosh (L \Lambda)\right)}{6 \Lambda\left(2 \cos (L \Lambda)-2 L^{2} \Lambda^{2} \Omega+L \Lambda \operatorname{sen}(L \Lambda)+2 L^{2} \Lambda^{2} \Omega \cosh (L \Lambda)-2\right)}
\end{gathered}
$$




$$
\begin{gathered}
f_{x 5}=\frac{-q_{1}\left(6 \cos (L \Lambda)-\frac{3 L^{2} \Lambda^{2}}{2}-6 L^{2} \Lambda^{2} \Omega-\frac{3 L^{4} \Lambda^{4} \Omega}{2}+\frac{3 L^{2} \Lambda^{2} \cos (L \Lambda)}{2}\right)}{3 L \Lambda^{2}\left(2 \cos (L \Lambda)-2 L^{2} \Lambda^{2} \Omega+L \Lambda \operatorname{sen}(L \Lambda)+2 L^{2} \Lambda^{2} \Omega \cosh (L \Lambda)-2\right)}+ \\
\frac{-q_{1}\left(L^{3} \Lambda^{3} \operatorname{sen}(L \Lambda)+3 L \Lambda \operatorname{sen}(L \Lambda)+6 L^{2} \Lambda^{2} \Omega \cos (L \Lambda)+\frac{3 L^{4} \Lambda^{4} \Omega \cos (L \Lambda)}{2}\right)}{6 L \Lambda^{2}\left(2 \cos (L \Lambda)-2 L^{2} \Lambda^{2} \Omega+L \Lambda \operatorname{sen}(L \Lambda)+2 L^{2} \Lambda^{2} \Omega \cosh (L \Lambda)-2\right)}+ \\
\frac{-q_{1}\left(3 L^{3} \Lambda^{3} \Omega \operatorname{sen}(L \Lambda)-6\right)}{6 L \Lambda^{2}\left(2 \cos (L \Lambda)-2 L^{2} \Lambda^{2} \Omega+L \Lambda \operatorname{sen}(L \Lambda)+2 L^{2} \Lambda^{2} \Omega \cosh (L \Lambda)-2\right)} \\
f_{x 6}=\frac{q_{1}\left(L^{2} \Lambda^{2} \Omega+1\right)\left(12 \cos (L \Lambda)-L^{2} \Lambda^{2}-6 L^{2} \Lambda^{2} \Omega-2 L^{2} \Lambda^{2} \cos (L \Lambda)\right)}{6 \Lambda^{2}\left(2 \cos (L \Lambda)-2 L^{2} \Lambda^{2} \Omega+L \Lambda \operatorname{sen}(L \Lambda)+2 L^{2} \Lambda^{2} \Omega \cosh (L \Lambda)-2\right)}+ \\
\frac{q_{1}\left(L^{2} \Lambda^{2} \Omega+1\right)\left(9 L \Lambda \operatorname{sen}(L \Lambda)+6 L^{2} \Lambda^{2} \Omega \cos (L \Lambda)+3 L^{3} \Lambda^{3} \Omega \operatorname{senh}(L \Lambda)-12\right)}{6 \Lambda^{2}\left(2 \cos (L \Lambda)-2 L^{2} \Lambda^{2} \Omega+L \Lambda \operatorname{sen}(L \Lambda)+2 L^{2} \Lambda^{2} \Omega \cosh (L \Lambda)-2\right)}
\end{gathered}
$$

Dessa forma, o elemento desenvolvido pode ser aplicado para situações de carregamento distribuído ao se calcular as cargas nodais equivalentes expostas neste capítulo. 


\section{6 \\ Aplicações Numéricas}

Para validação das formulações desenvolvidas neste trabalho, os elementos propostos foram implementados no Framoop, solver do software Ftool (Martha, 1999), e seus resultados foram comparados com soluções analíticas presentes na literatura e com o programa Mastan2 v3.5 (McGuire et al., 2000).

Nos exemplos, foram utilizadas as matrizes de rigidez elaboradas, identificados com as seguintes legendas, em relação à teoria de flexão considerada:

EBBT - Elementos que consideram a teoria de flexão de Euler Bernoulli;

TBT - Elementos que consideram a teoria de flexão de Timoshenko.

Os elementos se diferenciam ainda com relação aos termos não lineares considerados no tensor deformação, podendo se apresentar como:

Small - Não considerados os termos de grau elevado do tensor deformação;

Large - Considerados os termos de grau elevado do tensor deformação.

Por fim, os elementos também são diferenciados pelo número de termos na matriz de rigidez utilizada. A matriz geométrica usual desconsidera os termos de grau elevado do tensor deformação, resultando em apenas um termo da carga axial $P$. Contudo, ela também pode ser obtida a partir da aproximação da matriz de rigidez geométrica com funções de forma completas em séries de Taylor, obtendo-se mais termos da carga axial $P$. Sendo assim, é feita a seguinte diferenciação:

$2 \operatorname{tr}-2$ Termos (termo elástico + um termo da carga axial $P$, até grau 1);

3tr - 3 Termos (termo elástico + dois termos da carga axial $P$, até grau 2);

4tr - 4 Termos (termo elástico + três termos da carga axial $P$, até grau 3);

Complete - Funções hiperbólicas e trigonométricas.

Dessa forma, os elementos implementados e avaliados são os seguintes:

EBBT_Small_2tr - Teoria de flexão de Euler-Bernoulli, com dois termos na matriz de rigidez (um elástico e um da carga axial $\mathrm{P}$ ), sem considerar os termos de elevado grau do tensor deformação. 
EBBT_Small_3tr - Teoria de flexão de Euler-Bernoulli, com três termos na matriz de rigidez (um elástico e dois da carga axial P), sem considerar os termos de elevado grau do tensor deformação.

EBBT_Small_4tr - Teoria de flexão de Euler-Bernoulli, com quatro termos na matriz de rigidez (um elástico e três da carga axial P), sem considerar os termos de elevado grau do tensor deformação.

EBBT_Small_Complete - Teoria de flexão de Euler-Bernoulli, com matriz de rigidez geométrica com funções hiperbólicas e geométricas, sem considerar os termos de elevado grau do tensor deformação.

EBBT_Large_2tr - Teoria de flexão de Euler-Bernoulli, com dois termos na matriz de rigidez (um elástico e um da carga axial P), considerando-se os termos de elevado grau do tensor deformação.

EBBT_Large_3tr - Teoria de flexão de Euler-Bernoulli, com três termos na matriz de rigidez (um elástico e dois da carga axial $\mathrm{P}$ ), considerando-se os termos de elevado grau do tensor deformação.

EBBT_Large_4tr - Teoria de flexão de Euler-Bernoulli, com quatro termos na matriz de rigidez (um elástico e três da carga axial $\mathrm{P}$ ), considerando-se os termos de elevado grau do tensor deformação.

EBBT_Large_Complete - Teoria de flexão de Euler-Bernoulli, com matriz de rigidez geométrica com funções hiperbólicas e geométricas, considerando-se os termos de elevado grau do tensor deformação.

TBT_Small_2tr - Teoria de flexão de Timoshenko, com dois termos na matriz de rigidez (um elástico e um da carga axial $\mathrm{P}$ ), sem considerar os termos de elevado grau do tensor deformação.

TBT_Small_3tr - Teoria de flexão de Timoshenko, com três termos na matriz de rigidez (um elástico e dois da carga axial $\mathrm{P}$ ), sem considerar os termos de elevado grau do tensor deformação. 
TBT_Small_4tr - Teoria de flexão de Timoshenko, com quatro termos na matriz de rigidez (um elástico e três da carga axial P), sem considerar os termos de elevado grau do tensor deformação.

TBT_Small_Complete - Teoria de flexão de Timoshenko, com matriz de rigidez geométrica com funções hiperbólicas e geométricas, sem considerar os termos de elevado grau do tensor deformação.

TBT_Large_2tr - Teoria de flexão de Timoshenko, com dois termos na matriz de rigidez (um elástico e um da carga axial $\mathrm{P}$ ), considerando-se os termos de elevado grau do tensor deformação.

TBT_Large_3tr - Teoria de flexão de Timoshenko, com três termos na matriz de rigidez (um elástico e dois da carga axial P), considerando-se os termos de elevado grau do tensor deformação.

TBT_Large_4tr - Teoria de flexão de Timoshenko, com quatro termos na matriz de rigidez (um elástico e três da carga axial P), considerando-se os termos de elevado grau do tensor deformação.

TBT_Large_Complete - Teoria de flexão de Timoshenko com matriz de rigidez geométrica com funções hiperbólicas e geométricas, considerando-se os termos de elevado grau do tensor deformação.

A primeira verificação dos exemplos tem como objetivo avaliar a influência da teoria de flexão de Timoshenko e a consideração dos termos de grau elevado do tensor deformação, para estruturas com diferentes índices de esbeltez.

$\mathrm{Na}$ sequência, procura-se identificar a capacidade da matriz de rigidez, com formulação completa e com expansão em série, de descrever o comportamento da estrutura com apenas um elemento por barra na discretização da estrutura. Em um primeiro momento, emprega-se à teoria de flexão de Euler-Bernoulli e, em seguida, a teoria de flexão de Timoshenko.

Conforme explicado, anteriormente, também se utilizou para comparação o software Mastan2 v3.5. Neste caso, a legenda para os elementos utilizada apresenta-se da forma que se segue:

EBBT_Mastan - Elemento do Mastan2, que considera a Teoria de flexão de Euler-Bernoulli;

TBT_Mastan - Elemento do Mastan2, que considera a Teoria de flexão de Timoshenko. 


\section{1}

\section{Carga Crítica de Colunas}

O primeiro exemplo estuda a carga crítica para flambagem de colunas com diferentes condições de contorno. Para verificar a influência da teoria de flexão de Timoshenko na análise não linear, assim como, da consideração de termos de ordem elevada no tensor deformação, diferentes esbeltezas foram avaliadas. As colunas estudadas são apresentadas na Figura 6.1 e possuem comprimento $L=1 \mathrm{~m}$, módulo de elasticidade do material $E=10^{7} \mathrm{kN} / \mathrm{m}^{2}$, coeficiente de Poisson nulo $(v=0)$ e um fator de forma $\chi=1$ para a seção transversal.
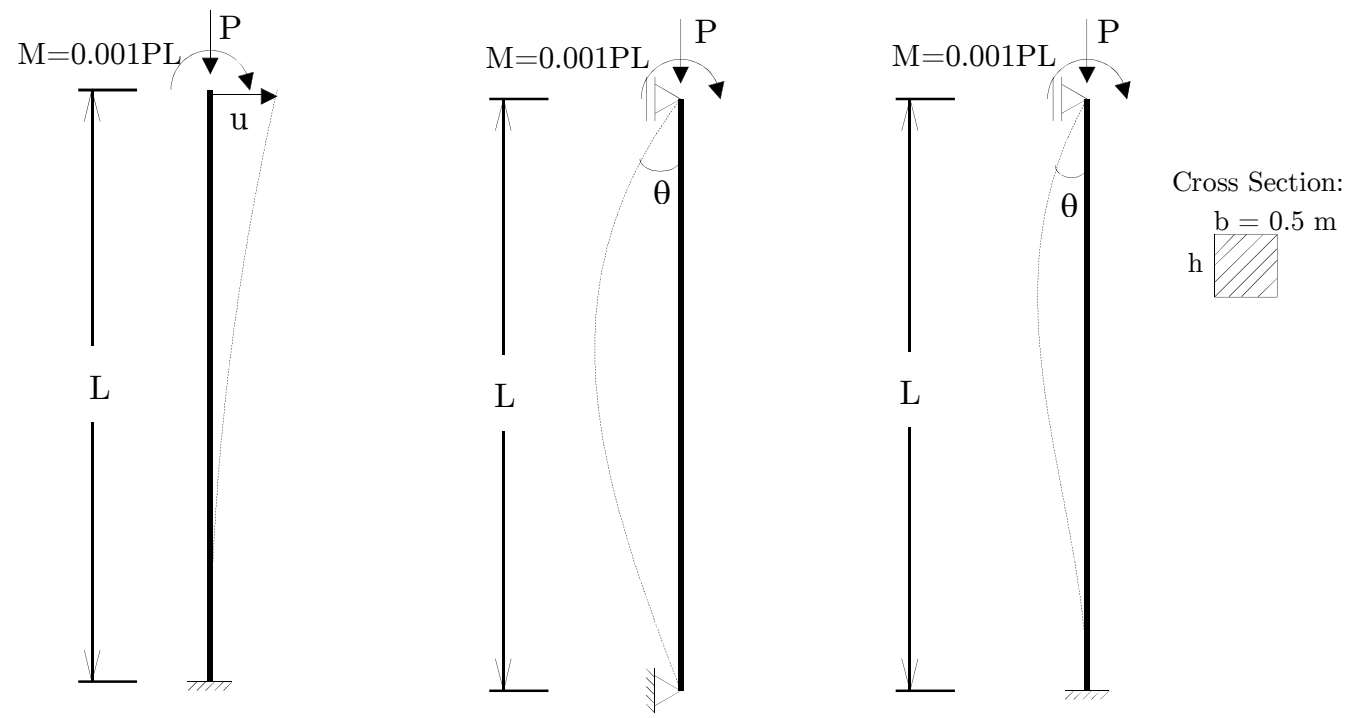

Figura 6.1 - Colunas analisadas

Fonte: Adaptado de Silva et al. (2016).

Incialmente, as colunas foram modeladas com cinco elementos, considerando ambas as teorias de flexão. A carga crítica de flambagem é normalizada pela rigidez à fexão da seção transversal $(E I)$. As curvas de equilíbrio foram obtidas considerando formulações e índices de esbeltez $(\lambda=L / h)$, porém, salienta-se que normalmente a esbeltez é obtida pela relação $\lambda=L / r$, em que $(r)$ é o raio de giração da seção transversal. Os resultados foram comparados com o software Mastan2 v3.5 e a carga de flambagem analítica de Euler.

Em sequência, é avaliada a formulação completa desenvolvida, em que são utilizadas as funções de forma completas no desenvolvimento da matriz de rigidez da estrutura. Nesse caso, utilizou-se apenas um elemento por coluna para o modelo. Para essa situação também foram avaliadas as teorias de flexão de EulerBernoulli e Timoshenko. 


\section{1 .1 \\ Matriz de Rigidez de Timoshenko considerando Termos de Grau Elevado no Tensor Deformação e Funções de Forma Cúbicas}

Na primeira sequência de verificações foram estudadas a influência da teoria de flexão de Timoshenko e a consideração de termos de grau elevado no Tensor Deformação, para o cálculo da carga crítica de coluna.

Para a coluna engastada e livre (Figura 6.1), desconsiderando a deformação por cisalhamento, a carga crítica de flambagem de Euler é calculada analiticamente como $P_{c r}=\pi^{2} E I /(2 L)^{2}$. Os resultados para a curva de equilíbrio, considerando diferentes índices de esbeltez, são apresentados na Figura 6.2.

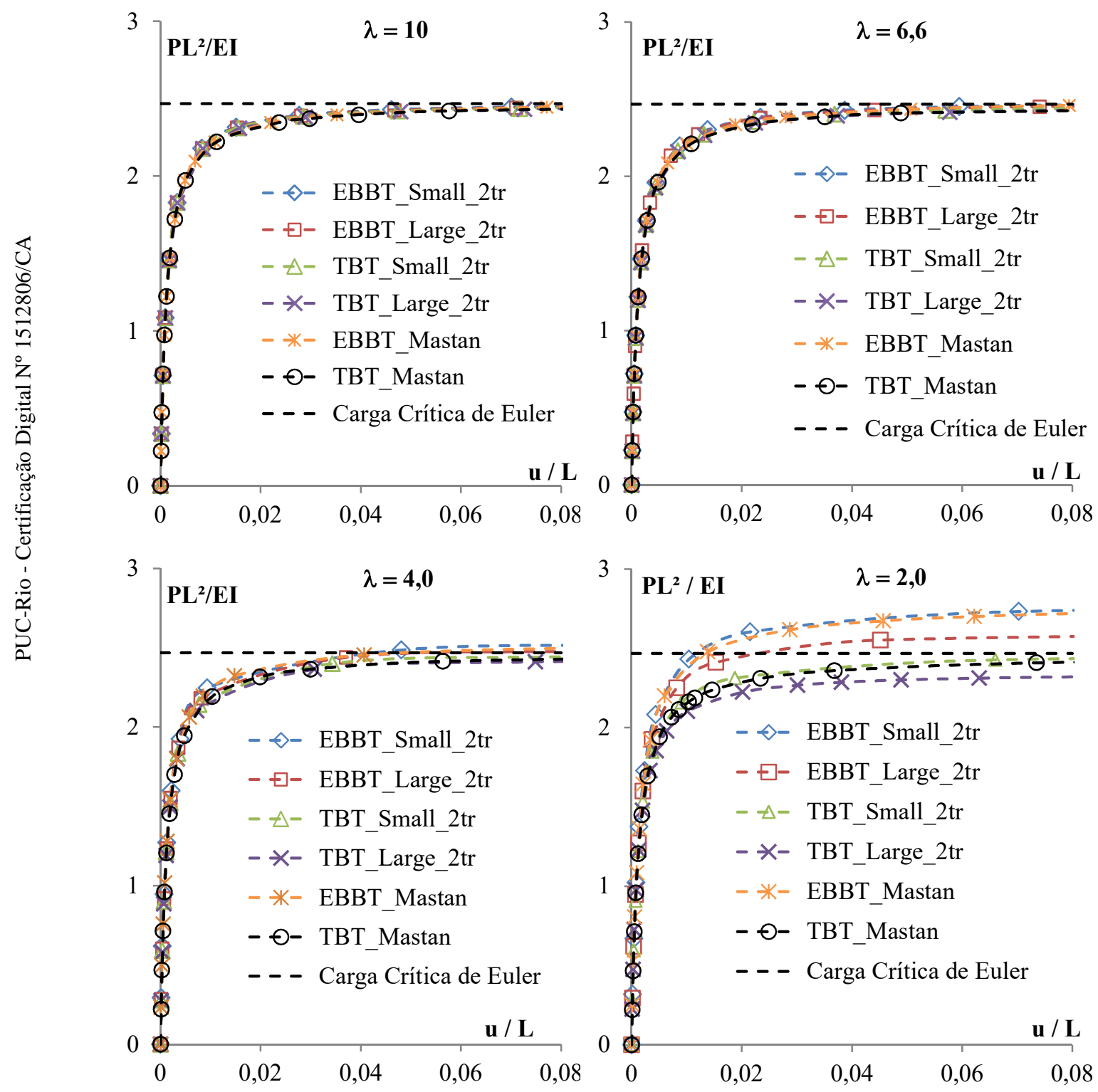

Figura 6.2 - Curva de Equilíbrio para coluna engastada e livre para diferentes índices de esbeltez com 5 elementos por barra

Fonte: Elaborada pelo autor (2019). 
Analisando as curvas de equilíbrio, pode ser observado que, para estruturas com elevado índice de esbeltez, o comportamento considerando teoria de EulerBernoulli e Timoshenko é similar. Além disso, não são percebidas relevantes diferenças ao se empregar ou não os termos de alta ordem no tensor deformação.

Entretanto, com a redução do índice de esbeltez, $\lambda \leq 4$, a influência da teoria de flexão considerada se torna evidente. Também nota-se uma clara diferença nas curvas ao se utilizar termos de alta ordem no tensor deformação. Assim, para cargas elevadas e com baixo índice de esbeltez, é importante considerar a teoria de flexão de Timoshenko, assim como os termos de alta ordem do tensor deformação.

Para a coluna biapoiada, a carga crítica de flambagem de Euler é calculada analiticamente como $P_{c r}=\pi^{2} E I /(L)^{2}$. Os resultados para a curva de equilíbrio, considerando diferentes índices de esbeltez, são apresentados na Figura 6.3.
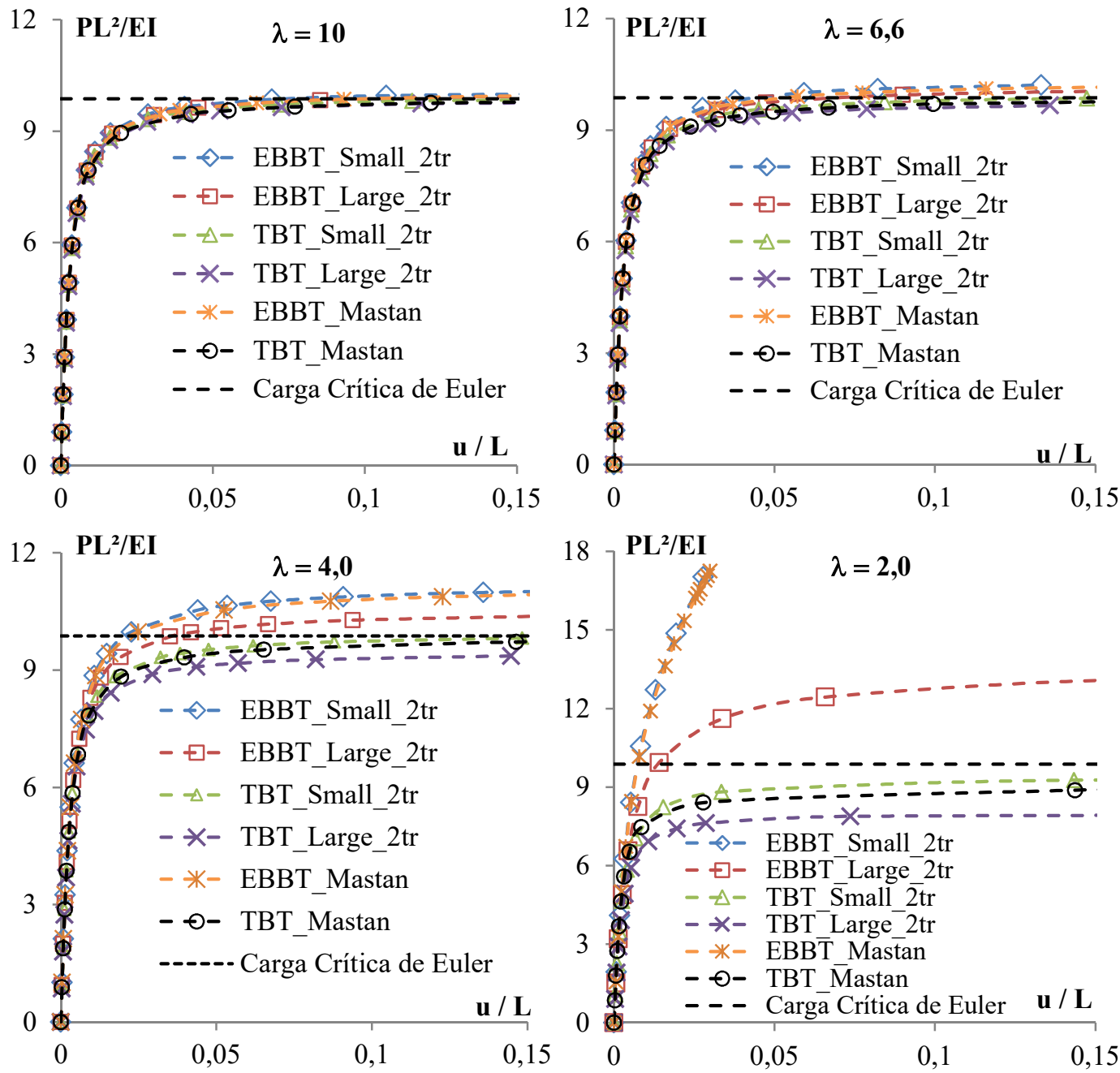

Figura 6.3 - Curva de Equilíbrio para coluna biapoiada para diferentes índices de esbeltez com 5 elementos por barra

Fonte: Elaborada pelo autor (2019). 
Para as curvas desenvolvidas na Figura 6.3, as mesmas conclusões anteriores podem ser observadas: Para estruturas com alto índice de esbeltez, o comportamento considerando a teoria de flexão de Euler-Bernoulli e Timoshenko é semelhante. Ainda, não é possível notar relevantes diferenças em relação à consideração ou não dos termos de ordem elevada do tensor deformação, o que justifica a sua usual não utilização.

Porém, com a redução do índice de esbeltez, $\lambda \leq 4$, a influência da teoria de flexão e o emprego ou não dos termos de alta ordem do tensor deformação (TBT_Large_2tr) fornecem resultados distintos dos usuais.

Para a coluna engastada e apoiada, a carga crítica de flambagem de Euler é calculada analiticamente como $P_{c r}=\pi^{2} E I /(0,7 L)^{2}$. Os resultados para a curva de equilíbrio, considerando diferentes índices de esbeltez, são apresentados na Figura 6.4 .

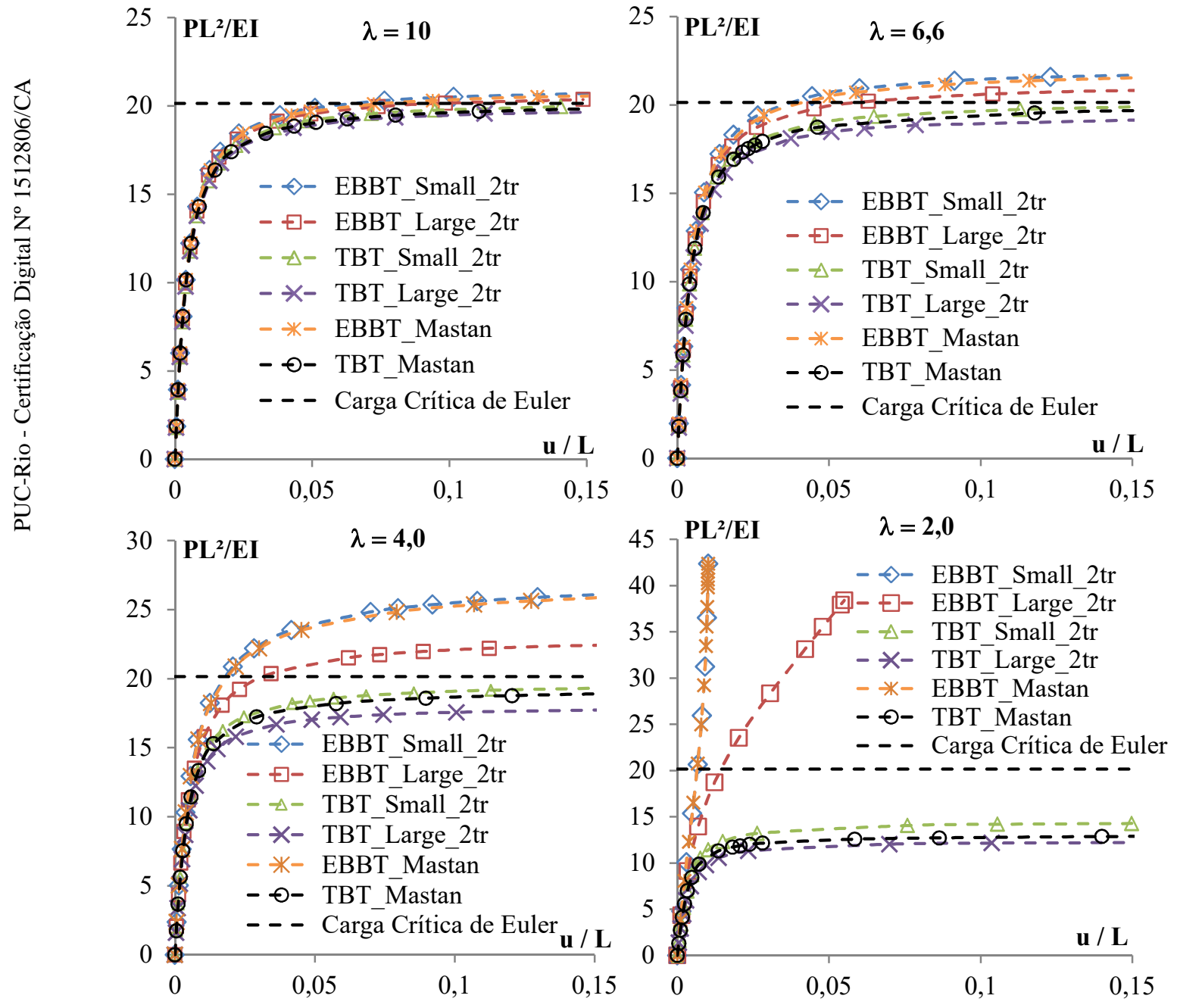

Figura 6.4 - Curva de Equilíbrio para coluna engastada e apoiada diferentes índices de esbeltez com 5 elementos por barra

Fonte: Elaborada pelo autor (2019). 
Para a situação de uma coluna engastada em um apoio e simplesmente apoiado em outro, pode-se observar as curvas de equilíbrio apresentadas na Figura 6.4. É possível notar que, mesmo para um alto índice de esbeltez na estrutura, as teorias de flexão já geram resultados um pouco distintos. Essa diferença se torna ainda mais evidente com a redução do índice de esbeltez.

A mesma conclusão pode ser observada para a consideração dos termos de elevada ordem no tensor deformação, para altos valores de índice de esbeltez temse uma pequena diferença entre os resultados, e com a redução desse índice, maior fica a diferença entre as respostas que levam em conta essa consideração ou não.

\section{1 .2}

\section{Matriz de Rigidez Completa de Euler-Bernoulli}

Neste item, avaliou-se a resposta das colunas, considerando a matriz de rigidez completa, ou seja, a matriz de rigidez desenvolvida a partir das funções de forma completas (a carga axial já está presente na função de interpolação). Para essa verificação, os elementos foram modelados com um elemento por barra.

Observando-se as curvas de equilíbrio anteriores, nota-se que, para uma coluna engastada e livre, para os diferentes índices de esbeltez, as formulações têm comportamento similares, com diferenças mais expressivas para um índice de esbeltez $\lambda=2$, portanto, ela será utilizada para avaliar o elemento, neste caso.

Assim, para a coluna engastada e livre, a sua resposta é dada conforme a Figura 6.5.

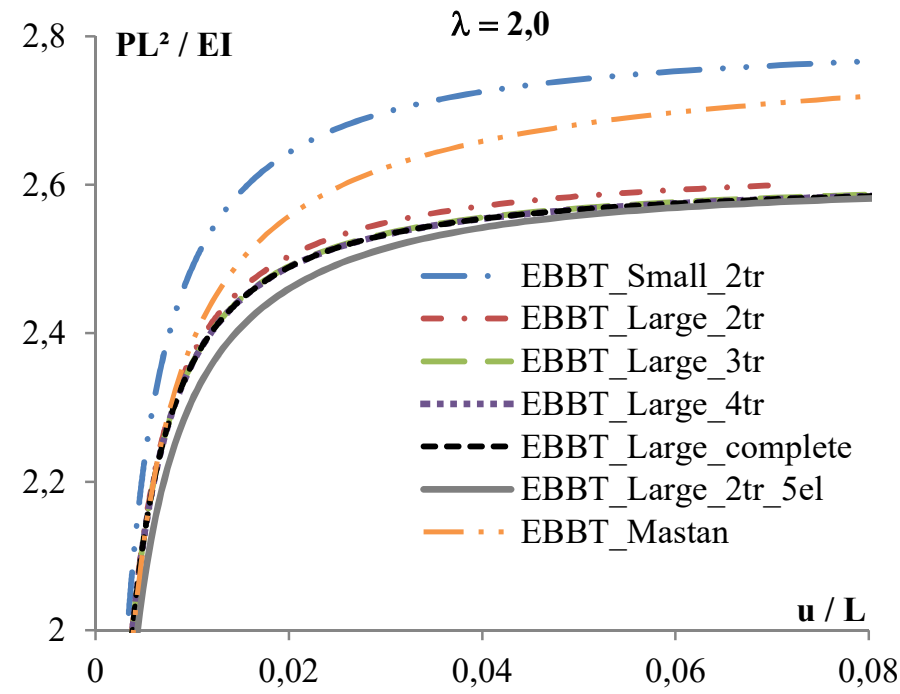

Figura 6.5 - Curva de Equilíbrio para coluna engastada com 1 elemento por barra Fonte: Elaborada pelo autor (2019). 
Pode-se observar que a formulação com funções de forma "completas" melhor se aproximaram da resposta em que se utilizam cinco elementos, sendo seguida pela aproximação de Taylor de 4 termos, 3 termos e, a formulação que considera funções de interpolação hermitianas e os temos de elevada ordem do tensor deformação (2 termos), respectivamente. Também é possível visualizar que a não consideração dos termos de elevado grau do tensor deformação (small) fornecem resultados acima da carga de flambagem da estrutura.

$\mathrm{Na}$ sequência, avaliou-se a coluna biapoiada e a resposta é ilustrada na Figura 6.6. Para essa situação, observou-se uma elevada discrepância entre os resultados ao se empregar diferentes teorias de flexão. Portanto, preferiu-se avaliar o elemento completo com um índice de esbeltez $(\lambda=6,6)$, em que são observadas diferenças entre as formulações "Small" e "Large", mas que ainda é razoavelmente descrita pela teoria de flexão de Euler-Bernoulli.

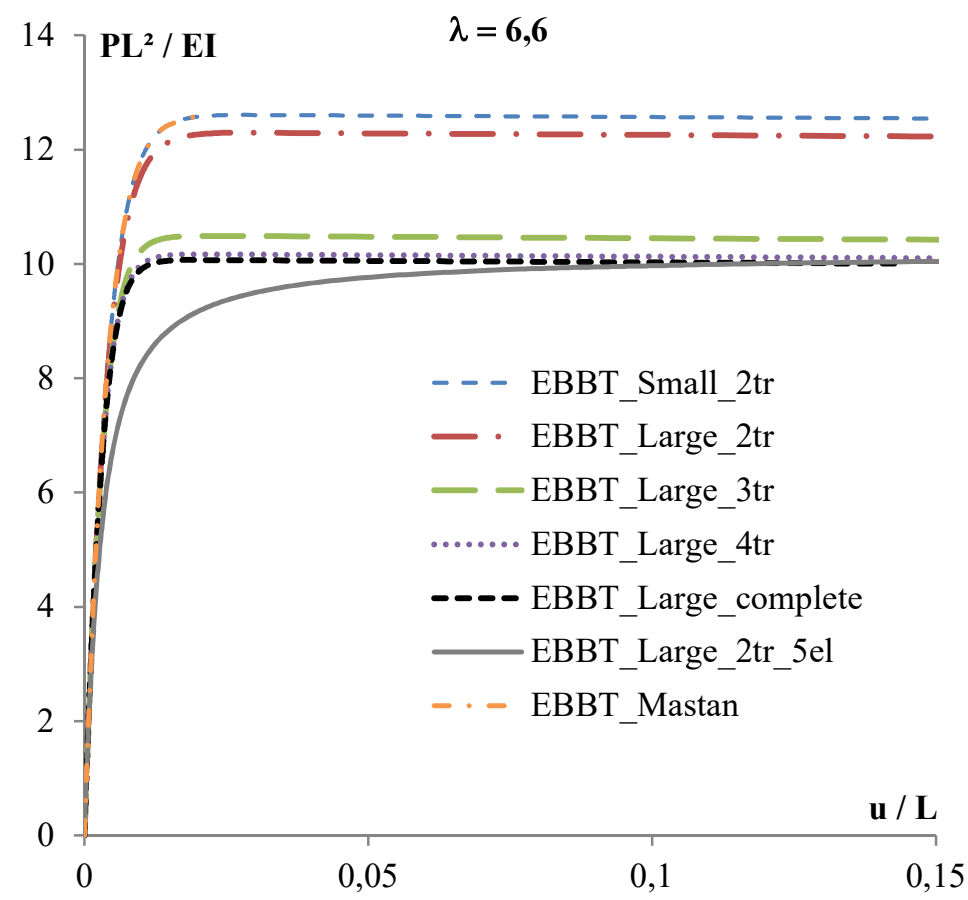

Figura 6.6 - Curva de Equilíbrio para coluna biapoiada com 1 elemento por barra Fonte: Elaborada pelo autor (2019).

Também é possível concluir que a formulação com funções de forma "completa" é a que melhor se aproxima da resposta em que se utilizam cinco elementos, sendo seguida pela aproximação de Taylor com $4^{\mathrm{a}}$ termos e 3 termos, respectivamente. Entretanto, o resultado da aproximação com 4 termos é bem próximo da "completa", com um custo computacional muito menor, na montagem da matriz, e sem instabilidade numérica (divisões por zero). 
Observa-se também que, para a matriz de rigidez usual, 2 termos, tanto a formulação que considera os termos de ordem elevada do tensor deformação ("Large"), como a que não os considera ("Small”) fornecem resultados bem acima da carga crítica estrutura.

Para a coluna engastada e apoiada também foi avaliado o elemento com formulação completa. Da mesma forma que a coluna biapoiada, o elemento "EBBT_Large_2or" não consegue predizer de forma satisfatória o comportamento da estrutura para baixa esbeltez. Ao se considerar um índice de esbeltez maior $(\lambda=6,6)$, nota-se que o elemento apresenta uma convergência para uma carga próxima a da flambagem e apresenta, diferenças entre as formulações "Small” e “Large". Os resultados encontrados são ilustrados na Figura 6.7.

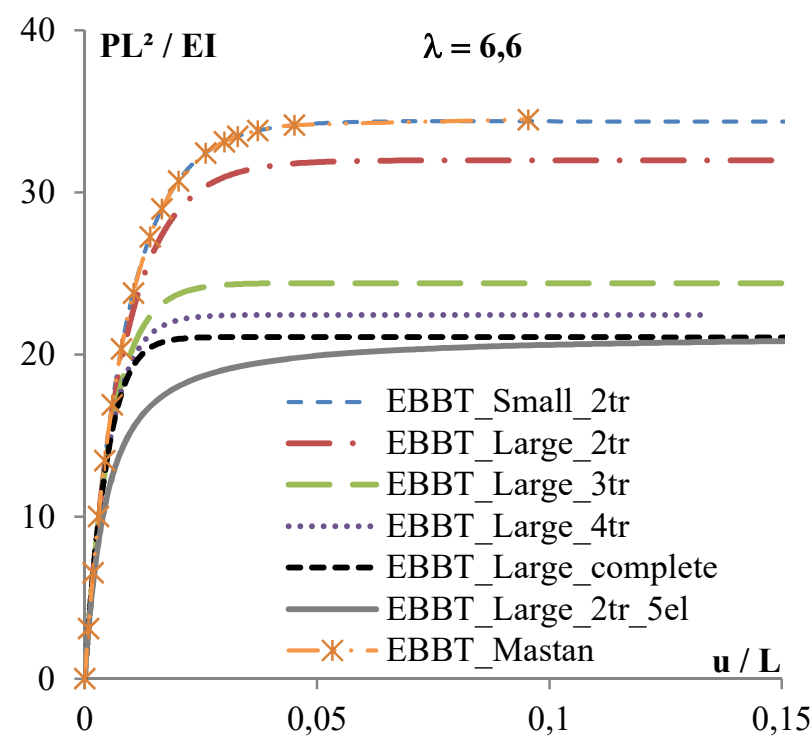

Figura 6.7 - Curva de Equilíbrio para coluna engastada e apoiada com 1 elemento por barra Fonte: Elaborada pelo autor (2019).

Da curva de equilíbrio fornecida, observa-se que, mais uma vez, a formulação com funções de forma "completa", com um elemento por barra, se aproximou da resposta em que se utilizam cinco elementos. Um resultado satisfatório também é fornecido pela matriz com aproximação de Taylor com 4 termos, seguida pela de 3, porém, com uma carga crítica acima da esperada.

A formulação em que se considera apenas os termos de primeira ordem da carga axial $P$ (EBBT_Large_2tr) convergirá para resultados muitos superiores à carga de flambagem, assim como, a simplificação da matriz de rigidez geométrica usual, em que não se utilizam todos os termos do tensor deformação (EBBT_Small_2tr). 


\subsection{3}

\section{Matriz de Rigidez Completa de Timoshenko}

Neste item, avaliou-se a resposta das colunas, considerando a matriz de rigidez completa, ou seja, a matriz de rigidez desenvolvida a partir das funções de forma completas (a carga axial já está presente na função de interpolação). Para essa verificação, os elementos foram modelados apenas com 1 elemento por barra.

Entretanto, agora, a teoria de flexão considerada foi a de Timoshenko e sua maior influência ocorre também para estruturas com baixa relação entre altura e espessura, ou seja, baixo índice de esbeltez. Para a validação da formulação desenvolvida, testou-se o menor índice de esbeltez desenvolvido anteriormente $(\lambda=2)$ para a coluna engastada e $(\lambda=4)$ para os demais casos, por já apresentar diferenças entre as teorias e a sua maior proximidade com estruturas reais.

A primeira verificação foi feita para a coluna engastada e a sua resposta é dada conforme a Figura 6.8 .

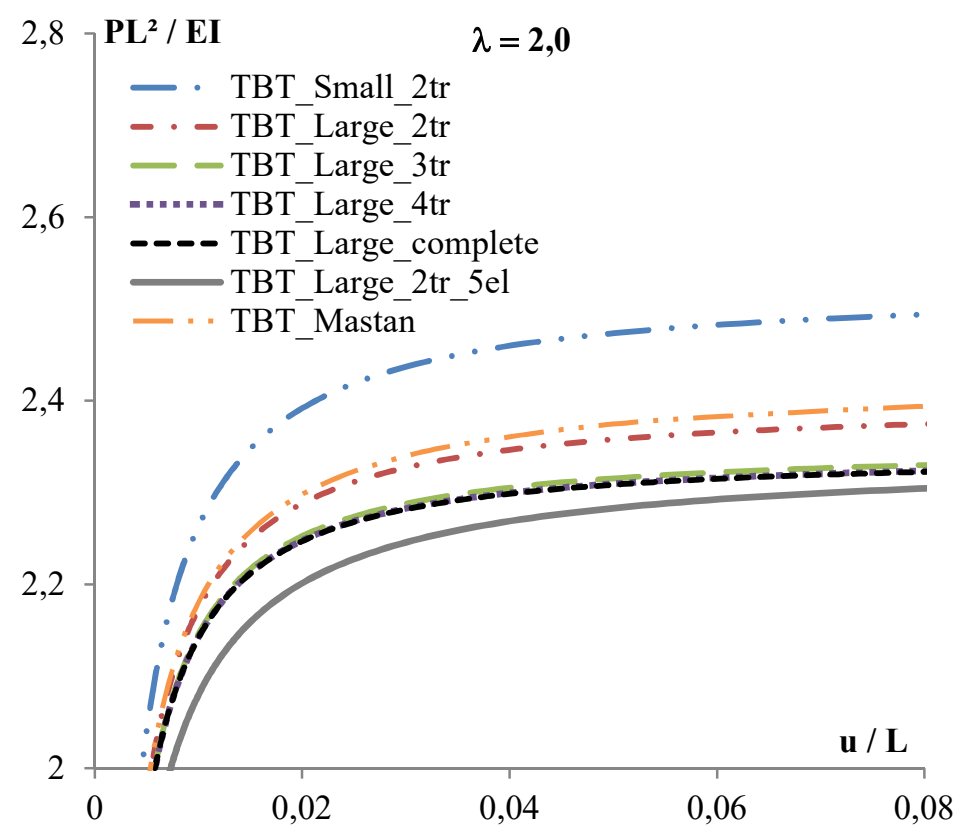

Figura 6.8 - Curva de Equilíbrio para coluna engasta com 1 elemento por barra (Timoshenko) Fonte: Elaborada pelo autor (2019).

A partir da curva de equilíbrio, observa-se que a formulação com funções de forma "completas" melhor se aproxima da resposta em que se utilizam cinco elementos, chegando na mesma carga de flambagem. Alinhada com essa resposta, está a matriz com aproximação de Taylor com 4 termos e, com pouca diferença, a matriz de rigidez com aproximação de Taylor de 3 termos. 
Com resultados superiores à carga de flambagem, tem-se a formulação que utiliza funções cúbicas de interpolação e os termos de elevada ordem do tensor deformação (TBT_Large_2tr) e, mais acima, a que não considera os termos de elevado grau do tensor deformação (TBT_Small_2tr).

Para a coluna biapoiada, o comportamento é dado conforme a Figura 6.9.

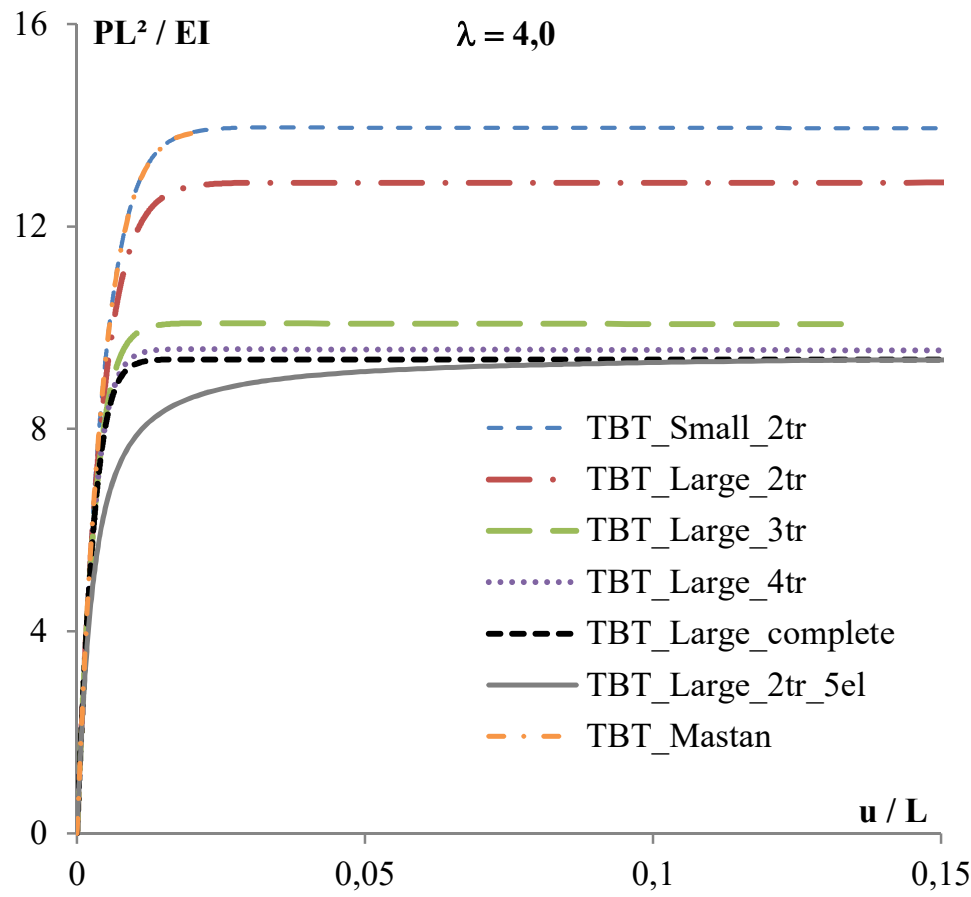

Figura 6.9 - Curva de Equilíbrio para coluna biapoiada com 1 elemento por barra (Timoshenko) Fonte: Elaborada pelo autor (2019).

Com os resultados apresentados, é possível visualizar que a formulação com funções de forma "completas" melhor se aproxima da resposta em que se utilizam cinco elementos, fornecendo a mesma carga crítica.

Em sequência, a resposta que mais se aproxima do resultado corresponde à matriz com aproximação de Taylor de 4 termos com pouca diferença da formulação "completa". Logo acima, tem-se a formulação com aproximação de Taylor de 3 termos.

A resposta fornecida pela usual matriz geométrica (small) fornece cargas de flambagem bem superiores, assim como a matriz também desenvolvida neste trabalho, que considera os termos de elevada ordem no tensor deformação, mas utiliza funções de forma cúbicas, sendo necessário então discretizar a estrutura.

Para o último exemplo de colunas isoladas, avaliou-se a coluna engastada em um apoio e simplesmente apoiada no outro, considerando a teoria de flexão de Timoshenko. A resposta é dada conforme a Figura 6.10. 


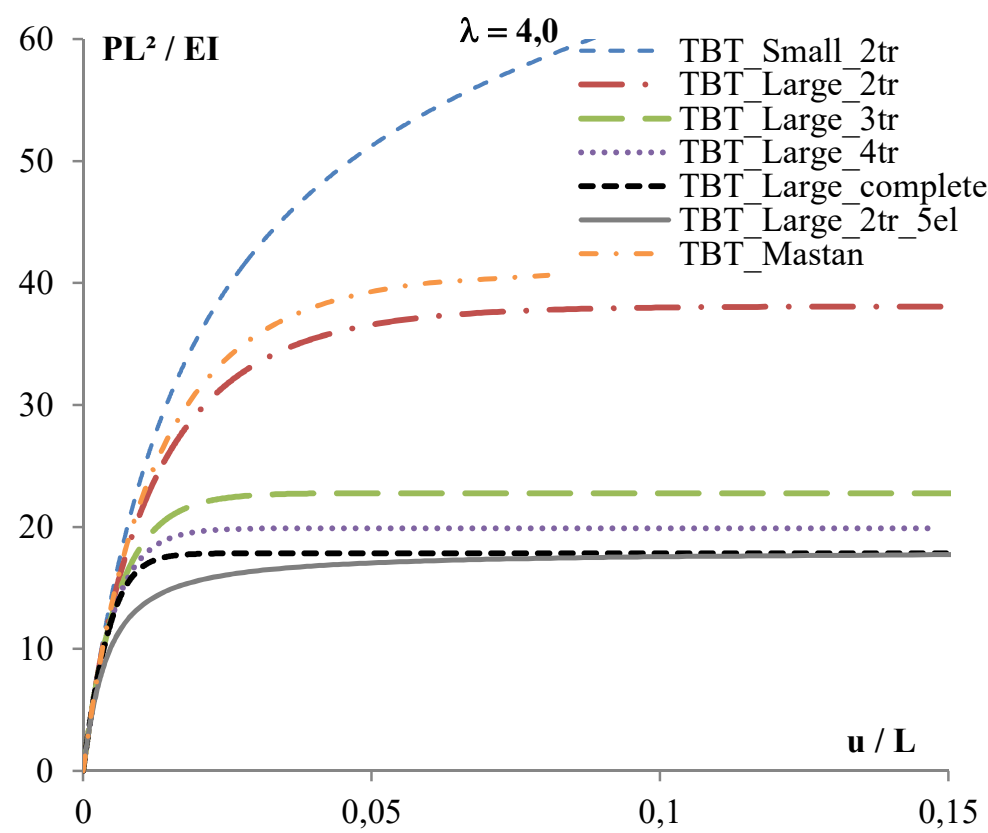

Figura 6.10 - Curva de Equilíbrio para coluna engastada e apoiada com 1 elemento por barra (Timoshenko)

Fonte: Elaborada pelo autor (2019).

Pode-se observar que essa coluna foi a mais difícil de prever o comportamento, entretanto, a formulação completa, mais uma vez, obteve a carga de flambagem da estrutura, utilizando apenas 1 elemento. Com uma relativa boa resposta pode-se citar ainda a matriz com aproximação de Taylor de 4 termos.

As demais matrizes forneceram resultados muito acima da carga de flambagem, indicando que a discretização da estrutura é fundamental.

\section{2 Carga Crítica de Viga Contínua}

O segundo exemplo estuda a influência da teoria de flexão empregada e a consideração dos termos de ordem elevada no tensor deformação na análise de uma viga-coluna contínua, submetida à cargas axiais nos apoios extremos. Esse problema é apresentado em Timoshenko e Gere (1963), conforme Figura 6.11.

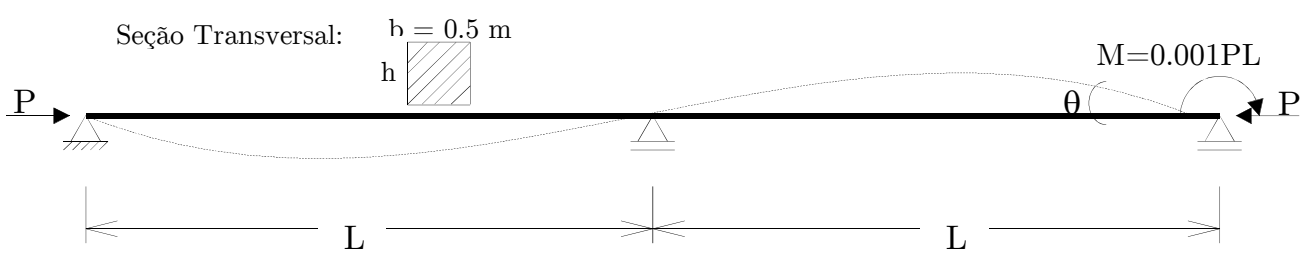

Figura 6.11 - Viga-coluna contínua

Fonte: Adaptado de Timoshenko e Gere (1963). 
O comprimento das barras e as propriedades do material e da seção transversal são as mesmas utilizadas no exemplo 6.1. Para verificar a influência da teoria de flexão de Timoshenko, assim como da consideração de termos de ordem elevada no tensor deformação, mais uma vez, realiza-se o estudo para diferentes índices de esbeltez. Também se empregou diferentes elementos e os resultados foram comparados com o software Mastan2 v3.5 e a carga de flambagem analítica apresentada em Timoshenko e Gere (1963).

Após essa análise, avaliou-se a formulação "completa" desenvolvida e empregou-se o elemento com matriz de rigidez, obtida das funções de forma completas. Nesse caso, utilizou-se apenas um elemento no vão da viga como modelo e ambas as teorias de flexão desenvolvidas nesse trabalho (EulerBernoulli e Timoshenko) foram estudadas para os casos críticos.

\subsection{1}

\section{Matriz de Rigidez de Timoshenko considerando Termos de Grau Elevado no Tensor Deformação e Funções de Forma Cúbicas}

A primeira verificação estudou a influência da teoria de flexão de Timoshenko e a consideração de termos de grau elevado no tensor deformação.

Para a viga-coluna contínua, Figura 6.11, segundo Timoshenko e Gere (1963), quando os vãos são iguais e desconsiderando a deformação por cisalhamento, a carga crítica de flambagem é calculada analiticamente como $P_{c r}=\pi^{2} E I /(L)^{2}$. Os resultados para a curva de equilíbrio, considerando diferentes índices de esbeltez, são apresentados na Figura 6.12 e Figura 6.13.

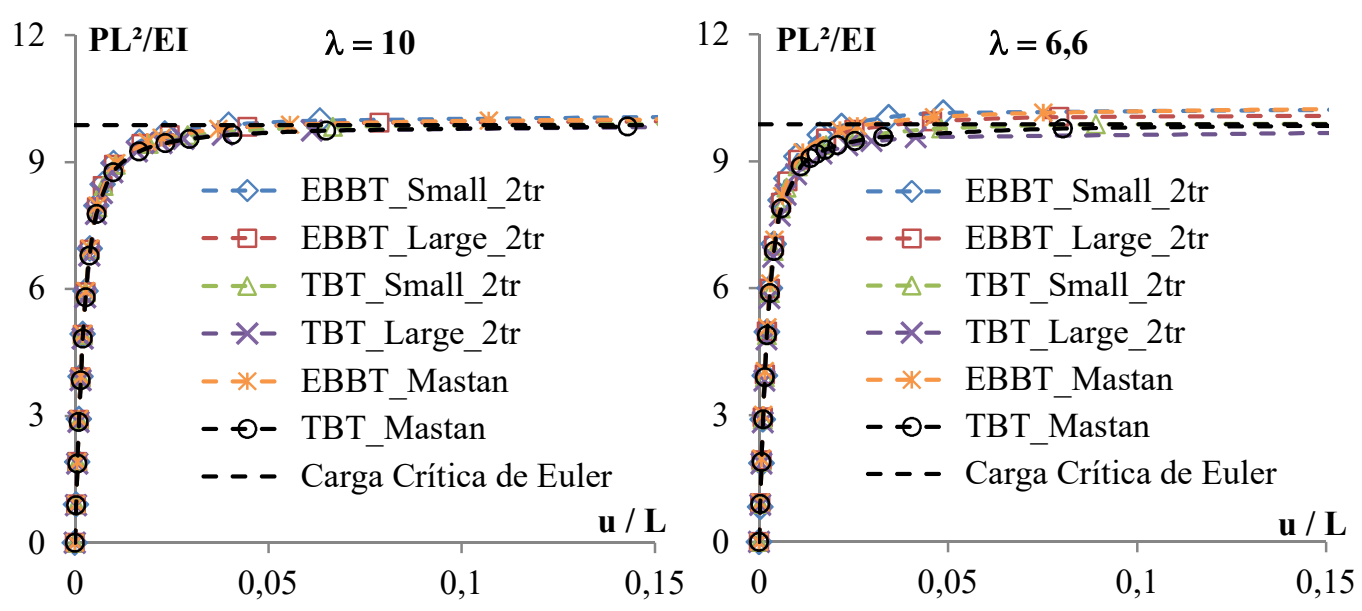

Figura 6.12 - Curva de Equilíbrio para viga-coluna contínua $\lambda=\mathbf{1 0}$ e $\boldsymbol{\lambda}=\mathbf{6}, \mathbf{6}$, com 5 elementos por barra

Fonte: Elaborada pelo autor (2019). 

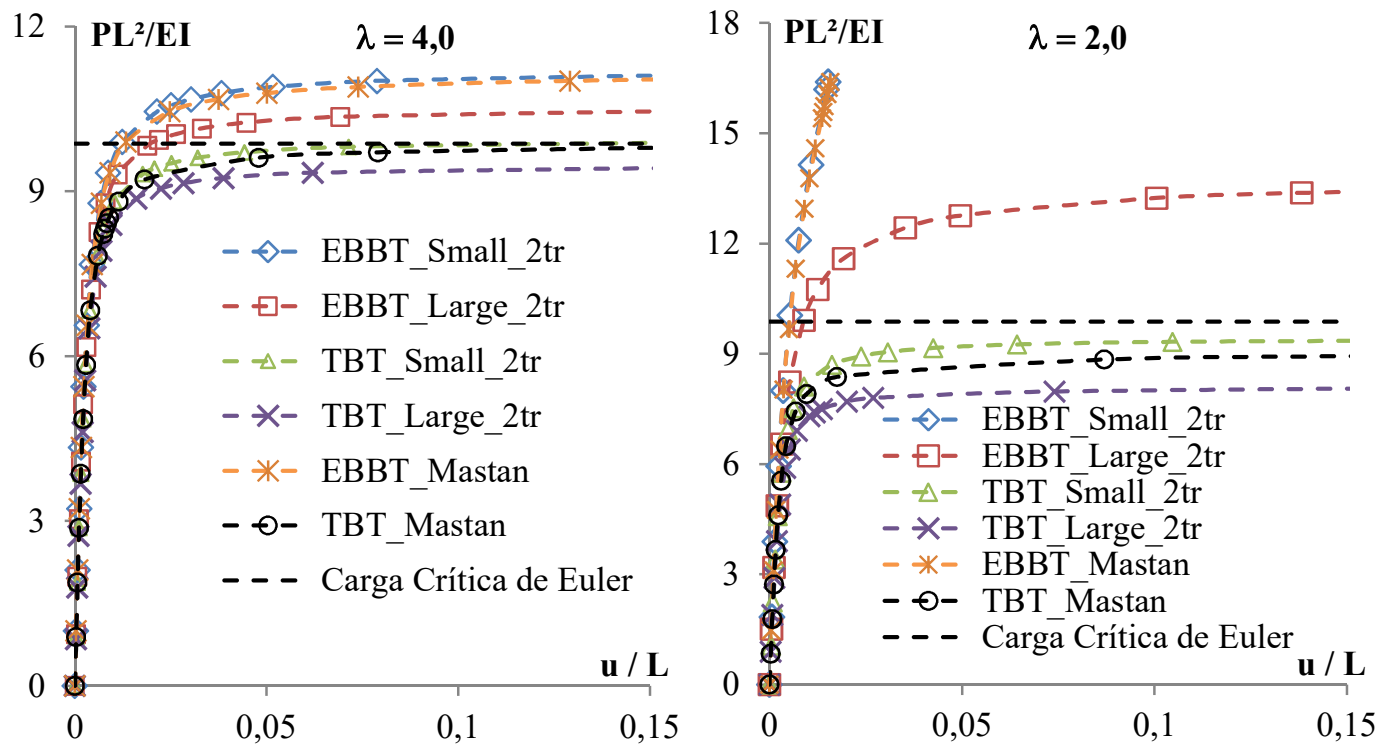

Figura 6.13 - Curva de Equilíbrio para viga-coluna contínua $\lambda=\mathbf{4}, \mathbf{0}$ e $\lambda=\mathbf{2 , 0}$, com 5 elementos por barra

Fonte: Elaborada pelo autor (2019).

Analisando os resultados obtidos, como no exemplo 6.1, para estruturas com índice de esbeltez elevado, a consideração da teoria de flexão de Euler-Bernoulli e Timoshenko fornece resultados idênticos. Da mesma forma, não se constata diferenças relevantes ao se empregar todos os termos do tensor deformação.

Contudo, com a redução do índice de esbeltez, $\lambda \leq 4$, observa-se que a adoção da teoria de flexão de Timoshenko fornece uma carga de flambagem menor para a estrutura do que o emprego da teoria de Euler-Bernoulli. Também é possível notar que, para essa situação, a consideração dos todos os termos do tensor deformação reduz ainda mais a carga crítica da estrutura, podendo se tornar um fator importante no dimensionamento otimizado da realidade atual.

\subsection{2}

\section{Matriz de Rigidez Completa de Euler-Bernoulli}

Neste item, avalia-se a resposta da matriz de rigidez proposta, desenvolvida com as funções de interpolação completas, considerando a teoria de flexão de Euler-Bernoulli. Para essa verificação, os vãos da viga-coluna foram modelados apenas com um único elemento.

Essa verificação é feita, considerando um índice de esbeltez de $\lambda=4$, pois é onde se observa maior diferença entre as matrizes "Large" e "Small", sem que a 
teoria de Euler-Bernoulli pare de descrever de forma satisfatória o problema, como para $\lambda=2$. Os resultados encontrados são apresentados na Figura 6.14.

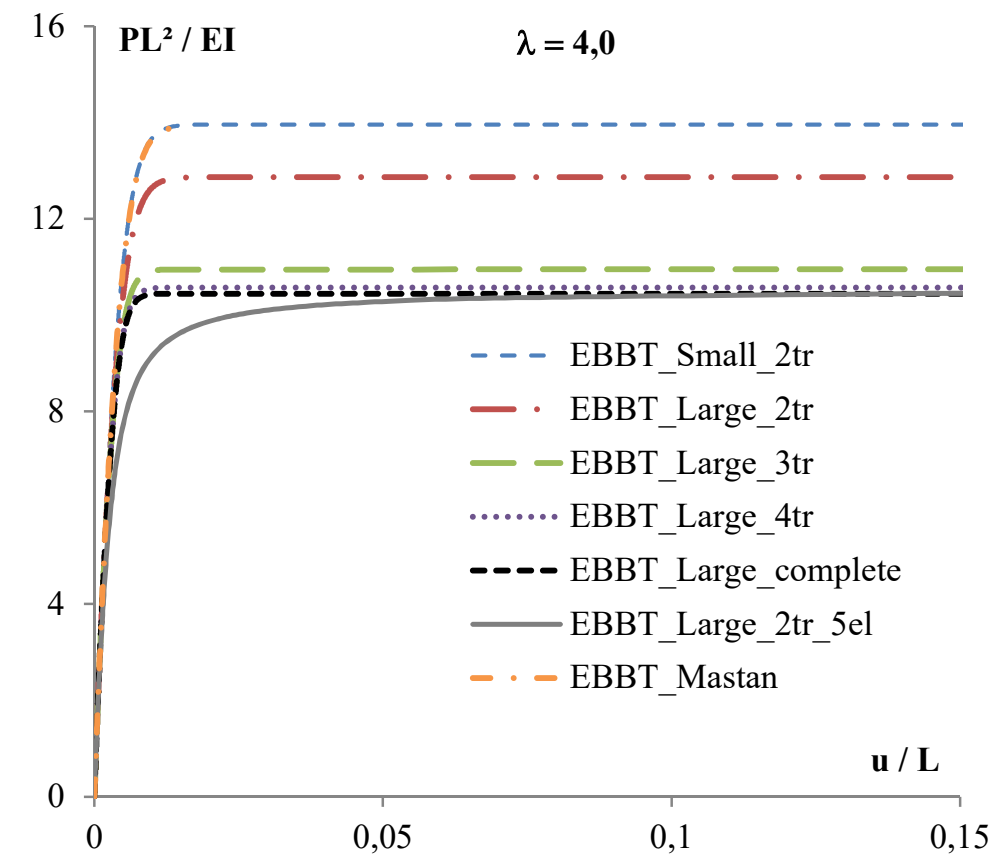

Figura 6.14 - Curva de Equilíbrio para viga-coluna contínua, com 1 elemento por barra Fonte: Elaborada pelo autor (2019).

Com a curva de equilíbrio construída, utilizando-se apenas um elemento por vão, percebe-se que a formulação completa, baseada na teoria de flexão de EulerBernoulli, encontra a carga crítica da viga-coluna e, ainda, que a aproximação em série de Taylor de 4 termos também fornece ótimos resultados. A aproximação com 3 termos fornece uma carga de flambagem um pouco superior, mas, ainda aceitável, considerando que apenas um elemento foi utilizado.

As demais formulações convergem para resultados de carga crítica superior ao esperado para o modelo. É preciso lembrar que para esse índice de esbeltez os resultados a favor da segurança são representados pela teoria de flexão de Timoshenko. Entretanto, o intuito é apenas de avaliar a capacidade da formulação completa, empregando todos os termos de ordem elevada do tensor deformação.

\subsection{3}

\section{Matriz de Rigidez Completa de Timoshenko}

Neste item, pretende-se avaliar a formulação completa proposta por este trabalho para a teoria de flexão de Timoshenko. Para essa verificação, os elementos foram modelados apenas com um elemento por barra. 
Ao se avaliar as curvas de equilíbrio apresentadas no início da aplicação numérica, Figura 6.12 e Figura 6.13, constata-se que já existe discrepância ao se empregar as diferentes teorias de flexão para o índice de esbeltez $\lambda=4$. Esse índice também fornece diferenças entre a consideração dos termos de ordem elevada do tensor deformação (Large) ou não (Small). Além disso, esse índice, é mais próximo de uma estrutura real, sendo, por isso, escolhida como situação crítica para validação da formulação aqui desenvolvida. Os resultados obtidos são expostos na Figura 6.15.

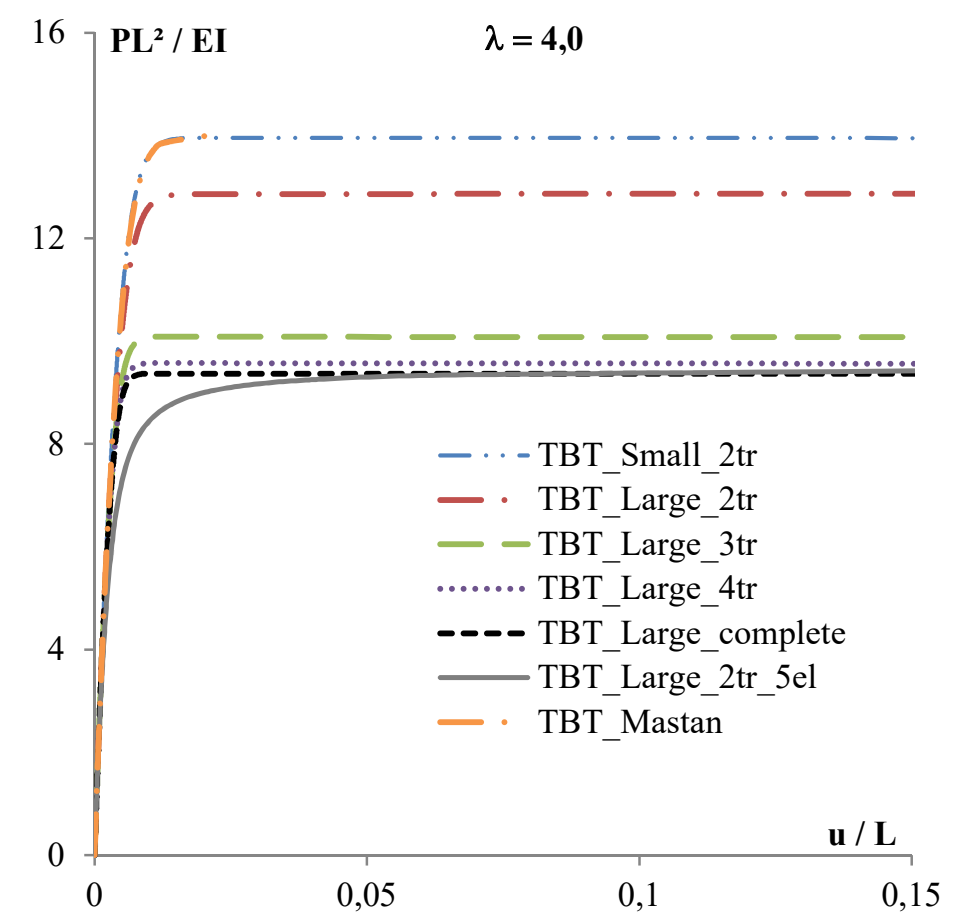

Figura 6.15 - Curva de Equilíbrio para viga-coluna contínua, com 1 elemento por barra (Timoshenko)

Fonte: Elaborada pelo autor (2019).

De modo análogo ao que ocorre considerando a teoria de flexão de EulerBernoulli, para a teoria de Timoshenko, a formulação completa, utilizando apenas um elemento, fornece a carga crítica do problema, com a aproximação de 4 termos em série de Taylor, obtendo comportamento similar. Para a aproximação com 3 termos, o resultado perde precisão. Entretanto, chega a convergir para um valor próximo, ao se comparar com a formulação usual de matriz de rigidez geométrica de Timoshenko (Small) e ainda, com a desenvolvida neste trabalho, que utiliza todos os termos do tensor deformação, porém, as funções de interpolação são cúbicas (Large). 


\section{3}

\section{Carga Crítica para Pórtico de Roorda}

O terceiro exemplo examina a influência da teoria de flexão e a consideração dos termos de ordem elevada do tensor deformação no pórtico de Roorda, submetido a uma carga vertical no nó livre. A estrutura analisada é apresentada na Figura 6.16. A seção transversal possui fator de forma $\chi=5 / 6$, coeficiente de Poisson $v=0,3$, módulo de elasticidade $E=10^{7} \mathrm{kN} / \mathrm{m}^{2}$ e comprimento $L=1 \mathrm{~m}$.

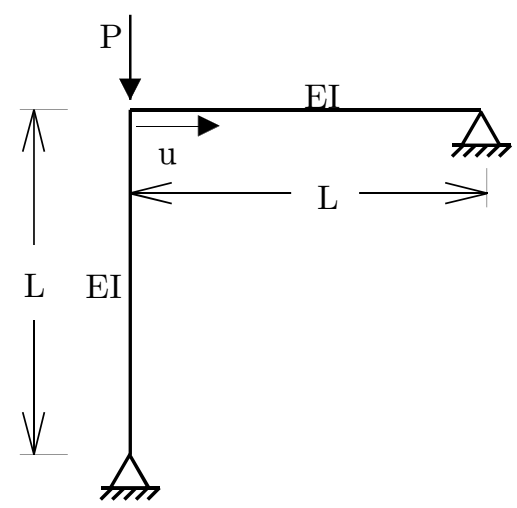

Figura 6.16 - Pórtico de Roorda

Fonte: Elaborada pelo autor (2019).

Desconsiderando a deformação por cisalhamento, a carga crítica do pórtico possui valor analítico dado pela equação (6.1).

$$
P_{c r}=-1,40694 \frac{\pi^{2} E I}{L^{2}}
$$

Porém, segundo Burgos e Martha (2013), que estudaram a influência do coeficiente $\Omega$ na carga crítica do pórtico de Roorda, ao se considerar a deformação por cisalhamento, essa carga pode ser obtida analiticamente, resolvendo a equação (6.2).

$$
\begin{gathered}
{\left[\mu^{2} L^{2}(1+6 \Omega)+3\right] \sin (\mu L)-3 \mu L \cos (\mu L)=0} \\
\mu^{2}=-P_{c r} / E I\left(1+P_{c r} / G \chi A\right)
\end{gathered}
$$

A próxima resolução segue a mesma metodologia dos exemplos anteriores. Na primeira etapa, avalia-se a matriz de rigidez geométrica desenvolvida neste trabalho, em que se consideram a teoria de flexão de Timoshenko, as funções de interpolação cúbicas e os termos de ordem elevada no tensor deformação. 
$\mathrm{Na}$ sequência, estudam-se as formulações "completas" desenvolvidas. Primeiro, avalia-se a formulação, empregando-se a teoria de flexão de EulerBernoulli e, depois, a de Timoshenko. Nessas formulações, a matriz de rigidez da estrutura é construída com funções de forma, que levam em conta a carga axial.

\subsection{1 Matriz de Rigidez de Timoshenko considerando Termos de Grau Elevado no Tensor Deformação e Funções de Forma Cúbicas}

Os resultados obtidos com as diferentes formulações que utilizam funções de forma cúbicas são apresentados na Figura 6.17 e Figura 6.18. As barras do pórtico foram discretizadas com cinco elementos em cada.

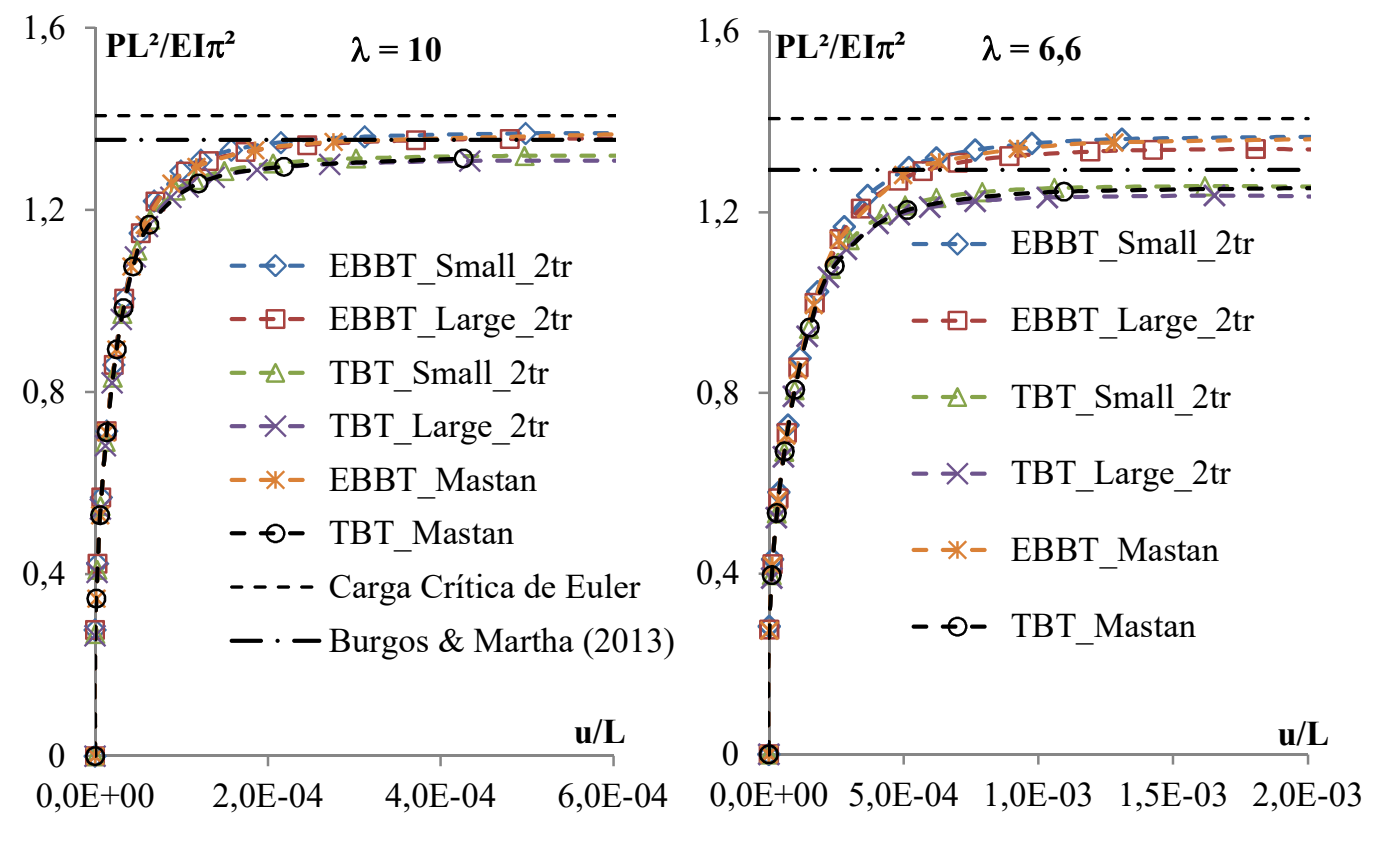

Figura 6.17 - Curva de Equilíbrio para Pórtico de Roorda $\lambda=\mathbf{1 0}$ e $\boldsymbol{\lambda}=\mathbf{6 , 6}$, com 5 elementos por barra

Fonte: Elaborada pelo autor (2019). 

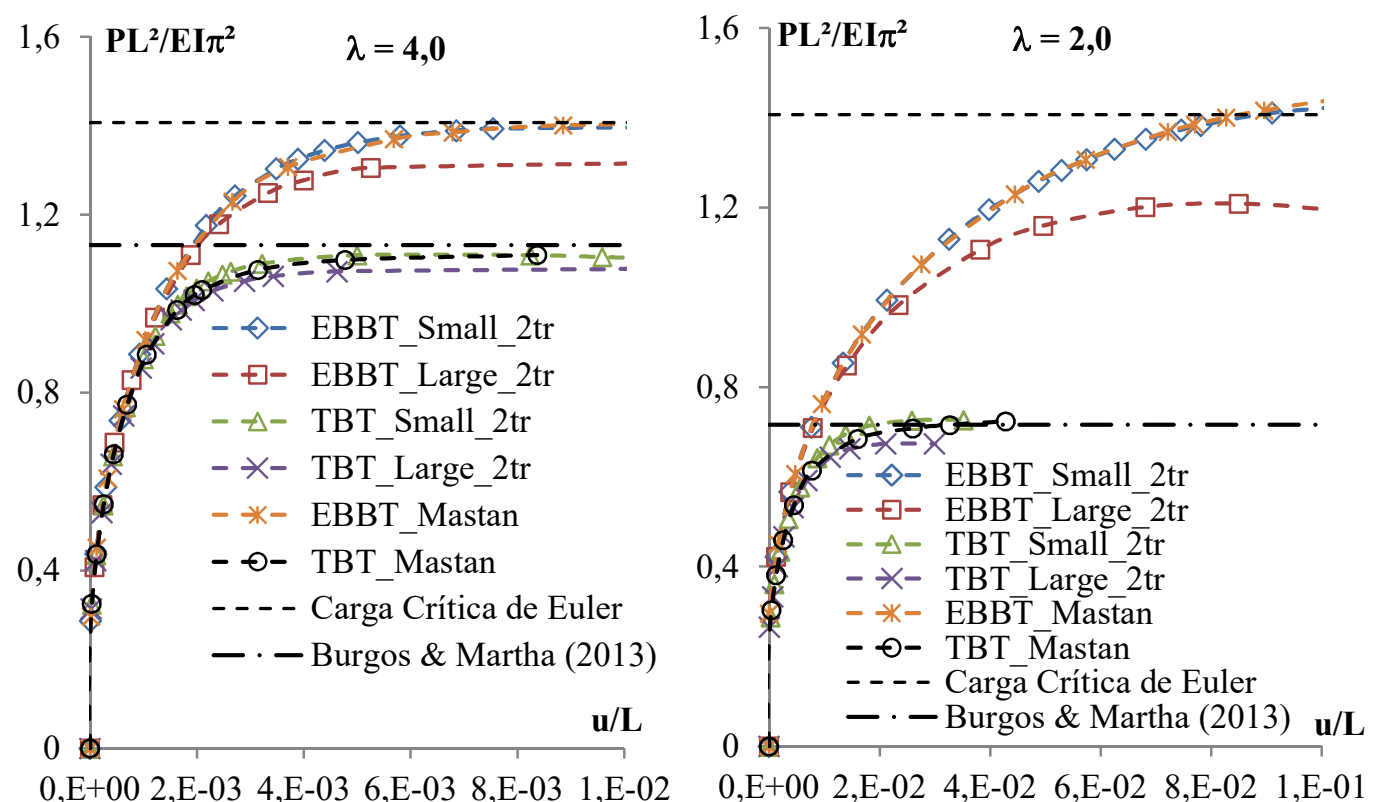

Figura 6.18 - Curva de Equilíbrio para Pórtico de Roorda $\lambda=4,0$ e $\lambda=2,0$, com 5 elementos por barra

Fonte: Elaborada pelo autor (2019).

Para $\lambda=10$, já existem diferenças entre as teorias de flexão e as curvas de equilíbrio, considerando a teoria de Euler-Bernoulli tendem a convergir para a carga crítica analítica. Com a redução do índice de esbeltez da estrutura, maior fica a diferença entre o comportamento da estrutura, empregando as diferentes teorias de flexão e considerando os termos de grau elevado do tensor deformação.

Pode-se observar, que para baixos valores de índice de esbeltez, $\lambda \leq 4$, a diferença entre a teoria de flexão considerada é evidente e a utilização da teoria de Euler-Bernoulli nessas situações pode levar a predições de carga crítica falhas. A diferença entre o emprego dos termos de ordem elevada do tensor deformação produz maiores diferenças no caso da teoria de flexão de Euler-Bernoulli, possuindo respostas mais próximas na teoria de Timoshenko.

\subsection{2}

\section{Matriz de Rigidez Completa de Euler-Bernoulli}

Para o problema em questão, optou-se por avaliar a curva de equilíbrio para estruturas com alto índice de esbeltez, por serem melhores descritas, empregandose a toeira de flexão de Euler-Bernoulli. Considerando $\lambda=6.6$, já são observadas diferenças nas respostas ao se empregar os termos de ordem elevada no tensor 
deformação. Assim, os resultados obtidos para essa esbeltez, empregando-se apenas um único elemento por barra, são expostos na Figura 6.19.

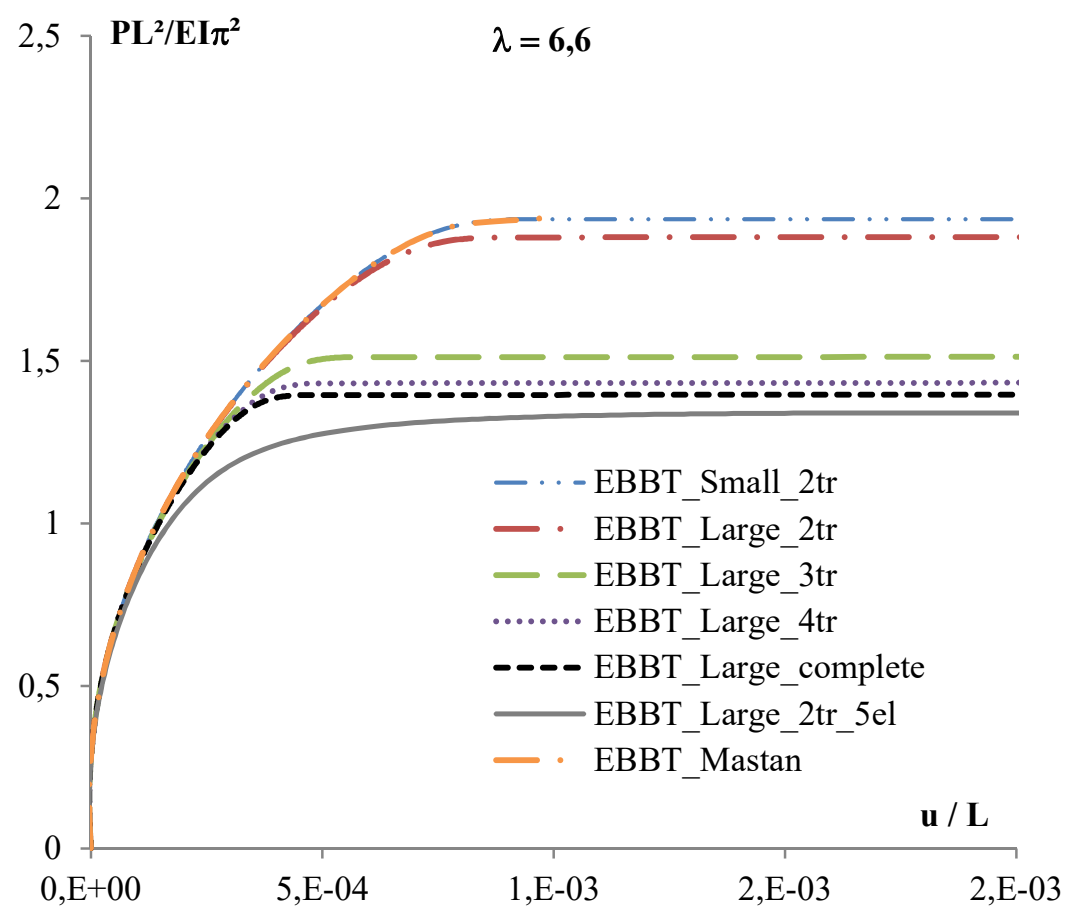

Figura 6.19 - Curva de Equilíbrio para pórtico de Roorda, com 1 elemento por barra Fonte: Elaborada pelo autor (2019).

Analisando os resultados, consegue-se visualizar que, novamente, a formulação completa, com apenas um elemento, consegue predizer com certa precisão a carga crítica da estrutura. Vale ressaltar, que o resultado encontrado pela aproximação de Taylor com 4 termos também fornece valores condizentes, utilizando-se um elemento. Para esse exemplo, pode-se notar ainda que a aproximação de Taylor de 3 termos com um único elemento também se aproxima do resultado esperado.

Ao se empregar formulações que utilizam as funções de interpolação cúbicas e não consideram a carga axial, mesmo utilizando os termos de ordem elevada no tensor deformação, são fornecidos resultados superiores para a carga crítica da estrutura, com o emprego de um único elemento por barra.

\subsection{3}

\section{Matriz de Rigidez Completa de Timoshenko}

Para o pórtico de Roorda, também foi avaliada a formulação completa desenvolvida neste trabalho. Essa validação foi feita, utilizando-se apenas um 
único elemento por barra e aplicada na situação em que ocorre maior diferença entre as teorias de flexão, mas, com dimensões ainda aceitáveis para uma estrutura real $(\lambda=4,0)$. As curvas de equilíbrio encontradas para as diferentes formulações são expostas na Figura 6.20.

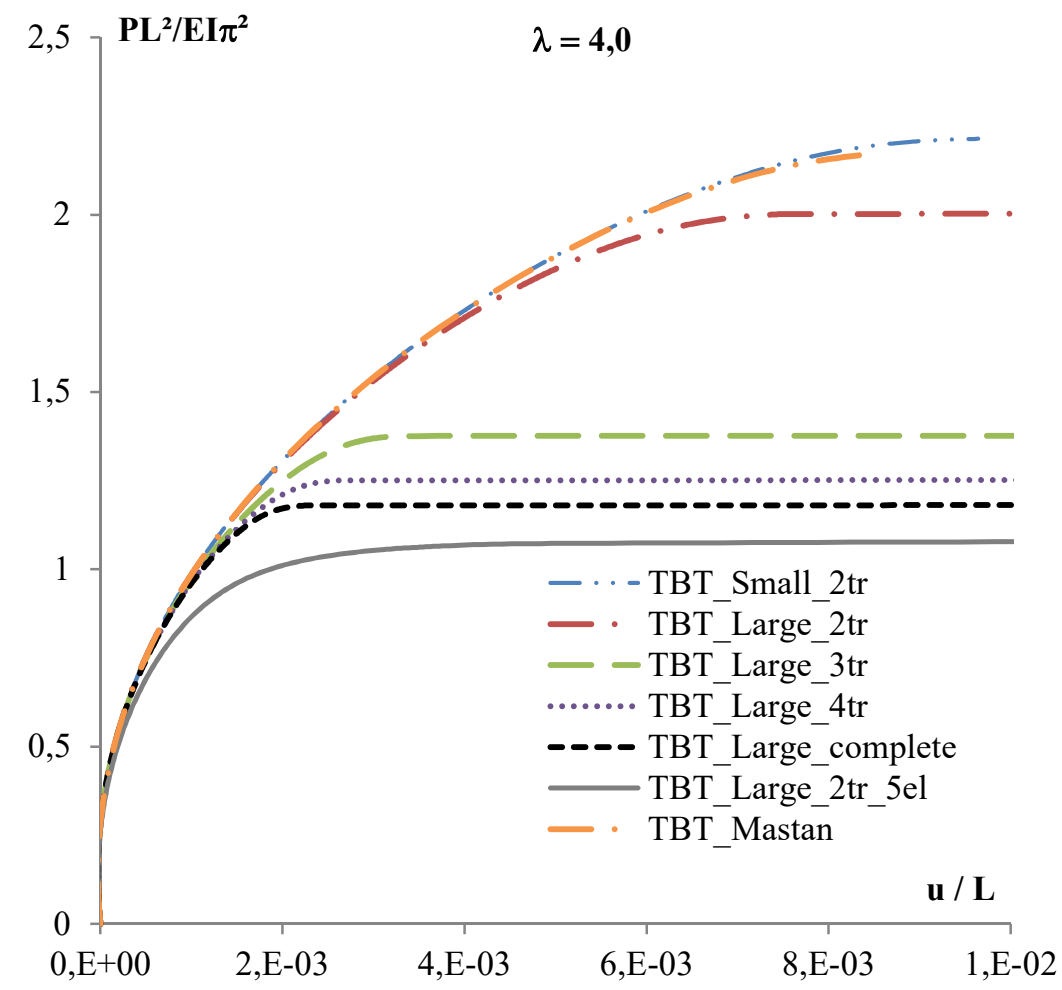

Figura 6.20 - Curva de Equilíbrio para pórtico de Roorda, com 1 elemento por barra (Timoshenko) Fonte: Elaborada pelo autor (2019).

De acordo com as curvas apresentadas, pode-se verificar que a formulação completa ("TBT_Large_complete"), com o emprego apenas de um único elemento, possui uma boa aproximação da carga crítica do pórtico.

As aproximações em série de Taylor para essa situação também apresentaram bons resultados, ainda que com uma menor precisão, sendo o melhor resultado para a aproximação com 4 termos, com uma variação de 15\% na carga crítica, enquanto que, para a completa essa variação é de apenas $9 \%$ no valor. A aproximação em série de Taylor de 3 termos perde ainda mais precisão, porém, o seu resultado continua melhor que as formulações usuais. No entanto, seria necessário utilizar mais elementos para melhor descrever o comportamento da estrutura.

Contudo, pode-se observar que, à medida que se aumenta a ordem da carga axial $P$ na formulação (termos na expansão em série) os resultados melhoram. 


\section{4}

\section{Carga Crítica para Pórtico}

O exemplo a seguir também estuda a influência da teoria de flexão e a consideração dos termos de ordem elevada do tensor deformação na análise de estruturas de barras. A estrutura analisada é o pórtico apresentado na Figura 6.21. A seção transversal possui fator de forma $\chi=5 / 6$, coeficiente de Poisson $v=0,3$, módulo de elasticidade $E=10^{7} \mathrm{kN} / \mathrm{m}^{2}$ e comprimento $L=1 \mathrm{~m}$.

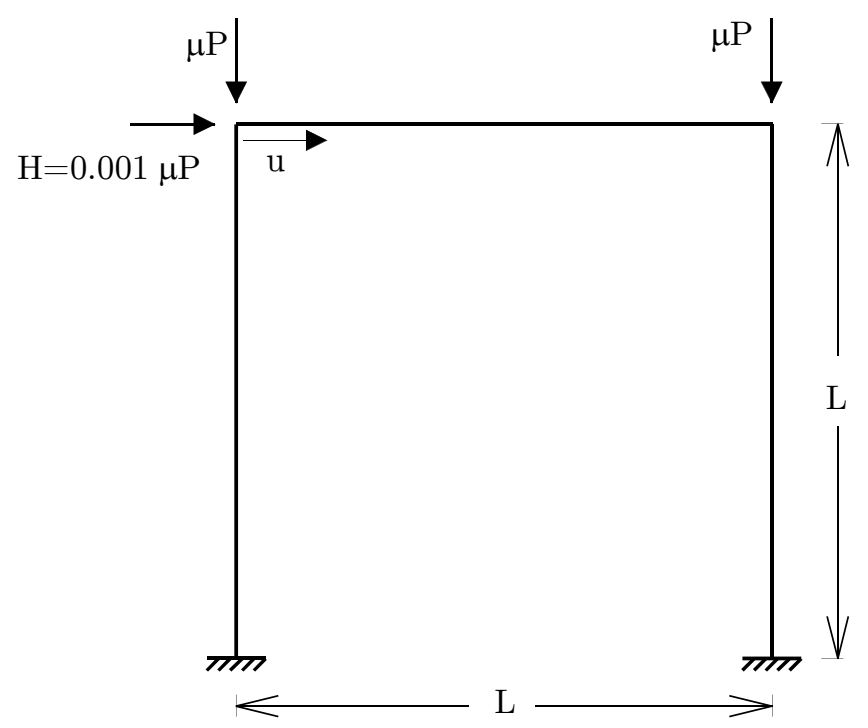

Figura 6.21 - Pórtico engastado na base

Fonte: Adaptado de Bazant e Cedolin (2010).

O pórtico é submetido a cargas verticais $(\mu P)$ nos nós livres e por uma pequena carga de perturbação horizontal $(H=0,001 \mu P)$. Bazant e Cedolin (2010) apresentam a solução analítica para esse problema, considerando a teoria de flexão de Euler-Bernoulli, baseada na carga crítica de flambagem de Euler, conforme a equação (6.3).

$$
\mu_{c r} P=0.744 \frac{\pi^{2} E I}{L^{2}}
$$

As formulações desenvolvidas neste trabalho foram avaliadas, com fundamento nessa solução analítica proposta e, utilizando-se do programa Mastan2 v3.5. 


\subsection{1 \\ Matriz de Rigidez de Timoshenko considerando Termos de Grau Elevado no Tensor Deformação e Funções de Forma Cúbicas}

Os resultados obtidos para o deslocamento horizontal do nó superior esquerdo, utilizando as diferentes formulações que empregam apenas as funções de interpolação cúbicas, são apresentados na Figura 6.22. As barras foram discretizadas com cinco elementos em cada.

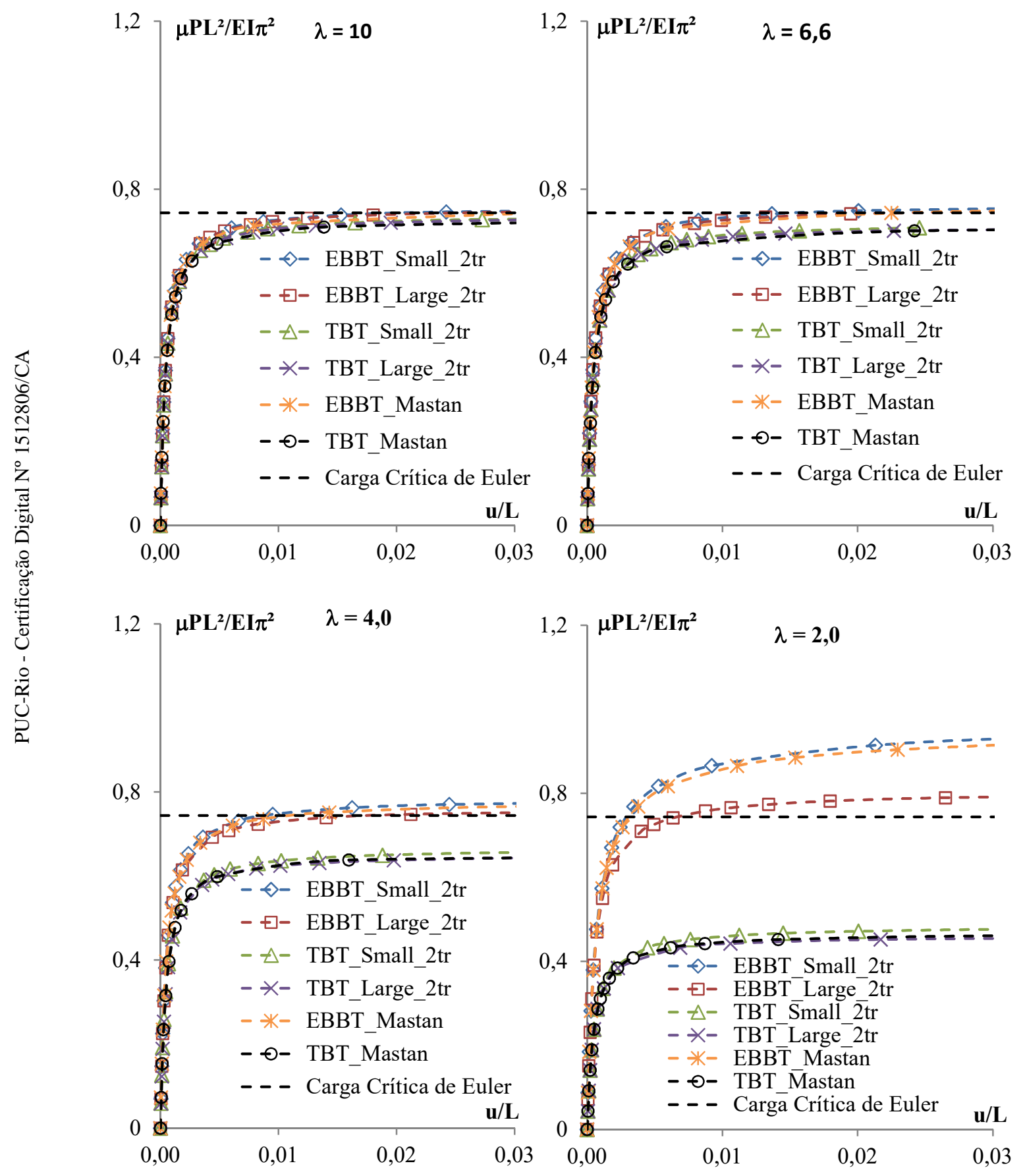

Figura 6.22 - Curva de Equilíbrio para Pórtico com diferentes $\lambda$, com 5 elementos por barra Fonte: Elaborada pelo autor (2019). 
Conforme já observado nos exemplos anteriores, e como esperado, para estruturas com elevado índice de esbeltez, a teoria de flexão utilizada para resolver o problema fornece os mesmos resultados para a carga crítica. Da mesma maneira, a consideração ou não dos termos de grau elevado no tensor deformação não gera diferenças relevantes na análise.

Entretanto, à medida que a esbeltez da estrutura é reduzida, a consideração da teoria de flexão de Timoshenko reduz consideravelmente a carga crítica da estrutura. Pode-se verificar que a utilização dos termos de grau elevado no tensor deformação também gera uma pequena alteração nessa carga de flambagem, sendo, para o caso aqui analisado, mais evidente para a teoria de flexão de EulerBernoulli e mais discreta quando se considera Timoshenko.

\subsection{2}

\section{Matriz de Rigidez Completa de Euler-Bernoulli}

Para avaliar a formulação desenvolvida neste trabalho: a matriz construída a partir das funções de forma completas e as aproximações em série de Taylor, empregando a teoria de Euler-Bernoulli e os termos de grau elevado no tensor deformação, reproduziu-se o pórtico anterior, com apenas um elemento por barra.

Para o problema em questão, optou-se por verificar o caso em que $\lambda=4$, uma vez que já apresenta diferenças na carga crítica entre os elementos "Small” e "Large", ou seja, entre a consideração ou não dos termos de ordem elevada no tensor deformação. Os resultados encontrados são apresentados na Figura 6.23. 


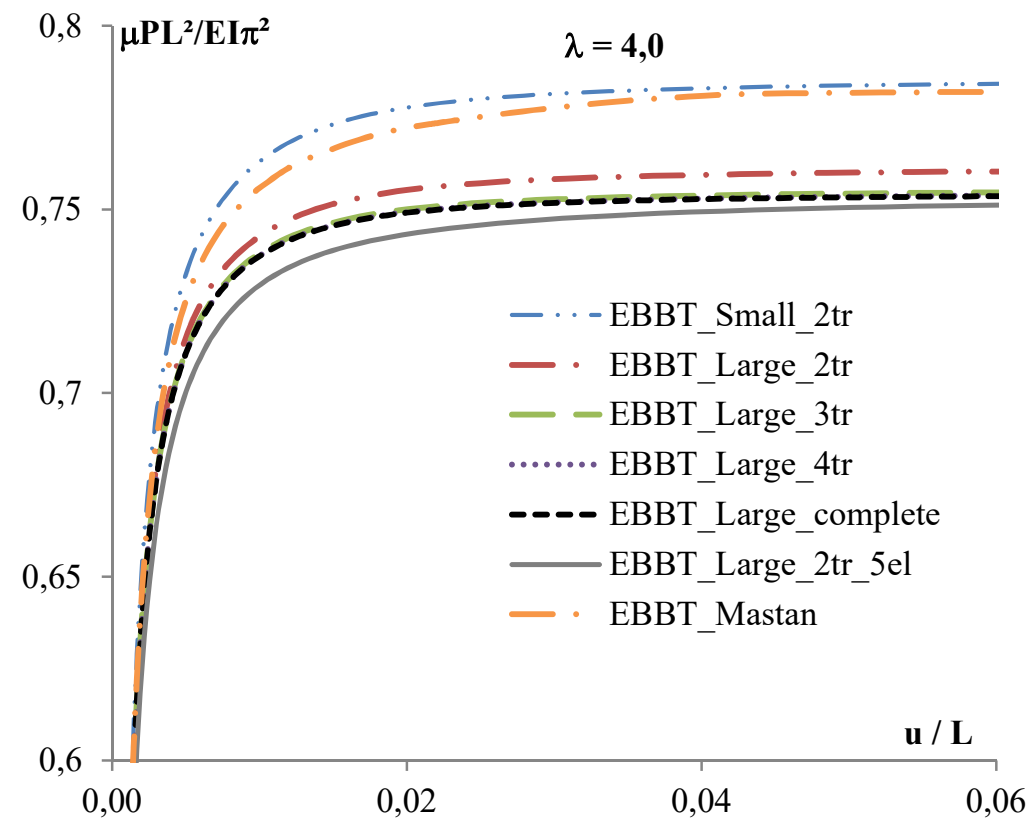

Figura 6.23 - Curva de Equilíbrio para pórtico, com 1 elemento por barra Fonte: Elaborada pelo autor (2019).

Para este problema, pode-se observar que, utilizando-se apenas um elemento por barra, todas as formulações conseguiram predizer o comportamento da estrutura de maneira satisfatória. Os resultados fornecidos pelas matrizes desenvolvidas nesse trabalho ("EBBT_Large_complete", "EBBT_Large_4tr e “EBBT_Large_3tr) conseguiram predizer a carga crítica da estrutura e ainda tiveram um comportamento melhor que a matriz de rigidez geométrica usual, representada no problema por "EEBT_Large_2tr".

Também é possível notar a influência que a consideração dos termos de grau elevado no tensor deformação exerce para o problema, visto que a sua utilização , no problema, reduz a carga de previsão de flambagem.

\subsection{3}

\section{Matriz de Rigidez Completa de Timoshenko}

A última verificação deste exemplo refere-se às matrizes desenvolvidas nesta Tese, em que se considera a teoria de Timoshenko. Para esta análise, optouse, igualmente, por avaliar a estrutura com índice de esbeltez $\lambda=4$, pelas diferenças observadas entre as teorias de flexão e por sua maior proximidade com uma estrutura real quando comparada com um índice $\lambda=2$. Foi utilizado um elemento por barra e os resultados estão expostos na Figura 6.24. 


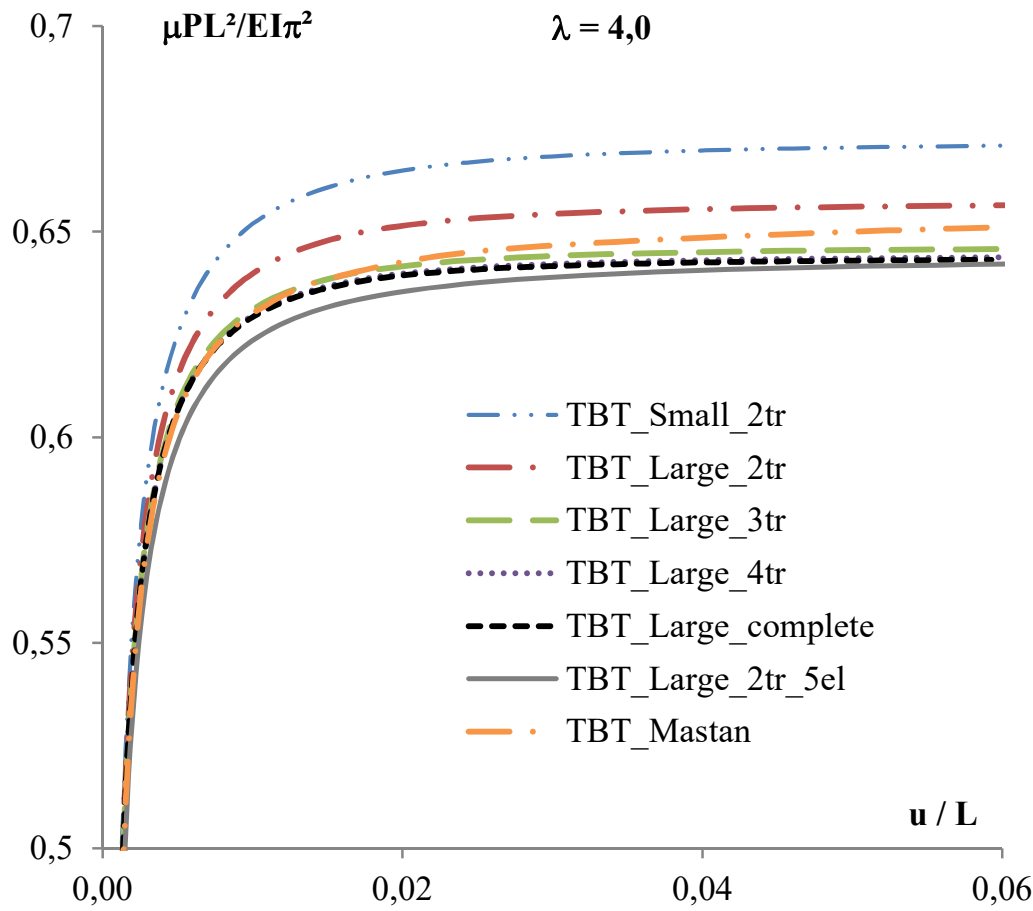

Figura 6.24 - Curva de Equilíbrio para pórtico, com 1 elemento por barra (Timoshenko)

Fonte: Elaborada pelo autor (2019).

Pela curva de equilíbrio exposta, pode-se observar que, utilizando-se apenas um elemento por barra em conjunto com a teoria de flexão de Timoshenko, todas as formulações conseguiram predizer, de forma satisfatória, o comportamento da estrutura.

Entretanto, as matrizes com formulação completa fornecem um resultado ainda melhor que todas as outras, com a aproximação em série de Taylor com 4 termos, obtendo resultado sobreposto à formulação completa. A aproximação em série de Taylor com 3 termos também possui boa aproximação. A matriz desenvolvida apenas com as funções cúbicas também previu a carga crítica, porém, obtendo o pior resultado.

Mais uma vez, é nítida a diferença ao se empregar os termos de ordem elevada do tensor deformação ("Large") ou não (“Small”), mesmo empregando-se a teoria de flexão de Timoshenko.

\section{5}

\section{Carga Crítica para Pórtico Espacial}

Para a aplicação numérica seguinte, avaliou-se a influência da teoria de vigas e da consideração dos termos de ordem elevada do tensor deformação em 
um pórtico espacial de um pavimento. A estrutura analisada é apresentada na Figura 6.25 e possui seção transversal, com fator de forma $\chi=5 / 6$, coeficiente de Poisson $v=0,3$, módulo de elasticidade $E=10^{7} \mathrm{kN} / \mathrm{m}^{2}$ e comprimento $L=1 \mathrm{~m}$.

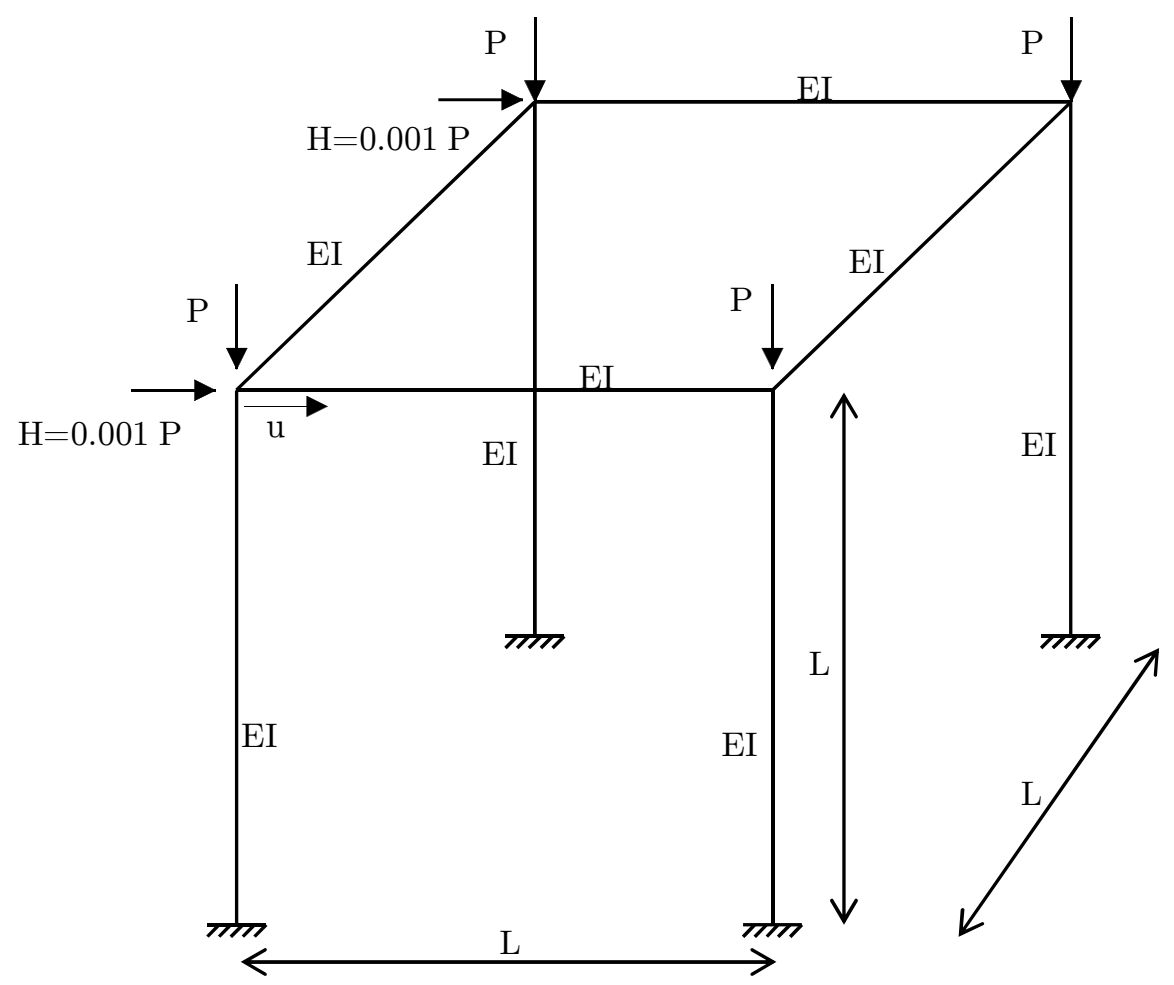

Figura 6.25 - Pórtico espacial

Fonte: Elaborada pelo autor (2019).

O pórtico é submetido a cargas verticais $(P)$ nos nós livres e por duas pequenas cargas de perturbação horizontais $(H=0,001 P)$. Os pilares e vigas foram modelados com a mesma seção transversal e, para verificar a influência da teoria de flexão, esta seção foi variada de maneira a reduzir o índice de esbeltez.

Inicialmente, para resolver o problema, e por não se empregar uma solução analítica no problema, fez-se um estudo de convergência de resultado, utilizando o Mastan2 v3.5 para escolha da discretização dos elementos. Este estudo é apresentado na Figura 6.26. Pode-se observar que, para uma discretização de quatro elementos (168 graus de liberdade) e oito elementos (360 graus de liberdade), a resposta não se altera significativamente. Portanto, optou-se por utilizar uma discretização de quatro elementos por barra para os resultados iniciais, com matrizes geométricas usuais e a de Timoshenko desenvolvida neste trabalho. 


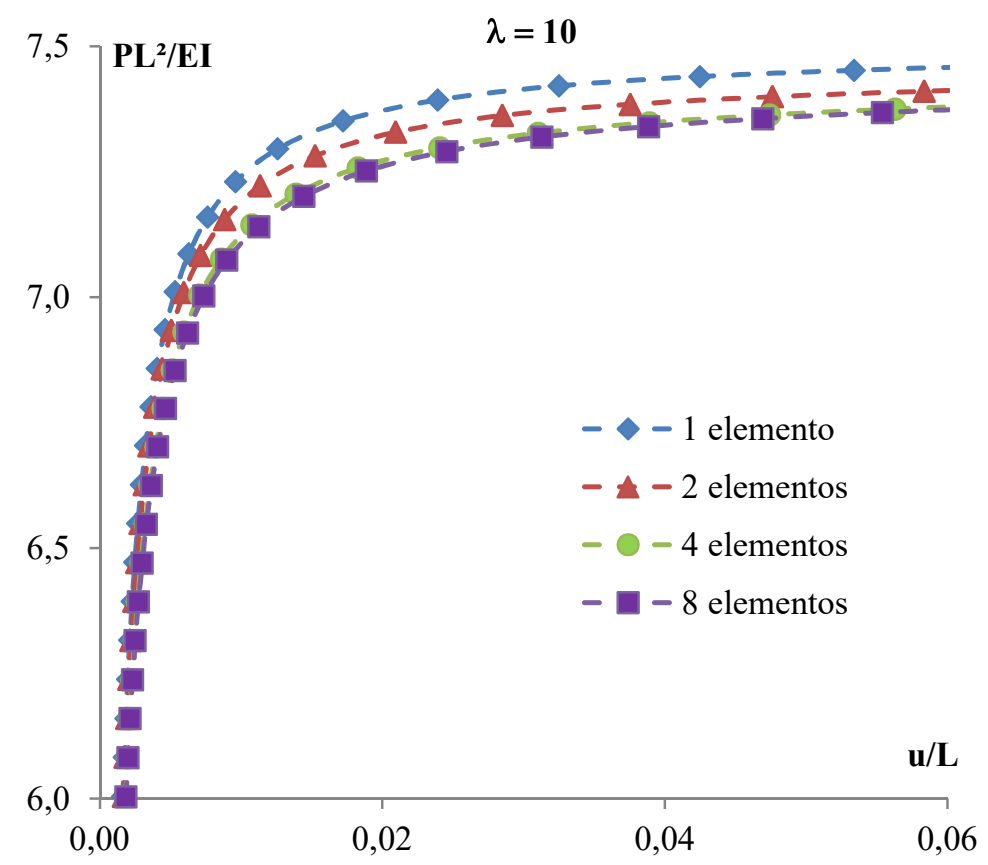

Figura 6.26 - Estudo de convergência para pórtico espacial

Fonte: Elaborada pelo autor (2019).

A Figura 6.27 mostra a deformada do pórtico espacial, com um fator de amplificação de escala de 10 vezes.

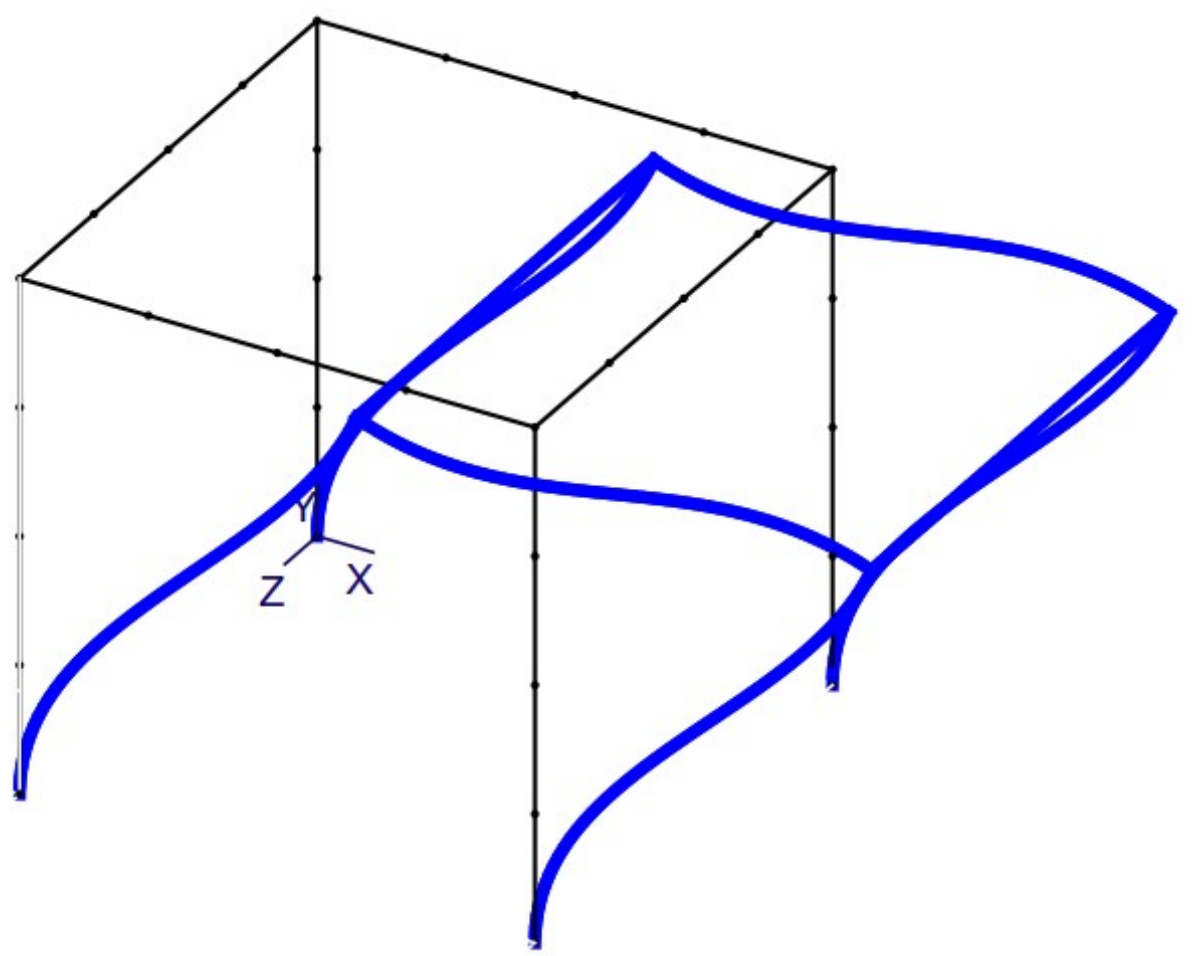

Figura 6.27 - Deformada do pórtico espacial

Fonte: Elaborada pelo autor (2019) - Obtida com o Mastan2 V.3.5. 


\subsection{1 \\ Matriz de Rigidez de Timoshenko considerando Termos de Grau Elevado no Tensor Deformação e Funções de Forma Cúbicas}

Os resultados obtidos para o deslocamento horizontal $(u)$ do nó superior, indicado na Figura 6.25, utilizando as diferentes formulações e empregando funções de forma cúbicas, com a variação dos termos do tensor deformação, são apresentados na Figura 6.28 e Figura 6.29. As barras foram discretizadas com quatro elementos em cada, de acordo com o estudo de convergência realizado.

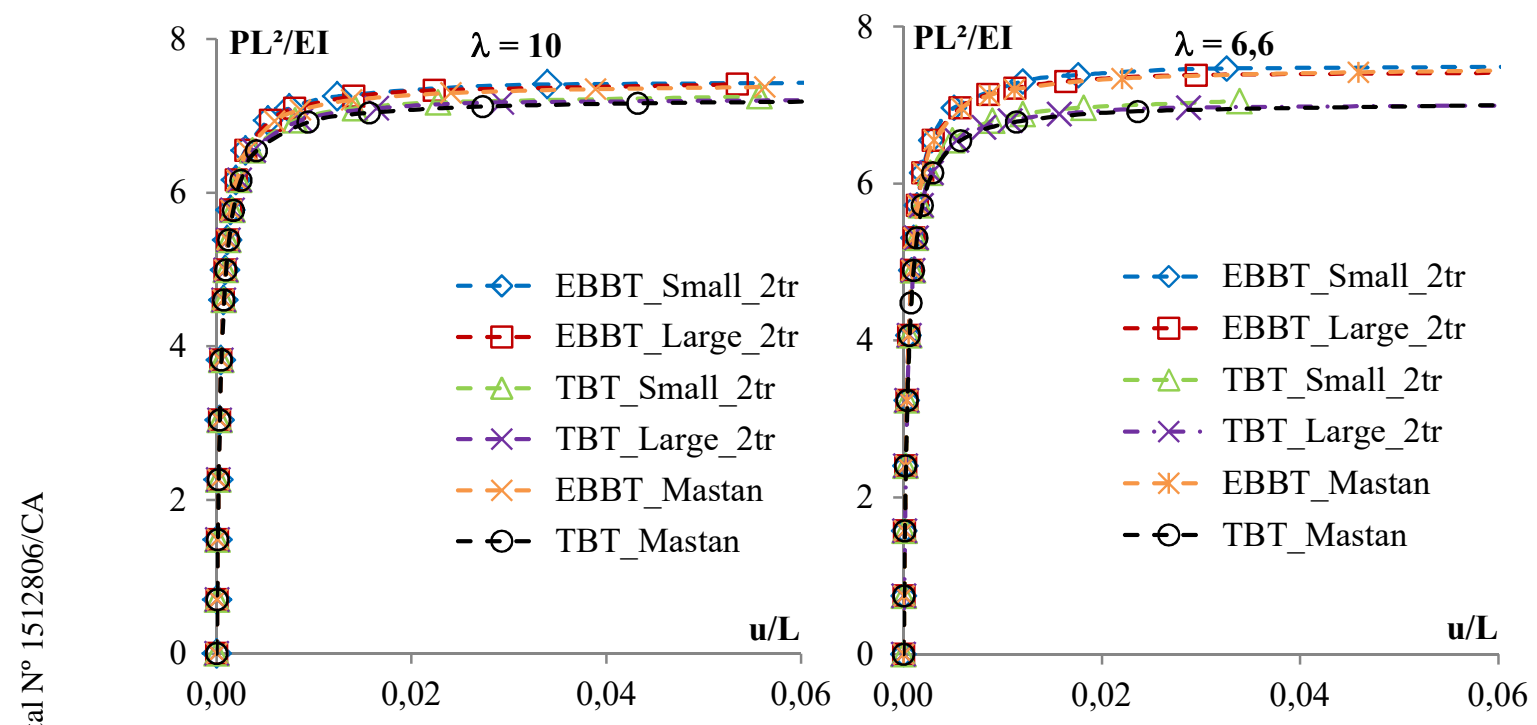

Figura 6.28 - Curva de Equilíbrio para pórtico espacial de um pavimento $\boldsymbol{\lambda}=\mathbf{1 0}$ e $\boldsymbol{\lambda}=\mathbf{6 , 6}$, com 4 elementos por barra

Fonte: Elaborada pelo autor (2019).
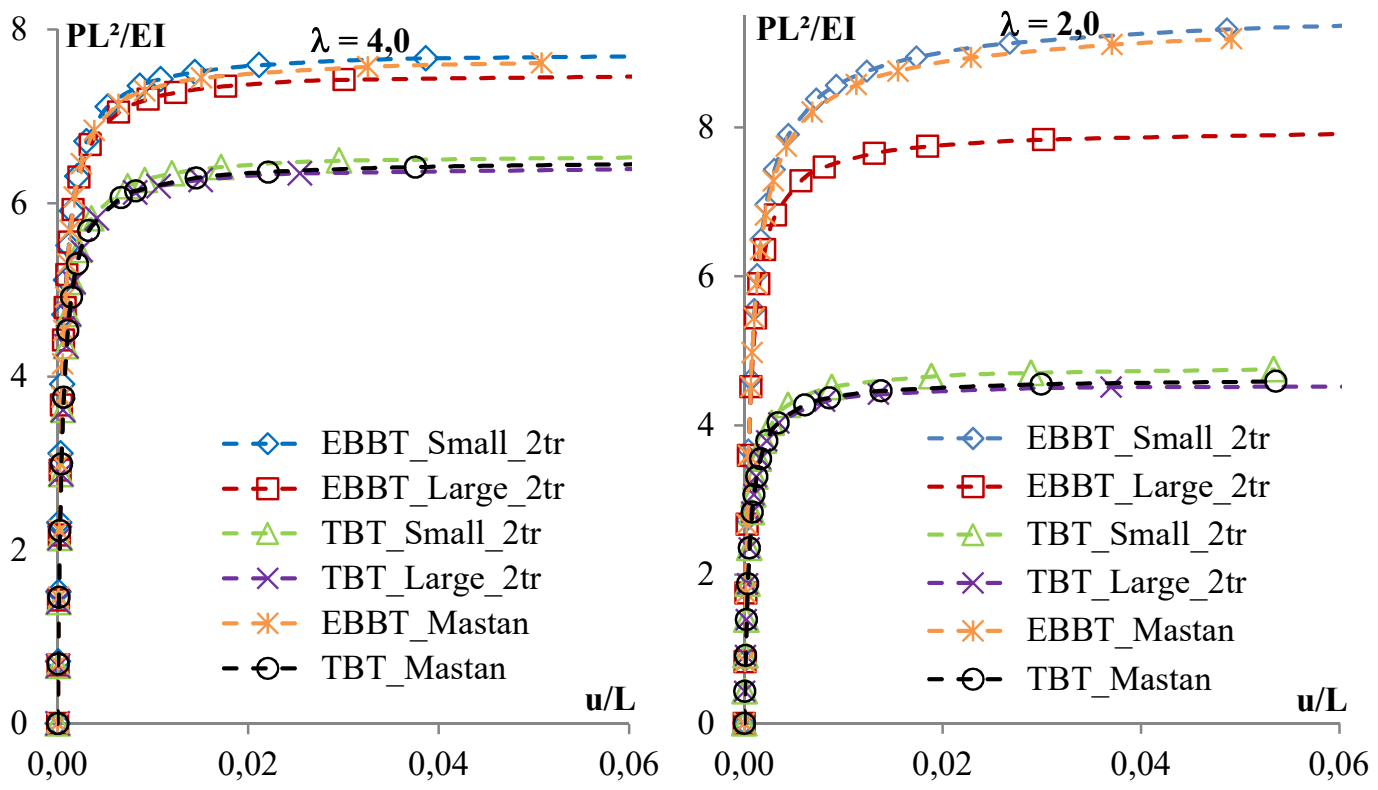

Figura 6.29 - Curva de Equilíbrio para pórtico espacial de um pavimento $\boldsymbol{\lambda}=\mathbf{4 , 0}$ e $\boldsymbol{\lambda}=\mathbf{2}, \mathbf{0}$, com 4 elementos por barra

Fonte: Elaborada pelo autor (2019). 
Como para as análises no plano, no problema tridimensional observa-se a influência da teoria de flexão empregada para estruturas com baixo índice de esbeltez. Também se visualiza que, para essas situações, a consideração dos termos de ordem elevada do tensor deformação também fornece cargas críticas abaixo do valor encontrado, sem a utilização desses termos.

O elemento desenvolvido nesta Tese, em que se empregam a teoria de flexão de Timoshenko, as funções de forma cúbicas e os termos de ordem elevada do tensor deformação, fornece resultados um pouco abaixo dos obtidos pelo Mastan2 v3.5.

\subsection{2}

\section{Matriz de Rigidez Completa de Euler-Bernoulli}

Para avaliar a formulação tridimensional desenvolvida, empregando a teoria de Euler-Bernoulli, os termos de grau elevado no tensor deformação, as funções de forma completas e as aproximações em série de Taylor, reproduziu-se o pórtico anterior, com apenas um elemento por barra.

Para o problema em questão, optou-se por verificar o caso em que $\lambda=2,0$, por apresentar curva bem definida e diferenças na carga crítica entre os elementos "Small" e "Large" e por ser uma situação crítica. Ainda que se deva observar que a teoria de flexão de Timoshenko seria mais indicada para essa situação, o intuito é verificar se a formulação desenvolvida consegue prever o comportamento dado por uma malha de elementos, utilizando discretização de apenas um elemento por barra.

Os resultados encontrados são apresentados na Figura 6.30. Observa-se que, utilizando-se apenas um elemento por barra, a matriz de rigidez considerando aproximação em série de Taylor de 4 termos sobrepõe a formulação completa. Dessa forma, é a que mais se aproxima da curva de equilíbrio da estrutura e prediz a exata carga crítica da estrutura. A aproximação em série com 3 termos também produz um bom resultado, quase sobrepondo a curva da matriz de 4 termos. 


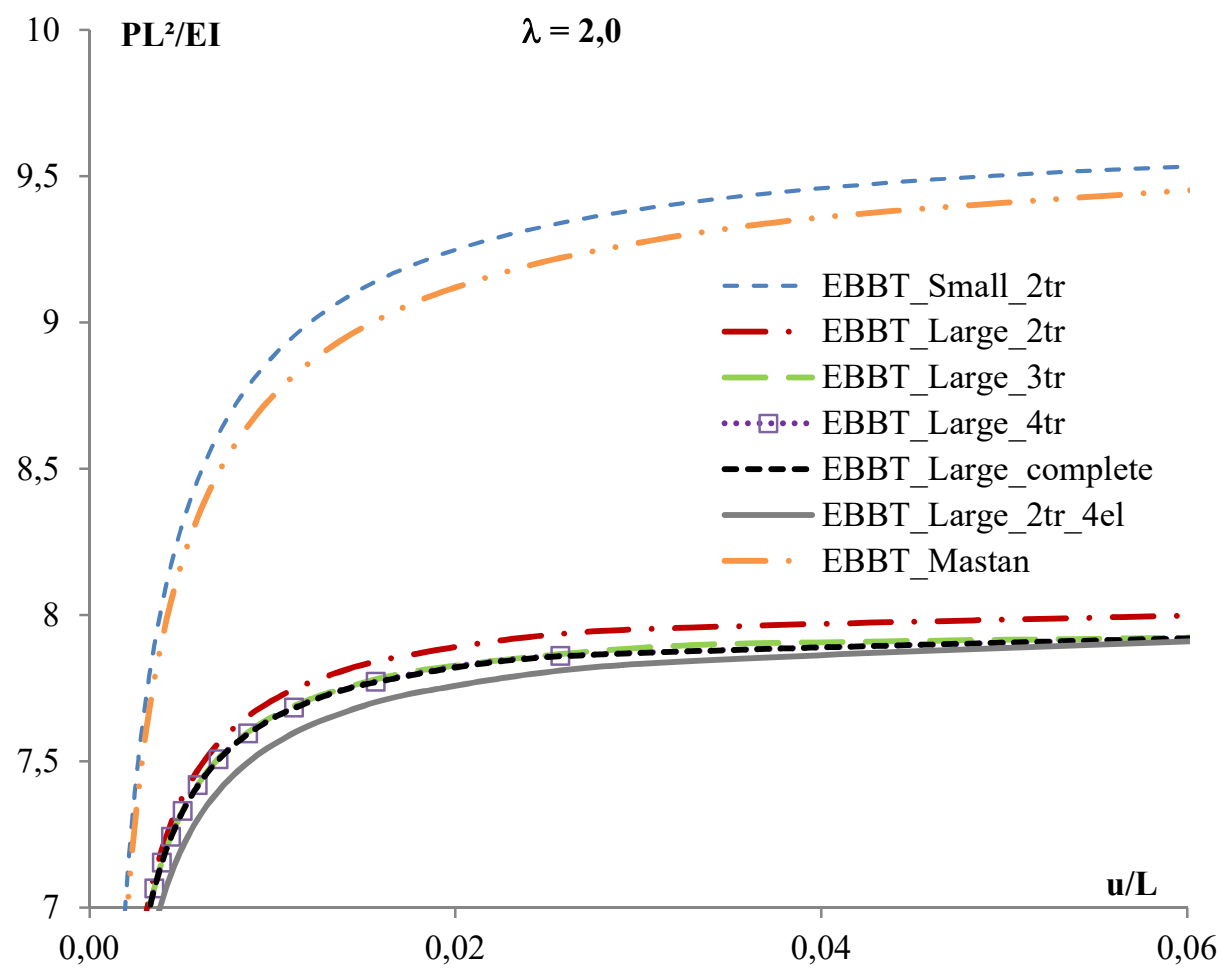

Figura 6.30 - Curva de Equilíbrio para pórtico espacial, com 1 elemento por barra Fonte: Elaborada pelo autor (2019).

Também é possível notar que a matriz usual de Euler-Bernoulli, com os termos de ordem elevada do tensor deformação (“EBBT_Large_2or”), converge um pouco acima da carga crítica. A diferença entre os resultados das formulações nessa situação é pequena, no entanto, a aproximação em série de Taylor com 4 termos fornece o melhor resultado.

Das curvas obtidas, percebe-se também que a não consideração dos termos de ordem elevada do tensor deformação leva a cargas críticas superiores no que se refere à expectativa, ainda mais ao sem empregar reduzido número de elementos na discretização da estrutura.

\subsection{3}

\section{Matriz de Rigidez Completa de Timoshenko}

A última avaliação refere-se às matrizes desenvolvidas nesta Tese, em que se considera a teoria de Timoshenko. Para esta análise, optou-se por avaliar a situação mais crítica das desenvolvidas anteriormente, $\lambda=2,0$, em que existe maior diferença entre as teorias de flexão empregadas. Foi utilizado um elemento por barra e os resultados estão expostos na Figura 6.31. 


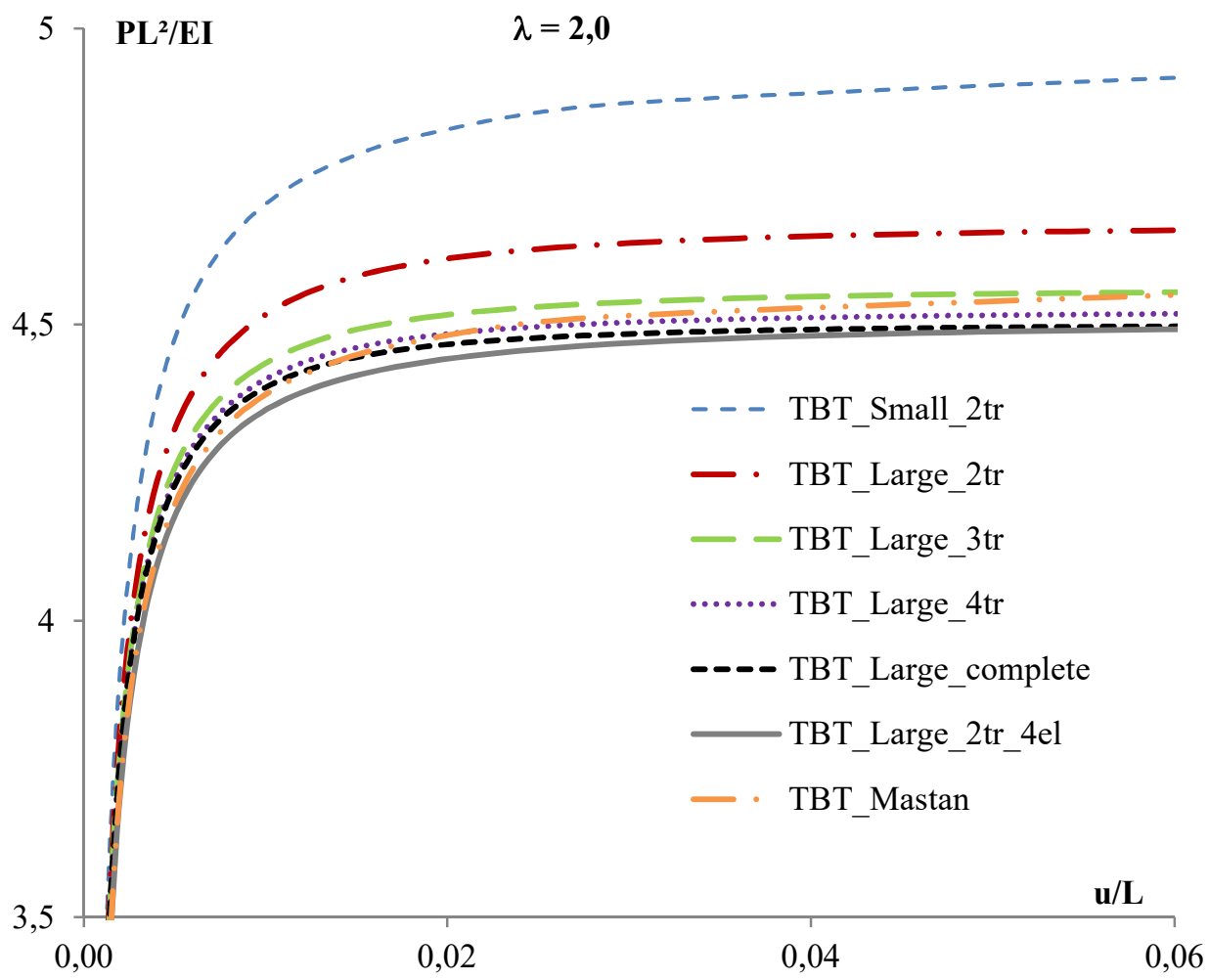

Figura 6.31 - Curva de Equilíbrio para pórtico espacial, com 1 elemento por barra (Timoshenko) Fonte: Elaborada pelo autor (2019).

Das curvas de equilíbrio obtidas, verifica-se que a formulação completa melhor se aproxima da curva considerada como resposta. Contudo, a matriz geométrica escrita com aproximação em série de Taylor com 4 termos também se aproxima da resposta da estrutura, resultando em diferenças mínimas na carga crítica.

Com bons resultados, também se tem a aproximação em série de Taylor com 3 termos, com diferença menor que 2\%. A matriz de rigidez com apenas 2 termos (elástico e geométrico), também desenvolvida neste trabalho, com um único elemento, possui uma diferença na carga crítica de $4 \%$. Nota-se que para esse exemplo especificamente, o elemento TBT_Mastan também forneceu bons resultados.

Mais uma vez, pode-se observar que, ao se utilizar uma malha reduzida (mínima), tem-se uma importante influência da consideração dos termos de ordem elevada do tensor deformação, pois a sua não consideração elevou a carga crítica do problema em torno de $10 \%$. 


\section{6}

\section{Carga Crítica para Pórtico Espacial com Cobertura em Treliça}

O exemplo seguinte avalia as formulações desenvolvidas em um pórtico espacial com a cobertura na forma de uma treliça tridimensional conforme a Figura 6.32.

Como nos exemplos anteriores, a estrutura analisada possui seção transversal, com fator de forma $\chi=5 / 6$, coeficiente de Poisson $v=0,3$, módulo de elasticidade $E=10^{7} \mathrm{kN} / \mathrm{m}^{2}$ e comprimento $L=1 \mathrm{~m}$.

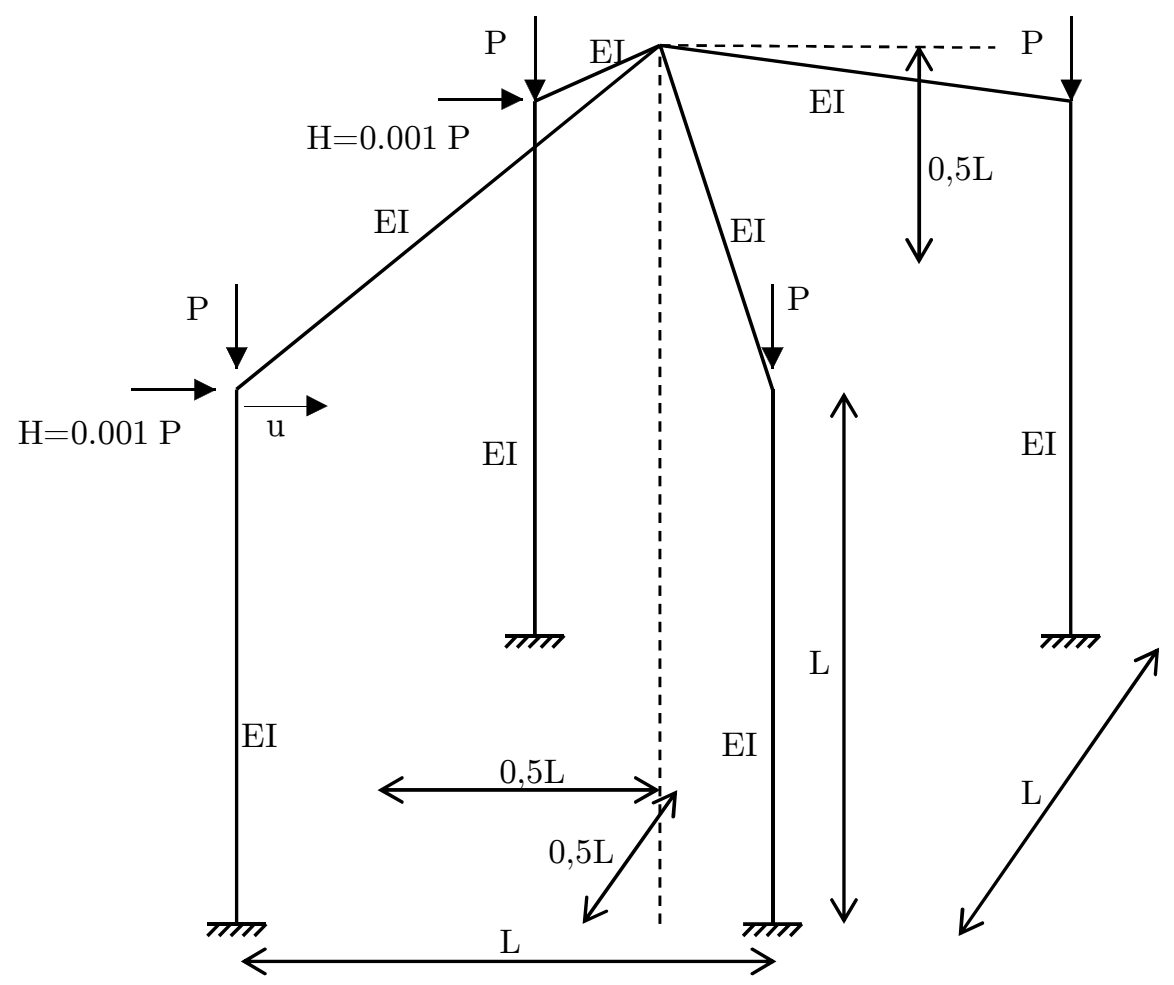

Figura 6.32 - Pórtico espacial com cobertura em treliça

Fonte: Elaborada pelo autor (2019).

O pórtico é submetido a cargas verticais $(P)$ nos nós superiores dos pilares e por duas pequenas cargas de perturbação horizontais $(H=0,001 P)$. As barras modelados com a mesma seção transversal e, para verificar a influência da teoria de flexão, esta seção foi variada de maneira a reduzir o índice de esbeltez.

Foi utilizada a mesma discretização de barras do exemplo anterior. A Figura 6.33 mostra a deformada do pórtico, com um fator de amplificação de escala de 10 vezes. 


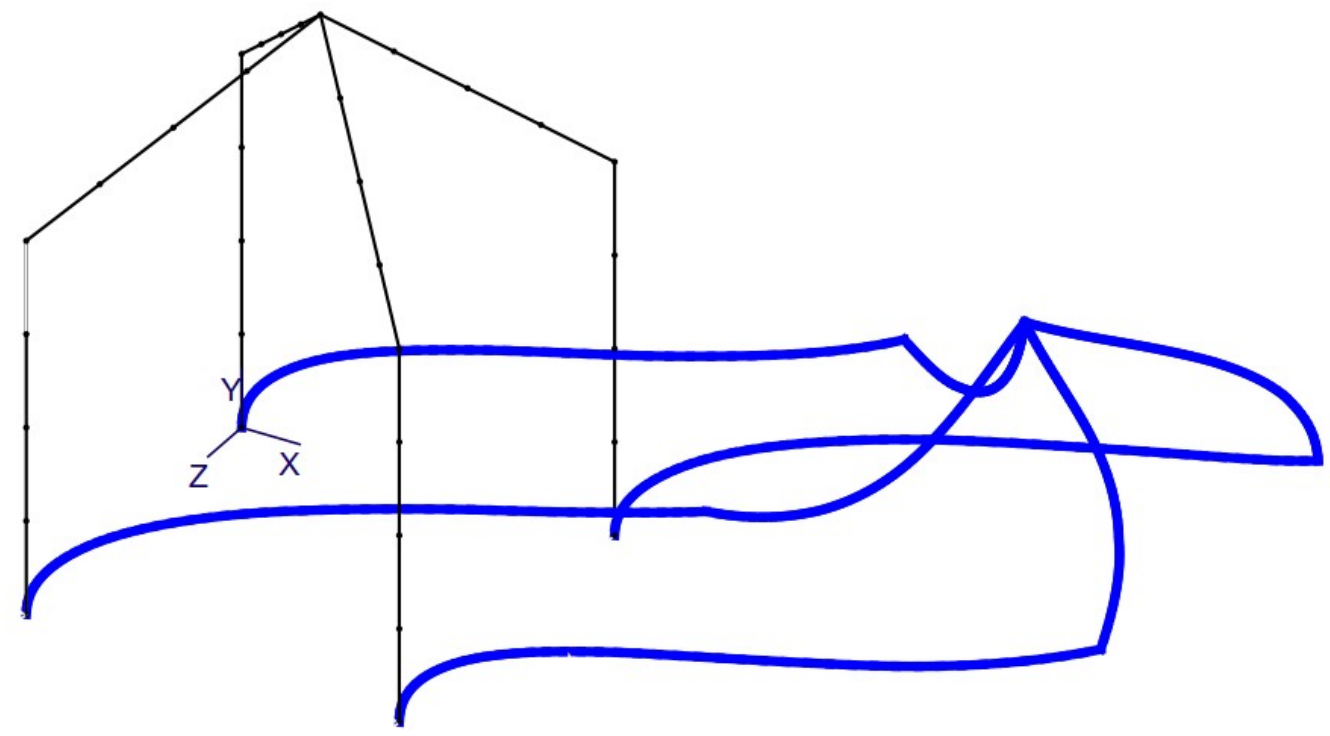

Figura 6.33 - Deformada do pórtico espacial com cobertura em treliça

Fonte: Elaborada pelo autor (2019) - Obtida com o Mastan2 V.3.5.

\subsection{1}

\section{Matriz de Rigidez de Timoshenko considerando Termos de Grau Elevado no Tensor Deformação e Funções de Forma Cúbicas}

Com esse sistema estrutural, o pórtico apresenta uma redução considerável em sua carga de flambagem, em relação ao exemplo anterior. Os resultados obtidos para o deslocamento horizontal $(u)$ do nó superior, indicado na Figura 6.32, utilizando as diferentes formulações e empregando funções de forma cúbicas, com a variação dos termos do tensor deformação, são apresentados na Figura 6.34 e Figura 6.35.

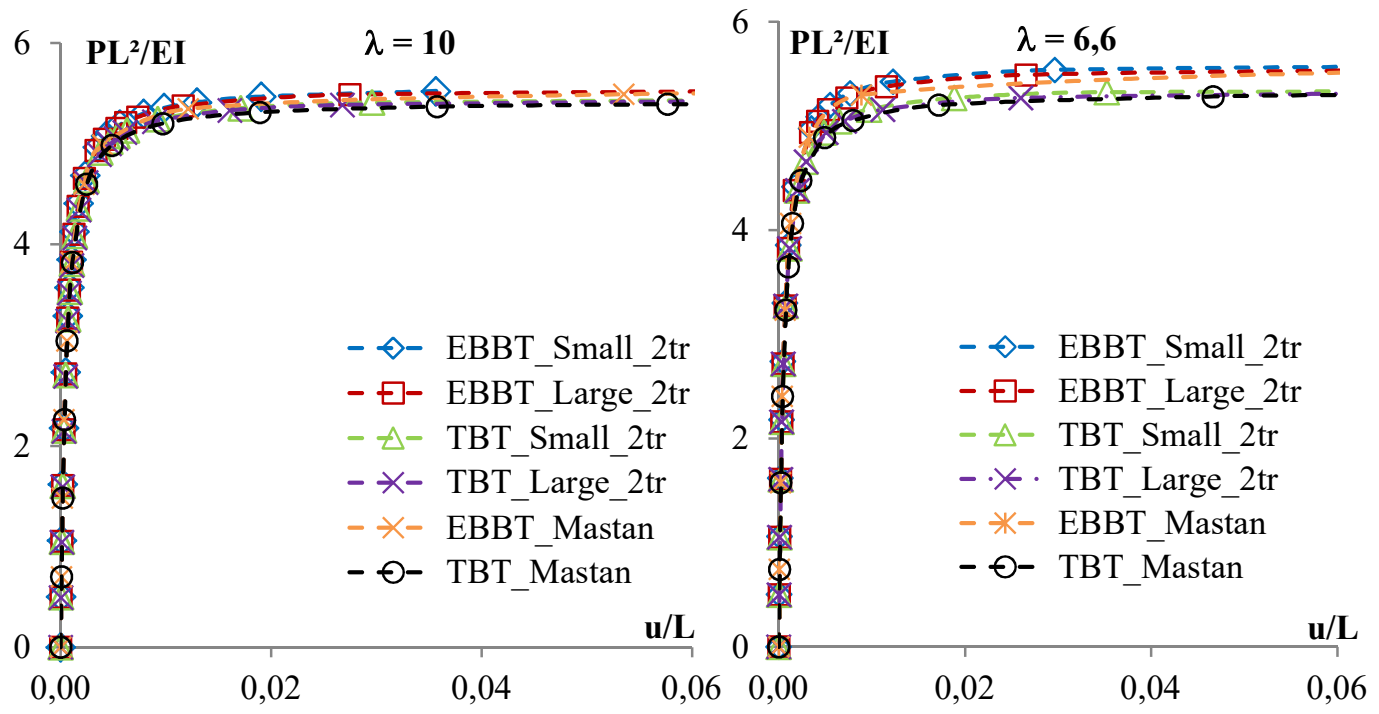

Figura 6.34 - Curva de Equilíbrio para pórtico espacial com cobertura em treliça $\lambda=\mathbf{1 0}$ e $\boldsymbol{\lambda}=\mathbf{6}, \mathbf{6}$, com 4 elementos por barra

Fonte: Elaborada pelo autor (2019). 


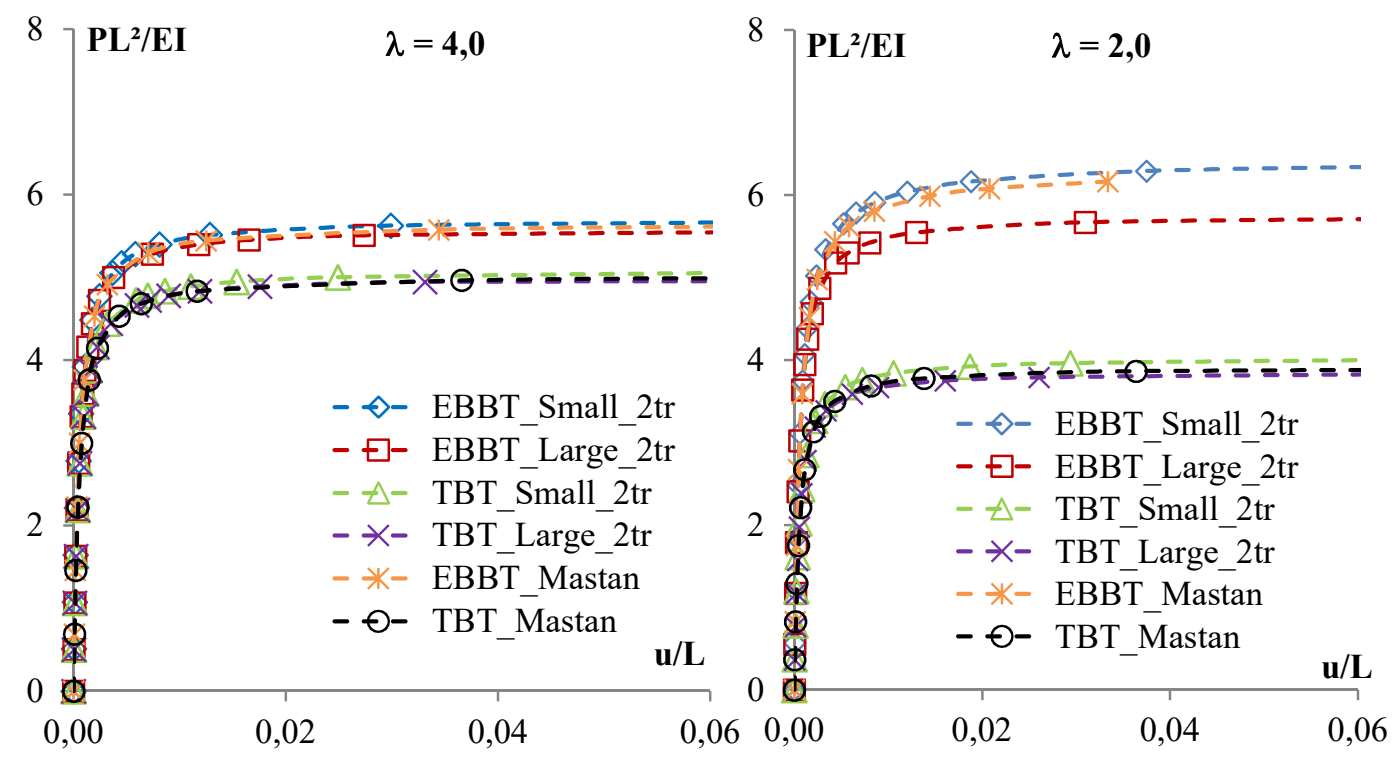

Figura 6.35 - Curva de Equilíbrio para pórtico espacial com cobertura em treliça $\boldsymbol{\lambda}=\mathbf{4 , 0} \mathrm{e}$ $\boldsymbol{\lambda}=\mathbf{2}, \mathbf{0}$, com 4 elementos por barra

Fonte: Elaborada pelo autor (2019).

Para o problema em questão também observa-se a influência da teoria de flexão empregada para estruturas com baixo índice de esbeltez. Assim como, visualiza-se que a consideração dos termos de ordem elevada do tensor deformação produz uma pequena redução nas cargas críticas da estrutura.

O elemento desenvolvido nesta Tese, em que se empregam a teoria de flexão de Timoshenko, as funções de forma cúbicas e os termos de ordem elevada do tensor deformação, fornece resultados um pouco abaixo dos obtidos pelo Mastan2 v3.5, a medida que o índice de esbeltez é reduzido.

\subsection{2 \\ Matriz de Rigidez Completa de Euler-Bernoulli}

Para avaliar a formulação tridimensional desenvolvida, empregando a teoria de Euler-Bernoulli, os termos de grau elevado no tensor deformação, as funções de forma completas e as aproximações em série de Taylor, reproduziu-se o pórtico, com apenas um elemento por barra.

Para o problema em questão, optou-se por verificar o caso em que $\lambda=10$, por ser melhor descrita pela teoria de flexão de Euler-Bernoulli. Os resultados encontrados são apresentados na Figura 6.36. 


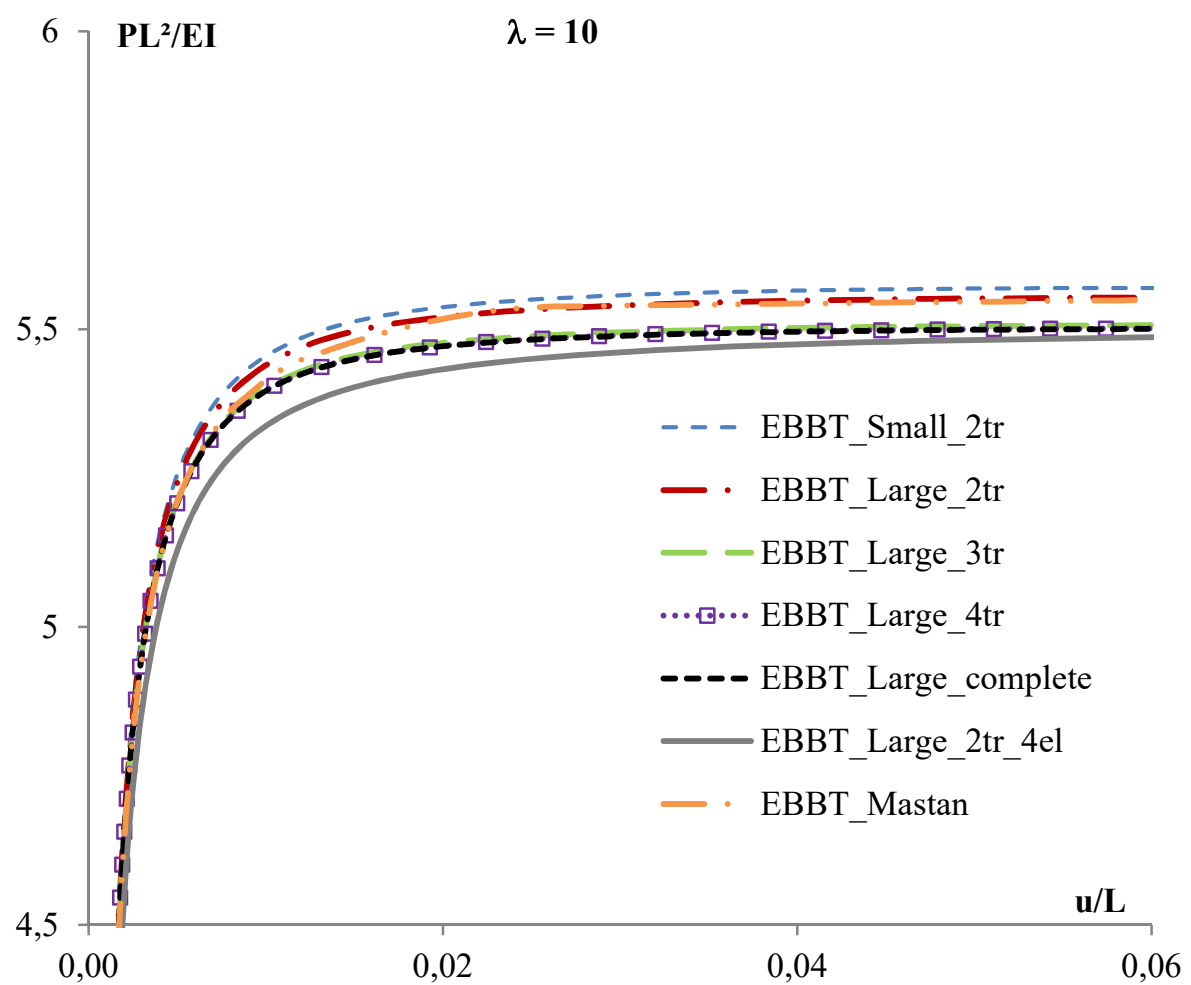

Figura 6.36 - Curva de Equilíbrio para pórtico espacial com cobertura em treliça, com 1 elemento por barra

Fonte: Elaborada pelo autor (2019).

Observa-se que, utilizando-se apenas um elemento por barra, a matriz de rigidez considerando aproximação em série de Taylor de 4 termos, mais uma vez sobrepõe a formulação completa, se aproxima da curva de equilíbrio da estrutura e prediz a exata carga crítica da estrutura. A aproximação em série com 3 termos também produz um bom resultado, praticamente sobrepondo-se a curva da matriz de 4 termos.

Também visualiza-se que a matriz usual de Euler-Bernoulli, com os termos de ordem elevada do tensor deformação ("EBBT_Large_2or"), converge um pouco acima da carga crítica, com uma pequena diferença ao se considerar os termos de ordem elevada no tensor deformação.

\subsection{3}

Matriz de Rigidez Completa de Timoshenko

Neste tópico avalia-se a formulação desenvolvida considerando a teoria de flexão de Timoshenko. Para esta análise, optou-se por estudar a estrutura com um índice de esbeltez reduzido, mas, ainda com proximidade em relação à estruturas 
usuais, $\lambda=4,0$. Foi utilizado um elemento por barra e os resultados estão expostos na Figura 6.37.

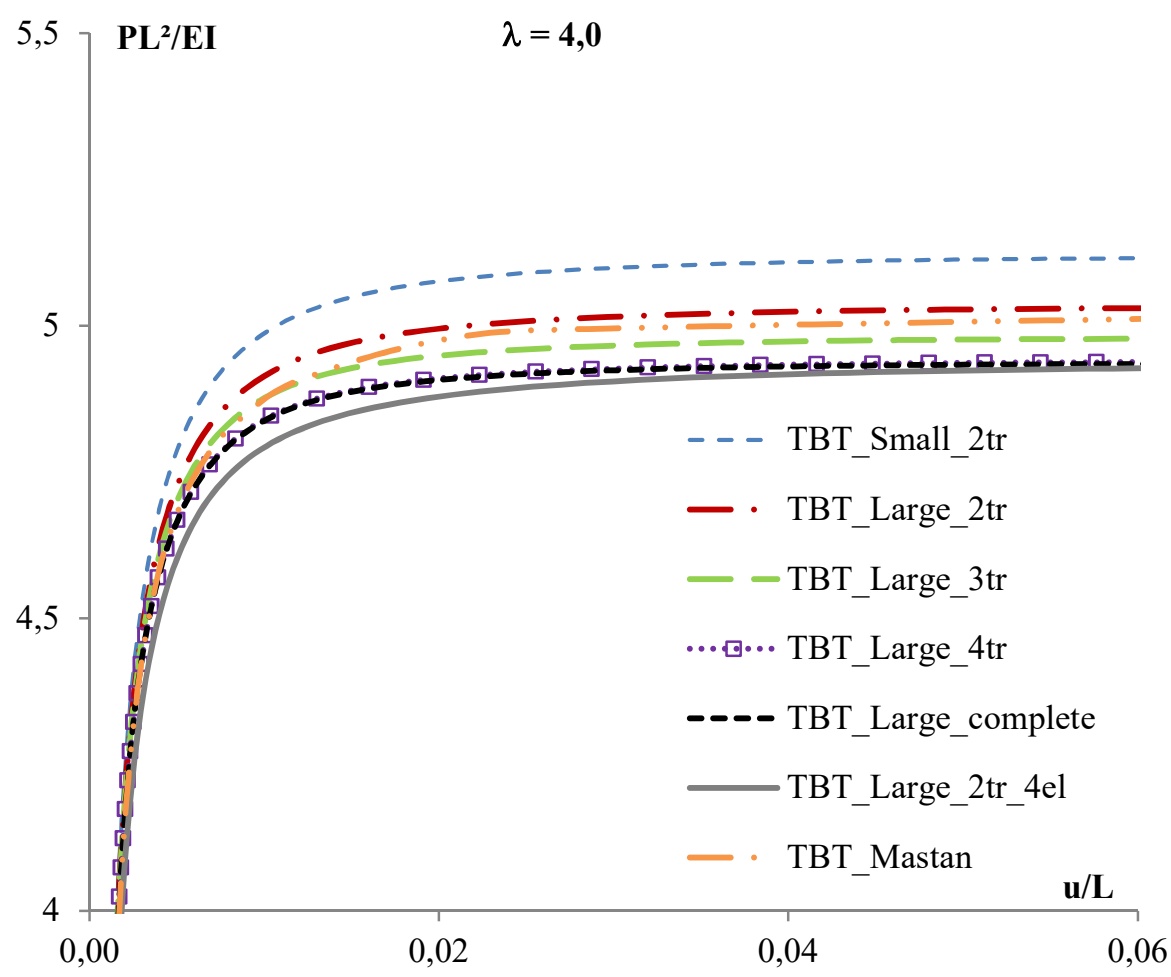

Figura 6.37 - Curva de Equilíbrio para pórtico espacial com cobertura em treliça, com 1 elemento por barra (Timoshenko)

Fonte: Elaborada pelo autor (2019).

Dos resultados apresentados, verifica-se que a matriz geométrica escrita com aproximação em série de Taylor com 4 termos obtém a mesma trajetória que a formulação completa e se aproxima da resposta da estrutura, resultando na mesma carga crítica. Na sequência, o melhor resposta é dada pela aproximação em série de Taylor com 3 termos.

As formulações baseadas em funções de interpolação cúbicas, usuais, apresentam cargas críticas mais elevadas, sendo que, a não consideração dos termos de ordem elevada no tensor deformação ("Small”) aumentam mais ainda essa carga.

\section{7}

\section{Carga Crítica para Pórtico de Roorda Espacial}

O exemplo seguinte avalia as formulações desenvolvidas em uma estrutura espacial com forma semelhante ao pórtico de Roorda apresentado no plano. A 
estrutura analisada é apresentada na Figura 6.38. Possui seção transversal com fator de forma $\chi=5 / 6$, coeficiente de Poisson $v=0,3$, módulo de elasticidade $E=10^{7} \mathrm{kN} / \mathrm{m}^{2}$ e comprimento $L=1 \mathrm{~m}$.
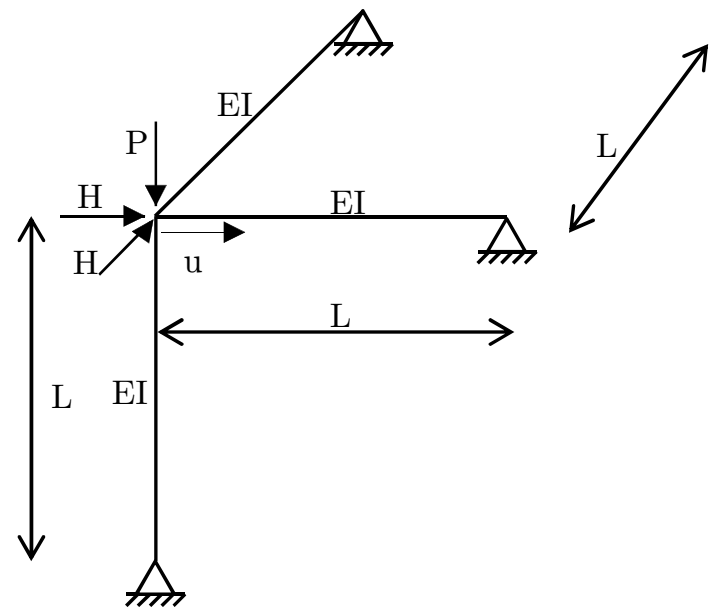

Figura 6.38 - Pórtico de Roorda Espacial

Fonte: Elaborada pelo autor (2019).

O pórtico é submetido a uma carga vertical $(P)$ no nó livre e por duas pequenas cargas de perturbação horizontais $(H=0,001 P)$. Os pilares e vigas foram modelados com a mesma seção transversal e, para verificar a influência da teoria de flexão, esta seção foi variada de maneira a reduzir o índice de esbeltez.

A Figura 6.39 mostra a deformada da estrutura, após a análise não linear, com um fator de amplificação de escala de 10 vezes.

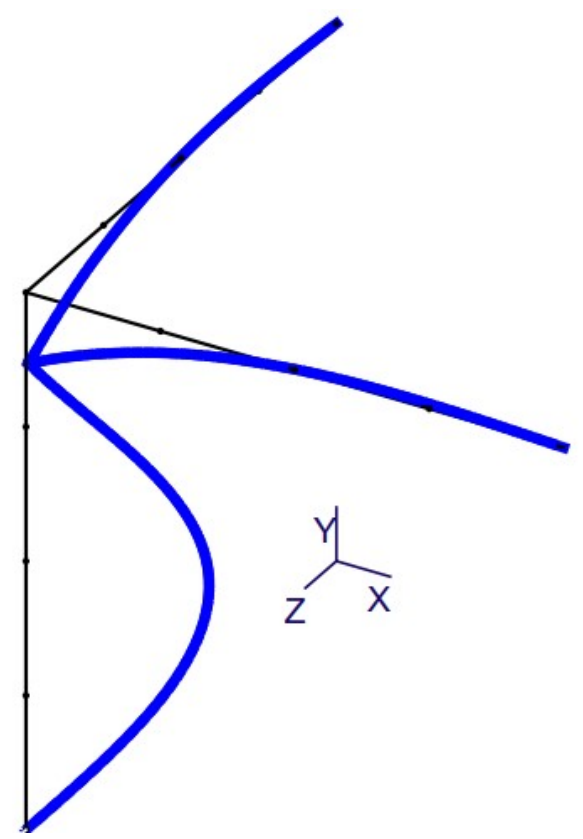

Figura 6.39 - Deformada para pórtico de Roorda espacial

Fonte: Elaborada pelo autor (2019) - Obtida com o Mastan2 V.3.5. 


\subsection{1 \\ Matriz de Rigidez de Timoshenko considerando Termos de Grau Elevado no Tensor Deformação e Funções de Forma Cúbicas}

Os resultados obtidos para o deslocamento horizontal $(u)$ do nó livre, indicado na Figura 6.38, utilizando as diferentes formulações, com o emprego das funções de forma cúbicas e variando os termos do tensor deformação, são apresentados na Figura 6.40 e Figura 6.41. As barras também foram discretizadas com quatro elementos, baseando-se no estudo de convergência realizado no exemplo de pórtico espacial.
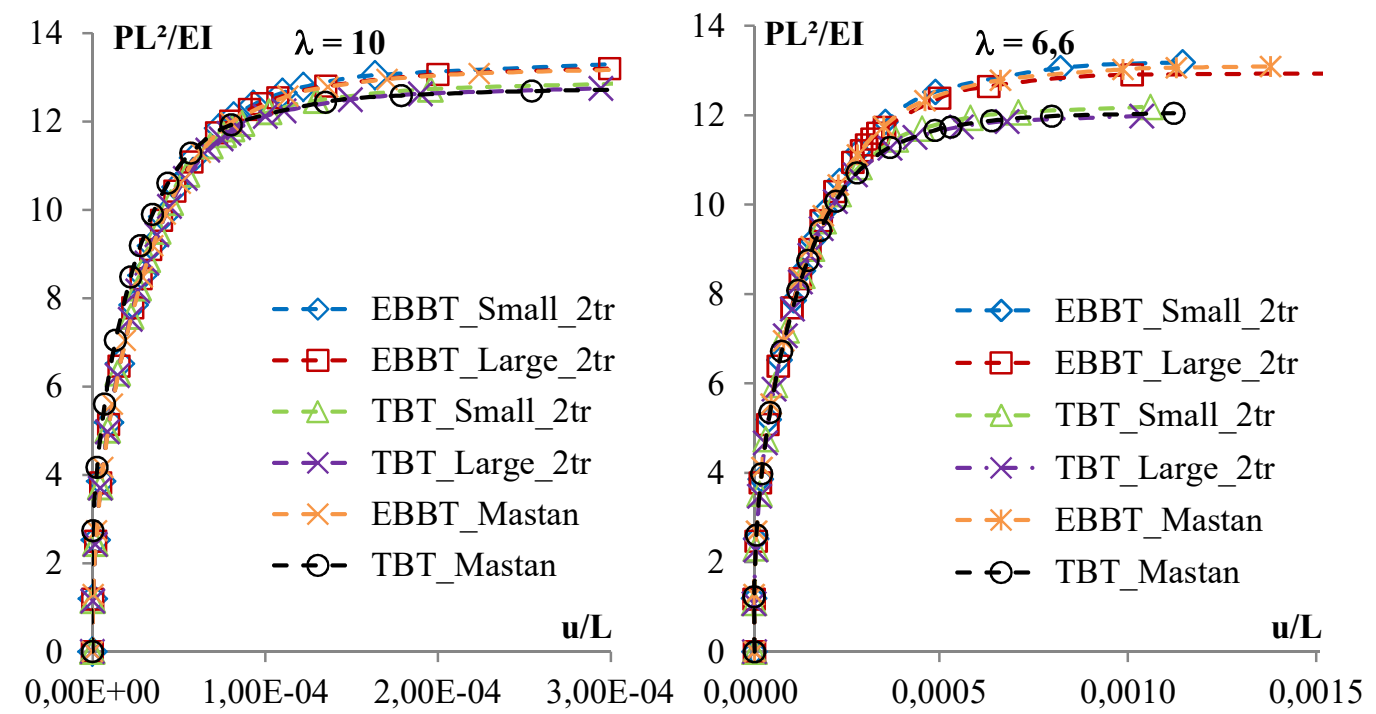

Figura 6.40 - Curva de Equilíbrio para pórtico de Roorda espacial $\lambda=\mathbf{1 0}$ e $\boldsymbol{\lambda}=\mathbf{6}, \mathbf{6}$, com 4 elementos por barra

Fonte: Elaborada pelo autor (2019).
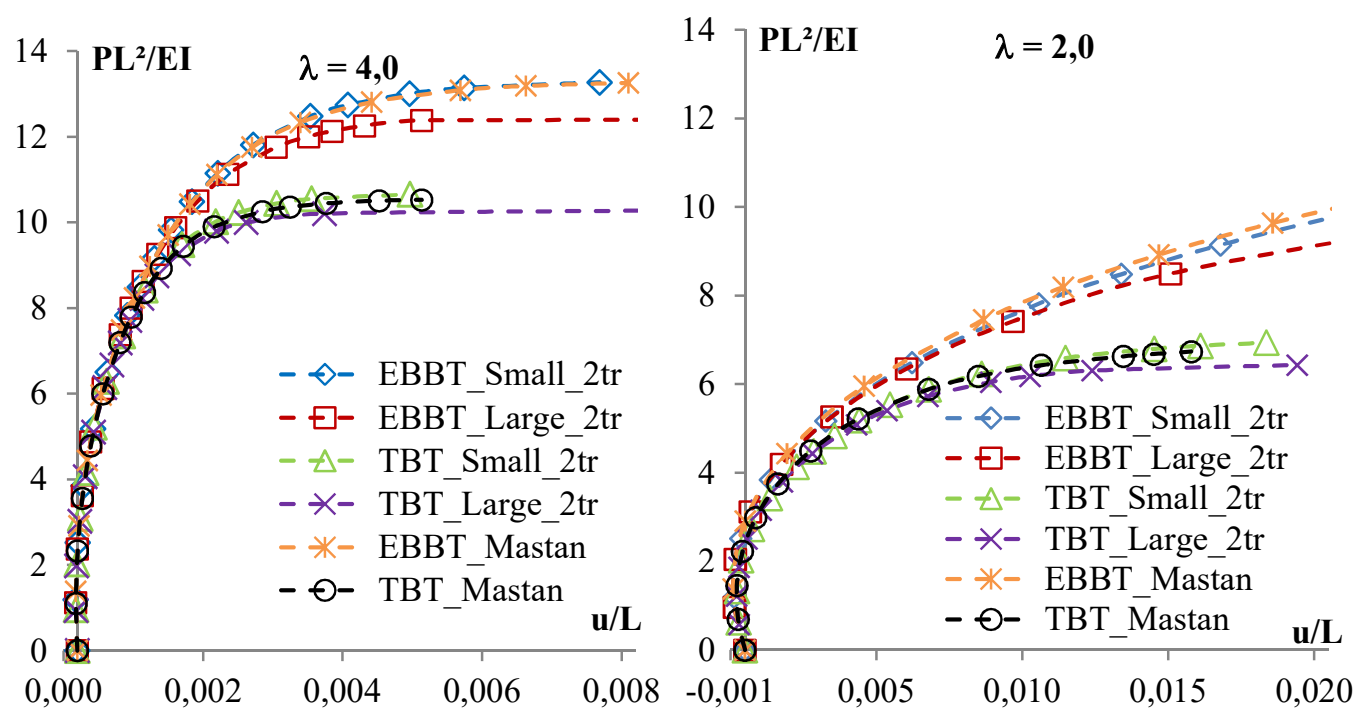

Figura 6.41 - Curva de Equilibrio para pórtico de Roorda espacial $\boldsymbol{\lambda}=\mathbf{4 , 0}$ e $\boldsymbol{\lambda}=\mathbf{2 , 0}$, com 4 elementos por barra

Fonte: Elaborada pelo autor (2019). 
As curvas de equilíbrio construídas evidenciam que, à medida que a esbeltez da estrutura é reduzida, maior é a importância do emprego da teoria de flexão de Timoshenko para prever o comportamento da estrutura. Inclusive, para o caso estudado, até mesmo para um índice de esbeltez elevado, $L / h=10$, notam-se diferenças nos resultados para a teoria de flexão considerada.

Ainda analisando os gráficos anteriores, visualiza-se que a matriz de rigidez geométrica de Timoshenko, considerando os termos de ordem elevada do tensor deformação, desenvolvida nesta Tese, fornece uma carga crítica abaixo da fornecida pelo Mastan2 v3.5. Portanto, verifica-se que o emprego destes termos pode fornecer melhores resultados ao problema. Esta influência fica mais evidente para estruturas com baixo índice de esbeltez.

\subsection{2}

\section{Matriz de Rigidez Completa de Euler-Bernoulli}

Para avaliar a formulação tridimensional completa desenvolvida neste trabalho, ou seja, em que são utilizadas as funções de interpolação "completas", os termos de grau elevado do tensor deformação e a teoria de flexão de EulerBernoulli, reproduziu-se o pórtico anterior com uma discretização mínima, apenas um elemento por barra.

Neste problema, optou-se por reproduzir o exemplo com maior esbeltez na estrutura $(L / h=10)$. Os resultados são apresentados na Figura 6.42.

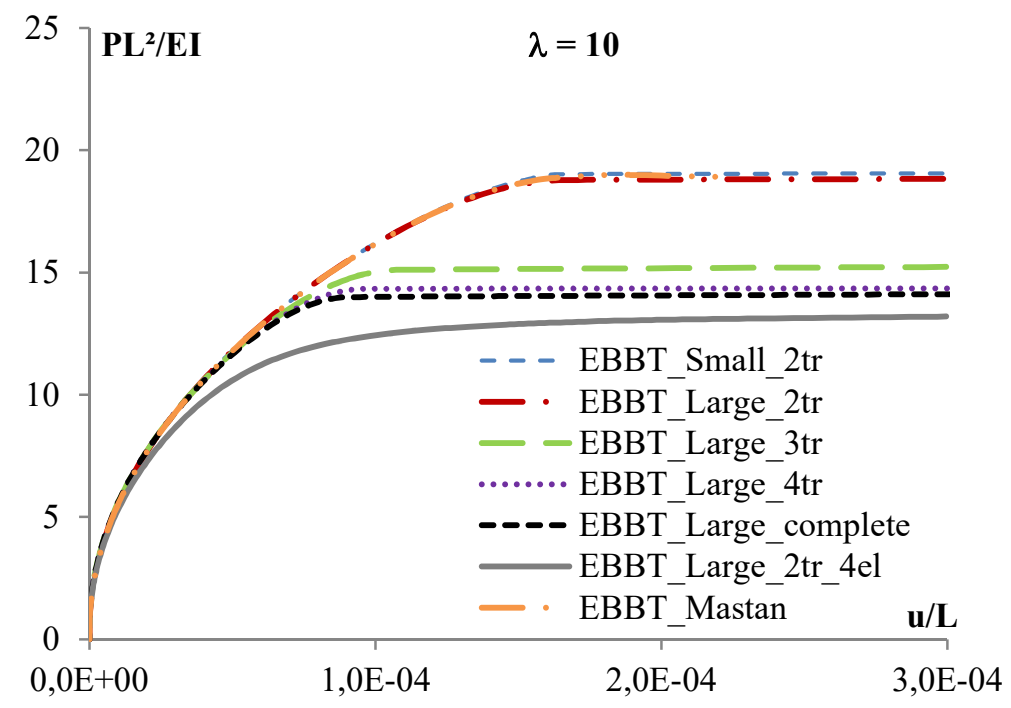

Figura 6.42 - Curva de Equilíbrio para pórtico de Roorda espacial $\lambda=\mathbf{1 0}$, com 2 elementos por barra (Euler-Bernoulli)

Fonte: Elaborada pelo autor (2019). 
Da curva de equilíbrio apresentada, é possível observar que a formulação completa e as matrizes de rigidez geométrica que utilizam as aproximações em série de Taylor com 4 e 3 termos obtiveram os melhores resultados para previsão da carga crítica da estrutura ao se empregar um número reduzido de elementos. A formulação completa e a aproximação em 4 termos são quase sobrepostas.

A matriz usual de Euler Bernoulli, obtida das funções de forma hermitianas (“EBBT_Large_2or”), teve um resultado acima das obtidas a partir das funções de forma completas. A formulação que não considera todos os termos do tensor deformação e a interação entre torção e flexão (“EBBT_Small_2or”) fornece uma carga crítica um pouco mais elevada, mas quase sobrepondo o caminho de equilíbrio do elemento "EBBT_Large_2or".

\subsection{3}

\section{Matriz de Rigidez Completa de Timoshenko}

O próximo passo é verificar a formulação completa, empregando, entretanto, a teoria de flexão de Timoshenko. Portanto, avaliou-se a capacidade dessa formulação de predizer a carga crítica da estrutura com uma discretização mínima das barras. Da mesma maneira que para a teoria de Euler-Bernoulli. Foi empregada discretização mínima da estrutura, ou seja, um elemento por barra.

Para avaliar essa teoria empregou-se uma situação mais crítica, porém ainda próxima de estruturas reais $(L / h=4)$. Os resultados são expostos na Figura 6.43

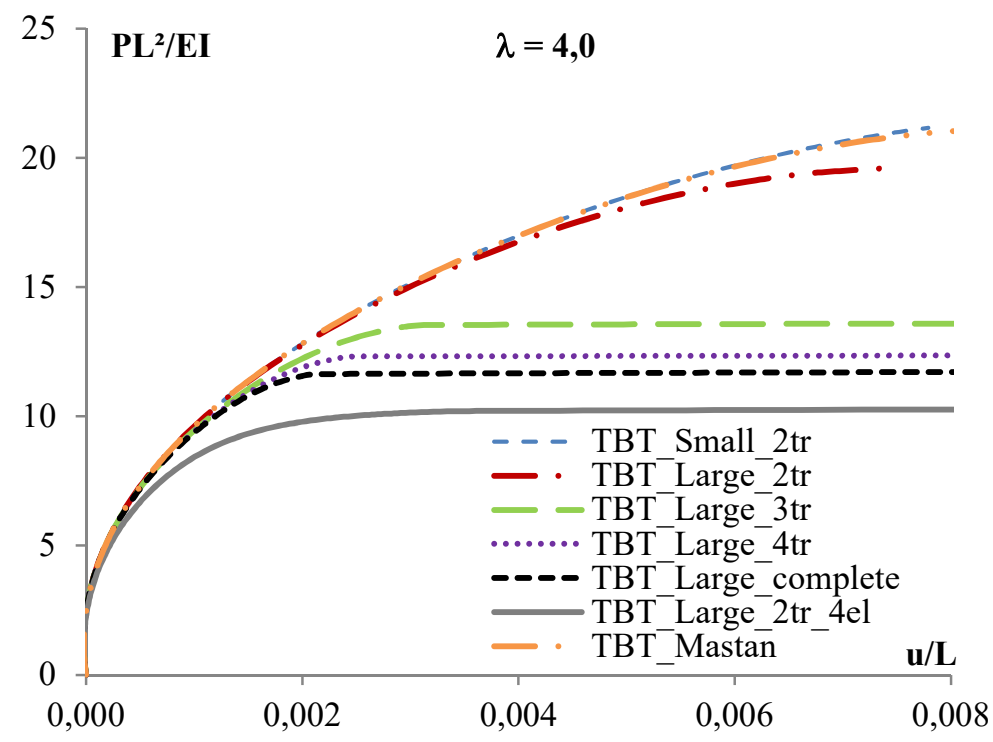

Figura 6.43 - Curva de Equilíbrio para pórticode Roorda espacial $\boldsymbol{\lambda}=\mathbf{4 , 0}$, com 1 elemento por barra (Timoshenko)

Fonte: Elaborada pelo autor (2019). 
Para a teoria de flexão de Timoshenko, a formulação completa novamente se aproxima da resposta da estrutura. Também se pode observar que as aproximações em série de Taylor com 4 e 3 termos, ambas desenvolvidas a partir da formulação completa, fornecem claramente a melhor aproximação para a carga crítica da estrutura ao se utilizar apenas um elemento por barra como discretização quando comparadas as formulações usuais, ainda que, com certa imprecisão.

A formulação considerando os termos de ordem elevada do tensor deformação e funções de forma cúbicas desenvolvidas neste trabalho, fornece resultados bem acima das formulações encontradas pelas aproximações em série de Taylor, mas, ainda é um pouco melhor que o obtido pelo software Mastan2 v3.5. Estas formulações com funções de forma cúbicas não conseguem prever a carga crítica da estrutura, com diferenças da ordem de $100 \%$, contra $16 \%$ da formulação baseada em funções de forma "completas".

Mais uma vez, observa-se a influência desses termos de ordem elevada no tensor deformação e da interação entre a flexão e a torção, pois a carga crítica obtida para o elemento que desconsidera essas influências é superior a todas as demais.

\section{8}

\section{Carga Crítica para Pórtico Espacial com Pilar Inclinado}

O exemplo de estrutura espacial aqui apresentado avalia as formulações desenvolvidas em uma estrutura com pilares inclinados. A estrutura analisada é apresentada na Figura 6.44, possuindo seção transversal com fator de forma $\chi=5 / 6$, coeficiente de Poisson $v=0,3$, módulo de elasticidade $E=10^{7} \mathrm{kN} / \mathrm{m}^{2}$ e comprimento $L=1 \mathrm{~m}$. 


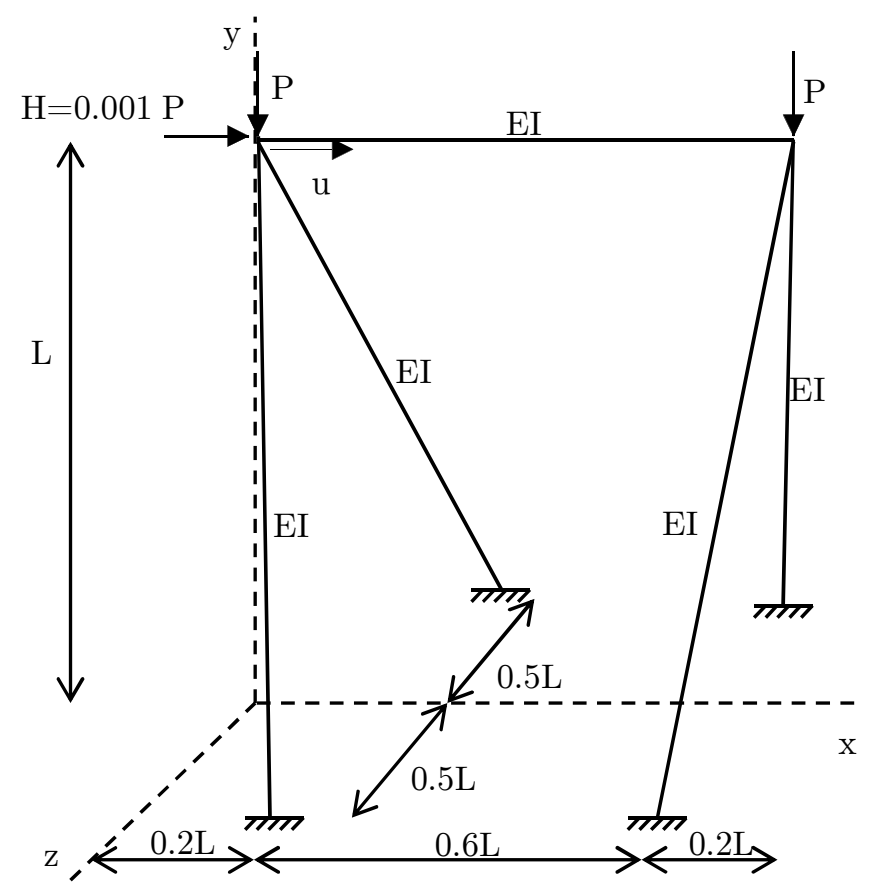

Figura 6.44 - Pórtico espacial com pilares inclinados

Fonte: Elaborada pelo autor (2019) - Adaptada de Zugic et al. (2016).

O pórtico é submetido às cargas verticais $(P)$ nos nós livres e por uma pequena carga de perturbação horizontal $(H=0,001 P)$ no nó livre superior esquerdo. Os pilares e vigas foram modelados com a mesma seção transversal e, para verificar a influência da teoria de flexão, esta seção foi variada de maneira a reduzir o índice de esbeltez.

Inicialmente, para resolver o problema, em razão de que não se emprega uma solução analítica para tal, fez-se um estudo de convergência de resultado, utilizando-se o Mastan2 v3.5 para escolha da discretização dos elementos. Este estudo é apresentado na Figura 6.45. 


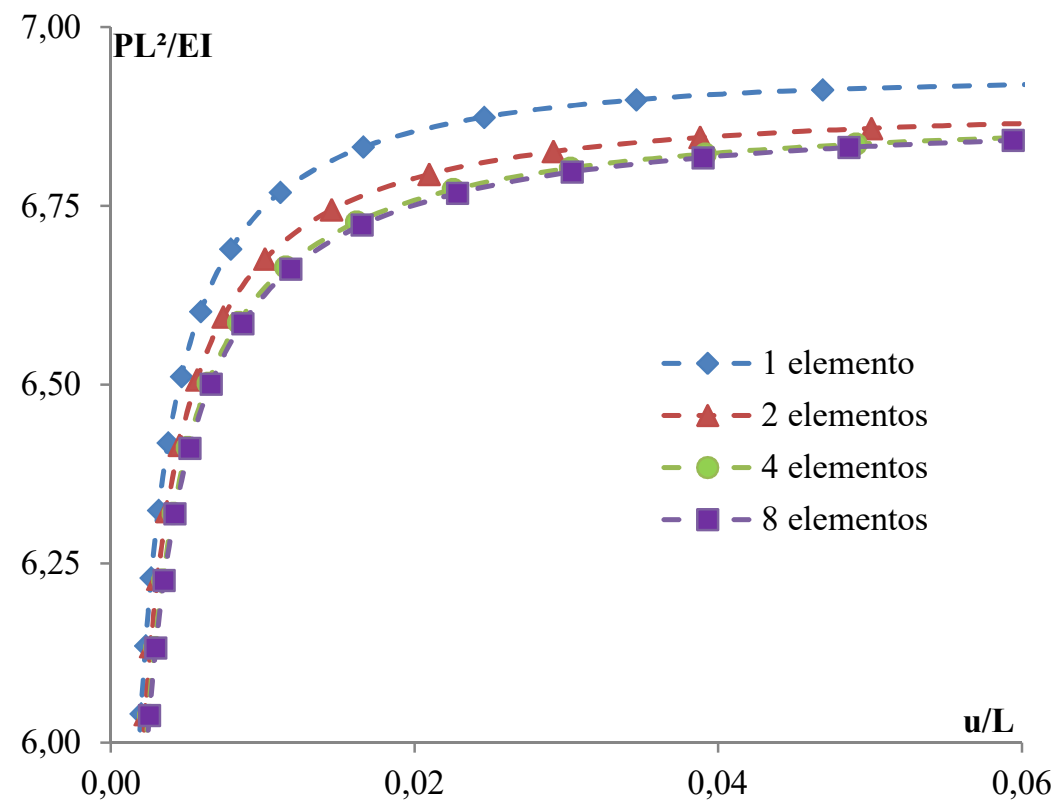

Figura 6.45 - Estudo de convergência para pórtico espacial com barra inclinada Fonte: Elaborada pelo autor (2019).

Como para o pórtico espacial, pode-se observar que, para uma discretização de 4 elementos (168 graus de liberdade) e 8 elementos (360 graus de liberdade), a resposta não se altera significativamente. Portanto, optou-se por se utilizar uma discretização de quatro elementos por barra para os resultados iniciais com matrizes geométricas usuais e a de Timoshenko, desenvolvida neste trabalho.

A Figura 6.46 mostra a deformada da estrutura em uma escala ampliada em dez vezes, para melhor visualização.
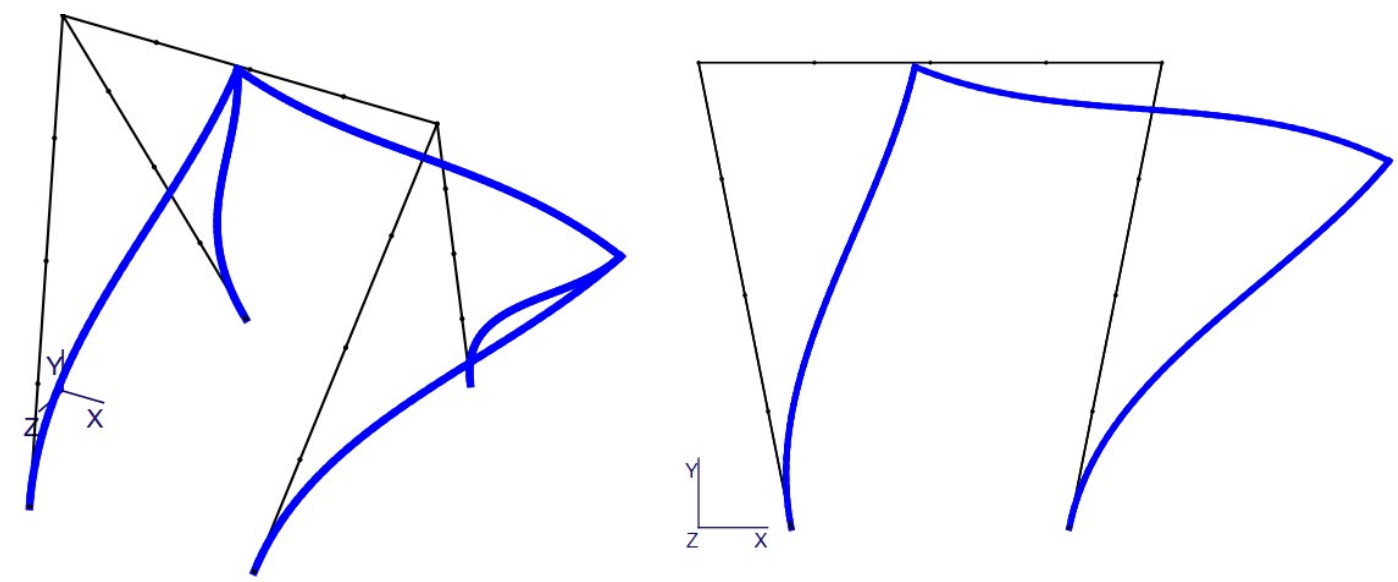

Figura 6.46 - Deformada para pórtico espacial com pilares inclinados

Fonte: Elaborada pelo autor (2019) - Obtida com o Mastan2 V.3.5. 


\subsection{1 \\ Matriz de Rigidez de Timoshenko considerando Termos de Grau Elevado no Tensor Deformação e Funções de Forma Cúbicas}

Os resultados obtidos para o deslocamento horizontal $(u)$ do nó livre, indicado na Figura 6.44, utilizando-se as diferentes formulações e empregando-se funções de forma cúbicas, com variação dos termos do tensor deformação, são apresentados na Figura 6.47 e Figura 6.48. As barras foram discretizadas com quatro elementos, de acordo com o estudo de convergência realizado.

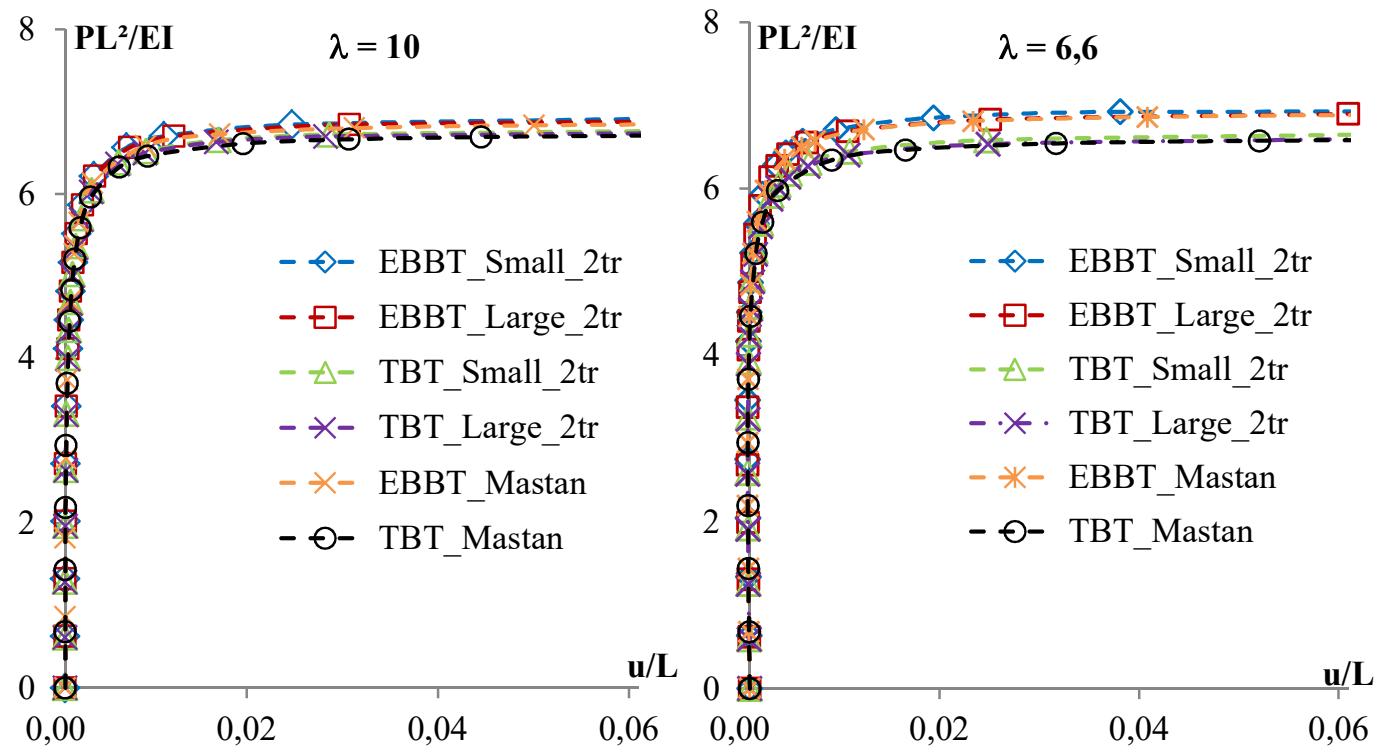

Figura 6.47 - Curva de Equilíbrio para pórtico espacial com pilares inclinados $\lambda=\mathbf{1 0}$ e $\boldsymbol{\lambda}=\mathbf{6 , 6}$, com 4 elementos por barra

Fonte: Elaborada pelo autor (2019).
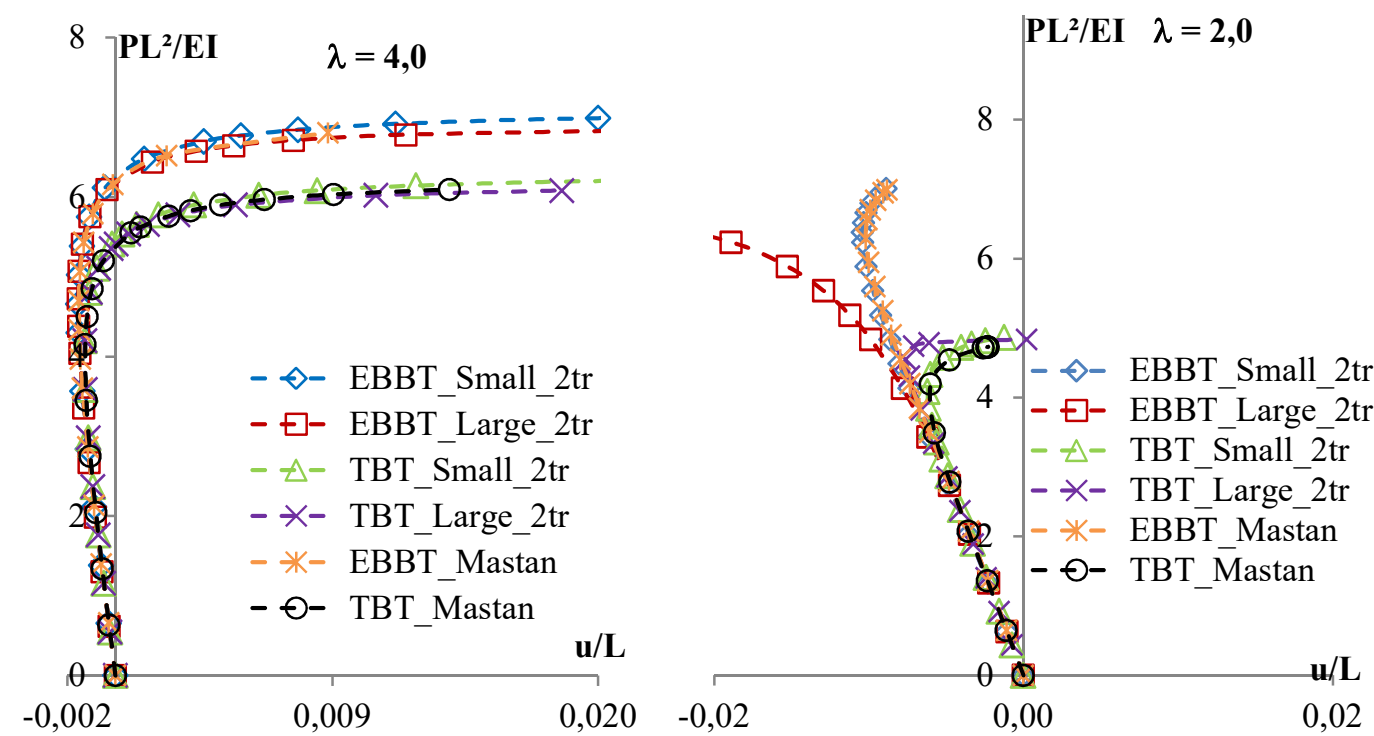

Figura 6.48 - Curva de Equilíbrio para pórtico espacial com pilares inclinados $\boldsymbol{\lambda}=\mathbf{4 , 0}$ e $\boldsymbol{\lambda}=\mathbf{2 , 0}$, com 4 elementos por barra

Fonte: Elaborada pelo autor (2019). 
As curvas de equilíbrio construídas evidenciam que, à medida que a esbeltez da estrutura é reduzida, maior é a relevância do emprego da teoria de flexão de Timoshenko para prever o comportamento da estrutura. Inclusive, para o caso estudado, até mesmo para um índice de esbeltez elevado, $L / h=10$, notam-se diferenças nos resultados para a teoria de flexão considerada.

Os gráficos anteriores também mostram que a matriz de rigidez geométrica de Timoshenko, considerando os termos de ordem elevada do tensor deformação, desenvolvida nesta Tese, apresenta uma carga crítica abaixo da fornecida pelo Mastan2 v3.5. Portanto, verifica-se que o emprego destes termos pode fornecer melhores resultados ao problema. Essa influência fica mais evidente para estruturas com baixo índice de esbeltez.

\subsection{2}

\section{Matriz de Rigidez Completa de Euler-Bernoulli}

Para avaliar a formulação tridimensional completa desenvolvida neste trabalho, em que se utilizam as funções de interpolação completas, os termos de grau elevado do tensor deformação e a teoria de flexão de Euler-Bernoulli, reproduziu-se o pórtico anterior com uma discretização mínima, apenas um elemento por barra.

Neste problema, optou-se reproduzir o exemplo desenvolvido com esbeltez $(L / h=4)$, por ser uma situação crítica, mas com curvas de equilíbrio bem definidas. Os resultados considerando a teoria de flexão de Euler Bernoulli são apresentados na Figura 6.49. 


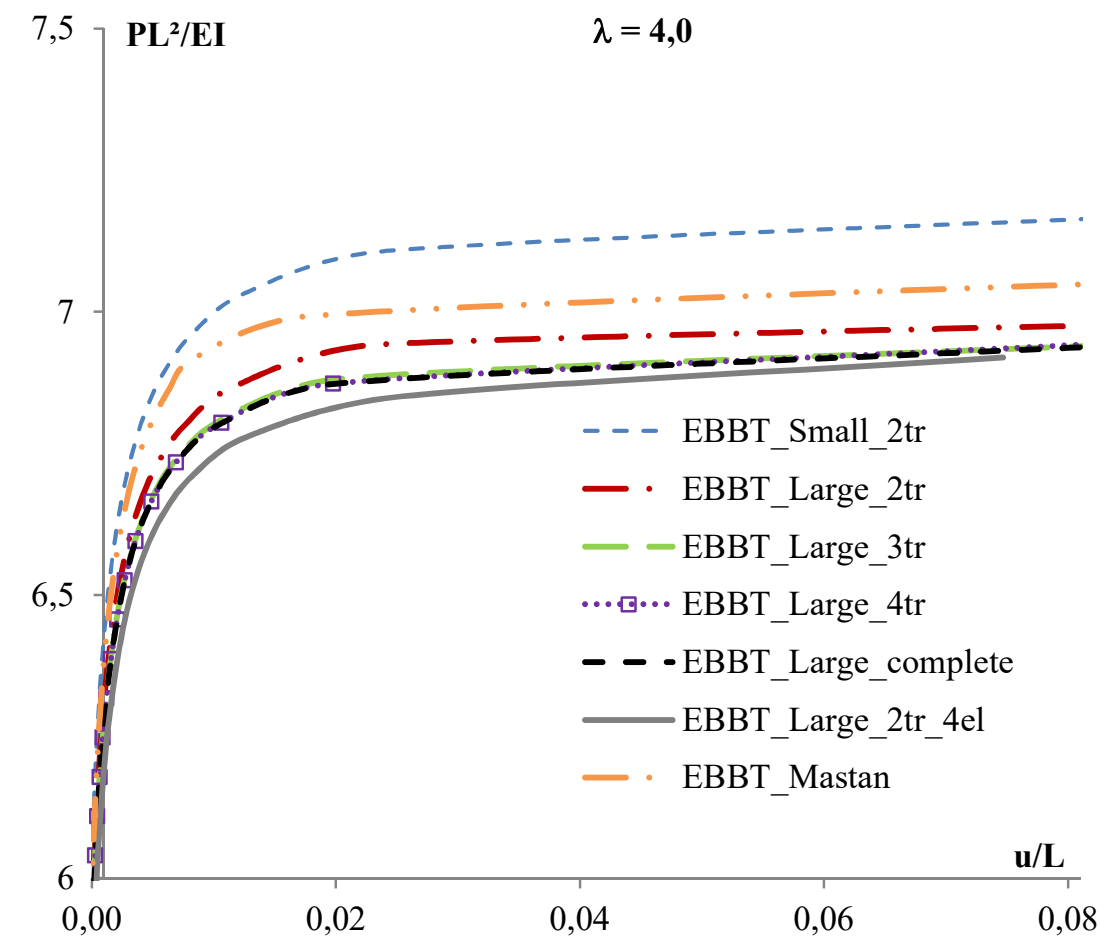

Figura 6.49 - Curva de Equilíbrio para pórtico espacial com pilares inclinados $\boldsymbol{\lambda}=\mathbf{4 , 0}$, com 1 elemento por barra (Euler-Bernoulli)

Fonte: Elaborada pelo autor (2019).

Da curva de equilíbrio apresentada, é possível observar que as matrizes de rigidez geométrica que utilizam as aproximações em série de Taylor com 4 e 3 termos sobrepõem a trajetória da formulação completa e obtiveram os melhores resultados, em relação aos desenvolvimentos convencionais, para previsão da carga crítica da estrutura ao se empregar uma discretização mínima da estrutura.

A matriz usual de Euler Bernoulli, obtida das funções de forma hermitianas (“EBBT_Large_2or”), teve um resultado acima das matrizes obtidas a partir das funções de forma completas. A formulação que não considera todos os termos do tensor deformação e a interação entre torção e flexão ("EBBT_Small_2or”) fornece uma carga crítica ainda mais elevada, evidenciando a importância desses termos e da interação entre os esforços.

\subsection{3}

\section{Matriz de Rigidez Completa de Timoshenko}

Em seguida, verifica-se a formulação completa, empregando, no entanto, a teoria de flexão de Timoshenko. Para isso, avalia-se a capacidade dessa formulação de predizer a carga crítica da estrutura com uma discretização mínima 
das barras. Da mesma maneira que para a teoria de Euler-Bernoulli, adotou-se a discretização de apenas um elemento por barra.

Para a avaliação dessa teoria, empregou-se a situação mais crítica desenvolvida anteriormente $(L / h=4)$, mas que possui uma curva de equilíbrio bem definida. Os resultados obtidos estão expostos na Figura 6.50.

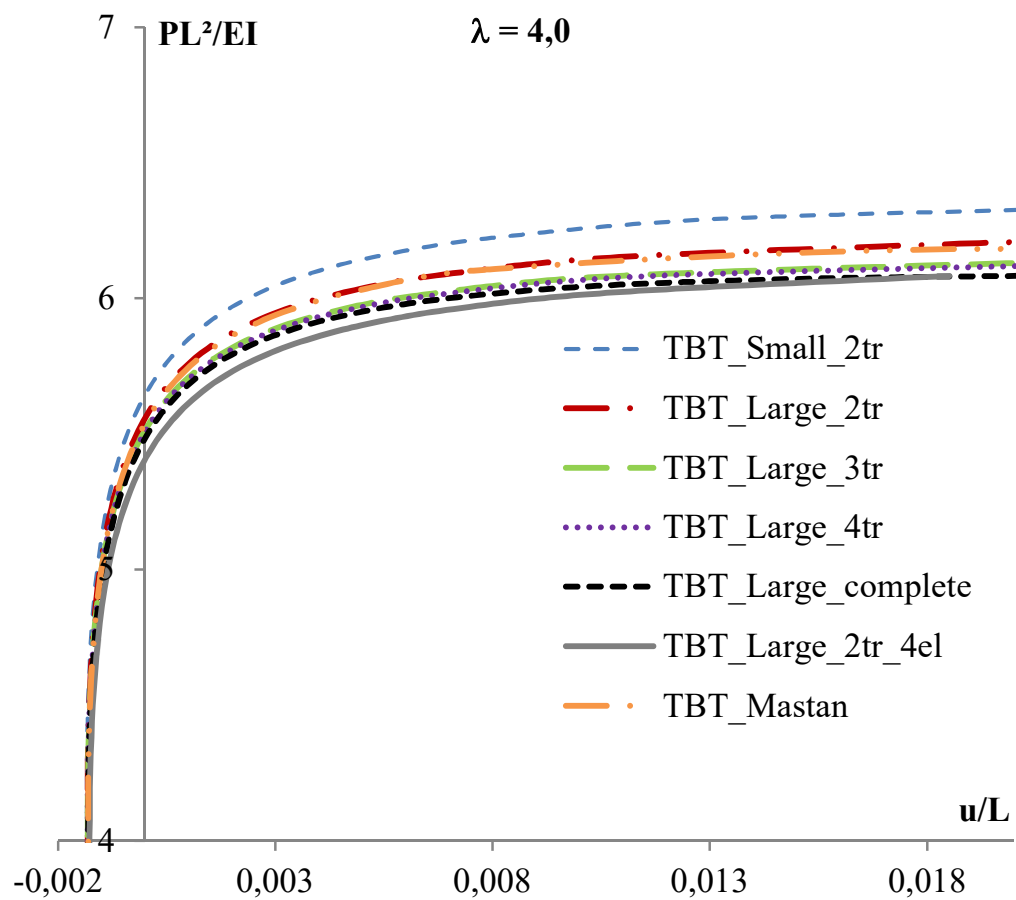

Figura 6.50 - Curva de Equilíbrio para pórtico espacial com pilares inclinados $\lambda=\mathbf{4}, \mathbf{0}$, com 1 elemento por barra (Timoshenko)

Fonte: Elaborada pelo autor (2019).

Assim como nos demais exemplos, a formulação completa desenvolvida neste trabalho, considerando a teoria de flexão de Timoshenko, também apresentou bons resultados ao se aproximar da trajetória de equilíbrio da estrutura discretizada. Pode-se observar que as aproximações em série de Taylor com 4 e 3 termos, ambas desenvolvidas a partir da formulação completa, também fornecem satisfatórias aproximações para a carga crítica da estrutura ao se utilizar apenas um elemento por barra como discretização.

A formulação considerando os termos de ordem elevada do tensor deformação e funções de forma cúbicas desenvolvidas nesse trabalho, fornece resultados pouco acima das encontradas pelas aproximações em série de Taylor e semelhante ao software Mastan2 v3.5.

Observa-se a influência desses termos de ordem elevada no tensor deformação e da interação entre a flexão e a torção, pois a carga crítica obtida 
para o elemento que desconsidera essas influências (formulação usual), mais uma vez, é superior a todas as demais.

\section{9}

\section{Carga Crítica para Pórtico Espacial com Torção}

Para a aplicação numérica seguinte, avaliou-se a influência da teoria de vigas e da consideração dos termos de ordem elevada do tensor deformação em um pórtico espacial de um pavimento com as mesmas características do exemplo 6.5. O pórtico analisado é apresentado na Figura 6.51 e também possui seção transversal com fator de forma $\chi=5 / 6$, coeficiente de Poisson $v=0,3$, módulo de elasticidade $E=10^{7} \mathrm{kN} / \mathrm{m}^{2}$ e comprimento $L=1 \mathrm{~m}$.

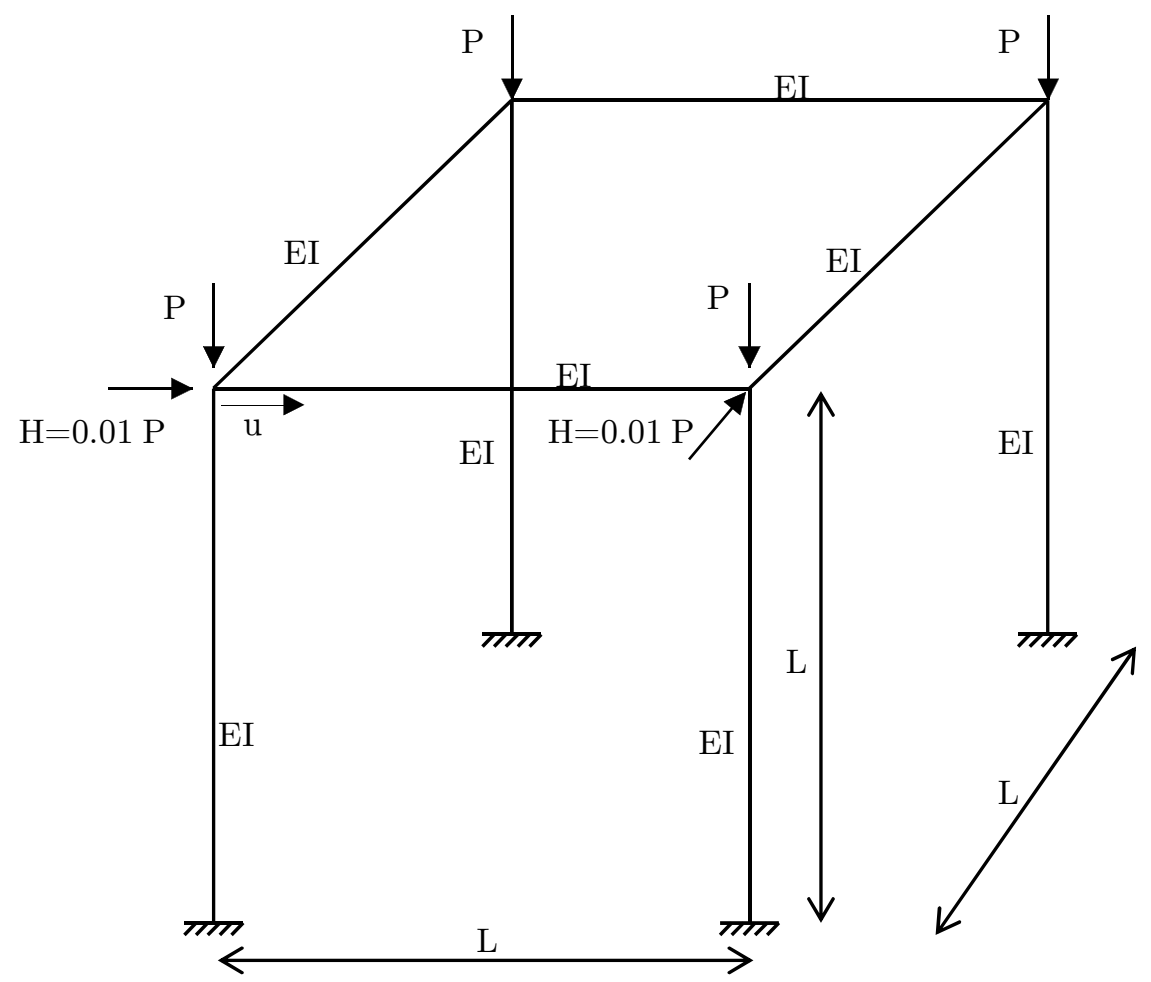

Figura 6.51 - Pórtico espacial com torção

Fonte: Elaborada pelo autor (2019).

Entretanto, desta vez o pórtico é submetido às cargas verticais $(P)$ nos nós livres e por duas cargas horizontais maiores $(H=0,01 P)$, uma na direção $x$ e outra na direção $z$. Os pilares e vigas foram modelados com a mesma seção transversal e, para verificar a influência da teoria de flexão, esta seção foi variada de maneira a reduzir o índice de esbeltez. 
Utilizando o estudo de convergência realizado no exemplo 7.5, optou-se por utilizar uma discretização de 4 elementos por barra para os resultados iniciais com as matrizes geométricas usuais e a de Timoshenko, desenvolvida neste trabalho.

A Figura 6.52, Figura 6.53 e Figura 6.54 mostram a deformada da estrutura evidenciando a torção sofrida pelo pórtico espacial com fator de escala ampliado em dez vezes.

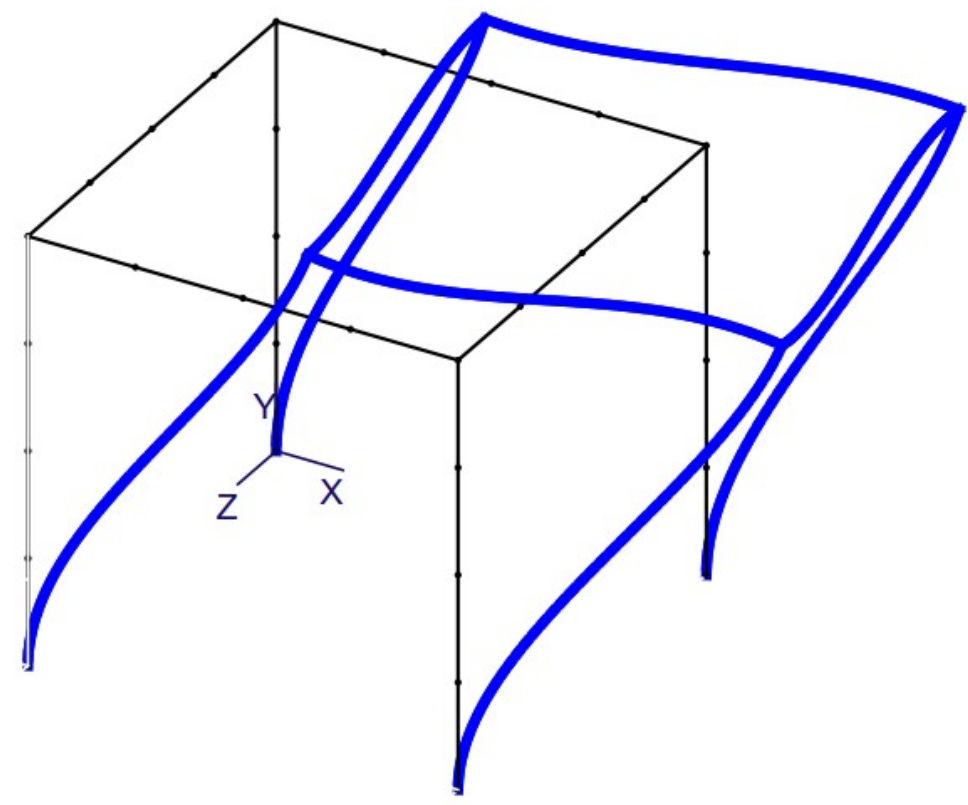

Figura 6.52 - Deformada pórtico espacial com torção vista isométrica

Fonte: Elaborada pelo autor (2019) - Obtida com o Mastan2 V.3.5.

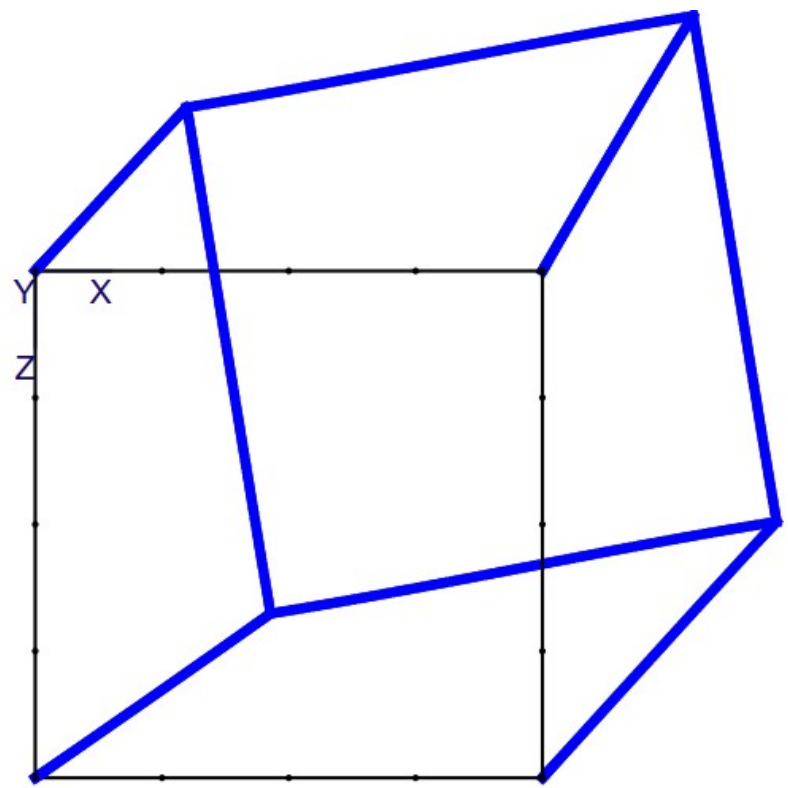

Figura 6.53 - Deformada pórtico espacial com torção vista superior Fonte: Elaborada pelo autor (2019) - Obtida com o Mastan2 V.3.5. 


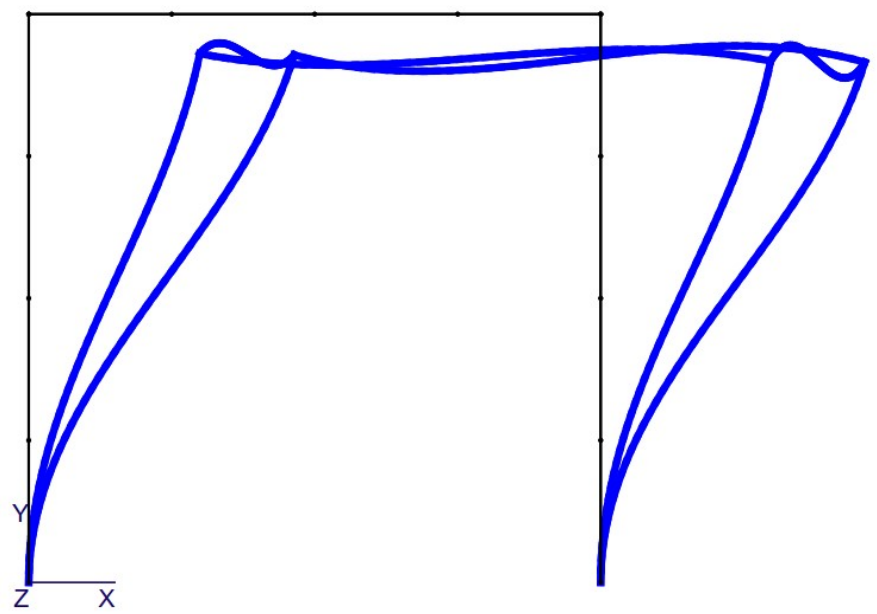

Figura 6.54 - Deformada pórtico espacial com torção vista frontal

Fonte: Elaborada pelo autor (2019) - Obtida com o Mastan2 V.3.5.

\subsection{1}

\section{Matriz de Rigidez de Timoshenko considerando Termos de Grau Elevado no Tensor Deformação e Funções de Forma Cúbicas}

Os resultados obtidos para o deslocamento horizontal $(u)$ do nó livre, utilizando as diferentes formulações, com o emprego de funções de forma cúbicas e variando os termos do tensor deformação, são apresentados na Figura $6.55 \mathrm{e}$ Figura 6.56. As barras foram discretizadas com quatro elementos, de acordo com o estudo de convergência realizado anteriormente.

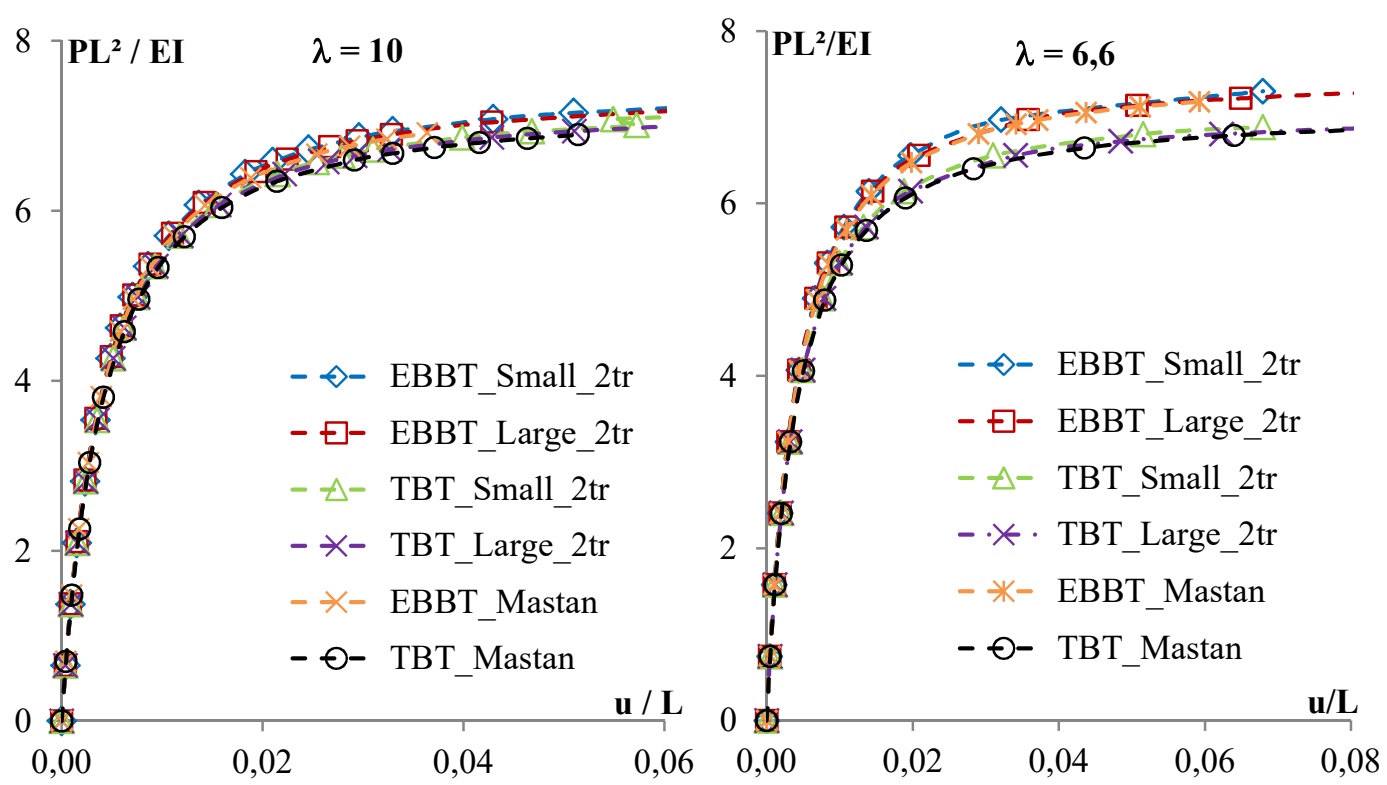

Figura 6.55 - Curva de Equilíbrio para pórtico espacial com torção $\boldsymbol{\lambda}=\mathbf{1 0}$ e $\boldsymbol{\lambda}=\mathbf{6}, \mathbf{6}$, com 4 elementos por barra

Fonte: Elaborada pelo autor (2019). 


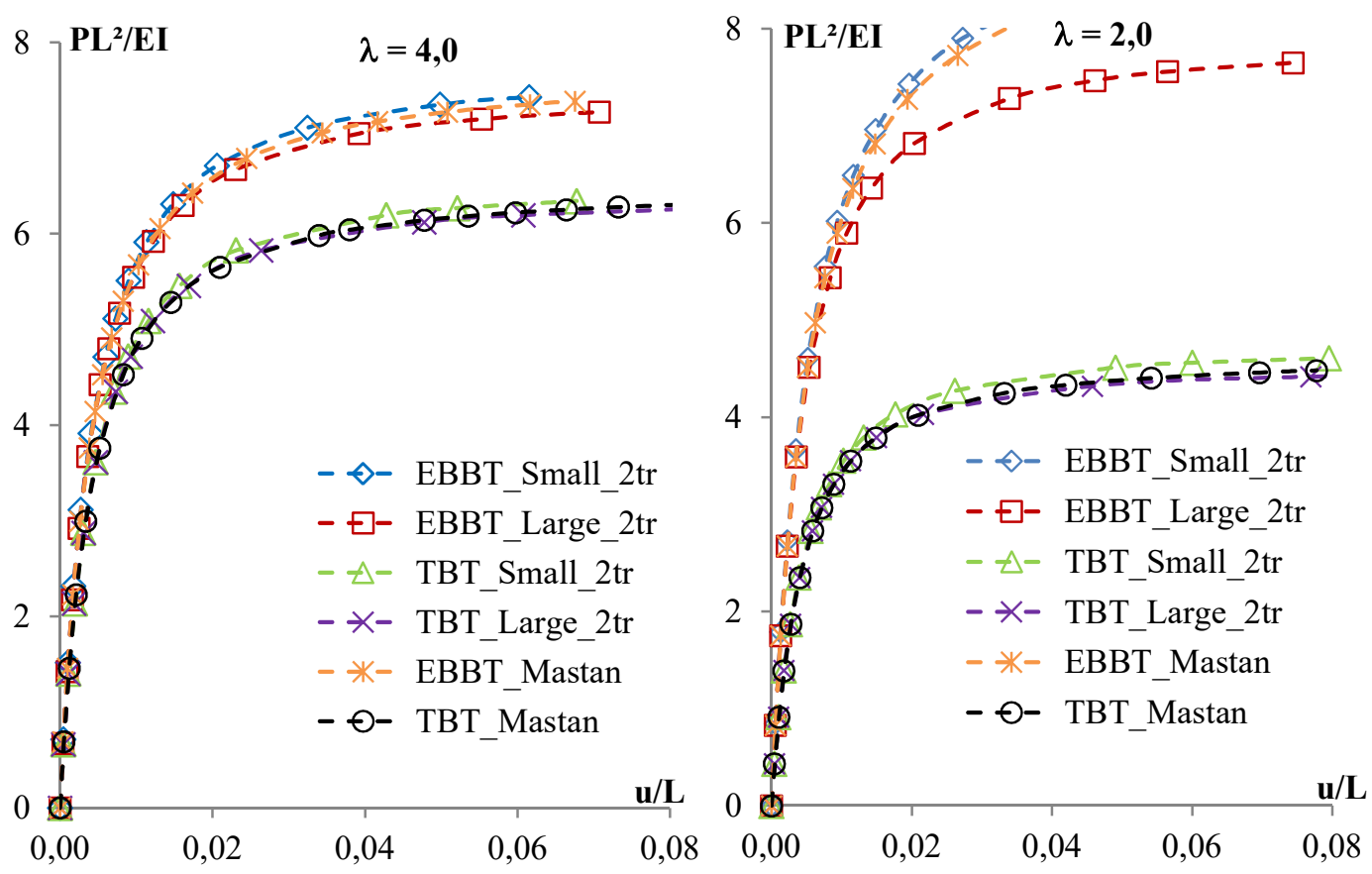

Figura 6.56 - Curva de Equilíbrio para pórtico espacial com torção $\lambda=\mathbf{4 , 0}$ e $\lambda=\mathbf{2 , 0}$, com 4 elementos por barra

Fonte: Elaborada pelo autor (2019).

Das curvas de equilíbrio obtidas, pode-se observar que a matriz de rigidez geométrica, considerando a teoria de flexão de Timoshenko e empregando as funções de forma cúbica (equilíbrio de elemento infinitesimal na configuração indeformada) e os termos de ordem elevada do tensor deformação, desenvolvida neste trabalho, também descreve bem o comportamento de estruturas espaciais, inclusive com torção.

À medida que o índice de esbeltez da estrutura é reduzido, a teoria de flexão considerada tem maior impacto, e mesmo para uma estrutura com uma esbeltez relativamente alta, $\lambda=10$, demonstrando diferenças entre as teorias.

A consideração dos termos de ordem elevada do tensor deformação também influencia no comportamento da estrutura, ficando mais evidente com a redução do índice de esbeltez da estrutura e considerando a teoria de flexão de EulerBernoulli.

Os gráficos anteriores mostram, mais uma vez que, a matriz de rigidez geométrica de Timoshenko, considerando os termos de ordem elevada do tensor deformação, desenvolvida nesta Tese, fornece uma carga crítica abaixo da fornecida pelo Mastan2 v3.5, com a redução do índice de esbeltez. 


\subsection{2}

\section{Matriz de Rigidez Completa de Euler-Bernoulli}

Para avaliar a formulação tridimensional completa, em que se utilizam as funções de interpolação que contemplam a força axial, os termos de grau elevado do tensor deformação e a teoria de flexão de Euler-Bernoulli, desenvolvida neste trabalho, reproduziu-se o pórtico anterior com uma discretização mínima, apenas um elemento por barra.

Neste problema, optou-se por reproduzir o exemplo desenvolvido com esbeltez $(L / h=10)$, por já gerar alterações entre as teorias de flexão e pelo fato de a teoria de flexão de Euler-Bernoulli se aplicar melhor a esta situação. Os resultados encontrados são apresentados na Figura 6.57.

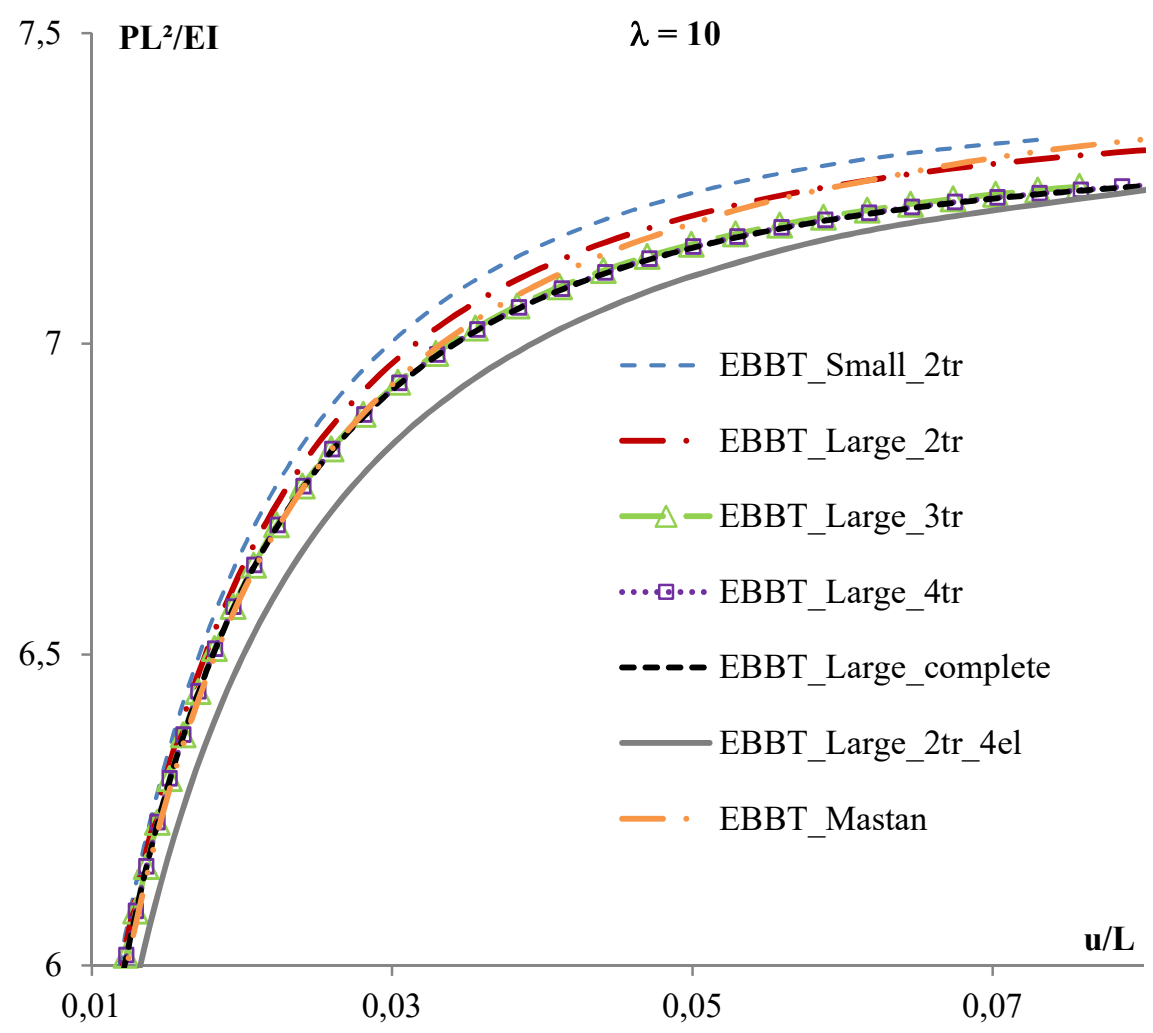

Figura 6.57 - Curva de Equilíbrio para pórtico espacial com torção $\lambda=\mathbf{1 0}$, com 1 elemento por barra (Euler-Bernoulli)

Fonte: Elaborada pelo autor (2019).

Pode-se observar que a formulação completa e empregando a série de Taylor com 4 e 3 termos se sobrepõem e fornecem os melhores resultados, com curvas mais aproximadas da estrutura discretizada com quatro elementos, encontrando a mesma carga crítica, mesmo com a influência da torção. 
A matriz de rigidez geométrica usual de Euler-Bernoulli, empregando os termos de ordem elevada no tensor deformação ("EBBT_Large_2or"), fornece uma curva um pouco acima e com uma carga crítica também superior. A mesma teoria de flexão, porém desconsiderando a interação entre os planos e os termos de ordem elevada no tensor deformação (“EBBT_Small_2or”), fornece o resultado mais distante da que se considerou como resposta, a partir do estudo de convergência.

\subsection{3}

\section{Matriz de Rigidez Completa de Timoshenko}

Neste trabalho, também foi desenvolvida uma formulação completa, empregando-se a teoria de flexão de Timoshenko. Portanto, ela também é avaliada neste exemplo para verificar sua capacidade de predizer a carga crítica de um pórtico espacial com torção, empregando-se uma discretização mínima das barras.

Para esta avaliação, optou-se por empregar um pórtico espacial com índice de esbeltez menor, $L / h=4$, mas ainda mais próximo de estruturas reais. Os resultados encontrados estão expostos na Figura 6.58.

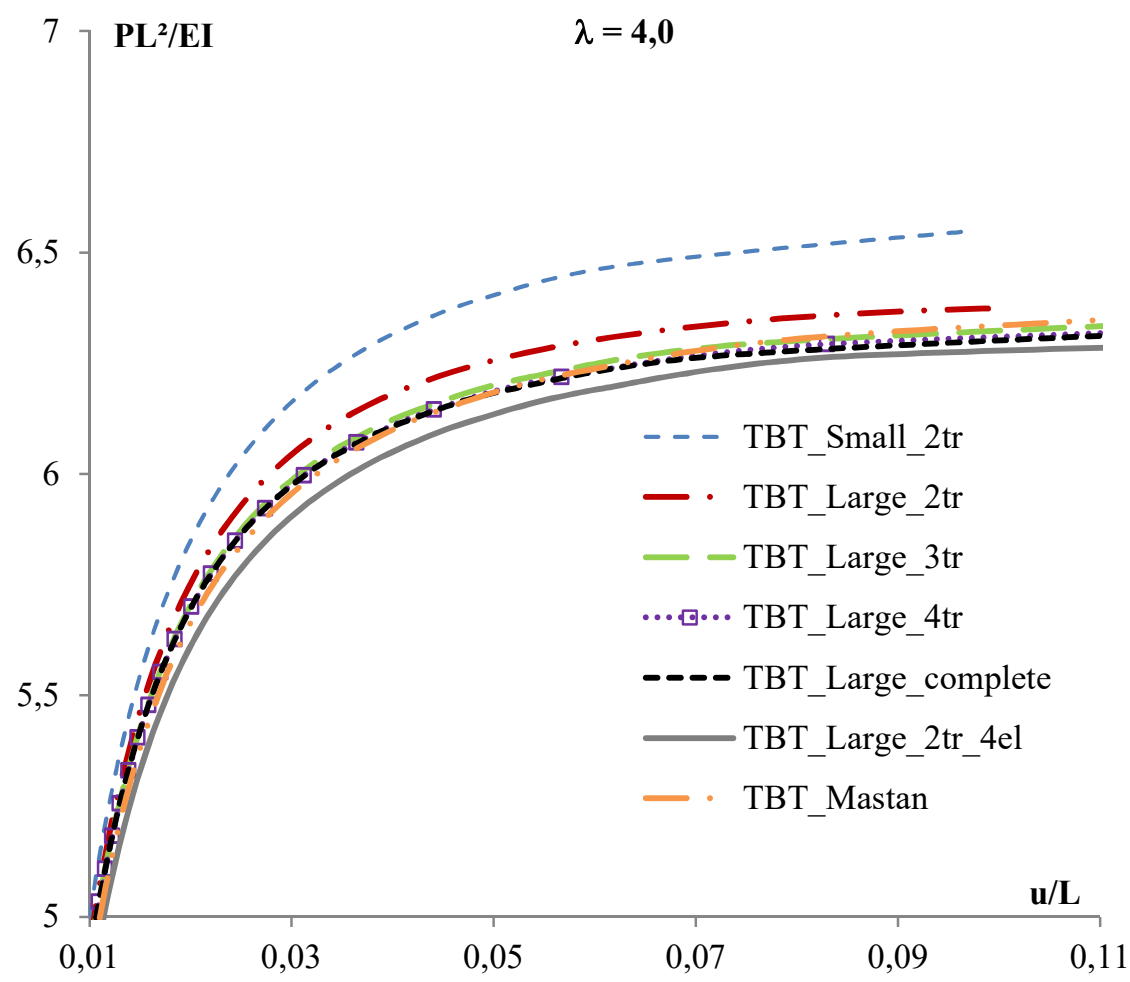

Figura 6.58 - Curva de Equilíbrio para pórtico espacial com torção $\boldsymbol{\lambda}=\mathbf{4 , 0}$, com 1 elemento por barra (Timoshenko)

Fonte: Elaborada pelo autor (2019). 
Observa-se que, mesmo para um pórtico espacial com torção, a formulação completa desenvolvida aproxima a curva de equilíbrio de uma estrutura discretizada. O emprego da série de Taylor com 4 e 3 termos também fornece boa previsão ao se empregar uma discretização mínima da estrutura.

A matriz de rigidez geométrica para Timoshenko, também desenvolvida neste trabalho, com a utilização das funções de forma cúbicas e dos termos de ordem elevada do tensor deformação (“TBT_Large_2or”), gera resultados acima das curvas em expansão em série de Taylor. Pode-se visualizar, ainda, que o elemento que não considera a interação entre os planos e nem os termos de ordem elevada no tensor deformação fornece resultados mais distantes do considerado ideal pelo estudo de convergência. Esse resultado discrepante é mais evidente para índices de esbeltez menores, em que se considera teoria de flexão de Timoshenko.

O software Mastan2 v3.5 também apresenta bons resultados, mas fornece cargas críticas acima das formulações que empregam a série de Taylor.

\subsection{0}

\section{Carga Crítica para Pórtico Espacial com Pilares Inclinados e Torção}

O último exemplo avalia as formulações desenvolvidas em uma estrutura espacial com barras inclinadas e torção, apresentado na Figura 6.59.

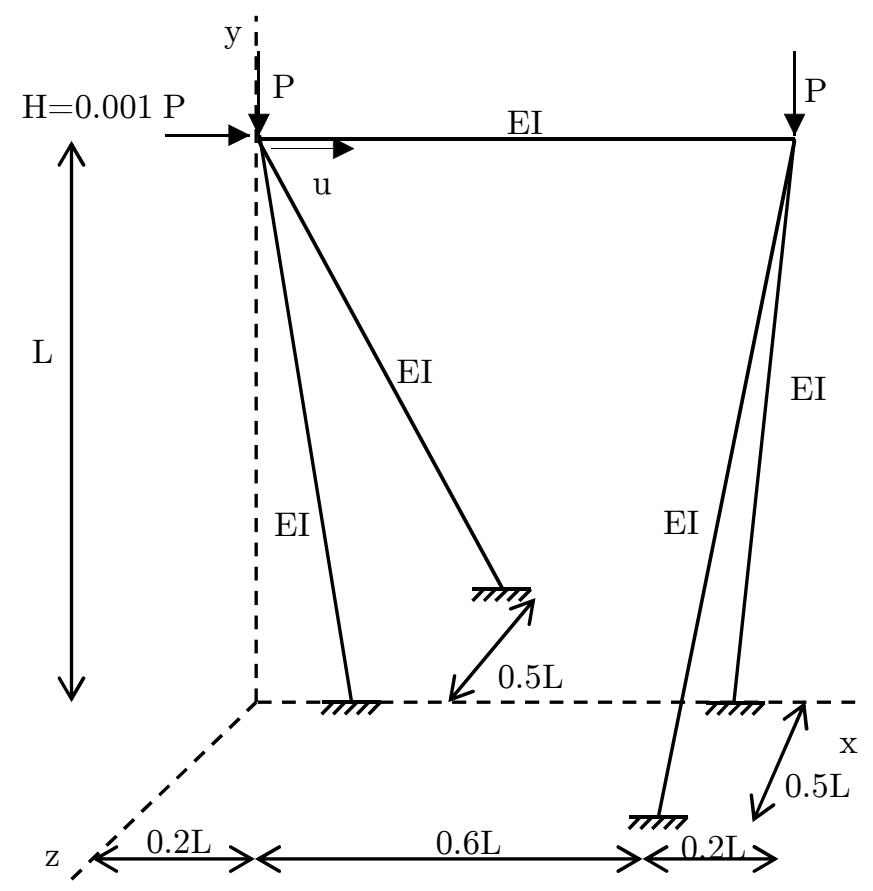

Figura 6.59 - Pórtico espacial com pilares inclinados e torção Fonte: Elaborada pelo autor (2019) - Adaptada de Zugic et al. (2016). 
A estrutura possui seção transversal, com fator de forma $\chi=5 / 6$, coeficiente de Poisson $v=0,3$, módulo de elasticidade $E=10^{7} \mathrm{kN} / \mathrm{m}^{2}$ e comprimento $L=1 \mathrm{~m}$.

O pórtico também é submetido às cargas verticais $(P)$ nos nós livres e por uma pequena carga de perturbação horizontal $(H=0,001 P)$ no nó livre superior esquerdo. Os pilares e vigas foram modelados com a mesma seção transversal e, para verificar a influência da teoria de flexão, esta seção foi variada de maneira a reduzir o índice de esbeltez.

A Figura 6.60 e Figura 6.61 mostram a deformada da estrutura com um fator de amplificação em 10 vezes, evidenciando o comportamento do pórtico espacial.

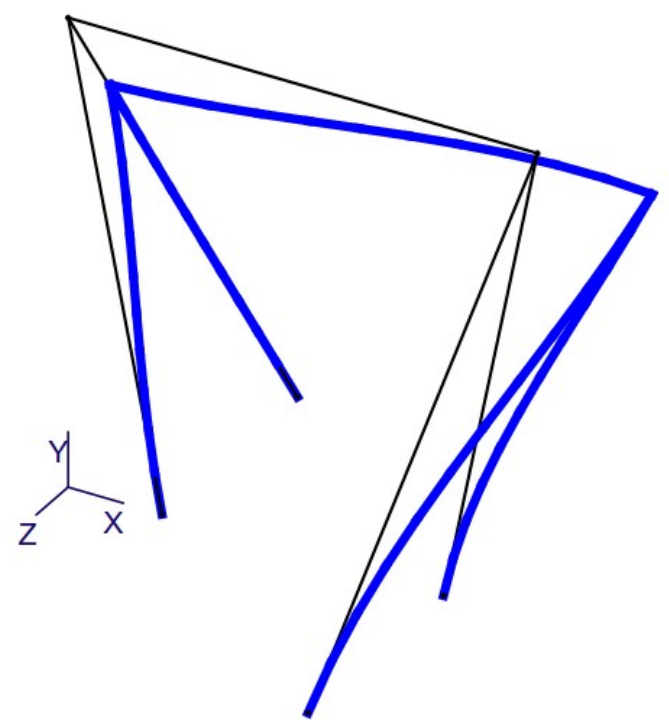

Figura 6.60 - Deformada pórtico espacial com pilares inclinados e torção vista isométrica Fonte: Elaborada pelo autor (2019) - Obtida com o Mastan2 V.3.5.

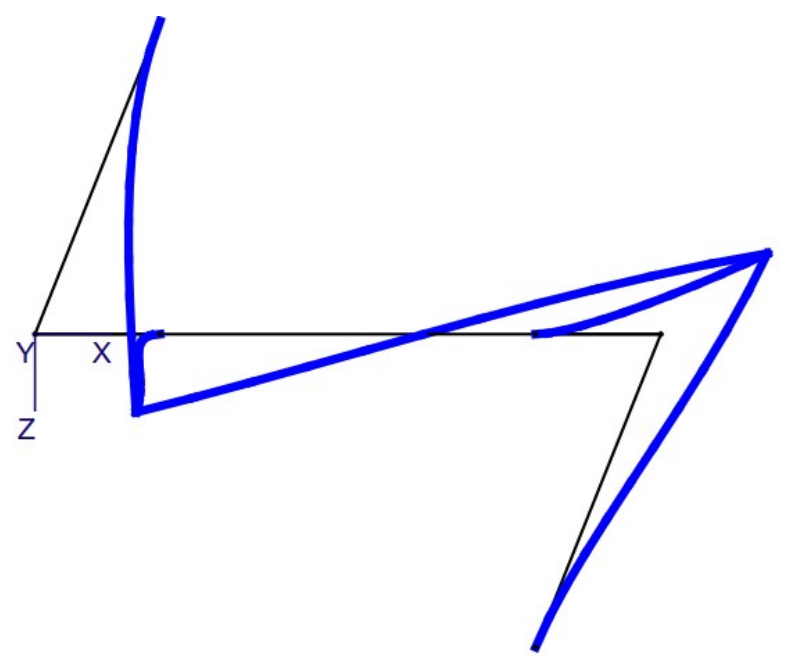

Figura 6.61 - Deformada pórtico espacial com pilares inclinados e torção vista superior Fonte: Elaborada pelo autor (2019) - Obtida com o Mastan2 V.3.5. 


\subsection{0 .1}

\section{Matriz de Rigidez de Timoshenko considerando Termos de Grau Elevado no Tensor Deformação e Funções de Forma Cúbicas}

Conforme os exemplos anteriores, a primeira verificação trata do elemento formulado que considera teoria de flexão de Timoshenko e utiliza funções de interpolação cúbicas (equilíbrio de elemento infinitesimal em sua configuração indeformada). Isso é realizado em um contexto de avaliação da influência da teoria de flexão e do emprego de termos de grau elevado do tensor deformação no comportamento de estruturas.

Assim, os resultados obtidos para o deslocamento horizontal $(u)$ do nó livre superior esquerdo são apresentados na Figura 6.62 e Figura 6.63. Baseado no estudo de convergência realizado no exemplo 6.8, que possui uma estrutura similar, as barras foram discretizadas com quatro elementos.
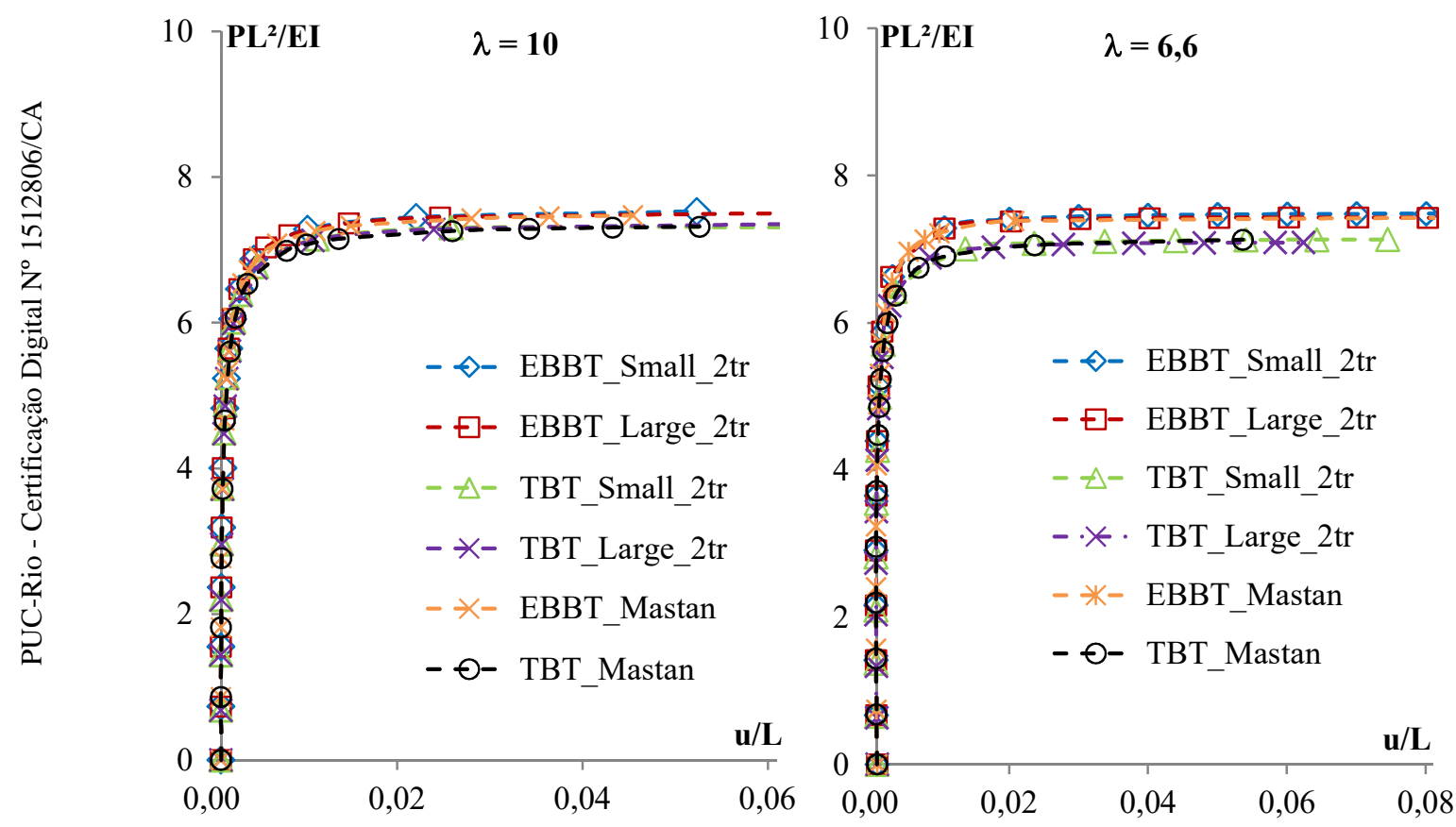

Figura 6.62 - Curva de Equilíbrio para pórtico espacial com barra inclinada e torção $\lambda=\mathbf{1 0}$ e $\boldsymbol{\lambda}=\mathbf{6 , 6}$, com 4 elementos por barra

Fonte: Elaborada pelo autor (2019). 


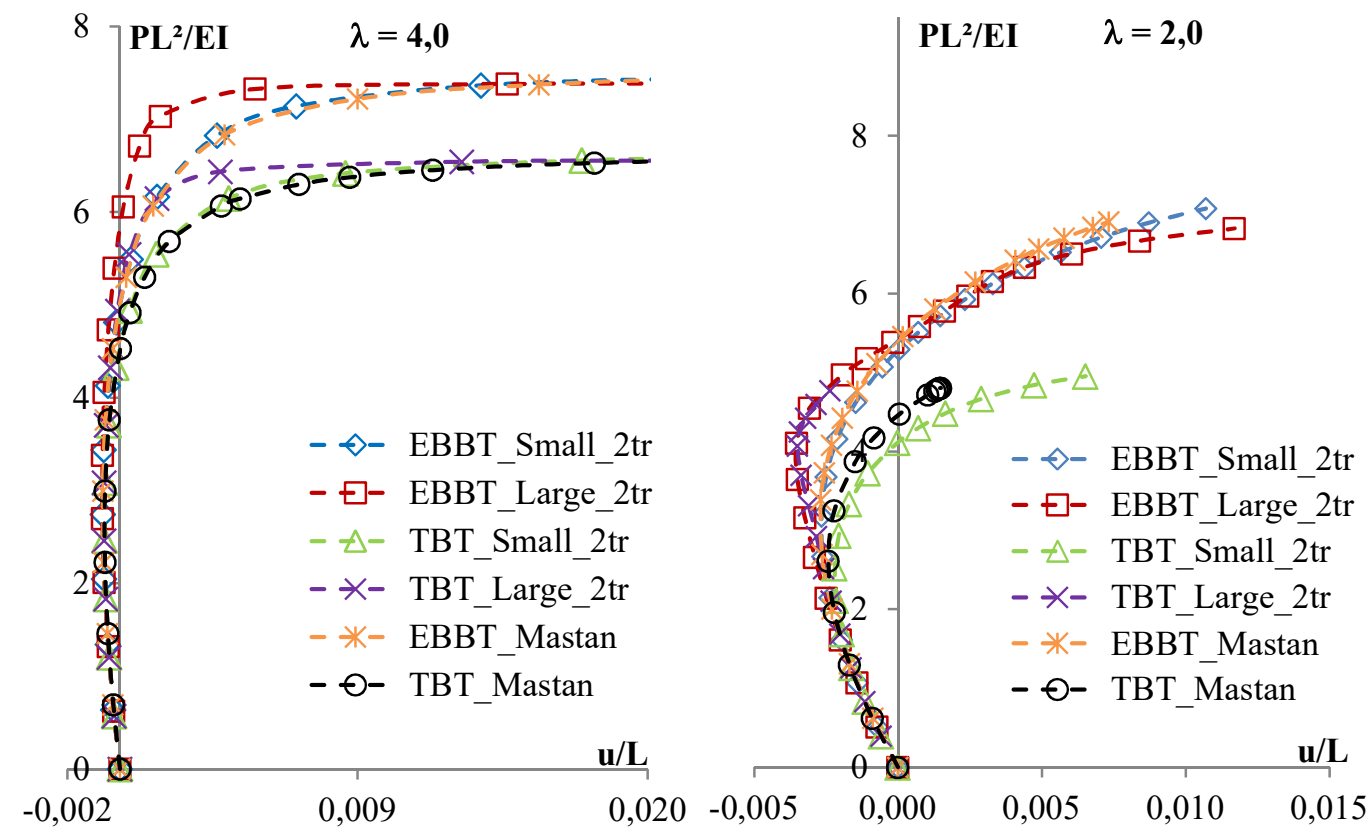

Figura 6.63 - Curva de Equilíbrio para pórtico espacial com barra inclinada e torção $\boldsymbol{\lambda}=\mathbf{4 , 0}$ e $\lambda=2, \mathbf{0}$, com 4 elementos por barra

Fonte: Elaborada pelo autor (2019).

Pelas curvas de equilíbrio construídas, pode-se observar na estrutura em questão, mesmo para um índice de esbeltez alto, $L / h=10$, já existem diferenças entre as teorias de flexão empregadas. Esta diferença fica mais evidente com a redução da esbeltez da estrutura.

Também é possível perceber a influência da consideração dos termos de ordem elevada no tensor deformação, fornecendo curvas distintas para valores reduzidos de índice de esbeltez $(L / h=10)$. Esse comportamento é destacado para ambas as teorias de flexão e consegue-se visualizar que o elemento desenvolvido na primeira parte deste trabalho, que considera a teoria de flexão de Timoshenko e emprega os termos de ordem elevada no tensor deformação, fornece comportamento semelhante ao mesmo elemento, considerando-se a teoria de flexão de Euler-Bernoulli, apresentando, uma curva mais abaixo.

\subsection{0 .2}

\section{Matriz de Rigidez Completa de Euler-Bernoulli}

Para avaliar a formulação tridimensional completa empregando-se a teoria de flexão de Euler-Bernoulli, desenvolvida neste trabalho, reproduziu-se o pórtico anterior com uma discretização mínima, apenas um elemento por barra. 
Neste problema, optou-se reproduzir o exemplo desenvolvido com esbeltez $(L / h=10)$, pois, mesmo apresentando alterações entre as teorias de flexão, é o caso melhor descrito pela teoria de flexão de Euler-Bernoulli. Os resultados encontrados são apresentados na Figura 6.64.

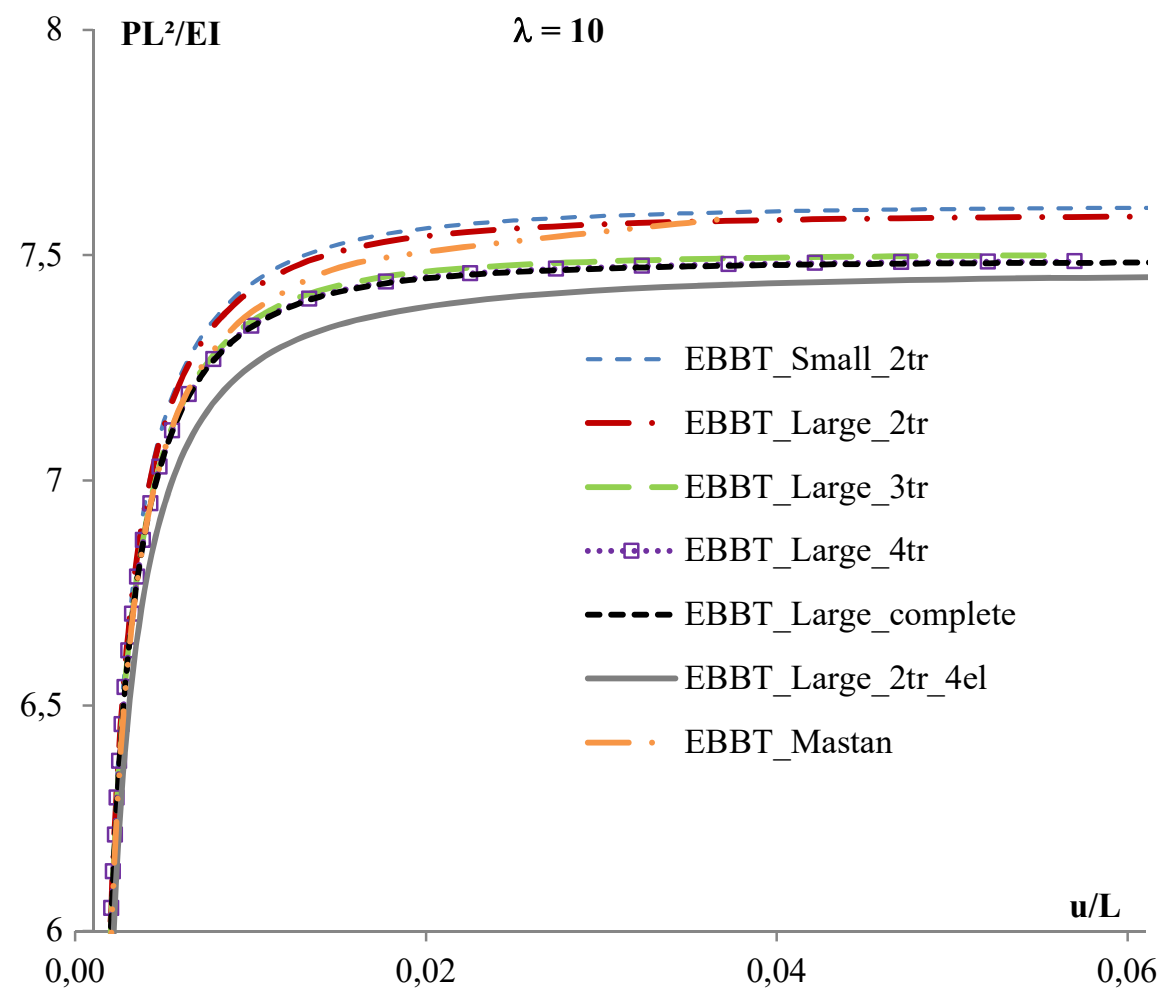

Figura 6.64 - Curva de Equilíbrio para pórtico espacial com barra inclinada e torção $\lambda=\mathbf{1 0}$, com 1 elemento por barra (Euler-Bernoulli)

Fonte: Elaborada pelo autor (2019).

Analisando os resultados encontrados, observa-se que, novamente, a formulação completa e as que empregam a série de Taylor com 4 e 3 termos apresentam as curvas mais próximas à adotada como resposta do problema, da estrutura discretizada, resultando na mesma carga crítica. A aproximação em 4 termos inclusive obtém os mesmos resultados da matriz completa.

A formulação desenvolvida utilizando o elemento infinitesimal indeformado, funções de interpolação hermitianas (“EBBT_Large_2or”), ainda que empregue todos os termos do tensor deformação, resulta em uma carga crítica superior as encontradas com a utilização da série de Taylor.

O elemento que desconsidera as interações entre os planos e os termos de ordem elevada do tensor deformação (“EBBT_Small_2or”) gera os resultados mais distantes da curva resposta. 


\subsection{0 .3}

\section{Matriz de Rigidez Completa de Timoshenko}

Neste trabalho, também foi desenvolvida uma formulação completa, empregando a teoria de flexão de Timoshenko. Portanto, ela também é avaliada para este exemplo, de maneira a verificar sua capacidade de predizer a carga crítica de um pórtico espacial com barras inclinadas e torção, empregando-se uma discretização mínima das barras.

Para esta avaliação, optou-se por empregar um pórtico espacial com índice de esbeltez $L / h=6,6$, por apresentar diferenças no comportamento da estrutura ao se considerar as diferentes teorias de flexão e, também, por possuir um caminho de equilíbrio com curva melhor definida e, ainda, ser mais próximo de uma relação real de estruturas. Os resultados encontrados estão expostos na Figura 6.65 .

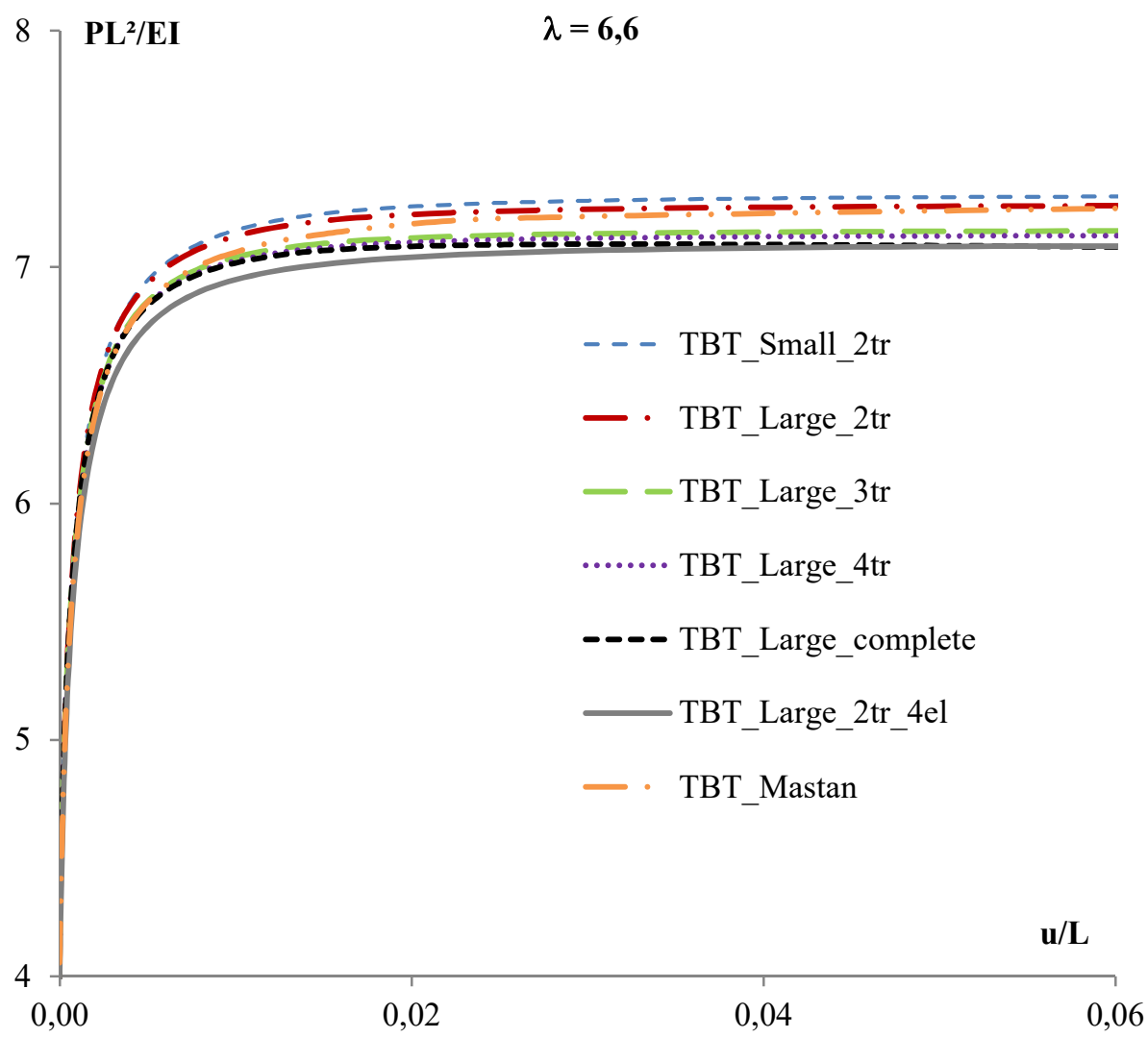

Figura 6.65 - Curva de Equilíbrio para pórtico espacial com barra inclinada e torção $\boldsymbol{\lambda}=\mathbf{6 , 6}$, com 1 elemento por barra (Timoshenko)

Fonte: Elaborada pelo autor (2019).

A partir das curvas de equilíbrio obtidas para a estrutura, com discretização mínima de barras, pode-se observar que as formulação completa é a que mais se 
aproxima da curva resposta adotada com mesma carga crítica para a estrutura. $\mathrm{Na}$ sequência a aproximação em série de Taylor com 4 e 3 termos fornecem a melhor aproximação para carga crítica da estrutura.

A formulação que emprega apenas dois termos (um elástico e um geométrico), possui caminho de equilíbrio acima das apresentadas em série de Taylor. A curva mais distante da resposta é dada pelo elemento que desconsidera a interação entre os planos e os termos de ordem elevada do tensor deformação.

A Figura 6.66 e a Figura 6.67 resumem os resultados encontrados para os exemplos desenvolvidos considerando a teoria de flexão de Euler-Bernoulli e Timoshenko, respectivamente. Conforme demonstrado nas curvas de equilíbrio elaboradas nos problemas, a formulação completa empregando apenas um único elemento obteve os valores mais próximos para a carga crítica das estruturas com barras discretizadas em mais elementos. Os resultados apresentados pela formulação em série de Taylor com 4 componentes também são satisfatórios quanto a completa ao se utilizar apenas um elemento como discretização.

A aproximação em série de Taylor com 3 termos possui resultados intermediários, enquanto que, as matrizes usuais demonstraram necessidade de discretização para solução do problema. 


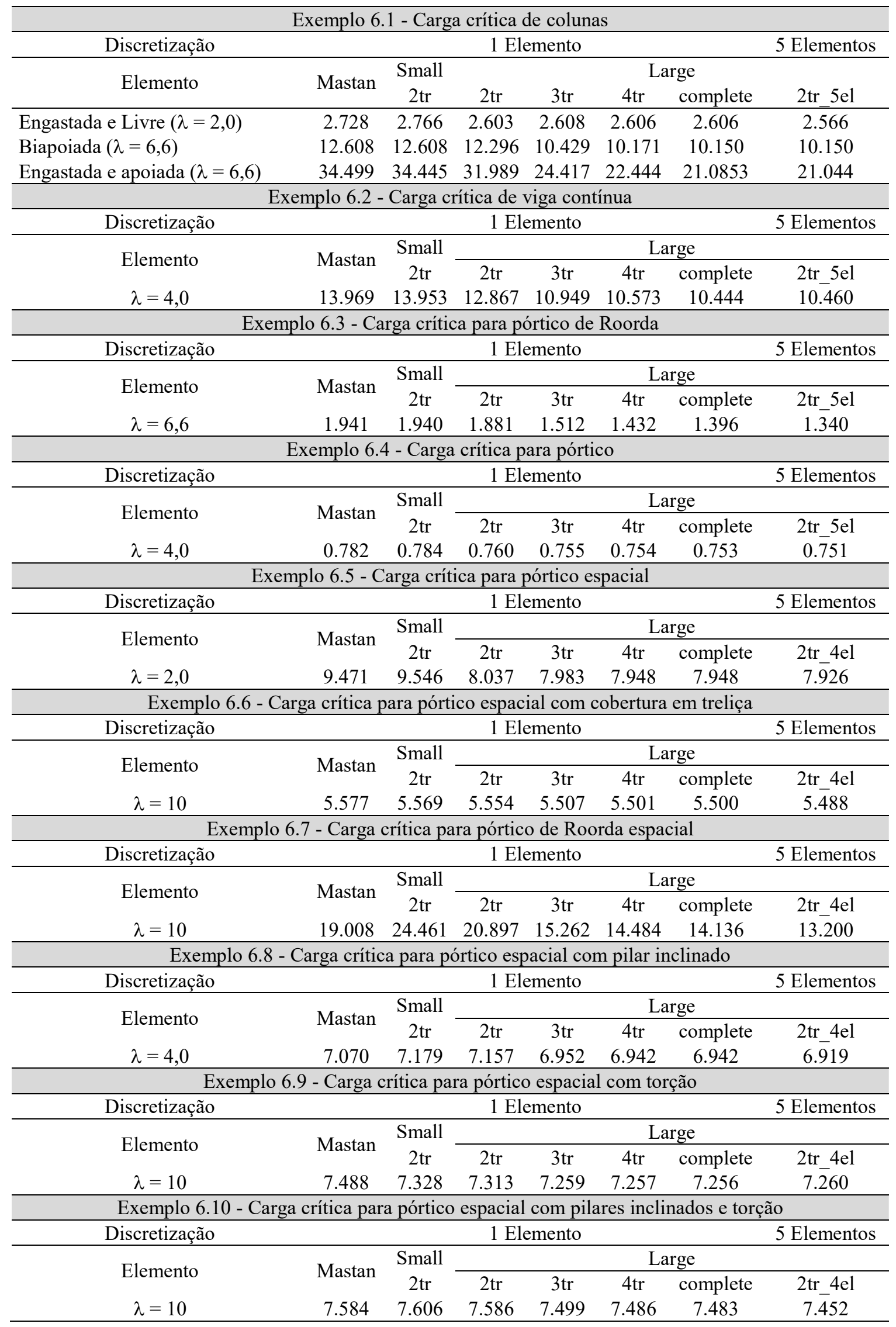

Figura 6.66 - Resumo dos resultados numéricos para a teoria de flexão de Euler-Bernoulli

Fonte: Elaborada pelo autor (2019). 


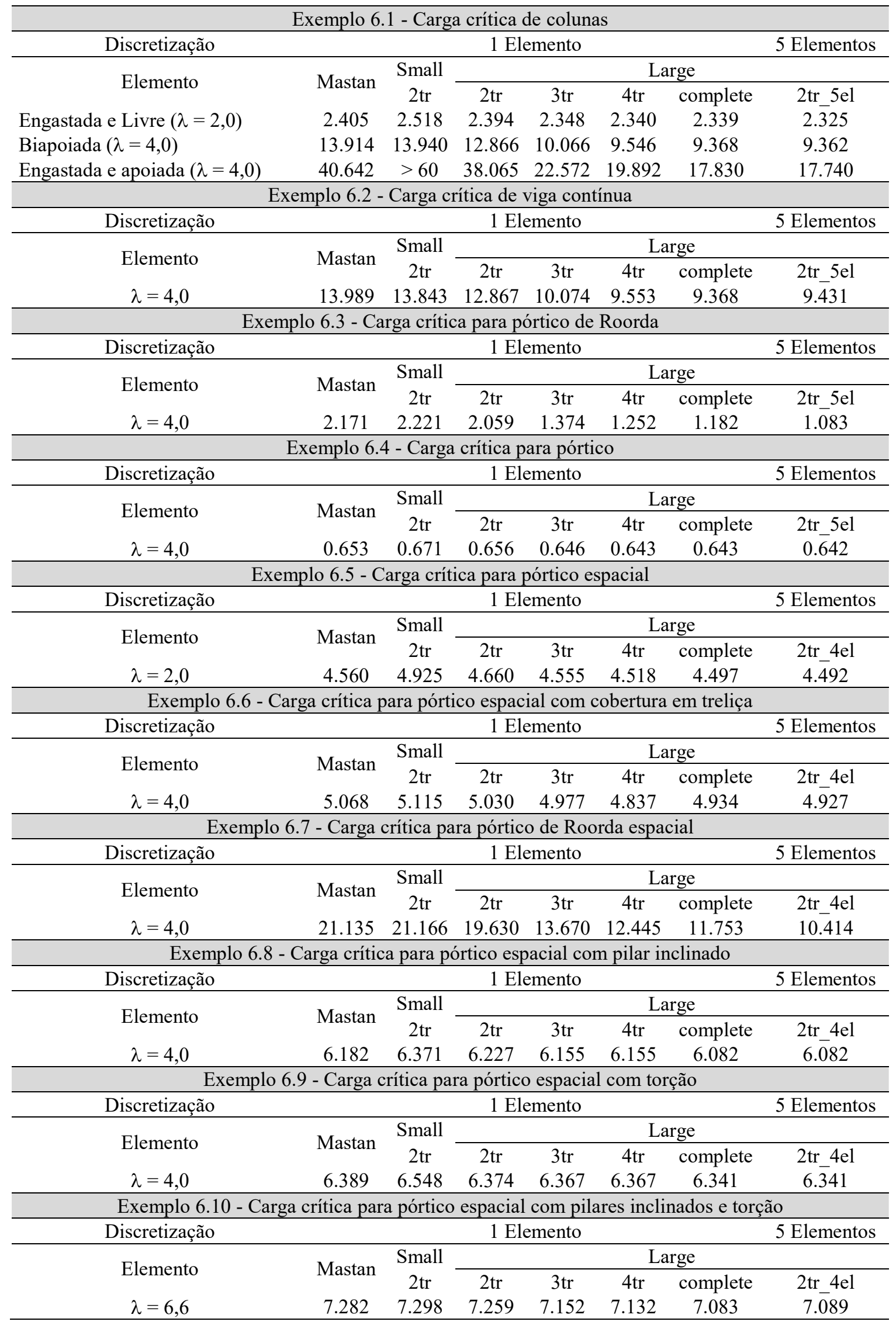

Figura 6.67 - Resumo dos resultados numéricos para a teoria de flexão de Timoshenko

Fonte: Elaborada pelo autor (2019). 


\section{7 \\ Conclusão}

Em virtude dos objetivos definidos para este trabalho, da revisão bibliográfica, dos exemplos apresentados e dos argumentos defendidos, ao término deste estudo, é possível apontar importantes conclusões sobre as formulações desenvolvidas, sua eficiência e influência nos resultados da resposta não linear de estruturas de barras espaciais. Este capítulo sintetiza estas conclusões e considerações, como também apresenta sugestões para trabalhos futuros e desdobramentos sobre a abordagem proposta.

\section{1 \\ Considerações Finais}

Com vistas a atender ao objetivo principal delineado para este estudo, qual seja, o desenvolvimento de uma matriz de rigidez tangente tridimensional, por meio das funções de interpolação, considerando a carga axial presente no elemento, a deformação por cisalhamento e os termos de ordem elevada do tensor deformação, o presente trabalho apresentou uma formulação unificada para integrar as soluções do problema de não linearidade geométrica, para grandes deslocamentos e rotações, objetivando reduzir a influência da discretização da estrutura na resposta numérica.

A formulação apresentada considera tanto a não linearidade geométrica em nível de elemento, ao empregar uma descrição cinemática Lagrangeana atualizada em conjunto com termos de ordem elevada do tensor deformação, como também a não linearidade em nível infinitesimal, com funções de interpolação que levam em conta a carga axial do elemento, obtidas diretamente da solução da equação diferencial do equilíbrio de um elemento infinitesimal deformado. A formulação ainda emprega as teorias de flexão de Euler-Bernoulli e Timoshenko e utiliza metodologias para solução de sistemas não lineares. 
O elemento desenvolvido consiste na matriz de rigidez tangente e nas cargas equivalentes nodais, ambas obtidas a partir das funções de forma "completas". Esta matriz de rigidez foi construída para estruturas espaciais, com a influência dos planos de flexão, a interação entre torção e carga axial e também as rotações finitas. A formulação desenvolvida foi expandida em série de Taylor, considerando 3 e 4 termos, aprimorando a matriz de rigidez tangente para ambas as teorias que possuem apenas 2 termos (uma parcela elástica e uma geométrica).

Neste trabalho, também foi construída a matriz de rigidez tangente, considerando grandes deslocamentos e rotações para a teoria de flexão de Timoshenko, correspondente a usual de Euler-Bernoulli. A matriz em referência também poderia ser obtida pela expansão em série de Taylor de 2 termos. Entretanto, foi desenvolvida a partir de uma descrição Lagrangeana atualizada, utilizando-se os termos de ordem elevada no tensor deformação, com o emprego de funções de forma cúbicas, obtidas da solução da equação diferencial do equilíbrio de um elemento indeformado, de forma similar à obtida para a teoria de flexão de Euler-Bernoulli.

Esse elemento, com grandes rotações e deslocamentos, a teoria de flexão de Timoshenko e as funções de interpolação cúbicas, pode ser escrito sem nenhum termo adicional ou grau de liberdade a mais, pois a matriz de rigidez é obtida das funções de interpolação, originadas da solução da equação diferencial do problema.

Esse elemento desenvolvido foi, então, o primeiro a ser avaliado em diferentes aplicações numéricas, tanto para estruturas planas, como para estruturas espaciais, de maneira a avaliar a influência da teoria de flexão e a consideração de termos de ordem elevada no tensor deformação para a resposta não linear da estrutura. Inicialmente foram analisadas colunas isoladas com diferentes condições de contorno. Na sequência, analisou-se uma viga-coluna contínua, um pórtico de Roorda e um pórtico plano com três barras. Em todos esses exemplos, variou-se a seção transversal da estrutura, de maneira a alterar o seu índice de esbeltez.

De modo semelhante, avaliou-se essa formulação para estruturas espaciais, um pórtico espacial de um pavimento, um com cobertura treliçada, um pórtico espacial com três barras, uma em cada eixo, e um pórtico com barras inclinadas. 
Em seguida, os exemplos exploraram o efeito de torção, aplicando um carregamento diferente no pórtico espacial de um pavimento e inserindo uma assimetria no pórtico espacial com barras inclinadas, gerando, assim, rotação nessas estruturas.

Os exemplos apresentados ilustraram claramente que o elemento desenvolvido conseguiu prever de maneira satisfatória a carga crítica de estruturas planas e espaciais, considerando a teoria de flexão de Timsohenko. Pode-se observar que a consideração dessa teoria de flexão reduz de forma considerável a carga crítica para estruturas com baixo índice de esbeltez. Também se pode concluir que o emprego dos termos de ordem elevada do tensor deformação também reduz essa carga crítica, à medida que o índice de esbeltez é reduzido.

$\mathrm{Na}$ sequência, para os mesmos exemplos, avaliou-se a formulação completa e as expansões em série de Taylor com 3 e 4 termos. Para esta verificação, empregou-se a menor discretização possível, qual seja, um elemento por barra. Em cada uma dessas aplicações numéricas, primeiro verificou-se as formulações, considerando a teoria de flexão de Euler-Bernoulli e, em seguida, a teoria de Timoshenko.

Em todas as verificações que consideraram a teoria de Euler-Bernoulli, pode-se comprovar que a formulação completa conseguiu prever, utilizando uma discretização mínima, a carga crítica das estruturas, de forma satisfatória, para alto índice de esbeltez, obtendo, assim, um resultado bem melhor do que ao se empregar as formulações usuais. As aproximações em série de Taylor de 4 termos, apresentaram resultados muito próximos à formulação completa, muitas vezes com trajetórias de equilíbrio sobrepostas, sem, contudo, apresentar a instabilidade numérica dessa formulação, sendo sugerida, portanto, para implementações de análise não linear geométrica de estruturas 3-D. Em algumas situações, a formulação completa possui dificuldades de convergência em razão de problemas numéricos, como divisões de zero por zero, e não somente para o início dos passos de carga do problema não linear, pois, mesmo para cargas maiores, alguns elementos poderiam estar descarregados, gerando essa instabilidade.

A formulação com expansão em série de Taylor com 3 termos possui resultados intermediários entre a formulação completa e as usuais, entretanto, 
sempre com resultados melhores que as convencionais, ao se empregar uma discretização mínima da estrutura.

Resultados similares aos encontrados a partir da teoria de flexão de EulerBernoulli foram obtidos para a teoria de flexão de Timoshenko. Contudo, a teoria de Euler-Bernoulli não descreve bem os problemas com baixo índice de esbeltez, sendo indicado, neste caso, o emprego da teoria de Timoshenko.

A formulação "completa" baseado na teoria de flexão de Timoshenko apresentou, de maneira precisa, os resultados para a previsão da carga crítica dos exemplos desenvolvidos, com uma discretização mínima da estrutura. $\mathrm{Na}$ sequência, os melhores resultados, muito semelhantes à formulação "completa", quase sobrepondo as trajetórias de equilíbrio, foram obtidos pela formulação que emprega aproximação em série de Taylor de 4 termos, sem a instabilidade numérica, sendo, portanto, sugerida para implementações de análise não linear geométrica de estruturas 3-D com baixo índice de esbeltez, ou em materiais com elevada constante $\Omega$, devido a relação entre módulo de rigidez ao cisalhamento transversal e à flexão.

A aproximação em série de Taylor com 3 termos, considerando a teoria de flexão de Timoshenko e uma discretização mínima da estrutura, também possui resultados intermediários, entre a formulação completa e a desenvolvida, empregando apenas 2 termos, entretanto, sempre com resultados melhores.

À medida que se utiliza mais elementos na discretização da estrutura, as formulações possuem resultados sobrepostos, o que indica que as formulações desenvolvidas são coerentes. Também, ao se considerar o alto índice de esbeltez, as formulações para ambas as teorias de flexão e com consideração ou não de termos de ordem elevada no tensor deformação se aproximam, visto que a estrutura não sofre influência da teoria de flexão e, como usualmente, os termos de ordem elevada podem ser desprezados.

Como resultado das análises realizadas, pode-se concluir que a formulação integrada desenvolvida é capaz de prever o comportamento não linear e calcular a carga crítica de estruturas planas e espaciais, considerando grandes deslocamentos e rotações, para diferentes teorias de flexão de barras e utilizando uma discretização mínima da estrutura. Mesmo em situações de acentuada não linearidade, esta formulação integrada desenvolvida fornece resultados melhores que as formulações usuais de não linearidade geométrica. 
Diante disso, verificou-se, então, que a formulação desenvolvida constitui uma boa alternativa para situações em que a discretização da estrutura precisa ser reduzida, casos em que a formulação convencional não atenderá de maneira satisfatória. Também descreve situações em que a deformação por cisalhamento é importante, como em estruturas com baixo índice de esbeltez e com materiais compósitos.

Entretanto, pode-se observar que, mesmo integrando as soluções do problema de não linearidade geométrica, e utilizando funções de interpolação, obtidas da solução da equação diferencial do problema, não foi possível descrever de maneira precisa a trajetória de equilíbrio da estrutura, e não evitando-se a total necessidade da discretização das barras, a exemplo de uma análise linear. Isso ocorre em razão de que, com a discretização, a carga axial se altera para cada elemento, aproximando-se mais do resultado. Ao se empregar apenas um elemento por barra, a carga axial é constante naquele elemento, reduzindo a precisão da resposta. Uma possível melhora nos resultados também pode ser obtida com introdução de funções de interpolação para o deslocamento axial baseada em campos de deslocamentos consistentes.

\section{2 \\ Desenvolvimentos Futuros}

Fundamentado nos estudos realizados, o presente trabalho aponta para o desenvolvimento de futuras pesquisas que avaliem os resultados das formulações apresentadas em análises não lineares de edificações usuais, para verificar sua utilização em projetos de estruturas, sem a necessidade de discretização das barras e com métodos simplificados para análise não linear geométrica como o método dos dois ciclos iterativos (two-cycle).

Outra sugestão que este trabalho indica é a expansão das formulações, desenvolvendo elemento apoiado em bases elásticas, para análises de interação solo-estrutura. Seguindo racícionio semelhante, sugere-se, ainda, o desenvolvimento de elementos com ligações semirrígidas, ou seja, extremidades com molas longitudinais e rotacionais. Considerar a imperfeição geométrica para o cálculo da capacidade de carga das colunas. 
Expandir a formulação para barras com seções variáveis, assimétricas, paredes finas e elementos com torção não uniforme. Adaptar os elementos desenvolvidos para uma formulação corrotacional na expectativa de aperfeiçoar a resposta da estrutura, inclusive no estado pós-crítico.

Utilizar o desenvolvimento apresentado para outras teorias de flexão, como a teoria de Timoshenko alternativa, ou teorias refinadas ou de alta ordem.

Empregar funções de interpolação consistentes para o deslocamento axial e para a rotação em torno do eixo axial do elemento, tendo em vista que, neste trabalho, essas funções foram apenas lineares.

Por fim, a implementação das matrizes com aproximação em série de Taylor no Ftool, por não apresentarem instabilidade numérica e fornecerem bons resultados para análises com discretização reduzida da estrutura. 


\section{Referências bibliográficas}

AGUIAR, L. L.; ALMEIDA, C. A.; PAULINO, G. H. A three-dimensional multilayered pipe beam element: nonlinear analysis. Computers and Structures, vol. 138, p. 142-161, 2014.

AL-BERMANI, F. G. A.; KITIPORNCHAI, S. Nonlinear analysis of thin-walled structures using least element / member. Journal of Structural Engineering. v. 116, n. 1, p. 215-234, 1990.

AREIZA-HURTADO, M., VEGA-POSADA, C.; ARISTIZÁBAL-OCHOA, J. D. Second-order stiffness matrix and loading vector of a beam-column with semirigid connections on an elastic foundation. Journal of Engineering Mehanics, vol. 131, n.7, p. 752-762, 2005.

ARISTIZÁBAL-OCHOA, J. D. Matrix method for stability and second-order analysis of Timoshenko beam-column structures with semi-rigid connections. Engineering Structures, vol. 34, p. 289-302, 2012.

Slope-deflection equations for stability and second-order analysis of Timoshenko beam-column structures with semi-rigid connections. Engineering Structures, vol. 30, p. 2517-2527, 2008.

. Tension and compression stability and second-order analyses of threedimensional multicolumn systems: effects of shear deformations. Journal of Engineering Mehanics, vol. 133, n.1, p. 106-116, 2007.

First- and second-order stiffness matrices and load vector of beamcolumns with semirigid connections. Journal of Structural Engineering, vol. 123, n. 5, p. 669-678, 1997.

AYDOGAN, M. Stiffness-matrix formulation of beams with shear effect on elastic foundation. Journal of Structural Engineering, vol. 121, n. 9, p. 12651270, 1995.

BALLING, R. J.; LYON, J. W. Second-order analysis of plane frames with one element per member. Journal of Structural Engineering. v. 137, n. 11, p. 13501358, 2011.

BATHE, K. J. Finite element procedures. Prentice-Hall, Englewoods Cliffs, NJ USA, 1996.

; BOLOURCHI, S. Large displacement analysis of three-dimensional beam structures. International Journal for Numerical Methods in Engineering. v. 14, p. 961-986, 1979. 
BATTINI, J. M. Co-rotational beam elements in instability problems. 2002. Tese (Doutorado) - Departamento de Mecânica, Instituto Real de Tecnologia, Estocolmo, Suécia.

BAZANT, Z. P.; CEDOLIN, L. Stability of structures. World Scientific Publishing Co. Pte. Ltd., Singapura, 2010.

BICKFORD, W. B. A consistent higher order beam theory. Developments in Theoretical and Applied Mechanics. v. 11, p. 137-150, 1982.

BURGOS, R. B.; SILVA, R. R.; MARTHA, L. F. Avaliação de Cargas Críticas e Comportamento Pós-Crítico Inicial de Pórticos Planos. In: XXXV Iberian Latin American Congres on Computational Methods in Engineering, 2005, Guarapari, Brasil.

; MARTHA, L. F. Exact shape functions and tangent stiffness matrix for the buckling of beam-columns considering shear deformation. In: XXXIV Iberian Latin American Congres on Computational Methods in Engineering, 2013, Pirenópolis, Brasil.

CHAN, S. L.; GU, J. X. Exact tangent stiffness for imperfect beam-column members. Journal of Structural Engineering, vol. 126, n. 9, p. 1094-1102, 2000 .

CHEN, D. C. Geometric nonlinear analysis of three-dimensional structures. 1994. Dissertação (Mestrado em Engenharia Civil) - Programa de Pós-Graduação, Universidade de Cornell, Ithaca, NY.

CHEN, W. F.; LUI, E.M. Stability design of steel frames. CRC Press, Boca Raton, USA, 1991.

CHIWANGA, M.; VALSANGKAR, A. J. Generalized beam element on twoparameter elastic foundation. Journal of Structural Engineering, vol. 114, n. 6, p. 1414-1427, 1988.

CONCI, A. Análise de estruturas reticuladas de aço com consideração de empenamento e não-linearidades geométrica e material. 1988. Tese (Doutorado em Engenharia Civil) - Departamento de Engenharia Civil e Ambiental, Pontifícia Universidade Católica do Rio de Janeiro, Rio de Janeiro.

CRISFIELD, M. A. Non-linear finite element analysis of solids and structures. vol.1, John Wiley \& Sons Inc, NY, USA, 1991.

DAVIS, R.; HENSHELL, R. D.; WARBURTON, G. B. A Timoshenko beam element. Journal of Sound and Vibration. v. 22, n. 4, p. 475-487, 1972.

EISENBERGER, M.; YANKELEVSKY, D. Z. Exact stiffness matrix for beams on elastic foundation. Computers and Structures, vol. 21, n. 6, p. 1355-1359, 1985. 
FELIPPA, C. A. Nonlinear Finite Element Methods / NFEM. 2017. Notas de aula do curso de análise não linear pelo método dos elementos finitos, Aerospace Engineering Sciences, Universidade of Colorado, Boulder, USA.

FRIEDMAN, Z.; KOSMATKA, J. B. An improved two-node Timoshenko beam finite element. Computers and Structures, vol. 47, n. 3, p. 473-481, 1993.

GIRHAMMAR, U. A.; GOPU, V. K. A. Composite beam-columns with interlayer slip - exact analysis. Journal of Structural Engineering, vol. 119, n. 4, p. 1265$1282,1993$.

GOTO, Y.; CHEN, W. F. Second-order elastic analysis for frame design. Journal of Structural Engineering, vol. 113, n. 7, p. 1501-1519, 1987.

HA, K. H. Stiffness matrix for exact solution of sandwich beam and frame systems. Journal of Structural Engineering. v. 119, n. 4, p. 1150-1167, 1993.

HEYLIGER, P.R.; REDDY, J. N. A higher order beam finite element for bending and vibration problems. Journal of Sound and Vibration. v.126, n. 2, p. 309326, 1988.

LEON, S. E.; PAULINO, G. H.; PEREIRA, A.; MENEZES, I. V. M.; LAGES, E. N. A unified library of nonlinear solution schemes. Applied Mechanics Reviews. v.64, 2011.

LEVINSON, M. A new rectangular beam theory. Journal of Sound and Vibration. v. 74, n. 1, p. 81-87, 1981.

KIEN, N. D. A Timoshenko beam element for large displacement analysis of planar beams and frames. International Journal of Structural Stability and Dynamics, v. 12, n. 6, 2012.

KRENK, S. Non-linear Modeling and Analysis of Solids and Strctures. Cambridge University Press, NY, USA, 2009.

MARTHA, L. F. Ftool: A structural educational interactive tool. Proceedings of Workshop in Multimedia Computer Techniques in Engineering Education, Institute for Structural Analysis, Technical University of Graz, Austria, p. 51-65, 1999.

F. Análise de estruturas: conceitos e métodos básicos. 2.ed. Elsevier, Rio de Janeiro, 2017.

Análise matricial de estruturas com orientação a objetos. Elsevier, Rio de Janeiro, 2018.

; BURGOS, R. B. Possíveis inconsistências na consideração da distorção por cisalhamento numa viga sumetida a carregamento axial. In: Congresso Brasileiro do Concreto, 57, 2015, Bonito. Anais... Bonito: Instituto Brasileiro do Concreto, 2015. 
Diferenças na consideração da distorção no modelo de Timoshenko de uma viga submetida a carregamento axial. In: Jornadas Sul Americanas de Engenharia Estrutural, Montevidéu, 2014,.

MCGUIRE, W.; GALLAGHER, R. H.; ZIEMIAN, R. D. Matrix structural analysis. John Wiley \& Sons Inc, NY, USA, 2000.

MEGHARE, T.K.; JADHAO, P. D. A simple higher order theory for bending analysis of steel beams. International Journal of Civil Engineering. v.2, p.31$38,2015$.

MENIN, R. C. G.; SILVA, W. T. M. Resposta Pós-Crítica de Pórticos Planos Discretizados com Elementos de Viga De Euler-Bernoulli Utilizando uma Formulação Co-Rotacional. In: XXIV Iberian Latin American Congres on Computational Methods in Engineering, Ouro Preto, Brasil, 2003.

MONTEIRO, F. A. C. Uma formulação Co-rotacional geral: Aplicação a pórticos espaciais. 2004. Dissertação (Mestrado em Engenharia) - Engenharia Aeronáutica e Mecânica, Instituto Tecnológioco de Aeronáutica, São José dos Campos.

MORFIDIS, K. Exact matrices for beams on three-parameter elastic foundation. Computers and Structures, vol. 85, pp. 1243-1256, 2007.

; AVRAMIDIS, I. E. Formulation of a generalized beam element on a two-parameter elastic foundation with semi-rigid connections and rigid offsets. Computers and Structures, vol. 80, p. 1919-1934, 2002.

NANAKORN, P.; VU, L. N. A 2D field-consistent beam element for large displacement analysis using the total Lagrangian formulation. Finite Elements in Analysis and Design, vol. 42, p. 1240-1247, 2006.

NUKULCHAI, W. K.; DAYAWANSA, P. H.; KARASUDHI, P. An exact finite element model for deep beams. International Journal of Structures, vol. 1, n. 1, p. 1-7, 1981.

OLIVEIRA, G. C.; SILVA, W. T. M. Análise não linear de arcos utilizando o element de viga unificado Bernoulli-Timoshenko e a formulação corotacional. Revista Eletrônica de Engenharia Civil, vol. 13, n. 2, p. 1-16, 2017.

ONU, G. Shear effect in beam finite element on two-parameter elastic foundation. Journal of Structural Engineering, vol. 126, n. 9, p. 1104-1107, 2000.

. Finite elements on generalized elastic foundation in Timoshenko beam theory. Journal of Engineering Mechanics, vol. 134, n. 9, p. 763-776, 2008.

PACOSTE, C.; ERIKSSON, A. Element behavior in post-critical plane frames analysis. Computer Methods in Applied Mechanics and Engineering, vol. 125, p. 319-343, 1995. 
Beam elements in instability problems. Computer Methods in Applied Mechanics and Engineering, vol. 144, p. 163-197, 1997.

PEREIRA, A. Projeto ótimo de pórticos planos com restrição à flambagem. 2002. Dissertação (Mestrado em Engenharia Civil) - Departamento de Engenharia Civil e Ambiental, Pontifícia Universidade Católica do Rio de Janeiro, Rio de Janeiro.

PETROLITO, J. Stifness analysis of beams using a higher-order theory. Computers and Structures. v.55, p.33-39, 1995.

PILKEY, W. D.; KANG, W.; SCHRAMM, U. New structural matrices for a beam element with shear deformation. Finite Elements in Analysis and Design. v.19, p.25-44, 1995.

RANGEL, R. L. Ferramenta educacional para análise de estruturas com não linearidade geométrica. 2019. Dissertação (Mestrado em Andamento em Engenharia Civil) - Departamento de Engenharia Civil e Ambiental, Pontifícia Universidade Católica do Rio de Janeiro, Rio de Janeiro.

REDDY, J. N. A refined nonlinear theory of plates with transverse shear deformation. International Journal of Solids and Structures. v.20, p.881-896, 1984.

On locking-free shear deformable beam finite elements, Computer methods in applied mechanics and engineering, vol. 149, p. 113-132, 1997.

; WANG, C. M.; LEE, K. H. Relationships between bending solutions of classical and shear deformation beam theories. International Journal of Solids and Structures, vol. 34, n. 26, p. 3373-338, 1997.

SANTANA, M. V. B.; SILVEIRA, R. A. M. Sistema Computacional gráfico interativo para problemas de instabilidade em pórticos planos. In: XXXV Iberian Latin American Congress on Computational Methods in Engineering, Fortaleza, Brasil, 2014.

SCHRAMM, U.; KITIS, L.; KANG, W.; PILKEY, W. D. On the shear deformation coefficient in beam theory. Finite Elements in Analysis and Design. v.16, p.141-162, 1994.

SHRIMA, L. M.; GIGER M. W. Timoshenko beam element resting on twoparameter elastic foundation, Journal of Engineering Mechanics, vol. 118, n. 2, p. 280-295, 1992.

SILVA, J. L.; LEMES, I. J. M.; SILVEIRA, R. A. M.; SILVA, A. R. D. Influência da teoria de viga na análise geometricamente não linear de estruturas reticuladas. In: XXXVII Iberian Latin American Congress on Computational Methods in Engineering, Brasilia, Brasil, 2016. 
SO, A. K. W.; CHAN, S. L. Buckling and geometrically nonlinear analysis of frames using one element / member. Journal of Constructional Steel Research, vol. 20, p. 271-289, 1991.

TANG, Y. Q.; ZHOU, Z. H.; CHAN, S. L. Nonlinear beam-column element under consistent deformation. World Scientific Publishing Company, vol. 15, n.5, p. 123-144, 2015.

TEH, L. H.; CLARKE, M. J. Co-rotational and Lagrangian formulations for elastic three-dimensional beam finite elements. Journal of Constructional Steel Research, vol. 48, p. 123-144, 1998.

TESSlER, A.; GHERLONE, M. C. M. Refinement of Timoshenko beam theory for composite and sandwich beams using zigzag kinematics. Washington, DC: NASA, 2007. 45 p. (NASA TP-2007-215086).

TUDJONO, S.; HAN, A.; NGUYEN, D. K.; KIRYU, S.; GAN, B. S. Exact shape functions for Timoshenko beam element. Journal of Computer Engineering, vol. 19, n. 3, p. 12-20, 2017.

TIMOSHENKO, S. P.; GERE, J. M. Theory of Elastic Stability. 2.ed. McGraw Hill, Singapura, 1963.

TING, B. Y.; MOCKRY, E. F. Beam on elastic foundation finite element, Journal of Structural Engineering, vol. 110, n. 10, p. 2324-2339, 1984.

YANG, Y. B.; LEU, L. J. Non-linear stiffnesses in analysis of planar frames. Computer Methods in Applied Mechanics and Engineering, vol. 117, p. 233247, 1994.

YANG, Y. B.; KUO, S. R. Theory \& analysis of nonlinear framed structures, Prentice Hall, Simon \& Schuster (Asia) Pte 1td, Singapura, 1994.

YSHII, Y. Formulação Co-rotacional para pórticos planos. 2002. Dissertação (Mestrado em Engenharia) - Engenharia Aeronáutica e Mecânica, Instituto Tecnológioco de Aeronáutica, São José dos Campos.

YUNHUA, L. Explanation and elimination of shear locking and membrane locking with field consistence approach. Computer Methods in Applied Mechanics and Engineering, vol. 162, p. 249-269, 1998.

ZHAOHUA, F.; COOK, R. D. Beam elements on two-parameter elastic foundations. Journal of Engineering Mechanics, vol. 109, n. 6, p. 1390-1402, 1983.

ZUGIC, L.; BRCIC, S.; GOPCEVIC, S. Computer-based analysis of spatial frames according to second order theory. Gradevinar, vol. 68, n. 5, p. 381-398, 2016. 


\section{Apêndice A}

\section{Funções de Forma para Elementos Rotulados:}

Comportamento à Flexão

Para elementos articulados, as funções de forma desenvolvidas no trabalho se alteram. A Figura A.1 mostra a interpolação de deslocamentos realizada em uma barra rotulada (rótula na extremidade inicial). A dedução das funções de forma é realizada com a mesma metodologia utilizada no capítulo 3, entretanto, para se levar em consideração a presença da articulação em uma das extremidades do elemento também se utiliza a solução homogênea para momentos fletores.
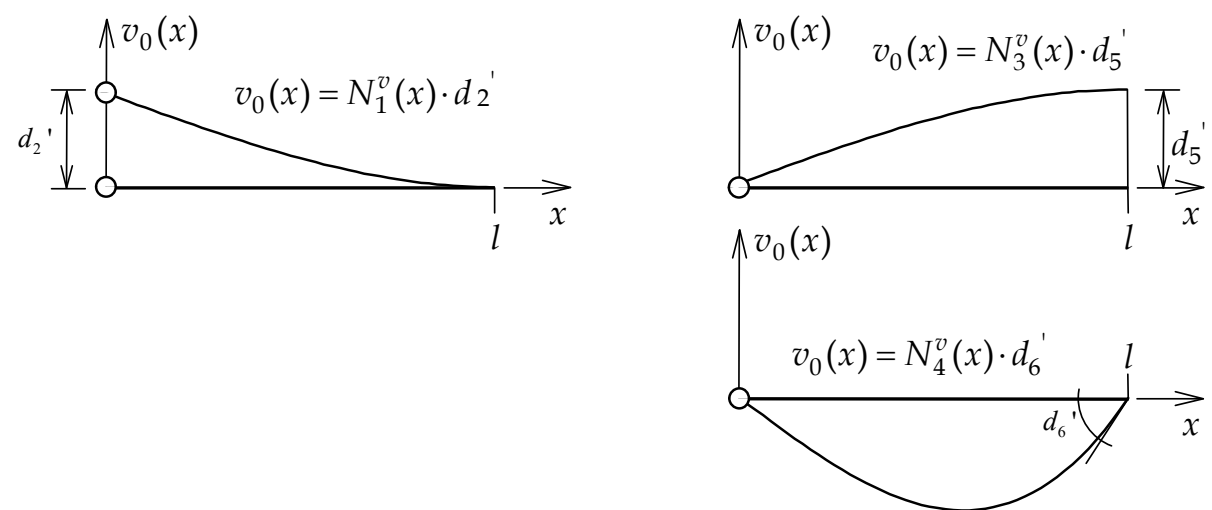

Figura A.1 - Interpolação de deslocamentos para barra articulada Fonte: Adaptada de Martha (2018).

\section{A.1}

Funções de Forma Segundo a Teoria de Euler-Bernoulli para Elemento na Configuração Indeformada (Rótula na Esquerda)

$$
\begin{gathered}
v_{h}(x)=c_{1}+c_{2} x+c_{3} \frac{x^{2}}{2}+c_{4} \frac{x^{3}}{6} \\
\theta_{h}(x)=c_{2}+c_{3} x+c_{4} \frac{x^{2}}{2} \\
\frac{M(x)}{E I}=\frac{d \theta_{h}(x)}{d x}=c_{3}+c_{4} x
\end{gathered}
$$




$$
\begin{gathered}
\left\{\begin{array}{c}
\boldsymbol{v}_{0}(\boldsymbol{x}) \\
\boldsymbol{\theta}(\boldsymbol{x}) \\
\boldsymbol{M}(\boldsymbol{x})
\end{array}\right\}=[\boldsymbol{X}] .\{\boldsymbol{C}\},\{\boldsymbol{C}\}=\left\{\begin{array}{l}
c_{1} \\
c_{2} \\
c_{3} \\
c_{4}
\end{array}\right\}, X=\left[\begin{array}{llll}
1 & x & x^{2} / 2 & x^{3} / 6 \\
0 & 1 & x & x^{2} / 2 \\
0 & 0 & 1 & x
\end{array}\right] \\
\left\{\boldsymbol{d}^{\prime}\right\}=\left\{\begin{array}{c}
d_{2}^{\prime} \\
0 \\
d_{5}^{\prime} \\
d_{6}^{\prime}
\end{array}\right\}=\left\{\begin{array}{c}
v_{0}(0) \\
v_{0}(L) / E I \\
\theta(L)
\end{array}\right\}=\left[\begin{array}{cccc}
1 & 0 & 0 & 0 \\
0 & 0 & 1 & 0 \\
1 & l & L^{2} / 2 & L^{3} / 6 \\
0 & 1 & l & L^{2} / 2
\end{array}\right] \cdot\left\{\begin{array}{l}
c_{1} \\
c_{2} \\
c_{3} \\
c_{4}
\end{array}\right\} \\
\rightarrow[\boldsymbol{H}] .\{\boldsymbol{C}\}=\left\{\boldsymbol{d}^{\prime}\right\} \\
N_{2}^{v}(x)=\frac{x^{3}}{2 L^{3}}-\frac{3 x^{2}}{2 L^{2}}+1 \quad N_{5}^{v}(x)=\frac{3 x}{2 L}-\frac{x^{3}}{2 L^{3}} \quad N_{6}^{v}(x)=\frac{x^{3}}{2 L^{2}}-\frac{x}{2} \\
N_{2}^{\theta}(x)=\frac{3 x^{2}}{2 L^{3}}-\frac{3}{2 L} \quad N_{5}^{\theta}(x)=\frac{3}{2 L}-\frac{3 x^{2}}{2 L^{3}} \quad N_{6}^{\theta}(x)=\frac{3 x^{2}}{2 L^{2}}-\frac{1}{2}
\end{gathered}
$$

\section{A.2}

Funções de Forma Segundo a Teoria de Euler-Bernoulli para Elemento na Configuração Indeformada (Rótula na Direita)

$$
\begin{aligned}
& v_{h}(x)=c_{1}+c_{2} x+c_{3} \frac{x^{2}}{2}+c_{4} \frac{x^{3}}{6} \\
& \theta_{h}(x)=c_{2}+c_{3} x+c_{4} \frac{x^{2}}{2} \\
& \frac{M(x)}{E I}=\frac{d \theta_{h}(x)}{d x}=c_{3}+c_{4} x \\
& \left\{\begin{array}{l}
\boldsymbol{v}_{\mathbf{0}}(\boldsymbol{x}) \\
\boldsymbol{\theta}(\boldsymbol{x}) \\
\boldsymbol{M}(\boldsymbol{x})
\end{array}\right\}=[\boldsymbol{X}] .\{\boldsymbol{C}\}, \quad\{\boldsymbol{C}\}=\left\{\begin{array}{l}
c_{1} \\
c_{2} \\
c_{3} \\
c_{4}
\end{array}\right\}, X=\left[\begin{array}{cccc}
1 & x & x^{2} / 2 & x^{3} / 6 \\
0 & 1 & x & x^{2} / 2 \\
0 & 0 & 1 & x
\end{array}\right] \\
& \left\{\boldsymbol{d}^{\prime}\right\}=\left\{\begin{array}{c}
d_{2}^{\prime} \\
d_{3}^{\prime} \\
d_{5}^{\prime} \\
0
\end{array}\right\}=\left\{\begin{array}{c}
v_{0}(0) \\
\theta(0) \\
v_{0}(L) \\
M(L) / E I
\end{array}\right\}=\left[\begin{array}{cccc}
1 & 0 & 0 & 0 \\
0 & 1 & 0 & 0 \\
1 & L & L^{2} / 2 & L^{3} / 6 \\
0 & 0 & 1 & L
\end{array}\right] \cdot\left\{\begin{array}{c}
c_{1} \\
c_{2} \\
c_{3} \\
c_{4}
\end{array}\right\}
\end{aligned}
$$




$$
\begin{gathered}
\rightarrow[H] \cdot\{\boldsymbol{C}\}=\left\{\boldsymbol{d}^{\prime}\right\} \\
\left\{\begin{array}{c}
\boldsymbol{v}_{\mathbf{0}}(\boldsymbol{x}) \\
\boldsymbol{\theta}(\boldsymbol{x})
\end{array}\right\}=[\boldsymbol{X}] \cdot[\boldsymbol{H}]^{-1} \cdot\left\{\boldsymbol{d}^{\prime}\right\} \Rightarrow[\boldsymbol{N}]=[\boldsymbol{X}] .[\boldsymbol{H}]^{-1} \\
N_{2}^{v}(x)=\frac{x^{3}}{2 L^{3}}-\frac{3 x^{2}}{2 L^{2}}+1 \quad N_{3}^{v}(x)=x-\frac{3 x^{2}}{2 L}+\frac{x^{3}}{2 L^{2}} \quad N_{5}^{v}(x)=\frac{3 x^{2}}{2 L^{2}}-\frac{x^{3}}{2 L^{3}} \\
N_{2}^{\theta}(x)=\frac{3 x^{2}}{2 L^{3}}-\frac{3 x}{L^{2}} \quad N_{3}^{\theta}(x)=\frac{3 x^{2}}{2 L^{2}}-\frac{3 x}{L}+1 \quad N_{5}^{\theta}(x)=\frac{3 x}{L^{2}}-\frac{3 x^{2}}{2 L^{3}}
\end{gathered}
$$

\section{A.3}

Funções de Forma Segundo a Teoria de Timoshenko para Elemento na Configuração Indeformada (Rótula na Esquerda)

$$
\begin{aligned}
& v_{h}(x)=c_{1}+c_{2} x+c_{3} \frac{x^{2}}{2}+c_{4}\left(\frac{x^{3}}{6}-L^{2} \Omega x\right) \\
& \theta_{h}(x)=c_{2}+c_{3} x+c_{4} \frac{x^{2}}{2} \\
& \frac{M(x)}{E I}=\frac{d \theta_{h}(x)}{d x}=c_{3}+c_{4} x \\
& \left\{\begin{array}{c}
\boldsymbol{v}_{\mathbf{0}}(\boldsymbol{x}) \\
\boldsymbol{\theta}(\boldsymbol{x}) \\
\boldsymbol{M}(\boldsymbol{x})
\end{array}\right\}=[\boldsymbol{X}] .\{\boldsymbol{C}\}, \quad\{\boldsymbol{C}\}=\left\{\begin{array}{l}
c_{1} \\
c_{2} \\
c_{3} \\
c_{4}
\end{array}\right\}, X=\left(\begin{array}{cccc}
1 & x & \frac{x^{2}}{2} & \frac{x^{3}}{6}-L^{2} \Omega x \\
0 & 1 & x & \frac{x^{2}}{2} \\
0 & 0 & 1 & x
\end{array}\right) \\
& \left\{\boldsymbol{d}^{\prime}\right\}=\left\{\begin{array}{c}
d_{2}^{\prime} \\
0 \\
d_{5}^{\prime} \\
d_{6}^{\prime}
\end{array}\right\}=\left\{\begin{array}{c}
v_{0}(0) \\
M(0) / E I \\
v_{0}(L) \\
\theta(L)
\end{array}\right\}=\left(\begin{array}{cccc}
1 & 0 & 0 & 0 \\
0 & 0 & 1 & 0 \\
1 & L & \frac{L^{2}}{2} & \frac{L^{3}}{6}-L^{3} \Omega \\
0 & 1 & L & \frac{L^{2}}{2}
\end{array}\right) \cdot\left\{\begin{array}{c}
c_{1} \\
c_{2} \\
c_{3} \\
c_{4}
\end{array}\right\} \\
& \rightarrow[\boldsymbol{H}] .\{\boldsymbol{C}\}=\left\{\boldsymbol{d}^{\prime}\right\} \\
& \left\{\begin{array}{c}
\boldsymbol{v}_{0}(x) \\
\theta(x)
\end{array}\right\}=[X] \cdot[H]^{-1} \cdot\left\{d^{\prime}\right\} \Rightarrow[N]=[X] \cdot[H]^{-1} \\
& N_{2}^{v}(x)=-\frac{(L-x)\left(L x-6 L^{2} \Omega-2 L^{2}+x^{2}\right)}{2 L^{3}(3 \Omega+1)}
\end{aligned}
$$


Apêndice A

Funções de Forma para Elementos Rotulados: Comportamento à Flexão

$$
\begin{gathered}
N_{5}^{v}(x)=\frac{x\left(6 L^{2} \Omega+3 L^{2}-x^{2}\right)}{2 L^{3}(3 \Omega+1)} \\
N_{6}^{v}(x)=-\frac{x\left(L^{2}-x^{2}\right)}{2 L^{2}(3 \Omega+1)} \\
N_{2}^{\theta}(x)=-\frac{3\left(L^{2}-x^{2}\right)}{2 L^{3}(3 \Omega+1)} \quad N_{5}^{\theta}(x)=\frac{3\left(L^{2}-x^{2}\right)}{2 L^{3}(3 \Omega+1)} \\
N_{6}^{\theta}(x)=\frac{6 L^{2} \Omega-L^{2}+3 x^{2}}{2 L^{2}(3 \Omega+1)}
\end{gathered}
$$

\section{A.4}

Funções de Forma Segundo a Teoria de Timoshenko para Elemento na Configuração Indeformada (Rótula na Direita)

$$
\begin{aligned}
& v_{h}(x)=c_{1}+c_{2} x+c_{3} \frac{x^{2}}{2}+c_{4}\left(\frac{x^{3}}{6}-L^{2} \Omega x\right) \\
& \theta_{h}(x)=c_{2}+c_{3} x+c_{4} \frac{x^{2}}{2} \\
& \frac{M(x)}{E I}=\frac{d \theta_{h}(x)}{d x}=c_{3}+c_{4} x \\
& \left\{\begin{array}{c}
\boldsymbol{v}_{0}(\boldsymbol{x}) \\
\boldsymbol{\theta}(\boldsymbol{x}) \\
\boldsymbol{M}(\boldsymbol{x})
\end{array}\right\}=[\boldsymbol{X}] .\{\boldsymbol{C}\}, \quad\{\boldsymbol{C}\}=\left\{\begin{array}{l}
c_{1} \\
c_{2} \\
c_{3} \\
c_{4}
\end{array}\right\}, X=\left(\begin{array}{cccc}
1 & x & \frac{x^{2}}{2} & \frac{x^{3}}{6}-L^{2} \Omega x \\
0 & 1 & x & \frac{x^{2}}{2} \\
0 & 0 & 1 & x
\end{array}\right) \\
& \left\{\boldsymbol{d}^{\prime}\right\}=\left\{\begin{array}{c}
d_{2}^{\prime} \\
d_{3}^{\prime} \\
d_{5}^{\prime} \\
0
\end{array}\right\}=\left\{\begin{array}{c}
v_{0}(0) \\
\theta(0) \\
v_{0}(L) \\
M(L) / E I
\end{array}\right\}=\left(\begin{array}{cccc}
1 & 0 & 0 & 0 \\
0 & 1 & 0 & 0 \\
1 & L & \frac{L^{2}}{2} & \frac{L^{3}}{6}-L^{3} \Omega \\
0 & 0 & 1 & L
\end{array}\right) \cdot\left\{\begin{array}{c}
c_{1} \\
c_{2} \\
c_{3} \\
c_{4}
\end{array}\right\} \\
& \rightarrow[\boldsymbol{H}] .\{\boldsymbol{C}\}=\left\{\boldsymbol{d}^{\prime}\right\} \\
& \left\{\begin{array}{c}
\boldsymbol{v}_{\mathbf{0}}(\boldsymbol{x}) \\
\boldsymbol{\theta}(\boldsymbol{x})
\end{array}\right\}=[X] \cdot[H]^{-1} \cdot\left\{\mathrm{d}^{\prime}\right\} \Rightarrow[\boldsymbol{N}]=[\mathrm{X}] \cdot[\boldsymbol{H}]^{-1}
\end{aligned}
$$


Apêndice A

$$
\begin{gathered}
N_{2}^{v}(x)=\frac{(L-x)\left(2 L x+6 L^{2} \Omega+2 L^{2}-x^{2}\right)}{2 L^{3}(3 \Omega+1)} \\
N_{3}^{v}(x)=\frac{x\left(2 L^{2}-3 L x+x^{2}\right)}{2 L^{2}(3 \Omega+1)} \\
N_{5}^{v}(x)=\frac{x\left(6 \Omega L^{2}+3 L x-x^{2}\right)}{2 L^{3}(3 \Omega+1)} \\
N_{2}^{\theta}(x)=-\frac{3 x(2 L-x)}{2 L^{3}(3 \Omega+1)} \\
N_{3}^{\theta}(x)=\frac{6 L^{2} \Omega-6 L x+2 L^{2}+3 x^{2}}{2 L^{2}(3 \Omega+1)} \\
N_{5}^{\theta}(x)=\frac{3 x(2 L-x)}{2 L^{3}(3 \Omega+1)}
\end{gathered}
$$

\section{A.5 \\ Funções de Forma Segundo a Teoria de Euler-Bernoulli para \\ Elemento na Configuração Deformada (Rótula na Esquerda)}

Tração:

$$
\begin{aligned}
& v_{h}(x)=c_{1} \sinh (\mu x)+c_{2} \cosh (\mu x)+c_{3} x+c_{4} \\
& \theta_{h}(x)=c_{1} \mu \cosh (\mu x)+c_{2} \mu \sinh (\mu x)+c_{3} \\
& \frac{M(x)}{E I}=\frac{d \theta_{h}(x)}{d x}=C_{2} \mu^{2} \cosh (\mu x)+C_{1} \mu^{2} \sinh (\mu x) \\
& \left\{\begin{array}{c}
\boldsymbol{v}_{\mathbf{0}}(\boldsymbol{x}) \\
\boldsymbol{\theta}(\boldsymbol{x}) \\
\boldsymbol{M}(\boldsymbol{x})
\end{array}\right\}=[\boldsymbol{X}] .\{\boldsymbol{C}\}, \quad\{\boldsymbol{C}\}=\left\{\begin{array}{l}
c_{1} \\
c_{2} \\
c_{3} \\
c_{4}
\end{array}\right\}, X=\left(\begin{array}{cccc}
\sinh (\mu x) & \cosh (\mu x) & x & 1 \\
\mu \cosh (\mu x) & \mu \sinh (\mu x) & 1 & 0 \\
\mu^{2} \sinh (\mu x) & \mu^{2} \cosh (\mu x) & 0 & 0
\end{array}\right) \\
& \left\{\boldsymbol{d}^{\prime}\right\}=\left\{\begin{array}{c}
d_{2}^{\prime} \\
0 \\
d_{5}^{\prime} \\
d_{6}^{\prime}
\end{array}\right\}=\left\{\begin{array}{c}
v_{0}(0) \\
M(0) / E I \\
v_{0}(L) \\
\theta(L)
\end{array}\right\}=\left(\begin{array}{cccc}
0 & 1 & 0 & 1 \\
0 & \mu^{2} & 0 & 0 \\
\sinh (L \mu) & \cosh (L \mu) & L & 1 \\
\mu \cosh (L \mu) & \mu \sinh (L \mu) & 1 & 0
\end{array}\right) \cdot\left\{\begin{array}{c}
c_{1} \\
c_{2} \\
c_{3} \\
c_{4}
\end{array}\right\} \\
& \rightarrow[\boldsymbol{H}] .\{\boldsymbol{C}\}=\left\{\boldsymbol{d}^{\prime}\right\}
\end{aligned}
$$




$$
\begin{gathered}
\left\{\begin{array}{c}
\boldsymbol{v}_{\mathbf{0}}(\boldsymbol{x}) \\
\boldsymbol{\theta}(\boldsymbol{x})
\end{array}\right\}=[\boldsymbol{X}] \cdot[\boldsymbol{H}]^{-1} \cdot\left\{\boldsymbol{d}^{\prime}\right\} \Rightarrow[\boldsymbol{N}]=[\boldsymbol{X}] \cdot[\boldsymbol{H}]^{-1} \\
N_{2}^{v}(x)=\frac{\sinh (L \mu)-\sinh (\mu x)-L \mu \cosh (L \mu)+\mu x \cosh (L \mu)}{\sinh (L \mu)-L \mu \cosh (L \mu)} \\
N_{5}^{v}(x)=\frac{\sinh (\mu x)-\mu x \cosh (L \mu)}{\sinh (L \mu)-L \mu \cosh (L \mu)} \\
N_{6}^{v}(x)=-\frac{L \sinh (\mu x)-x \sinh (L \mu)}{\sinh (L \mu)-L \mu \cosh (L \mu)} \\
N_{2}^{\theta}(x)=\frac{\mu(\cosh (L \mu)-\cosh (\mu x))}{\sinh (L \mu)-L \mu \cosh (L \mu)} \\
N_{5}^{\theta}(x)=-\frac{\mu(\cosh (L \mu)-\cosh (\mu x))}{\sinh (L \mu)-L \mu \cosh (L \mu)} \\
N_{6}^{\theta}(x)=\frac{\sinh (L \mu)-L \mu \cosh (\mu x)}{\sinh (L \mu)-L \mu \cosh (L \mu)}
\end{gathered}
$$

Compressão:

$$
\begin{gathered}
v_{h}(x)=c_{1} \sin (\mu x)+c_{2} \cos (\mu x)+c_{3} x+c_{4} \\
\theta_{h}(x)=c_{1} \mu \cos (\mu x)-c_{2} \mu \operatorname{senh}(\mu x)+c_{3} \\
\frac{M(x)}{E I}=\frac{d \theta_{h}(x)}{d x}=-C_{2} \mu^{2} \cos (\mu x)-C_{1} \mu^{2} \sin (\mu x)
\end{gathered}
$$

$$
\begin{aligned}
& \left\{\begin{array}{l}
\boldsymbol{v}_{\mathbf{0}}(\boldsymbol{x}) \\
\boldsymbol{\theta}(\boldsymbol{x}) \\
\boldsymbol{M}(\boldsymbol{x})
\end{array}\right\}=[\boldsymbol{X}] .\{\boldsymbol{C}\}, \quad\{\boldsymbol{C}\}=\left\{\begin{array}{l}
c_{1} \\
c_{2} \\
c_{3} \\
c_{4}
\end{array}\right\}, X=\left(\begin{array}{cccc}
\sin (\mu x) & \cos (\mu x) & x & 1 \\
\mu \cos (\mu x) & -\mu \sin (\mu x) & 1 & 0 \\
-\mu^{2} \sin (\mu x) & -\mu^{2} \cos (\mu x) & 0 & 0
\end{array}\right) \\
& \left\{\boldsymbol{d}^{\prime}\right\}=\left\{\begin{array}{c}
d_{2}^{\prime} \\
0 \\
d_{5}^{\prime} \\
d_{6}^{\prime}
\end{array}\right\}=\left\{\begin{array}{c}
v_{0}(0) \\
M(0) / E I \\
v_{0}(L) \\
\theta(L)
\end{array}\right\}=\left(\begin{array}{cccc}
0 & 1 & 0 & 1 \\
0 & -\mu^{2} & 0 & 0 \\
\sin (L \mu) & \cos (L \mu) & L & 1 \\
\mu \cos (L \mu) & -\mu \sin (L \mu) & 1 & 0
\end{array}\right) \cdot\left\{\begin{array}{c}
c_{1} \\
c_{2} \\
c_{3} \\
c_{4}
\end{array}\right\} \\
& \rightarrow[\boldsymbol{H}] .\{\boldsymbol{C}\}=\left\{\boldsymbol{d}^{\prime}\right\} \\
& \left\{\begin{array}{c}
\boldsymbol{v}_{0}(x) \\
\theta(x)
\end{array}\right\}=[X] \cdot[H]^{-1} \cdot\left\{d^{\prime}\right\} \Rightarrow[N]=[X] .[H]^{-1}
\end{aligned}
$$




$$
\begin{gathered}
N_{2}^{v}(x)=\frac{\sin (L \mu)-\sin (\mu x)-L \mu \cos (L \mu)+\mu x \cos (L \mu)}{\sin (L \mu)-L \mu \cos (L \mu)} \\
N_{5}^{v}(x)=\frac{\sin (\mu x)-\mu x \cos (L \mu)}{\sin (L \mu)-L \mu \cos (L \mu)} \\
N_{6}^{v}(x)=-\frac{L \sin (\mu x)-x \sin (L \mu)}{\sin (L \mu)-L \mu \cos (L \mu)} \\
N_{2}^{\theta}(x)=\frac{\mu(\cos (L \mu)-\cos (\mu x))}{\sin (L \mu)-L \mu \cos (L \mu)} \\
N_{5}^{\theta}(x)=-\frac{\mu(\cos (L \mu)-\cos (\mu x))}{\sin (L \mu)-L \mu \cos (L \mu)} \\
N_{6}^{\theta}(x)=\frac{\sin (L \mu)-L \mu \cos (\mu x)}{\sin (L \mu)-L \mu \cos (L \mu)}
\end{gathered}
$$

\section{A.6}

Funções de Forma Segundo a Teoria de Euler-Bernoulli para Elemento na Configuração Deformada (Rótula na Direita)

Tração:

$$
\begin{aligned}
& v_{h}(x)=c_{1} \sinh (\mu x)+c_{2} \cosh (\mu x)+c_{3} x+c_{4} \\
& \theta_{h}(x)=c_{1} \mu \cosh (\mu x)+c_{2} \mu \sinh (\mu x)+c_{3} \\
& \frac{M(x)}{E I}=\frac{d \theta_{h}(x)}{d x}=C_{2} \mu^{2} \cosh (\mu x)+C_{1} \mu^{2} \sinh (\mu x) \\
& \left\{\begin{array}{c}
\boldsymbol{v}_{\mathbf{0}}(\boldsymbol{x}) \\
\boldsymbol{\theta}(\boldsymbol{x}) \\
\boldsymbol{M}(\boldsymbol{x})
\end{array}\right\}=[\boldsymbol{X}] .\{\boldsymbol{C}\}, \quad\{\boldsymbol{C}\}=\left\{\begin{array}{l}
c_{1} \\
c_{2} \\
c_{3} \\
c_{4}
\end{array}\right\}, X=\left(\begin{array}{cccc}
\sinh (\mu x) & \cosh (\mu x) & x & 1 \\
\mu \cosh (\mu x) & \mu \sinh (\mu x) & 1 & 0 \\
\mu^{2} \sinh (\mu x) & \mu^{2} \cosh (\mu x) & 0 & 0
\end{array}\right) \\
& \left\{\boldsymbol{d}^{\prime}\right\}=\left\{\begin{array}{c}
d_{2}^{\prime} \\
d_{3}^{\prime} \\
d_{5}^{\prime} \\
0
\end{array}\right\}=\left\{\begin{array}{c}
v_{0}(0) \\
\theta(0) \\
v_{0}(L) \\
M(L) / E I
\end{array}\right\}=\left(\begin{array}{cccc}
0 & 1 & 0 & 1 \\
\mu & 0 & 1 & 0 \\
\sinh (L \mu) & \cosh (L \mu) & L & 1 \\
\mu^{2} \sinh (L \mu) & \mu^{2} \cosh (L \mu) & 0 & 0
\end{array}\right) \cdot\left\{\begin{array}{c}
c_{1} \\
c_{2} \\
c_{3} \\
c_{4}
\end{array}\right\} \\
& \rightarrow[\boldsymbol{H}] .\{\boldsymbol{C}\}=\left\{\boldsymbol{d}^{\prime}\right\}
\end{aligned}
$$




$$
\begin{gathered}
\left\{\begin{array}{c}
\boldsymbol{v}_{\mathbf{0}}(\boldsymbol{x}) \\
\boldsymbol{\theta}(\boldsymbol{x})
\end{array}\right\}=[\boldsymbol{X}] \cdot[\boldsymbol{H}]^{-1} \cdot\left\{\boldsymbol{d}^{\prime}\right\} \Rightarrow[\boldsymbol{N}]=[\boldsymbol{X}] \cdot[\boldsymbol{H}]^{-1} \\
N_{2}^{v}(x)=\frac{\sinh (\mu(L-x))-L \mu \cosh (L \mu)+\mu x \cosh (L \mu)}{\sinh (L \mu)-L \mu \cosh (L \mu)} \\
N_{3}^{v}(x)=\frac{x \sinh (L \mu)-L \sinh (L \mu)+L \sinh (\mu(L-x))}{\sinh (L \mu)-L \mu \cosh (L \mu)} \\
N_{5}^{v}(x)=-\frac{\sinh (\mu(L-x))-\sinh (L \mu)+\mu x \cosh (L \mu)}{\sinh (L \mu)-L \mu \cosh (L \mu)} \\
N_{2}^{\theta}(x)=\frac{\mu(\cosh (L \mu)-\cosh (\mu(L-x)))}{\sinh (L \mu)-L \mu \cosh (L \mu)} \\
N_{3}^{\theta}(x)=\frac{\sinh (L \mu)-L \mu \cosh (\mu(L-x))}{\sinh (L \mu)-L \mu \cosh (L \mu)} \\
N_{5}^{\theta}(x)=-\frac{\mu(\cosh (L \mu)-\cosh (\mu(L-x)))}{\sinh (L \mu)-L \mu \cosh (L \mu)}
\end{gathered}
$$

Compressão

$$
\begin{gathered}
v_{h}(x)=c_{1} \sin (\mu x)+c_{2} \cos (\mu x)+c_{3} x+c_{4} \\
\theta_{h}(x)=c_{1} \mu \cos (\mu x)-c_{2} \mu \operatorname{senh}(\mu x)+c_{3} \\
\frac{M(x)}{E I}=\frac{d \theta_{h}(x)}{d x}=-C_{2} \mu^{2} \cos (\mu x)-C_{1} \mu^{2} \sin (\mu x)
\end{gathered}
$$

$$
\begin{gathered}
\left\{\begin{array}{c}
\boldsymbol{v}_{\mathbf{0}}(\boldsymbol{x}) \\
\boldsymbol{\theta}(\boldsymbol{x}) \\
\boldsymbol{M}(\boldsymbol{x})
\end{array}\right\}=[\boldsymbol{X}] .\{\boldsymbol{C}\},\{\boldsymbol{C}\}=\left\{\begin{array}{l}
c_{1} \\
c_{2} \\
c_{3} \\
c_{4}
\end{array}\right\}, X=\left(\begin{array}{cccc}
\sin (\mu x) & \cos (\mu x) & x & 1 \\
\mu \cos (\mu x) & -\mu \sin (\mu x) & 1 & 0 \\
-\mu^{2} \sin (\mu x) & -\mu^{2} \cos (\mu x) & 0 & 0
\end{array}\right) \\
\left\{\boldsymbol{d}^{\prime}\right\}=\left\{\begin{array}{l}
d_{2}^{\prime} \\
d_{3}^{\prime} \\
d_{5}^{\prime} \\
0
\end{array}\right\}=\left\{\begin{array}{c}
v_{0}(0) \\
\theta(0) \\
v_{0}(L) \\
M(L) / E I
\end{array}\right\}=\left(\begin{array}{cccc}
0 & 1 & 0 & 1 \\
\mu & 0 & 1 & 0 \\
\sin (L \mu) & \cos (L \mu) & L & 1 \\
-\mu^{2} \sin (L \mu) & -\mu^{2} \cos (L \mu) & 0 & 0
\end{array}\right) \cdot\left\{\begin{array}{l}
c_{1} \\
c_{2} \\
c_{3} \\
c_{4}
\end{array}\right\} \\
\rightarrow[\boldsymbol{H}] .\{\boldsymbol{C}\}=\left\{\boldsymbol{d}^{\prime}\right\} \\
\left\{\begin{array}{c}
\boldsymbol{v}_{\mathbf{0}}(\boldsymbol{x}) \\
\boldsymbol{\theta}(\boldsymbol{x})
\end{array}\right\}=[\boldsymbol{X}] .[\boldsymbol{H}]^{-1} \cdot\left\{\boldsymbol{d}^{\prime}\right\} \Rightarrow[\boldsymbol{N}]=[\boldsymbol{X}] .[\boldsymbol{H}]^{-1}
\end{gathered}
$$




$$
\begin{gathered}
N_{2}^{v}(x)=\frac{\sin (\mu(L-x))-L \mu \cos (L \mu)+\mu x \cos (L \mu)}{\sin (L \mu)-L \mu \cos (L \mu)} \\
N_{3}^{v}(x)=\frac{x \sin (L \mu)-L \sin (L \mu)+L \sin (\mu(L-x))}{\sin (L \mu)-L \mu \cos (L \mu)} \\
N_{5}^{v}(x)=-\frac{\sin (\mu(L-x))-\sin (L \mu)+\mu x \cos (L \mu)}{\sin (L \mu)-L \mu \cos (L \mu)} \\
N_{2}^{\theta}(x)=\frac{\mu(\cos (L \mu)-\cos (\mu(L-x)))}{\sin (L \mu)-L \mu \cos (L \mu)} \\
N_{3}^{\theta}(x)=\frac{\sin (L \mu)-L \mu \cos (\mu(L-x))}{\sin (L \mu)-L \mu \cos (L \mu)} \\
N_{5}^{\theta}(x)=-\frac{\mu(\cos (L \mu)-\cos (\mu(L-x)))}{\sin (L \mu)-L \mu \cos (L \mu)}
\end{gathered}
$$

\section{A.7 \\ Funções de Forma Segundo a Teoria de Timoshenko para Elemento na Configuração Deformada (Rótula na Esquerda)}

Tração:

$$
\begin{aligned}
& v_{h}(x)=\left(1-\Omega L^{2} \Lambda^{2}\right)\left[c_{1} \sinh (\Lambda x)+c_{2} \cosh (\Lambda x)\right]+c_{3} x+c_{4} \\
& \theta_{h}(x)=\Lambda\left[c_{1} \cosh (\Lambda x)+c_{2} \operatorname{senh}(\Lambda x)\right]+c_{3} \\
& \frac{M(x)}{E I}=\frac{d \theta_{h}(x)}{d x}=\Lambda\left(C_{2} \Lambda \cosh (\Lambda x)+C_{1} \Lambda \sinh (\Lambda x)\right) \\
& \left\{\begin{array}{c}
\boldsymbol{v}_{\mathbf{0}}(\boldsymbol{x}) \\
\boldsymbol{\theta}(\boldsymbol{x}) \\
\boldsymbol{M}(\boldsymbol{x})
\end{array}\right\}=[\boldsymbol{X}] .\{\boldsymbol{C}\}, \quad\{\boldsymbol{C}\}=\left\{\begin{array}{l}
c_{1} \\
c_{2} \\
c_{3} \\
c_{4}
\end{array}\right\} \\
& \left(\begin{array}{cccc}
-\sinh (\Lambda x)\left(L^{2} \Lambda^{2} \Omega-1\right) & -\cosh (\Lambda x)\left(L^{2} \Lambda^{2} \Omega-1\right) & x & 1 \\
\Lambda \cosh (\Lambda x) & \Lambda \sinh (\Lambda x) & 1 & 0 \\
\Lambda^{2} \sinh (\Lambda x) & \Lambda^{2} \cosh (\Lambda x) & 0 & 0
\end{array}\right) \cdot\left\{\begin{array}{l}
c_{1} \\
c_{2} \\
c_{3} \\
c_{4}
\end{array}\right\} \\
& \left\{\boldsymbol{d}^{\prime}\right\}=\left\{\begin{array}{c}
d_{2}^{\prime} \\
0 \\
d_{5}^{\prime} \\
d_{6}^{\prime}
\end{array}\right\}=\left\{\begin{array}{c}
v_{0}(0) \\
M(0) / E I \\
v_{0}(L) \\
\theta(L)
\end{array}\right\}=
\end{aligned}
$$




$$
\begin{gathered}
\left\{\begin{array}{cccc}
0 & 1-L^{2} \Lambda^{2} \Omega & 0 & 1 \\
0 & \Lambda^{2} & 0 & 0 \\
-\sinh (L \Lambda)\left(L^{2} \Lambda^{2} \Omega-1\right) & -\cosh (L \Lambda)\left(L^{2} \Lambda^{2} \Omega-1\right) & L & 1 \\
\Lambda \cosh (L \Lambda) & \Lambda \sinh (L \Lambda) & 1 & 0
\end{array}\right) \cdot\left\{\begin{array}{l}
c_{1} \\
c_{2} \\
c_{3} \\
c_{4}
\end{array}\right\} \\
\rightarrow[\boldsymbol{H}] \cdot\{\boldsymbol{C}\}=\left\{\boldsymbol{d}^{\prime}\right\} \\
\left.\begin{array}{c}
\boldsymbol{v}_{\mathbf{0}}(\boldsymbol{x}) \\
\boldsymbol{\theta}(\boldsymbol{x})
\end{array}\right\}=[\boldsymbol{X}] \cdot[\boldsymbol{H}]^{-1} \cdot\left\{\boldsymbol{d}^{\prime}\right\} \Rightarrow[\boldsymbol{N}]=[\boldsymbol{X}] \cdot[\boldsymbol{H}]^{-1} \\
N_{2}^{v}(x)=-\frac{\sinh (L \Lambda)-\sinh (\Lambda x)-L \Lambda \cosh (L \Lambda)+\Lambda x \cosh (L \Lambda)-L^{2} \Lambda^{2} \Omega \sinh (L \Lambda)+L^{2} \Lambda^{2} \Omega \sinh (\Lambda x)}{L \Lambda \cosh (L \Lambda)-\sinh (L \Lambda)+L^{2} \Lambda^{2} \Omega \sinh (L \Lambda)} \\
N_{5}^{v}(x)=\frac{\Lambda x \cosh (L \Lambda)-\sinh (\Lambda x)+L^{2} \Lambda^{2} \Omega \sinh (\Lambda x)}{L \Lambda \cosh (L \Lambda)-\sinh (L \Lambda)+L^{2} \Lambda^{2} \Omega \sinh (L \Lambda)} \\
N_{6}^{v}(x)=-\frac{\left(L^{2} \Lambda^{2} \Omega-1\right)(L \sinh (\Lambda x)-x \sinh (L \Lambda))}{L \Lambda \cosh (L \Lambda)-\sinh (L \Lambda)+L^{2} \Lambda^{2} \Omega \sinh (L \Lambda)} \\
N_{2}^{\theta}(x)=-\frac{L \Lambda \cosh (\Lambda x)-\sinh (L \Lambda)+L^{2} \Lambda^{2} \Omega \sinh (L \Lambda)}{L \Lambda \cosh (L \Lambda)-\sinh (L \Lambda)+L^{2} \Lambda^{2} \Omega \sinh (L \Lambda)} \\
N_{5}^{\theta}(x)=\frac{\Lambda(\cosh (L \Lambda)-\cosh (\Lambda x))}{L \Lambda \cosh (L \Lambda)-\sinh (L \Lambda)+L^{2} \Lambda^{2} \Omega \sinh (L \Lambda)}
\end{gathered}
$$

Compressão:

$$
\begin{aligned}
& v_{h}(x)=\left(1+\Omega L^{2} \Lambda^{2}\right)\left[c_{1} \sin (\Lambda x)+c_{2} \cos (\Lambda x)\right]+c_{3} x+c_{4} \\
& \theta_{h}(x)=\Lambda\left[c_{1} \cos (\Lambda x)-c_{2} \operatorname{sen}(\Lambda x)\right]+c_{3} \\
& \frac{M(x)}{E I}=\frac{d \theta_{h}(x)}{d x}=-\Lambda\left(C_{2} \Lambda \cos (\Lambda x)+C_{1} \Lambda \sin (\Lambda x)\right) \\
& \left\{\begin{array}{l}
\boldsymbol{v}_{\mathbf{0}}(\boldsymbol{x}) \\
\boldsymbol{\theta}(\boldsymbol{x}) \\
\boldsymbol{M}(\boldsymbol{x})
\end{array}\right\}=[\boldsymbol{X}] .\{\boldsymbol{C}\}, \quad\{\boldsymbol{C}\}=\left\{\begin{array}{l}
c_{1} \\
c_{2} \\
c_{3} \\
c_{4}
\end{array}\right\} \\
& \left(\begin{array}{cccc}
\sin (\Lambda x)\left(\Omega L^{2} \Lambda^{2}+1\right) & \cos (\Lambda x)\left(\Omega L^{2} \Lambda^{2}+1\right) & x & 1 \\
\Lambda \cos (\Lambda x) & -\Lambda \sin (\Lambda x) & 1 & 0 \\
-\Lambda^{2} \sin (\Lambda x) & -\Lambda^{2} \cos (\Lambda x) & 0 & 0
\end{array}\right) \cdot\left\{\begin{array}{l}
c_{1} \\
c_{2} \\
c_{3} \\
c_{4}
\end{array}\right\}
\end{aligned}
$$




$$
\begin{aligned}
& \left\{\boldsymbol{d}^{\prime}\right\}=\left\{\begin{array}{c}
d_{2}^{\prime} \\
0 \\
d_{5}^{\prime} \\
d_{6}^{\prime}
\end{array}\right\}=\left\{\begin{array}{c}
v_{0}(0) \\
M(0) / E I \\
v_{0}(L) \\
\theta(L)
\end{array}\right\}= \\
& \left(\begin{array}{cccc}
0 & \Omega L^{2} \Lambda^{2}+1 & 0 & 1 \\
0 & -\Lambda^{2} & 0 & 0 \\
\sin (L \Lambda)\left(\Omega L^{2} \Lambda^{2}+1\right) & \cos (L \Lambda)\left(\Omega L^{2} \Lambda^{2}+1\right) & L & 1 \\
\Lambda \cos (L \Lambda) & -\Lambda \sin (L \Lambda) & 1 & 0
\end{array}\right) \cdot\left\{\begin{array}{l}
c_{1} \\
c_{2} \\
c_{3} \\
c_{4}
\end{array}\right\} \\
& \rightarrow[\boldsymbol{H}] .\{\boldsymbol{C}\}=\left\{\boldsymbol{d}^{\prime}\right\} \\
& \left\{\begin{array}{c}
\boldsymbol{v}_{0}(x) \\
\theta(x)
\end{array}\right\}=[X] \cdot[H]^{-1} \cdot\left\{d^{\prime}\right\} \Rightarrow[N]=[X] \cdot[H]^{-1} \\
& N_{2}^{v}(x)=\frac{\sin (L \Lambda)-\sin (\Lambda x)-L \Lambda \cos (L \Lambda)+\Lambda x \cos (L \Lambda)+L^{2} \Lambda^{2} \Omega \sin (L \Lambda)-L^{2} \Lambda^{2} \Omega \sin (\Lambda x)}{\sin (L \Lambda)-L \Lambda \cos (L \Lambda)+L^{2} \Lambda^{2} \Omega \sin (L \Lambda)} \\
& N_{5}^{v}(x)=\frac{\sin (\Lambda x)-\Lambda x \cos (L \Lambda)+L^{2} \Lambda^{2} \Omega \sin (\Lambda x)}{\sin (L \Lambda)-L \Lambda \cos (L \Lambda)+L^{2} \Lambda^{2} \Omega \sin (L \Lambda)} \\
& N_{6}^{v}(x)=-\frac{\left(\Omega L^{2} \Lambda^{2}+1\right)(L \sin (\Lambda x)-x \sin (L \Lambda))}{\sin (L \Lambda)-L \Lambda \cos (L \Lambda)+L^{2} \Lambda^{2} \Omega \sin (L \Lambda)} \\
& N_{2}^{\theta}(x)=\frac{\Lambda(\cos (L \Lambda)-\cos (\Lambda x))}{\sin (L \Lambda)-L \Lambda \cos (L \Lambda)+L^{2} \Lambda^{2} \Omega \sin (L \Lambda)} \\
& N_{5}^{\theta}(x)=-\frac{\Lambda(\cos (L \Lambda)-\cos (\Lambda x))}{\sin (L \Lambda)-L \Lambda \cos (L \Lambda)+L^{2} \Lambda^{2} \Omega \sin (L \Lambda)} \\
& N_{6}^{\theta}(x)=\frac{\sin (L \Lambda)-L \Lambda \cos (\Lambda x)+L^{2} \Lambda^{2} \Omega \sin (L \Lambda)}{\sin (L \Lambda)-L \Lambda \cos (L \Lambda)+L^{2} \Lambda^{2} \Omega \sin (L \Lambda)}
\end{aligned}
$$

\section{A.8 \\ Funções de Forma Segundo a Teoria de Timoshenko para Elemento na Configuração Indeformada (Rótula na Direita)}

Tração:

$$
\begin{gathered}
v_{h}(x)=\left(1-\Omega L^{2} \Lambda^{2}\right)\left[c_{1} \sinh (\Lambda x)+c_{2} \cosh (\Lambda x)\right]+c_{3} x+c_{4} \\
\theta_{h}(x)=\Lambda\left[c_{1} \cosh (\Lambda x)+c_{2} \operatorname{senh}(\Lambda x)\right]+c_{3} \\
\frac{M(x)}{E I}=\frac{d \theta_{h}(x)}{d x}=\Lambda\left(C_{2} \Lambda \cosh (\Lambda x)+C_{1} \Lambda \sinh (\Lambda x)\right)
\end{gathered}
$$




$$
\begin{aligned}
& \left\{\begin{array}{c}
\boldsymbol{v}_{\mathbf{0}}(\boldsymbol{x}) \\
\boldsymbol{\theta}(\boldsymbol{x}) \\
\boldsymbol{M}(\boldsymbol{x})
\end{array}\right\}=[\boldsymbol{X}] .\{\boldsymbol{C}\}, \quad\{\boldsymbol{C}\}=\left\{\begin{array}{l}
c_{1} \\
c_{2} \\
c_{3} \\
c_{4}
\end{array}\right\} \\
& \left(\begin{array}{cccc}
-\sinh (\Lambda x)\left(L^{2} \Lambda^{2} \Omega-1\right) & -\cosh (\Lambda x)\left(L^{2} \Lambda^{2} \Omega-1\right) & x & 1 \\
\Lambda \cosh (\Lambda x) & \Lambda \sinh (\Lambda x) & 1 & 0 \\
\Lambda^{2} \sinh (\Lambda x) & \Lambda^{2} \cosh (\Lambda x) & 0 & 0
\end{array}\right) \cdot\left\{\begin{array}{l}
c_{1} \\
c_{2} \\
c_{3} \\
c_{4}
\end{array}\right\} \\
& \left\{\boldsymbol{d}^{\prime}\right\}=\left\{\begin{array}{c}
d_{2}^{\prime} \\
d_{3}^{\prime} \\
d_{5}^{\prime} \\
0
\end{array}\right\}=\left\{\begin{array}{c}
v_{0}(0) \\
\theta(0) \\
v_{0}(L) \\
M(L) / E I
\end{array}\right\}= \\
& \left(\begin{array}{cccc}
0 & 1-L^{2} \Lambda^{2} \Omega & 0 & 1 \\
\Lambda & 0 & 1 & 0 \\
-\sinh (L \Lambda)\left(L^{2} \Lambda^{2} \Omega-1\right) & -\cosh (L \Lambda)\left(L^{2} \Lambda^{2} \Omega-1\right) & L & 1 \\
\Lambda^{2} \sinh (L \Lambda) & \Lambda^{2} \cosh (L \Lambda) & 0 & 0
\end{array}\right) \cdot\left\{\begin{array}{l}
c_{1} \\
c_{2} \\
c_{3} \\
c_{4}
\end{array}\right\} \\
& \rightarrow[\boldsymbol{H}] .\{\boldsymbol{C}\}=\left\{\boldsymbol{d}^{\prime}\right\} \\
& \left\{\begin{array}{c}
v_{0}(x) \\
\theta(x)
\end{array}\right\}=[X] \cdot[H]^{-1} \cdot\left\{d^{\prime}\right\} \Rightarrow[N]=[X] \cdot[H]^{-1} \\
& N_{2}^{v}(x)=-\frac{\sinh (\Lambda(L-x))-L \Lambda \cosh (L \Lambda)+\Lambda x \cosh (L \Lambda)-L^{2} \Lambda^{2} \Omega \sinh (\Lambda(L-x))}{L \Lambda \cosh (L \Lambda)-\sinh (L \Lambda)+L^{2} \Lambda^{2} \Omega \sinh (L \Lambda)} \\
& N_{3}^{v}(x)=\frac{\left(L^{2} \Lambda^{2} \Omega-1\right)(x \sinh (L \Lambda)-L \sinh (L \Lambda)+L \sinh (\Lambda(L-x)))}{L \Lambda \cosh (L \Lambda)-\sinh (L \Lambda)+L^{2} \Lambda^{2} \Omega \sinh (L \Lambda)} \\
& N_{5}^{v}(x)=\frac{\sinh (\Lambda(L-x))-\sinh (L \Lambda)+\Lambda x \cosh (L \Lambda)+L^{2} \Lambda^{2} \Omega \sinh (L \Lambda)-L^{2} \Lambda^{2} \Omega \sinh (\Lambda(L-x))}{L \Lambda \cosh (L \Lambda)-\sinh (L \Lambda)+L^{2} \Lambda^{2} \Omega \sinh (L \Lambda)} \\
& N_{2}^{\theta}(x)=-\frac{\Lambda(\cosh (L \Lambda)-\cosh (\Lambda(L-x)))}{L \Lambda \cosh (L \Lambda)-\sinh (L \Lambda)+L^{2} \Lambda^{2} \Omega \sinh (L \Lambda)} \\
& N_{3}^{\theta}(x)=\frac{L \Lambda \cosh (\Lambda(L-x))-\sinh (L \Lambda)+L^{2} \Lambda^{2} \Omega \sinh (L \Lambda)}{L \Lambda \cosh (L \Lambda)-\sinh (L \Lambda)+L^{2} \Lambda^{2} \Omega \sinh (L \Lambda)} \\
& N_{5}^{\theta}(x)=\frac{\Lambda(\cosh (L \Lambda)-\cosh (\Lambda(L-x)))}{L \Lambda \cosh (L \Lambda)-\sinh (L \Lambda)+L^{2} \Lambda^{2} \Omega \sinh (L \Lambda)}
\end{aligned}
$$

Compressão:

$$
v_{h}(x)=\left(1+\Omega L^{2} \Lambda^{2}\right)\left[c_{1} \sin (\Lambda x)+c_{2} \cos (\Lambda x)\right]+c_{3} x+c_{4}
$$




$$
\begin{aligned}
& \theta_{h}(x)=\Lambda\left[c_{1} \cos (\Lambda x)-c_{2} \operatorname{sen}(\Lambda x)\right]+c_{3} \\
& \frac{M(x)}{E I}=\frac{d \theta_{h}(x)}{d x}=-\Lambda\left(C_{2} \Lambda \cos (\Lambda x)+C_{1} \Lambda \sin (\Lambda x)\right) \\
& \left\{\begin{array}{l}
\boldsymbol{v}_{\mathbf{0}}(\boldsymbol{x}) \\
\boldsymbol{\theta}(\boldsymbol{x}) \\
\boldsymbol{M}(\boldsymbol{x})
\end{array}\right\}=[\boldsymbol{X}] .\{\boldsymbol{C}\}, \quad\{\boldsymbol{C}\}=\left\{\begin{array}{l}
c_{1} \\
c_{2} \\
c_{3} \\
c_{4}
\end{array}\right\}, \\
& \left(\begin{array}{cccc}
\sin (\Lambda x)\left(\Omega L^{2} \Lambda^{2}+1\right) & \cos (\Lambda x)\left(\Omega L^{2} \Lambda^{2}+1\right) & x & 1 \\
\Lambda \cos (\Lambda x) & -\Lambda \sin (\Lambda x) & 1 & 0 \\
-\Lambda^{2} \sin (\Lambda x) & -\Lambda^{2} \cos (\Lambda x) & 0 & 0
\end{array}\right) \cdot\left\{\begin{array}{l}
c_{1} \\
c_{2} \\
c_{3} \\
c_{4}
\end{array}\right\} \\
& \left\{\boldsymbol{d}^{\prime}\right\}=\left\{\begin{array}{c}
d_{2}^{\prime} \\
d_{3}^{\prime} \\
d_{5}^{\prime} \\
0
\end{array}\right\}=\left\{\begin{array}{c}
v_{0}(0) \\
\theta(0) \\
v_{0}(L) \\
M(L) / E I
\end{array}\right\}= \\
& \left(\begin{array}{cccc}
0 & \Omega L^{2} \Lambda^{2}+1 & 0 & 1 \\
\Lambda & 0 & 1 & 0 \\
\sin (L \Lambda)\left(\Omega L^{2} \Lambda^{2}+1\right) & \cos (L \Lambda)\left(\Omega L^{2} \Lambda^{2}+1\right) & L & 1 \\
-\Lambda^{2} \sin (L \Lambda) & -\Lambda^{2} \cos (L \Lambda) & 0 & 0
\end{array}\right) \cdot\left\{\begin{array}{l}
c_{1} \\
c_{2} \\
c_{3} \\
c_{4}
\end{array}\right\} \\
& \rightarrow[\boldsymbol{H}] .\{\boldsymbol{C}\}=\left\{\boldsymbol{d}^{\prime}\right\} \\
& \left\{\begin{array}{c}
\boldsymbol{v}_{0}(x) \\
\theta(x)
\end{array}\right\}=[X] \cdot[H]^{-1} \cdot\left\{d^{\prime}\right\} \Rightarrow[N]=[X] \cdot[H]^{-1} \\
& N_{2}^{v}(x)=\frac{\sin (\Lambda(L-x))-L \Lambda \cos (L \Lambda)+\Lambda x \cos (L \Lambda)+L^{2} \Lambda^{2} \Omega \sin (\Lambda(L-x))}{\sin (L \Lambda)-L \Lambda \cos (L \Lambda)+L^{2} \Lambda^{2} \Omega \sin (L \Lambda)} \\
& N_{3}^{v}(x)=\frac{\left(\Omega L^{2} \Lambda^{2}+1\right)(x \sin (L \Lambda)-L \sin (L \Lambda)+L \sin (\Lambda(L-x)))}{\sin (L \Lambda)-L \Lambda \cos (L \Lambda)+L^{2} \Lambda^{2} \Omega \sin (L \Lambda)} \\
& N_{5}^{v}(x)=-\frac{\sin (\Lambda(L-x))-\sin (L \Lambda)+\Lambda x \cos (L \Lambda)-L^{2} \Lambda^{2} \Omega \sin (L \Lambda)+L^{2} \Lambda^{2} \Omega \sin (\Lambda(L-x))}{\sin (L \Lambda)-L \Lambda \cos (L \Lambda)+L^{2} \Lambda^{2} \Omega \sin (L \Lambda)} \\
& N_{2}^{\theta}(x)=\frac{\Lambda(\cos (L \Lambda)-\cos (\Lambda(L-x)))}{\sin (L \Lambda)-L \Lambda \cos (L \Lambda)+L^{2} \Lambda^{2} \Omega \sin (L \Lambda)} \\
& N_{3}^{\theta}(x)=\frac{\sin (L \Lambda)-L \Lambda \cos (\Lambda(L-x))+L^{2} \Lambda^{2} \Omega \sin (L \Lambda)}{\sin (L \Lambda)-L \Lambda \cos (L \Lambda)+L^{2} \Lambda^{2} \Omega \sin (L \Lambda)} \\
& N_{5}^{\theta}(x)=-\frac{\Lambda(\cos (L \Lambda)-\cos (\Lambda(L-x)))}{\sin (L \Lambda)-L \Lambda \cos (L \Lambda)+L^{2} \Lambda^{2} \Omega \sin (L \Lambda)}
\end{aligned}
$$




\section{Apêndice $B$}

Matrizes de Rigidez Locais Considerando Teoria de Flexão de Euler-Bernoulli 
B.1

Matriz de Rigidez Geométrica Local com Funções de Forma Cúbicas: Planos Indepedentes (EBBT_Large)

\begin{tabular}{|c|c|c|c|c|c|c|c|c|c|c|c|}
\hline$\frac{P}{L}$ & 0 & 0 & 0 & $-\frac{M_{y 1}}{L}$ & $-\frac{M_{z 1}}{L}$ & $-\frac{P}{L}$ & 0 & 0 & 0 & $-\frac{M_{y 2}}{L}$ & $-\frac{M_{z 2}}{L}$ \\
\hline 0 & $\frac{6 P}{5 L}+\frac{12 P I_{z}}{A L^{3}}$ & 0 & 0 & 0 & $\frac{P}{10}+\frac{6 P I_{z}}{A L^{2}}$ & 0 & $-\frac{6 P}{5 L}-\frac{12 P I_{z}}{A L^{3}}$ & 0 & 0 & 0 & $\frac{P}{10}+\frac{6 P I_{z}}{A L^{2}}$ \\
\hline 0 & 0 & $\frac{6 P}{5 L}+\frac{12 P I_{y}}{A L^{3}}$ & 0 & $-\frac{P}{10}-\frac{6 P I_{y}}{A L^{2}}$ & 0 & 0 & 0 & $-\frac{6 P}{5 L}-\frac{12 P I_{y}}{A L^{3}}$ & 0 & $-\frac{P}{10}-\frac{6 P I_{y}}{A L^{2}}$ & 0 \\
\hline 0 & 0 & 0 & 0 & 0 & 0 & 0 & 0 & 0 & 0 & 0 & 0 \\
\hline$-\frac{M_{y 1}}{L}$ & 0 & $-\frac{P}{10}-\frac{6 P I_{y}}{A L^{2}}$ & 0 & $\frac{2 P L}{15}+\frac{4 P I_{y}}{A L}$ & 0 & $\frac{M_{y 1}}{L}$ & 0 & $\frac{P}{10}+\frac{6 P I_{y}}{A L^{2}}$ & 0 & $\frac{2 P I_{y}}{A L}-\frac{P L}{30}$ & 0 \\
\hline$-\frac{M_{z 1}}{L}$ & $\frac{P}{10}+\frac{6 P I_{z}}{A L^{2}}$ & 0 & 0 & 0 & $\frac{2 P L}{15}+\frac{4 P I_{z}}{A L}$ & $\frac{M_{z 1}}{L}$ & $-\frac{P}{10}-\frac{6 P I_{z}}{A L^{2}}$ & 0 & 0 & 0 & $\frac{2 P I_{z}}{A L}-\frac{P L}{30}$ \\
\hline$-\frac{P}{L}$ & 0 & 0 & 0 & $\frac{M_{y 1}}{L}$ & $\frac{M_{z 1}}{L}$ & $\frac{P}{L}$ & 0 & 0 & 0 & $\frac{M_{y 2}}{L}$ & $\frac{M_{z 2}}{L}$ \\
\hline 0 & $-\frac{6 P}{5 L}-\frac{12 P I_{z}}{A L^{3}}$ & 0 & 0 & 0 & $-\frac{P}{10}-\frac{6 P I_{z}}{A L^{2}}$ & 0 & $\frac{6 P}{5 L}+\frac{12 P I_{z}}{A L^{3}}$ & 0 & 0 & 0 & $-\frac{P}{10}-\frac{6 P I_{z}}{A L^{2}}$ \\
\hline 0 & 0 & $-\frac{6 P}{5 L}-\frac{12 P I_{y}}{A L^{3}}$ & 0 & $\frac{P}{10}+\frac{6 P I_{y}}{A L^{2}}$ & 0 & 0 & 0 & $\frac{6 P}{5 L}+\frac{12 P I_{y}}{A L^{3}}$ & 0 & $\frac{P}{10}+\frac{6 P I_{y}}{A L^{2}}$ & 0 \\
\hline 0 & 0 & 0 & 0 & 0 & 0 & 0 & 0 & 0 & 0 & 0 & 0 \\
\hline$-\frac{M_{y 2}}{L}$ & 0 & $-\frac{P}{10}-\frac{6 P I_{y}}{A L^{2}}$ & 0 & $\frac{2 P I_{y}}{A L}-\frac{P L}{30}$ & 0 & $\frac{M_{y 2}}{L}$ & 0 & $\frac{P}{10}+\frac{6 P I_{y}}{A L^{2}}$ & 0 & $\frac{2 P L}{15}+\frac{4 P I_{y}}{A L}$ & 0 \\
\hline$-\frac{M_{z 2}}{L}$ & $\frac{P}{10}+\frac{6 P I_{z}}{A L^{2}}$ & 0 & 0 & 0 & $\frac{2 P I_{z}}{A L}-\frac{P L}{30}$ & $\frac{M_{z 2}}{L}$ & $-\frac{P}{10}-\frac{6 P I_{z}}{A L^{2}}$ & 0 & 0 & 0 & $\frac{2 P L}{15}+\frac{4 P I_{z}}{A L}$ \\
\hline
\end{tabular}




\section{B.2}

Matriz de Rigidez Geométrica Local com Funções de Forma Cúbicas: Interação Torção com Carga Axial (EBBT_Large)

\begin{tabular}{|c|c|c|c|c|c|c|c|c|c|c|c|}
\hline 0 & 0 & 0 & 0 & 0 & 0 & 0 & 0 & 0 & 0 & 0 & 0 \\
\hline 0 & 0 & 0 & $\frac{M_{y 1}}{L}$ & $\frac{M_{x 2}}{L}$ & 0 & 0 & 0 & 0 & $\frac{M_{y 2}}{L}$ & $-\frac{M_{x 2}}{L}$ & 0 \\
\hline 0 & 0 & 0 & $\frac{M_{z 1}}{L}$ & 0 & $\frac{M_{x 2}}{L}$ & 0 & 0 & 0 & $\frac{M_{z 2}}{L}$ & 0 & $-\frac{M_{x 2}}{L}$ \\
\hline 0 & $\frac{M_{y 1}}{L}$ & $\frac{M_{z 1}}{L}$ & $\frac{J_{P} P}{A L}$ & $\frac{M_{z 1}}{6}+\frac{M_{z 2}}{6}$ & $-\frac{M_{y 1}}{6}-\frac{M_{y 2}}{6}$ & 0 & $-\frac{M_{y 1}}{L}$ & $-\frac{M_{z 1}}{L}$ & $-\frac{J_{P} P}{A L}$ & $-\frac{M_{z 1}}{6}-\frac{M_{z 2}}{6}$ & $\frac{M_{y 1}}{6}+\frac{M_{y 2}}{6}$ \\
\hline 0 & $\frac{M_{x 2}}{L}$ & 0 & $\frac{M_{z 1}}{6}+\frac{M_{z 2}}{6}$ & 0 & 0 & 0 & $-\frac{M_{x 2}}{L}$ & 0 & $-\frac{M_{z 1}}{6}-\frac{M_{z 2}}{6}$ & 0 & $\frac{M_{x 2}}{2}$ \\
\hline 0 & 0 & $\frac{M_{x 2}}{L}$ & $-\frac{M_{y 1}}{6}-\frac{M_{y 2}}{6}$ & 0 & 0 & 0 & 0 & $-\frac{M_{x 2}}{L}$ & $\frac{M_{y 1}}{6}+\frac{M_{y 2}}{6}$ & $-\frac{M_{x 2}}{2}$ & 0 \\
\hline 0 & 0 & 0 & 0 & 0 & 0 & 0 & 0 & 0 & 0 & 0 & 0 \\
\hline 0 & 0 & 0 & $-\frac{M_{y 1}}{L}$ & $-\frac{M_{x 2}}{L}$ & 0 & 0 & 0 & 0 & $-\frac{M_{y 2}}{L}$ & $\frac{M_{x 2}}{L}$ & 0 \\
\hline 0 & 0 & 0 & $-\frac{M_{z 1}}{L}$ & 0 & $-\frac{M_{x 2}}{L}$ & 0 & 0 & 0 & $-\frac{M_{z 2}}{L}$ & 0 & $\frac{M_{x 2}}{L}$ \\
\hline 0 & $\frac{M_{y 2}}{L}$ & $\frac{M_{z 2}}{L}$ & $-\frac{J_{P} P}{A L}$ & $-\frac{M_{z 1}}{6}-\frac{M_{z 2}}{6}$ & $\frac{M_{y 1}}{6}+\frac{M_{y 2}}{6}$ & 0 & $-\frac{M_{y 2}}{L}$ & $-\frac{M_{z 2}}{L}$ & $\frac{J_{P} P}{A L}$ & $\frac{M_{z 1}}{6}+\frac{M_{z 2}}{6}$ & $-\frac{M_{y 1}}{6}-\frac{M_{y 2}}{6}$ \\
\hline 0 & $-\frac{M_{x 2}}{L}$ & 0 & $-\frac{M_{z 1}}{6}-\frac{M_{z 2}}{6}$ & 0 & $-\frac{M_{x 2}}{2}$ & 0 & $\frac{M_{x 2}}{L}$ & 0 & $\frac{M_{z 1}}{6}+\frac{M_{z 2}}{6}$ & 0 & 0 \\
\hline 0 & 0 & $-\frac{M_{x 2}}{L}$ & $\frac{M_{y 1}}{6}+\frac{M_{y 2}}{6}$ & $\frac{M_{x 2}}{2}$ & 0 & 0 & 0 & $\frac{M_{x 2}}{L}$ & $-\frac{M_{y 1}}{6}-\frac{M_{y 2}}{6}$ & 0 & 0 \\
\hline
\end{tabular}


B.3

Matriz de Rigidez Geométrica Local Final com Funções de Forma Cúbicas (EBBT_Large)

\begin{tabular}{|c|c|c|c|c|c|c|c|c|c|c|c|}
\hline$\frac{P}{L}$ & 0 & 0 & 0 & $-\frac{M_{y 1}}{L}$ & $-\frac{M_{z 1}}{L}$ & $-\frac{P}{L}$ & 0 & 0 & 0 & $-\frac{M_{y 2}}{L}$ & $-\frac{M_{z 2}}{L}$ \\
\hline 0 & $\frac{6 P}{5 L}+\frac{12 P I_{z}}{A L^{3}}$ & 0 & $\frac{M_{y 1}}{L}$ & $\frac{M_{x 2}}{L}$ & $\frac{P}{10}+\frac{6 P I_{z}}{A L^{2}}$ & 0 & $-\frac{6 P}{5 L}-\frac{12 P I_{z}}{A L^{3}}$ & 0 & $\frac{M_{y 2}}{L}$ & $-\frac{M_{x 2}}{L}$ & $\frac{P}{10}+\frac{6 P I_{z}}{A L^{2}}$ \\
\hline 0 & 0 & $\frac{6 P}{5 L}+\frac{12 P I_{y}}{A L^{3}}$ & $\frac{M_{z 1}}{L}$ & $-\frac{P}{10}-\frac{6 P I_{y}}{A L^{2}}$ & $\frac{M_{x 2}}{L}$ & 0 & 0 & $-\frac{6 P}{5 L}-\frac{12 P I_{y}}{A L^{3}}$ & $\frac{M_{z 2}}{L}$ & $-\frac{P}{10}-\frac{6 P I_{y}}{A L^{2}}$ & $-\frac{M_{x 2}}{L}$ \\
\hline 0 & $\frac{M_{y 1}}{L}$ & $\frac{M_{z 1}}{L}$ & $\frac{J_{P} P}{A L}$ & $\frac{M_{z 2}}{6}-\frac{M_{z 1}}{3}$ & $\frac{M_{y 1}}{3}-\frac{M_{y 2}}{6}$ & 0 & $-\frac{M_{y 1}}{L}$ & $-\frac{M_{z 1}}{L}$ & $-\frac{J_{P} P}{A L}$ & $-\frac{M_{z 1}}{6}-\frac{M_{z 2}}{6}$ & $\frac{M_{y 1}}{6}+\frac{M_{y 2}}{6}$ \\
\hline$\frac{M_{y 1}}{L}$ & $\frac{M_{x 2}}{L}$ & $-\frac{P}{10}-\frac{6 P I_{y}}{A L^{2}}$ & $\frac{M_{z 2}}{6}-\frac{M_{z 1}}{3}$ & $\frac{2 P L}{15}+\frac{4 P I_{y}}{A L}$ & 0 & $\frac{M_{y 1}}{L}$ & $-\frac{M_{x 2}}{L}$ & $\frac{P}{10}+\frac{6 P I_{y}}{A L^{2}}$ & $-\frac{M_{z 1}}{6}-\frac{M_{z 2}}{6}$ & $\frac{2 P I_{y}}{A L}-\frac{P L}{30}$ & $\frac{M_{x 2}}{2}$ \\
\hline$\frac{M_{z 1}}{L}$ & $\frac{P}{10}+\frac{6 P I_{z}}{A L^{2}}$ & $\frac{M_{x 2}}{L}$ & $\frac{M_{y 1}}{3}-\frac{M_{y 2}}{6}$ & 0 & $\frac{2 P L}{15}+\frac{4 P I_{z}}{A L}$ & $\frac{M_{z 1}}{L}$ & $-\frac{P}{10}-\frac{6 P I_{z}}{A L^{2}}$ & $-\frac{M_{x 2}}{L}$ & $\frac{M_{y 1}}{6}+\frac{M_{y 2}}{6}$ & $-\frac{M_{x 2}}{2}$ & $\frac{2 P I_{z}}{A L}-\frac{P L}{30}$ \\
\hline$-\frac{P}{L}$ & 0 & 0 & 0 & $\frac{M_{y 1}}{L}$ & $\frac{M_{z 1}}{L}$ & $\frac{P}{L}$ & 0 & 0 & 0 & $\frac{M_{y 2}}{L}$ & $\frac{M_{z 2}}{L}$ \\
\hline 0 & $-\frac{6 P}{5 L}-\frac{12 P I_{z}}{A L^{3}}$ & 0 & $-\frac{M_{y 1}}{L}$ & $-\frac{M_{x 2}}{L}$ & $-\frac{P}{10}-\frac{6 P I_{z}}{A L^{2}}$ & 0 & $\frac{6 P}{5 L}+\frac{12 P I_{z}}{A L^{3}}$ & 0 & $-\frac{M_{y 2}}{L}$ & $\frac{M_{x 2}}{L}$ & $-\frac{P}{10}-\frac{6 P I_{z}}{A L^{2}}$ \\
\hline 0 & 0 & $-\frac{6 P}{5 L}-\frac{12 P I_{y}}{A L^{3}}$ & $-\frac{M_{z 1}}{L}$ & $\frac{P}{10}+\frac{6 P I_{y}}{A L^{2}}$ & $-\frac{M_{x 2}}{L}$ & 0 & 0 & $\frac{6 P}{5 L}+\frac{12 P I_{y}}{A L^{3}}$ & $-\frac{M_{z 2}}{L}$ & $\frac{P}{10}+\frac{6 P I_{y}}{A L^{2}}$ & $\frac{M_{x 2}}{L}$ \\
\hline 0 & $\frac{M_{y 2}}{L}$ & $\frac{M_{z 2}}{L}$ & $-\frac{J_{P} P}{A L}$ & $-\frac{M_{z 1}}{6}-\frac{M_{z 2}}{6}$ & $\frac{M_{y 1}}{6}+\frac{M_{y 2}}{6}$ & 0 & $-\frac{M_{y 2}}{L}$ & $-\frac{M_{z 2}}{L}$ & $\frac{J_{P} P}{A L}$ & $\frac{M_{z 1}}{6}-\frac{M_{z 2}}{3}$ & $\frac{M_{y 2}}{3}-\frac{M_{y 1}}{6}$ \\
\hline$\frac{M_{y 2}}{L}$ & $-\frac{M_{x 2}}{L}$ & $-\frac{P}{10}-\frac{6 P I_{y}}{A L^{2}}$ & $-\frac{M_{z 1}}{6}-\frac{M_{z 2}}{6}$ & $\frac{2 P I_{y}}{A L}-\frac{P L}{30}$ & $-\frac{M_{x 2}}{2}$ & $\frac{M_{y 2}}{L}$ & $\frac{M_{x 2}}{L}$ & $\frac{P}{10}+\frac{6 P I_{y}}{A L^{2}}$ & $\frac{M_{z 1}}{6}-\frac{M_{z 2}}{3}$ & $\frac{2 P L}{15}+\frac{4 P I_{y}}{A L}$ & 0 \\
\hline$\frac{M_{z 2}}{L}$ & $\frac{P}{10}+\frac{6 P I_{z}}{A L^{2}}$ & $-\frac{M_{x 2}}{L}$ & $\frac{M_{y 1}}{6}+\frac{M_{y 2}}{6}$ & $\frac{M_{x 2}}{2}$ & $\frac{2 P I_{z}}{A L}-\frac{P L}{30}$ & $\frac{M_{z 2}}{L}$ & $-\frac{P}{10}-\frac{6 P I_{z}}{A L^{2}}$ & $\frac{M_{x 2}}{L}$ & $\frac{M_{y 2}}{3}-\frac{M_{y 1}}{6}$ & 0 & $\frac{2 P L}{15}+\frac{4 P I_{z}}{A L}$ \\
\hline
\end{tabular}


B.4

Matriz de Rigidez Local com Funções de Forma Completas: “1a Ordem” (EBBT_Complete) - Tração

\begin{tabular}{|c|c|c|c|c|c|c|c|c|c|c|c|}
\hline$\frac{E A}{L}$ & 0 & 0 & 0 & 0 & 0 & $-\frac{E A}{L}$ & 0 & 0 & 0 & 0 & 0 \\
\hline 0 & $\frac{12 E I_{z}}{L^{3}} \frac{\left(\mu_{y} L\right)^{3} C_{y}}{12 D_{y}{ }^{2}}$ & 0 & 0 & 0 & $\frac{6 E I_{z}}{L^{2}} \frac{\left(\mu_{y} L\right)^{3} C_{y}}{12 D_{y}{ }^{2}}$ & 0 & $-\frac{12 E I_{z}}{L^{3}} \frac{\left(\mu_{y} L\right)^{3} C_{y}}{12 D_{y}{ }^{2}}$ & 0 & 0 & 0 & $\frac{6 E I_{z}}{L^{2}} \frac{\left(\mu_{y} L\right)^{3} C_{y}}{12 D_{y}{ }^{2}}$ \\
\hline 0 & 0 & $\frac{12 E I_{y}}{L^{3}} \frac{\left(\mu_{z} L\right)^{3} C_{z}}{12 D_{z}{ }^{2}}$ & 0 & $-\frac{6 E I_{y}}{L^{2}} \frac{\left(\mu_{z} L\right)^{3} C_{z}}{12 D_{z}^{2}}$ & 0 & 0 & 0 & $-\frac{12 E I_{y}}{L^{3}} \frac{\left(\mu_{z} L\right)^{3} C_{z}}{12 D_{z}{ }^{2}}$ & 0 & $-\frac{6 E I_{y}}{L^{2}} \frac{\left(\mu_{z} L\right)^{3} C_{z}}{12 D_{z}{ }^{2}}$ & 0 \\
\hline 0 & 0 & 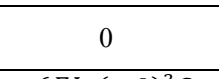 & $\frac{G I_{x}}{L}$ & 0 & 0 & 0 & 0 & 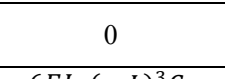 & $-\frac{G I_{x}}{L}$ & 0 & 0 \\
\hline 0 & 0 & $-\frac{6 E I_{y}}{L^{2}} \frac{\left(\mu_{z} L\right)^{3} C_{z}}{12 D_{z}{ }^{2}}$ & 0 & $\frac{4 E I_{y}}{L} \frac{\mu_{z} L B_{z}}{8 D_{z}{ }^{2}}$ & 0 & 0 & 0 & $\frac{6 E I_{y}}{L^{2}} \frac{\left(\mu_{z} L\right)^{3} C_{z}}{12 D_{z}{ }^{2}}$ & 0 & $\frac{2 E I_{y}}{L} \frac{\mu_{z} L F_{z}}{4 D_{z}{ }^{2}}$ & 0 \\
\hline 0 & $\frac{6 E I_{z}}{L^{2}} \frac{\left(\mu_{y} L\right)^{3} C_{y}}{12 D_{y}^{2}}$ & 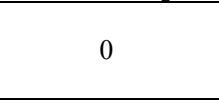 & 0 & 0 & $\frac{4 E I_{z}}{L} \frac{\mu_{y} L B_{y}}{8 D_{y}^{2}}$ & 0 & $-\frac{6 E I_{z}}{L^{3}} \frac{\left(\mu_{y} L\right)^{3} C_{y}}{12 D_{y}{ }^{2}}$ & 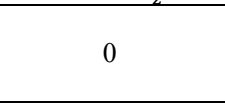 & 0 & 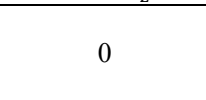 & $\frac{2 E I_{z}}{L} \frac{\mu_{y} L F_{y}}{4 D_{y}{ }^{2}}$ \\
\hline$-\frac{E A}{L}$ & 0 & 0 & 0 & 0 & 0 & $\frac{E A}{L}$ & 0 & 0 & 0 & 0 & 0 \\
\hline 0 & $-\frac{12 E I_{z}}{L^{3}} \frac{\left(\mu_{y} L\right)^{3} C_{y}}{12 D_{y}{ }^{2}}$ & 0 & 0 & 0 & $-\frac{6 E I_{z}}{L^{2}} \frac{\left(\mu_{y} L\right)^{3} C_{y}}{12 D_{y}{ }^{2}}$ & 0 & $\frac{12 E I_{z}}{L^{3}} \frac{\left(\mu_{y} L\right)^{3} C_{y}}{12 D_{y}{ }^{2}}$ & 0 & 0 & 0 & $-\frac{6 E I_{z}}{L^{2}} \frac{\left(\mu_{y} L\right)^{3} C_{y}}{12 D_{y}^{2}}$ \\
\hline 0 & 0 & $-\frac{12 E I_{y}}{L^{3}} \frac{\left(\mu_{z} L\right)^{3} C_{z}}{12 D_{z}^{2}}$ & 0 & $\frac{6 E I_{y}}{L^{2}} \frac{\left(\mu_{z} L\right)^{3} C_{z}}{12 D_{z}^{2}}$ & 0 & 0 & 0 & $\frac{12 E I_{y}}{L^{3}} \frac{\left(\mu_{z} L\right)^{3} C_{z}}{12 D_{z}^{2}}$ & 0 & $\frac{6 E I_{y}}{L^{2}} \frac{\left(\mu_{z} L\right)^{3} C_{z}}{12 D_{z}{ }^{2}}$ & 0 \\
\hline 0 & 0 & 0 & $-\frac{G I_{x}}{L}$ & 0 & 0 & 0 & 0 & 0 & $\frac{G I_{x}}{L}$ & 0 & \\
\hline 0 & 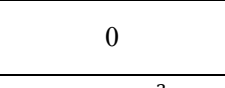 & $-\frac{6 E I_{y}}{L^{2}} \frac{\left(\mu_{z} L\right)^{3} C_{z}}{12 D_{z}^{2}}$ & 0 & $\frac{2 E I_{y}}{L} \frac{\mu_{z} L F_{z}}{4 D_{z}{ }^{2}}$ & 0 & 0 & 0 & $\frac{6 E I_{y}}{L^{2}} \frac{\left(\mu_{z} L\right)^{3} C_{z}}{12 D_{z}^{2}}$ & 0 & $\frac{4 E I_{y}}{L} \frac{\mu_{z} L B_{z}}{8 D_{z}{ }^{2}}$ & 0 \\
\hline 0 & $\frac{6 E I_{z}}{L^{2}} \frac{\left(\mu_{y} L\right)^{3} C_{y}}{12 D_{y}^{2}}$ & 0 & 0 & 0 & $\frac{2 E I_{z}}{L} \frac{\mu_{y} L F_{y}}{4 D_{y}{ }^{2}}$ & 0 & $-\frac{6 E I_{z}}{L^{2}} \frac{\left(\mu_{y} L\right)^{3} C_{y}}{12 D_{y}{ }^{2}}$ & 0 & 0 & 0 & $\frac{4 E I_{z}}{L} \frac{\mu_{y} L B_{y}}{8 D_{y}^{2}}$ \\
\hline
\end{tabular}

$C_{y}=\left(\sinh \left(\mu_{y} L\right)-\mu_{y} L\right)\left(\cosh \left(\mu_{y} L\right)-1\right) ; D_{y}=\mu_{y} L \sinh \left(\mu_{y} L\right)-2 \cosh \left(\mu_{y} L\right)+2 ; C_{z}=\left(\sinh \left(\mu_{z} L\right)-\mu_{z} L\right)\left(\cosh \left(\mu_{z} L\right)-1\right) ; D_{z}=\mu_{z} L \sinh \left(\mu_{z} L\right)-2 \cosh \left(\mu_{z} L\right)+2$

$B_{y}=\left(L^{3} \mu_{y}{ }^{3}-2 \mu_{y} L \cosh \left(\mu_{y} L\right)^{2}+2 \mu_{y} L \cosh \left(\mu_{y} L\right)\right)+\sinh \left(\mu_{y} L\right)\left(2 \cosh \left(\mu_{y} L\right)-2 L^{2} \mu_{y}{ }^{2}+L^{2} \mu_{y}{ }^{2} \cosh \left(\mu_{y} L\right)-2\right) ; F_{y}=\left(\sinh \left(\mu_{y} L\right)-\mu_{y} L \cosh \left(\mu_{y} L\right)\right)\left(\mu_{y}{ }^{2} L^{2}-2 \cosh \left(\mu_{y} L\right)+2\right)$

$B_{z}=\left(L^{3} \mu_{z}{ }^{3}-2 \mu_{z} L \cosh \left(\mu_{z} L\right)^{2}+2 \mu_{z} L \cosh \left(\mu_{z} L\right)\right)+\sinh \left(\mu_{z} L\right)\left(2 \cosh \left(\mu_{z} L\right)-2 L^{2} \mu_{z}{ }^{2}+L^{2} \mu_{z}{ }^{2} \cosh \left(\mu_{z} L\right)-2\right) ; F_{z}=\left(\sinh \left(\mu_{z} L\right)-\mu_{z} L \cosh \left(\mu_{z} L\right)\right)\left(\mu_{z}{ }^{2} L^{2}-2 \cosh \left(\mu_{z} L\right)+2\right)$ 
B.5

Matriz de Rigidez Local com Funções de Forma Completas: "1a Ordem” (EBBT_Complete) - Compressão

\begin{tabular}{|c|c|c|c|c|c|c|c|c|c|c|c|}
\hline$\frac{E A}{L}$ & 0 & 0 & 0 & 0 & 0 & $-\frac{E A}{L}$ & 0 & 0 & 0 & 0 & 0 \\
\hline 0 & $\frac{12 E I_{z}}{L^{3}} \frac{\left(\mu_{y} L\right)^{3} C_{y}}{12 D_{y}^{2}}$ & 0 & 0 & 0 & $\frac{6 E I_{z}}{L^{2}} \frac{\left(\mu_{y} L\right)^{3} C_{y}}{12 D_{y}^{2}}$ & 0 & $-\frac{12 E I_{z}}{L^{3}} \frac{\left(\mu_{y} L\right)^{3} C_{y}}{12 D_{y}^{2}}$ & 0 & 0 & 0 & $\frac{6 E I_{z}}{L^{2}} \frac{\left(\mu_{y} L\right)^{3} C_{y}}{12 D_{y}^{2}}$ \\
\hline 0 & 0 & $\frac{12 E I_{y}}{L^{3}} \frac{\left(\mu_{z} L\right)^{3} C_{z}}{12 D_{z}{ }^{2}}$ & 0 & $-\frac{6 E I_{y}}{L^{2}} \frac{\left(\mu_{z} L\right)^{3} C_{z}}{12 D_{z}{ }^{2}}$ & 0 & 0 & 0 & $-\frac{12 E I_{y}}{L^{3}} \frac{\left(\mu_{z} L\right)^{3} C_{z}}{12 D_{z}{ }^{2}}$ & 0 & $-\frac{6 E I_{y}}{L^{2}} \frac{\left(\mu_{z} L\right)^{3} C_{z}}{12 D_{z}{ }^{2}}$ & 0 \\
\hline 0 & 0 & 0 & $\frac{G I_{x}}{L}$ & 0 & 0 & 0 & 0 & 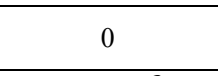 & $-\frac{G I_{x}}{L}$ & 0 & 0 \\
\hline 0 & 0 & $-\frac{6 E I_{y}}{L^{2}} \frac{\left(\mu_{z} L\right)^{3} C_{z}}{12 D_{z}{ }^{2}}$ & 0 & $\frac{4 E I_{y}}{L} \frac{\mu_{z} L B_{z}}{16 D_{z}{ }^{2}}$ & 0 & 0 & 0 & $\frac{6 E I_{y}}{L^{2}} \frac{\left(\mu_{z} L\right)^{3} C_{z}}{12 D_{z}{ }^{2}}$ & 0 & $\frac{2 E I_{y}}{L} \frac{\mu_{z} L F_{z}}{4 D_{z}{ }^{2}}$ & 0 \\
\hline 0 & $\frac{6 E I_{z}}{L^{2}} \frac{\left(\mu_{y} L\right)^{3} C_{y}}{12 D_{y}{ }^{2}}$ & 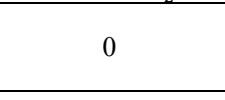 & 0 & 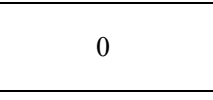 & $\frac{4 E I_{z}}{L} \frac{\mu_{y} L B_{y}}{16 D_{y}{ }^{2}}$ & 0 & $-\frac{6 E I_{z}}{L^{3}} \frac{\left(\mu_{y} L\right)^{3} C_{y}}{12 D_{y}{ }^{2}}$ & 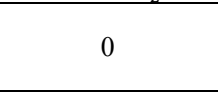 & 0 & $2=$ & $\frac{2 E I_{z}}{L} \frac{\mu_{y} L F_{y}}{4 D_{y}^{2}}$ \\
\hline$-\frac{E A}{L}$ & 0 & 0 & 0 & 0 & 0 & $\frac{E A}{L}$ & 0 & 0 & 0 & 0 & 0 \\
\hline 0 & $-\frac{12 E I_{z}}{L^{3}} \frac{\left(\mu_{y} L\right)^{3} C_{y}}{12 D_{y}^{2}}$ & 0 & 0 & 0 & $-\frac{6 E I_{z}}{L^{2}} \frac{\left(\mu_{y} L\right)^{3} C_{y}}{12 D_{y}{ }^{2}}$ & 0 & $\frac{12 E I_{z}}{L^{3}} \frac{\left(\mu_{y} L\right)^{3} C_{y}}{12 D_{y}^{2}}$ & 0 & 0 & 0 & $-\frac{6 E I_{z}}{L^{2}} \frac{\left(\mu_{y} L\right)^{3} C_{y}}{12 D_{y}^{2}}$ \\
\hline 0 & 0 & $-\frac{12 E I_{y}}{L^{3}} \frac{\left(\mu_{z} L\right)^{3} C_{z}}{12 D_{z}{ }^{2}}$ & 0 & $\frac{6 E I_{y}}{L^{2}} \frac{\left(\mu_{z} L\right)^{3} C_{z}}{12 D_{z}{ }^{2}}$ & 0 & 0 & 0 & $\frac{12 E I_{y}}{L^{3}} \frac{\left(\mu_{z} L\right)^{3} C_{z}}{12 D_{z}{ }^{2}}$ & 0 & $\frac{6 E I_{y}}{L^{2}} \frac{\left(\mu_{z} L\right)^{3} C_{z}}{12 D_{z}{ }^{2}}$ & 0 \\
\hline 0 & 0 & 0 & $-\frac{G I_{x}}{L}$ & 0 & 0 & 0 & 0 & 0 & $\frac{G I_{x}}{L}$ & 0 & \\
\hline 0 & 0 & $-\frac{6 E I_{y}}{L^{2}} \frac{\left(\mu_{z} L\right)^{3} C_{z}}{12 D_{z}{ }^{2}}$ & 0 & $\frac{2 E I_{y}}{L} \frac{\mu_{z} L F_{z}}{4 D_{z}{ }^{2}}$ & 0 & 0 & 0 & $\frac{6 E I_{y}}{L^{2}} \frac{\left(\mu_{z} L\right)^{3} C_{z}}{12 D_{z}{ }^{2}}$ & 0 & $\frac{4 E I_{y}}{L} \frac{\mu_{z} L B_{z}}{16 D_{z}{ }^{2}}$ & 0 \\
\hline 0 & $\frac{6 E I_{z}}{L^{2}} \frac{\left(\mu_{y} L\right)^{3} C_{y}}{12 D_{y}{ }^{2}}$ & 0 & 0 & 0 & $\frac{2 E I_{z}}{L} \frac{\mu_{y} L F_{y}}{4 D_{y}{ }^{2}}$ & 0 & $-\frac{6 E I_{z}}{L^{2}} \frac{\left(\mu_{y} L\right)^{3} C_{y}}{12 D_{y}{ }^{2}}$ & 0 & 0 & 0 & $\frac{4 E I_{z}}{L} \frac{\mu_{y} L B_{y}}{16 D_{y}^{2}}$ \\
\hline
\end{tabular}

$C_{y}=2 \sin \left(\mu_{y} L / 2\right)^{2}\left(\mu_{y} L-\sin \left(\mu_{y} L\right)\right) ; D_{y}=4 \sin \left(\mu_{y} L / 2\right)^{2}-\mu_{y} L \sin \left(\mu_{y} L\right) ; C_{z}=2 \sin \left(\mu_{z} L / 2\right)^{2}\left(\mu_{z} L-\sin \left(\mu_{z} L\right)\right) ; D_{z}=4 \sin \left(\mu_{z} L / 2\right)^{2}-\mu_{z} L \sin \left(\mu_{z} L\right)$

$B_{y}=\left(2 L^{3} \mu_{y}{ }^{3}-2 \sin \left(2 \mu_{y} L\right)-4 \mu_{y} L \sin \left(\mu_{y} L\right)^{2}+8 \mu_{y} L \sin \left(\frac{\mu_{y} L}{2}\right)^{2}+L^{2} \mu_{y}{ }^{2} \sin \left(2 \mu_{y} L\right)\right)-\sin \left(\mu_{y} L\right)\left(4 L^{2} \mu_{y}{ }^{2}-4\right) ; F_{y}=\left(L^{2} \mu_{y}{ }^{2}-4 \sin \left(\frac{\mu_{y} L}{2}\right)^{2}\right)\left(\sin \left(\mu_{y} L\right)+\mu_{y} L\left(2 \sin \left(\frac{\mu_{y} L}{2}\right)^{2}-1\right)\right)$

$B_{z}=\left(2 L^{3} \mu_{z}^{3}-2 \sin \left(2 \mu_{z} L\right)-4 \mu_{z} L \sin \left(\mu_{z} L\right)^{2}+8 \mu_{z} L \sin \left(\frac{\mu_{z} L}{2}\right)^{2}+L^{2} \mu_{z}^{2} \sin \left(2 \mu_{z} L\right)\right)-\sin \left(\mu_{z} L\right)\left(4 L^{2} \mu_{z}^{2}-4\right) ; F_{z}=\left(L^{2} \mu_{z}^{2}-4 \sin \left(\frac{\mu_{z} L}{2}\right)^{2}\right)\left(\sin \left(\mu_{z} L\right)+\mu_{z} L\left(2 \sin \left(\frac{\mu_{z} L}{2}\right)^{2}-1\right)\right)$ 
Apêndice B

B.6

Matriz de Rigidez Local com Funções de Forma Completas: “2”ardem” (EBBT_Complete) - Tração

\begin{tabular}{|c|c|c|c|c|c|c|c|c|c|c|c|}
\hline$\frac{P}{L}$ & 0 & 0 & 0 & $-\frac{M_{y a}}{L}$ & $-\frac{M_{z a}}{L}$ & $-\frac{P}{L}$ & 0 & 0 & 0 & $-\frac{M_{y b}}{L}$ & $-\frac{M_{z b}}{L}$ \\
\hline 0 & $\frac{P \alpha_{y}}{\beta_{y}}+\frac{P I_{z} \mu_{y}{ }^{3} C_{y}}{A D_{y}{ }^{2}}$ & 0 & 0 & 0 & $\frac{P \gamma_{y}}{2 \beta_{y}}+\frac{P I_{z} \mu_{y}{ }^{3} C_{y}}{2 A D_{y}{ }^{2}}$ & 0 & $-\frac{P \alpha_{y}}{\beta_{y}}-\frac{P I_{z} \mu_{y}{ }^{3} C_{y}}{A D_{y}{ }^{2}}$ & 0 & 0 & 0 & $\frac{P \gamma_{y}}{2 \beta_{y}}+\frac{P I_{z} \mu_{y}{ }^{3} C_{y}}{2 A D_{y}{ }^{2}}$ \\
\hline 0 & 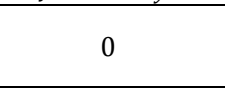 & $\frac{P \alpha_{z}}{\beta_{z}}+\frac{P I_{y} \mu_{z}{ }^{3} C_{z}}{A D_{z}{ }^{2}}$ & 0 & $-\frac{P \gamma_{z}}{2 \beta_{z}}-\frac{P I_{y} \mu_{z}{ }^{3} C_{z}}{2 A D_{z}{ }^{2}}$ & $x_{1}$ & 0 & 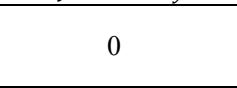 & $-\frac{P \alpha_{z}}{\beta_{z}}-\frac{P I_{y} \mu_{z}{ }^{3} C_{z}}{A D_{z}{ }^{2}}$ & 0 & $-\frac{P \gamma_{z}}{2 \beta_{z}}-\frac{P I_{y} \mu_{z}{ }^{3} C_{z}}{2 A D_{z}{ }^{2}}$ & (5) \\
\hline 0 & 0 & 0 & 0 & 0 & 0 & 0 & 0 & 0 & 0 & 0 & 0 \\
\hline$\frac{M_{y a}}{L}$ & 0 & $-\frac{P \gamma_{z}}{2 \beta_{z}}-\frac{P I_{y} \mu_{z}{ }^{3} C_{z}}{2 A D_{z}{ }^{2}}$ & 0 & $\frac{P \rho_{z}}{4 \mu_{z} D_{z}{ }^{2}}+\frac{P I_{y} \mu_{z} \omega_{z}}{2 A D_{z}{ }^{2}}$ & 0 & $\frac{M_{y a}}{L}$ & 0 & $\frac{P \gamma_{z}}{2 \beta_{z}}+\frac{P I_{y} \mu_{z}{ }^{3} C_{z}}{2 A D_{z}{ }^{2}}$ & 0 & $\frac{P \eta_{z}}{2 \mu_{z} D_{z}{ }^{2}}+\frac{P I_{y} \mu_{z} \Psi_{z}}{2 A D_{z}{ }^{2}}$ & 0 \\
\hline$\frac{M_{z a}}{L}$ & $\frac{P \gamma_{y}}{2 \beta_{y}}+\frac{P I_{z} \mu_{y}{ }^{3} C_{y}}{2 A D_{y}{ }^{2}}$ & 0 & 0 & 0 & $\frac{P \rho_{y}}{4 \mu_{y} D_{y}{ }^{2}}+\frac{P I_{z} \mu_{y} \omega_{y}}{2 A D_{y}{ }^{2}}$ & $\frac{M_{z a}}{L}$ & $-\frac{P \gamma_{y}}{2 \beta_{y}}-\frac{P I_{z} \mu_{y}{ }^{3} C_{y}}{2 A D_{y}{ }^{2}}$ & 0 & 0 & 0 & $\frac{P \eta_{y}}{2 \mu_{y} D_{y}{ }^{2}}+\frac{P I_{z} \mu_{y} \Psi_{y}}{2 A D_{y}{ }^{2}}$ \\
\hline$-\frac{P}{L}$ & ( & 0 & 0 & $\frac{M_{y a}}{L}$ & $\frac{M_{z a}}{L}$ & $\frac{P}{L}$ & ( & 0 & 0 & $\frac{M_{y b}}{L}$ & $\frac{M_{z b}}{L}$ \\
\hline 0 & $-\frac{P \alpha_{y}}{\beta_{y}}-\frac{P I_{z} \mu_{y}{ }^{3} C_{y}}{A D_{y}{ }^{2}}$ & 0 & 0 & 0 & $-\frac{P \gamma_{y}}{2 \beta_{y}}-\frac{P I_{z} \mu_{y}{ }^{3} C_{y}}{2 A D_{y}{ }^{2}}$ & 0 & $\frac{P \alpha_{y}}{\beta_{y}}+\frac{P I_{z} \mu_{y}{ }^{3} C_{y}}{A D_{y}{ }^{2}}$ & 0 & 0 & 0 & $-\frac{P \gamma_{y}}{2 \beta_{y}}-\frac{P I_{z} \mu_{y}{ }^{3} C_{y}}{2 A D_{y}{ }^{2}}$ \\
\hline 0 & 0 & $-\frac{P \alpha_{z}}{\beta_{z}}-\frac{P I_{y} \mu_{z}{ }^{3} C_{z}}{A D_{z}{ }^{2}}$ & 0 & $\frac{P \gamma_{z}}{2 \beta_{z}}+\frac{P I_{y} \mu_{z}{ }^{3} C_{z}}{2 A D_{z}{ }^{2}}$ & 0 & 0 & 0 & $\frac{P \alpha_{z}}{\beta_{z}}+\frac{P I_{y} \mu_{z}{ }^{3} C_{z}}{A D_{z}{ }^{2}}$ & 0 & $\frac{P \gamma_{z}}{2 \beta_{z}}+\frac{P I_{y} \mu_{z}{ }^{3} C_{z}}{2 A D_{z}{ }^{2}}$ & 0 \\
\hline 0 & 0 & 0 & 0 & 0 & 0 & 0 & 0 & 0 & 0 & 0 & 0 \\
\hline$\frac{M_{y b}}{L}$ & 0 & $-\frac{P \gamma_{z}}{2 \beta_{z}}-\frac{P I_{y} \mu_{z}{ }^{3} C_{z}}{2 A D_{z}{ }^{2}}$ & 0 & $\frac{P \eta_{z}}{2 \mu_{z} D_{z}{ }^{2}}+\frac{P I_{y} \mu_{z} \Psi_{z}}{2 A D_{z}{ }^{2}}$ & 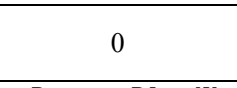 & $\frac{M_{y b}}{L}$ & 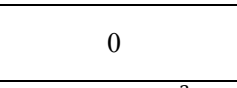 & $\frac{P \gamma_{z}}{2 \beta_{z}}+\frac{P I_{y} \mu_{z}{ }^{3} C_{z}}{2 A D_{z}{ }^{2}}$ & 0 & $\frac{P \rho_{z}}{4 \mu_{z} D_{z}{ }^{2}}+\frac{P I_{y} \mu_{z} \omega_{z}}{2 A D_{z}{ }^{2}}$ & 0 \\
\hline$\frac{M_{z b}}{L}$ & $\frac{P \gamma_{y}}{2 \beta_{y}}+\frac{P I_{z} \mu_{y}{ }^{3} C_{y}}{2 A D_{y}{ }^{2}}$ & $x_{2}$ & 0 & $\therefore 2=28$ & $\frac{P \eta_{y}}{2 \mu_{y} D_{y}{ }^{2}}+\frac{P I_{z} \mu_{y} \Psi_{y}}{2 A D_{y}{ }^{2}}$ & $\frac{M_{z b}}{L}$ & $-\frac{P \gamma_{y}}{2 \beta_{y}}-\frac{P I_{z} \mu_{y}{ }^{3} C_{y}}{2 A D_{y}{ }^{2}}$ & 12 & 0 & $12 z=2$ & $\frac{P \rho_{y}}{4 \mu_{y} D_{y}{ }^{2}}+\frac{P I_{z} \mu_{y} \omega_{y}}{2 A D_{y}{ }^{2}}$ \\
\hline
\end{tabular}

$D_{y}=\mu_{y} L \sinh \left(\mu_{y} L\right)-2 \cosh \left(\mu_{y} L\right)+2 ; C_{y}=\left(\sinh \left(\mu_{y} L\right)-\mu_{y} L\right)\left(\cosh \left(\mu_{y} L\right)-1\right) ; \alpha_{y}=2 L \mu_{y}{ }^{2}+L \mu_{y}{ }^{2} \cosh \left(\mu_{y} L\right)-3 \mu_{y} \sinh \left(\mu_{y} L\right) ; \beta_{y}=4 \cosh \left(\mu_{y} L\right)+\mu_{y}{ }^{2} L^{2}+\mu_{y}{ }^{2} L^{2} \cosh \left(\mu_{y} L\right)-4 \mu_{y} L \operatorname{senh}\left(\mu_{y} L\right)-4 ;$ $D_{z}=\mu_{z} L \sinh \left(\mu_{z} L\right)-2 \cosh \left(\mu_{z} L\right)+2 ; C_{z}=\left(\sinh \left(\mu_{z} L\right)-\mu_{z} L\right)\left(\cosh \left(\mu_{z} L\right)-1\right) ; \alpha_{z}=2 L \mu_{z}^{2}+L \mu_{z}^{2} \cosh \left(\mu_{z} L\right)-3 \mu_{z} \sinh \left(\mu_{z} L\right) ; \beta_{z}=4 \cosh \left(\mu_{z} L\right)+\mu_{z}^{2} L^{2}+\mu_{z}^{2} L^{2} \cosh \left(\mu_{z} L\right)-4 \mu_{z} L \operatorname{senh}\left(\mu_{z} L\right)-4 ;$

$\gamma_{y}=\mu_{y}^{2} L^{2}-4 \cosh \left(\mu_{y} L\right)+\mu_{y} L \sinh \left(\mu_{y} L\right)+4 ; \gamma_{z}=\mu_{z}^{2} L^{2}-4 \cosh \left(\mu_{z} L\right)+\mu_{z} L \sinh \left(\mu_{z} L\right)+4$

$\rho_{y}=2 \sinh \left(2 \mu_{y} L\right)-4 \sinh \left(\mu_{y} L\right)-2 \mu_{y}{ }^{3} L^{3}+4 \mu_{y}{ }^{2} L^{2} \sinh \left(\mu_{y} L\right)+\mu_{y}{ }^{2} L^{2} \sinh \left(2 \mu_{y} L\right)+4 \mu_{y} L \cosh \left(\mu_{y} L\right)-4 \mu_{y} L \cosh \left(2 \mu_{y} L\right) ; \eta_{y}=2 \sinh \left(\mu_{y} L\right)-\sinh \left(2 \mu_{y} L\right)-6 \mu_{y} L+\mu_{y}{ }^{3} L^{3} \cosh \left(\mu_{y} L\right)-3 \mu_{y}{ }^{2} L^{2} \sinh \left(\mu_{y} L\right)+6 \mu_{y} L \cosh \left(\mu_{y} L\right)$

$\rho_{z}=2 \sinh \left(2 \mu_{z} L\right)-4 \sinh \left(\mu_{z} L\right)-2 \mu_{z}{ }^{3} L^{3}+4 \mu_{z}{ }^{2} L^{2} \sinh \left(\mu_{z} L\right)+\mu_{z}{ }^{2} L^{2} \sinh \left(2 \mu_{z} L\right)+4 \mu_{z} L \cosh \left(\mu_{z} L\right)-4 \mu_{z} L \cosh \left(2 \mu_{z} L\right) ; \eta_{z}=2 \sinh \left(\mu_{z} L\right)-\sinh \left(2 \mu_{z} L\right)-6 \mu_{z} L+\mu_{z}{ }^{3} L^{3} \cosh \left(\mu_{z} L\right)-3 \mu_{z}{ }^{2} L^{2} \sinh \left(\mu_{z} L\right)+6 \mu_{z} L \cosh \left(\mu_{z} L\right)$

$\omega_{y}=\sinh \left(2 \mu_{y} L\right)-2 \sinh \left(\mu_{y} L\right)+\mu_{y}{ }^{3} L^{3}-2 \mu_{y}{ }^{2} L^{2} \sinh \left(\mu_{y} L\right)+\frac{\mu_{y}{ }^{2} L^{2} \sinh \left(2 \mu_{y} L\right)}{2}+2 \mu_{y} L \cosh \left(\mu_{y} L\right)-2 \mu_{y} L \cosh \left(\mu_{y} L\right)^{2} ; \Psi_{y}=\left(\sinh \left(\mu_{y} L\right)-\mu_{y} L \cosh \left(\mu_{y} L\right)\right)\left(\mu_{y}{ }^{2} L^{2}-2 \cosh \left(\mu_{y} L\right)+2\right)$

$\omega_{z}=\sinh \left(2 \mu_{z} L\right)-2 \sinh \left(\mu_{z} L\right)+\mu_{z}{ }^{3} L^{3}-2 \mu_{z}{ }^{2} L^{2} \sinh \left(\mu_{z} L\right)+\frac{\mu_{z}{ }^{2} L^{2} \sinh \left(2 \mu_{z} L\right)}{2}+2 \mu_{z} L \cosh \left(\mu_{z} L\right)-2 \mu_{z} L \cosh \left(\mu_{z} L\right)^{2} ; \Psi_{z}=\left(\sinh \left(\mu_{z} L\right)-\mu_{z} L \cosh \left(\mu_{z} L\right)\right)\left(\mu_{z}{ }^{2} L^{2}-2 \cosh \left(\mu_{z} L\right)+2\right)$ 
Apêndice B

B.7

Matriz de Rigidez Local com Funções de Forma Completas: “2a Ordem” (EBBT_Complete) - Compressão

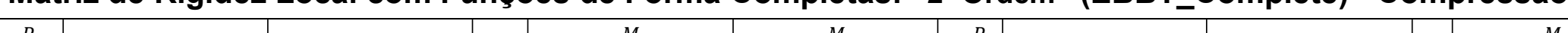

\begin{tabular}{|c|c|c|c|c|c|c|c|c|c|c|c|}
\hline$\frac{P}{L}$ & 0 & 0 & 0 & $-\frac{M_{y a}}{L}$ & $-\frac{M_{z a}}{L}$ & $-\frac{P}{L}$ & 0 & 0 & 0 & $-\frac{M_{y b}}{L}$ & $-\frac{M_{z b}}{L}$ \\
\hline 0 & $\frac{P \alpha_{y}}{\beta_{y}}+\frac{P I_{z} \mu_{y}{ }^{3} C_{y}}{A D_{y}{ }^{2}}$ & 0 & 0 & 0 & $\frac{P \gamma_{y}}{2 \beta_{y}}+\frac{P I_{z} \mu_{y}{ }^{3} C_{y}}{2 A D_{y}{ }^{2}}$ & 0 & $-\frac{P \alpha_{y}}{\beta_{y}}-\frac{P I_{z} \mu_{y}{ }^{3} C_{y}}{A D_{y}{ }^{2}}$ & 0 & 0 & 0 & $\frac{P \gamma_{y}}{2 \beta_{y}}+\frac{P I_{z} \mu_{y}{ }^{3} C_{y}}{2 A D_{y}{ }^{2}}$ \\
\hline 0 & 0 & $\frac{P \alpha_{z}}{\beta_{z}}+\frac{P I_{y} \mu_{z}{ }^{3} C_{z}}{A D_{z}{ }^{2}}$ & 0 & $-\frac{P \gamma_{z}}{2 \beta_{z}}-\frac{P I_{y} \mu_{z}{ }^{3} C_{z}}{2 A D_{z}^{2}}$ & 0 & 0 & 0 & $-\frac{P \alpha_{z}}{\beta_{z}}-\frac{P I_{y} \mu_{z}{ }^{3} C_{z}}{A D_{z}{ }^{2}}$ & 0 & $-\frac{P \gamma_{z}}{2 \beta_{z}}-\frac{P I_{y} \mu_{z}^{3} C_{z}}{2 A D_{z}^{2}}$ & 0 \\
\hline 0 & 0 & 0 & 0 & 0 & 0 & 0 & 0 & 0 & 0 & 0 & 0 \\
\hline$-\frac{M_{y a}}{L}$ & 0 & $-\frac{P \gamma_{z}}{2 \beta_{z}}-\frac{P I_{y} \mu_{z}{ }^{3} C_{z}}{2 A D_{z}{ }^{2}}$ & 0 & $\frac{P \rho_{z}}{4 \mu_{z} D_{z}{ }^{2}}+\frac{P I_{y} \mu_{z} \omega_{z}}{2 A D_{z}{ }^{2}}$ & 0 & $\frac{M_{y a}}{L}$ & 0 & $\frac{P \gamma_{z}}{2 \beta_{z}}+\frac{P I_{y} \mu_{z}{ }^{3} C_{z}}{2 A D_{z}{ }^{2}}$ & 0 & $\frac{P \eta_{z}}{2 \mu_{z} D_{z}{ }^{2}}+\frac{P I_{y} \mu_{z} \Psi_{z}}{2 A D_{z}{ }^{2}}$ & 0 \\
\hline$-\frac{M_{z a}}{L}$ & $\frac{P \gamma_{y}}{2 \beta_{y}}+\frac{P I_{z} \mu_{y}{ }^{3} C_{y}}{2 A D_{y}{ }^{2}}$ & 0 & 0 & 0 & $\frac{P \rho_{y}}{4 \mu_{y} D_{y}{ }^{2}}+\frac{P I_{z} \mu_{y} \omega_{y}}{2 A D_{y}{ }^{2}}$ & $\frac{M_{z a}}{L}$ & $-\frac{P \gamma_{y}}{2 \beta_{y}}-\frac{P I_{z} \mu_{y}{ }^{3} C_{y}}{2 A D_{y}{ }^{2}}$ & 0 & 0 & 0 & $\frac{P \eta_{y}}{2 \mu_{y} D_{y}{ }^{2}}+\frac{P I_{z} \mu_{y} \Psi_{y}}{2 A D_{y}{ }^{2}}$ \\
\hline$-\frac{P}{L}$ & 0 & 0 & 0 & $\frac{M_{y a}}{L}$ & $\frac{M_{z a}}{L}$ & $\frac{P}{L}$ & 0 & 0 & 0 & $\frac{M_{y b}}{L}$ & $\frac{M_{z b}}{L}$ \\
\hline 0 & $-\frac{P \alpha_{y}}{\beta_{y}}-\frac{P I_{z} \mu_{y}{ }^{3} C_{y}}{A D_{y}{ }^{2}}$ & 0 & 0 & 0 & $-\frac{P \gamma_{y}}{2 \beta_{y}}-\frac{P I_{z} \mu_{y}{ }^{3} C_{y}}{2 A D_{y}{ }^{2}}$ & 0 & $\frac{P \alpha_{y}}{\beta_{y}}+\frac{P I_{z} \mu_{y}{ }^{3} C_{y}}{A D_{y}{ }^{2}}$ & 0 & 0 & 0 & $-\frac{P \gamma_{y}}{2 \beta_{y}}-\frac{P I_{z} \mu_{y}{ }^{3} C_{y}}{2 A D_{y}{ }^{2}}$ \\
\hline 0 & 0 & $-\frac{P \alpha_{z}}{\beta_{z}}-\frac{P I_{y} \mu_{z}{ }^{3} C_{z}}{A D_{z}{ }^{2}}$ & 0 & $\frac{P \gamma_{z}}{2 \beta_{z}}+\frac{P I_{y} \mu_{z}{ }^{3} C_{z}}{2 A D_{z}{ }^{2}}$ & 0 & 0 & 0 & $\frac{P \alpha_{z}}{\beta_{z}}+\frac{P I_{y} \mu_{z}{ }^{3} C_{z}}{A D_{z}{ }^{2}}$ & 0 & $\frac{P \gamma_{z}}{2 \beta_{z}}+\frac{P I_{y} \mu_{z}{ }^{3} C_{z}}{2 A D_{z}{ }^{2}}$ & 0 \\
\hline 0 & 0 & 0 & 0 & 0 & 0 & 0 & 0 & 0 & 0 & 0 & 0 \\
\hline$\frac{M_{y b}}{L}$ & 0 & $-\frac{P \gamma_{z}}{2 \beta_{z}}-\frac{P I_{y} \mu_{z}{ }^{3} C_{z}}{2 A D_{z}{ }^{2}}$ & 0 & $\frac{P \eta_{z}}{2 \mu_{z} D_{z}{ }^{2}}+\frac{P I_{y} \mu_{z} \Psi_{z}}{2 A D_{z}{ }^{2}}$ & 0 & $\frac{M_{y b}}{L}$ & 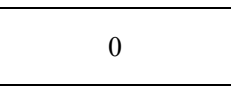 & $\frac{P \gamma_{z}}{2 \beta_{z}}+\frac{P I_{y} \mu_{z}{ }^{3} C_{z}}{2 A D_{z}{ }^{2}}$ & 0 & $\frac{P \rho_{z}}{4 \mu_{z} D_{z}{ }^{2}}+\frac{P I_{y} \mu_{z} \omega_{z}}{2 A D_{z}{ }^{2}}$ & 0 \\
\hline$\frac{M_{z b}}{L}$ & $\frac{P \gamma_{y}}{2 \beta_{y}}+\frac{P I_{z} \mu_{y}{ }^{3} C_{y}}{2 A D_{y}{ }^{2}}$ & $L_{P Z} \quad L_{1} D_{Z}$ & 0 & $\mu_{Z}=Z_{Z} \quad-N_{Z}$ & $\frac{P \eta_{y}}{2 \mu_{y} D_{y}{ }^{2}}+\frac{P I_{z} \mu_{y} \Psi_{y}}{2 A D_{y}{ }^{2}}$ & $\frac{M_{z b}}{L}$ & $-\frac{P \gamma_{y}}{2 \beta_{y}}-\frac{P I_{z} \mu_{y}{ }^{3} C_{y}}{2 A D_{y}{ }^{2}}$ & $-4 P_{Z} \quad L 1 D_{Z}$ & 0 & $x_{Z}=Z$ & $\frac{P \rho_{y}}{4 \mu_{y} D_{y}{ }^{2}}+\frac{P I_{z} \mu_{y} \omega_{y}}{2 A D_{y}{ }^{2}}$ \\
\hline
\end{tabular}

$D_{y}=4 \sin \left(\mu_{y} L / 2\right)^{2}-\mu_{y} L \sin \left(\mu_{y} L\right) ; C_{y}=2 \sin \left(\mu_{y} L / 2\right)^{2}\left(\mu_{y} L-\sin \left(\mu_{y} L\right)\right) ; \alpha_{y}=2 L \mu_{y}{ }^{2}+L \mu_{y}{ }^{2} \cos \left(\mu_{y} L\right)-3 \mu_{y} \sin \left(\mu_{y} L\right) ; \beta_{y}=\mu_{y}{ }^{2} L^{2}-4 \cos \left(\mu_{y} L\right)+\mu_{y}{ }^{2} L^{2} \cos \left(\mu_{y} L\right)-4 \mu_{y} L \operatorname{sen}\left(\mu_{y} L\right)+4 ;$

$D_{z}=4 \sin \left(\mu_{z} L / 2\right)^{2}-\mu_{z} L \sin \left(\mu_{z} L\right) ; C_{z}=2 \sin \left(\mu_{z} L / 2\right)^{2}\left(\mu_{z} L-\sin \left(\mu_{z} L\right)\right) ; \alpha_{z}=2 L \mu_{z}{ }^{2}+L \mu_{z}^{2} \cos \left(\mu_{z} L\right)-3 \mu_{z} \sin \left(\mu_{z} L\right) ; \beta_{z}=\mu_{z}^{2} L^{2}-4 \cos \left(\mu_{z} L\right)+\mu_{z}^{2} L^{2} \cos \left(\mu_{z} L\right)-4 \mu_{z} L \operatorname{sen}\left(\mu_{z} L\right)+4 ;$

$\gamma_{y}=\mu_{y}^{2} L^{2}+4 \cos \left(\mu_{y} L\right)+\mu_{y} L \sin \left(\mu_{y} L\right)-4 ; \gamma_{z}=\mu_{z}^{2} L^{2}+4 \cos \left(\mu_{z} L\right)+\mu_{z} L \sin \left(\mu_{z} L\right)-4$

$\rho_{y}=2 \sin \left(2 \mu_{y} L\right)-4 \sin \left(\mu_{y} L\right)+2 \mu_{y}{ }^{3} L^{3}-4 \mu_{y}{ }^{2} L^{2} \sin \left(\mu_{y} L\right)-\mu_{y}{ }^{2} L^{2} \sin \left(2 \mu_{y} L\right)+4 \mu_{y} L \cos \left(\mu_{y} L\right)-4 \mu_{y} L \cos \left(2 \mu_{y} L\right) ; \eta_{y}=2 \sin \left(\mu_{y} L\right)-\sin \left(2 \mu_{y} L\right)-6 \mu_{y} L-\mu_{y}{ }^{3} L^{3} \cos \left(\mu_{y} L\right)+3 \mu_{y}{ }^{2} L^{2} \sin \left(\mu_{y} L\right)+6 \mu_{y} L \cos \left(\mu_{y} L\right)$

$\rho_{z}=2 \sin \left(2 \mu_{z} L\right)-4 \sin \left(\mu_{z} L\right)+2 \mu_{z}{ }^{3} L^{3}-4 \mu_{z}{ }^{2} L^{2} \sin \left(\mu_{z} L\right)-\mu_{z}{ }^{2} L^{2} \sin \left(2 \mu_{z} L\right)+4 \mu_{z} L \cos \left(\mu_{z} L\right)-4 \mu_{z} L \cos \left(2 \mu_{z} L\right) ; \eta_{z}=2 \sin \left(\mu_{z} L\right)-\sin \left(2 \mu_{z} L\right)-6 \mu_{z} L-\mu_{z}{ }^{3} L^{3} \cos \left(\mu_{z} L\right)+3 \mu_{z}{ }^{2} L^{2} \sin \left(\mu_{z} L\right)+6 \mu_{z} L \cos \left(\mu_{z} L\right)$

$\omega_{y}=2 \sin \left(\mu_{y} L\right)-\sin \left(2 \mu_{y} L\right)+\mu_{y}{ }^{3} L^{3}-2 \mu_{y}{ }^{2} L^{2} \sin \left(\mu_{y} L\right)+\frac{\mu_{y}{ }^{2} L^{2} \sin \left(2 \mu_{y} L\right)}{2}-2 \mu_{y} L \cos \left(\mu_{y} L\right)+2 \mu_{y} L \cos \left(\mu_{y} L\right)^{2} ; \Psi_{y}=\left(\sin \left(\mu_{y} L\right)-\mu_{y} L \cos \left(\mu_{y} L\right)\right)\left(\mu_{y}{ }^{2} L^{2}+2 \cos \left(\mu_{y} L\right)-2\right)$

$\omega_{z}=2 \sin \left(\mu_{z} L\right)-\sin \left(2 \mu_{z} L\right)+\mu_{z}{ }^{3} L^{3}-2 \mu_{z}^{2} L^{2} \sin \left(\mu_{z} L\right)+\frac{\mu_{z}^{2} L^{2} \sin \left(2 \mu_{z} L\right)}{2}-2 \mu_{z} L \cos \left(\mu_{z} L\right)+2 \mu_{z} L \cos \left(\mu_{z} L\right)^{2} ; \Psi_{z}=\left(\sin \left(\mu_{z} L\right)-\mu_{z} L \cos \left(\mu_{z} L\right)\right)\left(\mu_{z}{ }^{2} L^{2}+2 \cos \left(\mu_{z} L\right)-2\right)$ 
Apêndice B

B.8

Matriz de Rigidez Local com Funções de Forma Completas: Interação Torção com Carga Axial (EBBT_Complete) - Tração

\begin{tabular}{|c|c|c|c|c|c|c|c|c|c|c|c|}
\hline 0 & 0 & 0 & 0 & 0 & 0 & 0 & 0 & 0 & 0 & 0 & 0 \\
\hline 0 & 0 & 0 & $\frac{M_{y a}}{L}$ & $-\frac{M_{x b} \mu_{y}{ }^{2} \psi}{\left(\mu_{y}{ }^{2}-\mu_{z}{ }^{2}\right) D_{y}}$ & 0 & 0 & 0 & 0 & $\frac{M_{y b}}{L}$ & $\frac{M_{x b} \mu_{y}^{2} \psi}{\left(\mu_{y}{ }^{2}-\mu_{z}{ }^{2}\right) D_{y}}$ & 0 \\
\hline 0 & 0 & 0 & $\frac{M_{z a}}{L}$ & 0 & $-\frac{M_{x b} \mu_{z}{ }^{2} \psi}{\left(\mu_{y}{ }^{2}-\mu_{z}{ }^{2}\right) D_{z}}$ & 0 & 0 & 0 & $\frac{M_{z b}}{L}$ & 0 & $\frac{M_{x b} \mu_{z}^{2} \psi}{\left(\mu_{y}^{2}-\mu_{z}^{2}\right) D_{z}}$ \\
\hline 0 & $\frac{M_{y a}}{L}$ & $\frac{M_{z a}}{L}$ & $\frac{J_{p} P}{A L}$ & $\frac{\left(M_{z a}+M_{z b}\right) \varphi_{z}}{L^{2} \mu_{z}^{2} \phi_{z}}-\frac{M_{z a}}{2}$ & $-\frac{\left(M_{y a}+M_{y b}\right) \varphi_{y}}{L^{2} \mu_{y}^{2} \phi_{y}}+\frac{M_{y a}}{2}$ & 0 & $-\frac{M_{y a}}{L}$ & $-\frac{M_{z a}}{L}$ & $-\frac{J_{p} P}{A L}$ & $-\frac{\left(M_{z a}+M_{z b}\right) \varphi_{z}}{L^{2} \mu_{z}^{2} \phi_{z}}$ & $\frac{\left(M_{y a}+M_{y b}\right) \varphi_{y}}{L^{2} \mu_{y}^{2} \phi_{y}}$ \\
\hline 0 & $\frac{M_{x b} \mu_{y}^{2} \psi}{\left(\mu_{y}{ }^{2}-\mu_{z}^{2}\right) D_{y}}$ & 0 & $\frac{\left(M_{z a}+M_{z b}\right) \varphi_{z}}{L^{2} \mu_{z}^{2} \phi_{z}}-\frac{M_{z a}}{2}$ & 0 & $-\frac{M_{x b} L \varphi_{1}}{\left(\mu_{y}^{2}-\mu_{z}^{2}\right) D}$ & 0 & $\frac{M_{x b} \mu_{y}{ }^{2} \psi}{\left(\mu_{y}{ }^{2}-\mu_{z}{ }^{2}\right) D_{y}}$ & 0 & $-\frac{\left(M_{z a}+M_{z b}\right) \varphi_{z}}{L^{2} \mu_{z}{ }^{2} \phi_{z}}$ & 0 & $-\frac{M_{x b} \varphi_{2}}{\left(\mu_{y}^{2}-\mu_{z}^{2}\right) D}$ \\
\hline 0 & 0 & $\frac{M_{x b} \mu_{z}^{2} \psi}{\left(\mu_{y}{ }^{2}-\mu_{z}{ }^{2}\right) D_{z}}$ & $-\frac{\left(M_{y a}+M_{y b}\right) \varphi_{y}}{L^{2} \mu_{y}^{2} \phi_{y}}+\frac{M_{y a}}{2}$ & $-\frac{M_{x b} L \varphi_{1}}{\left(\mu_{y}{ }^{2}-\mu_{z}{ }^{2}\right) D}$ & 0 & 0 & 0 & $\frac{M_{x b} \mu_{z}^{2} \psi}{\left(\mu_{y}{ }^{2}-\mu_{z}^{2}\right) D_{z}}$ & $\frac{\left(M_{y a}+M_{y b}\right) \varphi_{y}}{L^{2} \mu_{y}{ }^{2} \phi_{y}}$ & $\frac{M_{x b} \varphi_{2}}{\left(\mu_{y}^{2}-\mu_{z}^{2}\right) D}$ & 0 \\
\hline 0 & 0 & \begin{tabular}{l|}
0 \\
\end{tabular} & $\begin{array}{c}0 \\
\end{array}$ & 0 & 0 & 0 & 0 & 0 & 0 & 0 & 0 \\
\hline 0 & 0 & 0 & $-\frac{M_{y a}}{L}$ & $\frac{M_{x} \mu_{y}{ }^{2} \psi}{\left(\mu_{y}^{2}-\mu_{z}{ }^{2}\right) D_{y}}$ & 0 & 0 & 0 & 0 & $-\frac{M_{y b}}{L}$ & $-\frac{M_{x b} \mu_{y}{ }^{2} \psi}{\left(\mu_{y}{ }^{2}-\mu_{z}{ }^{2}\right) D_{y}}$ & 0 \\
\hline 0 & 0 & 0 & $-\frac{M_{z a}}{L}$ & 0 & $\frac{M_{x b} \mu_{z}{ }^{2} \psi}{\left(\mu_{y}{ }^{2}-\mu_{z}{ }^{2}\right) D_{z}}$ & 0 & 0 & 0 & $-\frac{M_{z b}}{L}$ & 0 & $-\frac{M_{x b} \mu_{z}^{2} \psi}{\left(\mu_{y}{ }^{2}-\mu_{z}{ }^{2}\right) D_{z}}$ \\
\hline 0 & $\frac{M_{y b}}{L}$ & $\frac{M_{z b}}{L}$ & $-\frac{J_{p} P}{A L}$ & $-\frac{\left(M_{z a}+M_{z b}\right) \varphi_{z}}{L^{2} \mu_{z}^{2} \phi_{z}}$ & $\frac{\left(M_{y a}+M_{y b}\right) \varphi_{y}}{L^{2} \mu_{y}{ }^{2} \phi_{y}}$ & 0 & $-\frac{M_{y b}}{L}$ & $-\frac{M_{z b}}{L}$ & $\frac{J_{p} P}{A L}$ & $\frac{\left(M_{z a}+M_{z b}\right) \varphi_{z}}{L^{2} \mu_{z}{ }^{2} \phi_{z}}-\frac{M_{z b}}{2}$ & $-\frac{\left(M_{y a}+M_{y b}\right) \varphi_{y}}{L^{2} \mu_{y} \phi_{y}}+\frac{M_{y b}}{2}$ \\
\hline 0 & $\frac{M_{x b} \mu_{y}^{2} \psi}{\left(\mu_{y}^{2}-\mu_{z}^{2}\right) D_{y}}$ & 0 & $-\frac{\left(M_{z a}+M_{z b}\right) \varphi_{z}}{L^{2} \mu_{z}^{2} \phi_{z}}$ & 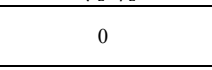 & $\frac{M_{x b} \varphi_{2}}{\left(\mu_{y}{ }^{2}-\mu_{z}{ }^{2}\right) D}$ & 0 & $-\frac{M_{x b} \mu_{y}{ }^{2} \psi}{\left(\mu_{y}{ }^{2}-\mu_{z}{ }^{2}\right) D_{y}}$ & 0 & $\frac{\left(M_{z a}+M_{z b}\right) \varphi_{z}}{L^{2} \mu_{z} \phi_{z}}-\frac{M_{z b}}{2}$ & 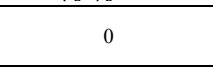 & $\frac{M_{x b} L \varphi_{1}}{\left(\mu_{y}{ }^{2}-\mu_{z}{ }^{2}\right) D}$ \\
\hline 0 & 0 & $\frac{M_{x b} \mu_{z}{ }^{2} \psi}{\left(\mu_{y}{ }^{2}-\mu_{z}{ }^{2}\right) D_{z}}$ & $\frac{\left(M_{y a}+M_{y b}\right) \varphi_{y}}{L^{2} \mu_{y}{ }^{2} \phi_{y}}$ & $-\frac{M_{x b} \varphi_{2}}{\left(\mu_{y}{ }^{2}-\mu_{z}{ }^{2}\right) D}$ & 0 & 0 & 0 & $-\frac{M_{x b} \mu_{z}{ }^{2} \psi}{\left(\mu_{y}{ }^{2}-\mu_{z}{ }^{2}\right) D_{z}}$ & $-\frac{\left(M_{y a}+M_{y b}\right) \varphi_{y}}{L^{2} \mu_{y}{ }^{2} \phi_{y}}+\frac{M_{y b}}{2}$ & $\frac{M_{x b} L \varphi_{1}}{\left(\mu_{y}{ }^{2}-\mu_{z}{ }^{2}\right) D}$ & 0 \\
\hline
\end{tabular}

$\varphi_{y}=\left[\mu_{y} L-2 \sinh \left(\mu_{y} L\right)-2 \cosh \left(\mu_{y} L\right)+\mu_{y} L\left(\cosh \left(\mu_{y} L\right)+\sinh \left(\mu_{y} L\right)-1\right)\right] ; \phi_{y}=\left(\cosh \left(\mu_{y} L\right)+\sinh \left(\mu_{y} L\right)-1\right) ; D_{y}=\sinh \left(\frac{\mu_{z} L}{2}\right)\left(2 \sinh \left(\frac{\mu_{y} L}{2}\right)-\mu_{y} L \cosh \left(\frac{\mu_{y} L}{2}\right)\right)$

$\varphi_{z}=\left[\mu_{z} L-2 \sinh \left(\mu_{z} L\right)-2 \cosh \left(\mu_{z} L\right)+\mu_{z} L\left(\cosh \left(\mu_{z} L\right)+\sinh \left(\mu_{z} L\right)-1\right)\right] ; \phi_{z}=\left(\cosh \left(\mu_{z} L\right)+\sinh \left(\mu_{z} L\right)-1\right) ; D_{z}=\sinh \left(\frac{\mu_{y} L}{2}\right)\left(2 \sinh \left(\frac{\mu_{z} L}{2}\right)-\mu_{z} L \cosh \left(\frac{\mu_{z} L}{2}\right)\right) ; \psi=\mu_{y} \cosh \left(\frac{\mu_{y} L}{2}\right) \sinh \left(\frac{\mu_{z} L}{2}\right)-\mu_{z} \cosh \left(\frac{\mu_{z} L}{2}\right) \sinh \left(\frac{\mu_{y} L}{2}\right)$

$D=2\left(4 \sinh \left(\frac{L \mu_{y}}{2}\right)^{2}-L \mu_{y} \sinh \left(L \mu_{y}\right)\right)\left(4 \sinh \left(\frac{L \mu_{z}}{2}\right)^{2}-L \mu_{z} \sinh \left(L \mu_{z}\right)\right.$ 
$\varphi_{1}=4 \mu_{y} \mu_{z}^{2} \sinh \left(L \mu_{y}\right)-4 \mu_{z}^{3} \sinh \left(L \mu_{z}\right)-4 \mu_{y}^{3} \sinh \left(L \mu_{y}\right)+4 \mu_{y}^{2} \mu_{z} \sinh \left(L \mu_{z}\right)+8 \mu_{y}^{3} \cosh \left(\frac{L \mu_{y}}{2}\right) \cosh \left(\frac{L \mu_{z}}{2}\right)^{2} \sinh \left(\frac{L \mu_{y}}{2}\right)+8 \mu_{z}^{3} \cosh \left(\frac{L \mu_{y}}{2}\right)^{2} \cosh \left(\frac{L \mu_{z}}{2}\right) \sinh \left(\frac{L \mu_{z}}{2}\right)+4 L \mu_{y}^{2} \mu_{z}^{2} \sinh \left(\frac{L \mu_{y}}{2}\right)^{2}+4 L \mu_{y}^{2} \mu_{z}^{2} \sinh \left(\frac{L \mu_{z}}{2}\right)^{2}+$ 
B.9

Matriz de Rigidez Local com Funções de Forma Completas: Interação Torção com Carga Axial (EBBT_Complete) -

Compressão

\begin{tabular}{|c|c|c|c|c|c|c|c|c|c|c|c|}
\hline 0 & 0 & 0 & 0 & 0 & 0 & 0 & 0 & 0 & 0 & 0 & 0 \\
\hline 0 & 0 & 0 & $\frac{M_{y a}}{L}$ & $-\frac{M_{x b} \mu_{y}^{2} \psi_{y}}{\left(\mu_{y}^{2}-\mu_{z}^{2}\right) D}$ & 0 & 0 & 0 & 0 & $\frac{M_{y b}}{L}$ & $\frac{M_{x b} \mu_{y}{ }^{2} \psi_{y}}{\left(\mu_{y}{ }^{2}-\mu_{z}{ }^{2}\right) D}$ & 0 \\
\hline 0 & 0 & 0 & $\frac{M_{z a}}{L}$ & 0 & $-\frac{M_{x b} \mu_{z}^{2} \psi_{z}}{\left(\mu_{y}^{2}-\mu_{z}^{2}\right) D}$ & 0 & 0 & 0 & $\frac{M_{z b}}{L}$ & 0 & $\frac{M_{x b} \mu_{z}^{2} \psi_{z}}{\left(\mu_{y}{ }^{2}-\mu_{z}^{2}\right) D}$ \\
\hline 0 & $\frac{M_{y a}}{L}$ & $\frac{M_{z a}}{L}$ & $\frac{J_{p} P}{A L}$ & $\frac{\left(M_{z a}+M_{z b}\right) \varphi_{z}}{L^{2} \mu_{z}{ }^{2} \phi_{z}}-\frac{M_{z a}}{2}$ & $-\frac{\left(M_{y a}+M_{y b}\right) \varphi_{y}}{L^{2} \mu_{y} \phi_{y}}+\frac{M_{y a}}{2}$ & 0 & $-\frac{M_{y a}}{L}$ & $-\frac{M_{z a}}{L}$ & $-\frac{J_{p} P}{A L}$ & $-\frac{\left(M_{z a}+M_{z b}\right) \varphi_{z}}{L^{2} \mu_{z}^{2} \phi_{z}}$ & $\frac{\left(M_{y a}+M_{y b}\right) \varphi_{y}}{L^{2} \mu_{y}^{2} \phi_{y}}$ \\
\hline 0 & $-\frac{M_{x b} \mu_{y}^{2} \psi_{y}}{\left(\mu_{y}{ }^{2}-\mu_{z}^{2}\right) D}$ & 0 & $\frac{\left(M_{z a}+M_{z b}\right) \varphi_{z}}{L^{2} \mu_{z}^{2} \phi_{z}}-\frac{M_{z a}}{2}$ & 0 & $-\frac{M_{x b} \varphi_{1}}{\left(\mu_{y}{ }^{2}-\mu_{z}{ }^{2}\right) D}$ & 0 & $\frac{M_{x b} \mu_{y}{ }^{2} \psi_{y}}{\left(\mu_{y}{ }^{2}-\mu_{z}^{2}\right) D}$ & 0 & $-\frac{\left(M_{z a}+M_{z b}\right) \varphi_{z}}{L^{2} \mu_{z}^{2} \phi_{z}}$ & 0 & $-\frac{M_{x b} \varphi_{2}}{\left(\mu_{y}^{2}-\mu_{z}^{2}\right) D}$ \\
\hline 0 & 0 & $-\frac{M_{x b} \mu_{z}{ }^{2} \psi_{z}}{\left(\mu_{y}{ }^{2}-\mu_{z}{ }^{2}\right) D}$ & $-\frac{\left(M_{y a}+M_{y b}\right) \varphi_{y}}{L^{2} \mu_{y}{ }^{2} \phi_{y}}+\frac{M_{y a}}{2}$ & $-\frac{M_{x b} \varphi_{1}}{\left(\mu_{y}{ }^{2}-\mu_{z}^{2}\right) D}$ & 0 & 0 & 0 & $\frac{M_{x p} \mu_{z}^{2} \psi_{z}}{\left(\mu_{y}{ }^{2}-\mu_{z}^{2}\right) D}$ & $\frac{\left(M_{y a}+M_{y b}\right) \varphi_{y}}{L^{2} \mu_{y}^{2} \phi_{y}}$ & $\frac{M_{x b} \varphi_{2}}{\left(\mu_{y}^{2}-\mu_{z}^{2}\right) D}$ & 0 \\
\hline 0 & 0 & 0 & 0 & 0 & 0 & 0 & 0 & 0 & 0 & 0 & 0 \\
\hline 0 & 0 & 0 & $-\frac{M_{y a}}{L}$ & $\frac{M_{x b} \mu_{y}{ }^{2} \psi_{y}}{\left(\mu_{y}{ }^{2}-\mu_{z}{ }^{2}\right) D}$ & 0 & 0 & 0 & 0 & $-\frac{M_{y b}}{L}$ & $-\frac{M_{x b} \mu_{y}{ }^{2} \psi_{y}}{\left(\mu_{y}{ }^{2}-\mu_{z}{ }^{2}\right) D}$ & 0 \\
\hline 0 & 0 & 0 & $-\frac{M_{z a}}{L}$ & 0 & $\frac{M_{x p} \mu_{z}{ }^{2} \psi_{z}}{\left(\mu_{y}{ }^{2}-\mu_{z}{ }^{2}\right) D}$ & 0 & 0 & 0 & $-\frac{M_{z b}}{L}$ & 0 & $-\frac{M_{x b} \mu_{z}{ }^{2} \psi_{z}}{\left(\mu_{y}{ }^{2}-\mu_{z}{ }^{2}\right) D}$ \\
\hline 0 & $\frac{M_{y b}}{L}$ & $\frac{M_{z b}}{L}$ & $-\frac{J_{p} P}{A L}$ & $-\frac{\left(M_{z a}+M_{z b}\right) \varphi_{z}}{L^{2} \mu_{z}^{2} \phi_{z}}$ & $\frac{\left(M_{y a}+M_{y b}\right) \varphi_{y}}{L^{2} \mu_{y}^{2} \phi_{y}}$ & 0 & $-\frac{M_{y b}}{L}$ & $-\frac{M_{z b}}{L}$ & $\frac{J_{p} P}{A L}$ & $\frac{\left(M_{z a}+M_{z b}\right) \varphi_{z}}{L^{2} \mu_{z}{ }^{2} \phi_{z}}-\frac{M_{z b}}{2}$ & $-\frac{\left(M_{y a}+M_{y b}\right) \varphi_{y}}{L^{2} \mu_{y}{ }^{2} \phi_{y}}+\frac{M_{y b}}{2}$ \\
\hline 0 & $\frac{M_{x b} \mu_{y}{ }^{2} \psi_{y}}{\left(\mu_{y}{ }^{2}-\mu_{z}^{2}\right) D}$ & 0 & $-\frac{\left(M_{z a}+M_{z b}\right) \varphi_{z}}{L^{2} \mu_{z}^{2} \phi_{z}}$ & 0 & $\frac{M_{x b} \varphi_{2}}{\left(\mu_{y}^{2}-\mu_{z}^{2}\right) D}$ & 0 & $-\frac{M_{x b} \mu_{y}{ }^{2} \psi_{y}}{\left(\mu_{y}{ }^{2}-\mu_{z}^{2}\right) D}$ & 0 & $\frac{\left(M_{z a}+M_{z b}\right) \varphi_{z}}{L^{2} \mu_{z}^{2} \phi_{z}}-\frac{M_{z b}}{2}$ & 0 & $\frac{M_{x b} \varphi_{1}}{\left(\mu_{y}{ }^{2}-\mu_{z}^{2}\right) D}$ \\
\hline 0 & 0 & $\frac{M_{x b} \mu_{z}^{2} \psi_{z}}{\left(\mu_{y}{ }^{2}-\mu_{z}{ }^{2}\right) D}$ & $\frac{\left(M_{y a}+M_{y b}\right) \varphi_{y}}{L^{2} \mu_{y}^{2} \phi_{y}}$ & $-\frac{M_{x b} \varphi_{2}}{\left(\mu_{y}-\mu_{z}^{2}\right) D}$ & 0 & 0 & 0 & $-\frac{M_{x b} \mu_{z}{ }^{2} \psi_{z}}{\left(\mu_{y}{ }^{2}-\mu_{z}{ }^{2}\right) D}$ & $-\frac{\left(M_{y a}+M_{y b}\right) \varphi_{y}}{L^{2} \mu_{y}{ }^{2} \phi_{y}}+\frac{M_{y b}}{2}$ & $\frac{M_{x b} \varphi_{1}}{\left(\mu_{y}{ }^{2}-\mu_{z}{ }^{2}\right) D}$ & 0 \\
\hline
\end{tabular}

$\varphi_{y}=\left[4 \cos \left(\mu_{y} L\right)-\mu_{y}{ }^{2} L^{2}-\mu_{y}{ }^{2} L^{2} \cos \left(\mu_{y} L\right)+4 \mu_{y} L \sin \left(\mu_{y} L\right)-4\right] ; \phi_{y}=\left(2 \cos \left(\mu_{y} L\right)+\mu_{y} L \sin \left(\mu_{y} L\right)-2\right)$

$\varphi_{z}=\left[4 \cos \left(\mu_{z} L\right)-\mu_{z}^{2} L^{2}-\mu_{z}^{2} L^{2} \cos \left(\mu_{z} L\right)+4 \mu_{z} L \sin \left(\mu_{z} L\right)-4\right] ; \phi_{z}=\left(2 \cos \left(\mu_{z} L\right)+\mu_{z} L \sin \left(\mu_{z} L\right)-2\right)$

$D=\left(4 \sin \left(\frac{L \mu_{y}}{2}\right)^{2}-L \mu_{y} \sin \left(L \mu_{y}\right)\right)\left(4 \sin \left(\frac{L \mu_{z}}{2}\right)^{2}-L \mu_{z} \sin \left(L \mu_{z}\right)\right)$

$\psi_{y}=\mu_{y}^{2}\left(4 \mu_{y} \sin \left(L \mu_{y}\right) \sin \left(\frac{L \mu_{z}}{2}\right)^{2}-4 \mu_{z} \sin \left(L \mu_{z}\right) \sin \left(\frac{L \mu_{y}}{2}\right)^{2}\right)-L \mu_{y}^{2}\left(4 \mu_{z}^{2} \sin \left(\frac{L \mu_{y}}{2}\right)^{2} \sin \left(\frac{L \mu_{z}}{2}\right)^{2}-4 \mu_{z}^{2} \sin \left(\frac{L \mu_{y}}{2}\right)^{2}+\mu_{y} \mu_{z} \sin \left(L \mu_{y}\right) \sin \left(L \mu_{z}\right)\right)$ 
Apêndice $B$

$\psi_{z}=\mu_{z}^{2}\left(4 \mu_{y} \sin \left(L \mu_{y}\right) \sin \left(\frac{L \mu_{z}}{2}\right)^{2}-4 \mu_{z} \sin \left(L \mu_{z}\right) \sin \left(\frac{L \mu_{y}}{2}\right)^{2}\right)+L \mu_{z}^{2}\left(4 \mu_{y}^{2} \sin \left(\frac{L \mu_{y}}{2}\right)^{2} \sin \left(\frac{L \mu_{z}}{2}\right)^{2}-4 \mu_{y}^{2} \sin \left(\frac{L \mu_{z}}{2}\right)^{2}+\mu_{y} \mu_{z} \sin \left(L \mu_{y}\right) \sin \left(L \mu_{z}\right)\right)$

$$
\begin{aligned}
& \varphi_{1}=\frac{L\left(4 \mu_{y}^{3} \sin \left(L \mu_{y}\right) \sin \left(\frac{L \mu_{z}}{2}\right)^{2}+4 \mu_{z}^{3} \sin \left(L \mu_{z}\right) \sin \left(\frac{L \mu_{y}}{2}\right)^{2}-4 \mu_{y} \mu_{z}^{2} \sin \left(L \mu_{y}\right) \sin \left(\frac{L \mu_{z}}{2}\right)^{2}-4 \mu_{y}^{2} \mu_{z} \sin \left(L \mu_{z}\right) \sin \left(\frac{L \mu_{y}}{2}\right)^{2}+4 L \mu_{y}^{2} \mu_{z}^{2} \sin \left(\frac{L \mu_{y}}{2}\right)^{2}+4 L \mu_{y}^{2} \mu_{z}^{2} \sin \left(\frac{L \mu_{z}}{2}\right)^{2}-8 L \mu_{y}^{2} \mu_{z}^{2} \sin \left(\frac{L \mu_{y}}{2}\right)^{2} \sin \left(\frac{L \mu_{z}}{2}\right)^{2}\right)}{2}-\frac{L^{2} \mu_{y} \mu_{z} \sin \left(L \mu_{y}\right) \sin \left(L \mu_{z} z\left(\mu_{y}^{2}+\mu_{z}^{2}\right)\right.}{2} \\
& \varphi_{2}=\mu_{z}^{2}\left(2 \mu_{y}^{2}\left(L^{2} \sin \left(\frac{L \mu_{y}}{2}\right)^{2}-L^{2} \sin \left(\frac{L \mu_{z}}{2}\right)^{2}\right)-8 \sin \left(\frac{L \mu_{y}}{2}\right)^{2} \sin \left(\frac{L \mu_{z}}{2}\right)^{2}+4 L \mu_{y} \sin \left(L \mu_{y}\right) \sin \left(\frac{L \mu_{z}}{2}\right)^{2}\right)+8 \mu_{y}^{2} \sin \left(\frac{L \mu_{y}}{2}\right)^{2} \sin \left(\frac{L \mu_{z}}{2}\right)^{2}-4 L \mu_{y}^{2} \mu_{z} \sin \left(L \mu_{z}\right) \sin \left(\frac{L \mu_{y}}{2}\right)^{2}
\end{aligned}
$$


Apêndice $B$

B.10

Matriz de Rigidez Local com Aproximação em Série de Taylor (EBBT_2tr; EBBT_3tr e EBBT_4tr)

\begin{tabular}{|c|c|c|c|c|c|c|c|c|c|c|c|}
\hline $\begin{array}{l}\frac{P}{L} \\
+\frac{E A}{L}\end{array}$ & 0 & 0 & 0 & $-\frac{M_{y a}}{L}$ & $-\frac{M_{z a}}{L}$ & $\begin{array}{c}P \\
-\frac{P}{L} \\
-\frac{E A}{L}\end{array}$ & 0 & 0 & 0 & $-\frac{M_{y b}}{L}$ & $-\frac{M_{z b}}{L}$ \\
\hline 0 & $\begin{array}{l}\frac{12 E I_{z}}{L^{3}}+P\left(\frac{6}{5 L}+\frac{12 I_{z}}{A L^{3}}\right) \\
+P^{2}\left(-\frac{L}{700 E I_{z}}\right) \\
+P^{3}\left(\frac{\frac{L^{3}}{21000}+\frac{L I_{z}}{7\left(E I_{z}\right)^{2}}}{31500\left(E I_{z}\right)^{2}}\right)\end{array}$ & 0 & $\frac{M_{y a}}{L}$ & $\begin{array}{l}\frac{M_{x 2}}{L}+P\left(-\frac{L M_{x 2}}{60 E I_{y}}\right) \\
+P^{2}\left(\frac{L^{3} M_{x 2}}{2520\left(E I_{y}\right)^{2}}\right. \\
\left.+\frac{L^{3} M_{x 2}}{8400 E^{2} I_{y} I_{z}}\right) \\
-P^{3}\left(\frac{L^{5} M_{x 2}}{100800\left(E I_{y}\right)^{3}}\right. \\
+\frac{L^{5} M_{x 2}}{756000 E^{3} I_{y} I_{z}{ }^{2}} \\
\left.+\frac{L^{5} M_{x 2}}{302400 E^{3} I_{y} I_{z}}\right) \\
\end{array}$ & $\begin{array}{l}\frac{6 E I_{z}}{L^{2}}+P\left(\frac{6 I_{z}}{A A^{2}}+\frac{1}{10}\right) \\
+P^{2}\left(-\frac{L^{2}}{1400 E I_{z}}\right) \\
+P^{3}\left(\frac{L^{4}}{\frac{42000}{120 I^{2}}+\frac{L^{2} I_{z}}{\left(E I_{z}\right)^{2}}}\right. \\
\left.-\frac{L^{4}}{63000\left(E I_{z}\right)^{2}}\right)\end{array}$ & 0 & $\begin{array}{l}-\frac{12 E I_{z}}{L^{3}} \\
-P\left(\frac{6}{5 L}+\frac{12 I_{z}}{A L^{3}}\right) \\
+P^{2}\left(\frac{L}{700 E I_{z}}\right) \\
+P^{3}\left(-\frac{L^{3}}{21000}+\frac{L I_{z}}{700 A}\right. \\
\left.+\frac{L^{3}}{31500\left(E I_{z}\right)^{2}}\right)\end{array}$ & 0 & $\frac{M_{y b}}{L}$ & $\begin{array}{l}-\frac{M_{x 2}}{L}+P\left(\frac{L M_{x 2}}{60 E I_{y}}\right) \\
-P^{2}\left(\frac{L^{3} M_{x 2}}{2520\left(E I_{y}\right)^{2}}\right. \\
\left.+\frac{L^{3} M_{x 2}}{8400 E^{2} I_{y} I_{z}}\right) \\
+P^{3}\left(\frac{L^{5} M_{x 2}}{100800\left(E I_{y}\right)^{3}}\right. \\
+\frac{L^{5} M_{x 2}}{756000 E^{3} I_{y} I_{z}{ }^{2}} \\
\left.+\frac{L^{5} M_{x 2}}{302400 E^{3} I_{y} I_{z}}\right) \\
\end{array}$ & $\begin{array}{l}\frac{6 E I_{z}}{L^{2}}+P\left(\frac{6 I_{z}}{A L^{2}}+\frac{1}{10}\right) \\
+P^{2}\left(-\frac{L^{2}}{1400 E I_{z}}\right) \\
+P^{3}\left(\frac{L^{4}}{\frac{42000}{\left(E I_{z}\right)^{2}} \frac{L^{2} I_{z}}{(400 A}}\right. \\
\left.-\frac{L^{4}}{63000\left(E I_{z}\right)^{2}}\right)\end{array}$ \\
\hline 0 & 0 & $\begin{array}{l}\frac{12 E I_{y}}{L^{3}}+P\left(\frac{6}{5 L}+\frac{12 I_{y}}{A L^{3}}\right) \\
+P^{2}\left(-\frac{L}{700 E I_{y}}\right) \\
+P^{3}\left(\frac{L^{3}}{\frac{21000}{\left(E I_{y}\right)^{2}}+\frac{L I_{y}}{2}}\right. \\
\left.-\frac{L^{3}}{31500\left(E I_{y}\right)^{2}}\right)\end{array}$ & $\frac{M_{z a}}{L}$ & $\begin{array}{l}-\frac{6 E I_{y}}{L^{2}}-P\left(\frac{6 I_{y}}{A L^{2}}+\frac{1}{10}\right) \\
+P^{2}\left(\frac{L^{2}}{1400 E I_{y}}\right) \\
+P^{3}\left(-\frac{L^{4}}{42000}+\frac{L^{2} I_{y}}{1400 A}\right. \\
\left(E I_{y}\right)^{2} \\
\left.+\frac{L^{4}}{63000\left(E I_{y}\right)^{2}}\right)\end{array}$ & $\begin{aligned} & \frac{M_{x 2}}{L}-P\left(\frac{L M_{x 2}}{60 E I_{z}}\right) \\
+ & P^{2}\left(\frac{L^{3} M_{x 2}}{2520\left(E I_{z}\right)^{2}}\right. \\
+ & \left.\frac{L^{3} M_{x 2}}{8400 E^{2} I_{y} I_{z}}\right) \\
- & P^{3}\left(\frac{L^{5} M_{x 2}}{100800\left(E I_{z}\right)^{3}}\right. \\
+ & \frac{L^{5} M_{x 2}}{756000 E^{3} I_{y}^{2} I_{z}} \\
+ & \left.\frac{L^{5} M_{x 2}}{302400 E^{3} I_{y} I_{z}^{2}}\right)\end{aligned}$ & 0 & 0 & $\begin{array}{l}-\frac{12 E I_{y}}{L^{3}} \\
-P\left(\frac{6}{5 L}+\frac{12 I_{y}}{A L^{3}}\right) \\
+P^{2}\left(\frac{L}{700 E I_{y}}\right) \\
+P^{3}\left(-\frac{L^{3}}{21000}+\frac{L I_{y}}{700 A}\right. \\
\left.+\frac{L^{3}}{31500\left(E I_{y}\right)^{2}}\right)\end{array}$ & $\frac{M_{z b}}{L}$ & $\begin{array}{l}-\frac{6 E I_{y}}{L^{2}} \\
-P\left(\frac{6 I_{y}}{A L^{2}}+\frac{1}{10}\right) \\
+P^{2}\left(\frac{L^{2}}{1400 E I_{y}}\right) \\
+P^{3}\left(-\frac{\frac{L^{4}}{42000}+\frac{L^{2} I_{y}}{1400 A}}{\left(E I_{y}\right)^{2}}\right. \\
\left.+\frac{L^{4}}{63000\left(E I_{y}\right)^{2}}\right)\end{array}$ & $\begin{array}{l}-\frac{M_{x 2}}{L}+P\left(\frac{L M_{x 2}}{60 E I_{z}}\right) \\
-P^{2}\left(\frac{L^{3} M_{x 2}}{2550\left(E I_{z}\right)^{2}}\right. \\
\left.+\frac{L^{3} M_{x 2}}{8400 E^{2} I_{y} I_{z}}\right) \\
+P^{3}\left(\frac{L^{5} M_{x 2}}{100800\left(E I_{z}\right)^{3}}\right. \\
+\frac{L^{5} M_{x 2}}{756000 E^{3} I_{y}{ }^{2} I_{z}} \\
\left.+\frac{L^{5} M_{x 2}}{302400 E^{3} I_{y} I_{z}{ }^{2}}\right)\end{array}$ \\
\hline 0 & $\frac{M_{y a}}{L}$ & $\frac{M_{z a}}{L}$ & $\frac{G I_{x}}{L}+\frac{J_{p} P}{A L}$ & $\begin{array}{c}\frac{M_{z b}}{6}-\frac{M_{z a}}{3} \\
+P\left(-\frac{L^{2}\left(M_{z a}+M_{z b}\right)}{360 E I_{y}}\right) \\
+P^{2}\left(\frac{L^{4}\left(M_{z a}+M_{z b}\right)}{15120\left(E I_{y}\right)^{2}}\right) \\
+P^{3}\left(-\frac{L^{6}\left(M_{z a}+M_{z b}\right)}{604800\left(E I_{y}\right)^{3}}\right)\end{array}$ & $\begin{array}{c}\frac{M_{y a}}{3}-\frac{M_{y b}}{6} \\
+P\left(\frac{L^{2}\left(M_{y a}+M_{y b}\right)}{360 E I_{z}}\right) \\
+P^{2}\left(-\frac{L^{4}\left(M_{y a}+M_{y b}\right)}{15120\left(E I_{z}\right)^{2}}\right) \\
+P^{3}\left(\frac{L^{6}\left(M_{y a}+M_{y b}\right)}{604800\left(E I_{z}\right)^{3}}\right)\end{array}$ & 0 & $-\frac{M_{y a}}{L}$ & $-\frac{M_{z a}}{L}$ & $-\frac{G I_{x}}{L}-\frac{J_{p} P}{A L}$ & $\begin{array}{l}\quad-\frac{M_{z a}}{6}-\frac{M_{z b}}{6} \\
+P\left(\frac{L^{2}\left(M_{z a}+M_{z b}\right)}{360 E I_{y}}\right) \\
+P^{2}\left(-\frac{L^{4}\left(M_{z a}+M_{z b}\right.}{15120\left(E I_{y}\right)^{2}}\right. \\
+P^{3}\left(\frac{L^{6}\left(M_{z a}+M_{z b}\right)}{604800\left(E I_{y}\right)^{3}}\right)\end{array}$ & $\begin{array}{l}\frac{M_{y a}}{6}+\frac{M_{y b}}{6} \\
+P\left(-\frac{L^{2}\left(M_{y a}+M_{y b}\right)}{360 E I_{z}}\right) \\
+P^{2}\left(\frac{L^{4}\left(M_{y a}+M_{y b}\right)}{15120\left(E I_{z}\right)^{2}}\right) \\
+P^{3}\left(-\frac{L^{6}\left(M_{y a}+M_{y b}\right)}{604800\left(E I_{z}\right)^{3}}\right.\end{array}$ \\
\hline
\end{tabular}


Apêndice $B$

\begin{tabular}{|c|c|c|c|c|c|c|c|c|c|c|c|}
\hline$\frac{M_{y a}}{L}$ & $\begin{array}{l}\frac{M_{x 2}}{L}+P\left(-\frac{L M_{x 2}}{60 E I_{y}}\right) \\
+P^{2}\left(\frac{L^{3} M_{x 2}}{2520\left(E I_{y}\right)^{2}}\right. \\
\left.+\frac{L^{3} M_{x 2}}{8400 E^{2} I_{I} I_{z} I_{2}}\right) \\
-P^{3}\left(\frac{L^{5} M_{x 2}}{1008000\left(E I_{y}\right)^{3}}\right. \\
+\frac{L^{5} M_{x 2}}{75600 E^{3} I_{y 2} I_{2}^{2}} \\
\left.+\frac{L^{2} M_{x 2}}{30240 E^{3} I_{y}^{2} I_{z}}\right)\end{array}$ & $\begin{array}{l}-\frac{6 E I_{y}}{L^{2}}-P\left(\frac{6 I_{y}}{\left(L^{2}\right.}+\frac{1}{10}\right) \\
+P^{2}\left(\frac{L^{2}}{1400 E I_{y}}\right) \\
+P^{3}\left(-\frac{L^{4}}{42000}+\frac{L^{2} y_{y}}{1400 A}\right. \\
+\frac{L^{4}}{\left(E I_{y}\right)^{2}} \\
\left.+\frac{600\left(E I_{y}\right)^{2}}{63}\right)\end{array}$ & $\begin{array}{c}\frac{M_{z b}}{6}-\frac{M_{z a}}{3} \\
+P\left(-\frac{L^{2}\left(M_{z a}+M_{z b}\right)}{360 E I_{y}}\right) \\
+P^{2}\left(\frac{L^{4}\left(M_{z a}+M_{z b}\right)}{15120\left(E y_{y}\right)^{2}}\right) \\
+P^{3}\left(-\frac{L^{6}\left(M_{z a}+M_{z b}\right)}{604800\left(E I_{y}\right)^{3}}\right)\end{array}$ & $\begin{array}{l}\frac{4 E I_{y}}{L}+P\left(\frac{2 L}{15}+\frac{4 I_{y}}{A L}\right) \\
+P^{2}\left(-\frac{11^{3}}{6300 E I_{y}}\right) \\
+P^{3}\left(\frac{L^{5}}{\frac{9000}{\left(11 L^{3} I_{y}\right.}} \frac{\left.1 E I_{y}\right)^{2}}{2}\right. \\
\left.-\frac{L^{5}}{13500\left(E I_{y}\right)^{2}}\right)\end{array}$ & 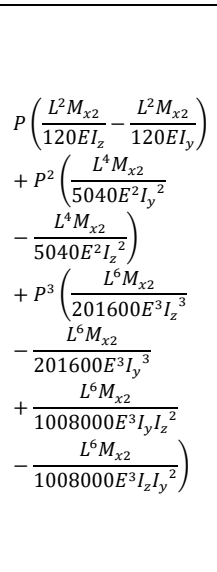 & $\frac{m_{y a}}{L}$ & $\begin{array}{l}-\frac{M_{x 2}}{L}+P\left(\frac{L M_{x 2}}{60 E I_{y}}\right) \\
-P^{2}\left(\frac{L^{3}{ }_{x 2}}{2520\left(E I_{y}\right)^{2}}\right. \\
\left.+\frac{L^{3} M_{x 2}}{8400 E^{2} I_{I} I_{2}}\right) \\
+P^{3}\left(\frac{L^{5} M_{x 2}}{\left(1000800\left(E I_{y}\right)^{3}\right.}\right. \\
+\frac{L^{5} M_{x 2}}{75600 E^{3} I_{y z} I_{z}^{2}} \\
\left.+\frac{L^{5} M_{x 2}}{30240 E^{3} I_{y}^{2} I_{z}}\right)\end{array}$ & $\begin{array}{l}\frac{6 E I_{y}}{L^{2}}+P\left(\frac{6 I_{y}}{A L^{2}}+\frac{1}{10}\right) \\
+P^{2}\left(-\frac{L^{2}}{1400 E I_{y}}\right)^{2} \\
+P^{3}\left(\frac{L^{4}}{\frac{42000}{\left(2 I_{y} I_{y}\right)^{2}}}\right. \\
\left.-\frac{L^{4}}{63000\left(E I_{y}\right)^{2}}\right)\end{array}$ & $\begin{array}{c}-\frac{M_{z a}}{6}-\frac{M_{z b}}{6} \\
+P\left(\frac{L^{6}\left(M_{z a}+M_{z b}\right)}{360 E I_{y}}\right) \\
+P^{2}\left(-\frac{L^{4}\left(M_{z a}+M_{z b}\right.}{15120\left(E I_{y}\right)^{2}}\right) \\
+P^{3}\left(\frac{L^{6}\left(M_{z a}+M_{z b}\right)}{604800\left(E I_{y}\right)^{3}}\right)\end{array}$ & $\begin{array}{l}\frac{2 E I_{y}}{L}+P\left(\frac{2 I_{y}}{A L}-\frac{L}{30}\right) \\
+P^{2}\left(\frac{13 L^{3}}{12600 E I_{y}}\right) \\
+P^{3}\left(-\frac{\frac{11 L^{5}}{126000}+\frac{13}{122}}{\left(E I_{y}\right)^{2}}\right. \\
\left.+\frac{11 L^{5}}{189000\left(E I_{y}\right)^{2}}\right)\end{array}$ & 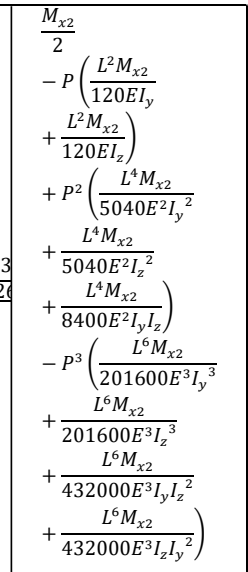 \\
\hline$\frac{M_{z a}}{L}$ & 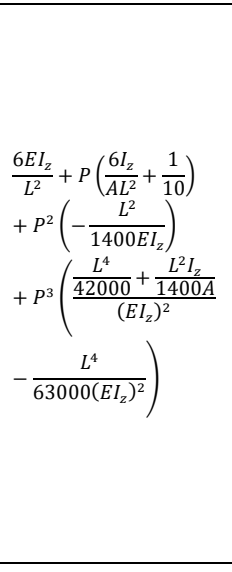 & 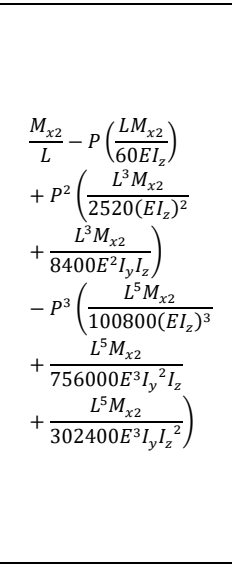 & 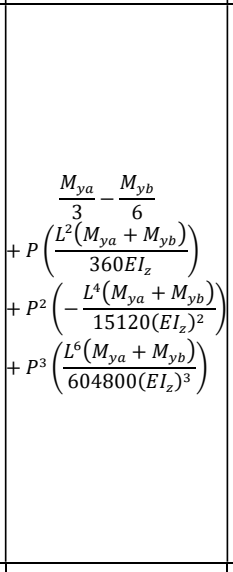 & 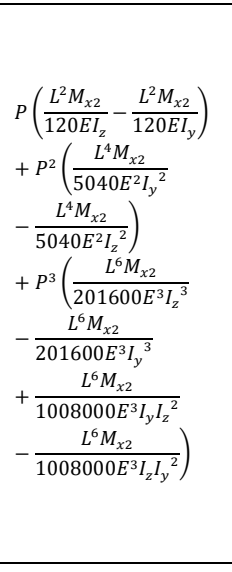 & $\begin{array}{l}\frac{4 E I_{2}}{L}+P\left(\frac{2 L}{15}+\frac{4 I_{z}}{4 L}\right) \\
+P^{2}\left(-\frac{11 L^{3}}{6600 I_{2}}\right) \\
+P^{3}\left(\frac{L^{5}}{9000}+\frac{11 L^{3} I_{2}}{\left(E I_{2}\right)^{2}}\right. \\
\left.-\frac{L^{5}}{13500\left(E I_{2}\right)^{2}}\right)\end{array}$ & $\frac{y_{z a}}{L}$ & $\begin{array}{l}-\frac{6 E I_{z}}{L^{2}}-P\left(\frac{6 I_{z}}{A L^{2}}+\frac{1}{10}\right) \\
+P^{2}\left(\frac{L^{2}}{1400 I^{2}}\right) \\
+P^{3}\left(-\frac{L^{4}}{42000}+\frac{L^{2} I_{z}}{140 A}\right. \\
\left.+\frac{L^{4}}{\left.6300\left(E I_{z}\right)^{2}\right)^{2}}\right)\end{array}$ & 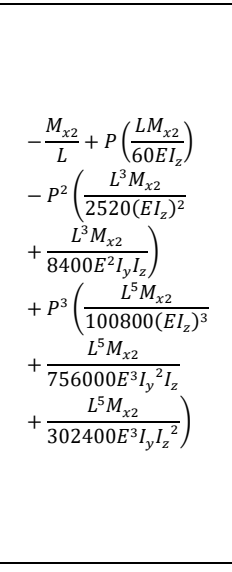 & $\begin{array}{l}\frac{M_{y a}}{6}+\frac{M_{y b}}{6} \\
+P\left(-\frac{L^{2}\left(M_{y a}+M_{y b}\right.}{360 E I_{z}}\right) \\
+P^{2}\left(\frac{\left.L^{4}\left(M_{y a}\right) M_{y b}\right)}{15120\left(E I_{z}\right)^{2}}\right) \\
+P^{3}\left(-\frac{L^{6}\left(M_{y a}+M_{y b}\right.}{604800\left(E I_{z}\right)}\right)\end{array}$ & 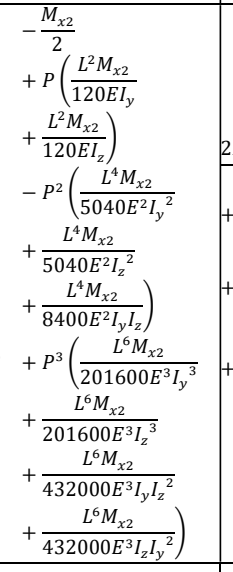 & $\begin{array}{l}\frac{2 E I_{z}}{L}+P\left(\frac{2 I_{z}}{A L}-\frac{L}{30}\right) \\
+P^{2}\left(\frac{13 L^{3}}{12600 E I_{z}}\right) \\
+P^{3}\left(-\frac{11 L^{5}}{126000}+\frac{133^{3} I_{2}}{12600}\right. \\
\left.+\frac{\left.1 E I_{z}\right)^{2}}{18900 L^{5}\left(E I_{2}\right)^{2}}\right)\end{array}$ \\
\hline $\begin{array}{r}-\frac{P}{L} \\
\frac{E A}{L} \\
\end{array}$ & 0 & 0 & 0 & $\frac{M_{y a}}{L}$ & $\frac{M_{z a}}{L}$ & $+\frac{E A}{L}$ & 0 & 0 & 0 & $\frac{M_{y b}}{L}$ & $\frac{M_{z b}}{L}$ \\
\hline
\end{tabular}


Apêndice $B$

Matrizes de Rigidez Locais Considerando Teoria de Flexão de Euler-Bernoulli

\begin{tabular}{|c|c|c|c|c|c|c|c|c|c|c|c|}
\hline 0 & $\begin{array}{l}-\frac{12 E I_{z}}{L^{3}}-P\left(\frac{6}{5 L}+\frac{12 I_{z}}{A L^{3}}\right) \\
+P^{2}\left(\frac{L}{700 E I_{z}}\right) \\
+P^{3}\left(-\frac{\frac{L^{3}}{21000}+\frac{L I_{z}}{700 A}}{\left(E I_{z}\right)^{2}}\right. \\
\left.+\frac{L^{3}}{31500\left(E I_{z}\right)^{2}}\right)\end{array}$ & 0 & $-\frac{M_{y a}}{L}$ & $\begin{array}{l}-\frac{M_{x 2}}{L}+P\left(\frac{L M_{x 2}}{60 E I_{y}}\right) \\
-P^{2}\left(\frac{L^{3} M_{x 2}}{2520\left(E I_{y}\right)^{2}}\right. \\
\left.+\frac{L^{3} M_{x 2}}{8400 E^{2} I_{y} I_{z}}\right) \\
+P^{3}\left(\frac{L^{5} M_{x 2}}{100800\left(E I_{y}\right)^{3}}\right. \\
+\frac{L^{5} M_{x 2}}{756000 E^{3} I_{y} I_{z}^{2}} \\
\left.+\frac{L^{5} M_{x 2}}{302400 E^{3} I_{y}{ }^{2} I_{z}}\right)\end{array}$ & $\begin{array}{l}-\frac{6 E I_{z}}{L^{2}}-P\left(\frac{6 I_{z}}{2 A L^{2}}+\frac{1}{10}\right) \\
+P^{2}\left(\frac{L^{2}}{1400 E I_{z}}\right) \\
+P^{3}\left(-\frac{L^{4}}{42000}+\frac{L^{2} I_{z}}{1400 A}\right. \\
\left(E I_{z}\right)^{2}\end{array}$ & 0 & $\begin{array}{l}\frac{12 E I_{z}}{L^{3}}+P\left(\frac{6}{5 L}+\frac{12 I_{z}}{A L^{3}}\right) \\
+P^{2}\left(-\frac{L}{700 E I_{z}}\right) \\
+P^{3}\left(\frac{L^{3}}{\frac{21000}{\left(E I_{z}\right)^{2}}+\frac{L I_{z}}{2}}\right. \\
\left.-\frac{L^{3}}{31500\left(E I_{z}\right)^{2}}\right)\end{array}$ & 0 & $-\frac{M_{y b}}{L}$ & $\begin{array}{l}\frac{M_{x 2}}{L}+P\left(-\frac{L M_{x 2}}{60 E I_{y}}\right) \\
+P^{2}\left(\frac{L^{3} M_{x 2}}{2520\left(E I_{y}\right)^{2}}\right. \\
\left.+\frac{L^{3} M_{x 2}}{8400 E^{2} I_{y} I_{z}}\right) \\
-P^{3}\left(\frac{L^{5} M_{x 2}}{100800\left(E I_{y}\right)^{3}}\right. \\
+\frac{L^{5} M_{x 2}}{756000 E^{3} I_{y} I_{z}^{2}} \\
\left.+\frac{L^{5} M_{x 2}}{302400 E^{3} I_{y}^{2} I_{z}}\right)\end{array}$ & $\begin{array}{l}-\frac{6 E I_{z}}{L^{2}} \\
-P\left(\frac{6 I_{z}}{A L^{2}}+\frac{1}{10}\right) \\
+P^{2}\left(\frac{L^{2}}{1400 E I_{z}}\right) \\
+P^{3}\left(-\frac{L^{4}}{42000}+\frac{L^{2} I_{z}}{1400}\right. \\
\left.+\frac{\left.L^{2} I_{z}\right)^{2}}{63000\left(E I_{z}\right)^{2}}\right)\end{array}$ \\
\hline 0 & 0 & $\begin{aligned} & -\frac{12 E I_{y}}{L^{3}} \\
& P\left(\frac{6}{5 L}+\frac{12 I_{y}}{A L^{3}}\right) \\
+ & P^{2}\left(\frac{L}{700 E I_{y}}\right) \\
+ & P^{3}\left(-\frac{L^{3}}{21000}+\frac{L I_{y}}{\left(E I_{y}\right)^{2}}\right. \\
+ & \left.\frac{L^{3}}{31500\left(E I_{y}\right)^{2}}\right)\end{aligned}$ & $-\frac{M_{z a}}{L}$ & $\begin{array}{l}\frac{6 E I_{y}}{L^{2}}+P\left(\frac{6 I_{y}}{A L^{2}}+\frac{1}{10}\right) \\
+P^{2}\left(-\frac{L^{2}}{1400 E I_{y}}\right) \\
+P^{3}\left(\frac{L^{4}}{\frac{42000}{\left(E I_{y}\right)^{2}}+\frac{L^{2} I_{y}}{(400 A}}\right. \\
\left.-\frac{L^{4}}{63000\left(E I_{y}\right)^{2}}\right)\end{array}$ & $\begin{array}{l}-\frac{M_{x 2}}{L}+P\left(\frac{L M_{x 2}}{60 E I_{z}}\right) \\
-P^{2}\left(\frac{L^{3} M_{x 2}}{2520\left(E I_{z}\right)^{2}}\right. \\
\left.+\frac{L^{3} M_{x 2}}{8400 E^{2} I_{y} I_{z}}\right) \\
+P^{3}\left(\frac{L^{5} M_{x 2}}{100800\left(E I_{z}\right)^{3}}\right. \\
+\frac{L^{5} M_{x 2}}{7560000^{3} I_{y}{ }^{2} I_{z}} \\
\left.+\frac{L^{5} M_{x 2}}{302400 E^{3} I_{y} I_{z}^{2}}\right)\end{array}$ & $\frac{M_{y b}}{L}$ & 0 & $\begin{array}{l}\frac{12 E I_{y}}{L^{3}}+P\left(\frac{6}{5 L}+\frac{12 I_{y}}{A L^{3}}\right) \\
+P^{2}\left(-\frac{L}{700 E I_{y}}\right) \\
+P^{3}\left(\frac{L^{3}}{\frac{21000}{7}+\frac{L I_{y}}{700 A}}\right. \\
\left.-\frac{\left.L^{3} I_{y}\right)^{2}}{31500\left(E I_{2}\right)^{2}}\right)\end{array}$ & $-\frac{M_{z b}}{L}$ & $\begin{array}{l}\frac{6 E I_{y}}{L^{2}} \\
+P\left(\frac{6 I_{y}}{A L^{2}}+\frac{1}{10}\right) \\
+P^{2}\left(-\frac{L^{2}}{1400 E I_{y}}\right) \\
+P^{3}\left(\frac{\frac{L^{4}}{42000}+\frac{L^{2} I_{y}}{1400 A}}{\left(E I_{y}\right)^{2}}\right. \\
\left.-\frac{L^{4}}{63000\left(E I_{y}\right)^{2}}\right)\end{array}$ & $\begin{array}{l}\left.\frac{M_{x 2}-P\left(\frac{L M_{x 2}}{L}-60 E I_{z}\right.}{60}\right) \\
+P^{2}\left(\frac{L^{3} M_{x 2}}{2520\left(E I_{z}\right)^{2}}\right. \\
\left.+\frac{L^{3} M_{x 2}}{8400 E^{2} I_{y} I_{z}}\right) \\
-P^{3}\left(\frac{L^{5} M_{x 2}}{100800\left(E I_{z}\right)^{3}}\right. \\
+\frac{L^{5} M_{x 2}}{756000 E^{3} I_{y} I_{z} I_{z}} \\
\left.+\frac{L^{5} M_{x 2}}{302400 E^{3} I_{y} I_{z}^{2}}\right)\end{array}$ \\
\hline 0 & $\frac{M_{y b}}{L}$ & $\frac{M_{z b}}{L}$ & $-\frac{G I_{x}}{L}-\frac{J_{p} P}{A L}$ & $\begin{aligned} & -\frac{M_{z a}}{6}-\frac{M_{z b} b}{6} \\
+ & P\left(\frac{L^{2}\left(M_{z a}+M_{z b}\right)}{360 E I_{y}}\right) \\
+ & P^{2}\left(-\frac{L^{4}\left(M_{z a}+M_{z b}\right)}{15120\left(E I_{y}\right)^{2}}\right) \\
+ & P^{3}\left(\frac{L^{6}\left(M_{z a}+M_{z b}\right)}{604800\left(E I_{y}\right)^{3}}\right)\end{aligned}$ & $\begin{array}{l}\frac{M_{y a}}{6}+\frac{M_{y b}}{6} \\
+P\left(-\frac{L^{2}\left(M_{y a}+M_{y b}\right)}{360 E I_{z}}\right) \\
+P^{2}\left(\frac{L^{4}\left(M_{y a}+M_{y b}\right)}{15120\left(E I_{z}\right)^{2}}\right) \\
+P^{3}\left(-\frac{L^{6}\left(M_{y a}+M_{y b}\right)}{604800\left(E I_{2}\right)^{3}}\right)\end{array}$ & $\frac{M_{z b}}{L}$ & $-\frac{M_{y b}}{L}$ & $-\frac{M_{z b}}{L}$ & $\frac{G I_{x}}{L}+\frac{J_{p} P}{A L}$ & $\begin{array}{l}\frac{M_{z a}}{6}-\frac{M_{z b}}{3} \\
+P\left(-\frac{L^{2}\left(M_{z a}+M_{z b}\right)}{360 E I_{y}}\right) \\
+P^{2}\left(\frac{L^{4}\left(M_{z a}+M_{z b}\right)}{15120\left(E I_{y}\right)^{2}}\right) \\
+P^{3}\left(-\frac{L^{6}\left(M_{z a}+M_{z b}\right)}{604800\left(E I_{y}\right)}\right)\end{array}$ & $\begin{array}{l}\frac{M_{y b}}{3}-\frac{M_{y a}}{6} \\
+P\left(\frac{L^{2}\left(M_{y a}+M_{y b}\right)}{360 E I_{z}}\right) \\
+P^{2}\left(-\frac{L^{4}\left(M_{y a}+M_{y b}\right)}{15120\left(E I_{z}\right)^{2}}\right. \\
+P^{3}\left(\frac{L^{6}\left(M_{y a}+M_{y b}\right)}{604800\left(E I_{z}\right)^{3}}\right)\end{array}$ \\
\hline
\end{tabular}




\begin{tabular}{|c|c|c|c|c|c|c|c|c|c|c|c|}
\hline$\frac{M_{y b}}{L}$ & $\begin{array}{l}-\frac{M_{x 2}}{L}+P\left(\frac{L M_{x 2}}{60 E I_{y}}\right) \\
-P^{2}\left(\frac{L^{3} M_{x 2}}{2520\left(E I_{y}\right)^{2}}\right. \\
\left.+\frac{L^{3} M_{x 2}}{8400 E^{2} I_{y} I_{z}}\right) \\
+P^{3}\left(\frac{L^{5} M_{x 2}}{100800\left(E I_{y}\right)^{3}}\right. \\
+\frac{L^{5} M_{x 2}}{756000 E^{3} I_{y} I_{z}^{2}} \\
\left.+\frac{L^{5} M_{x 2}}{302400 E^{3} I_{y}{ }^{2} I_{z}}\right)\end{array}$ & $\begin{array}{l}-\frac{6 E I_{y}}{L^{2}}-P\left(\frac{6 I_{y}}{A L^{2}}+\frac{1}{10}\right) \\
+P^{2}\left(\frac{L^{2}}{1400 E I_{y}}\right) \\
+P^{3}\left(-\frac{\frac{L^{4}}{42000}+\frac{L^{2} I_{y}}{1400}}{\left(E I_{y}\right)^{2}}\right. \\
\left.+\frac{L^{4}}{63000\left(E I_{y}\right)^{2}}\right)\end{array}$ & $\begin{array}{c}-\frac{M_{z a}}{6}-\frac{M_{z b}}{6} \\
+P\left(\frac{L^{2}\left(M_{z a}+M_{z b}\right)}{360 E I_{y}}\right) \\
+P^{2}\left(-\frac{L^{4}\left(M_{z a}+M_{z b}\right)}{15120\left(E I_{y}\right)^{2}}\right) \\
+P^{3}\left(\frac{L^{6}\left(M_{z a}+M_{z b}\right)}{604800\left(E I_{y}\right)^{3}}\right)\end{array}$ & $\begin{array}{l}\frac{2 E I_{y}}{L}+P\left(\frac{2 I_{y}}{A L}-\frac{L}{30}\right) \\
+P^{2}\left(\frac{1 L^{3}}{12600 E I_{y}}\right) \\
+P^{3}\left(-\frac{11 L^{5}}{126000}+\frac{13 L^{3} I_{y}}{12600 A}\right. \\
\left(E I_{y}\right)^{2} \\
\left.+\frac{11 L^{5}}{189000\left(E I_{y}\right)^{2}}\right)\end{array}$ & $\begin{array}{l}-\frac{M_{x 2}}{2} \\
+P\left(\frac{L^{2} M_{x 2}}{120 I_{y}}\right. \\
\left.+\frac{L^{2} M_{x 2}}{120 I_{z}}\right) \\
-P^{2}\left(\frac{L^{4} M_{x 2}}{5040 E^{2} I_{y}{ }^{2}}\right. \\
+\frac{L^{4} M_{x 2}}{5040 E^{2} I_{z}{ }^{2}} \\
\left.+\frac{L^{4} M_{x 2}}{8400 E^{2} I_{y} I_{2}}\right) \\
+P^{3}\left(\frac{L^{6} M_{x 2}}{201600 E^{3} I_{y}{ }^{3}}\right. \\
+\frac{L^{6} M_{x 2}}{201600 E^{3} I_{z}{ }^{3}} \\
+\frac{L^{6} M_{x 2}}{432000 E^{3} I_{y} I_{z}{ }^{2}} \\
\left.+\frac{L^{6} M_{x 2}}{432000 E^{3} I_{z} I_{y}{ }^{2}}\right) \\
\end{array}$ & 0 & $\begin{array}{l}\frac{M_{x 2}}{L}+P\left(-\frac{L M_{x 2}}{60 E I_{y}}\right) \\
+P^{2}\left(\frac{L^{3} M_{x 2}}{2520\left(E I_{y}\right)^{2}}\right. \\
\left.+\frac{L^{3} M_{x 2}}{8400 E^{2} I_{y} I_{z}}\right) \\
-P^{3}\left(\frac{L^{5} M_{x 2}}{100800\left(E I_{y}\right)^{3}}\right. \\
+\frac{L^{5} M_{x 2}}{756000 E^{3} I_{y} I_{z}{ }^{2}} \\
\left.+\frac{L^{5} M_{x 2}}{302400 E^{3} I_{y} I_{z}}\right)\end{array}$ & $\begin{array}{l}\frac{6 E I_{y}}{L^{2}}+P\left(\frac{6 I_{y}}{A L^{2}}+\frac{1}{10}\right) \\
+P^{2}\left(-\frac{L^{2}}{1400 E I_{y}}\right) \\
+P^{3}\left(\frac{\frac{L^{4}}{42000}+\frac{L^{2} I_{y}}{1400 A}}{\left(E I_{y}\right)^{2}}\right. \\
\left.-\frac{L^{4}}{63000\left(E I_{y}\right)^{2}}\right)\end{array}$ & $\begin{array}{l}\frac{M_{z a}}{6}-\frac{M_{z b}}{3} \\
+P\left(-\frac{L^{2}\left(M_{z a}+M_{z b}\right)}{360 E I_{y}}\right. \\
+P^{2}\left(\frac{L^{4}\left(M_{z a}+M_{z b}\right)}{15120\left(E I_{y}\right)^{2}}\right) \\
+P^{3}\left(-\frac{L^{6}\left(M_{z a}+M_{z b}\right.}{604800\left(E I_{y}\right)}\right)\end{array}$ & $\begin{array}{l}\frac{4 E I_{y}}{L}+P\left(\frac{2 L}{15}+\frac{4 I_{y}}{A L}\right) \\
+P^{2}\left(-\frac{1 L^{3}}{6300 E I_{y}}\right) \\
+P^{3}\left(\frac{L^{5}}{\frac{9000}{60}+\frac{11 L^{3} y_{y}}{6300}}\right. \\
\left(E I_{y}\right)^{2} \\
\left.-\frac{L^{5}}{13500\left(E I_{y}\right)^{2}}\right)\end{array}$ & $\begin{array}{l}P\left(\frac{L^{2} M_{x 2}}{120 E I_{y}}-\frac{L^{2} M_{x 2}}{120 E I_{z}}\right) \\
+P^{2}\left(\frac{L^{4} M_{x 2}}{5040 E^{2} I_{z}{ }^{2}}\right. \\
\left.-\frac{L^{4} M_{x 2}}{5040 E^{2} I_{y}{ }^{2}}\right) \\
+P^{3}\left(\frac{L^{6} M_{x 2}}{201600 E^{3} I_{y}{ }^{3}}\right. \\
-\frac{L^{6} M_{x 2}}{201600 E^{3} I_{Z}{ }^{3}} \\
-\frac{L^{6} M_{x 2}}{1008000 E^{3} I_{y} I_{z}{ }^{2}} \\
\left.+\frac{L^{6} M_{x 2}}{1008000 E^{3} I_{z} I_{y}{ }^{2}}\right)\end{array}$ \\
\hline$\frac{M_{z b}}{L}$ & $\begin{array}{l}\frac{6 E I_{z}}{L^{2}}+P\left(\frac{6 I_{z}}{A L^{2}}+\frac{1}{10}\right) \\
+P^{2}\left(-\frac{L^{2}}{1400 E I_{z}}\right) \\
+P^{3}\left(\frac{L^{4}}{\frac{42000}{\left(E I_{z}\right)^{2}}+\frac{L^{2} I_{z}}{(400 A}}\right. \\
\left.-\frac{L^{4}}{63000\left(E I_{z}\right)^{2}}\right)\end{array}$ & $\begin{array}{l}-\frac{M_{x 2}}{L}+P\left(\frac{L M_{x 2}}{60 E I_{z}}\right) \\
-P^{2}\left(\frac{L^{3} M_{x 2}}{2520\left(E I_{z}\right)^{2}}\right. \\
\left.+\frac{L^{3} M_{x 2}}{8400 E^{2} I_{y} I_{z}}\right) \\
+P^{3}\left(\frac{L^{5} M_{x 2}}{100080\left(E I_{z}\right)^{3}}\right. \\
+\frac{L^{5} M_{x 2}}{756000 E^{3} I_{y} I_{z}} \\
\left.+\frac{L^{5} M_{x 2}}{302400 E^{3} I_{y} I_{z} I^{2}}\right)\end{array}$ & 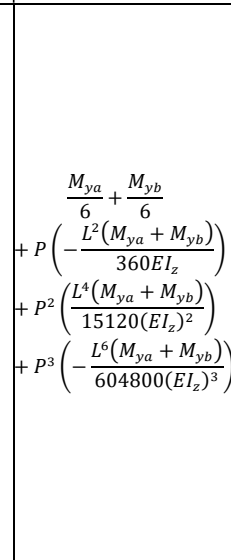 & $\begin{array}{l}\frac{M_{x 2}}{2} \\
-P\left(\frac{L^{2} M_{x 2}}{120 E I_{y}}\right. \\
\left.+\frac{L^{2} M_{x 2}}{120 E I_{z}}\right)^{4} M_{x 2} \\
+P^{2}\left(\frac{L^{4}}{5040 E^{2} I_{y}{ }^{2}}\right. \\
+\frac{L^{4} M_{x 2}}{5040{ }^{2} I_{z}^{2}} \\
\left.+\frac{L^{4} M_{x 2}}{840 E^{2} I_{y} I_{I}}\right) \\
-P^{3}\left(\frac{L^{6} M_{x 2}}{201600 E^{3} I_{y}{ }^{3}}\right. \\
+\frac{L^{6} M_{x 2}}{20160 E^{3} I_{z}^{3}} \\
+\frac{L^{6} M_{x 2}}{432000 E^{3} I_{y} I_{z}^{2}} \\
\left.+\frac{L^{6} M_{x 2}}{432000 E^{3} I_{I} I_{y}{ }^{2}}\right)\end{array}$ & $\begin{array}{l}\frac{2 E I_{z}}{L}+P\left(\frac{2 I_{z}}{A L}-\frac{L}{30}\right) \\
+P^{2}\left(\frac{13 L^{3}}{12600 E I_{z}}\right) \\
+P^{3}\left(-\frac{\frac{11 L^{5}}{126000}+\frac{13 L^{3} I_{z}}{12600 A}}{\left(E I_{z}\right)^{2}}\right. \\
\left.+\frac{11 L^{5}}{189000\left(E I_{z}\right)^{2}}\right)\end{array}$ & & $\begin{array}{l}-\frac{6 E I_{z}}{L^{2}}-P\left(\frac{6 I_{z}}{A L^{2}}+\frac{1}{10}\right) \\
+P^{2}\left(\frac{L^{2}}{1400 E I_{z}}\right) \\
+P^{3}\left(-\frac{\frac{L^{4}}{42000}+\frac{L^{2} I_{z}}{1400 A}}{\left(E I_{z}\right)^{2}}\right. \\
\left.+\frac{L^{4}}{63000\left(E I_{z}\right)^{2}}\right)\end{array}$ & $\begin{array}{l}\frac{M_{x 2}}{L}-P\left(\frac{L M_{x 2}}{60 E I_{x}}\right) \\
+P^{2}\left(\frac{L^{3} M_{x 2}}{2520\left(E I_{z}\right)^{2}}\right. \\
\left.+\frac{L^{3} M_{x 2}}{8400 E^{2} I_{y} I_{z}}\right) \\
-P^{3}\left(\frac{L^{5} M_{x 2}}{100800\left(E I_{z}\right)^{3}}\right. \\
+\frac{L^{5} M_{x 2}}{756000 E^{3} I_{y}^{2} I_{z}} \\
\left.+\frac{L^{5} M_{x 2}}{302400 E^{3} I_{y} I_{z}^{2}}\right)\end{array}$ & $\begin{array}{l}\frac{M_{y b}}{3}-\frac{M_{y a}}{6} \\
+P\left(\frac{L^{2}\left(M_{y a}+M_{y b}\right)}{360 E I_{z}}\right) \\
+P^{2}\left(-\frac{L^{4}\left(M_{y a}+M_{y y}\right.}{15120\left(E I_{z}\right)}\right) \\
+P^{3}\left(\frac{L^{6}\left(M_{y a}+M_{y b}\right)}{604800\left(E I_{z}\right)^{3}}\right.\end{array}$ & $\begin{array}{l}P\left(\frac{L^{2} M_{x 2}}{120 E I_{y}}\right. \\
\left.-\frac{L^{2} M_{x 2}}{120 E I_{z}}\right) \\
+P^{2}\left(\frac{L^{4} M_{x 2}}{5040 E^{2} I_{z}^{2}}\right. \\
\left.-\frac{L^{4} M_{x 2}}{5040 E^{2} I_{y}^{2}}\right) \\
+P^{3}\left(\frac{L^{6} M_{x 2}}{201600 E^{3} I_{y}{ }^{3}}\right. \\
-\frac{L^{6} M_{x 2}}{20160 E^{3} I_{z}{ }^{3}} \\
-\frac{L^{6} M_{x 2}}{1008000 E^{3} I_{y} I_{z}^{2}} \\
\left.+\frac{L^{6} M_{x 2}}{1008000 E^{3} I_{z} I_{y}^{2}}\right)\end{array}$ & $\begin{array}{l}\frac{4 E I_{z}}{L}+P\left(\frac{2 L}{15}+\frac{4 I_{z}}{A L}\right) \\
+P^{2}\left(-\frac{11 L^{3}}{6300 E I_{z}}\right) \\
+P^{3}\left(\frac{L^{5}}{9000}+\frac{11 L^{3} I_{z}}{\left.6 E I_{z}\right)^{2}}\right. \\
\left.-\frac{L^{5}}{13500\left(E I_{z}\right)^{2}}\right)\end{array}$ \\
\hline
\end{tabular}

Conforme explicitado ao longo do texto, a expansão da matriz de rigidez em série de Taylor pode ser utilizada das seguintes formas:

EBBT_2tr - Emprega-se 2 Termos (termo elástico + um termo da carga axial $P$, até grau 1);

EBBT_3tr - Emprega-se 3 Termos (termo elástico + dois termos da carga axial $P$, até grau 2);

EBBT_4tr - Emprega-se 4 Termos (termo elástico + três termos da carga axial $P$, até grau 3); 


\section{Apêndice C}

Matrizes de Rigidez Locais Considerando Teoria de Flexão de Timoshenko 
Apêndice $C$

C.1

Matriz de Rigidez Geométrica Local com Funções de Forma Cúbicas: Planos Independentes (TBT_Large)

\begin{tabular}{|c|c|c|c|c|c|c|c|c|c|c|c|}
\hline$\frac{P}{L}$ & 0 & 0 & 0 & $-\frac{M_{y 1}}{L}$ & $-\frac{M_{z 1}}{L}$ & $\begin{array}{l}-\frac{P}{L} \\
\end{array}$ & 0 & 0 & 0 & $-\frac{M_{y 2}}{L}$ & $-\frac{M_{z 2}}{L}$ \\
\hline & $6 P\left(120 \Omega_{y}^{2}+20 \Omega_{y}+1\right)$ & & & & $P$ & & $6 P\left(120 \Omega_{y}{ }^{2}+20 \Omega_{y}+1\right)$ & & & & $P$ \\
\hline 0 & \begin{tabular}{|l}
$5 L\left(12 \Omega_{y}+1\right)^{2}$ \\
$+\frac{12 P I_{z}}{A L^{3}\left(12 \Omega_{y}+1\right)^{2}}$
\end{tabular} & 0 & 0 & 0 & $\begin{array}{l}\overline{10\left(12 \Omega_{y}+1\right)^{2}} \\
+\frac{6 P I_{z}}{A L^{2}\left(12 \Omega_{y}+1\right)^{2}}\end{array}$ & 0 & $\begin{array}{c}5 L\left(12 \Omega_{y}+1\right)^{2} \\
\frac{12 P I_{z}}{A L^{3}\left(12 \Omega_{y}+1\right)^{2}}\end{array}$ & 0 & 0 & 0 & $\begin{array}{l}\overline{10\left(12 \Omega_{y}+1\right)^{2}} \\
+\frac{6 P I_{z}}{A L^{2}\left(12 \Omega_{y}+1\right)^{2}}\end{array}$ \\
\hline 0 & 0 & $\begin{array}{l}\frac{6 P\left(120 \Omega_{z}^{2}+20 \Omega_{z}+1\right)}{5 L\left(12 \Omega_{z}+1\right)^{2}} \\
+\frac{12 P I_{y}}{A L^{3}\left(12 \Omega_{z}+1\right)^{2}}\end{array}$ & 0 & $\begin{array}{l}-\frac{P}{10\left(12 \Omega_{z}+1\right)^{2}} \\
-\frac{6 P I_{y}}{A L^{2}\left(12 \Omega_{z}+1\right)^{2}}\end{array}$ & 0 & 0 & 0 & $\begin{array}{l}-\frac{6 P\left(120 \Omega_{z}^{2}+20 \Omega_{z}+1\right)}{5 L\left(12 \Omega_{z}+1\right)^{2}} \\
\frac{12 P I_{y}}{A L^{3}\left(12 \Omega_{z}+1\right)^{2}}\end{array}$ & 0 & $\begin{array}{l}-\frac{P}{10\left(12 \Omega_{z}+1\right)^{2}} \\
-\frac{6 P I_{y}}{A L^{2}\left(12 \Omega_{z}+1\right)^{2}}\end{array}$ & 0 \\
\hline 0 & 0 & 0 & 0 & 0 & 0 & 0 & 0 & 0 & 0 & 0 & 0 \\
\hline$\frac{M_{y 1}}{L}$ & 0 & $\begin{array}{l}-\frac{P}{10\left(12 \Omega_{z}+1\right)^{2}} \\
-\frac{6 P I_{y}}{A L^{2}\left(12 \Omega_{z}+1\right)^{2}}\end{array}$ & 0 & $\begin{array}{l}\frac{2 P L\left(90 \Omega_{z}{ }^{2}+15 \Omega_{z}+1\right)}{15\left(12 \Omega_{z}+1\right)^{2}} \\
+\frac{4 P I_{y}\left(36 \Omega_{z}{ }^{2}+6 \Omega_{z}+1\right)}{A L}\end{array}$ & 0 & $\frac{M_{y 1}}{L}$ & 0 & $\begin{array}{l}\frac{P}{10\left(12 \Omega_{z}+1\right)^{2}} \\
+\frac{6 P I_{y}}{A L^{2}\left(12 \Omega_{z}+1\right)^{2}}\end{array}$ & 0 & $\begin{array}{l}-\frac{P L\left(360 \Omega_{z}{ }^{2}+60 \Omega_{z}+1\right)}{30\left(12 \Omega_{z}+1\right)^{2}} \\
-\frac{2 P I_{y}\left(72 \Omega_{z}{ }^{2}+12 \Omega_{z}-1\right)}{A L\left(12 \Omega_{z}+1\right)^{2}} \\
\end{array}$ & 0 \\
\hline$\frac{M_{z 1}}{L}$ & $\begin{array}{l}\frac{P}{10\left(12 \Omega_{y}+1\right)^{2}} \\
+\frac{6 P I_{z}}{A L^{2}\left(12 \Omega_{y}+1\right)^{2}}\end{array}$ & 0 & 0 & 0 & $\begin{array}{l}\frac{2 P L\left(90 \Omega_{y}{ }^{2}+15 \Omega_{y}+1\right)}{15\left(12 \Omega_{y}+1\right)^{2}} \\
+\frac{4 P I_{z}\left(36 \Omega_{y}{ }^{2}+6 \Omega_{y}+1\right)}{A L\left(12 \Omega_{y}+1\right)^{2}}\end{array}$ & $\frac{M_{z 1}}{L}$ & $\begin{array}{l}-\frac{P}{10\left(12 \Omega_{y}+1\right)^{2}} \\
-\frac{6 P I_{z}}{A L^{2}\left(12 \Omega_{y}+1\right)^{2}}\end{array}$ & 0 & 0 & 0 & $\begin{array}{l}\frac{P L\left(360 \Omega_{y}{ }^{2}+60 \Omega_{y}+1\right)}{30\left(12 \Omega_{y}+1\right)^{2}} \\
\frac{2 P I_{z}\left(72 \Omega_{y}{ }^{2}+12 \Omega_{y}-1\right)}{A L\left(12 \Omega_{y}+1\right)^{2}}\end{array}$ \\
\hline$\frac{P}{L}$ & 0 & 0 & 0 & $\frac{M_{y 1}}{L}$ & $\frac{M_{z 1}}{L}$ & $\frac{P}{L}$ & 0 & 0 & 0 & $\frac{M_{y 2}}{L}$ & $\frac{M_{z 2}}{L}$ \\
\hline 0 & $\begin{array}{l}-\frac{6 P\left(120 \Omega_{y}{ }^{2}+20 \Omega_{y}+1\right.}{5 L\left(12 \Omega_{y}+1\right)^{2}} \\
\frac{12 P I_{z}}{A L^{3}\left(12 \Omega_{y}+1\right)^{2}}\end{array}$ & 0 & 0 & 0 & $\begin{array}{l}-\frac{P}{10\left(12 \Omega_{y}+1\right)^{2}} \\
-\frac{6 P I_{z}}{A L^{2}\left(12 \Omega_{y}+1\right)^{2}}\end{array}$ & 0 & $\begin{array}{l}\frac{6 P\left(120 \Omega_{y}{ }^{2}+20 \Omega_{y}+1\right)}{5 L\left(12 \Omega_{y}+1\right)^{2}} \\
+\frac{12 P I_{z}}{A L^{3}\left(12 \Omega_{y}+1\right)^{2}}\end{array}$ & 0 & 0 & 0 & $\begin{array}{l}-\frac{P}{10\left(12 \Omega_{y}+1\right)^{2}} \\
-\frac{6 P I_{z}}{A L^{2}\left(12 \Omega_{y}+1\right)^{2}}\end{array}$ \\
\hline 0 & 0 & $\begin{array}{l}\frac{6 P\left(120 \Omega_{z}{ }^{2}+20 \Omega_{z}+1\right)}{5 L\left(12 \Omega_{z}+1\right)^{2}} \\
\frac{12 P I_{y}}{A L^{3}\left(12 \Omega_{z}+1\right)^{2}}\end{array}$ & 0 & $\begin{array}{l}\frac{P}{10\left(12 \Omega_{z}+1\right)^{2}} \\
+\frac{6 P I_{y}}{A L^{2}\left(12 \Omega_{z}+1\right)^{2}}\end{array}$ & 0 & 0 & 0 & $\begin{array}{l}6 P\left(120 \Omega_{z}^{2}+20 \Omega_{z}+1\right) \\
5 L\left(12 \Omega_{z}+1\right)^{2} \\
+\frac{12 P I_{y}}{A L^{3}\left(12 \Omega_{z}+1\right)^{2}}\end{array}$ & 0 & $\begin{array}{l}\frac{P}{10\left(12 \Omega_{z}+1\right)^{2}} \\
+\frac{6 P I_{y}}{A L^{2}\left(12 \Omega_{z}+1\right)^{2}}\end{array}$ & 0 \\
\hline 0 & 0 & 0 & 0 & 0 & 0 & 0 & 0 & 0 & 0 & 0 & 0 \\
\hline
\end{tabular}


Apêndice $C$

\begin{tabular}{|c|c|c|c|c|c|c|c|c|c|c|c|}
\hline$\frac{M_{y 2}}{L}$ & 0 & $\begin{array}{l}-\frac{P}{10\left(12 \Omega_{z}+1\right)^{2}} \\
-\frac{6 P I_{y}}{A L^{2}\left(12 \Omega_{z}+1\right)^{2}}\end{array}$ & 0 & $\begin{array}{l}-\frac{P L\left(360 \Omega_{z}{ }^{2}+60 \Omega_{z}+1\right)}{30\left(12 \Omega_{z}+1\right)^{2}} \\
-\frac{2 P I_{y}\left(72 \Omega_{z}{ }^{2}+12 \Omega_{z}-1\right)}{A L\left(12 \Omega_{z}+1\right)^{2}}\end{array}$ & 0 & $\frac{M_{y 2}}{L}$ & 0 & $\begin{array}{l}\frac{P}{10\left(12 \Omega_{z}+1\right)^{2}} \\
+\frac{6 P I_{y}}{A L^{2}\left(12 \Omega_{z}+1\right)^{2}}\end{array}$ & 0 & $\begin{array}{l}\frac{2 P L\left(90 \Omega_{2}{ }^{2}+15 \Omega_{z}+1\right)}{15\left(12 \Omega_{z}+1\right)^{2}} \\
+\frac{4 P I_{y}\left(36 \Omega_{z}^{2}+6 \Omega_{z}+1\right)}{A L}\end{array}$ & 0 \\
\hline$\frac{M_{z 2}}{L}$ & $\begin{array}{l}\frac{P}{10\left(12 \Omega_{y}+1\right)^{2}} \\
+\frac{6 P I_{z}}{A L^{2}\left(12 \Omega_{y}+1\right)^{2}}\end{array}$ & 0 & 0 & 0 & $\begin{array}{l}-\frac{P L\left(360 \Omega_{y}{ }^{2}+60 \Omega_{y}+1\right)}{30\left(12 \Omega_{y}+1\right)^{2}} \\
-\frac{2 P I_{z}\left(72 \Omega_{y}{ }^{2}+12 \Omega_{y}-1\right)}{A L\left(12 \Omega_{y}+1\right)^{2}}\end{array}$ & \begin{tabular}{|l}
$M_{22}$ \\
$L$ \\
\end{tabular} & $\begin{array}{l}-\frac{P}{10\left(12 \Omega_{y}+1\right)^{2}} \\
-\frac{6 P I_{z}}{A L^{2}\left(12 \Omega_{y}+1\right)^{2}}\end{array}$ & 0 & 0 & 0 & $\begin{array}{l}\frac{2 P L\left(90 \Omega_{y}{ }^{2}+15 \Omega_{y}+1\right)}{15\left(12 \Omega_{y}+1\right)^{2}} \\
+\frac{4 P I_{z}\left(36 \Omega_{y}{ }^{2}+6 \Omega_{y}+1\right)}{A L\left(12 \Omega_{y}+1\right)^{2}}\end{array}$ \\
\hline
\end{tabular}


Apêndice $C$

\section{C.2}

Matriz de Rigidez Geométrica Local com Funções de Forma Cúbicas: Interação Torção com Carga Axial (TBT_Large)

\begin{tabular}{|c|c|c|c|c|c|c|c|c|c|c|c|}
\hline 0 & 0 & 0 & 0 & 0 & 0 & 0 & 0 & 0 & 0 & 0 & 0 \\
\hline 0 & 0 & 0 & $\frac{M_{y 1}}{L}$ & $\frac{M_{x 2}}{L\left(12 \Omega_{y}+1\right)}$ & 0 & 0 & 0 & 0 & $\frac{M_{y 2}}{L}$ & $-\frac{M_{x 2}}{L\left(12 \Omega_{y}+1\right)}$ & 0 \\
\hline 0 & 0 & 0 & $\frac{M_{z 1}}{L}$ & 0 & $\frac{M_{x 2}}{L\left(12 \Omega_{z}+1\right)}$ & 0 & 0 & 0 & $\frac{M_{z 2}}{L}$ & 0 & $-\frac{M_{x 2}}{L\left(12 \Omega_{z}+1\right)}$ \\
\hline 0 & $\frac{M_{y 1}}{L}$ & $\frac{M_{z 1}}{L}$ & $\frac{J_{P} P}{A L}$ & $\frac{M_{z 1}}{6}+\frac{M_{z 2}}{6}$ & $-\frac{M_{y 1}}{6}-\frac{M_{y 2}}{6}$ & 0 & $-\frac{M_{y 1}}{L}$ & $-\frac{M_{z 1}}{L}$ & $-\frac{J_{P} P}{A L}$ & $-\frac{M_{z 1}}{6}-\frac{M_{z 2}}{6}$ & $\frac{M_{y 1}}{6}+\frac{M_{y 2}}{6}$ \\
\hline 0 & $\frac{M_{x 2}}{L\left(12 \Omega_{y}+1\right)}$ & 0 & $\frac{M_{z 1}}{6}+\frac{M_{z 2}}{6}$ & 0 & $-\frac{6 M_{x 2}\left(\Omega_{y}-\Omega_{z}\right)}{\left(12 \Omega_{y}+1\right)\left(12 \Omega_{z}+1\right)}$ & 0 & $-\frac{M_{x 2}}{L\left(12 \Omega_{y}+1\right)}$ & 0 & $-\frac{M_{z 1}}{6}-\frac{M_{z 2}}{6}$ & 0 & $-\frac{M_{x 2}\left(144 \Omega_{y} \Omega_{z}-1\right)}{2\left(12 \Omega_{y}+1\right)\left(12 \Omega_{z}+1\right)}$ \\
\hline 0 & 0 & $\frac{M_{x 2}}{L\left(12 \Omega_{z}+1\right)}$ & $-\frac{M_{y 1}}{6}-\frac{M_{y 2}}{6}$ & $-\frac{6 M_{x 2}\left(\Omega_{y}-\Omega_{z}\right)}{\left(12 \Omega_{y}+1\right)\left(12 \Omega_{z}+1\right)}$ & 0 & 0 & 0 & $\frac{M_{x 2}}{L\left(12 \Omega_{z}+1\right)}$ & $\frac{M_{y 1}}{6}+\frac{M_{y 2}}{6}$ & $\frac{M_{x 2}\left(144 \Omega_{y} \Omega_{z}-1\right)}{2\left(12 \Omega_{y}+1\right)\left(12 \Omega_{z}+1\right)}$ & 0 \\
\hline 0 & 0 & 0 & 0 & 0 & 0 & 0 & 0 & 0 & 0 & 0 & 0 \\
\hline 0 & 0 & 0 & $-\frac{M_{y 1}}{L}$ & $-\frac{M_{x 2}}{L\left(12 \Omega_{y}+1\right)}$ & 0 & 0 & 0 & 0 & $-\frac{M_{y 2}}{L}$ & $\frac{M_{x 2}}{L\left(12 \Omega_{y}+1\right)}$ & 0 \\
\hline 0 & 0 & 0 & $-\frac{M_{z 1}}{L}$ & 0 & $-\frac{M_{x 2}}{L\left(12 \Omega_{z}+1\right)}$ & 0 & 0 & 0 & $-\frac{M_{z 2}}{L}$ & 0 & $\frac{M_{x 2}}{L\left(12 \Omega_{z}+1\right)}$ \\
\hline 0 & $\frac{M_{y 2}}{L}$ & $\frac{M_{z 2}}{L}$ & $-\frac{J_{P} P}{A L}$ & $-\frac{M_{z 1}}{6}-\frac{M_{z 2}}{6}$ & $\frac{M_{y 1}}{6}+\frac{M_{y 2}}{6}$ & 0 & $-\frac{M_{y 2}}{L}$ & $-\frac{M_{z 2}}{L}$ & $\frac{J_{P} P}{A L}$ & $\frac{M_{z 1}}{6}+\frac{M_{z 2}}{6}$ & $-\frac{M_{y 1}}{6}-\frac{M_{y 2}}{6}$ \\
\hline 0 & $\frac{M_{x 2}}{L\left(12 \Omega_{y}+1\right)}$ & 0 & $-\frac{M_{z 1}}{6}-\frac{M_{z 2}}{6}$ & 0 & $\frac{M_{x 2}\left(144 \Omega_{y} \Omega_{z}-1\right)}{2\left(12 \Omega_{y}+1\right)\left(12 \Omega_{z}+1\right)}$ & 0 & $\frac{M_{x 2}}{L\left(12 \Omega_{y}+1\right)}$ & 0 & $\frac{M_{z 1}}{6}+\frac{M_{z 2}}{6}$ & 0 & $\frac{6 M_{x 2}\left(\Omega_{y}-\Omega_{z}\right)}{\left(12 \Omega_{y}+1\right)\left(12 \Omega_{z}+1\right)}$ \\
\hline 0 & 0 & $\frac{M_{x 2}}{L\left(12 \Omega_{z}+1\right)}$ & $\frac{M_{y 1}}{6}+\frac{M_{y 2}}{6}$ & $\frac{M_{x 2}\left(144 \Omega_{y} \Omega_{z}-1\right)}{2\left(12 \Omega_{y}+1\right)\left(12 \Omega_{z}+1\right)}$ & 0 & 0 & 0 & $\frac{M_{x 2}}{L\left(12 \Omega_{z}+1\right)}$ & $-\frac{M_{y 1}}{6}-\frac{M_{y 2}}{6}$ & $\frac{6 M_{x 2}\left(\Omega_{y}-\Omega_{z}\right)}{\left(12 \Omega_{y}+1\right)\left(12 \Omega_{z}+1\right)}$ & 0 \\
\hline
\end{tabular}


Apêndice $C$

C.3

Matriz de Rigidez Geométrica Local Final com Funções de Forma Cúbicas (TBT_Large)

\begin{tabular}{|c|c|c|c|c|c|c|c|c|c|c|c|}
\hline$\frac{P}{L}$ & 0 & 0 & 0 & $-\frac{M_{y 1}}{L}$ & $-\frac{M_{z 1}}{L}$ & $-\frac{P}{L}$ & 0 & 0 & 0 & $-\frac{M_{y 2}}{L}$ & $-\frac{M_{z 2}}{L}$ \\
\hline 0 & $\begin{array}{l}\frac{6 P\left(120 \Omega_{y}{ }^{2}+20 \Omega_{y}+1\right)}{5 L\left(12 \Omega_{y}+1\right)^{2}} \\
+\frac{12 P I_{z}}{A L^{3}\left(12 \Omega_{y}+1\right)^{2}}\end{array}$ & 0 & $\frac{M_{y 1}}{L}$ & $\frac{M_{x 2}}{L\left(12 \Omega_{y}+1\right)}$ & $\begin{array}{l}\frac{P}{10\left(12 \Omega_{y}+1\right)^{2}} \\
+\frac{6 P I_{z}}{A L^{2}\left(12 \Omega_{y}+1\right)^{2}}\end{array}$ & 0 & $\begin{array}{l}-\frac{6 P\left(120 \Omega_{y}{ }^{2}+20 \Omega_{y}+1\right)}{5 L\left(12 \Omega_{y}+1\right)^{2}} \\
-\frac{12 P I_{z}}{A L^{3}\left(12 \Omega_{y}+1\right)^{2}}\end{array}$ & 0 & $\frac{M_{y 2}}{L}$ & $-\frac{M_{x 2}}{L\left(12 \Omega_{y}+1\right)}$ & $\begin{array}{l}\frac{P}{P} \frac{L}{10\left(12 \Omega_{y}+1\right)^{2}} \\
+\frac{6 P I_{z}}{A L^{2}\left(12 \Omega_{y}+1\right)^{2}}\end{array}$ \\
\hline 0 & 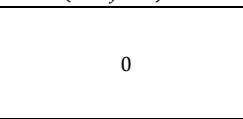 & $\begin{array}{l}\frac{6 P\left(120 \Omega_{z}{ }^{2}+20 \Omega_{z}+1\right)}{5 L\left(12 \Omega_{z}+1\right)^{2}} \\
+\frac{12 P I_{y}}{A L^{3}\left(12 \Omega_{z}+1\right)^{2}}\end{array}$ & $\frac{M_{z 1}}{L}$ & $\begin{array}{l}-\frac{P}{10\left(12 \Omega_{z}+1\right)^{2}} \\
-\frac{6 P I_{y}}{A L^{2}\left(12 \Omega_{z}+1\right)^{2}}\end{array}$ & $\frac{M_{x 2}}{L\left(12 \Omega_{z}+1\right)}$ & 0 & 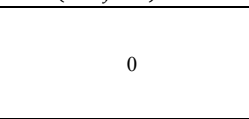 & $\begin{array}{l}\frac{6 P\left(120 \Omega_{z}{ }^{2}+20 \Omega_{z}\right.}{5 L\left(12 \Omega_{z}+1\right)^{2}} \\
\frac{12 P I_{y}}{A L^{3}\left(12 \Omega_{z}+1\right)^{2}}\end{array}$ & $\frac{M_{22}}{L}$ & $\begin{array}{l}-\frac{P}{10\left(12 \Omega_{z}+1\right)^{2}} \\
-\frac{6 P I_{y}}{A L^{2}\left(12 \Omega_{z}+1\right)^{2}}\end{array}$ & $-\frac{M_{x 2}}{L\left(12 \Omega_{z}+1\right)}$ \\
\hline 0 & $\frac{M_{y 1}}{L}$ & $\frac{M_{z 1}}{L}$ & $\frac{J_{P} P}{A L}$ & $\frac{M_{z 2}}{6}-\frac{M_{z 1}}{3}$ & $\frac{M_{y 1}}{3}-\frac{M_{y 2}}{6}$ & 0 & $-\frac{M_{y 1}}{L}$ & $-\frac{M_{z 1}}{L}$ & $-\frac{J_{P} P}{A L}$ & $-\frac{M_{21}}{6}-\frac{M_{22}}{6}$ & $\frac{M_{y 1}}{6}+\frac{M_{y 2}}{6}$ \\
\hline$\frac{M_{y 1}}{L}$ & $\frac{M_{x 2}}{L\left(12 \Omega_{y}+1\right)}$ & $\begin{array}{l}-\frac{P}{10\left(12 \Omega_{z}+1\right)^{2}} \\
-\frac{6 P I_{y}}{A L^{2}\left(12 \Omega_{z}+1\right)^{2}} \\
\end{array}$ & $\frac{M_{z 2}}{6}-\frac{M_{z 1}}{3}$ & \begin{tabular}{|l}
$2 P L\left(90 \Omega_{z}{ }^{2}+15 \Omega_{z}+1\right)$ \\
$15\left(12 \Omega_{z}+1\right)^{2}$ \\
$+\frac{4 P I_{y}\left(36 \Omega_{z}{ }^{2}+6 \Omega_{z}+1\right)}{A L}$
\end{tabular} & $-\frac{6 M_{x 2}\left(\Omega_{y}-\Omega_{z}\right)}{\left(12 \Omega_{y}+1\right)\left(12 \Omega_{z}+1\right)}$ & $\frac{M_{y 1}}{L}$ & $-\frac{M_{x 2}}{L\left(12 \Omega_{y}+1\right)}$ & $\begin{array}{l}\frac{P}{10\left(12 \Omega_{z}+1\right)^{2}} \\
+\frac{6 P I_{y}}{A L^{2}\left(12 \Omega_{z}+1\right)^{2}} \\
\end{array}$ & $-\frac{M_{z 1}}{6}-\frac{M_{z 2}}{6}$ & $\begin{array}{l}-\frac{P L\left(360 \Omega_{z}{ }^{2}+60 \Omega_{z}+1\right.}{30\left(12 \Omega_{z}+1\right)^{2}} \\
-\frac{2 P I_{y}\left(72 \Omega_{z}{ }^{2}+12 \Omega_{z}-\right.}{A L\left(12 \Omega_{z}+1\right)^{2}} \\
\end{array}$ & $-\frac{M_{x 2}\left(144 \Omega_{y} \Omega_{z}-1\right)}{2\left(12 \Omega_{y}+1\right)\left(12 \Omega_{z}+1\right)}$ \\
\hline$\frac{M_{z 1}}{L}$ & $\begin{array}{l}\frac{P}{10\left(12 \Omega_{y}+1\right)^{2}} \\
+\frac{6 P I_{z}}{A L^{2}\left(12 \Omega_{y}+1\right)^{2}}\end{array}$ & $\frac{M_{x 2}}{L\left(12 \Omega_{z}+1\right)}$ & $\frac{M_{y 1}}{3}-\frac{M_{y 2}}{6}$ & $-\frac{6 M_{x z}\left(\Omega_{y}-\Omega_{z}\right)}{\left(12 \Omega_{y}+1\right)\left(12 \Omega_{z}+1\right)}$ & $\begin{array}{l}\frac{2 P L\left(90 \Omega_{y}{ }^{2}+15 \Omega_{y}+1\right)}{15\left(12 \Omega_{y}+1\right)^{2}} \\
+\frac{4 P I_{z}\left(36 \Omega_{y}{ }^{2}+6 \Omega_{y}+1\right)}{A L\left(12 \Omega_{y}+1\right)^{2}}\end{array}$ & $\frac{M_{z 1}}{L}$ & $\begin{array}{l}-\frac{P}{10\left(12 \Omega_{y}+1\right)^{2}} \\
-\frac{6 P I_{z}}{A L^{2}\left(12 \Omega_{y}+1\right)^{2}}\end{array}$ & $-\frac{M_{x 2}}{L\left(12 \Omega_{z}+1\right)}$ & $\frac{M_{y 1}}{6}+\frac{M_{y 2}}{6}$ & $\frac{M_{x 2}\left(144 \Omega_{y} \Omega_{z}-1\right)}{2\left(12 \Omega_{y}+1\right)\left(12 \Omega_{z}+1\right.}$ & $\begin{array}{l}-\frac{P L\left(360 \Omega_{y}{ }^{2}+60 \Omega_{y}+1\right)}{30\left(12 \Omega_{y}+1\right)^{2}} \\
-\frac{2 P I_{z}\left(72 \Omega_{y}{ }^{2}+12 \Omega_{y}-1\right)}{A L\left(12 \Omega_{y}+1\right)^{2}}\end{array}$ \\
\hline $\begin{array}{l}\frac{P}{L} \\
\end{array}$ & 0 & 0 & 0 & $\frac{M_{y 1}}{L}$ & $\frac{M_{z 1}}{L}$ & $\frac{P}{L}$ & 0 & 0 & 0 & $\frac{M_{y 2}}{L}$ & $\frac{M_{\mathrm{z} 2}}{L}$ \\
\hline 0 & $\begin{array}{l}\frac{6 P\left(120 \Omega_{y}{ }^{2}+20 \Omega_{y}+1\right)}{5 L\left(12 \Omega_{y}+1\right)^{2}} \\
\frac{12 P I_{z}}{A L^{3}\left(12 \Omega_{y}+1\right)^{2}}\end{array}$ & 0 & $-\frac{M_{y 1}}{L}$ & $-\frac{M_{x 2}}{L\left(12 \Omega_{y}+1\right)}$ & $\begin{array}{l}-\frac{P}{10\left(12 \Omega_{y}+1\right)^{2}} \\
-\frac{6 P I_{z}}{A L^{2}\left(12 \Omega_{y}+1\right)^{2}}\end{array}$ & 0 & $\begin{array}{l}\frac{6 P\left(120 \Omega_{y}{ }^{2}+20 \Omega_{y}+1\right)}{5 L\left(12 \Omega_{y}+1\right)^{2}} \\
+\frac{12 P I_{z}}{A L^{3}\left(12 \Omega_{y}+1\right)^{2}}\end{array}$ & 0 & $-\frac{M_{y 2}}{L}$ & $\frac{M_{x 2}}{L\left(12 \Omega_{y}+1\right)}$ & $\begin{array}{l}-\frac{P}{10\left(12 \Omega_{y}+1\right)^{2}} \\
-\frac{6 P I_{z}}{A L^{2}\left(12 \Omega_{y}+1\right)^{2}}\end{array}$ \\
\hline 0 & 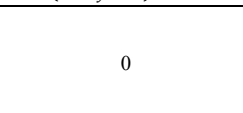 & $\begin{array}{l}-\frac{6 P\left(120 \Omega_{z}{ }^{2}+20 \Omega_{z}+1\right)}{5 L\left(12 \Omega_{z}+1\right)^{2}} \\
-\frac{12 P I_{y}}{A L^{3}\left(12 \Omega_{z}+1\right)^{2}}\end{array}$ & $-\frac{M_{z 1}}{L}$ & $\begin{array}{l}\frac{P}{10\left(12 \Omega_{z}+1\right)^{2}} \\
+\frac{6 P I_{y}}{A L^{2}\left(12 \Omega_{z}+1\right)^{2}}\end{array}$ & $-\frac{M_{x 2}}{L\left(12 \Omega_{z}+1\right)}$ & 0 & 0 & \begin{tabular}{|c|}
$6 P\left(120 \Omega_{z}{ }^{2}+20 \Omega_{z}+\right.$ \\
$5 L\left(12 \Omega_{z}+1\right)^{2}$ \\
$+\frac{12 P I_{y}}{A L^{3}\left(12 \Omega_{z}+1\right)^{2}}$
\end{tabular} & $-\frac{M_{22}}{L}$ & $\begin{array}{l}\frac{P}{10\left(12 \Omega_{z}+1\right)^{2}} \\
+\frac{6 P I_{y}}{A L^{2}\left(12 \Omega_{z}+1\right)^{2}}\end{array}$ & $\frac{M_{x 2}}{L\left(12 \Omega_{z}+1\right)}$ \\
\hline 0 & $\frac{M_{y 2}}{L}$ & $\frac{M_{z 2}}{L}$ & $-\frac{J_{P} P}{A L}$ & $-\frac{M_{z 1}}{6}-\frac{M_{z 2}}{6}$ & $\frac{M_{y 1}}{6}+\frac{M_{y 2}}{6}$ & 0 & $-\frac{M_{y 2}}{L}$ & $-\frac{M_{z 2}}{L}$ & $\frac{J_{P} P}{A L}$ & $\frac{M_{z 1}}{6}-\frac{M_{z 2}}{3}$ & $\frac{M_{y 2}}{3}-\frac{M_{y 1}}{6}$ \\
\hline$\frac{M_{y 2}}{L}$ & $-\frac{M_{x 2}}{L\left(12 \Omega_{y}+1\right)}$ & $\begin{array}{l}-\frac{P}{10\left(12 \Omega_{z}+1\right)^{2}} \\
-\frac{6 P I_{y}}{A L^{2}\left(12 \Omega_{z}+1\right)^{2}} \\
\end{array}$ & $-\frac{M_{z 1}}{6}-\frac{M_{z 2}}{6}$ & \begin{tabular}{|c|}
$-P L\left(360 \Omega_{z}{ }^{2}+60 \Omega_{z}+1\right)$ \\
$30\left(12 \Omega_{z}+1\right)^{2}$ \\
$-\frac{2 P I_{y}\left(72 \Omega_{z}^{2}+12 \Omega_{z}-1\right)}{A L\left(12 \Omega_{z}+1\right)^{2}}$ \\
\end{tabular} & $\frac{M_{x 2}\left(144 \Omega_{y} \Omega_{z}-1\right)}{2\left(12 \Omega_{y}+1\right)\left(12 \Omega_{z}+1\right)}$ & $\frac{M_{y 2}}{L}$ & $\frac{M_{x 2}}{L\left(12 \Omega_{y}+1\right)}$ & $\begin{array}{l}\frac{P}{10\left(12 \Omega_{z}+1\right)^{2}} \\
+\frac{6 P I_{y}}{A L^{2}\left(12 \Omega_{z}+1\right)^{2}} \\
\end{array}$ & $\frac{M_{z 1}}{6}-\frac{M_{z 2}}{3}$ & \begin{tabular}{|c|}
$2 P L\left(90 \Omega_{z}^{2}+15 \Omega_{z}+1\right)$ \\
$15\left(12 \Omega_{z}+1\right)^{2}$ \\
$+\frac{4 P I_{y}\left(36 \Omega_{z}^{2}+6 \Omega_{z}+1\right.}{A L}$ \\
\end{tabular} & $\frac{6 M_{x 2}\left(\Omega_{y}-\Omega_{z}\right)}{\left(12 \Omega_{y}+1\right)\left(12 \Omega_{z}+1\right)}$ \\
\hline$\frac{M_{z 2}}{L}$ & $\begin{array}{l}\frac{P}{10\left(12 \Omega_{y}+1\right)^{2}} \\
+\frac{6 P I_{z}}{A L^{2}\left(12 \Omega_{y}+1\right)^{2}}\end{array}$ & $-\frac{M_{x 2}}{L\left(12 \Omega_{z}+1\right)}$ & $\frac{M_{y 1}}{6}+\frac{M_{y 2}}{6}$ & $-\frac{M_{x 2}\left(144 \Omega_{y} \Omega_{z}-1\right)}{2\left(12 \Omega_{y}+1\right)\left(12 \Omega_{z}+1\right)}$ & $\begin{array}{l}-\frac{P L\left(360 \Omega_{y}{ }^{2}+60 \Omega_{y}+1\right)}{30\left(12 \Omega_{y}+1\right)^{2}} \\
-\frac{2 P I_{z}\left(72 \Omega_{y}{ }^{2}+12 \Omega_{y}-1\right)}{A L\left(12 \Omega_{y}+1\right)^{2}}\end{array}$ & $\frac{M_{z 2}}{L}$ & $\begin{array}{l}-\frac{P}{10\left(12 \Omega_{y}+1\right)^{2}} \\
-\frac{6 P I_{z}}{A L^{2}\left(12 \Omega_{y}+1\right)^{2}}\end{array}$ & $\frac{M_{x 2}}{L\left(12 \Omega_{z}+1\right)}$ & $\frac{M_{y 2}}{3}-\frac{M_{y 1}}{6}$ & $\frac{6 M_{x 2}\left(\Omega_{y}-\Omega_{z}\right)}{\left(12 \Omega_{y}+1\right)\left(12 \Omega_{z}+1\right)}$ & $\begin{array}{l}\frac{2 P L\left(90 \Omega_{y}{ }^{2}+15 \Omega_{y}+1\right)}{15\left(12 \Omega_{y}+1\right)^{2}} \\
+\frac{4 P I_{z}\left(36 \Omega_{y}{ }^{2}+6 \Omega_{y}+1\right)}{A L\left(12 \Omega_{y}+1\right)^{2}}\end{array}$ \\
\hline
\end{tabular}




\section{4}

Matriz de Rigidez Local com Funções de Forma Completas: "1a Ordem” (TBT_Complete) - Tração

\begin{tabular}{|c|c|c|c|c|c|c|c|c|c|c|c|}
\hline$\frac{E A}{L}$ & 0 & 0 & 0 & 0 & 0 & $-\frac{E A}{L}$ & 0 & 0 & 0 & 0 & 0 \\
\hline 0 & $\frac{12 E I_{z}}{L^{3}} \frac{\left(\Lambda_{y} L\right)^{3} C_{y}}{12 D_{y}^{2}}$ & 0 & 0 & 0 & $\frac{6 E I_{z}}{L^{2}} \frac{\left(\Lambda_{y} L\right)^{3} C_{y}}{12 D_{y}^{2}}$ & 0 & $-\frac{12 E I_{z}}{L^{3}} \frac{\left(\Lambda_{y} L\right)^{3} C_{y}}{12 D_{y}^{2}}$ & 0 & 0 & 0 & $\frac{6 E I_{z}}{L^{2}} \frac{\left(\Lambda_{y} L\right)^{3} C_{y}}{12 D_{y}{ }^{2}}$ \\
\hline 0 & 0 & $\frac{12 E I_{y}}{L^{3}} \frac{\left(\Lambda_{z} L\right)^{3} C_{z}}{12 D_{z}{ }^{2}}$ & 0 & $-\frac{6 E I_{y}}{L^{2}} \frac{\left(\Lambda_{z} L\right)^{3} C_{z}}{12 D_{z}^{2}}$ & 0 & 0 & 0 & $-\frac{12 E I_{y}}{L^{3}} \frac{\left(\Lambda_{z} L\right)^{3} C_{z}}{12 D_{z}^{2}}$ & 0 & $-\frac{6 E I_{y}}{L^{2}} \frac{\left(\Lambda_{z} L\right)^{3} C_{z}}{12 D_{z}^{2}}$ & 0 \\
\hline 0 & 0 & 0 & $\frac{G I_{x}}{L}$ & 0 & 0 & 0 & 0 & 0 & $-\frac{G I_{x}}{L}$ & 0 & 0 \\
\hline 0 & 0 & $-\frac{6 E I_{y}}{L^{2}} \frac{\left(\Lambda_{z} L\right)^{3} C_{z}}{12 D_{z}{ }^{2}}$ & 0 & $\frac{4 E I_{y}}{L} \frac{\Lambda_{z} L B_{z}}{8 \phi_{z}}$ & 0 & 0 & 0 & $\frac{6 E I_{y}}{L^{2}} \frac{\left(\Lambda_{z} L\right)^{3} C_{z}}{12 D_{z}{ }^{2}}$ & 0 & $\frac{2 E I_{y}}{L} \frac{\Lambda_{z} L F_{z}}{8 \phi_{z}}$ & 0 \\
\hline 0 & $\frac{6 E I_{z}}{L^{2}} \frac{\left(\Lambda_{y} L\right)^{3} C_{y}}{12 D_{y}{ }^{2}}$ & 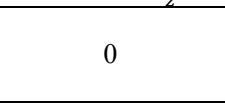 & 0 & 0 & $\frac{4 E I_{z}}{L} \frac{\Lambda_{y} L B_{y}}{8 \phi_{y}}$ & 0 & $-\frac{6 E I_{z}}{L^{3}} \frac{\left(\Lambda_{y} L\right)^{3} C_{y}}{12 D_{y}{ }^{2}}$ & $N_{Z}+N_{Z}$ & 0 & $-T_{Z}$ & $\frac{2 E I_{z}}{L} \frac{\Lambda_{y} L F_{y}}{8 \phi_{y}}$ \\
\hline$-\frac{E A}{L}$ & 0 & 0 & 0 & 0 & 0 & $\frac{E A}{L}$ & 0 & 0 & 0 & 0 & 0 \\
\hline 0 & $-\frac{12 E I_{z}}{L^{3}} \frac{\left(\Lambda_{y} L\right)^{3} C_{y}}{12 D_{y}{ }^{2}}$ & 0 & 0 & 0 & $-\frac{6 E I_{z}}{L^{2}} \frac{\left(\Lambda_{y} L\right)^{3} C_{y}}{12 D_{y}{ }^{2}}$ & 0 & $\frac{12 E I_{z}}{L^{3}} \frac{\left(\Lambda_{y} L\right)^{3} C_{y}}{12 D_{y}{ }^{2}}$ & 0 & 0 & 0 & $-\frac{6 E I_{z}}{L^{2}} \frac{\left(\Lambda_{y} L\right)^{3} C_{y}}{12 D_{y}{ }^{2}}$ \\
\hline 0 & 0 & $-\frac{12 E I_{y}}{L^{3}} \frac{\left(\Lambda_{z} L\right)^{3} C_{z}}{12 D_{z}^{2}}$ & 0 & $\frac{6 E I_{y}}{L^{2}} \frac{\left(\Lambda_{z} L\right)^{3} C_{z}}{12 D_{z}^{2}}$ & 0 & 0 & 0 & $\frac{12 E I_{y}}{L^{3}} \frac{\left(\Lambda_{z} L\right)^{3} C_{z}}{12 D_{z}{ }^{2}}$ & 0 & $\frac{6 E I_{y}}{L^{2}} \frac{\left(\Lambda_{z} L\right)^{3} C_{z}}{12 D_{z}{ }^{2}}$ & 0 \\
\hline 0 & 0 & 0 & $-\frac{G I_{x}}{L}$ & 0 & 0 & 0 & 0 & 0 & $\frac{G I_{x}}{L}$ & 0 & \\
\hline 0 & 0 & $-\frac{6 E I_{y}}{L^{2}} \frac{\left(\Lambda_{z} L\right)^{3} C_{z}}{12 D_{z}^{2}}$ & 0 & $\frac{2 E I_{y}}{L} \frac{\Lambda_{z} L F_{z}}{8 \phi_{z}}$ & 0 & 0 & 0 & $\frac{6 E I_{y}}{L^{2}} \frac{\left(\Lambda_{z} L\right)^{3} C_{z}}{12 D_{z}{ }^{2}}$ & 0 & $\frac{4 E I_{y}}{L} \frac{\Lambda_{z} L B_{z}}{8 \phi_{z}}$ & 0 \\
\hline 0 & $\frac{6 E I_{z}}{L^{2}} \frac{\left(\Lambda_{y} L\right)^{3} C_{y}}{12 D_{y}{ }^{2}}$ & 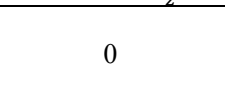 & 0 & 0 & $\frac{2 E I_{z}}{L} \frac{\Lambda_{y} L F_{y}}{8 \phi_{y}}$ & 0 & $-\frac{6 E I_{z}}{L^{2}} \frac{\left(\Lambda_{y} L\right)^{3} C_{y}}{12 D_{y}{ }^{2}}$ & 0 & 0 & 0 & $\frac{4 E I_{z}}{L} \frac{\Lambda_{y} L B_{y}}{8 \phi_{y}}$ \\
\hline
\end{tabular}

$C_{y}=2\left(\sinh \left(L \Lambda_{y}\right)-L \Lambda_{y}\right)+\Omega_{y}\left(L^{3} \Lambda_{y}^{3}+L^{2} \Lambda_{y}^{2} \sinh \left(L \Lambda_{y}\right)\right) ; \quad D_{y}=2 L \Lambda_{y} \cosh \left(\frac{L \Lambda_{y}}{2}\right)-4 \sinh \left(\frac{L \Lambda_{y}}{2}\right)+4 L^{2} \Lambda_{y}^{2} \Omega_{y} \sinh \left(\frac{L \Lambda_{y}}{2}\right)$

$C_{z}=2\left(\sinh \left(L \Lambda_{z}\right)-L \Lambda_{z}\right)+\Omega_{z}\left(L^{3} \Lambda_{z}^{3}+L^{2} \Lambda_{z}^{2} \sinh \left(L \Lambda_{z}\right)\right) ; \quad D_{z}=2 L \Lambda_{z} \cosh \left(\frac{L \Lambda_{z}}{2}\right)-4 \sinh \left(\frac{L \Lambda_{z}}{2}\right)+4 L^{2} \Lambda_{z}^{2} \Omega_{z} \sinh \left(\frac{L \Lambda_{z}}{2}\right)$ 
$\phi_{y}=4 \sinh \left(L \Lambda_{y}\right)^{2}-16 \sinh \left(\frac{L \Lambda_{y}}{2}\right)^{2}+4 L \Lambda_{y} \sinh \left(L \Lambda_{y}\right)+L^{2} \Lambda_{y}{ }^{2} \sinh \left(L \Lambda_{y}\right)^{2}+4 L^{4} \Lambda_{y}{ }^{4} \Omega_{y}{ }^{2} \sinh \left(L \Lambda_{y}\right)^{2}-16 L^{4} \Lambda_{y}{ }^{4} \Omega_{y}{ }^{2} \sinh \left(\frac{L \Lambda_{y}}{2}\right)^{2}-4 L^{3} \Lambda_{y}{ }^{3} \Omega_{y} \sinh \left(L \Lambda_{y}\right)-4 L \Lambda_{y} \cosh \left(L \Lambda_{y}\right) \sinh \left(L \Lambda_{y}\right)+$ $-8 L^{2} \Lambda_{y}^{2} \Omega_{y} \sinh \left(L \Lambda_{y}\right)^{2}+32 L^{2} \Lambda_{y}^{2} \Omega_{y} \sinh \left(\frac{L \Lambda_{y}}{2}\right)^{2}+4 L^{3} \Lambda_{y}{ }^{3} \Omega_{y} \cosh \left(L \Lambda_{y}\right) \sinh \left(L \Lambda_{y}\right)$

$\phi_{z}=4 \sinh \left(L \Lambda_{z}\right)^{2}-16 \sinh \left(\frac{L \Lambda_{z}}{2}\right)^{2}+4 L \Lambda_{z} \sinh \left(L \Lambda_{z}\right)+L^{2} \Lambda_{z}{ }^{2} \sinh \left(L \Lambda_{z}\right)^{2}+4 L^{4} \Lambda_{z}{ }^{4} \Omega_{z}{ }^{2} \sinh \left(L \Lambda_{z}\right)^{2}-16 L^{4} \Lambda_{z}^{4} \Omega_{z}{ }^{2} \sinh \left(\frac{L \Lambda_{z}}{2}\right)^{2}-4 L^{3} \Lambda_{z}{ }^{3} \Omega_{z} \sinh \left(L \Lambda_{z}\right)-4 L \Lambda_{z} \cosh \left(L \Lambda_{z}\right) \sinh \left(L \Lambda_{z}\right)+$ $-8 L^{2} \Lambda_{z}^{2} \Omega_{z} \sinh \left(L \Lambda_{z}\right)^{2}+32 L^{2} \Lambda_{z}^{2} \Omega_{z} \sinh \left(\frac{L \Lambda_{z}}{2}\right)^{2}+4 L^{3} \Lambda_{z}^{3} \Omega_{z} \cosh \left(L \Lambda_{z}\right) \sinh \left(L \Lambda_{z}\right)$

$B_{y}=L^{3} \Lambda_{y}{ }^{3}-2 \sinh \left(L \Lambda_{y}\right)+2 \cosh \left(L \Lambda_{y}\right) \sinh \left(L \Lambda_{y}\right)-L^{5} \Lambda_{y}{ }^{5} \Omega_{y}-2 L \Lambda_{y} \sinh \left(L \Lambda_{y}\right)^{2}-2 L^{2} \Lambda_{y}{ }^{2} \sinh \left(L \Lambda_{y}\right)+4 L \Lambda_{y} \sinh \left(\frac{L \Lambda_{y}}{2}\right)^{2}+2 L^{2} \Lambda_{y}{ }^{2} \Omega_{y} \sinh \left(L \Lambda_{y}\right)+4 L^{4} \Lambda_{y}{ }^{4} \Omega_{y} \sinh \left(L \Lambda_{y}\right)+L^{2} \Lambda_{y}{ }^{2} \cosh \left(L \Lambda_{y}\right) \sinh \left(L \Lambda_{y}\right)$ $+2 L^{4} \Lambda_{y}{ }^{4} \Omega_{y}{ }^{2} \sinh \left(L \Lambda_{y}\right)-12 L^{3} \Lambda_{y}{ }^{3} \Omega_{y} \sinh \left(\frac{L \Lambda_{y}}{2}\right)^{2}-2 L^{6} \Lambda_{y}{ }^{6} \Omega_{y}{ }^{2} \sinh \left(L \Lambda_{y}\right)-2 L^{6} \Lambda_{y}{ }^{6} \Omega_{y}{ }^{3} \sinh \left(L \Lambda_{y}\right)+2 L^{5} \Lambda_{y}{ }^{5} \Omega_{y}{ }^{2} \sinh \left(L \Lambda_{y}\right)^{2}+12 L^{5} \Lambda_{y}{ }^{5} \Omega_{y}{ }^{2} \sinh \left(\frac{L \Lambda_{y}}{2}\right)^{2}-4 L^{7} \Lambda_{y}{ }^{7} \Omega_{y}{ }^{3} \sinh \left(\frac{L \Lambda_{y}}{2}\right)^{2}+$ $-2 L^{2} \Lambda_{y}{ }^{2} \Omega_{y} \cosh \left(L \Lambda_{y}\right) \sinh \left(L \Lambda_{y}\right)+L^{4} \Lambda_{y}{ }^{4} \Omega_{y} \cosh \left(L \Lambda_{y}\right) \sinh \left(L \Lambda_{y}\right)-2 L^{4} \Lambda_{y}{ }^{4} \Omega_{y}{ }^{2} \cosh \left(L \Lambda_{y}\right) \sinh \left(L \Lambda_{y}\right)+2 L^{6} \Lambda_{y}{ }^{6} \Omega_{y}{ }^{3} \cosh \left(L \Lambda_{y}\right) \sinh \left(L \Lambda_{y}\right)$ $B_{z}=L^{3} \Lambda_{z}^{3}-2 \sinh \left(L \Lambda_{z}\right)+2 \cosh \left(L \Lambda_{z}\right) \sinh \left(L \Lambda_{z}\right)-L^{5} \Lambda_{z}^{5} \Omega_{z}-2 L \Lambda_{z} \sinh \left(L \Lambda_{z}\right)^{2}-2 L^{2} \Lambda_{z}^{2} \sinh \left(L \Lambda_{z}\right)+4 L \Lambda_{z} \sinh \left(\frac{L \Lambda_{z}}{2}\right)^{2}+2 L^{2} \Lambda_{z}{ }^{2} \Omega_{z} \sinh \left(L \Lambda_{z}\right)+4 L^{4} \Lambda_{z}^{4} \Omega_{z} \sinh \left(L \Lambda_{z}\right)+L^{2} \Lambda_{z}{ }^{2} \cosh \left(L \Lambda_{z}\right) \sinh \left(L \Lambda_{z}\right)$ $+2 L^{4} \Lambda_{z}{ }^{4} \Omega_{z}{ }^{2} \sinh \left(L \Lambda_{z}\right)-12 L^{3} \Lambda_{z}{ }^{3} \Omega_{z} \sinh \left(\frac{L \Lambda_{z}}{2}\right)^{2}-2 L^{6} \Lambda_{z}{ }^{6} \Omega_{z}{ }^{2} \sinh \left(L \Lambda_{z}\right)-2 L^{6} \Lambda_{z}{ }^{6} \Omega_{z}{ }^{3} \sinh \left(L \Lambda_{z}\right)+2 L^{5} \Lambda_{z}{ }^{5} \Omega_{z}{ }^{2} \sinh \left(L \Lambda_{z}\right)^{2}+12 L^{5} \Lambda_{z}{ }^{5} \Omega_{z}{ }^{2} \sinh \left(\frac{L \Lambda_{z}}{2}\right)^{2}-4 L^{7} \Lambda_{z}{ }^{7} \Omega_{z}{ }^{3} \sinh \left(\frac{L \Lambda_{z}}{2}\right)^{2}+$ $-2 L^{2} \Lambda_{z}^{2} \Omega_{z} \cosh \left(L \Lambda_{z}\right) \sinh \left(L \Lambda_{z}\right)+L^{4} \Lambda_{z}^{4} \Omega_{z} \cosh \left(L \Lambda_{z}\right) \sinh \left(L \Lambda_{z}\right)-2 L^{4} \Lambda_{z}^{4} \Omega_{z}{ }^{2} \cosh \left(L \Lambda_{z}\right) \sinh \left(L \Lambda_{z}\right)+2 L^{6} \Lambda_{z}^{6} \Omega_{z}^{3} \cosh \left(L \Lambda_{z}\right) \sinh \left(L \Lambda_{z}\right)$

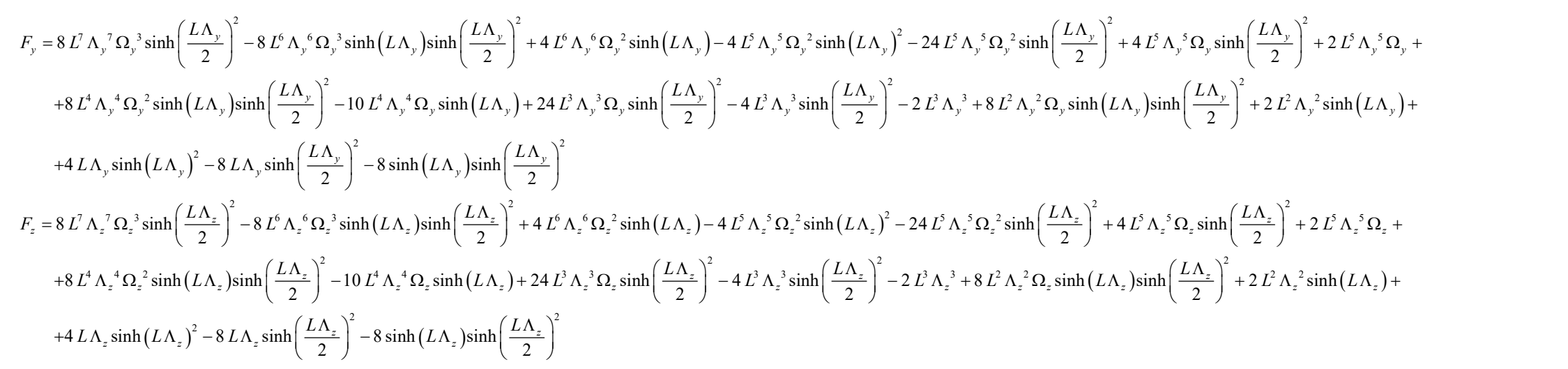




\section{C.5}

Matriz de Rigidez Local com Funções de Forma Completas: "1a Ordem” (TBT_Complete) - Compressão

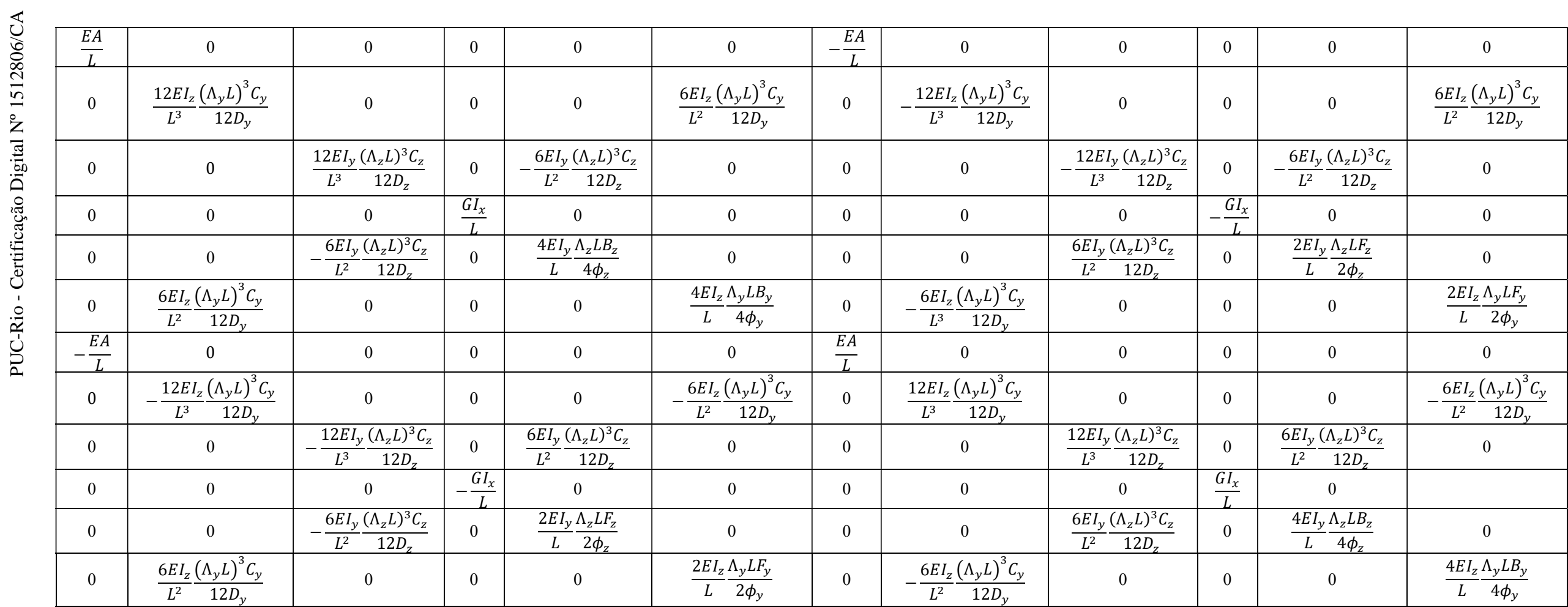

$C_{y}=\left(\sin \left(L \Lambda_{y}\right)-L \Lambda_{y}-L^{3} \Lambda_{y}^{3} \Omega_{y}-L^{2} \Lambda_{y}{ }^{2} \Omega_{y} \sin \left(L \Lambda_{y}\right)\right)$

$D_{y}=4 \cos \left(L \Lambda_{y}\right)-L^{2} \Lambda_{y}{ }^{2}-8 L^{2} \Lambda_{y}{ }^{2} \Omega_{y}-L^{2} \Lambda_{y}{ }^{2} \cos \left(L \Lambda_{y}\right)+4 L \Lambda_{y} \sin \left(L \Lambda_{y}\right)-4 L^{4} \Lambda_{y}{ }^{4} \Omega_{y}{ }^{2}+8 L^{2} \Lambda_{y}{ }^{2} \Omega_{y} \cos \left(L \Lambda_{y}\right)+4 L^{3} \Lambda_{y}{ }^{3} \Omega_{y} \sin \left(L \Lambda_{y}\right)+4 L^{4} \Lambda_{y}{ }^{4} \Omega_{y}{ }^{2} \cos \left(L \Lambda_{y}\right)-4$

$C_{z}=\left(\sin \left(L \Lambda_{z}\right)-L \Lambda_{z}-L^{3} \Lambda_{z}^{3} \Omega_{z}-L^{2} \Lambda_{z}^{2} \Omega_{z} \sin \left(L \Lambda_{z}\right)\right)$;

$D_{z}=4 \cos \left(L \Lambda_{z}\right)-L^{2} \Lambda_{z}{ }^{2}-8 L^{2} \Lambda_{z}{ }^{2} \Omega_{z}-L^{2} \Lambda_{z}{ }^{2} \cos \left(L \Lambda_{z}\right)+4 L \Lambda_{z} \sin \left(L \Lambda_{z}\right)-4 L^{4} \Lambda_{z}{ }^{4} \Omega_{z}{ }^{2}+8 L^{2} \Lambda_{z}{ }^{2} \Omega_{z} \cos \left(L \Lambda_{z}\right)+4 L^{3} \Lambda_{z}{ }^{3} \Omega_{z} \sin \left(L \Lambda_{z}\right)+4 L^{4} \Lambda_{z}^{4} \Omega_{z}{ }^{2} \cos \left(L \Lambda_{z}\right)-4$ 
Apêndice C

$\phi_{y}=4 \cos \left(2 L \Lambda_{y}\right)-16 \cos \left(L \Lambda_{y}\right)+L^{2} \Lambda_{y}{ }^{2}+24 L^{2} \Lambda_{y}{ }^{2} \Omega_{y}-L^{2} \Lambda_{y}{ }^{2} \cos \left(2 L \Lambda_{y}\right)-8 L \Lambda_{y} \sin \left(L \Lambda_{y}\right)+4 L \Lambda_{y} \sin \left(2 L \Lambda_{y}\right)+12 L^{4} \Lambda_{y}{ }^{4} \Omega_{y}{ }^{2}-32 L^{2} \Lambda_{y}{ }^{2} \Omega_{y} \cos \left(L \Lambda_{y}\right)+8 L^{2} \Lambda_{y}{ }^{2} \Omega_{y} \cos \left(2 L \Lambda_{y}\right)-8 L^{3} \Lambda_{y}{ }^{3} \Omega_{y} \sin \left(L \Lambda_{y}\right)+$ $+4 L^{3} \Lambda_{y}{ }^{3} \Omega_{y} \sin \left(2 L \Lambda_{y}\right)-16 L^{4} \Lambda_{y}{ }^{4} \Omega_{y}{ }^{2} \cos \left(L \Lambda_{y}\right)+4 L^{4} \Lambda_{y}{ }^{4} \Omega_{y}{ }^{2} \cos \left(2 L \Lambda_{y}\right)+12$

$\phi_{z}=4 \cos \left(2 L \Lambda_{z}\right)-16 \cos \left(L \Lambda_{z}\right)+L^{2} \Lambda_{z}{ }^{2}+24 L^{2} \Lambda_{z}{ }^{2} \Omega_{z}-L^{2} \Lambda_{z}{ }^{2} \cos \left(2 L \Lambda_{z}\right)-8 L \Lambda_{z} \sin \left(L \Lambda_{z}\right)+4 L \Lambda_{z} \sin \left(2 L \Lambda_{z}\right)+12 L^{4} \Lambda_{z}^{4} \Omega_{z}{ }^{2}-32 L^{2} \Lambda_{z}{ }^{2} \Omega_{z} \cos \left(L \Lambda_{z}\right)+8 L^{2} \Lambda_{z}{ }^{2} \Omega_{z} \cos \left(2 L \Lambda_{z}\right)-8 L^{3} \Lambda_{z}{ }^{3} \Omega_{z} \sin \left(L \Lambda_{z}\right)+$ $+4 L^{3} \Lambda_{z}^{3} \Omega_{z} \sin \left(2 L \Lambda_{z}\right)-16 L^{4} \Lambda_{z}^{4} \Omega_{z}{ }^{2} \cos \left(L \Lambda_{z}\right)+4 L^{4} \Lambda_{z}{ }^{4} \Omega_{z}{ }^{2} \cos \left(2 L \Lambda_{z}\right)+12$

$B_{y}=-\sin \left(2 L \Lambda_{y}\right)+2 \sin \left(L \Lambda_{y}\right)+L^{3} \Lambda_{y}{ }^{3}+L \Lambda_{y}+6 L^{3} \Lambda_{y}{ }^{3} \Omega_{y}+L^{5} \Lambda_{y}{ }^{5} \Omega_{y}-2 L^{2} \Lambda_{y}{ }^{2} \sin \left(L \Lambda_{y}\right)+\frac{L^{2} \Lambda_{y}{ }^{2} \sin \left(2 L \Lambda_{y}\right)}{2}-2 L \Lambda_{y} \cos \left(L \Lambda_{y}\right)+L \Lambda_{y} \cos \left(2 L \Lambda_{y}\right)+7 L^{5} \Lambda_{y}{ }^{5} \Omega_{y}{ }^{2}+2 L^{7} \Lambda_{y}{ }^{7} \Omega_{y}{ }^{3}-6 L^{3} \Lambda_{y}{ }^{3} \Omega_{y} \cos \left(L \Lambda_{y}\right)+$ $+2 L^{2} \Lambda_{y}{ }^{2} \Omega_{y} \sin \left(L \Lambda_{y}\right)-L^{2} \Lambda_{y}{ }^{2} \Omega_{y} \sin \left(2 L \Lambda_{y}\right)-4 L^{4} \Lambda_{y}{ }^{4} \Omega_{y} \sin \left(L \Lambda_{y}\right)-\frac{L^{4} \Lambda_{y}{ }^{4} \Omega_{y} \sin \left(2 L \Lambda_{y}\right)}{2}-6 L^{5} \Lambda_{y}{ }^{5} \Omega_{y}{ }^{2} \cos \left(L \Lambda_{y}\right)-L^{5} \Lambda_{y}{ }^{5} \Omega_{y}{ }^{2} \cos \left(2 L \Lambda_{y}\right)-2 L^{7} \Lambda_{y}{ }^{7} \Omega_{y}{ }^{3} \cos \left(L \Lambda_{y}\right)-2 L^{4} \Lambda_{y}{ }^{4} \Omega_{y}{ }^{2} \sin \left(L \Lambda_{y}\right)+$ $+L^{4} \Lambda_{y}{ }^{4} \Omega_{y}{ }^{2} \sin \left(2 L \Lambda_{y}\right)-2 L^{6} \Lambda_{y}{ }^{6} \Omega_{y}{ }^{2} \sin \left(L \Lambda_{y}\right)-2 L^{6} \Lambda_{y}{ }^{6} \Omega_{y}{ }^{3} \sin \left(L \Lambda_{y}\right)+L^{6} \Lambda_{y}{ }^{6} \Omega_{y}{ }^{3} \sin \left(2 L \Lambda_{y}\right)$

$B_{z}=-\sin \left(2 L \Lambda_{z}\right)+2 \sin \left(L \Lambda_{z}\right)+L^{3} \Lambda_{z}^{3}+L \Lambda_{z}+6 L^{3} \Lambda_{z}^{3} \Omega_{z}+L^{5} \Lambda_{z}^{5} \Omega_{z}-2 L^{2} \Lambda_{z}{ }^{2} \sin \left(L \Lambda_{z}\right)+\frac{L^{2} \Lambda_{z}{ }^{2} \sin \left(2 L \Lambda_{z}\right)}{2}-2 L \Lambda_{z} \cos \left(L \Lambda_{z}\right)+L \Lambda_{z} \cos \left(2 L \Lambda_{z}\right)+7 L^{5} \Lambda_{z}{ }^{5} \Omega_{z}{ }^{2}+2 L^{7} \Lambda_{z}{ }^{7} \Omega_{z}{ }^{3}-6 L^{3} \Lambda_{z}{ }^{3} \Omega_{z} \cos \left(L \Lambda_{z}\right)+$ $+2 L^{2} \Lambda_{z}{ }^{2} \Omega_{z} \sin \left(L \Lambda_{z}\right)-L^{2} \Lambda_{z}{ }^{2} \Omega_{z} \sin \left(2 L \Lambda_{z}\right)-4 L^{4} \Lambda_{z}{ }^{4} \Omega_{z} \sin \left(L \Lambda_{z}\right)-\frac{L^{4} \Lambda_{z}{ }^{4} \Omega_{z} \sin \left(2 L \Lambda_{z}\right)}{2}-6 L^{5} \Lambda_{z}^{5} \Omega_{z}{ }^{2} \cos \left(L \Lambda_{z}\right)-L^{5} \Lambda_{z}^{5} \Omega_{z}{ }^{2} \cos \left(2 L \Lambda_{z}\right)-2 L^{7} \Lambda_{z}{ }^{7} \Omega_{z}{ }^{3} \cos \left(L \Lambda_{z}\right)-2 L^{4} \Lambda_{z}{ }^{4} \Omega_{z}{ }^{2} \sin \left(L \Lambda_{z}\right)+$ $+L^{4} \Lambda_{z}^{4} \Omega_{z}^{2} \sin \left(2 L \Lambda_{z}\right)-2 L^{6} \Lambda_{z}^{6} \Omega_{z}{ }^{2} \sin \left(L \Lambda_{z}\right)-2 L^{6} \Lambda_{z}^{6} \Omega_{z}^{3} \sin \left(L \Lambda_{z}\right)+L^{6} \Lambda_{z}^{6} \Omega_{z}{ }^{3} \sin \left(2 L \Lambda_{z}\right)$

$F_{y}=\sin \left(2 L \Lambda_{y}\right)-2 \sin \left(L \Lambda_{y}\right)-L \Lambda_{y}-6 L^{3} \Lambda_{y}{ }^{3} \Omega_{y}-L^{3} \Lambda_{y}{ }^{3} \cos \left(L \Lambda_{y}\right)+L^{2} \Lambda_{y}{ }^{2} \sin \left(L \Lambda_{y}\right)+2 L \Lambda_{y} \cos \left(L \Lambda_{y}\right)-L \Lambda_{y} \cos \left(2 L \Lambda_{y}\right)-7 L^{5} \Lambda_{y}{ }^{5} \Omega_{y}{ }^{2}-2 L^{7} \Lambda_{y}{ }^{7} \Omega_{y}{ }^{3}+6 L^{3} \Lambda_{y}{ }^{3} \Omega_{y} \cos \left(L \Lambda_{y}\right)-L^{5} \Lambda_{y}{ }^{5} \Omega_{y} \cos \left(L \Lambda_{y}\right)+$ $-2 L^{2} \Lambda_{y}{ }^{2} \Omega_{y} \sin \left(L \Lambda_{y}\right)+L^{2} \Lambda_{y}{ }^{2} \Omega_{y} \sin \left(2 L \Lambda_{y}\right)+5 L^{4} \Lambda_{y}{ }^{4} \Omega_{y} \sin \left(L \Lambda_{y}\right)+6 L^{5} \Lambda_{y}{ }^{5} \Omega_{y}{ }^{2} \cos \left(L \Lambda_{y}\right)+L^{5} \Lambda_{y}{ }^{5} \Omega_{y}{ }^{2} \cos \left(2 L \Lambda_{y}\right)+2 L^{7} \Lambda_{y}{ }^{7} \Omega_{y}{ }^{3} \cos \left(L \Lambda_{y}\right)+2 L^{4} \Lambda_{y}{ }^{4} \Omega_{y}{ }^{2} \sin \left(L \Lambda_{y}\right)-L^{4} \Lambda_{y}{ }^{4} \Omega_{y}{ }^{2} \sin \left(2 L \Lambda_{y}\right)+$ $+2 L^{6} \Lambda_{y}{ }^{6} \Omega_{y}{ }^{2} \sin \left(L \Lambda_{y}\right)+2 L^{6} \Lambda_{y}{ }^{6} \Omega_{y}{ }^{3} \sin \left(L \Lambda_{y}\right)-L^{6} \Lambda_{y}{ }^{6} \Omega_{y}{ }^{3} \sin \left(2 L \Lambda_{y}\right)$

$F_{z}=\sin \left(2 L \Lambda_{z}\right)-2 \sin \left(L \Lambda_{z}\right)-L \Lambda_{z}-6 L^{3} \Lambda_{z}^{3} \Omega_{z}-L^{3} \Lambda_{z}^{3} \cos \left(L \Lambda_{z}\right)+L^{2} \Lambda_{z}{ }^{2} \sin \left(L \Lambda_{z}\right)+2 L \Lambda_{z} \cos \left(L \Lambda_{z}\right)-L \Lambda_{z} \cos \left(2 L \Lambda_{z}\right)-7 L^{5} \Lambda_{z}^{5} \Omega_{z}{ }^{2}-2 L^{7} \Lambda_{z}^{7} \Omega_{z}^{3}+6 L^{3} \Lambda_{z}^{3} \Omega_{z} \cos \left(L \Lambda_{z}\right)-L^{5} \Lambda_{z}^{5} \Omega_{z} \cos \left(L \Lambda_{z}\right)+$ $-2 L^{2} \Lambda_{z}{ }^{2} \Omega_{z} \sin \left(L \Lambda_{z}\right)+L^{2} \Lambda_{z}{ }^{2} \Omega_{z} \sin \left(2 L \Lambda_{z}\right)+5 L^{4} \Lambda_{z}{ }^{4} \Omega_{z} \sin \left(L \Lambda_{z}\right)+6 L^{5} \Lambda_{z}{ }^{5} \Omega_{z}{ }^{2} \cos \left(L \Lambda_{z}\right)+L^{5} \Lambda_{z}{ }^{5} \Omega_{z}{ }^{2} \cos \left(2 L \Lambda_{z}\right)+2 L^{7} \Lambda_{z}{ }^{7} \Omega_{z}{ }^{3} \cos \left(L \Lambda_{z}\right)+2 L^{4} \Lambda_{z}{ }^{4} \Omega_{z}{ }^{2} \sin \left(L \Lambda_{z}\right)-L^{4} \Lambda_{z}{ }^{4} \Omega_{z}{ }^{2} \sin \left(2 L \Lambda_{z}\right)+$ $+2 L^{6} \Lambda_{z}^{6} \Omega_{z}{ }^{2} \sin \left(L \Lambda_{z}\right)+2 L^{6} \Lambda_{z}^{6} \Omega_{z}{ }^{3} \sin \left(L \Lambda_{z}\right)-L^{6} \Lambda_{z}{ }^{6} \Omega_{z}{ }^{3} \sin \left(2 L \Lambda_{z}\right)$ 


\section{6}

Matriz de Rigidez Local com Funções de Forma Completas: “2ª Ordem” (TBT_Complete) - Tração

\begin{tabular}{|c|c|c|c|c|c|c|c|c|c|c|c|}
\hline$\frac{P}{L}$ & 0 & 0 & 0 & $-\frac{M_{y a}}{L}$ & $-\frac{M_{z a}}{L}$ & $-\frac{P}{L}$ & 0 & 0 & 0 & $-\frac{M_{y b}}{L}$ & $-\frac{M_{z b}}{L}$ \\
\hline 0 & $\frac{P \alpha_{y}}{\beta_{y}}+\frac{P I_{z} \Lambda_{y}{ }^{3} C_{y}}{A D_{y}{ }^{2}}$ & 0 & 0 & 0 & $\frac{P \gamma_{y}}{2 \beta_{y}}+\frac{P I_{z} \Lambda_{y}{ }^{3} C_{y}}{2 A D_{y}{ }^{2}}$ & 0 & $-\frac{P \alpha_{y}}{\beta_{y}}-\frac{P I_{z} \Lambda_{y}{ }^{3} C_{y}}{A D_{y}{ }^{2}}$ & 0 & 0 & 0 & $\frac{P \gamma_{y}}{2 \beta_{y}}+\frac{P I_{z} \Lambda_{y}{ }^{3} C_{y}}{2 A D_{y}{ }^{2}}$ \\
\hline 0 & 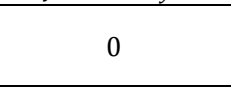 & $\frac{P \alpha_{z}}{\beta_{z}}+\frac{P I_{y} \Lambda_{z}{ }^{3} C_{z}}{A D_{z}{ }^{2}}$ & 0 & $-\frac{P \gamma_{z}}{2 \beta_{z}}-\frac{P I_{y} \Lambda_{z}{ }^{3} C_{z}}{2 A D_{z}{ }^{2}}$ & 20 & 0 & 2. & $-\frac{P \alpha_{z}}{\beta_{z}}-\frac{P I_{y} \Lambda_{z}{ }^{3} C_{z}}{A D_{z}{ }^{2}}$ & 0 & $-\frac{P \gamma_{z}}{2 \beta_{z}}-\frac{P I_{y} \Lambda_{z}{ }^{3} C_{z}}{2 A D_{z}{ }^{2}}$ & 20 \\
\hline 0 & 0 & 0 & 0 & 0 & 0 & 0 & 0 & 0 & 0 & 0 & 0 \\
\hline$\frac{M_{y a}}{L}$ & 0 & $-\frac{P \gamma_{z}}{2 \beta_{z}}-\frac{P I_{y} \Lambda_{z}{ }^{3} C_{z}}{2 A D_{z}{ }^{2}}$ & 0 & $\frac{P \varphi_{z}}{2 \Lambda_{z} \phi_{z}}+\frac{P I_{y} \Lambda_{z} \omega_{z}}{2 A \phi_{z}}$ & 0 & $\frac{M_{y a}}{L}$ & 0 & $\frac{P \gamma_{z}}{2 \beta_{z}}+\frac{P I_{y} \Lambda_{z}{ }^{3} C_{z}}{2 A D_{z}{ }^{2}}$ & 0 & $\frac{P \eta_{z}}{2 \Lambda_{z} \phi_{z}}+\frac{P I_{y} \Lambda_{z} \Psi_{z}}{2 A \phi_{z}}$ & 0 \\
\hline$\frac{M_{z a}}{L}$ & $\frac{P \gamma_{y}}{2 \beta_{y}}+\frac{P I_{z} \Lambda_{y}{ }^{3} C_{y}}{2 A D_{y}{ }^{2}}$ & 0 & 0 & 0 & $\frac{P \varphi_{y}}{2 \Lambda_{y} \phi_{y}}+\frac{P I_{z} \Lambda_{y} \omega_{y}}{2 A \phi_{y}}$ & $\frac{M_{z a}}{L}$ & $-\frac{P \gamma_{y}}{2 \beta_{y}}-\frac{P I_{z} \Lambda_{y}{ }^{3} C_{y}}{2 A D_{y}{ }^{2}}$ & 0 & 0 & 0 & $\frac{P \eta_{y}}{2 \Lambda_{y} \phi_{y}}+\frac{P I_{z} \Lambda_{y} \Psi_{y}}{2 A \phi_{y}}$ \\
\hline$-\frac{P}{L}$ & 2. & 0 & 0 & $\frac{M_{y a}}{L}$ & $\frac{M_{z a}}{L}$ & $\frac{P}{L}$ & 然 & 0 & 0 & $\frac{M_{y b}}{L}$ & $\frac{M_{z b}}{L}$ \\
\hline 0 & $-\frac{P \alpha_{y}}{\beta_{y}}-\frac{P I_{z} \Lambda_{y}{ }^{3} C_{y}}{A D_{y}{ }^{2}}$ & 0 & 0 & 0 & $-\frac{P \gamma_{y}}{2 \beta_{y}}-\frac{P I_{z} \Lambda_{y}{ }^{3} C_{y}}{2 A D_{y}{ }^{2}}$ & 0 & $\frac{P \alpha_{y}}{\beta_{y}}+\frac{P I_{z} \Lambda_{y}{ }^{3} C_{y}}{A D_{y}{ }^{2}}$ & 0 & 0 & 0 & $-\frac{P \gamma_{y}}{2 \beta_{y}}-\frac{P I_{z} \Lambda_{y}{ }^{3} C_{y}}{2 A D_{y}{ }^{2}}$ \\
\hline 0 & 0 & $-\frac{P \alpha_{z}}{\beta_{z}}-\frac{P I_{y} \Lambda_{z}{ }^{3} C_{z}}{A D_{z}{ }^{2}}$ & 0 & $\frac{P \gamma_{z}}{2 \beta_{z}}+\frac{P I_{y} \Lambda_{z}{ }^{3} C_{z}}{2 A D_{z}{ }^{2}}$ & 0 & 0 & 0 & $\frac{P \alpha_{z}}{\beta_{z}}+\frac{P I_{y} \Lambda_{z}{ }^{3} C_{z}}{A D_{z}{ }^{2}}$ & 0 & $\frac{P \gamma_{z}}{2 \beta_{z}}+\frac{P I_{y} \Lambda_{z}{ }^{3} C_{z}}{2 A D_{z}{ }^{2}}$ & 0 \\
\hline 0 & 0 & 0 & 0 & 0 & 0 & 0 & 0 & 0 & 0 & 0 & 0 \\
\hline$\frac{M_{y b}}{L}$ & 0 & $-\frac{P \gamma_{z}}{2 \beta_{z}}-\frac{P I_{y} \Lambda_{z}{ }^{3} C_{z}}{2 A D_{z}{ }^{2}}$ & 0 & $\frac{P \eta_{z}}{2 \Lambda_{z} \phi_{z}}+\frac{P I_{y} \Lambda_{z} \Psi_{z}}{2 A \phi_{z}}$ & 0 & $\frac{M_{y b}}{L}$ & 0 & $\frac{P \gamma_{z}}{2 \beta_{z}}+\frac{P I_{y} \Lambda_{z}{ }^{3} C_{z}}{2 A D_{z}{ }^{2}}$ & 0 & $\frac{P \varphi_{z}}{2 \Lambda \phi_{z}}+\frac{P I_{y} \Lambda_{z} \omega_{z}}{2 A \phi_{z}}$ & 0 \\
\hline$\frac{M_{z b}}{L}$ & $\frac{P \gamma_{y}}{2 \beta_{y}}+\frac{P I_{z} \Lambda_{y}{ }^{3} C_{y}}{2 A D_{y}{ }^{2}}$ & $x_{2}+2$ & 0 & 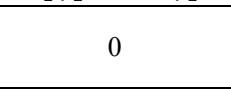 & $\frac{P \eta_{y}}{2 \Lambda_{y} \phi_{y}}+\frac{P I_{z} \Lambda_{y} \Psi_{y}}{2 A \phi_{y}}$ & $\frac{M_{z b}}{L}$ & $-\frac{P \gamma_{y}}{2 \beta_{y}}-\frac{P I_{z} \Lambda_{y}{ }^{3} C_{y}}{2 A D_{y}{ }^{2}}$ & $-r_{Z} \quad-\quad-\mathrm{L}_{2}$ & 0 & $T_{12}=12$ & $\frac{P \varphi_{y}}{2 \Lambda_{y} \phi_{y}}+\frac{P I_{z} \Lambda_{y} \omega_{y}}{2 A \phi_{y}}$ \\
\hline
\end{tabular}

$D_{y}=\left(L \Lambda_{y} \sinh \left(L \Lambda_{y}\right)-2 L^{2} \Lambda_{y}{ }^{2} \Omega_{y}-2 \cosh \left(L \Lambda_{y}\right)+2 L^{2} \Lambda_{y}{ }^{2} \Omega_{y} \cosh \left(L \Lambda_{y}\right)+2\right) ; \alpha_{y}=\Lambda_{y}\left(3 L \Lambda_{y}-3 \sinh \left(L \Lambda_{y}\right)-2 L^{3} \Lambda_{y}{ }^{3} \Omega_{y}+L^{5} \Lambda_{y}{ }^{5} \Omega_{y}{ }^{2}+2 L \Lambda_{y} \sinh \left(\frac{L \Lambda_{y}}{2}\right)^{2}+2 L^{2} \Lambda_{y}{ }^{2} \Omega_{y} \sinh \left(L \Lambda_{y}\right)+L^{4} \Lambda_{y}{ }^{4} \Omega_{y}{ }^{2} \sinh \left(L \Lambda_{y}\right) ; C_{y}=\left(\cosh \left(L \Lambda_{y}\right)-1\right)\left(\sinh \left(L \Lambda_{y}\right)-L \Lambda_{y}\right)\right.$ $D_{z}=\left(L \Lambda_{z} \sinh \left(L \Lambda_{z}\right)-2 L^{2} \Lambda_{z}^{2} \Omega_{z}-2 \cosh \left(L \Lambda_{z}\right)+2 L^{2} \Lambda_{z}^{2} \Omega_{z} \cosh \left(L \Lambda_{z}\right)+2\right) ; \alpha_{z}=\Lambda_{z}\left(3 L \Lambda_{z}-3 \sinh \left(L \Lambda_{z}\right)-2 L^{3} \Lambda_{z}^{3} \Omega_{z}+L^{5} \Lambda_{z}^{5} \Omega_{z}^{2}+2 L \Lambda_{z} \sinh \left(\frac{L \Lambda_{z}}{2}\right)^{2}+2 L^{2} \Lambda_{z}^{2} \Omega_{y} \sinh \left(L \Lambda_{z}\right)+L^{4} \Lambda_{z}^{4} \Omega_{z}^{2} \sinh \left(L \Lambda_{z}\right)\right) ; C_{z}=\left(\cosh \left(L \Lambda_{z}\right)-1\right)\left(\sinh \left(L \Lambda_{z}\right)-L \Lambda_{z}\right)$ $\beta_{y}=2\left(L^{2} \Lambda_{y}{ }^{2}+4 \sinh \left(\frac{L \Lambda_{y}}{2}\right)^{2}-2 L \Lambda_{y} \sinh \left(L \Lambda_{y}\right)+L^{2} \Lambda_{y}{ }^{2} \sinh \left(\frac{L \Lambda_{y}}{2}\right)^{2}+4 L^{4} \Lambda_{y}{ }^{4} \Omega_{y}{ }^{2} \sinh \left(\frac{L \Lambda_{y}}{2}\right)^{2}+2 L^{3} \Lambda_{y}{ }^{3} \Omega_{y} \sinh \left(L \Lambda_{y}\right)-8 L^{2} \Lambda_{y}{ }^{2} \Omega_{y} \sinh \left(\frac{L \Lambda_{y}}{2}\right)^{2}\right) ; \gamma_{y}=\left(L^{2} \Lambda_{y}{ }^{2} \Omega_{y}-1\right)^{2}\left(L^{2} \Lambda_{y}{ }^{2}-8 \sinh \left(\frac{L \Lambda_{y}}{2}\right)^{2}+L \Lambda_{y} \sinh \left(L \Lambda_{y}\right)\right)$ $\beta_{z}=2\left(L^{2} \Lambda_{z}{ }^{2}+4 \sinh \left(\frac{L \Lambda_{z}}{2}\right)^{2}-2 L \Lambda_{z} \sinh \left(L \Lambda_{z}\right)+L^{2} \Lambda_{z}{ }^{2} \sinh \left(\frac{L \Lambda_{z}}{2}\right)^{2}+4 L^{4} \Lambda_{z}^{4} \Omega_{z}{ }^{2} \sinh \left(\frac{L \Lambda_{z}}{2}\right)^{2}+2 L^{3} \Lambda_{z}^{3} \Omega_{z} \sinh \left(L \Lambda_{z}\right)-8 L^{2} \Lambda_{z}^{2} \Omega_{z} \sinh \left(\frac{L \Lambda_{z}}{2}\right)^{2}\right) ; \gamma_{z}=\left(L^{2} \Lambda_{z}{ }^{2} \Omega_{z}-1\right)^{2}\left(L^{2} \Lambda_{z}{ }^{2}-8 \sinh \left(\frac{L \Lambda_{z}}{2}\right)^{2}+L \Lambda_{z} \sinh \left(L \Lambda_{z}\right)\right)$ 
$\phi_{y}=4 L^{4} \Lambda_{y}{ }^{4} \Omega_{y}{ }^{2} \sinh \left(L \Lambda_{y}\right)^{2}-16 L^{4} \Lambda_{y}{ }^{4} \Omega_{y}{ }^{2} \sinh \left(\frac{L \Lambda_{y}}{2}\right)^{2}+8 L^{3} \Lambda_{y}{ }^{3} \Omega_{y} \sinh \left(L \Lambda_{y}\right) \sinh \left(\frac{L \Lambda_{y}}{2}\right)^{2}-8 L^{2} \Lambda_{y}{ }^{2} \Omega_{y} \sinh \left(L \Lambda_{y}\right)^{2}+32 L^{2} \Lambda_{y}{ }^{2} \Omega_{y} \sinh \left(\frac{L \Lambda_{y}}{2}\right)^{2}+L^{2} \Lambda_{y}{ }^{2} \sinh \left(L \Lambda_{y}\right)^{2}-8 L \Lambda_{y} \sinh \left(L \Lambda_{y}\right) \sinh \left(\frac{L \Lambda_{y}}{2}\right)^{2}+4 \sinh \left(L \Lambda_{y}\right)^{2}-16 \sinh \left(\frac{L \Lambda_{y}}{2}\right)^{2}$ $\phi_{z}=4 L^{4} \Lambda_{z}{ }^{4} \Omega_{z}{ }^{2} \sinh \left(L \Lambda_{z}\right)^{2}-16 L^{4} \Lambda_{z}{ }^{4} \Omega_{z}{ }^{2} \sinh \left(\frac{L \Lambda_{z}}{2}\right)^{2}+8 L^{3} \Lambda_{z}{ }^{3} \Omega_{z} \sinh \left(L \Lambda_{z}\right) \sinh \left(\frac{L \Lambda_{z}}{2}\right)^{2}-8 L^{2} \Lambda_{z}{ }^{2} \Omega_{z} \sinh \left(L \Lambda_{z}\right)^{2}+32 L^{2} \Lambda_{z}{ }^{2} \Omega_{z} \sinh \left(\frac{L \Lambda_{z}}{2}\right)^{2}+L^{2} \Lambda_{z}{ }^{2} \sinh \left(L \Lambda_{z}\right)^{2}-8 L \Lambda_{z} \sinh \left(L \Lambda_{z}\right) \sinh \left(\frac{L \Lambda_{z}}{2}\right)^{2}+4 \sinh \left(L \Lambda_{z}\right)^{2}-16 \sinh \left(\frac{L \Lambda_{z}}{2}\right)^{2}$ $\varphi_{y}=\left(L^{2} \Lambda_{y}{ }^{2} \Omega_{y}-1\right)^{2}\left(-4 L^{5} \Lambda_{y}^{5} \Omega_{y}{ }^{2} \sinh \left(\frac{L \Lambda_{y}}{2}\right)^{2}+4 L^{4} \Lambda_{y}{ }^{4} \Omega_{y}{ }^{2} \sinh \left(L \Lambda_{y}\right) \sinh \left(\frac{L \Lambda_{y}}{2}\right)^{2}-2 L^{4} \Lambda_{y}^{4} \Omega_{y} \sinh \left(L \Lambda_{y}\right)+2 L^{3} \Lambda_{y}{ }^{3} \Omega_{y} \sinh \left(L \Lambda_{y}\right)^{2}+8 L^{3} \Lambda_{y}{ }^{3} \Omega_{y} \sinh \left(\frac{L \Lambda_{y}}{2}\right)^{2}-L^{3} \Lambda_{y}{ }^{3}-8 L^{2} \Lambda_{y}{ }^{2} \Omega_{y} \sinh \left(L \Lambda_{y}\right) \sinh \left(\frac{L \Lambda_{y}}{2}\right)^{2}+2 L^{2} \Lambda_{y}{ }^{2} \sinh \left(L \Lambda_{y}\right) \sinh \left(\frac{L \Lambda_{y}}{2}\right)^{2}+\right.$ $\left.+3 L^{2} \Lambda_{y}^{2} \sinh \left(L \Lambda_{y}\right)-4 L \Lambda_{y} \sinh \left(L \Lambda_{y}\right)^{2}+4 L \Lambda_{y} \sinh \left(\frac{L \Lambda_{y}}{2}\right)^{2}+4 \sinh \left(L \Lambda_{y}\right) \sinh \left(\frac{L \Lambda_{y}}{2}\right)^{2}\right)$

$\varphi_{z}=\left(L^{2} \Lambda_{z}^{2} \Omega_{z}-1\right)^{2}\left(-4 L^{5} \Lambda_{z}^{5} \Omega_{z}^{2} \sinh \left(\frac{L \Lambda_{z}}{2}\right)^{2}+4 L^{4} \Lambda_{z}^{4} \Omega_{z}^{2} \sinh \left(L \Lambda_{z}\right) \sinh \left(\frac{L \Lambda_{z}}{2}\right)^{2}-2 L^{4} \Lambda_{z}^{4} \Omega_{z} \sinh \left(L \Lambda_{z}\right)+2 L^{3} \Lambda_{z}^{3} \Omega_{z} \sinh \left(L \Lambda_{z}\right)^{2}+8 L^{3} \Lambda_{z}^{3} \Omega_{z} \sinh \left(\frac{L \Lambda_{z}}{2}\right)^{2}-L^{3} \Lambda_{z}^{3}-8 L^{2} \Lambda_{z}^{2} \Omega_{z} \sinh \left(L \Lambda_{z}\right) \sinh \left(\frac{L \Lambda_{z}}{2}\right)^{2}+2 L^{2} \Lambda_{z}^{2} \sinh \left(L \Lambda_{z}\right) \sinh \left(\frac{L \Lambda_{z}}{2}\right)^{2}+\right.$ $\left.+3 L^{2} \Lambda_{z}^{2} \sinh \left(L \Lambda_{z}\right)-4 L \Lambda_{z} \sinh \left(L \Lambda_{z}\right)^{2}+4 L \Lambda_{z} \sinh \left(\frac{L \Lambda_{z}}{2}\right)^{2}+4 \sinh \left(L \Lambda_{z}\right) \sinh \left(\frac{L \Lambda_{z}}{2}\right)^{2}\right)$

$\eta_{y}=\left(L^{2} \Lambda_{y}{ }^{2} \Omega_{y}-1\right)^{2}\left(4 L^{5} \Lambda_{y}{ }^{5} \Omega_{y}{ }_{y}^{2} \sinh \left(\frac{L \Lambda_{y}}{2}\right)^{2}-4 L^{4} \Lambda_{y}{ }^{4} \Omega_{y}{ }^{2} \sinh \left(L \Lambda_{y}\right) \sinh \left(\frac{L \Lambda_{y}}{2}\right)^{2}+2 L^{4} \Lambda_{y}{ }^{4} \Omega_{y} \sinh \left(L \Lambda_{y}\right)-2 L^{3} \Lambda_{y}{ }^{3} \Omega_{y} \sinh \left(L \Lambda_{y}\right)^{2}-8 L^{3} \Lambda_{y}{ }^{3} \Omega_{y} \sinh \left(\frac{L \Lambda_{y}}{2}\right)^{2}+2 L^{3} \Lambda_{y}{ }^{3} \sinh \left(\frac{L \Lambda_{y}}{2}\right)^{2}+L^{3} \Lambda_{y}{ }^{3}+8 L^{2} \Lambda_{y}{ }^{2} \Omega_{y} \sinh \left(L \Lambda_{y}\right) \sinh \left(\frac{L \Lambda_{y}}{2}\right)^{2}+\right.$ $\left.-3 L^{2} \Lambda_{y}^{2} \sinh \left(L \Lambda_{y}\right)+12 L \Lambda_{y} \sinh \left(\frac{L \Lambda_{y}}{2}\right)^{2}-4 \sinh \left(L \Lambda_{y}\right) \sinh \left(\frac{L \Lambda_{y}}{2}\right)^{2}\right)$

$\eta_{z}=\left(L^{2} \Lambda_{z}{ }^{2} \Omega_{z}-1\right)^{2}\left(4 L^{5} \Lambda_{z}^{5} \Omega_{z}^{2} \sinh \left(\frac{L \Lambda_{z}}{2}\right)^{2}-4 L^{4} \Lambda_{z}^{4} \Omega_{z}^{2} \sinh \left(L \Lambda_{z}\right) \sinh \left(\frac{L \Lambda_{z}}{2}\right)^{2}+2 L^{4} \Lambda_{z}^{4} \Omega_{z} \sinh \left(L \Lambda_{z}\right)-2 L^{3} \Lambda_{z}^{3} \Omega_{z} \sinh \left(L \Lambda_{z}\right)^{2}-8 L^{3} \Lambda_{z}^{3} \Omega_{z} \sinh \left(\frac{L \Lambda_{z}}{2}\right)^{2}+2 L^{3} \Lambda_{z}^{3} \sinh \left(\frac{L \Lambda_{z}}{2}\right)^{2}+L^{3} \Lambda_{z}^{3}+8 L^{2} \Lambda_{z}^{2} \Omega_{z} \sinh \left(L \Lambda_{z}\right) \sinh \left(\frac{L \Lambda_{z}}{2}\right)^{2}+\right.$ $\left.-3 L^{2} \Lambda_{z}^{2} \sinh \left(L \Lambda_{z}\right)+12 L \Lambda_{z} \sinh \left(\frac{L \Lambda_{z}}{2}\right)^{2}-4 \sinh \left(L \Lambda_{z}\right) \sinh \left(\frac{L \Lambda_{z}}{2}\right)^{2}\right)$

$\omega_{y}=4 L^{5} \Lambda_{y}{ }^{5} \Omega_{y}{ }^{2} \sinh \left(\frac{L \Lambda_{y}}{2}\right)^{2}+4 L^{4} \Lambda_{y}{ }^{4} \Omega_{y}{ }^{2} \sinh \left(L \Lambda_{y}\right) \sinh \left(\frac{L \Lambda_{y}}{2}\right)^{2}+2 L^{4} \Lambda_{y}{ }^{4} \Omega_{y} \sinh \left(L \Lambda_{y}\right)+2 L^{3} \Lambda_{y}{ }^{3} \Omega_{y} \sinh \left(L \Lambda_{y}\right)^{2}-8 L^{3} \Lambda_{y}{ }^{3} \Omega_{y} \sinh \left(\frac{L \Lambda_{y}}{2}\right)^{2}+L^{3} \Lambda_{y}{ }^{3}-8 L^{2} \Lambda_{y}{ }^{2} \Omega_{y} \sinh \left(L \Lambda_{y}\right) \sinh \left(\frac{L \Lambda_{y}}{2}\right)^{2}+2 L^{2} \Lambda_{y}{ }^{2} \sinh \left(L \Lambda_{y}\right) \sinh \left(\frac{L \Lambda_{y}}{2}\right)^{2}+$

$-L^{2} \Lambda_{y}^{2} \sinh \left(L \Lambda_{y}\right)-2 L \Lambda_{y} \sinh \left(L \Lambda_{y}\right)^{2}+4 L \Lambda_{y} \sinh \left(\frac{L \Lambda_{y}}{2}\right)^{2}+4 \sinh \left(L \Lambda_{y}\right) \sinh \left(\frac{L \Lambda_{y}}{2}\right)^{2}$

$\omega_{z}=4 L^{5} \Lambda_{z}^{5} \Omega_{z}^{2} \sinh \left(\frac{L \Lambda_{z}}{2}\right)^{2}+4 L^{4} \Lambda_{z}{ }^{4} \Omega_{z}{ }^{2} \sinh \left(L \Lambda_{z}\right) \sinh \left(\frac{L \Lambda_{z}}{2}\right)^{2}+2 L^{4} \Lambda_{z}^{4} \Omega_{z} \sinh \left(L \Lambda_{z}\right)+2 L^{3} \Lambda_{z}^{3} \Omega_{z} \sinh \left(L \Lambda_{z}\right)^{2}-8 L^{3} \Lambda_{z}^{3} \Omega_{z} \sinh \left(\frac{L \Lambda_{z}}{2}\right)^{2}+L^{3} \Lambda_{z}^{3}-8 L^{2} \Lambda_{z}{ }^{2} \Omega_{z} \sinh \left(L \Lambda_{z}\right) \sinh \left(\frac{L \Lambda_{z}}{2}\right)^{2}+2 L^{2} \Lambda_{z}{ }^{2} \sinh \left(L \Lambda_{z}\right) \sinh \left(\frac{L \Lambda_{z}}{2}\right)^{2}+$

$-L^{2} \Lambda_{z}^{2} \sinh \left(L \Lambda_{z}\right)-2 L \Lambda_{z} \sinh \left(L \Lambda_{z}\right)^{2}+4 L \Lambda_{z} \sinh \left(\frac{L \Lambda_{z}}{2}\right)^{2}+4 \sinh \left(L \Lambda_{z}\right) \sinh \left(\frac{L \Lambda_{z}}{2}\right)^{2}$

$\psi_{y}=-4 L^{5} \Lambda_{y}{ }^{5} \Omega_{y}{ }^{2} \sinh \left(\frac{L \Lambda_{y}}{2}\right)^{2}-4 L^{4} \Lambda_{y}{ }^{4} \Omega_{y}{ }^{2} \sinh \left(L \Lambda_{y}\right) \sinh \left(\frac{L \Lambda_{y}}{2}\right)^{2}-2 L^{4} \Lambda_{y}{ }^{4} \Omega_{y} \sinh \left(L \Lambda_{y}\right)-2 L^{3} \Lambda_{y}{ }^{3} \Omega_{y} \sinh \left(L \Lambda_{y}\right)^{2}+8 L^{3} \Lambda_{y}{ }^{3} \Omega_{y} \sinh \left(\frac{L \Lambda_{y}}{2}\right)^{2}-2 L^{3} \Lambda_{y}{ }^{3} \sinh \left(\frac{L \Lambda_{y}}{2}\right)^{2}-L^{3} \Lambda_{y}{ }^{3}+8 L^{2} \Lambda_{y}{ }^{2} \Omega_{y} \sinh \left(L \Lambda_{y}\right) \sinh \left(\frac{L \Lambda_{y}}{2}\right)^{2}+$

$+L^{2} \Lambda_{y}^{2} \sinh \left(L \Lambda_{y}\right)+2 L \Lambda_{y} \sinh \left(L \Lambda_{y}\right)^{2}-4 L \Lambda_{y} \sinh \left(\frac{L \Lambda_{y}}{2}\right)^{2}-4 \sinh \left(L \Lambda_{y}\right) \sinh \left(\frac{L \Lambda_{y}}{2}\right)^{2}$

$\psi_{z}=-4 L^{5} \Lambda_{z}^{5} \Omega_{z}{ }^{2} \sinh \left(\frac{L \Lambda_{z}}{2}\right)^{2}-4 L^{4} \Lambda_{z}^{4} \Omega_{z}{ }^{2} \sinh \left(L \Lambda_{z}\right) \sinh \left(\frac{L \Lambda_{z}}{2}\right)^{2}-2 L^{4} \Lambda_{z}^{4} \Omega_{z} \sinh \left(L \Lambda_{z}\right)-2 L^{3} \Lambda_{z}^{3} \Omega_{z} \sinh \left(L \Lambda_{z}\right)^{2}+8 L^{3} \Lambda_{z}^{3} \Omega_{z} \sinh \left(\frac{L \Lambda_{z}}{2}\right)^{2}-2 L^{3} \Lambda_{z}^{3} \sinh \left(\frac{L \Lambda_{z}}{2}\right)^{2}-L^{3} \Lambda_{z}^{3}+8 L^{2} \Lambda_{z}{ }^{2} \Omega_{z} \sinh \left(L \Lambda_{z}\right) \sinh \left(\frac{L \Lambda_{z}}{2}\right)^{2}+$

$+L^{2} \Lambda_{z}^{2} \sinh \left(L \Lambda_{z}\right)+2 L \Lambda_{z} \sinh \left(L \Lambda_{z}\right)^{2}-4 L \Lambda_{z} \sinh \left(\frac{L \Lambda_{z}}{2}\right)^{2}-4 \sinh \left(L \Lambda_{z}\right) \sinh \left(\frac{L \Lambda_{z}}{2}\right)^{2}$ 


\section{7}

Matriz de Rigidez Local com Funções de Forma Completas: “2a Ordem” (TBT_Complete) - Compressão

\begin{tabular}{|c|c|c|c|c|c|c|c|c|c|c|c|}
\hline$\frac{P}{L}$ & 0 & 0 & 0 & $-\frac{M_{y a}}{L}$ & $-\frac{M_{z a}}{L}$ & $-\frac{P}{L}$ & 0 & 0 & 0 & $-\frac{M_{y b}}{L}$ & $-\frac{M_{z b}}{L}$ \\
\hline 0 & $\frac{P \alpha_{y}}{\beta_{y}}+\frac{P I_{z} \Lambda_{y}{ }^{3} C_{y}}{A D_{y}{ }^{2}}$ & 0 & 0 & 0 & $\frac{P \gamma_{y}}{2 \beta_{y}}+\frac{P I_{z} \Lambda_{y}{ }^{3} C_{y}}{2 A D_{y}{ }^{2}}$ & 0 & $-\frac{P \alpha_{y}}{\beta_{y}}-\frac{P I_{z} \Lambda_{y}{ }^{3} C_{y}}{A D_{y}{ }^{2}}$ & 0 & 0 & 0 & $\frac{P \gamma_{y}}{2 \beta_{y}}+\frac{P I_{z} \Lambda_{y}{ }^{3} C_{y}}{2 A D_{y}{ }^{2}}$ \\
\hline 0 & r & $\frac{P \alpha_{z}}{\beta_{z}}+\frac{P I_{y} \Lambda_{z}{ }^{3} C_{z}}{A D_{z}{ }^{2}}$ & 0 & $-\frac{P \gamma_{z}}{2 \beta_{z}}-\frac{P I_{y} \Lambda_{z}{ }^{3} C_{z}}{2 A D_{z}{ }^{2}}$ & rar & 0 & res & $-\frac{P \alpha_{z}}{\beta_{z}}-\frac{P I_{y} \Lambda_{z}^{3} C_{z}}{A D_{z}^{2}}$ & 0 & $-\frac{P \gamma_{z}}{2 \beta_{z}}-\frac{P I_{y} \Lambda_{z}^{3} C_{z}}{2 A D_{z}^{2}}$ & res \\
\hline 0 & 0 & 0 & 0 & 0 & 0 & 0 & 0 & 0 & 0 & 0 & 0 \\
\hline$\frac{M_{y a}}{L}$ & 0 & $-\frac{P \gamma_{z}}{2 \beta_{z}}-\frac{P I_{y} \Lambda_{z}{ }^{3} C_{z}}{2 A D_{z}{ }^{2}}$ & 0 & $\frac{P \varphi_{z}}{2 \Lambda_{z} \phi_{z}}+\frac{P I_{y} \Lambda_{z} \omega_{z}}{4 A \phi_{z}}$ & 0 & $\frac{M_{y a}}{L}$ & 0 & $\frac{P \gamma_{z}}{2 \beta_{z}}+\frac{P I_{y} \Lambda_{z}{ }^{3} C_{z}}{2 A D_{z}{ }^{2}}$ & 0 & $\frac{P \eta_{z}}{2 \Lambda_{z} \phi_{z}}+\frac{P I_{y} \Lambda_{z} \Psi_{z}}{2 A \phi_{z}}$ & 0 \\
\hline$\frac{M_{z a}}{L}$ & $\frac{P \gamma_{y}}{2 \beta_{y}}+\frac{P I_{z} \Lambda_{y}{ }^{3} C_{y}}{2 A D_{y}{ }^{2}}$ & 0 & 0 & 0 & $\frac{P \varphi_{y}}{2 \Lambda_{y} \phi_{y}}+\frac{P I_{z} \Lambda_{y} \omega_{y}}{4 A \phi_{y}}$ & $\frac{M_{z a}}{L}$ & $-\frac{P \gamma_{y}}{2 \beta_{y}}-\frac{P I_{z} \Lambda_{y}{ }^{3} C_{y}}{2 A D_{y}{ }^{2}}$ & 0 & 0 & 0 & $\frac{P \eta_{y}}{2 \Lambda_{y} \phi_{y}}+\frac{P I_{z} \Lambda_{y} \Psi_{y}}{2 A \phi_{y}}$ \\
\hline$-\frac{P}{L}$ & 0 & 0 & 0 & $\frac{M_{y a}}{L}$ & $\frac{M_{z a}}{L}$ & $\frac{P}{L}$ & 0 & 0 & 0 & $\frac{M_{y b}}{L}$ & $\frac{M_{z b}}{L}$ \\
\hline 0 & $-\frac{P \alpha_{y}}{\beta_{y}}-\frac{P I_{z} \Lambda_{y}{ }^{3} C_{y}}{A D_{y}{ }^{2}}$ & 0 & 0 & 0 & $-\frac{P \gamma_{y}}{2 \beta_{y}}-\frac{P I_{z} \Lambda_{y}{ }^{3} C_{y}}{2 A D_{y}{ }^{2}}$ & 0 & $\frac{P \alpha_{y}}{\beta_{y}}+\frac{P I_{z} \Lambda_{y}{ }^{3} C_{y}}{A D_{y}{ }^{2}}$ & 0 & 0 & 0 & $-\frac{P \gamma_{y}}{2 \beta_{y}}-\frac{P I_{z} \Lambda_{y}{ }^{3} C_{y}}{2 A D_{y}{ }^{2}}$ \\
\hline 0 & 0 & $-\frac{P \alpha_{z}}{\beta_{z}}-\frac{P I_{y} \Lambda_{z}{ }^{3} C_{z}}{A D_{z}{ }^{2}}$ & 0 & $\frac{P \gamma_{z}}{2 \beta_{z}}+\frac{P I_{y} \Lambda_{z}{ }^{3} C_{z}}{2 A D_{z}{ }^{2}}$ & 0 & 0 & 0 & $\frac{P \alpha_{z}}{\beta_{z}}+\frac{P I_{y} \Lambda_{z}{ }^{3} C_{z}}{A D_{z}{ }^{2}}$ & 0 & $\frac{P \gamma_{z}}{2 \beta_{z}}+\frac{P I_{y} \Lambda_{z}^{3} C_{z}}{2 A D_{z}{ }^{2}}$ & 0 \\
\hline 0 & 0 & 0 & 0 & 0 & 0 & 0 & 0 & 0 & 0 & 0 & 0 \\
\hline$\frac{M_{y b}}{L}$ & 0 & $-\frac{P \gamma_{z}}{2 \beta_{z}}-\frac{P I_{y} \Lambda_{z}{ }^{3} C_{z}}{2 A D_{z}{ }^{2}}$ & 0 & $\frac{P \eta_{z}}{2 \Lambda_{z} \phi_{z}}+\frac{P I_{y} \Lambda_{z} \Psi_{z}}{2 A \phi_{z}}$ & 0 & $\frac{M_{y b}}{L}$ & 0 & $\frac{P \gamma_{z}}{2 \beta_{z}}+\frac{P I_{y} \Lambda_{z}{ }^{3} C_{z}}{2 A D_{z}{ }^{2}}$ & 0 & $\frac{P \varphi_{z}}{2 \Lambda_{z} \phi_{z}}+\frac{P I_{y} \Lambda_{z} \omega_{z}}{4 A \phi_{z}}$ & 0 \\
\hline$\frac{M_{z b}}{L}$ & $\frac{P \gamma_{y}}{2 \beta_{y}}+\frac{P I_{z} \Lambda_{y}{ }^{3} C_{y}}{2 A D_{y}{ }^{2}}$ & 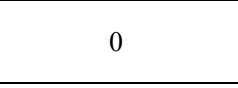 & 0 & 0 & $\frac{P \eta_{y}}{2 \Lambda_{y} \phi_{y}}+\frac{P I_{z} \Lambda_{y} \Psi_{y}}{2 A \phi_{y}}$ & $\frac{M_{z b}}{L}$ & $-\frac{P \gamma_{y}}{2 \beta_{y}}-\frac{P I_{z} \Lambda_{y}{ }^{3} C_{y}}{2 A D_{y}{ }^{2}}$ & 0 & 0 & 0 & $\frac{P \varphi_{y}}{2 \Lambda_{y} \phi_{y}}+\frac{P I_{z} \Lambda_{y} \omega_{y}}{4 A \phi_{y}}$ \\
\hline
\end{tabular}

$D_{y}=\left(4 \sin \left(\frac{L \Lambda_{y}}{2}\right)^{2}-L \Lambda_{y} \sin \left(L \Lambda_{y}\right)+4 L^{2} \Lambda_{y}{ }^{2} \Omega_{y} \sin \left(\frac{L \Lambda_{y}}{2}\right)^{2}\right) ; \alpha_{y}=\Lambda_{y}\left(3 L \Lambda_{y}-3 \sin \left(L \Lambda_{y}\right)+2 L^{3} \Lambda_{y}{ }^{3} \Omega_{y}+L^{5} \Lambda_{y}^{5} \Omega_{y}{ }^{2}-2 L \Lambda_{y} \sin \left(\frac{L \Lambda_{y}}{2}\right)^{2}-2 L^{2} \Lambda_{y}{ }^{2} \Omega_{y} \sin \left(L \Lambda_{y}\right)+L^{4} \Lambda_{y}{ }^{4} \Omega_{y}{ }^{2} \sin \left(L \Lambda_{y}\right)\right) ; C_{y}=2 \sin \left(\frac{L \Lambda_{y}}{2}\right)^{2}\left(L \Lambda_{y}-\sin \left(L \Lambda_{y}\right)\right)$

$D_{z}=\left(4 \sin \left(\frac{L \Lambda_{z}}{2}\right)^{2}-L \Lambda_{z} \sin \left(L \Lambda_{z}\right)+4 L^{2} \Lambda_{z}{ }^{2} \Omega_{z} \sin \left(\frac{L \Lambda_{z}}{2}\right)^{2}\right) ; \alpha_{z}=\Lambda_{y}\left(3 L \Lambda_{z}-3 \sin \left(L \Lambda_{z}\right)+2 L^{3} \Lambda_{z}^{3} \Omega_{z}+L^{5} \Lambda_{z}^{5} \Omega_{z}^{2}-2 L \Lambda_{z} \sin \left(\frac{L \Lambda_{z}}{2}\right)^{2}-2 L^{2} \Lambda_{z}{ }^{2} \Omega_{z} \sin \left(L \Lambda_{z}\right)+L^{4} \Lambda_{z}^{4} \Omega_{z}{ }^{2} \sin \left(L \Lambda_{z}\right)\right) ; C_{z}=2 \sin \left(\frac{L \Lambda_{z}}{2}\right)^{2}\left(L \Lambda_{z}-\sin \left(L \Lambda_{z}\right)\right)$

$\beta_{y}=2\left(L^{2} \Lambda_{y}{ }^{2}+4 \sin \left(\frac{L \Lambda_{y}}{2}\right)^{2}-2 L \Lambda_{y} \sin \left(L \Lambda_{y}\right)-L^{2} \Lambda_{y}{ }^{2} \sin \left(\frac{L \Lambda_{y}}{2}\right)^{2}+4 L^{4} \Lambda_{y}{ }^{4} \Omega_{y}{ }^{2} \sin \left(\frac{L \Lambda_{y}}{2}\right)^{2}-2 L^{3} \Lambda_{y}{ }^{3} \Omega_{y} \sin \left(L \Lambda_{y}\right)+8 L^{2} \Lambda_{y}{ }^{2} \Omega_{y} \sin \left(\frac{L \Lambda_{y}}{2}\right)^{2}\right) ; \gamma_{y}=\left(\Omega_{y} L^{2} \Lambda_{y}{ }^{2}+1\right)^{2}\left(L^{2} \Lambda_{y}{ }^{2}-8 \sin \left(\frac{L \Lambda_{y}}{2}\right)^{2}+L \Lambda_{y} \sin \left(L \Lambda_{y}\right)\right)$

$\beta_{z}=2\left(L^{2} \Lambda_{z}^{2}+4 \sin \left(\frac{L \Lambda_{z}}{2}\right)^{2}-2 L \Lambda_{z} \sin \left(L \Lambda_{z}\right)-L^{2} \Lambda_{z}^{2} \sin \left(\frac{L \Lambda_{z}}{2}\right)^{2}+4 L^{4} \Lambda_{z}^{4} \Omega_{z}^{2} \sin \left(\frac{L \Lambda_{z}}{2}\right)^{2}-2 L^{3} \Lambda_{z}^{3} \Omega_{z} \sin \left(L \Lambda_{z}\right)+8 L^{2} \Lambda_{z}^{2} \Omega_{z} \sin \left(\frac{L \Lambda_{z}}{2}\right)^{2}\right) ; \gamma_{z}=\left(\Omega_{z} L^{2} \Lambda_{z}^{2}+1\right)^{2}\left(L^{2} \Lambda_{z}^{2}-8 \sin \left(\frac{L \Lambda_{z}}{2}\right)^{2}+L \Lambda_{z} \sin \left(L \Lambda_{z}\right)\right)$ 
$\phi_{y}=4 L^{4} \Lambda_{y}{ }^{4} \Omega_{y}{ }^{2} \sin \left(L \Lambda_{y}\right)^{2}-16 L^{4} \Lambda_{y}{ }^{4} \Omega_{y}{ }^{2} \sin \left(\frac{L \Lambda_{y}}{2}\right)^{2}+8 L^{3} \Lambda_{y}{ }^{3} \Omega_{y} \sin \left(L \Lambda_{y}\right) \sin \left(\frac{L \Lambda_{y}}{2}\right)^{2}+8 L^{2} \Lambda_{y}{ }^{2} \Omega_{y} \sin \left(L \Lambda_{y}\right)^{2}-32 L^{2} \Lambda_{y}{ }^{2} \Omega_{y} \sin \left(\frac{L \Lambda_{y}}{2}\right)^{2}-L^{2} \Lambda_{y}{ }^{2} \sin \left(L \Lambda_{y}\right)^{2}+8 L \Lambda_{y} \sin \left(L \Lambda_{y}\right) \sin \left(\frac{L \Lambda_{y}}{2}\right)^{2}+4 \sin \left(L \Lambda_{y}\right)^{2}-16 \sin \left(\frac{L \Lambda_{y}}{2}\right)^{2}$

$\phi_{z}=4 L^{4} \Lambda_{z}^{4} \Omega_{z}{ }^{2} \sin \left(L \Lambda_{z}\right)^{2}-16 L^{4} \Lambda_{z}^{4} \Omega_{z}{ }^{2} \sin \left(\frac{L \Lambda_{z}}{2}\right)^{2}+8 L^{3} \Lambda_{z}^{3} \Omega_{z} \sin \left(L \Lambda_{z}\right) \sin \left(\frac{L \Lambda_{z}}{2}\right)^{2}+8 L^{2} \Lambda_{z}{ }^{2} \Omega_{z} \sin \left(L \Lambda_{z}\right)^{2}-32 L^{2} \Lambda_{z}{ }^{2} \Omega_{z} \sin \left(\frac{L \Lambda_{z}}{2}\right)^{2}-L^{2} \Lambda_{z}{ }^{2} \sin \left(L \Lambda_{z}\right)^{2}+8 L \Lambda_{z} \sin \left(L \Lambda_{z}\right) \sin \left(\frac{L \Lambda_{z}}{2}\right)^{2}+4 \sin \left(L \Lambda_{z}\right)^{2}-16 \sin \left(\frac{L \Lambda_{z}}{2}\right)^{2}$

$\varphi_{y}=-\left(\Omega_{y} L^{2} \Lambda_{y}{ }^{2}+1\right)^{2}\left(\sin \left(2 L \Lambda_{y}\right)+L^{3} \Lambda_{y}{ }^{3}+5 L^{3} \Lambda_{y}{ }^{3} \Omega_{y}-\frac{L^{2} \Lambda_{y}{ }^{2} \sin \left(2 L \Lambda_{y}\right)}{2}+2 L^{5} \Lambda_{y}{ }^{5} \Omega_{y}{ }^{2}+2 L \Lambda_{y}\left(2 \sin \left(L \Lambda_{y}\right)^{2}-1\right)+2 L^{2} \Lambda_{y}{ }^{2} \Omega_{y} \sin \left(2 L \Lambda_{y}\right)+L^{3} \Lambda_{y}{ }^{3} \Omega_{y}\left(2 \sin \left(L \Lambda_{y}\right)^{2}-1\right)+L^{4} \Lambda_{y}{ }^{4} \Omega_{y}{ }^{2} \sin \left(2 L \Lambda_{y}\right)\right)+\sin \left(L \Lambda_{y}\right)\left(\Omega_{y} L^{2} \Lambda_{y}{ }^{2}+1\right)^{2}\left(2 L^{4} \Lambda_{y}{ }^{4} \Omega_{y}{ }^{2}+2 L^{4} \Lambda_{y}{ }^{4} \Omega_{y}+4 L^{2} \Lambda_{y}{ }^{2} \Omega_{y}+2 L^{2} \Lambda_{y}{ }^{2}+2\right)+$

$-\left(\Omega_{y} L^{2} \Lambda_{y}^{2}+1\right)^{2}\left(2 \sin \left(\frac{L \Lambda_{y}}{2}\right)^{2}-1\right)\left(2 L^{5} \Lambda_{y}^{5} \Omega_{y}^{2}+4 L^{3} \Lambda_{y}^{3} \Omega_{y}-2 L \Lambda_{y}\right)$

$\varphi_{z}=-\left(\Omega_{z} L^{2} \Lambda_{z}^{2}+1\right)^{2}\left(\sin \left(2 L \Lambda_{z}\right)+L^{3} \Lambda_{z}^{3}+5 L^{3} \Lambda_{z}^{3} \Omega_{z}-\frac{L^{2} \Lambda_{z}^{2} \sin \left(2 L \Lambda_{z}\right)}{2}+2 L^{5} \Lambda_{z}^{5} \Omega_{z}^{2}+2 L \Lambda_{z}\left(2 \sin \left(L \Lambda_{z}\right)^{2}-1\right)+2 L^{2} \Lambda_{z}^{2} \Omega_{z} \sin \left(2 L \Lambda_{z}\right)+L^{3} \Lambda_{z}^{3} \Omega_{z}\left(2 \sin \left(L \Lambda_{z}\right)^{2}-1\right)+L^{4} \Lambda_{z}^{4} \Omega_{z}^{2} \sin \left(2 L \Lambda_{z}\right)\right)+\sin \left(L \Lambda_{z}\right)\left(\Omega_{z} L^{2} \Lambda_{z}^{2}+1\right)^{2}\left(2 L^{4} \Lambda_{z}^{4} \Omega_{z}^{2}+2 L^{4} \Lambda_{z}^{4} \Omega_{z}+4 L^{2} \Lambda_{z}^{2} \Omega_{z}+2 L^{2} \Lambda_{z}^{2}+2\right)+$

$-\left(\Omega_{z} L^{2} \Lambda_{z}^{2}+1\right)^{2}\left(2 \sin \left(\frac{L \Lambda_{z}}{2}\right)^{2}-1\right)\left(2 L^{5} \Lambda_{z}^{5} \Omega_{z}^{2}+4 L^{3} \Lambda_{z}^{3} \Omega_{z}-2 L \Lambda_{z}\right)$

$\eta_{y}=\left(\Omega_{y} L^{2} \Lambda_{y}{ }^{2}+1\right)^{2}\left(\sin \left(2 L \Lambda_{y}\right)+6 L \Lambda_{y}+5 L^{3} \Lambda_{y}{ }^{3} \Omega_{y}+2 L^{5} \Lambda_{y}{ }^{5} \Omega_{y}{ }^{2}+2 L^{2} \Lambda_{y}{ }^{2} \Omega_{y} \sin \left(2 L \Lambda_{y}\right)+L^{3} \Lambda_{y}{ }^{3} \Omega_{y}\left(2 \sin \left(L \Lambda_{y}\right)^{2}-1\right)+L^{4} \Lambda_{y}{ }^{4} \Omega_{y}{ }^{2} \sin \left(2 L \Lambda_{y}\right)\right)-\sin \left(L \Lambda_{y}\right)\left(\Omega_{y} L^{2} \Lambda_{y}{ }^{2}+1\right)^{2}\left(2 L^{4} \Lambda_{y}{ }^{4} \Omega_{y}{ }^{2}+2 L^{4} \Lambda_{y}{ }^{4} \Omega_{y}+4 L^{2} \Lambda_{y}{ }^{2} \Omega_{y}+3 L^{2} \Lambda_{y}{ }^{2}+2\right)+$

$+\left(\Omega_{y} L^{2} \Lambda_{y}{ }^{2}+1\right)^{2}\left(2 \sin \left(\frac{L \Lambda_{y}}{2}\right)^{2}-1\right)\left(2 L^{5} \Lambda_{y}^{5} \Omega_{y}{ }^{2}+4 L^{3} \Lambda_{y}{ }^{3} \Omega_{y}-L^{3} \Lambda_{y}{ }^{3}+6 L \Lambda_{y}\right)$

$\eta_{z}=\left(\Omega_{z} L^{2} \Lambda_{z}{ }^{2}+1\right)^{2}\left(\sin \left(2 L \Lambda_{z}\right)+6 L \Lambda_{z}+5 L^{3} \Lambda_{z}^{3} \Omega_{z}+2 L^{5} \Lambda_{z}^{5} \Omega_{z}{ }^{2}+2 L^{2} \Lambda_{z}{ }^{2} \Omega_{z} \sin \left(2 L \Lambda_{z}\right)+L^{3} \Lambda_{z}^{3} \Omega_{z}\left(2 \sin \left(L \Lambda_{z}\right)^{2}-1\right)+L^{4} \Lambda_{z}^{4} \Omega_{z}{ }^{2} \sin \left(2 L \Lambda_{z}\right)\right)-\sin \left(L \Lambda_{z}\right)\left(\Omega_{z} L^{2} \Lambda_{z}{ }^{2}+1\right)^{2}\left(2 L^{4} \Lambda_{z}{ }^{4} \Omega_{z}{ }^{2}+2 L^{4} \Lambda_{z}{ }^{4} \Omega_{z}+4 L^{2} \Lambda_{z}{ }^{2} \Omega_{z}+3 L^{2} \Lambda_{z}{ }^{2}+2\right)+$

$+\left(\Omega_{z} L^{2} \Lambda_{z}^{2}+1\right)^{2}\left(2 \sin \left(\frac{L \Lambda_{z}}{2}\right)^{2}-1\right)\left(2 L^{5} \Lambda_{z}^{5} \Omega_{z}^{2}+4 L^{3} \Lambda_{z}^{3} \Omega_{z}-L^{3} \Lambda_{z}^{3}+6 L \Lambda_{z}\right)$

$\omega_{y}=\sin \left(L \Lambda_{y}\right)\left(4 \cos \left(L \Lambda_{y}\right)+4 L^{2} \Lambda_{y}{ }^{2}-8 L^{2} \Lambda_{y}{ }^{2} \Omega_{y}+4 L^{4} \Lambda_{y}{ }^{4} \Omega_{y}-2 L^{2} \Lambda_{y}{ }^{2} \cos \left(L \Lambda_{y}\right)-4 L^{4} \Lambda_{y}{ }^{4} \Omega_{y}{ }^{2}+8 L^{2} \Lambda_{y}{ }^{2} \Omega_{y} \cos \left(L \Lambda_{y}\right)+4 L^{4} \Lambda_{y}{ }^{4} \Omega_{y}{ }^{2} \cos \left(L \Lambda_{y}\right)-4\right)+4 L^{5} \Lambda_{y}{ }^{5} \Omega_{y}{ }^{2} \cos \left(L \Lambda_{y}\right)-4 L^{5} \Lambda_{y}{ }^{5} \Omega_{y}{ }^{2}-4 L^{3} \Lambda_{y}{ }^{3} \Omega_{y} \cos \left(L \Lambda_{y}\right)^{2}+$ $+8 L^{3} \Lambda_{y}^{3} \Omega_{y} \cos \left(L \Lambda_{y}\right)-4 L^{3} \Lambda_{y}^{3} \Omega_{y}-2 L^{3} \Lambda_{y}^{3}-4 L \Lambda_{y} \cos \left(L \Lambda_{y}\right)^{2}+4 L \Lambda_{y} \cos \left(L \Lambda_{y}\right)$

$\omega_{z}=\sin \left(L \Lambda_{z}\right)\left(4 \cos \left(L \Lambda_{z}\right)+4 L^{2} \Lambda_{z}{ }^{2}-8 L^{2} \Lambda_{z}{ }^{2} \Omega_{z}+4 L^{4} \Lambda_{z}^{4} \Omega_{z}-2 L^{2} \Lambda_{z}{ }^{2} \cos \left(L \Lambda_{z}\right)-4 L^{4} \Lambda_{z}^{4} \Omega_{z}{ }^{2}+8 L^{2} \Lambda_{z}{ }^{2} \Omega_{z} \cos \left(L \Lambda_{z}\right)+4 L^{4} \Lambda_{z}^{4} \Omega_{z}{ }^{2} \cos \left(L \Lambda_{z}\right)-4\right)+4 L^{5} \Lambda_{z}^{5} \Omega_{z}{ }^{2} \cos \left(L \Lambda_{z}\right)-4 L^{5} \Lambda_{z}^{5} \Omega_{z}{ }^{2}-4 L^{3} \Lambda_{z}^{3} \Omega_{z} \cos \left(L \Lambda_{z}\right)^{2}+$

$+8 L^{3} \Lambda_{z}^{3} \Omega_{z} \cos \left(L \Lambda_{z}\right)-4 L^{3} \Lambda_{z}^{3} \Omega_{z}-2 L^{3} \Lambda_{z}^{3}-4 L \Lambda_{z} \cos \left(L \Lambda_{z}\right)^{2}+4 L \Lambda_{z} \cos \left(L \Lambda_{z}\right)$

$\psi_{y}=-\sin \left(L \Lambda_{y}\right)\left(2 \cos \left(L \Lambda_{y}\right)+L^{2} \Lambda_{y}{ }^{2}-4 L^{2} \Lambda_{y}{ }^{2} \Omega_{y}+2 L^{4} \Lambda_{y}{ }^{4} \Omega_{y}-2 L^{4} \Lambda_{y}{ }^{4} \Omega_{y}{ }^{2}+4 L^{2} \Lambda_{y}{ }^{2} \Omega_{y} \cos \left(L \Lambda_{y}\right)+2 L^{4} \Lambda_{y}{ }^{4} \Omega_{y}{ }^{2} \cos \left(L \Lambda_{y}\right)-2\right)-2 L^{5} \Lambda_{y}{ }^{5} \Omega_{y}{ }^{2} \cos \left(L \Lambda_{y}\right)+2 L^{5} \Lambda_{y}{ }^{5} \Omega_{y}{ }^{2}+2 L^{3} \Lambda_{y}{ }^{3} \Omega_{y} \cos \left(L \Lambda_{y}\right)^{2}-4 L^{3} \Lambda_{y}{ }^{3} \Omega_{y} \cos \left(L \Lambda_{y}\right)+$ $+2 L^{3} \Lambda_{y}^{3} \Omega_{y}+L^{3} \Lambda_{y}^{3} \cos \left(L \Lambda_{y}\right)+2 L \Lambda_{y} \cos \left(L \Lambda_{y}\right)^{2}-2 L \Lambda_{y} \cos \left(L \Lambda_{y}\right)$

$\psi_{z}=-\sin \left(L \Lambda_{z}\right)\left(2 \cos \left(L \Lambda_{z}\right)+L^{2} \Lambda_{z}{ }^{2}-4 L^{2} \Lambda_{z}^{2} \Omega_{z}+2 L^{4} \Lambda_{z}^{4} \Omega_{z}-2 L^{4} \Lambda_{z}^{4} \Omega_{z}{ }^{2}+4 L^{2} \Lambda_{z}{ }^{2} \Omega_{z} \cos \left(L \Lambda_{z}\right)+2 L^{4} \Lambda_{z}{ }^{4} \Omega_{z}{ }^{2} \cos \left(L \Lambda_{z}\right)-2\right)-2 L^{5} \Lambda_{z}^{5} \Omega_{z}{ }^{2} \cos \left(L \Lambda_{z}\right)+2 L^{5} \Lambda_{z}^{5} \Omega_{z}{ }^{2}+2 L^{3} \Lambda_{z}^{3} \Omega_{z} \cos \left(L \Lambda_{z}\right)^{2}-4 L^{3} \Lambda_{z}^{3} \Omega_{z} \cos \left(L \Lambda_{z}\right)+$ $+2 L^{3} \Lambda_{z}^{3} \Omega_{z}+L^{3} \Lambda_{z}^{3} \cos \left(L \Lambda_{z}\right)+2 L \Lambda_{z} \cos \left(L \Lambda_{z}\right)^{2}-2 L \Lambda_{z} \cos \left(L \Lambda_{z}\right)$ 
Apêndice $C$

\section{8}

Matriz de Rigidez Local com Funções de Forma Completas: Interação Torção com Carga Axial (TBT_Complete) - Tração

\begin{tabular}{|c|c|c|c|c|c|c|c|c|c|c|c|}
\hline 0 & 0 & 0 & 0 & 0 & 0 & 0 & 0 & 0 & 0 & 0 & 0 \\
\hline 0 & 0 & 0 & $\frac{M_{y a}}{L}$ & $-\frac{M_{x b} \Lambda_{y}{ }^{2} \psi}{\left(\Lambda_{y}^{2}-\Lambda_{z}^{2}\right) D_{y}}$ & 0 & 0 & 0 & 0 & $\frac{M_{y b}}{L}$ & $\frac{M_{x b} \Lambda_{y}^{2} \psi}{\left(\Lambda_{y}^{2}-\Lambda_{z}^{2}\right) D_{y}}$ & 0 \\
\hline 0 & 0 & 0 & $\frac{M_{z a}}{L}$ & 0 & $-\frac{M_{x b} \Lambda_{z}{ }^{2} \psi}{\left(\Lambda_{y}{ }^{2}-\Lambda_{z}{ }^{2}\right) D_{z}}$ & 0 & 0 & 0 & $\frac{M_{z b}}{L}$ & 0 & $\frac{M_{x b} \Lambda_{z}^{2} \psi}{\left(\Lambda_{y}^{2}-\Lambda_{z}^{2}\right) D_{z}}$ \\
\hline 0 & $\frac{M_{y a}}{L}$ & $\frac{M_{z a}}{L}$ & $\frac{J_{p} P}{A L}$ & $\frac{\left(M_{z a}+M_{z b}\right) \varphi_{z}}{L^{2} \Lambda_{z}{ }^{2} \phi_{z}}-\frac{M_{z a}}{2}$ & $-\frac{\left(M_{y a}+M_{y b}\right) \varphi_{y}}{L^{2} \Lambda_{y}^{2} \phi_{y}}+\frac{M_{y a}}{2}$ & 0 & $-\frac{M_{y a}}{L}$ & $-\frac{M_{z a}}{L}$ & $-\frac{J_{p} P}{A L}$ & $-\frac{\left(M_{z a}+M_{z b}\right) \varphi_{z}}{L^{2} \Lambda_{z}^{2} \phi_{z}}$ & $\frac{\left(M_{y a}+M_{y b}\right) \varphi_{y}}{L^{2} \Lambda_{y}{ }^{2} \phi_{y}}$ \\
\hline 0 & $-\frac{M_{x b} \Lambda_{y}{ }^{2} \psi}{\left(\Lambda_{y}{ }^{2}-\Lambda_{z}{ }^{2}\right) D_{y}}$ & 0 & $\frac{\left(M_{z a}+M_{z b}\right) \varphi_{z}}{L^{2} \Lambda_{z}^{2} \phi_{z}}-\frac{M_{z a}}{2}$ & 0 & $\frac{M_{x b} \varphi_{1}}{\left(\Lambda_{y}^{2}-\Lambda_{z}^{2}\right) D_{1}}$ & 0 & $\frac{M_{x b} \Lambda_{y}{ }^{2} \psi}{\left(\Lambda_{y}{ }^{2}-\Lambda_{z}{ }^{2}\right) D_{y}}$ & 0 & $-\frac{\left(M_{z a}+M_{z b}\right) \varphi_{z}}{L^{2} \Lambda_{z}^{2} \phi_{z}}$ & 0 & $-\frac{2 M_{x b} \varphi_{2}}{\left(\Lambda_{y}{ }^{2}-\Lambda_{z}{ }^{2}\right) D_{2}}$ \\
\hline 0 & 0 & $\frac{M_{x b} \Lambda_{z}^{2} \psi}{\left(\Lambda_{y}^{2}-\Lambda_{z}^{2}\right) D_{z}}$ & $-\frac{\left(M_{y a}+M_{y b}\right) \varphi_{y}}{L^{2} \Lambda_{y}^{2} \phi_{y}}+\frac{M_{y a}}{2}$ & $\frac{M_{x b} \varphi_{1}}{\left(\Lambda_{y}^{2}-\Lambda_{z}^{2}\right) D_{1}}$ & 0 & 0 & 0 & $\frac{M_{x b} \Lambda_{z}^{2} \psi}{\left(\Lambda_{y}^{2}-\Lambda_{z}^{2}\right) D_{z}}$ & $\frac{\left(M_{y a}+M_{y b}\right) \varphi_{y}}{L^{2} \Lambda_{y}{ }^{2} \phi_{y}}$ & $\frac{2 M_{x b} \varphi_{2}}{\left(\Lambda_{y}^{2}-\Lambda_{z}^{2}\right) D_{2}}$ & 0 \\
\hline 0 & 0 & \begin{tabular}{l|}
0 \\
\end{tabular} & $\begin{array}{c}0 \\
\end{array}$ & 0 & 0 & 0 & 0 & 0 & 0 & 0 & 0 \\
\hline 0 & 0 & 0 & $-\frac{M_{y a}}{L}$ & $\frac{M_{x b} \Lambda_{y}^{2} \psi}{\left(\Lambda_{y}^{2}-\Lambda_{z}^{2}\right) D_{y}}$ & 0 & 0 & 0 & 0 & $-\frac{M_{y b}}{L}$ & $-\frac{M_{x b} \Lambda_{y}^{2} \psi}{\left(\Lambda_{y}^{2}-\Lambda_{z}^{2}\right) D_{y}}$ & 0 \\
\hline 0 & 0 & 0 & $-\frac{M_{z a}}{L}$ & 0 & $\frac{M_{x x} \Lambda_{z}{ }^{2} \psi}{\left(\Lambda_{y}{ }^{2}-\Lambda_{z}{ }^{2}\right) D_{z}}$ & 0 & 0 & 0 & $-\frac{M_{z b}}{L}$ & 0 & $-\frac{M_{x b} \Lambda_{z}{ }^{2} \psi}{\left(\Lambda_{y}{ }^{2}-\Lambda_{z}{ }^{2}\right) D_{z}}$ \\
\hline 0 & $\frac{M_{y b}}{L}$ & $\frac{M_{z b}}{L}$ & $-\frac{J_{p} P}{A L}$ & $-\frac{\left(M_{z a}+M_{z b}\right) \varphi_{z}}{L^{2} \Lambda_{z}^{2} \phi_{z}}$ & $\frac{\left(M_{y a}+M_{y b}\right) \varphi_{y}}{L^{2} \Lambda_{y}{ }^{2} \phi_{y}}$ & 0 & $-\frac{M_{y b}}{L}$ & $-\frac{M_{z b}}{L}$ & $\frac{J_{p} P}{A L}$ & $\frac{\left(M_{z a}+M_{z b}\right) \varphi_{z}}{L^{2} \Lambda_{z}^{2} \phi_{z}}-\frac{M_{z b}}{2}$ & $-\frac{\left(M_{y a}+M_{y b}\right) \varphi_{y}}{L^{2} \Lambda_{y}{ }^{2} \phi_{y}}+\frac{M_{y b}}{2}$ \\
\hline 0 & $\frac{M_{x b} \Lambda_{y}{ }^{2} \psi}{\left(\Lambda_{y}{ }^{2}-\Lambda_{z}{ }^{2}\right) D_{y}}$ & 0 & $-\frac{\left(M_{z a}+M_{z b}\right) \varphi_{z}}{L^{2} \Lambda_{z}^{2} \phi_{z}}$ & 0 & $\frac{2 M_{x} \varphi \varphi_{2}}{\left(\Lambda_{y}^{2}{ }^{2}{ }_{z}^{2}\right) D_{2}}$ & 0 & $-\frac{M_{x b} \Lambda_{y}{ }^{2} \psi}{\left(\Lambda_{y}{ }^{2}-\Lambda_{z}{ }^{2}\right) D_{y}}$ & 0 & $\frac{\left(M_{z a}+M_{z b}\right) \varphi_{z}}{L^{2} \Lambda_{z}^{2} \phi_{z}}-\frac{M_{z b}}{2}$ & $x+5 x_{2}$ & $-\frac{M_{x b} \varphi_{1}}{\left(\Lambda_{y}{ }^{2}-\Lambda_{z}^{2}\right) D_{1}}$ \\
\hline 0 & 0 & $\frac{M_{x b} \Lambda_{z}{ }^{2} \psi}{\left(\Lambda_{y}{ }^{2}-\Lambda_{z}{ }^{2}\right) D_{z}}$ & $\frac{\left(M_{y a}+M_{y b}\right) \varphi_{y}}{L^{2} \Lambda_{y}{ }^{2} \phi_{y}}$ & $-\frac{2 M_{x b} \varphi_{2}}{\left(\Lambda_{y}^{2}-\Lambda_{z}^{2}\right) D_{2}}$ & 0 & 0 & 0 & $-\frac{M_{x b} \Lambda_{z}{ }^{2} \psi}{\left(\Lambda_{y}{ }^{2}-\Lambda_{z}{ }^{2}\right) D_{z}}$ & $-\frac{\left(M_{y a}+M_{y b}\right) \varphi_{y}}{L^{2} \Lambda_{y}{ }^{2} \phi_{y}}+\frac{M_{y b}}{2}$ & $-\frac{M_{x b} \varphi_{1}}{\left(\Lambda_{y}{ }^{2}-\Lambda_{z}{ }^{2}\right) D_{1}}$ & 0 \\
\hline
\end{tabular}

$\varphi_{y}=\left(1-\Omega_{y} \Lambda_{y}{ }^{2} L^{2}\right)\left[\Lambda_{y} L-2 \sinh \left(\Lambda_{y} L\right)-2 \cosh \left(\Lambda_{y} L\right)+\Lambda_{y} L\left(\cosh \left(\Lambda_{y} L\right)+\sinh \left(\Lambda_{y} L\right)\right)+2\right] ; D_{y}=\sinh \left(\frac{\Lambda_{z} L}{2}\right)\left(2 \sinh \left(\frac{\Lambda_{y} L}{2}\right)-\Lambda_{y} L \cosh \left(\frac{\Lambda_{y} L}{2}\right)-2 \Omega_{y} \Lambda_{y}{ }^{2} L^{2} \sinh \left(\frac{\Lambda_{y} L}{2}\right)\right) ; \phi_{y}=\left(\cosh \left(\Lambda_{y} L\right)+\sinh \left(\Lambda_{y} L\right)-1\right)$

$\varphi_{z}=\left(1-\Omega_{z} \Lambda_{z}^{2} L^{2}\right)\left[\Lambda_{z} L-2 \sinh \left(\Lambda_{z} L\right)-2 \cosh \left(\Lambda_{z} L\right)+\Lambda_{z} L\left(\cosh \left(\Lambda_{z} L\right)+\sinh \left(\Lambda_{z} L\right)\right)+2\right] ; D_{z}=\sinh \left(\frac{\Lambda_{y} L}{2}\right)\left(2 \sinh \left(\frac{\Lambda_{z} L}{2}\right)-\Lambda_{z} L \cosh \left(\frac{\Lambda_{z} L}{2}\right)-2 \Omega_{z} \Lambda_{z}^{2} L^{2} \sinh \left(\frac{\Lambda_{z} L}{2}\right)\right) ; \phi_{z}=\left(\cosh \left(\Lambda_{z} L\right)+\sinh \left(\Lambda_{z} L\right)-1\right)$

$\psi=\Lambda_{y} \cosh \left(\frac{\Lambda_{y} L}{2}\right) \sinh \left(\frac{\Lambda_{z} L}{2}\right)-\Lambda_{z} \cosh \left(\frac{\Lambda_{z} L}{2}\right) \sinh \left(\frac{\Lambda_{y} L}{2}\right) ; \quad D_{1}=\left(L \Lambda_{y} \sinh \left(L \Lambda_{y}\right)-4 \sinh \left(\frac{L \Lambda_{y}}{2}\right)^{2}+4 L^{2} \Lambda_{y}{ }^{2} \Omega_{y} \sinh \left(\frac{L \Lambda_{y}}{2}\right)^{2}\right)\left(L \Lambda_{z} \sinh \left(L \Lambda_{z}\right)-4 \sinh \left(\frac{L \Lambda_{z}}{2}\right)^{2}+4 L^{2} \Lambda_{z}^{2} \Omega_{z} \sinh \left(\frac{L \Lambda_{z}}{2}\right)^{2}\right)$

$D_{2}=\left(\Lambda_{y}^{2}-\Lambda_{z}^{2}\right)\left(L \Lambda_{y} \sinh \left(L \Lambda_{y}\right)-2 L^{2} \Lambda_{y}^{2} \Omega_{y}-2 \cosh \left(L \Lambda_{y}\right)+2 L^{2} \Lambda_{y}^{2} \Omega_{y} \cosh \left(L \Lambda_{y}\right)+2\right)\left(L \Lambda_{z} \sinh \left(L \Lambda_{z}\right)-2 L^{2} \Lambda_{z}^{2} \Omega_{z}-2 \cosh \left(L \Lambda_{z}\right)+2 L^{2} \Lambda_{z}^{2} \Omega_{z} \cosh \left(L \Lambda_{z}\right)+2\right)$ 
$\varphi_{1}=L^{3}\left(2 \Lambda_{y}{ }^{2} \Lambda_{z}^{3} \sinh \left(L \Lambda_{z}\right) \sinh \left(\frac{L \Lambda_{y}}{2}\right)^{2}\left(\Omega_{y}-\Omega_{z}\right)-2 \Lambda_{y}{ }^{3} \Lambda_{z}{ }^{2} \sinh \left(L \Lambda_{y}\right) \sinh \left(\frac{L \Lambda_{z}}{2}\right)^{2}\left(\Omega_{y}-\Omega_{z}\right)\right)+L\left(\Lambda_{y}{ }^{2}-\Lambda_{z}{ }^{2}\right)\left(\Lambda_{y} \sinh \left(L \Lambda_{y}\right)-\Lambda_{z} \sinh \left(L \Lambda_{z}\right)-\Lambda_{y} \sinh \left(L \Lambda_{y}\right)\left(2 \sinh \left(\frac{L \Lambda_{z}}{2}\right)^{2}+1\right)+\Lambda_{z} \sinh \left(L \Lambda_{z} z\left(2 \sinh \left(\frac{L \Lambda_{y}}{2}\right)^{2}+1\right)\right)+\right.$ $-\frac{L^{2} \Lambda_{y} \Lambda_{z}\left(4 \Lambda_{y} \Lambda_{z} \sinh \left(\frac{L \Lambda_{y}}{2}\right)^{2}+4 \Lambda_{y} \Lambda_{z} \sinh \left(\frac{L \Lambda_{z}}{2}\right)^{2}-\Lambda_{y}^{2} \sinh \left(L \Lambda_{y}\right) \sinh \left(L \Lambda_{z}\right)-\Lambda_{z}^{2} \sinh \left(L \Lambda_{y}\right) \sinh \left(L \Lambda_{z}\right)+8 \Lambda_{y} \Lambda_{z} \sinh \left(\frac{L \Lambda_{y}}{2}\right)^{2} \sinh \left(\frac{L \Lambda_{z}}{2}\right)^{2}\right)}{2}$

$\varphi_{z}=4 \Lambda_{y}{ }^{2}-4 \Lambda_{z}{ }^{2}-4 \Lambda_{y}{ }^{2} \cosh \left(\frac{L \Lambda_{y}}{2}\right)^{2}-4 \Lambda_{y}{ }^{2} \cosh \left(\frac{L \Lambda_{z}}{2}\right)^{2}+4 \Lambda_{z}{ }^{2} \cosh \left(\frac{L \Lambda_{y}}{2}\right)^{2}+4 \Lambda_{z}{ }^{2} \cosh \left(\frac{L \Lambda_{z}}{2}\right)^{2}-4 L^{2} \Lambda_{y}{ }^{4} \Omega_{y}+4 L^{2} \Lambda_{z}^{4} \Omega_{z}+4 \Lambda_{y}{ }^{2} \cosh \left(\frac{L \Lambda_{y}}{2}\right)^{2} \cosh \left(\frac{L \Lambda_{z}}{2}\right)^{2}-4 \Lambda_{z}{ }^{2} \cosh \left(\frac{L \Lambda_{y}}{2}\right)^{2} \cosh \left(\frac{L \Lambda_{z}}{2}\right)^{2}-2 L \Lambda_{y} \Lambda_{z}{ }^{2} \sinh \left(L \Lambda_{y}\right)+2 L \Lambda_{y}{ }^{2} \Lambda_{z} \sinh \left(L \Lambda_{z}\right)+$ $+L^{2} \Lambda_{y}^{2} \Lambda_{z}{ }^{2} \cosh \left(\frac{L \Lambda_{y}}{2}\right)^{2}-L^{2} \Lambda_{y}{ }^{2} \Lambda_{z}^{2} \cosh \left(\frac{L \Lambda_{z}}{2}\right)^{2}+4 L^{2} \Lambda_{y}{ }^{2} \Lambda_{z}{ }^{2} \Omega_{y}-4 L^{2} \Lambda_{y}{ }^{2} \Lambda_{z}{ }^{2} \Omega_{z}+4 L^{2} \Lambda_{y}{ }^{4} \Omega_{y} \cosh \left(\frac{L \Lambda_{y}}{2}\right)^{2}+4 L^{2} \Lambda_{y}{ }^{4} \Omega_{y} \cosh \left(\frac{L \Lambda_{z}}{2}\right)^{2}-4 L^{2} \Lambda_{z}^{4} \Omega_{z} \cosh \left(\frac{L \Lambda_{y}}{2}\right)^{2}-4 L^{2} \Lambda_{z}{ }^{4} \Omega_{z} \cosh \left(\frac{L \Lambda_{z}}{2}\right)^{2}-4 L^{4} \Lambda_{y}{ }^{2} \Lambda_{z}^{4} \Omega_{y} \Omega_{z}+4 L^{4} \Lambda_{y}^{4} \Lambda_{z}^{2} \Omega_{y} \Omega_{z}+$ $+L^{3} \Lambda_{y}{ }^{3} \Lambda_{z}{ }^{2} \Omega_{y} \sinh \left(L \Lambda_{y}\right)-L^{3} \Lambda_{y}{ }^{2} \Lambda_{z}^{3} \Omega_{z} \sinh \left(L \Lambda_{z}\right)-4 L^{2} \Lambda_{y}{ }^{2} \Lambda_{z}{ }^{2} \Omega_{y} \cosh \left(\frac{L \Lambda_{y}}{2}\right)^{2}-4 L^{2} \Lambda_{y}{ }^{2} \Lambda_{z}{ }^{2} \Omega_{z} \cosh \left(\frac{L \Lambda_{y}}{2}\right)^{2}-4 L^{2} \Lambda_{y}{ }^{2} \Lambda_{z}{ }^{2} \Omega_{y} \cosh \left(\frac{L \Lambda_{z}}{2}\right)^{2}+4 L^{2} \Lambda_{y}{ }^{2} \Lambda_{z}{ }^{2} \Omega_{z} \cosh \left(\frac{L \Lambda_{z}}{2}\right)^{2}-4 L^{2} \Lambda_{y}{ }^{4} \Omega_{y} \cosh \left(\frac{L \Lambda_{y}}{2}\right)^{2} \cosh \left(\frac{L \Lambda_{z}}{2}\right)^{2}+$ $+4 L^{2} \Lambda_{z}^{4} \Omega_{z} \cosh \left(\frac{L \Lambda_{y}}{2}\right)^{2} \cosh \left(\frac{L \Lambda_{z}}{2}\right)^{2}+L^{3} \Lambda_{y} \Lambda_{z}^{4} \Omega_{z} \sinh \left(L \Lambda_{y}\right)-L^{3} \Lambda_{y}{ }^{4} \Lambda_{z} \Omega_{y} \sinh \left(L \Lambda_{z}\right)+4 L \Lambda_{y} \Lambda_{z}{ }^{2} \cosh \left(\frac{L \Lambda_{y}}{2}\right) \cosh \left(\frac{L \Lambda_{z}}{2}\right)^{2} \sinh \left(\frac{L \Lambda_{y}}{2}\right)-4 L^{2} \Lambda_{y}{ }^{2} \Lambda_{z}{ }^{2} \Omega_{y} \cosh \left(\frac{L \Lambda_{y}}{2}\right)^{2} \cosh \left(\frac{L \Lambda_{z}}{2}\right)^{2}-4 L \Lambda_{y}{ }^{2} \Lambda_{z} \cosh \left(\frac{L \Lambda_{y}}{2}\right)^{2} \cosh \left(\frac{L \Lambda_{z}}{2}\right) \sinh \left(\frac{L \Lambda_{z}}{2}\right)+$ $-4 L^{2} \Lambda_{y}{ }^{2} \Lambda_{z}^{2} \Omega_{z} \cosh \left(\frac{L \Lambda_{y}}{2}\right)^{2} \cosh \left(\frac{L \Lambda_{z}}{2}\right)^{2}+4 L^{4} \Lambda_{y}{ }^{2} \Lambda_{z}^{4} \Omega_{y} \Omega_{z} \cosh \left(\frac{L \Lambda_{y}}{2}\right)^{2}-4 L^{4} \Lambda_{y}{ }^{4} \Lambda_{z}{ }^{2} \Omega_{y} \Omega_{z} \cosh \left(\frac{L \Lambda_{y}}{2}\right)^{2}+4 L^{4} \Lambda_{y}{ }^{2} \Lambda_{z}^{4} \Omega_{y} \Omega_{z} \cosh \left(\frac{L \Lambda_{z}}{2}\right)^{2}+2 L^{3} \Lambda_{y}{ }^{2} \Lambda_{z}^{3} \Omega_{z} \cosh \left(\frac{L \Lambda_{y}}{2}\right)^{2} \cosh \left(\frac{L \Lambda_{z}}{2}\right) \sinh \left(\frac{L \Lambda_{z}}{2}\right)-2 L^{3} \Lambda_{y}{ }^{3} \Lambda_{z}{ }^{2} \Omega_{y} \cosh \left(\frac{L \Lambda_{y}}{2}\right) \cosh \left(\frac{L \Lambda_{z}}{2}\right)^{2} \sinh \left(\frac{L \Lambda_{y}}{2}\right)+$ $-4 L^{4} \Lambda_{y}{ }^{4} \Lambda_{z}{ }^{2} \Omega_{y} \Omega_{z} \cosh \left(\frac{L \Lambda_{z}}{2}\right)^{2}-4 L^{4} \Lambda_{y}{ }^{2} \Lambda_{z}{ }^{4} \Omega_{y} \Omega_{z} \cosh \left(\frac{L \Lambda_{y}}{2}\right)^{2} \cosh \left(\frac{L \Lambda_{z}}{2}\right)^{2}+4 L^{4} \Lambda_{y}{ }^{4} \Lambda_{z}{ }^{2} \Omega_{y} \Omega_{z} \cosh \left(\frac{L \Lambda_{y}}{2}\right)^{2} \cosh \left(\frac{L \Lambda_{z}}{2}\right)^{2}-2 L^{3} \Lambda_{y} \Lambda_{z}{ }^{4} \Omega_{z} \cosh \left(\frac{L \Lambda_{y}}{2}\right) \cosh \left(\frac{L \Lambda_{z}}{2}\right)^{2} \sinh \left(\frac{L \Lambda_{y}}{2}\right)+2 L^{3} \Lambda_{y}{ }^{4} \Lambda_{z} \Omega_{y} \cosh \left(\frac{L \Lambda_{y}}{2}\right)^{2} \cosh \left(\frac{L \Lambda_{z}}{2}\right) \sinh \left(\frac{L \Lambda_{z}}{2}\right)$ 
C.9

Matriz de Rigidez Local com Funções de Forma Completas: Interação Torção com Carga Axial (TBT_Complete) -

Compressão

\begin{tabular}{|c|c|c|c|c|c|c|c|c|c|c|c|}
\hline 0 & 0 & 0 & 0 & 0 & 0 & 0 & 0 & 0 & 0 & 0 & 0 \\
\hline 0 & 0 & 0 & $\frac{M_{y a}}{L}$ & $\frac{M_{x b} \psi_{z}}{\left(\Lambda_{y}{ }^{2}-\Lambda_{z}^{2}\right) D}$ & 0 & 0 & 0 & 0 & $\frac{M_{y b}}{L}$ & $-\frac{M_{x b} \psi_{z}}{\left(\Lambda_{y}{ }^{2}-\Lambda_{z}{ }^{2}\right) D}$ & 0 \\
\hline 0 & 0 & 0 & $\frac{M_{z a}}{L}$ & 0 & $-\frac{M_{x b} \psi_{y}}{\left(\Lambda_{y}{ }^{2}-\Lambda_{z}{ }^{2}\right) D}$ & 0 & 0 & 0 & $\frac{M_{z b}}{L}$ & 0 & $\frac{M_{x b} \psi_{y}}{\left(\Lambda_{y}{ }^{2}-\Lambda_{z}{ }^{2}\right) D}$ \\
\hline 0 & $\frac{M_{y a}}{L}$ & $\frac{M_{z a}}{L}$ & $\frac{J_{p} P}{A L}$ & $\frac{\left(M_{z a}+M_{z b}\right) \varphi_{z}}{L^{2} \Lambda_{z}^{2} \phi_{z}}-\frac{M_{z a}}{2}$ & $-\frac{\left(M_{y a}+M_{y b}\right) \varphi_{y}}{L^{2} \Lambda_{y}^{2} \phi_{y}}+\frac{M_{y a}}{2}$ & 0 & $-\frac{M_{y a}}{L}$ & $-\frac{M_{z a}}{L}$ & $-\frac{J_{p} P}{A L}$ & $-\frac{\left(M_{z a}+M_{z b}\right) \varphi_{z}}{L^{2} \Lambda_{z}^{2} \phi_{z}}$ & $\frac{\left(M_{y a}+M_{y b}\right) \varphi_{y}}{L^{2} \Lambda_{y}{ }^{2} \phi_{y}}$ \\
\hline 0 & $\frac{M_{x b} \psi_{z}}{\left(\Lambda_{y}^{2}-\Lambda_{z}{ }^{2}\right) D}$ & 0 & $\frac{\left(M_{z a}+M_{z b}\right) \varphi_{z}}{L^{2} \Lambda_{z}^{2} \phi_{z}}-\frac{M_{z a}}{2}$ & 0 & $\frac{M_{x b} \psi_{1}}{\left(\Lambda_{y}^{2}-\Lambda_{z}^{2}\right) D}$ & 0 & $-\frac{M_{x b} \psi_{z}}{\left(\Lambda_{y}{ }^{2}-\Lambda_{z}{ }^{2}\right) D}$ & 0 & $-\frac{\left(M_{z a}+M_{z b}\right) \varphi_{z}}{L^{2} \Lambda_{z}^{2} \phi_{z}}$ & 0 & $-\frac{M_{x b} \psi_{2}}{\left(\Lambda_{y}{ }^{2}-\Lambda_{z}{ }^{2}\right) D}$ \\
\hline 0 & 0 & $\frac{M_{x b} \psi_{y}}{\left(\Lambda_{y}{ }^{2}-\Lambda_{z}^{2}\right) D}$ & $-\frac{\left(M_{y a}+M_{y b}\right) \varphi_{y}}{L^{2} \Lambda_{y}^{2} \phi_{y}}+\frac{M_{y a}}{2}$ & $\frac{M_{x b} \psi_{1}}{\left(\Lambda_{y}{ }^{2}-\Lambda_{z}^{2}\right) D}$ & 0 & 0 & 0 & $\frac{M_{x b} \psi_{y}}{\left(\Lambda_{y}^{2}-\Lambda_{z}^{2}\right) D}$ & $\frac{\left(M_{y a}+M_{y b}\right) \varphi_{y}}{L^{2} \Lambda_{y}^{2} \phi_{y}}$ & $\frac{M_{x b} \psi_{z}}{\left(\Lambda_{y}{ }^{2}-\Lambda_{z}{ }^{2}\right) D}$ & 0 \\
\hline 0 & 0 & \begin{tabular}{l|}
0 \\
\end{tabular} & $\begin{array}{l} \\
\end{array}$ & 0 & 0 & 0 & 0 & 0 & 0 & 0 & 0 \\
\hline 0 & 0 & 0 & $-\frac{M_{y a}}{L}$ & $-\frac{M_{x b} \psi_{z}}{\left(\Lambda_{y}^{2}-\Lambda_{z}^{2}\right) D}$ & 0 & 0 & 0 & 0 & $-\frac{M_{y b}}{L}$ & $\frac{M_{x b} \psi_{z}}{\left(\Lambda_{y}{ }^{2}-\Lambda_{z}{ }^{2}\right) D}$ & 0 \\
\hline 0 & 0 & 0 & $-\frac{M_{z a}}{L}$ & 0 & $\frac{M_{x b} \psi_{y}}{\left(\Lambda_{y}^{2}-\Lambda_{z}^{2}\right) D}$ & 0 & 0 & 0 & $-\frac{M_{z b}}{L}$ & 0 & $-\frac{M_{x b} \psi_{y}}{\left(\Lambda_{y}^{2}-\Lambda_{z}^{2}\right) D}$ \\
\hline 0 & $\frac{M_{y b}}{L}$ & $\frac{M_{z b}}{L}$ & $-\frac{J_{p} P}{A L}$ & $-\frac{\left(M_{z a}+M_{z b}\right) \varphi_{z}}{L^{2} \Lambda_{z}^{2} \phi_{z}}$ & $\frac{\left(M_{y a}+M_{y b}\right) \varphi_{y}}{L^{2} \Lambda_{y}^{2} \phi_{y}}$ & 0 & $-\frac{M_{y b}}{L}$ & $-\frac{M_{z b}}{L}$ & $\frac{J_{p} P}{A L}$ & $\frac{\left(M_{z a}+M_{z b}\right) \varphi_{z}}{L^{2} \Lambda_{z}^{2} \phi_{z}}-\frac{M_{z b}}{2}$ & $-\frac{\left(M_{y a}+M_{y b}\right) \varphi_{y}}{L^{2} \Lambda_{y}^{2} \phi_{y}}+\frac{M_{y b}}{2}$ \\
\hline 0 & $\frac{M_{x b} \psi_{z}}{\left(\Lambda_{y}{ }^{2}-\Lambda_{z}{ }^{2}\right) D}$ & 0 & $-\frac{\left(M_{z a}+M_{z b}\right) \varphi_{z}}{L^{2} \Lambda_{z}^{2} \phi_{z}}$ & 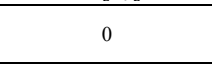 & $\frac{M_{x b} \psi_{2}}{\left(\Lambda_{y}^{2}-\Lambda_{z}^{2}\right) D}$ & 0 & $\frac{M_{x b} \psi_{z}}{\left(\Lambda_{y}^{2}-\Lambda_{z}^{2}\right) D}$ & 0 & $\frac{\left(M_{z a}+M_{z b}\right) \varphi_{z}}{L^{2} \Lambda_{z}^{2} \phi_{z}}-\frac{M_{z b}}{2}$ & 0 & $-\frac{M_{x b} \psi_{1}}{\left(\Lambda_{y}{ }^{2}-\Lambda_{z}{ }^{2}\right) D}$ \\
\hline 0 & 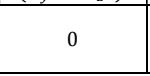 & $\frac{M_{x b} \psi_{y}}{\left(\Lambda_{y}{ }^{2}-\Lambda_{z}{ }^{2}\right) D}$ & $\frac{\left(M_{y a}+M_{y b}\right) \varphi_{y}}{L^{2} \Lambda_{y}{ }^{2} \phi_{y}}$ & $-\frac{M_{x b} \psi_{2}}{\left(\Lambda_{y}{ }^{2}-\Lambda_{z}{ }^{2}\right) D}$ & c & 0 & s & $-\frac{M_{x b} \psi_{y}}{\left(\Lambda_{y}{ }^{2}-\Lambda_{z}{ }^{2}\right) D}$ & $-\frac{\left(M_{y a}+M_{y b}\right) \varphi_{y}}{L^{2} \Lambda_{y}^{2} \phi_{y}}+\frac{M_{y b}}{2}$ & $-\frac{M_{x b} \psi_{1}}{\left(\Lambda_{y}{ }^{2}-\Lambda_{z}{ }^{2}\right) D}$ & 28 \\
\hline
\end{tabular}

$\varphi_{y}=2\left(\Omega_{y} L^{2} \Lambda_{y}{ }^{2}+1\right)\left(L^{2} \Lambda_{y}{ }^{2}+4 \sin \left(\frac{L \Lambda_{y}}{2}\right)^{2}-2 L \Lambda_{y} \sin \left(L \Lambda_{y}\right)-L^{2} \Lambda_{y}{ }^{2} \sin \left(\frac{L \Lambda_{y}}{2}\right)^{2}-L^{3} \Lambda_{y}{ }^{3} \Omega_{y} \sin \left(L \Lambda_{y}\right)+4 L^{2} \Lambda_{y}{ }^{2} \Omega_{y} \sin \left(\frac{L \Lambda_{y}}{2}\right)^{2}\right) ; \quad \phi_{y}=\left(4 \sin \left(\frac{L \Lambda_{y}}{2}\right)^{2}+2 L^{2} \Lambda_{y}{ }^{2} \Omega_{y}-L \Lambda_{y} \sin \left(L \Lambda_{y}\right)+2 L^{2} \Lambda_{y}{ }^{2} \Omega_{y}\left(2 \sin \left(\frac{L \Lambda_{y}}{2}\right)^{2}-1\right)\right)$

$\varphi_{z}=2\left(\Omega_{z} L^{2} \Lambda_{z}^{2}+1\right)\left(L^{2} \Lambda_{z}^{2}+4 \sin \left(\frac{L \Lambda_{z}}{2}\right)^{2}-2 L \Lambda_{z} \sin \left(L \Lambda_{z}\right)-L^{2} \Lambda_{z}^{2} \sin \left(\frac{L \Lambda_{z}}{2}\right)^{2}-L^{3} \Lambda_{z}^{3} \Omega_{z} \sin \left(L \Lambda_{z}\right)+4 L^{2} \Lambda_{z}^{2} \Omega_{z} \sin \left(\frac{L \Lambda_{z}}{2}\right)^{2}\right) ; \quad \phi_{z}=\left(4 \sin \left(\frac{L \Lambda_{z}}{2}\right)^{2}+2 L^{2} \Lambda_{z}^{2} \Omega_{z}-L \Lambda_{z} \sin \left(L \Lambda_{z}\right)+2 L^{2} \Lambda_{z}^{2} \Omega_{z}\left(2 \sin \left(\frac{L \Lambda_{z}}{2}\right)^{2}-1\right)\right)$

$D=\left(4 \sin \left(\frac{L \Lambda_{y}}{2}\right)^{2}-L \Lambda_{y} \sin \left(L \Lambda_{y}\right)+4 L^{2} \Lambda_{y}^{2} \Omega_{y} \sin \left(\frac{L \Lambda_{y}}{2}\right)^{2}\right)\left(4 \sin \left(\frac{L \Lambda_{z}}{2}\right)^{2}-L \Lambda_{z} \sin \left(L \Lambda_{z}\right)+4 L^{2} \Lambda_{z}^{2} \Omega_{z} \sin \left(\frac{L \Lambda_{z}}{2}\right)^{2}\right)$ 
$\psi_{y}=\Lambda_{z}^{2}\left(4 \Lambda_{y}\left(\sin \left(L \Lambda_{y}\right)-2 \cos \left(\frac{L \Lambda_{y}}{2}\right) \cos \left(\frac{L \Lambda_{z}}{2}\right)^{2} \sin \left(\frac{L \Lambda_{y}}{2}\right)\right)-4 L \Lambda_{y}^{2}\left(\cos \left(\frac{L \Lambda_{y}}{2}\right)^{2}-\cos \left(\frac{L \Lambda_{y}}{2}\right)^{2} \cos \left(\frac{L \Lambda_{z}}{2}\right)^{2}\right)+4 L^{2} \Lambda_{y}^{3}\left(\Omega_{y} \sin \left(L \Lambda_{y}\right)-2 \Omega_{y} \cos \left(\frac{L \Lambda_{y}}{2}\right) \cos \left(\frac{L \Lambda_{z}}{2}\right)^{2} \sin \left(\frac{L \Lambda_{y}}{2}\right)\right)\right)-$

$-\Lambda_{z}^{3}\left(4\left(\sin \left(L \Lambda_{z}\right)-2 \cos \left(\frac{L \Lambda_{y}}{2}\right)^{2} \cos \left(\frac{L \Lambda_{z}}{2}\right) \sin \left(\frac{L \Lambda_{z}}{2}\right)\right)+4 L^{2} \Lambda_{y}^{2}\left(\Omega_{y} \sin \left(L \Lambda_{z}\right)-2 \Omega_{y} \cos \left(\frac{L \Lambda_{y}}{2}\right)^{2} \cos \left(\frac{L \Lambda_{z}}{2}\right) \sin \left(\frac{L \Lambda_{z}}{2}\right)\right)-L \Lambda_{y} \sin \left(L \Lambda_{y}\right) \sin \left(L \Lambda_{z}\right)\right)$

$\psi_{z}=\Lambda_{y}^{2}\left(4 \Lambda_{z}\left(\sin \left(L \Lambda_{z}\right)-2 \cos \left(\frac{L \Lambda_{y}}{2}\right)^{2} \cos \left(\frac{L \Lambda_{z}}{2}\right) \sin \left(\frac{L \Lambda_{z}}{2}\right)\right)-4 L \Lambda_{z}^{2}\left(\cos \left(\frac{L \Lambda_{z}}{2}\right)^{2}-\cos \left(\frac{L \Lambda_{y}}{2}\right)^{2} \cos \left(\frac{L \Lambda_{z}}{2}\right)^{2}\right)+4 L^{2} \Lambda_{z}^{3}\left(\Omega_{z} \sin \left(L \Lambda_{z}\right)-2 \Omega_{z} \cos \left(\frac{L \Lambda_{y}}{2}\right)^{2} \cos \left(\frac{L \Lambda_{z}}{2}\right) \sin \left(\frac{L \Lambda_{z}}{2}\right)\right)\right)^{-}$

$-\Lambda_{y}^{3}\left(4\left(\sin \left(L \Lambda_{y}\right)-2 \cos \left(\frac{L \Lambda_{y}}{2}\right) \cos \left(\frac{L \Lambda_{z}}{2}\right)^{2} \sin \left(\frac{L \Lambda_{y}}{2}\right)\right)+4 L^{2} \Lambda_{z}^{2}\left(\Omega_{z} \sin \left(L \Lambda_{y}\right)-2 \Omega_{z} \cos \left(\frac{L \Lambda_{y}}{2}\right) \cos \left(\frac{L \Lambda_{z}}{2}\right)^{2} \sin \left(\frac{L \Lambda_{y}}{2}\right)\right)-L \Lambda_{z} \sin \left(L \Lambda_{y}\right) \sin \left(L \Lambda_{z}\right)\right)$

$\psi_{1}=\sin \left(\frac{L \Lambda_{z}}{2}\right)\left(2 L\left(\Lambda_{y}^{2}-\Lambda_{z}^{2}\right)\left(2 \Lambda_{z} \cos \left(\frac{L \Lambda_{z}}{2}\right)-2 \Lambda_{z} \cos \left(\frac{L \Lambda_{y}}{2}\right)^{2} \cos \left(\frac{L \Lambda_{z}}{2}\right)\right)-2 L^{3} \Lambda_{y}^{2} \Lambda_{z}^{2}\left(2 \Lambda_{z} \cos \left(\frac{L \Lambda_{z}}{2}\right)-2 \Lambda_{z} \cos \left(\frac{L \Lambda_{y}}{2}\right)^{2} \cos \left(\frac{L \Lambda_{z}}{2}\right)\right)\left(\Omega_{y}-\Omega_{z}\right)\right)+$

$-\sin \left(\frac{L \Lambda_{y}}{2}\right)\left(2 L\left(\Lambda_{y}^{2}-\Lambda_{z}^{2}\right)\left(2 \Lambda_{y} \cos \left(\frac{L \Lambda_{y}}{2}\right)-2 \Lambda_{y} \cos \left(\frac{L \Lambda_{y}}{2}\right) \cos \left(\frac{L \Lambda_{z}}{2}\right)^{2}\right)-2 L^{3} \Lambda_{y}^{2} \Lambda_{z}^{2}\left(2 \Lambda_{y} \cos \left(\frac{L \Lambda_{y}}{2}\right)-2 \Lambda_{y} \cos \left(\frac{L \Lambda_{y}}{2}\right) \cos \left(\frac{L \Lambda_{z}}{2}\right)^{2}\right)\left(\Omega_{y}-\Omega_{z}\right)\right)+$

$+\frac{L^{2} \Lambda_{y} \Lambda_{z}\left(\Lambda_{y}{ }^{2} \sin \left(L \Lambda_{y}\right) \sin \left(L \Lambda_{z}\right)-4 \Lambda_{y} \Lambda_{z} \cos \left(\frac{L \Lambda_{z}}{2}\right)^{2}-4 \Lambda_{y} \Lambda_{z} \cos \left(\frac{L \Lambda_{y}}{2}\right)^{2}+\Lambda_{z}^{2} \sin \left(L \Lambda_{y}\right) \sin \left(L \Lambda_{z}\right)+8 \Lambda_{y} \Lambda_{z} \cos \left(\frac{L \Lambda_{y}}{2}\right)^{2} \cos \left(\frac{L \Lambda_{z}}{2}\right)^{2}\right)}{2}$

$\psi_{2}=4 \Lambda_{y}^{2} \sin \left(\frac{L \Lambda_{y}}{2}\right)^{2} \sin \left(\frac{L \Lambda_{z}}{2}\right)^{2}-4 \Lambda_{z}^{2} \sin \left(\frac{L \Lambda_{y}}{2}\right)^{2} \sin \left(\frac{L \Lambda_{z}}{2}\right)^{2}+L^{2} \Lambda_{y}^{2} \Lambda_{z}^{2} \sin \left(\frac{L \Lambda_{y}}{2}\right)^{2}-L^{2} \Lambda_{y}^{2} \Lambda_{z}^{2} \sin \left(\frac{L \Lambda_{z}}{2}\right)^{2}+4 L^{2} \Lambda_{y}^{4} \Omega_{y} \sin \left(\frac{L \Lambda_{y}}{2}\right)^{2} \sin \left(\frac{L \Lambda_{z}}{2}\right)^{2}-4 L^{2} \Lambda_{z}^{4} \Omega_{z} \sin \left(\frac{L \Lambda_{y}}{2}\right)^{2} \sin \left(\frac{L \Lambda_{z}}{2}\right)^{2}+$

$+2 L \Lambda_{y} \Lambda_{z}{ }^{2} \sin \left(L \Lambda_{y}\right) \sin \left(\frac{L \Lambda_{z}}{2}\right)^{2}-2 L \Lambda_{y}{ }^{2} \Lambda_{z} \sin \left(L \Lambda_{z}\right) \sin \left(\frac{L \Lambda_{y}}{2}\right)^{2}-4 L^{2} \Lambda_{y}{ }^{2} \Lambda_{z}{ }^{2} \Omega_{y} \sin \left(\frac{L \Lambda_{y}}{2}\right)^{2} \sin \left(\frac{L \Lambda_{z}}{2}\right)^{2}+4 L^{2} \Lambda_{y}{ }^{2} \Lambda_{z}{ }^{2} \Omega_{z} \sin \left(\frac{L \Lambda_{y}}{2}\right)^{2} \sin \left(\frac{L \Lambda_{z}}{2}\right)^{2}-L^{3} \Lambda_{y}{ }^{4} \Lambda_{z} \Omega_{y} \sin \left(L \Lambda_{z}\right) \sin \left(\frac{L \Lambda_{y}}{2}\right)^{2}+$

$+L^{3} \Lambda_{y} \Lambda_{z}^{4} \Omega_{z} \sin \left(L \Lambda_{y}\right) \sin \left(\frac{L \Lambda_{z}}{2}\right)^{2}+L^{3} \Lambda_{y}^{3} \Lambda_{z}^{2} \Omega_{y} \sin \left(L \Lambda_{y}\right) \sin \left(\frac{L \Lambda_{z}}{2}\right)^{2}-L^{3} \Lambda_{y}{ }^{2} \Lambda_{z}^{3} \Omega_{z} \sin \left(L \Lambda_{z}\right) \sin \left(\frac{L \Lambda_{y}}{2}\right)^{2}-4 L^{4} \Lambda_{y}{ }^{2} \Lambda_{z}^{4} \Omega_{y} \Omega_{z} \sin \left(\frac{L \Lambda_{y}}{2}\right)^{2} \sin \left(\frac{L \Lambda_{z}}{2}\right)^{2}+4 L^{4} \Lambda_{y}^{4} \Lambda_{z}{ }^{2} \Omega_{y} \Omega_{z} \sin \left(\frac{L \Lambda_{y}}{2}\right)^{2} \sin \left(\frac{L \Lambda_{z}}{2}\right)^{2}$ 
Apêndice C

\section{C.10}

Matriz de Rigidez Local com Aproximação em Série de Taylor (TBT_2tr; TBT_3tr e TBT_4tr)

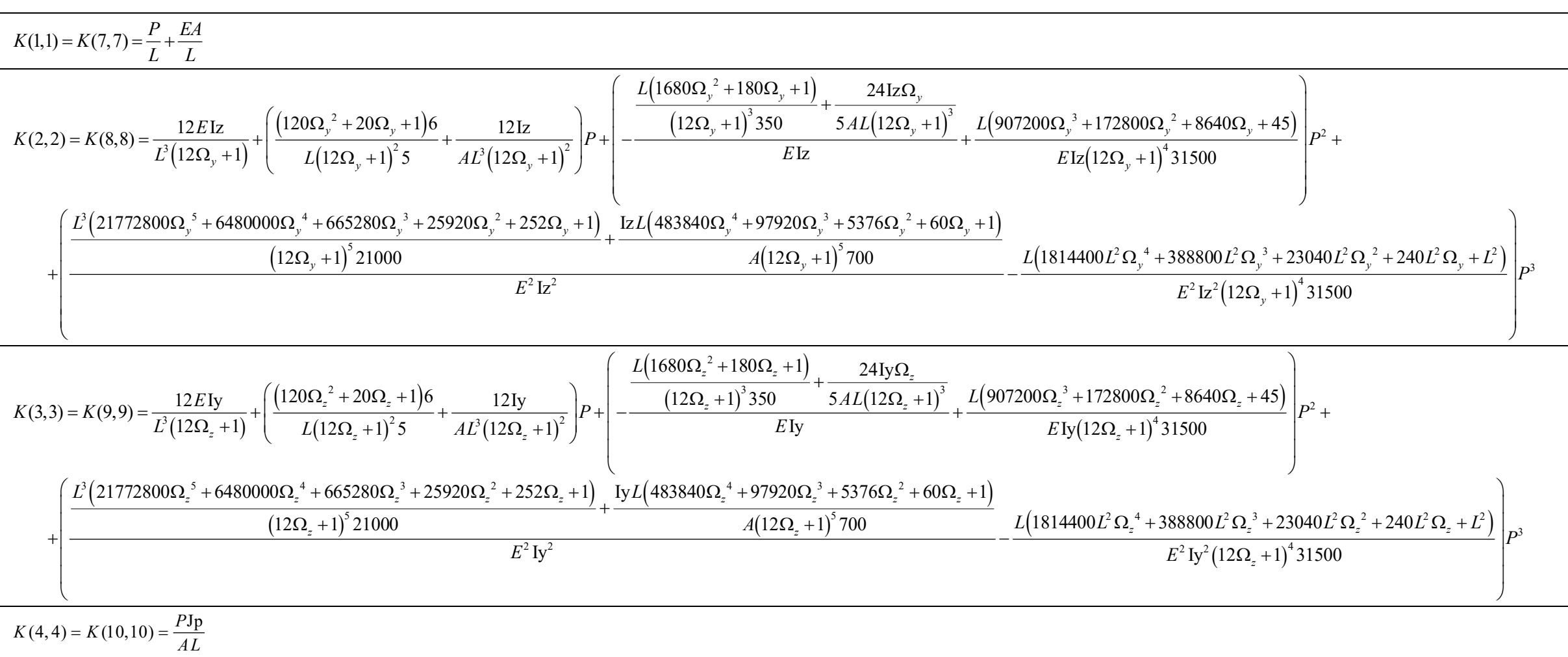


Apêndice C

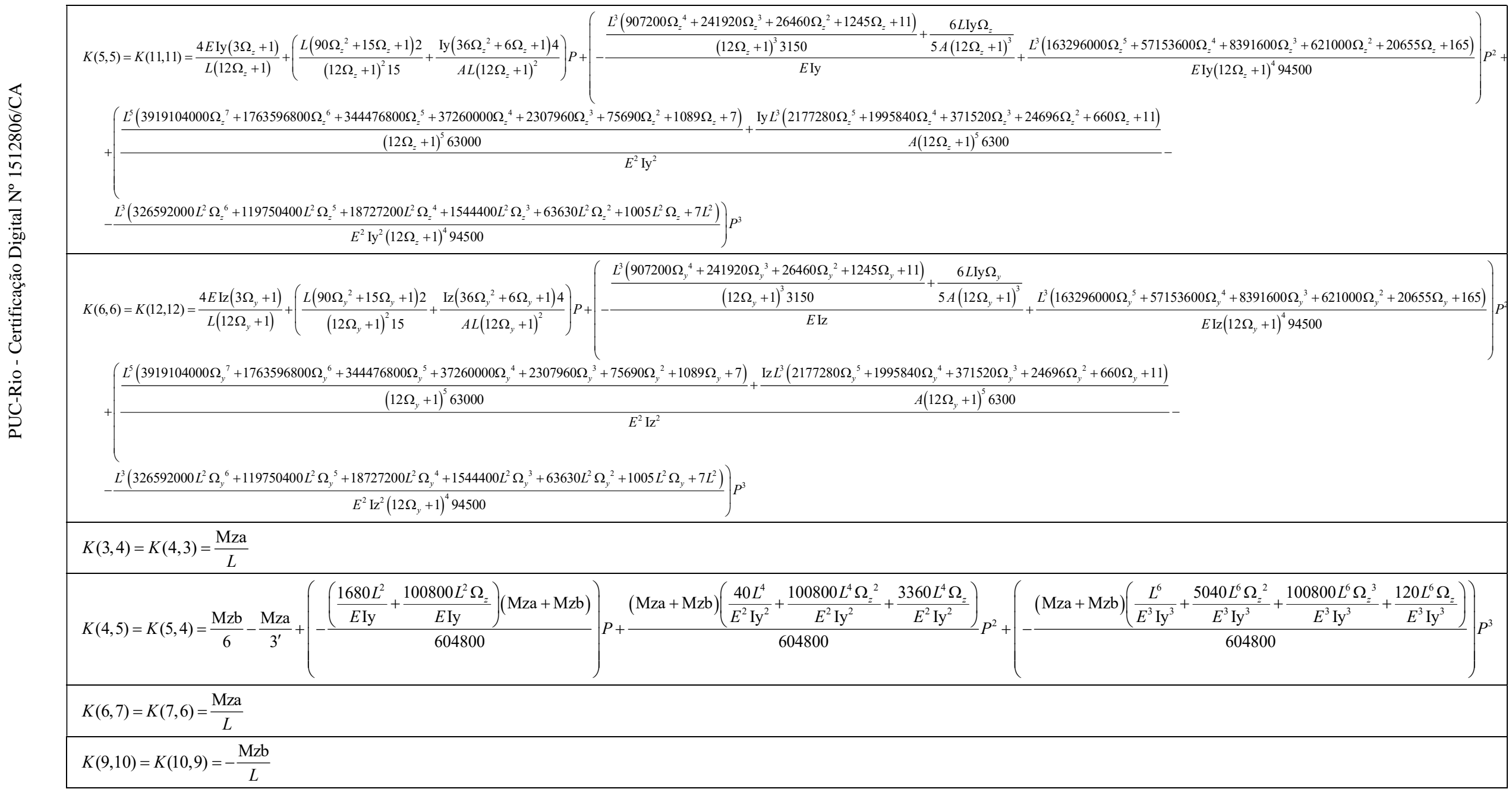


Apêndice C

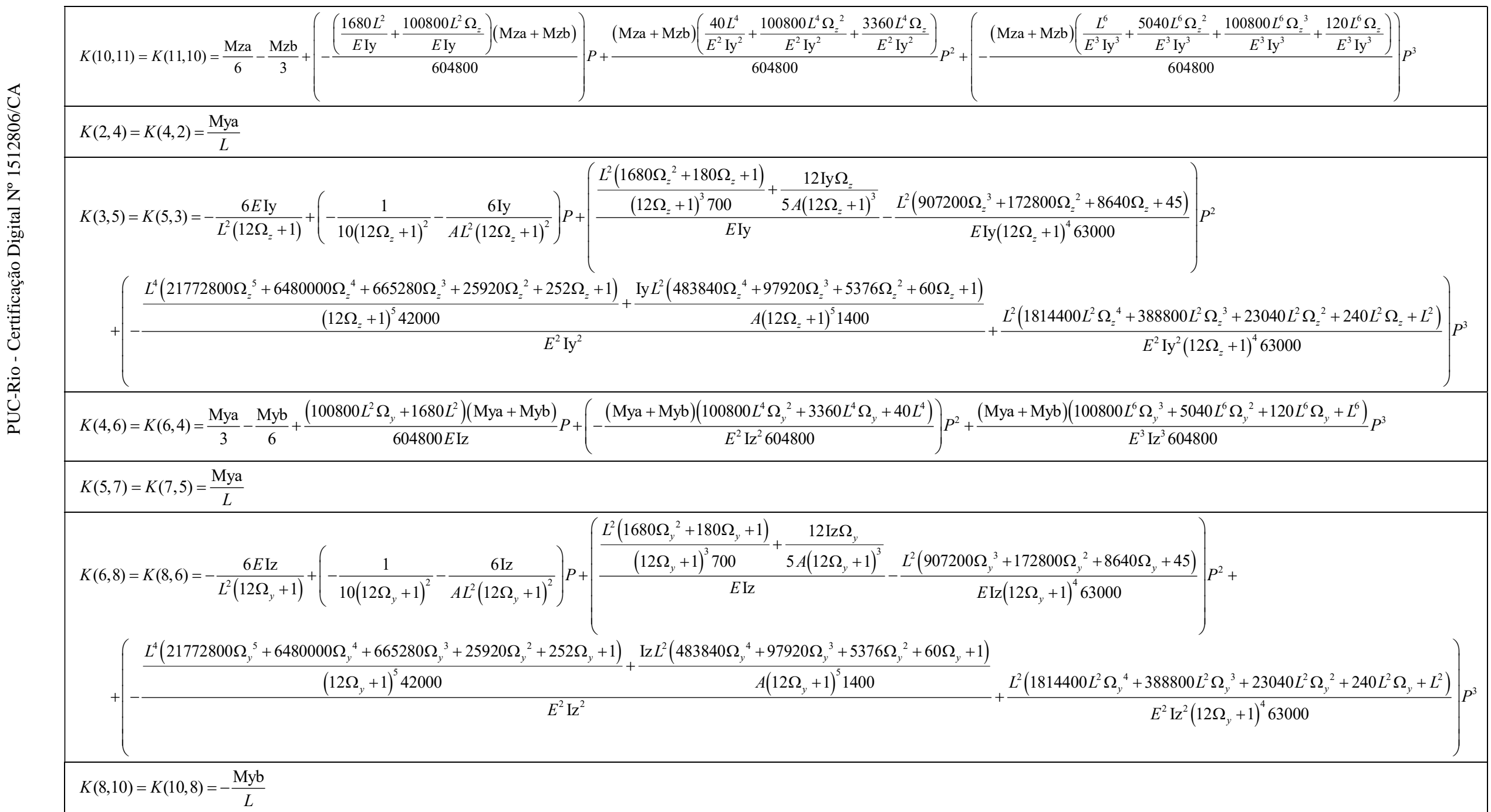


Apêndice C

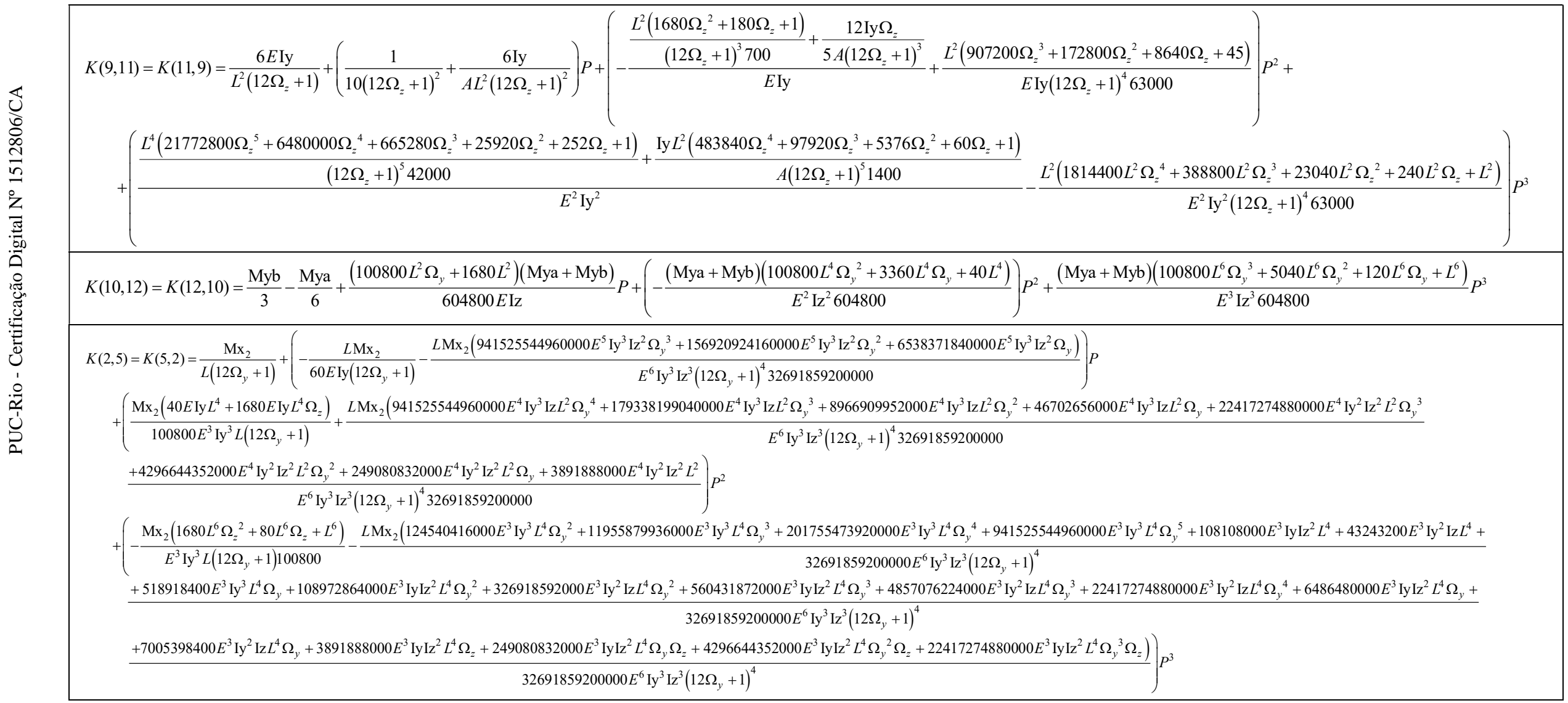


Apêndice C

$K(3,6)=K(6,3)=\frac{\mathrm{Mx}_{2}}{L\left(12 \Omega_{z}+1\right)}+\left(-\frac{L \mathrm{Mx}_{2}}{60 E \mathrm{Iz}\left(12 \Omega_{z}+1\right)}-\frac{L \mathrm{Mx}_{2}\left(941525544960000 E^{5} \mathrm{Iy}^{2} \mathrm{Iz}^{3} \Omega_{z}^{3}+156920924160000 E^{5} \mathrm{Iy}^{2} \mathrm{Iz}^{3} \Omega_{z}{ }^{2}+6538371840000 E^{5} \mathrm{Iy}^{2} \mathrm{Iz}^{3} \Omega_{z}\right)}{E^{6} \mathrm{Iy}^{3} \mathrm{Iz}^{3}\left(12 \Omega_{z}+1\right)^{4} 32691859200000}\right) P$

$+\left(\frac{\mathrm{Mx}_{2}\left(40 E \mathrm{Iz} L^{4}+1680 E \mathrm{Iz} L^{4} \Omega_{y}\right)}{100800 E^{3} \mathrm{Iz}^{3} L\left(12 \Omega_{z}+1\right)}+\frac{L \mathrm{Mx}_{2}\left(22417274880000 E^{4} \mathrm{Iy}^{2} \mathrm{Iz}^{2} L^{2} \Omega_{z}{ }^{3}+4296644352000 E^{4} \mathrm{Iy}^{2} \mathrm{Iz}^{2} L^{2} \Omega_{z}{ }^{2}+249080832000 E^{4} \mathrm{Iy}^{2} \mathrm{Iz}^{2} L^{2} \Omega_{z}+3891888000 E^{4} \mathrm{Iy}^{2} \mathrm{Iz}^{2} L^{2}+941525544960000 E^{4} \mathrm{IyIz}^{3} L^{2} \Omega_{z}{ }^{4}+\right.}{E^{6} \mathrm{Iy}^{3} \mathrm{Iz}^{3}\left(12 \Omega_{z}+1\right)^{4} 32691859200000}\right.$

$\left.\frac{\left.+179338199040000 E^{4} \mathrm{Iy} \mathrm{Iz}^{3} L^{2} \Omega_{z}+8966909952000 E^{4} \mathrm{Iy} \mathrm{Iz}^{3} L^{2} \Omega_{z}{ }^{2}+46702656000 E^{4} \mathrm{IyIz}^{3} L^{2} \Omega_{z}\right)}{E^{6} \mathrm{Iy}^{3} \mathrm{Iz}^{3}\left(12 \Omega_{z}+1\right)^{4} 32691859200000}\right) P^{2}$

$\left(-\frac{\mathrm{Mx}_{2}\left(1680 L^{6} \Omega_{y}{ }^{2}+80 L^{6} \Omega_{y}+L^{6}\right)}{E^{3} \mathrm{Iz}^{3} L\left(12 \Omega_{z}+1\right) 100800}-L \mathrm{Mx}_{2}\left(124540416000 E^{3} \mathrm{Iz}^{3} L^{4} \Omega_{z}{ }^{2}+11955879936000 E^{3} \mathrm{Iz}^{3} L^{4} \Omega_{z}{ }^{3}+201755473920000 E^{3} \mathrm{Iz}^{3} L^{4} \Omega_{z}{ }^{4}+941525544960000 E^{3} \mathrm{Iz}^{3} L^{4} \Omega_{z}{ }^{5}+43243200 E^{3} \mathrm{IyIz}^{2} L^{4}+108108000 E^{3} \mathrm{Iy}^{2} \mathrm{Iz}^{4} L^{4}+\right.\right.$

$E^{3} \mathrm{Iz}^{3} L\left(12 \Omega_{z}+1\right) 100800 \quad 32691859200000 E^{6} \mathrm{Iy}^{3} \mathrm{Iz}^{3}\left(12 \Omega_{z}+1\right)^{4}$

$+518918400 E^{3} \mathrm{Iz}^{3} L^{4} \Omega_{z}+326918592000 E^{3} \mathrm{IyIz}^{2} L^{4} \Omega_{z}{ }^{2}+108972864000 E^{3} \mathrm{Iy}^{2} \mathrm{Iz}^{4} \Omega_{z}{ }^{2}+4857076224000 E^{3} \mathrm{IyIz}^{2} L^{4} \Omega_{z}{ }^{3}+560431872000 E^{3} \mathrm{Iy}^{2} \mathrm{Iz}^{4} \Omega_{z}{ }^{3}+22417274880000 E^{3} \mathrm{IyIz}^{2} L^{4} \Omega_{z}{ }^{4}+3891888000 E^{3} \mathrm{Iy}^{2} \mathrm{Iz}^{4} \Omega_{y}+$

$32691859200000 E^{6} \mathrm{Iy}^{3} \mathrm{Iz}^{3}\left(12 \Omega_{z}+1\right)^{4}$ $\left.\frac{\left.+7005398400 E^{3} \mathrm{IyII}^{2} L^{4} \Omega_{z}+6486480000 E^{3} \mathrm{Iy}^{2} \mathrm{Iz}^{4} \Omega_{z}+249080832000 E^{3} \mathrm{Iy}^{2} \mathrm{Iz}^{4} \Omega_{y} \Omega_{z}+4296644352000 E^{3} \mathrm{Iy}^{2} \mathrm{Iz}^{4} \Omega_{y} \Omega_{z}{ }^{2}+22417274880000 E^{3} \mathrm{Iy}^{2} \mathrm{Iz}^{4} \Omega_{y} \Omega_{z}{ }^{3}\right)}{32691859200000 E^{6} \mathrm{Iy}^{3} \mathrm{Iz}^{3}(12 \Omega+1)^{4}}\right) P^{3}$

$K(5,8)=K(8,5)=-\frac{\mathrm{Mx}_{2}}{L\left(12 \Omega_{y}+1\right)}+\left(\frac{L \mathrm{Mx}_{2}}{60 E \operatorname{Iy}\left(12 \Omega_{y}+1\right)}+\frac{L \mathrm{Mx}_{2}\left(941525544960000 E^{5} \mathrm{Iy}^{3} \mathrm{Iz}^{2} \Omega_{y}{ }^{3}+156920924160000 E^{5} \mathrm{Iy}^{3} \mathrm{Iz}^{2} \Omega_{y}{ }^{2}+6538371840000 E^{5} \mathrm{Iy}^{3} \mathrm{Iz}^{2} \Omega_{y}\right)}{E^{6} \mathrm{Iy}^{3} \mathrm{Iz}^{3}\left(12 \Omega_{y}+1\right)^{4} 32691859200000}\right) P$

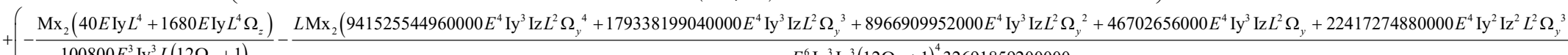

$+\left(-\frac{2}{100800 E^{3} \mathrm{Iy}^{3} L\left(12 \Omega_{y}+1\right)}-\frac{L E^{6} \mathrm{Iy}^{3} \mathrm{Iz}^{3}\left(12 \Omega_{y}+1\right)^{4} 32691859200000}{2}\right.$

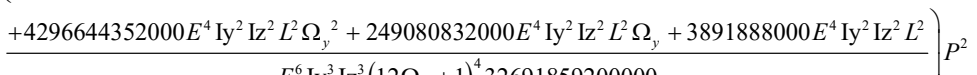

$E^{6} \mathrm{Iy}^{3} \mathrm{Iz}^{3}\left(12 \Omega_{y}+1\right)^{4} 32691859200000$

$\left(\mathrm{Mx}_{2}\left(1680 L^{6} \Omega_{z}{ }^{2}+80 L^{6} \Omega_{z}+L^{6}\right) \quad L \mathrm{Mx}_{2}\left(124540416000 E^{3} \mathrm{Iy}^{3} L^{4} \Omega_{y}{ }^{2}+11955879936000 E^{3} \mathrm{Iy}^{3} L^{4} \Omega_{y}{ }^{3}+201755473920000 E^{3} \mathrm{Iy}^{3} L^{4} \Omega_{y}{ }^{4}+941525544960000 E^{3} \mathrm{Iy}^{3} L^{4} \Omega_{y}{ }^{5}+108108000 E^{3} \mathrm{IyI}^{2} L^{4}+43243200 E^{3} \mathrm{Iy}^{2} \mathrm{Iz}^{4}+\right.\right.$

$\frac{32691859200000 E^{6} \mathrm{Iy}^{3} \mathrm{Iz}^{3}\left(12 \Omega_{y}+1\right)^{4}}{E^{3} \mathrm{Iy}^{3} L\left(12 \Omega_{y}+1\right) 100800}+\frac{L}{+50}$

$\underline{+518918400 E^{3} \mathrm{Iy}^{3} L^{4} \Omega_{y}+108972864000 E^{3} \mathrm{IyIz}^{2} L^{4} \Omega_{y}{ }^{2}+326918592000 E^{3} \mathrm{Iy}^{2} \mathrm{Iz}^{4} \Omega_{y}{ }^{2}+560431872000 E^{3} \mathrm{IyIz}^{2} L^{4} \Omega_{y}{ }^{3}+4857076224000 E^{3} \mathrm{Iy}^{2} \mathrm{IzL}^{4} \Omega_{y}{ }^{3}+22417274880000 E^{3} \mathrm{Iy}^{2} \mathrm{IzL}^{4} \Omega_{y}{ }^{4}+6486480000 E^{3} \mathrm{IyIz}^{2} L^{4} \Omega_{y}+}$ $32691859200000 E^{6} \mathrm{Iy}^{3} \mathrm{Iz}^{3}\left(12 \Omega_{y}+1\right)$

$\left.\frac{\left.+7005398400 E^{3} \mathrm{Iy}^{2} \mathrm{Iz}^{4} \Omega_{y}+3891888000 E^{3} \mathrm{IyIz}^{2} L^{4} \Omega_{z}+249080832000 E^{3} \mathrm{IyIz}^{2} L^{4} \Omega_{y} \Omega_{z}+4296644352000 E^{3} \mathrm{IyIz}^{2} L^{4} \Omega_{y}{ }^{2} \Omega_{z}+22417274880000 E^{3} \mathrm{IyIz}^{2} L^{4} \Omega_{y}{ }^{3} \Omega_{z}\right)}{32691859200000 E^{6} \mathrm{Iy}^{3} \mathrm{Iz}^{3}\left(12 \Omega_{y}+1\right)^{4}}\right) P^{3}$ 
Apêndice C

$K(6,9)=K(9,6)=-\frac{\mathrm{Mx}_{2}}{L\left(12 \Omega_{z}+1\right)}+\left(\frac{L \mathrm{Mx}_{2}}{60 E \mathrm{Iz}\left(12 \Omega_{z}+1\right)}+\frac{L \mathrm{Mx}_{2}\left(941525544960000 E^{5} \mathrm{Iy}^{2} \mathrm{Iz}^{3} \Omega_{z}^{3}+156920924160000 E^{5} \mathrm{Iy}^{2} \mathrm{Iz}^{3} \Omega_{z}{ }^{2}+6538371840000 E^{5} \mathrm{Iy}^{2} \mathrm{Iz}^{3} \Omega_{z}\right)}{E^{6} \mathrm{Iy}^{3} \mathrm{Iz}^{3}\left(12 \Omega_{z}+1\right)^{4} 32691859200000}\right) P$

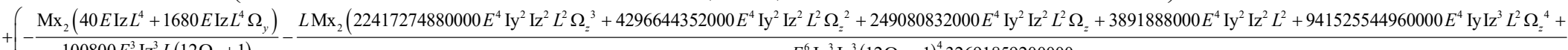

$\left(-\frac{100800 E^{3} \mathrm{Iz}^{3} L\left(12 \Omega_{z}+1\right)}{+17938890000 \mathrm{Iy}^{3} \mathrm{Iz}^{3}\left(12 \Omega_{z}+1\right)^{4} 32691859200000}\right.$

$\left.\frac{\left.+179338199040000 E^{4} \mathrm{Iy} \mathrm{Iz}^{3} L^{2} \Omega_{z}+8966909952000 E^{4} \mathrm{Iy} \mathrm{Iz}^{3} L^{2} \Omega_{z}{ }^{2}+46702656000 E^{4} \mathrm{IyIz}^{3} L^{2} \Omega_{z}\right)}{E^{6} \mathrm{Iy}^{3} \mathrm{Iz}^{3}\left(12 \Omega_{z}+1\right)^{4} 32691859200000}\right) P^{2}$

$+\left(\frac{\mathrm{Mx}_{2}\left(1680 L^{6} \Omega_{y}{ }^{2}+80 L^{6} \Omega_{y}+L^{6}\right)}{E^{3} \mathrm{Iz}^{3} L\left(12 \Omega_{z}+1\right) 100800}+\frac{L \mathrm{Mx}_{2}\left(124540416000 E^{3} \mathrm{Iz}^{3} L^{4} \Omega_{z}{ }^{2}+11955879936000 E^{3} \mathrm{Iz}^{3} L^{4} \Omega_{z}{ }^{3}+201755473920000 E^{3} \mathrm{Iz}^{3} L^{4} \Omega_{z}{ }^{4}+941525544960000 E^{3} \mathrm{Iz}^{3} L^{4} \Omega_{z}{ }^{5}+43243200 E^{3} \mathrm{IyII}^{2} L^{4}+108108000 E^{3} \mathrm{Iy}^{2} \mathrm{Iz}^{4}+\right.}{32691859200000 E^{6} \mathrm{Iy}^{3} \mathrm{Iz}^{3}\left(12 \Omega_{z}+1\right)^{4}}\right.$

$+518918400 E^{3} \mathrm{Iz}^{3} L^{4} \Omega_{z}+326918592000 E^{3} \mathrm{IyIz}^{2} L^{4} \Omega_{z}{ }^{2}+108972864000 E^{3} \mathrm{Iy}^{2} \mathrm{Iz}^{4} \Omega_{z}{ }^{2}+4857076224000 E^{3} \mathrm{IyII}^{2} L^{4} \Omega_{z}{ }^{3}+560431872000 E^{3} \mathrm{Iy}^{2} \mathrm{IzL}^{4} \Omega_{z}{ }^{3}+22417274880000 E^{3} \mathrm{IyIz}^{2} L^{4} \Omega_{z}{ }^{4}+3891888000 E^{3} \mathrm{Iy}^{2} \mathrm{Iz}^{4} \Omega_{v}+$ $32691859200000 E^{6} \mathrm{Iy}^{3} \mathrm{Iz}^{3}\left(12 \Omega_{z}+1\right)^{4}$ $\left.\frac{\left.+7005398400 E^{3} \mathrm{Iy} \mathrm{Iz}^{2} L^{4} \Omega_{z}+6486480000 E^{3} \mathrm{Iy}^{2} \mathrm{Iz}^{4} \Omega_{z}+249080832000 E^{3} \mathrm{Iy}^{2} \mathrm{IzL}^{4} \Omega_{y} \Omega_{z}+4296644352000 E^{3} \mathrm{Iy}^{2} \mathrm{Iz}^{4} \Omega_{y} \Omega_{z}{ }^{2}+22417274880000 E^{3} \mathrm{Iy}^{2} \mathrm{IzL}^{4} \Omega_{y} \Omega_{z}{ }^{3}\right)}{32691859200000 E^{6} \mathrm{Iy}^{3} \mathrm{Iz}^{3}\left(12 \Omega_{z}+1\right)^{4}}\right) P^{3}$

$K(8,11)=K(11,8)=\frac{\mathrm{Mx}_{2}}{L\left(12 \Omega_{y}+1\right)}+\left(-\frac{L \mathrm{Mx}_{2}}{60 E \operatorname{Iy}\left(12 \Omega_{y}+1\right)}-\frac{L \mathrm{Mx}_{2}\left(941525544960000 E^{5} \mathrm{Iy}^{3} \mathrm{Iz}^{2} \Omega_{y}{ }^{3}+156920924160000 E^{5} \mathrm{Iy}^{3} \mathrm{Iz}^{2} \Omega_{y}{ }^{2}+6538371840000 E^{5} \mathrm{Iy}^{3} \mathrm{Iz}^{2} \Omega_{y}\right)}{E^{6} \mathrm{Iy}^{3} \mathrm{Iz}^{3}\left(12 \Omega_{y}+1\right)^{4} 32691859200000}\right) P$

$+\left(\frac{\mathrm{Mx}_{2}\left(40 E \mathrm{Iy} L^{4}+1680 E \mathrm{Iy} L^{4} \Omega_{z}\right)}{100800 E^{3} \mathrm{Iy}^{3} L\left(12 \Omega_{y}+1\right)}+\frac{L \mathrm{Mx}_{2}\left(941525544960000 E^{4} \mathrm{Iy}^{3} \mathrm{IzL}^{2} \Omega_{y}{ }^{4}+179338199040000 E^{4} \mathrm{Iy}^{3} \mathrm{Iz}^{2} \Omega_{y}{ }^{3}+8966909952000 E^{4} \mathrm{Iy}^{3} \mathrm{Iz}^{2} \Omega_{y}{ }^{2}+46702656000 E^{4} \mathrm{Iy}^{3} \mathrm{Iz}^{2} \Omega_{y}+22417274880000 E^{4} \mathrm{Iy}^{2} \mathrm{Iz}^{2} L^{2} \Omega_{y}{ }^{3}\right.}{E^{6} \mathrm{Iy}^{3} \mathrm{Iz}^{3}\left(12 \Omega_{y}+1\right)^{4} 32691859200000}\right.$

$\left.+\frac{+4296644352000 E^{4} \mathrm{Iy}^{2} \mathrm{Iz}^{2} L^{2} \Omega_{y}{ }^{2}+249080832000 E^{4} \mathrm{Iy}^{2} \mathrm{Iz}^{2} L^{2} \Omega_{y}+3891888000 E^{4} \mathrm{Iy}^{2} \mathrm{Iz}^{2} L^{2}}{E^{6} \mathrm{Iy}}\right) P^{2}$

$$
E^{6} \mathrm{Iy}^{3} \mathrm{Iz}^{3}\left(12 \Omega_{y}+1\right)^{4} 32691859200000
$$

$\left(-\mathrm{Mx}_{2}\left(1680 L^{6} \Omega_{z}{ }^{2}+80 L^{6} \Omega_{z}+L^{6}\right)-L \mathrm{Mx}_{2}\left(124540416000 E^{3} \mathrm{Iy}^{3} L^{4} \Omega_{y}{ }^{2}+11955879936000 E^{3} \mathrm{Iy}^{3} L^{4} \Omega_{y}{ }^{3}+201755473920000 E^{3} \mathrm{Iy}^{3} L^{4} \Omega_{y}{ }^{4}+941525544960000 E^{3} \mathrm{Iy}^{3} L^{4} \Omega_{y}{ }^{5}+108108000 E^{3} \mathrm{IyI}^{2} L^{4}+43243200 E^{3} \mathrm{Iy}^{2} \mathrm{Iz} L^{4}+\right.\right.$
$E^{3} \mathrm{Iy}^{3} L\left(12 \Omega_{y}+1\right) 100800$
$32691859200000 E^{6} \mathrm{Iy}^{3} \mathrm{Iz}^{3}\left(12 \Omega_{y}+1\right)$

$+518918400 E^{3} \mathrm{Iy}^{3} L^{4} \Omega_{y}+108972864000 E^{3} \mathrm{IyIz}^{2} L^{4} \Omega_{y}{ }^{2}+326918592000 E^{3} \mathrm{Iy}^{2} \mathrm{Iz}^{4} \Omega_{y}{ }^{2}+560431872000 E^{3} \mathrm{IyIz}^{2} L^{4} \Omega_{y}{ }^{3}+4857076224000 E^{3} \mathrm{Iy}^{2} \mathrm{Iz}^{4} \Omega_{y}{ }^{3}+22417274880000 E^{3} \mathrm{Iy}^{2} \mathrm{IzL}^{4} \Omega_{y}{ }^{4}+6486480000 E^{3} \mathrm{IyIz}^{2} L^{4} \Omega_{y}+$ $32691859200000 E^{6} \mathrm{Iy}^{3} \mathrm{Iz}^{3}\left(12 \Omega_{y}+1\right)^{4}$

$\left.\frac{\left.+7005398400 E^{3} \mathrm{Iy}^{2} \mathrm{Iz}^{4} \Omega_{y}+3891888000 E^{3} \mathrm{IyIz}^{2} L^{4} \Omega_{z}+249080832000 E^{3} \mathrm{IyII}^{2} L^{4} \Omega_{y} \Omega_{z}+4296644352000 E^{3} \mathrm{IyIz}^{2} L^{4} \Omega_{y}{ }^{2} \Omega_{z}+22417274880000 E^{3} \operatorname{IyII}^{2} L^{4} \Omega_{y}{ }^{3} \Omega_{z}\right)}{32691859200000 E^{6} \mathrm{Iy}^{3} \mathrm{Iz}^{3}\left(12 \Omega_{y}+1\right)^{4}}\right) P^{3}$ 
Apêndice C

$K(9,12)=K(12,9)=\frac{\mathrm{Mx}_{2}}{L\left(12 \Omega_{z}+1\right)}+\left(-\frac{L \mathrm{Mx}_{2}}{60 E \mathrm{Iz}\left(12 \Omega_{z}+1\right)}-\frac{L \mathrm{Mx}_{2}\left(941525544960000 E^{5} \mathrm{Iy}^{2} \mathrm{Iz}^{3} \Omega_{z}{ }^{3}+156920924160000 E^{5} \mathrm{Iy}^{2} \mathrm{Iz}^{3} \Omega_{z}{ }^{2}+6538371840000 E^{5} \mathrm{Iy}^{2} \mathrm{Iz}^{3} \Omega_{z}\right)}{E^{6} \mathrm{Iy}^{3} \mathrm{Iz}^{3}\left(12 \Omega_{z}+1\right)^{4} 32691859200000}\right) P$

$+\left(\frac{\mathrm{Mx}_{2}\left(40 E \mathrm{Iz} L^{4}+1680 E \mathrm{Iz} L^{4} \Omega_{y}\right)}{100800 E^{3} \mathrm{Iz}^{3} L\left(12 \Omega_{z}+1\right)}+\frac{L \mathrm{Mx}_{2}\left(22417274880000 E^{4} \mathrm{Iy}^{2} \mathrm{Iz}^{2} L^{2} \Omega_{z}{ }^{3}+4296644352000 E^{4} \mathrm{Iy}^{2} \mathrm{Iz}^{2} L^{2} \Omega_{z}{ }^{2}+249080832000 E^{4} \mathrm{Iy}^{2} \mathrm{Iz}^{2} L^{2} \Omega_{z}+3891888000 E^{4} \mathrm{Iy}^{2} \mathrm{Iz}^{2} L^{2}+941525544960000 E^{4} \mathrm{IyIz}^{3} L^{2} \Omega_{z}{ }^{4}+\right.}{E^{6} \mathrm{Iy}^{3} \mathrm{Iz}^{3}\left(12 \Omega_{z}+1\right)^{4} 32691859200000}\right.$

$\left.\frac{\left.+179338199040000 E^{4} \mathrm{Iy} \mathrm{Iz}^{3} L^{2} \Omega_{z}+8966909952000 E^{4} \mathrm{IyIz}^{3} L^{2} \Omega_{z}{ }^{2}+46702656000 E^{4} \mathrm{IyIz}^{3} L^{2} \Omega_{z}\right)}{E^{6} \mathrm{Iy}^{3} \mathrm{Iz}^{3}\left(12 \Omega_{z}+1\right)^{4} 32691859200000}\right) P^{2}$

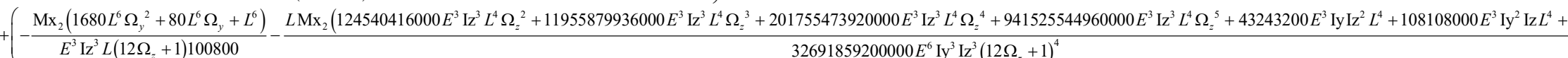

$E^{3} \mathrm{Iz}^{3} L\left(12 \Omega_{z}+1\right) 100800 \quad 32691859200000 E^{6} \mathrm{Iy}^{3} \mathrm{Iz}^{3}\left(12 \Omega_{z}+1\right)^{4}$

$+518918400 E^{3} \mathrm{Iz}^{3} L^{4} \Omega_{z}+326918592000 E^{3} \mathrm{IyIz}^{2} L^{4} \Omega_{z}{ }^{2}+108972864000 E^{3} \mathrm{Iy}^{2} \mathrm{Iz}^{4} \Omega_{z}{ }^{2}+4857076224000 E^{3} \mathrm{IyIz}^{2} L^{4} \Omega_{z}{ }^{3}+560431872000 E^{3} \mathrm{Iy}^{2} \mathrm{Iz}^{4} \Omega_{z}{ }^{3}+22417274880000 E^{3} \mathrm{IyIz}^{2} L^{4} \Omega_{z}{ }^{4}+3891888000 E^{3} \mathrm{Iy}^{2} \mathrm{Iz}^{4} \Omega^{4} \Omega_{y}+$ $32691859200000 E^{6} \mathrm{Iy}^{3} \mathrm{Iz}^{3}\left(12 \Omega_{z}+1\right)^{4}$

$\left.\underline{\left.+7005398400 E^{3} \mathrm{IyIz}^{2} L^{4} \Omega_{z}+6486480000 E^{3} \mathrm{Iy}^{2} \mathrm{Iz} L^{4} \Omega_{z}+249080832000 E^{3} \mathrm{Iy}^{2} \mathrm{Iz}^{4} \Omega_{y} \Omega_{z}+4296644352000 E^{3} \mathrm{Iy}^{2} \mathrm{Iz}^{4} \Omega_{y} \Omega_{z}{ }^{2}+22417274880000 E^{3} \mathrm{Iy}^{2} \mathrm{Iz}^{4} \Omega_{y} \Omega_{z}{ }^{3}\right)}\right) P^{3}$

$K(1,5)=K(5,1)=-\frac{\text { Mya }}{L}$

$K(2,6)=K(6,2)=\frac{6 E \mathrm{Iz}}{L^{2}\left(12 \Omega_{y}+1\right)}+\left(\frac{1}{10\left(12 \Omega_{y}+1\right)^{2}}+\frac{6 \mathrm{Iz}}{A L^{2}\left(12 \Omega_{y}+1\right)^{2}}\right) P+\left(-\frac{\frac{L^{2}\left(1680 \Omega_{y}{ }^{2}+180 \Omega_{y}+1\right)}{\left(12 \Omega_{y}+1\right)^{3} 700}+\frac{12 \mathrm{Iz} \Omega_{y}}{5 A\left(12 \Omega_{y}+1\right)^{3}}}{E \mathrm{Iz}}+\frac{L^{2}\left(907200 \Omega_{y}{ }^{3}+172800 \Omega_{y}{ }^{2}+8640 \Omega_{y}+45\right)}{E \operatorname{Iz}\left(12 \Omega_{y}+1\right)^{4} 63000}\right) P^{2}+$

$+\left(\frac{\frac{L^{4}\left(21772800 \Omega_{y}{ }^{5}+6480000 \Omega_{y}{ }^{4}+665280 \Omega_{y}{ }^{3}+25920 \Omega_{y}{ }^{2}+252 \Omega_{y}+1\right)}{\left(12 \Omega_{y}+1\right)^{5} 42000}+\frac{\operatorname{Iz} L^{2}\left(483840 \Omega_{y}{ }^{4}+97920 \Omega_{y}{ }^{3}+5376 \Omega_{y}{ }^{2}+60 \Omega_{y}+1\right)}{A\left(12 \Omega_{y}+1\right)^{5} 1400}}{E^{2} \mathrm{Iz}^{2}}-\frac{L^{2}\left(1814400 L^{2} \Omega_{y}{ }^{4}+388800 L^{2} \Omega_{y}{ }^{3}+23040 L^{2} \Omega_{y}{ }^{2}+240 L^{2} \Omega_{y}+L^{2}\right)}{E^{2} \mathrm{Iz}^{2}\left(12 \Omega_{y}+1\right)^{4} 63000} P^{3}\right.$

$K(4,8)=K(8,4)=-\frac{\text { Mya }}{L}$ 
Apêndice C

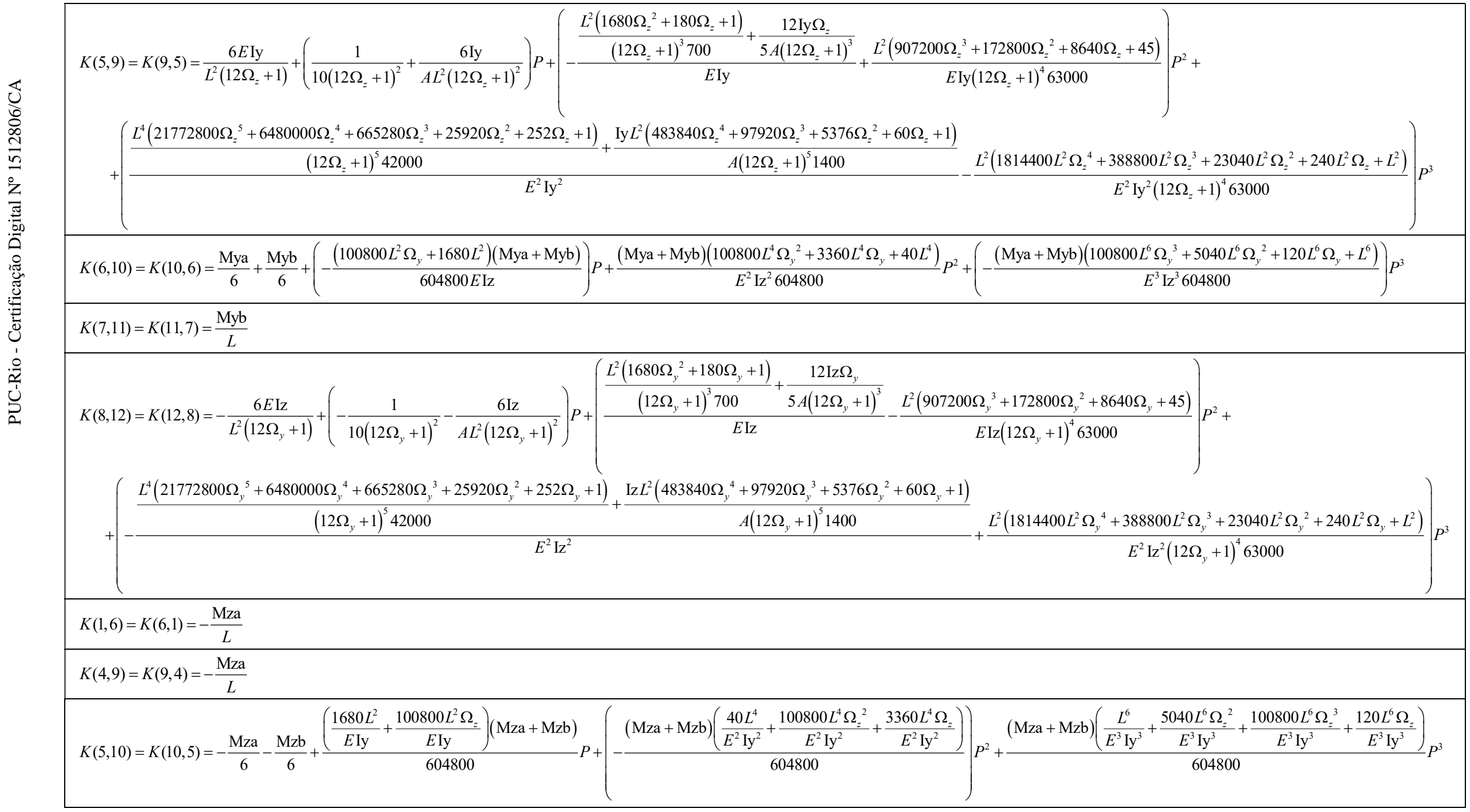


Apêndice $C$

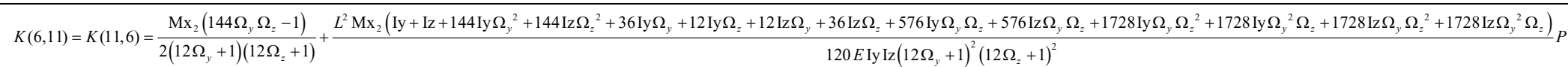

$\left(L^{4} \mathrm{Mx}_{2}\left(52254720 \mathrm{Iy}^{2} \Omega_{y}{ }^{4} \Omega_{z}{ }^{2}+8709120 \mathrm{Iy}^{2} \Omega_{y}{ }^{4} \Omega_{z}+362880 \mathrm{Iy}^{2} \Omega_{y}{ }^{4}+52254720 \mathrm{Iy}^{2} \Omega_{y}{ }^{3} \Omega_{z}{ }^{3}+27371520 \mathrm{Iy}^{2} \Omega_{y}{ }^{3} \Omega_{z}{ }^{2}+3473280 \mathrm{Iy}^{2} \Omega_{y}{ }^{3} \Omega_{z}+129600 \mathrm{Iy}^{2} \Omega_{y}{ }^{3}+5598720 \mathrm{Iy}^{2} \Omega_{y}{ }^{2} \Omega_{z}{ }^{3}+2799360 \mathrm{Iy}^{2} \Omega_{y}{ }^{2} \Omega_{z}{ }^{2}+349920 \mathrm{Iy}^{2} \Omega_{y}{ }^{2} \Omega_{z}+12960 \mathrm{Iy}^{2} \Omega_{y}{ }^{2}+\right.\right.$ $25200 E^{2} \mathrm{Iy}^{2} \mathrm{Iz}^{2}\left(12 \Omega_{y}+1\right)^{3}\left(12 \Omega_{z}+1\right)^{3}$

$+31104 \mathrm{Iy}^{2} \Omega_{y} \Omega_{z}{ }^{3}+63936 \mathrm{Iy}^{2} \Omega_{y} \Omega_{z}{ }^{2}+10008 \mathrm{Iy}^{2} \Omega_{y} \Omega_{z}+408 \mathrm{Iy}^{2} \Omega_{y}+720 \mathrm{Iy}^{2} \Omega_{z}{ }^{2}+120 \mathrm{Iy}^{2} \Omega_{z}+5 \mathrm{Iy}^{2}+1244160 \mathrm{IyIz} \Omega_{y}{ }^{3} \Omega_{z}{ }^{2}+134784 \mathrm{Iylz} \Omega_{y}{ }^{3} \Omega_{z}+2592 \mathrm{IyIz} \Omega_{y}{ }^{3}+1244160 \mathrm{IyIz} \Omega_{y}{ }^{2} \Omega_{z}{ }^{3}+622080 \mathrm{Iylz} \Omega_{y}{ }^{2} \Omega_{z}{ }^{2}+59616 \mathrm{IyIz} \Omega_{y}{ }^{2} \Omega_{z}+$ $25200 E^{2} \mathrm{Iy}^{2} \mathrm{Iz}^{2}\left(12 \Omega_{y}+1\right)^{3}\left(12 \Omega_{z}+1\right)^{3}$

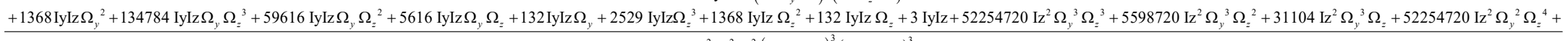
$25200 E^{2} \operatorname{Iy}^{2} \mathrm{Iz}^{2}\left(12 \Omega_{y}+1\right)^{3}\left(12 \Omega_{z}+1\right)^{3}$

$\left.\frac{\left.+27371520 \mathrm{Iz}^{2} \Omega_{y}{ }^{2} \Omega_{z}{ }^{3}+2799360 \mathrm{Iz}^{2} \Omega_{y}{ }^{2} \Omega_{z}{ }^{2}+63936 \mathrm{Iz}^{2} \Omega_{y}{ }^{2} \Omega_{z}+720 \mathrm{Iz}^{2} \Omega_{y}{ }^{2}+8709120 \mathrm{Iz}^{2} \Omega_{y} \Omega_{z}{ }^{4}+3473280 \mathrm{Iz}^{2} \Omega_{y} \Omega_{z}{ }^{3}+349920 \mathrm{Iz}^{2} \Omega_{y} \Omega_{z}{ }^{2}+10008 \mathrm{Iz}^{2} \Omega_{y} \Omega_{z}+120 \mathrm{Iz}^{2} \Omega_{y}+362880 \mathrm{Iz}^{2} \Omega_{z}{ }^{4}+129600 \mathrm{Iz}^{2} \Omega_{z}{ }^{3}+12960 \mathrm{Iz}^{2} \Omega_{z}{ }^{2}+408 \mathrm{Iz}^{2} \Omega_{z}+5 \mathrm{Iz}^{2}\right)}{25200 E^{2} \mathrm{Iy}^{2} \mathrm{Iz}^{2}\left(12 \Omega_{y}+1\right)^{3}\left(12 \Omega_{z}+1\right)^{3}}\right) P^{2}$

$+\left(\frac{L^{6} \mathrm{Mx}_{2}\left(648 \Omega_{z}+23040 \Omega_{y} \Omega_{z}{ }^{2}+2211840 \Omega_{y} \Omega_{z}{ }^{3}+37324800 \Omega_{y} \Omega_{z}{ }^{4}+174182400 \Omega_{y} \Omega_{z}{ }^{5}+33840 \Omega_{z}{ }^{2}+967680 \Omega_{z}{ }^{3}+13236480 \Omega_{z}{ }^{4}+80870400 \Omega_{z}{ }^{5}+174182400 \Omega_{z}{ }^{6}+96 \Omega_{y} \Omega_{z}+5\right)}{100800 E^{3}{ }^{3} y^{3}\left(12 \Omega_{y}+1\right)\left(12 \Omega_{z}+1\right)^{4}}+\right.$

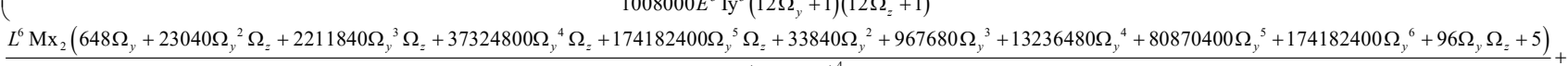
$1008000 E^{3} \mathrm{Iz}^{3}\left(12 \Omega_{y}+1\right)^{4}\left(12 \Omega_{z}+1\right)$

$+\frac{L^{6} \mathrm{Mx}_{2}\left(12441600 \Omega_{y}{ }^{4} \Omega_{z}+311040 \Omega_{y}{ }^{4}+12441600 \Omega_{y}{ }^{3} \Omega_{z}{ }^{2}+5495040 \Omega_{y}{ }^{3} \Omega_{z}+172800 \Omega_{y}{ }^{3}+1658880 \Omega_{y}{ }^{2} \Omega_{z}{ }^{2}+613440 \Omega_{y}{ }^{2} \Omega_{z}+20160 \Omega_{y}{ }^{2}+43200 \Omega_{y} \Omega_{z}{ }^{2}+20880 \Omega_{y} \Omega_{z}+660 \Omega_{y}+288 \Omega_{z}{ }^{2}+7\right)}{+}$ $3024000 E^{3} \mathrm{Iy} \mathrm{Iz}^{2}\left(12 \Omega_{y}+1\right)^{3}\left(12 \Omega_{z}+1\right)^{2}$

$\left.+\frac{L^{6} \mathrm{Mx}_{2}\left(12441600 \Omega_{y}{ }^{2} \Omega_{z}{ }^{3}+1658880 \Omega_{y}{ }^{2} \Omega_{z}{ }^{2}+43200 \Omega_{y}{ }^{2} \Omega_{z}+288 \Omega_{y}{ }^{2}+12441600 \Omega_{y} \Omega_{z}{ }^{4}+5495040 \Omega_{y} \Omega_{z}{ }^{3}+613440 \Omega_{y} \Omega_{z}{ }^{2}+20880 \Omega_{y} \Omega_{z}+228 \Omega_{y}+311040 \Omega_{z}{ }^{4}+172800 \Omega_{z}{ }^{3}+660 \Omega_{z}+7\right)}{{ }^{2}}\right) P^{3}$ $3024000 E^{3} \operatorname{Iy}^{2} \operatorname{Iz}\left(12 \Omega_{y}+1\right)^{2}\left(12 \Omega_{z}+1\right)^{3}$

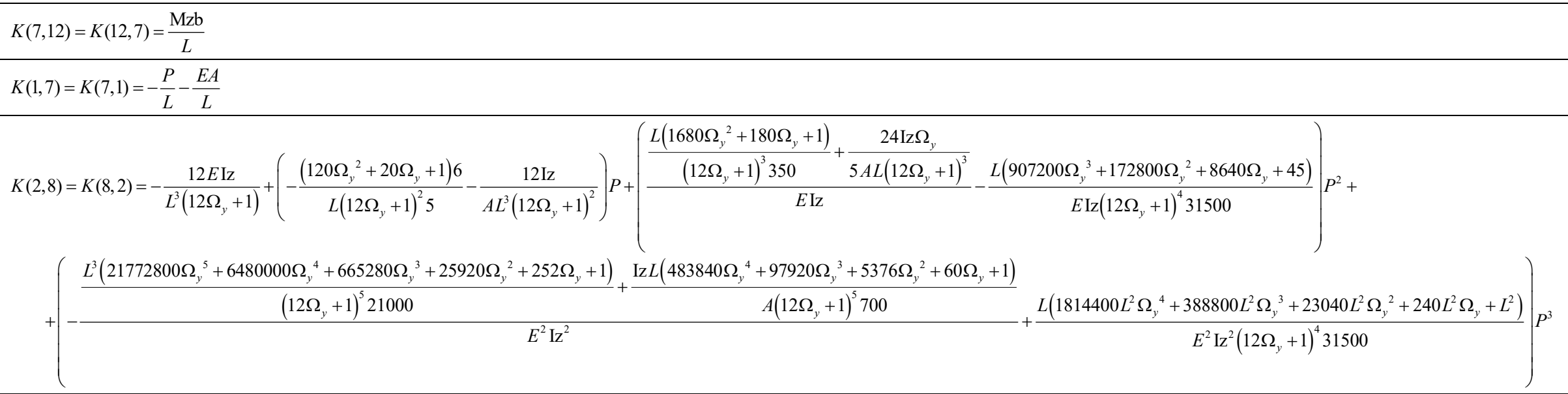


Apêndice $C$

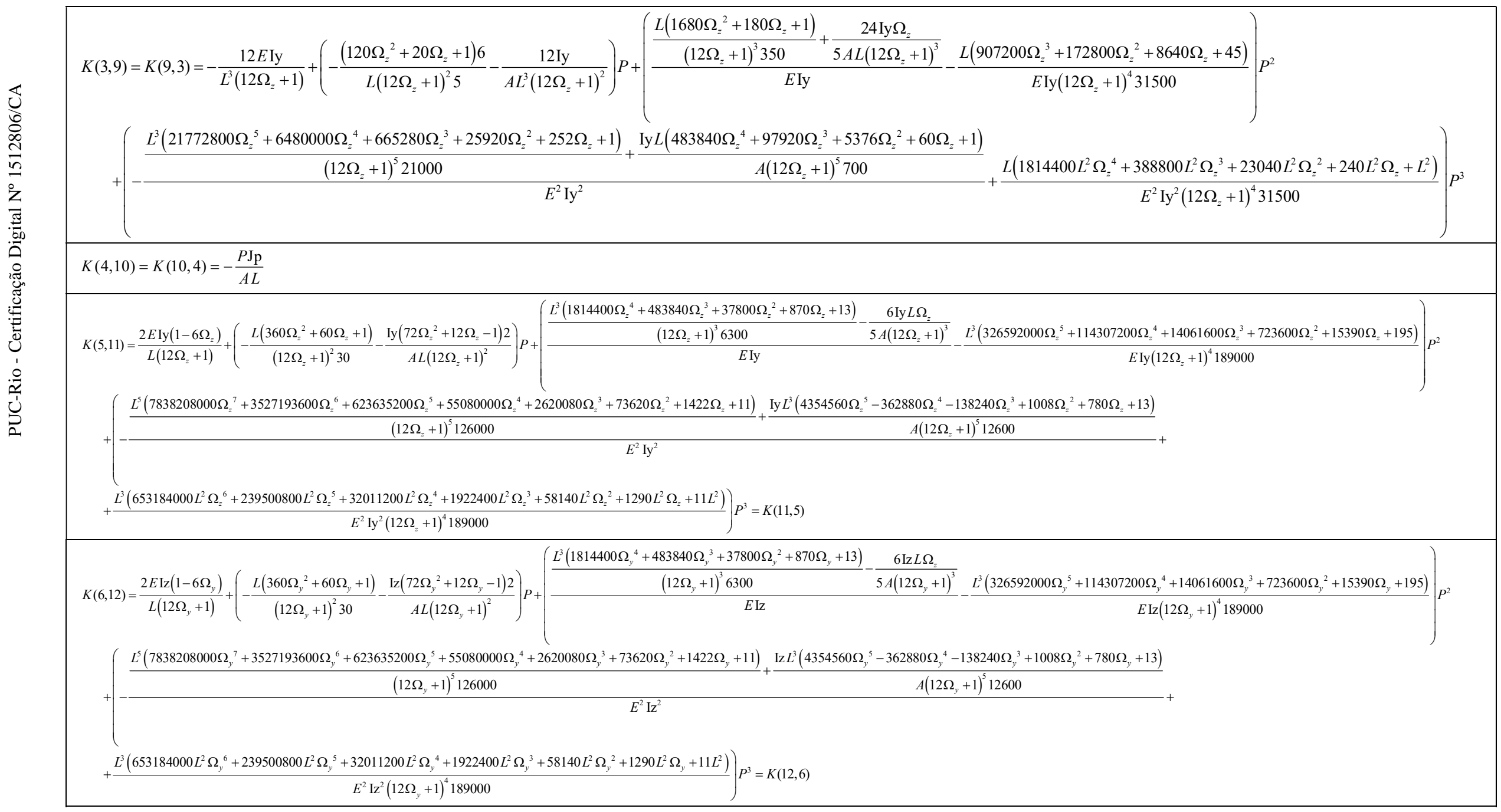


Apêndice $C$

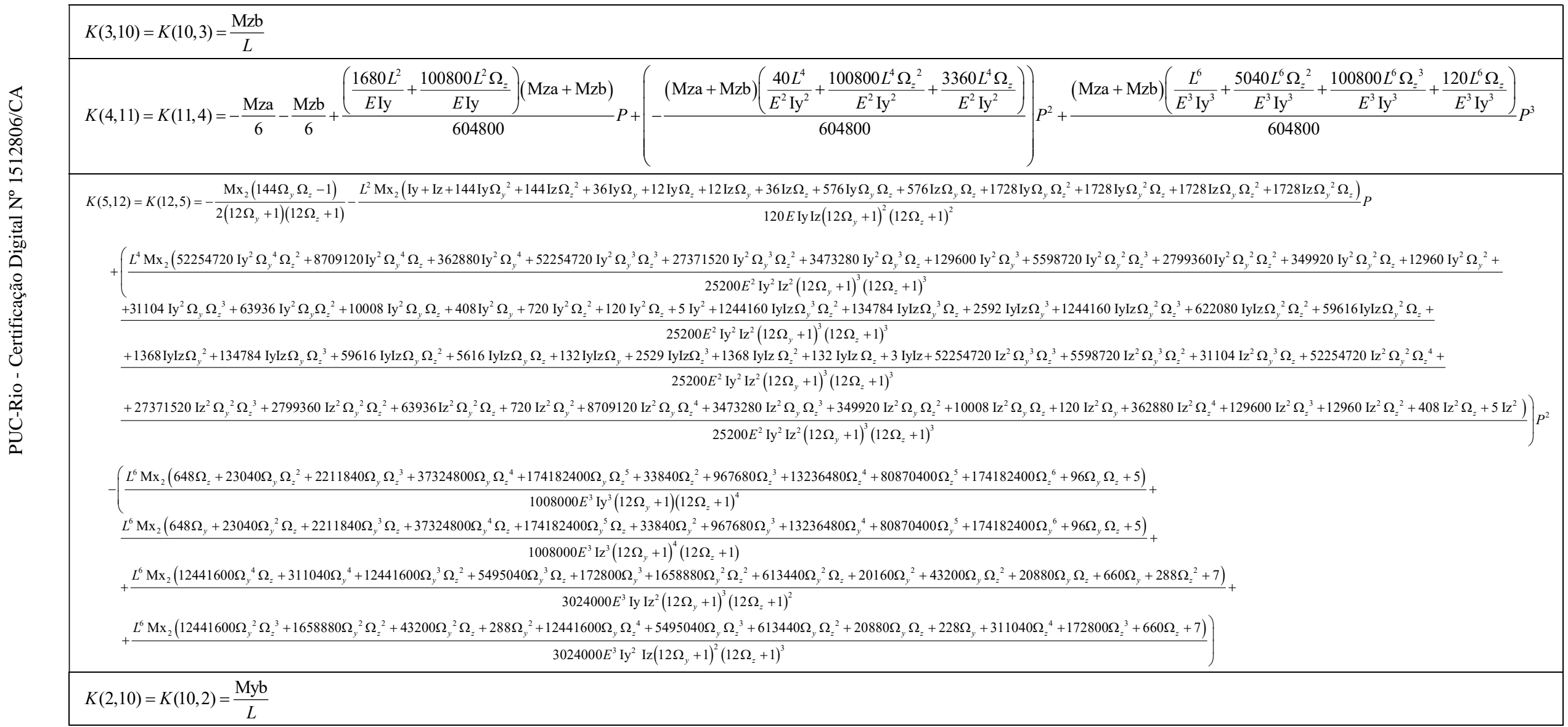


Apêndice C

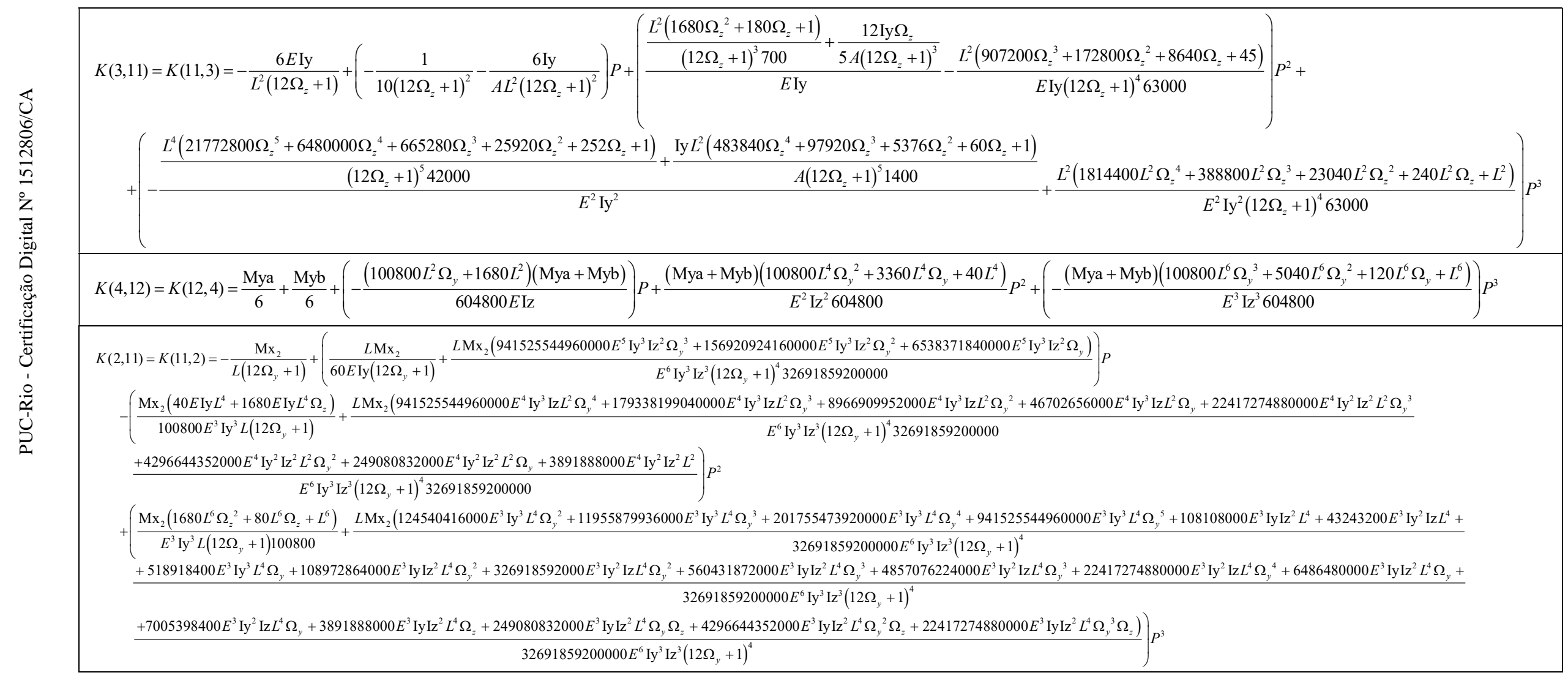


Apêndice $C$

$K(3,12)=K(12,3)=-\frac{\mathrm{Mx}_{2}}{L\left(12 \Omega_{z}+1\right)}+\left(\frac{L \mathrm{Mx}_{2}}{60 E \mathrm{Iz}\left(12 \Omega_{z}+1\right)}+\frac{L \mathrm{Mx}_{2}\left(941525544960000 E^{5} \mathrm{Iy}^{2} \mathrm{Iz}^{3} \Omega_{z}{ }^{3}+156920924160000 E^{5} \mathrm{Iy}^{2} \mathrm{Iz}^{3} \Omega_{z}{ }^{2}+6538371840000 E^{5} \mathrm{Iy}^{2} \mathrm{Iz}^{3} \Omega_{z}\right)}{E^{6} \mathrm{Iy}^{3} \mathrm{Iz}^{3}\left(12 \Omega_{z}+1\right)^{4} 32691859200000}\right) P$

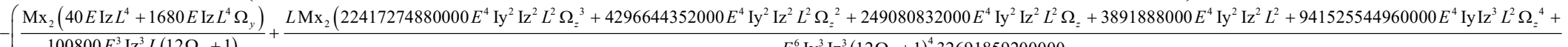

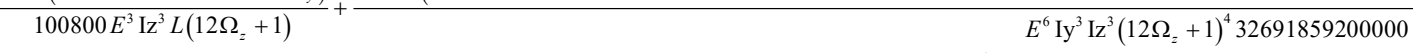

$\left.\frac{\left.+179338199040000 E^{4} \mathrm{Iy} \mathrm{Iz}^{3} L^{2} \Omega_{z}+8966909952000 E^{4} \mathrm{Iy} \mathrm{Iz}^{3} L^{2} \Omega_{z}{ }^{2}+46702656000 E^{4} \mathrm{Iy} \mathrm{Iz}^{3} L^{2} \Omega_{z}\right)}{E^{6} \mathrm{Iy}^{3} \mathrm{Iz}^{3}\left(12 \Omega_{z}+1\right)^{4} 32691859200000}\right) P^{2}$

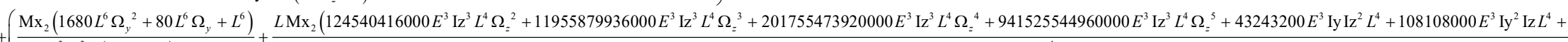

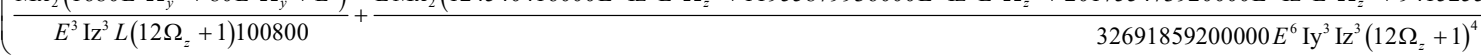

$+518918400 E^{3} \mathrm{Iz}^{3} L^{4} \Omega_{z}+326918592000 E^{3} \mathrm{Iy} \mathrm{Iz}^{2} L^{4} \Omega_{z}{ }^{2}+108972864000 E^{3} \mathrm{Iy}^{2} \mathrm{Iz}^{4} \Omega_{z}{ }^{2}+4857076224000 E^{3} \mathrm{Iy} \mathrm{Iz}^{2} L^{4} \Omega_{z}{ }^{3}+560431872000 E^{3} \mathrm{Iy}^{2} \mathrm{IzL}^{4} \Omega_{z}{ }^{3}+22417274880000 E^{3} \mathrm{Iy} \mathrm{Iz}^{2} L^{4} \Omega_{z}{ }^{4}+3891888000 E^{3} \mathrm{Iy}^{2} \mathrm{Iz}^{4} \Omega_{y}+$ $32691859200000 E^{6} \mathrm{Iy}^{3} \mathrm{Iz}^{3}\left(12 \Omega_{z}+1\right)^{4}$

$\left.\frac{\left.+7005398400 E^{3} \operatorname{Iy~Iz}^{2} L^{4} \Omega_{z}+6486480000 E^{3} \operatorname{Iy}^{2} \operatorname{Iz}^{4} \Omega_{z}+249080832000 E^{3} \mathrm{Iy}^{2} \operatorname{Iz}^{4} \Omega_{y} \Omega_{z}+4296644352000 E^{3} \mathrm{Iy}^{2} \mathrm{Iz}^{4} \Omega_{y} \Omega_{z}{ }^{2}+22417274880000 E^{3} \mathrm{Iy}^{2} \mathrm{Iz}^{4} \Omega_{y} \Omega_{z}{ }^{3}\right)}{32691859200000 E^{6} \mathrm{Iy}^{3} \mathrm{Iz}^{3}\left(12 \Omega_{z}+1\right)^{4}}\right) P^{3}$

$K(1,11)=K(11,1)=-\frac{\mathrm{Myb}}{L}$

$K(2,12)=K(12,2)=\frac{6 E \mathrm{Iz}}{L^{2}\left(12 \Omega_{y}+1\right)}+\left(\frac{1}{10\left(12 \Omega_{y}+1\right)^{2}}+\frac{6 \mathrm{Iz}}{A L^{2}\left(12 \Omega_{y}+1\right)^{2}}\right) P+\left(-\frac{\frac{L^{2}\left(1680 \Omega_{y}{ }^{2}+180 \Omega_{y}+1\right)}{\left(12 \Omega_{y}+1\right)^{3} 700}+\frac{12 \mathrm{Iz} \Omega_{y}}{5 A\left(12 \Omega_{y}+1\right)^{3}}}{E \mathrm{Iz}}+\frac{L^{2}\left(907200 \Omega_{y}{ }^{3}+172800 \Omega_{y}{ }^{2}+8640 \Omega_{y}+45\right)}{E \mathrm{Iz}\left(12 \Omega_{y}+1\right)^{4} 63000}\right) P^{2}+$

$\left(\frac{L^{4}\left(21772800 \Omega_{y}{ }^{5}+6480000 \Omega_{y}{ }^{4}+665280 \Omega_{y}{ }^{3}+25920 \Omega_{y}{ }^{2}+252 \Omega_{y}+1\right)}{\left(12 \Omega_{j}+1\right)^{5} 42000}+\frac{\operatorname{Iz} L^{2}\left(483840 \Omega_{y}{ }^{4}+97920 \Omega_{y}{ }^{3}+5376 \Omega_{y}{ }^{2}+60 \Omega_{y}+1\right)}{{ }^{5}}\right.$

\begin{tabular}{|c|c|c|}
\hline$\left(12 \Omega_{y}+1\right)^{5} 42000$ & $A\left(12 \Omega_{y}+1\right)^{5} 1400$ & $L^{2}\left(1814400 L^{2} \Omega_{y}{ }^{4}+388800 L^{2} \Omega_{y}{ }^{3}+23040 L^{2} \Omega_{y}{ }^{2}+240 L^{2} \Omega_{y}+L^{2}\right)$ \\
\hline$E^{2} \mathrm{Iz}^{2}$ & & $E^{2} \mathrm{Iz}^{2}\left(12 \Omega_{y}+1\right)^{4} 63000$ \\
\hline
\end{tabular}

$K(1,12)=K(12,1)=-\frac{\mathrm{Mzb}}{L}$ 
Apêndice C

$K(5,6)=K(6,5)=-\frac{6 \mathrm{Mx}_{2}\left(\Omega_{y}-\Omega_{z}\right)}{\left(12 \Omega_{y}+1\right)\left(12 \Omega_{z}+1\right)}+\frac{L^{2} \mathrm{Mx}\left(\operatorname{Iy}-\mathrm{Iz}+144 \mathrm{Iy} \Omega_{y}{ }^{2}-144 \mathrm{Iz} \Omega_{z}{ }^{2}+12 \operatorname{Iy} \Omega_{y}+12 \operatorname{Iy} \Omega_{z}-12 \mathrm{Iz} \Omega_{y}-12 \mathrm{Iz} \Omega_{z}-1728 \mathrm{Iy} \Omega_{y} \Omega_{z}{ }^{2}+1728 \mathrm{Iy} \Omega_{y}{ }^{2} \Omega_{z}-1728 \mathrm{Iz} \Omega_{y} \Omega_{z}{ }^{2}+1728 \mathrm{Iz} \Omega_{y}{ }^{2} \Omega_{z}\right)}{120 E \operatorname{IyI}\left(12 \Omega_{y}+1\right)^{2}\left(12 \Omega_{z}+1\right)^{2}} P$

$\left(L^{4} \mathrm{Mx}_{2}\left(52254720 \mathrm{Iy}^{2} \Omega_{y}{ }^{4} \Omega_{z}{ }^{2}+8709120 \mathrm{Iy}^{2} \Omega_{y}{ }^{4} \Omega_{z}+362880 \mathrm{Iy}^{2} \Omega_{y}{ }^{4}-52254720 \mathrm{Iy}^{2} \Omega_{y}{ }^{3} \Omega_{z}{ }^{3}+1244160 \mathrm{Iy}^{2} \Omega_{y}{ }^{3} \Omega_{z}{ }^{2}+1296000 \mathrm{Iy}^{2} \Omega_{y}{ }^{3} \Omega_{z}+69120 \mathrm{Iy}^{2} \Omega_{y}{ }^{3}-5598720 \mathrm{Iy}^{2} \Omega_{y}{ }^{2} \Omega_{z}{ }^{3}+116640 \mathrm{Iy}^{2} \Omega_{y}{ }^{2} \Omega_{z}+6480 \mathrm{Iy}^{2} \Omega_{y}{ }^{2}-31104 \mathrm{Iy}^{2} \Omega_{y} \Omega_{z}{ }^{3}+\right.\right.$ $25200 E^{2} \mathrm{Iy}^{2} \mathrm{Iz}^{2}\left(12 \Omega_{y}+1\right)^{3}\left(12 \Omega_{z}+1\right)^{3}$

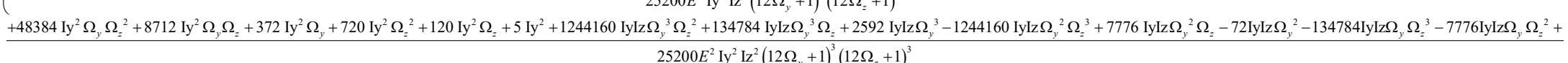

$\underline{-24 \mathrm{IyIz} \Omega_{y}-2592 \mathrm{IyIz} \Omega_{z}{ }^{3}+72 \mathrm{IyIz} \Omega_{z}{ }^{2}+24 \mathrm{IyIz} \Omega_{z}+52254720 \mathrm{Iz}^{2} \Omega_{y}{ }^{3} \Omega_{z}{ }^{3}+5598720 \mathrm{Iz}^{2} \Omega_{y}{ }^{3} \Omega_{z}{ }^{2}+31104 \mathrm{Iz}^{2} \Omega_{y}{ }^{3} \Omega_{z}-52254720 \mathrm{Iz}^{2} \Omega_{y}{ }^{2} \Omega_{z}{ }^{4}-1244160 \mathrm{Iz}^{2} \Omega_{y}{ }^{2} \Omega_{z}{ }^{3}-48384 \mathrm{Iz}^{2} \Omega_{y}{ }^{2} \Omega_{z}-720 \mathrm{Iz}^{2} \Omega_{y}{ }^{2}-8709120 \mathrm{Iz}^{2} \Omega_{y} \Omega_{z}{ }^{4}-1296000 \mathrm{Iz}{ }^{2} \Omega_{y} \Omega_{z}{ }^{3}+}$ $25200 E^{2} \mathrm{Iy}^{2} \mathrm{Iz}^{2}\left(12 \Omega_{y}+1\right)^{3}\left(12 \Omega_{z}+1\right)^{3}$

$\left.\frac{\left.-116640 \mathrm{Iz}^{2} \Omega_{y} \Omega_{z}{ }^{2}-8712 \mathrm{Iz}^{2} \Omega_{y}-120 \mathrm{Iz}^{2} \Omega_{y}-362880 \mathrm{Iz}^{2} \Omega_{z}{ }^{4}-69120 \mathrm{Iz}^{2} \Omega_{y} \Omega_{z}{ }^{3}-6480 \mathrm{Iz}^{2} \Omega_{z}{ }^{2}-372 \mathrm{Iz}^{2} \Omega_{z}-5 \mathrm{Iz}^{2}\right)}{25200 E^{2} \mathrm{Iy}^{2} \mathrm{Iz}^{2}\left(12 \Omega_{y}+1\right)^{3}\left(12 \Omega_{z}+1\right)^{3}}\right) P^{2}$

$+\left(\frac{\operatorname{IyL} L^{6}\left(49766400 \Omega_{y}{ }^{4} \Omega_{z}{ }^{2}+5391360 \Omega_{y}{ }^{4} \Omega_{z}+103680 \Omega_{y}{ }^{4}-49766400 \Omega_{y}{ }^{3} \Omega_{z}{ }^{3}+1244160 \Omega_{y}{ }^{3} \Omega_{z}{ }^{2}+449280 \Omega_{y}{ }^{3} \Omega_{z}-6635520 \Omega_{y}{ }^{2} \Omega_{z}{ }^{3}-311040 \Omega_{y}{ }^{2} \Omega_{z}{ }^{2}+8640 \Omega_{y}{ }^{2} \Omega_{z}-960 \Omega_{y}{ }^{2}-172800 \Omega_{y} \Omega_{z}{ }^{3}+11520 \Omega_{y} \Omega_{z}{ }^{2}+2400 \Omega_{y} \Omega_{z}+20 \Omega_{y}-1152 \Omega_{z}{ }^{3}+432 \Omega_{z}{ }^{2}+56 \Omega_{z}+1\right)}{}+\right.$ $1008000 E^{3} \mathrm{Iy}^{2} \mathrm{Iz}^{2}\left(12 \Omega_{p}+1\right)^{3}\left(12 \Omega_{z}+1\right)^{3}$

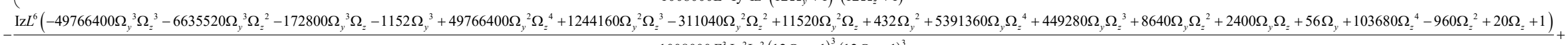
$1008000 E^{3} \mathrm{Iy}^{2} \mathrm{Iz}^{2}\left(12 \Omega_{v}+1\right)^{3}\left(12 \Omega_{z}+1\right)^{3}$

$+\frac{L^{6}\left(632 \Omega_{y}-23040 \Omega_{y}{ }^{2} \Omega_{z}-2211840 \Omega_{y}{ }^{3} \Omega_{z}-37324800 \Omega_{y}{ }^{4} \Omega_{z}-174182400 \Omega_{y}{ }^{5} \Omega_{z}+30000 \Omega_{y}{ }^{2}+599040 \Omega_{y}{ }^{3}+7015680 \Omega_{y}{ }^{4}+51840000 \Omega_{y}{ }^{5}+174182400 \Omega_{y}{ }^{6}-96 \Omega_{y} \Omega_{z}+5\right)}{+}+$

$1008000 E^{3} \mathrm{Iz}^{3}\left(12 \Omega_{y}+1\right)^{4}\left(12 \Omega_{z}+1\right)$

$L^{6}\left(-25082265600 \Omega_{\nu}{ }^{3} \Omega_{z}{ }^{5}-5374771200 \Omega_{\nu}{ }^{3} \Omega_{z}{ }^{4}-318504960 \Omega_{\nu}{ }^{3} \Omega_{z}{ }^{3}-3317760 \Omega_{\nu}{ }^{3} \Omega_{z}{ }^{2}-13824 \Omega_{\nu}{ }^{3} \Omega_{z}+25082265600 \Omega_{\nu}{ }^{2} \Omega_{z}{ }^{6}+3284582400 \Omega_{\nu}{ }^{2} \Omega_{z}{ }^{5}+114462720 \Omega_{\nu}{ }^{2} \Omega_{z}{ }^{4}+33177600 \Omega_{\nu}{ }^{2} \Omega_{z}{ }^{3}+3767040 \Omega_{\nu}{ }^{2} \Omega_{z}{ }^{2}+88704 \Omega_{\nu}{ }^{2} \Omega_{z}+720 \Omega_{\nu}{ }^{2}+\right.$ $1008000 E^{3} \mathrm{Iy}^{3}\left(12 \Omega_{y}+1\right)^{3}\left(12 \Omega_{z}+1\right)^{4}$

$\left.\frac{\left.+4180377600 \Omega_{y} \Omega_{z}{ }^{6}+1069977600 \Omega_{y} \Omega_{z}{ }^{5}+131051520 \Omega_{y} \Omega_{z}{ }^{4}+12165120 \Omega_{y} \Omega_{z}{ }^{3}+696960 \Omega_{y} \Omega_{z}{ }^{2}+15072 \Omega_{y} \Omega_{z}+120 \Omega_{y}+174182400 \Omega_{z}{ }^{6}+51840000 \Omega_{z}{ }^{5}+7015680 \Omega_{z}{ }^{4}+599040 \Omega_{z}{ }^{3}+30000 \Omega_{z}{ }^{2}+632 \Omega_{z}+5\right)}{1008000 E^{3} \mathrm{Iy}^{3}\left(12 \Omega_{y}+1\right)^{3}\left(12 \Omega_{z}+1\right)^{4}}\right) \mathrm{Mx}_{2} P^{3}$ 


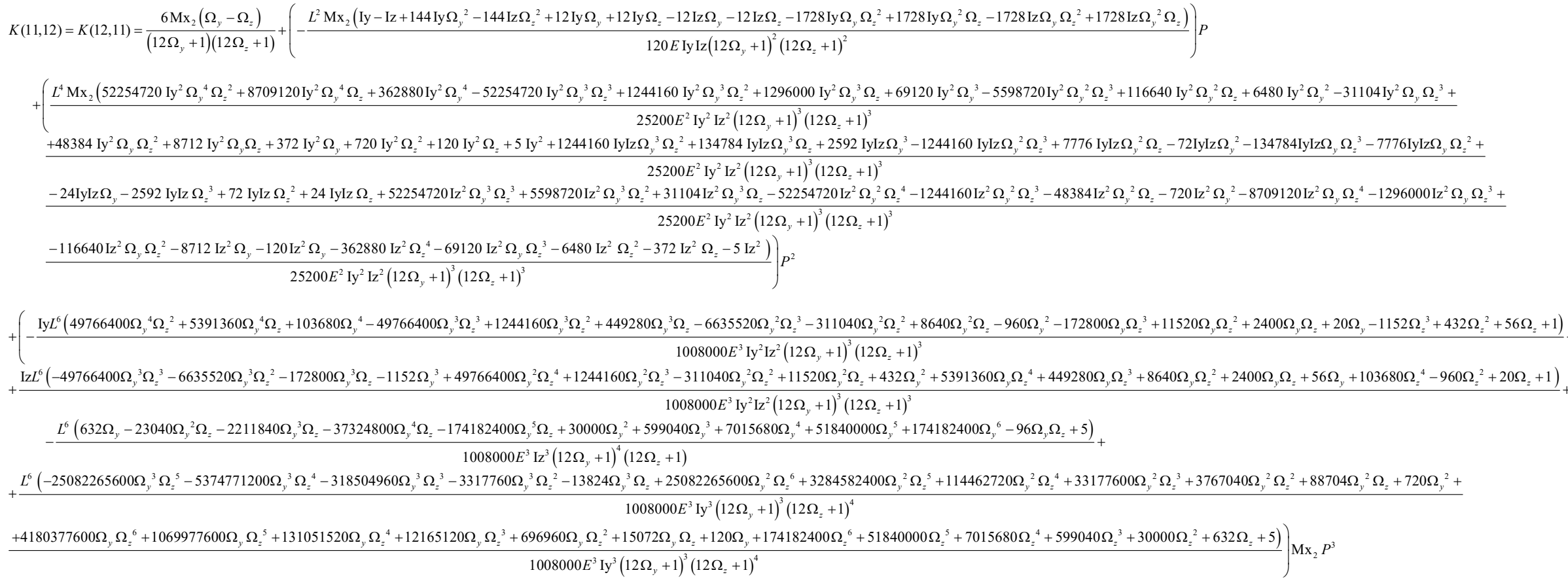

Conforme explicitado ao longo do texto, a expansão da matriz de rigidez em série de Taylor pode ser utilizada das seguintes formas:

TBT_2tr - Emprega-se 2 Termos (termo elástico + um termo da carga axial $P$, até grau 1);

TBT_3tr - Emprega-se 3 Termos (termo elástico + dois termos da carga axial $P$, até grau 2);

TBT_4tr - Emprega-se 4 Termos (termo elástico + três termos da carga axial $P$, até grau 3); 


\section{Apêndice D \\ Metodologias de Análise Não Linear}

Para uma análise não linear completa, além de se utilizar formulações não lineares em nível dos elementos, e, no caso desse trabalho, em nível do elemento infinitesimal, também deve-se empregar algoritmos que consigam descrever a trajetória de equilíbrio da estrutura. Assim, faz-se necessária a resolução de sistemas de equações não lineares.

Este tipo de equação pode ser resolvido com dois métodos matemáticos distintos. Para o traçado da trajetória de equilíbrio, em geral, utilizam-se de processos incrementais e iterativos. A segunda abordagem prediz pontos limites por meio de uma análise de auto-valor (McGuire et al., 2000).

Neste trabalho de pesquisa, utilizou-se de procedimentos incrementais e iterativos para o traçado das curvas de equilíbrio da estrutura sendo este capítulo baseado na pesquisa de Leon et al. (2011).

\section{D.1 \\ Metodologia de Solução}

A trajetória de equilíbrio de uma análise não linear pode ser construída por um método apenas incremental ou por um processo incremental-iterativo. Com uma fácil implementação, no processo apenas incremental, o carregamento é aplicado em pequenos incrementos na estrutura, porém, ao não se realizar os processos iterativos, a curva diverge da solução, pois o equilíbrio não é garantido a cada incremento de carga. Já para um procedimento incremental-iterativo, as correções são realizadas a cada incremento de carga até que o critério de convergência adotado seja satisfeito, reduzindo a distância entre a trajetória construída e a solução.

Devido a não linearidade do problema, as forças internas $\boldsymbol{q}\left(\boldsymbol{u}_{\boldsymbol{j}}^{\boldsymbol{i}}\right)$, funções dos deslocamentos nodais, $\boldsymbol{u}_{\boldsymbol{j}}^{\boldsymbol{i}}$, não estão necessariamente em equilíbrio com as forças 
externas aplicadas, $\mathbf{p}_{\boldsymbol{j}}^{\boldsymbol{i}}$. De acordo com Felippa (2017), as equações de equilíbrio discretas encontradas na análise não linear estática, através dos deslocamentos nodais, podem ser apresentadas sob a forma da força total residual, $\boldsymbol{r}_{\boldsymbol{j}}^{i}$, conforme a equação (D.1).

$$
r_{j}^{i}=\mathbf{p}_{j}^{i}-q\left(u_{j}^{i}\right)=0
$$

O deslocamento e as forças externas são calculados, adicionando-se a contribuição das configurações de equilíbrio previamente convergidas (incremento $i-1$ ) às atualizações fornecidas pela iteração $j$, do incremento $i$, conforme as equações (D.2) e (D.3).

$$
\begin{aligned}
& u_{j}^{i}=u^{i-1}+\Delta u_{j}^{i} \\
& p_{j}^{i}=p^{i-1}+\Delta p_{j}^{i}
\end{aligned}
$$

As atualizações incrementais no passo $i$ são calculadas, somando-se as contribuições da iteração anterior, $j$-1, com a da iteração corrente $j$, equações (D.4) e (D.5),

$$
\begin{aligned}
\Delta u_{j}^{i} & =\Delta u_{j-1}^{i}+\delta u_{j}^{i} \\
\Delta p_{j}^{i} & =\Delta p_{j-1}^{i}+\delta p_{j}^{i}
\end{aligned}
$$

$\Delta \boldsymbol{u}_{j}^{i}$ e $\Delta \mathbf{p}_{j}^{i}$ correspondem aos vetores de incremento de deslocamento e de força, respectivamente, enquanto que $\boldsymbol{\delta} \boldsymbol{u}_{\boldsymbol{j}}^{\boldsymbol{i}}$ e $\boldsymbol{\delta} \mathbf{p}_{\boldsymbol{j}}^{\boldsymbol{i}}$ são os deslocamentos e forças, respectivamente, na iteração $j$ do passo $i$.

Assim, o vetor residual, ou não balanceado, pode ser escrito como a equação (D.6) e o sistema de equações não lineares para ser resolvido na iteração $j$ do passo incremental $i$ é dado pela equação (D.7).

$$
\begin{gathered}
r_{j}^{i}=\mathrm{p}^{i-1}+\Delta \mathrm{p}_{j}^{i}-q\left(u^{i-1}+\Delta u_{j}^{i}\right)=0 \\
K_{j-1}^{i} \delta u_{j}^{i}=\mathbf{p}_{j}^{i}-q\left(u_{j-1}^{i}\right)
\end{gathered}
$$

A matriz $\boldsymbol{K}_{\boldsymbol{j}-\mathbf{1}}^{\boldsymbol{i}}$ é a matriz de rigidez tangente da estrutura, que pode ser calculada pelo método padrão. Esse cálculo é feito no início de cada iteração, ou pelo método modificado, apenas no início do passo incremental, que, apesar de um menor custo computacional, necessita de mais iterações para convergência. 


\section{D.2}

\section{Teoria do Espaço Dimensional $N+1$}

De acordo com Yang \& Kuo (1994), em uma análise não linear deve-se resolver um sistema com $N+1$ parâmetros, ou seja, $N$ componentes de deslocamentos, $\boldsymbol{\delta} \boldsymbol{u}_{\boldsymbol{j}}^{\boldsymbol{i}}$, e um fator de carga, $\lambda_{j}^{i}$. Assim, substituindo $\delta \mathbf{p}_{\boldsymbol{j}}^{\boldsymbol{i}}$ por $\delta \lambda_{j}^{i} \overline{\mathbf{p}}$, em que $\overline{\mathbf{p}}$ é um vetor de carregamento de referência, o vetor de forças externas aplicado na estrutura pode ser escrito conforme a equação (D.8).

$$
\mathbf{p}_{j}^{i}=\mathbf{p}^{i-1}+\Delta \boldsymbol{p}_{j-1}^{i}+\delta \lambda_{j}^{i} \overline{\mathbf{p}}
$$

O problema então da equação (D.7) pode ser reescrito, combinando-se as equações (D.6) e (D.8) e obtendo-se a relação (D.9).

$$
\boldsymbol{K}_{j-1}^{i} \delta \boldsymbol{u}_{j}^{i}=\boldsymbol{r}_{j-1}^{i}+\delta \lambda_{j}^{i} \overline{\mathbf{p}}
$$

Portanto, na equação (D.9) existem $N$ componentes de deslocamentos, $\boldsymbol{\delta} \boldsymbol{u}_{\boldsymbol{j}}^{\boldsymbol{i}}$, e um fator de carga, $\lambda_{j}^{i}$, ou seja, um sistema com $N+1$ incógnitas, porém com apenas $N$ equações. Dessa maneira, segundo Yang \& Kuo (1994) devemos inserir uma relação a mais no sistema, dada pela equação (D.10).

$$
\boldsymbol{a}_{\boldsymbol{j}}^{\boldsymbol{i}} \cdot \boldsymbol{\delta} \boldsymbol{u}_{\boldsymbol{j}}^{\boldsymbol{i}}+b_{j}^{i} \cdot \delta \lambda_{j}^{i}=c_{j}^{i}
$$

Isto resultará então em um sistema de $\mathrm{N}+1$ equações e incógnitas (D.11).

$$
\left[\begin{array}{cc}
\boldsymbol{K}_{\boldsymbol{j}-1}^{\boldsymbol{i}} & -\overline{\mathbf{p}} \\
\left(\boldsymbol{a}_{\boldsymbol{j}}^{\boldsymbol{i}}\right)^{\boldsymbol{T}} & b_{j}^{i}
\end{array}\right]\left\{\begin{array}{c}
\boldsymbol{\delta} \boldsymbol{u}_{\boldsymbol{j}}^{i} \\
\delta \lambda_{j}^{i}
\end{array}\right\}=\left\{\begin{array}{c}
\boldsymbol{r}_{j-1}^{i} \\
c_{j}^{i}
\end{array}\right\}
$$

A matriz do sistema, então, não é mais simétrica e a sua solução de uma maneira computacionalmente eficiente é apresentada em Batoz e Dhatt (1979, apud Leon et al., 2011), decompondo o vetor deslocamento da iteração em duas parcelas, conforme equação (D.12).

$$
\delta u_{j}^{i}=\delta \lambda_{j}^{i} \delta u_{p j}^{i}+\delta u_{r j}^{i}
$$

Dessa forma, a equação (D.9) é escrita em função dessas duas parcelas, de acordo com as equações (D.13) e (D.14).

$$
\begin{gathered}
K_{j-1}^{i} \delta u_{p j}^{i}=\overline{\mathrm{p}} \\
K_{j-1}^{i} \delta u_{r j}^{i}=r_{j-1}^{i}
\end{gathered}
$$


As variáveis $\boldsymbol{\delta} \boldsymbol{u}_{\boldsymbol{p} \boldsymbol{j}}^{\boldsymbol{i}}$ e $\boldsymbol{\delta} \boldsymbol{u}_{\boldsymbol{r} \boldsymbol{j}}^{\boldsymbol{i}}$ são calculadas, utilizando-se o sistema original com a matriz simétrica. Resta apenas o cálculo do parâmetro de carga, que é obtido com a solução da equação (D.10) para o parâmetro de carga e substituição em (D.12), obtendo-se a relação (D.15).

$$
\delta \lambda_{j}^{i}=\frac{c_{j}^{i}-\boldsymbol{a}_{\boldsymbol{j}}^{\boldsymbol{i}} \cdot \boldsymbol{\delta} \boldsymbol{u}_{\boldsymbol{r} \boldsymbol{j}}^{i}}{\boldsymbol{a}_{\boldsymbol{j}}^{i} \cdot \boldsymbol{\delta} \boldsymbol{u}_{\boldsymbol{p} \boldsymbol{j}}^{i}+b_{j}^{i}}
$$

Para cada metodologia de solução de análise não linear no espaço $(\mathrm{N}+1)$ serão fornecidos os parâmetros de restrição $\boldsymbol{a}_{\boldsymbol{j}}^{\boldsymbol{i}}, b_{j}^{i}$ e $c_{j}^{i}$.

\section{D.3 Metodologia Unificada de Solução Não Linear}

Os métodos para solução de sistemas não lineares como o controle de carga, controle de deslocamento, controle de comprimento de arco, controle de energia, controle de deslocamento generalizado e a estratégia do resíduo ortogonal, apesar de diferentes em suas formulações, podem ser escritos pela equação matricial (D.11) da teoria do espaço dimensional $N+1$.

Dentre esses métodos, os dos controle de carga e do comprimento de arco, utilizados neste trabalho, são expostos de maneira unificada no espaço dimensional $N+1$.

\section{D.3.1}

\section{Método de Controle de Carga}

Neste método, o carregamento externo é calculado na primeira iteração de cada passo incremental e mantido constante ao longo das iterações dentro de determinado passo, conforme Figura D.1. Assim, o fator de carga é dado pela relação (D.16).

$$
\delta \lambda_{j}^{i}=\left\{\begin{array}{cc}
\text { Valor prescrito } & (j=1) \\
0 & (j \geq 2)
\end{array}\right.
$$




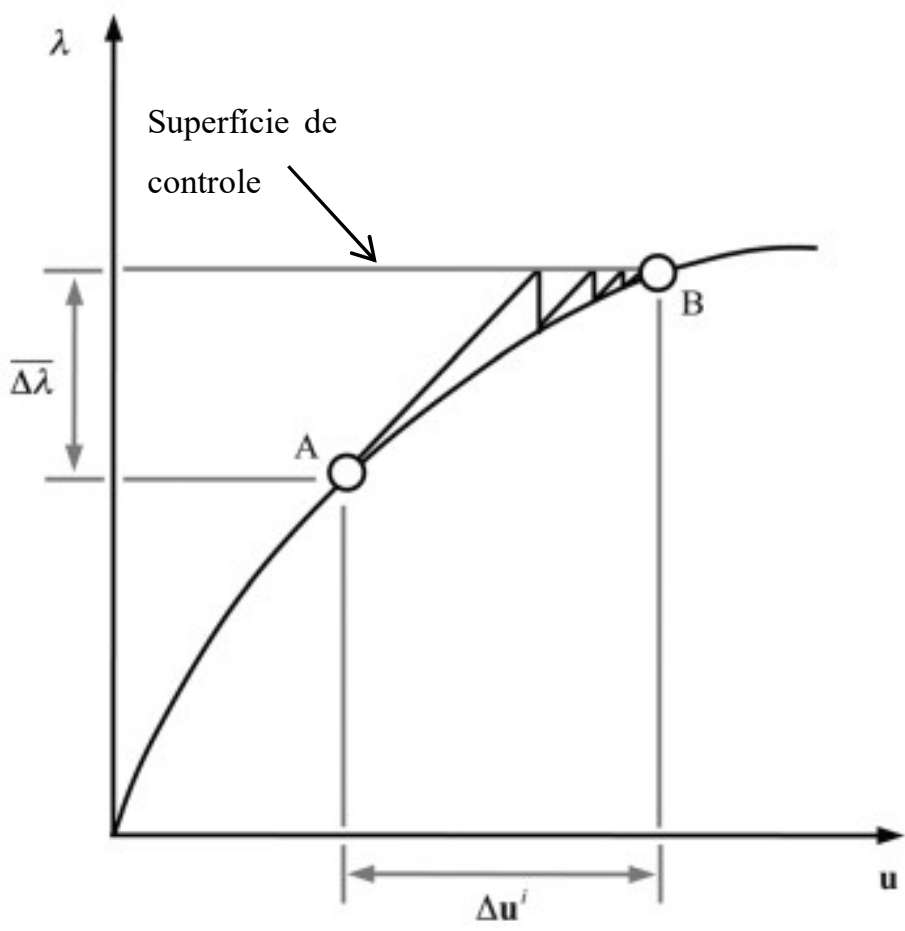

Figura D.1 - Método de controle de carga

Fonte: Leon et al. (2011).

Os parâmetros de restrição são obtidos das expressões (D.15) e (D.16), resultando nos valores apresentados em (D.17) a (D.19).

$$
\begin{gathered}
\boldsymbol{a}_{j}^{i}=0 \\
b_{j}^{i}=1 \\
c_{j}^{i}=\left\{\begin{array}{cc}
\overline{\Delta \lambda} & (j=1) \\
0 & (j \geq 2)
\end{array}\right.
\end{gathered}
$$

Em que $\Delta \lambda$ é um parâmetro de carga inicial dado. Como esse parâmetro é fornecido, esse método possui apenas $N$ incógnitas, os deslocamentos e a decomposição realizada da equação (D.9) na (D.11) não é necessária, podendo ser resolvido conforme (D.20).

$$
\begin{aligned}
& \boldsymbol{K}_{\boldsymbol{j}-\mathbf{1}}^{\boldsymbol{i}} \boldsymbol{\delta} \boldsymbol{u}_{\mathbf{1}}^{\boldsymbol{i}}=\overline{\Delta \lambda} \overline{\mathbf{p}}(j=1) \\
& \boldsymbol{K}_{\boldsymbol{j}-\mathbf{1}}^{\boldsymbol{i}} \boldsymbol{\delta} \boldsymbol{u}_{\boldsymbol{j}}^{\boldsymbol{i}}=\boldsymbol{r}_{\boldsymbol{j}-\mathbf{1}}^{\boldsymbol{i}} \quad(j \geq 2)
\end{aligned}
$$

Esse método atende ao desenvolvido neste trabalho, pois não foi estudado o comportamento pós-crítico, e essa metodologia apresenta dificuldades, com 
deslocamento excessivo, próximo aos pontos limites, pelo fato de o carregamento externo ser mantido constante

\section{D.3.2}

\section{Método de Controle de Comprimento de Arco}

O método em discussão restringe o caminho de solução a um comprimento de $\operatorname{arco}\left(\Delta s_{j}^{i}\right)$. O comprimento do arco é calculado através da norma do incremento, conforme equação (D.21).

$$
\Delta \boldsymbol{u}_{j}^{i} \cdot \Delta \boldsymbol{u}_{j}^{i}+\eta\left(\Delta \lambda_{j}^{i}\right)^{2}=\left(\Delta s_{j}^{i}\right)^{2}
$$

Em que $\eta$ é um parâmetro real não negativo, diferente para cada tipo de método do comprimento de arco (esférico, cilíndrico ou elíptico). Dessa forma, com a equação anterior, determina-se um comprimento de arco inicial, sendo as iterações mantidas na superfície criada pelo arco, conforme Figura D.2.

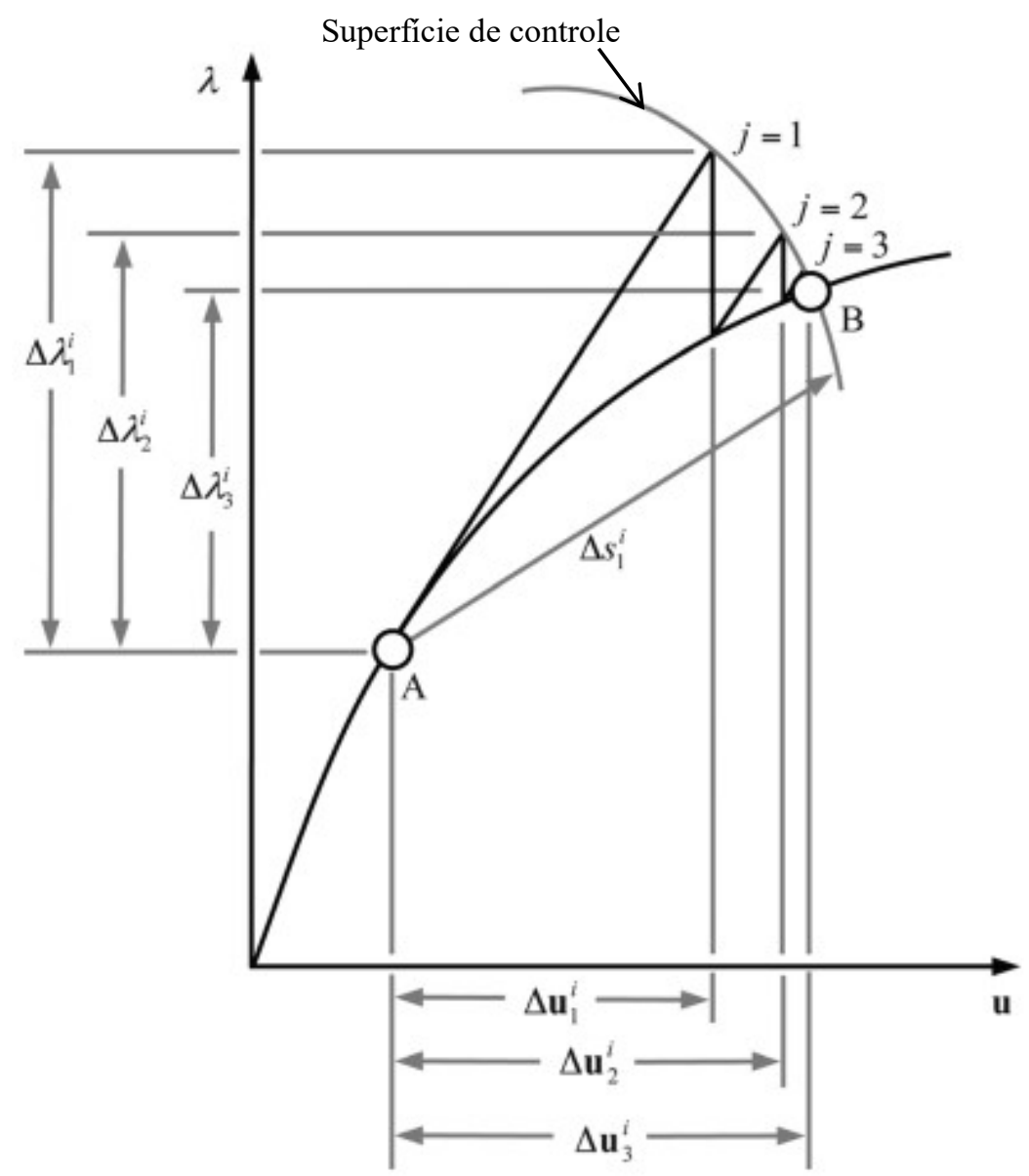

Figura D.2 - Método de controle de comprimento de arco

Fonte: Leon et al. (2011). 
A equação (D.21) pode ser escrita em relação às iterações, ao invés dos incrementos, conforme equação (D.22).

$$
\boldsymbol{\delta} \boldsymbol{u}_{\mathbf{1}}^{i} \cdot \boldsymbol{\delta} \boldsymbol{u}_{j}^{i}+\eta \delta \lambda_{1}^{i} \cdot \delta \lambda_{j}^{i}=\left(\delta s_{j}^{i}\right)^{2}
$$

Assim, obtêm-se os seguintes parâmetros de restrição (D.23) a (D.25),

$$
\begin{gathered}
\boldsymbol{a}_{\boldsymbol{j}}^{\boldsymbol{i}}=\boldsymbol{\delta} \boldsymbol{u}_{\mathbf{1}}^{\boldsymbol{i}}=\delta \lambda_{\mathbf{1}}^{i} \boldsymbol{\delta} \boldsymbol{u}_{\boldsymbol{p} \mathbf{1}}^{\boldsymbol{i}} \\
b_{j}^{i}=\eta \delta \lambda_{1}^{i} \\
c_{j}^{i}=\left\{\begin{array}{cc}
(\overline{\Delta S})^{2} & (j=1) \\
0 & (j \geq 2)
\end{array}\right.
\end{gathered}
$$

com $\Delta S$ sendo o comprimento de arco a ser utilizado na primeira iteração. Finalmente, o fator de carga será dado conforme (D.26).

$$
\delta \lambda_{j}^{i}= \begin{cases} \pm \frac{\overline{\Delta S}}{\sqrt{\boldsymbol{\delta} \boldsymbol{u}_{\boldsymbol{p} \mathbf{1}}^{\boldsymbol{i}} \cdot \boldsymbol{\delta} \boldsymbol{u}_{\boldsymbol{p} \mathbf{1}}^{i}+\eta}} & \text { para }(j=1) \\ -\frac{\boldsymbol{\delta} \boldsymbol{u}_{\mathbf{1}}^{\boldsymbol{i}} \cdot \boldsymbol{\delta} \boldsymbol{u}_{\boldsymbol{r} \boldsymbol{j}}^{i}}{\boldsymbol{\delta} \boldsymbol{u}_{\mathbf{1}}^{\boldsymbol{i}} \cdot \boldsymbol{\delta} \boldsymbol{u}_{\boldsymbol{p} \boldsymbol{j}}^{\boldsymbol{i}}+\eta \delta \lambda_{1}^{i}} & \text { para }(j \geq 2)\end{cases}
$$

O método do comprimento de arco é capaz de descrever complexas não linearidades, sendo também empregado neste trabalho em estruturas com maior não linearidade.

Em vista disso, o presente estudo beneficia-se desses métodos analisados, que foram implementados no Ftool (Martha, 1999) por Rangel (2019), baseando-se em Leon et al. (2011). Nos exemplos desenvolvidos nesta Tese, utilizou-se o método do controle de carga quando para barras discretizadas com mais de um elemento e o método do controle de arco para barras discretizadas com um elemento. 